\author{
UNIVERSIDAD NACIONAL DE LA PLATA \\ FACULTAD DE CIENCIAS JURÍDICAS Y SOCIALES \\ DOCTORADO EN CIENCIAS JURÍDICAS
}

Ricardo Sebastián Piana

\title{
La reforma de la Administración Pública en la Provincia de Buenos Aires
}

Su estudio en los años de la gestión 2002-2007

Tesis para optar al grado de Doctor en Ciencias Jurídicas por la Facultad de Ciencias Jurídicas y Sociales de la Universidad Nacional de La Plata

Directora: Dra. Myriam Consuelo Parmigiani de Barbará

Codirectora: Noemí B. Mellado

Jurado: Dra. Olga Luisa Salanueva

Dr. Mario Justo López (h)

Dr. Carlos Alfredo Botassi

Fecha de defensa: 14/12/12

Tesis aprobada con sobresaliente (10) y recomendada para publicar

La Plata 
Piana, Ricardo Sebastián

La reforma de la Administración Pública en la Provincia de Buenos Aires : su estudio en los años de la gestión 2002-2007 . - 1a ed. - La Plata : Ricardo Sebastián Piana, 2012.

E-Book.

ISBN 978-987-45238-0-8

1. Administración Pública. 2. Estado. 3. Buenos Aires. I. Título CDD 352

Fecha de catalogación: 15/11/2013

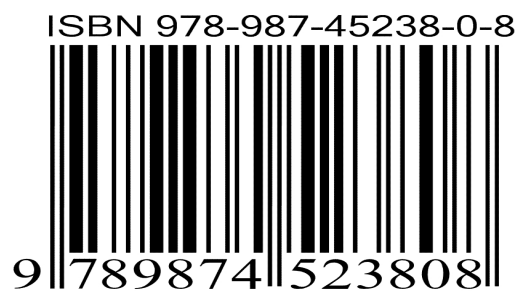




\section{INDICE}

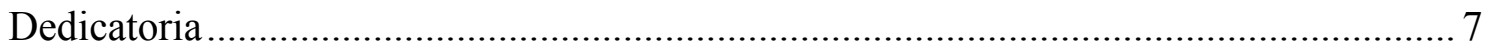

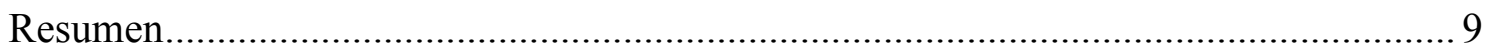

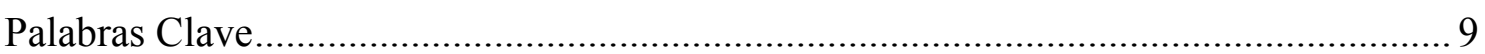

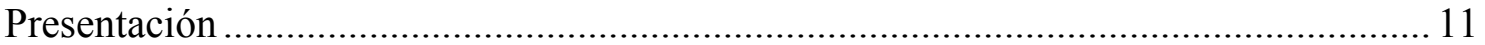

SECCIÓN PRIMERA - PROYECTO DE INVESTIGACIÓN ….................................. 19

PRIMERA PARTE - PRESENTACIÓN DEL TEMA Y DEL PROBLEMA ............... 21

SEGUNDA PARTE - ESTADO DE LA CUESTIÓN ….............................................. 23

TERCERA PARTE - HIPÓTESIS, OBJETIVOS Y METODOLOGÍA......................... 28

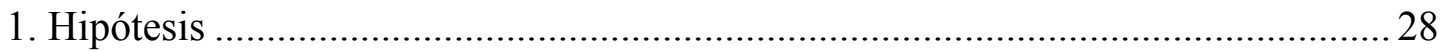

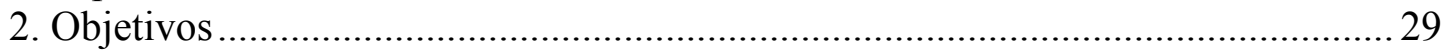

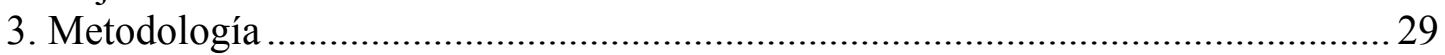

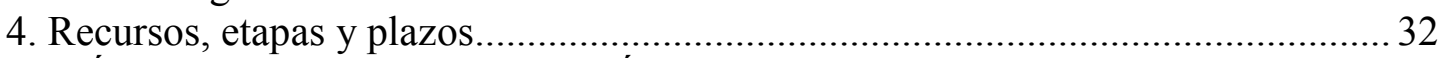

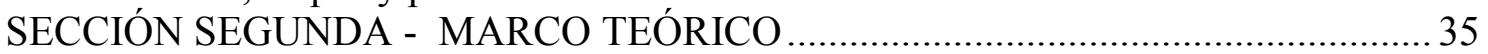

CAPÍTULO I. DE LA CRISIS DEL ESTADO A LA DE GOBERNABILIDAD ......... 37

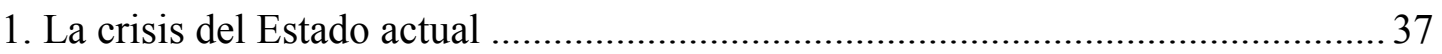

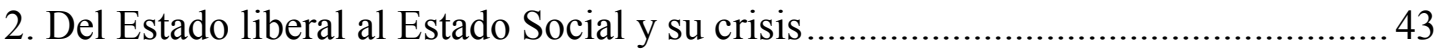

3. El constitucionalismo como principio legitimador ................................................ 50

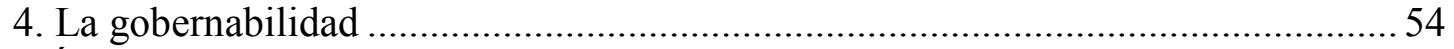

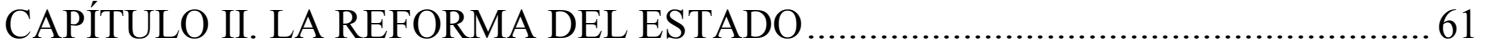

1. Reforma del Estado de primera generación: achicar el Estado.................................61

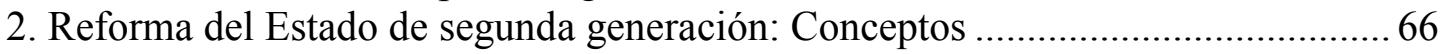

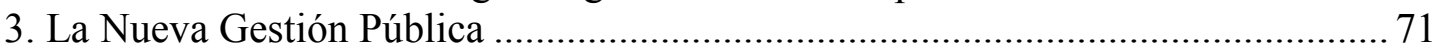

4. De las políticas de Gobierno Electrónico a las de Open Government........................76

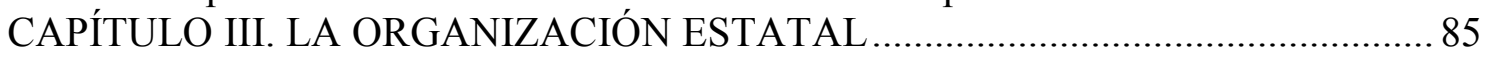

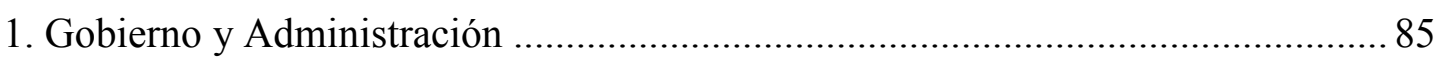

2. Organización burocrática y algunas notas sobre el modelo latinoamericano ......... 91

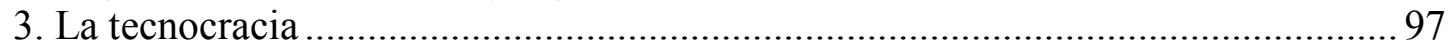

4. Los actuales modelos de reforma administrativa y las resistencias a las propuestas

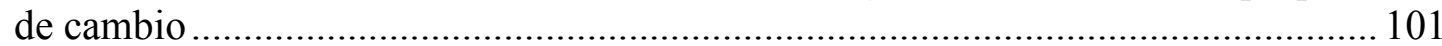

CAPÍTULO IV. LOS PARADIGMAS DEL BUEN GOBIERNO A TRAVÉS DE LAS

CÁRTAS Y CÓDIGOS DEL CONSEJO LATINOAMERICANO DE

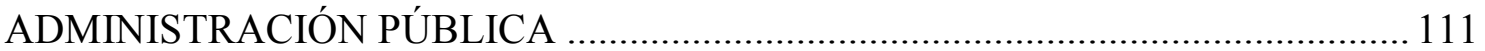

1. El Código Iberoamericano de Buen Gobierno....................................................... 111

2. La Carta Iberoamericana de Gobierno Electrónico .............................................. 117

3. La Carta Iberoamericana de Calidad en la Gestión Pública .................................. 130

4. La Carta Iberoamericana de Participación Ciudadana........................................... 137

SECCIÓN TERCERA - ESTUDIO DE LAS REFORMAS DEL ESTADO EN LA

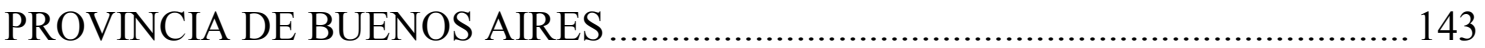

CAPÍTULO V. CONTEXTO JURÍDICO-INSTITUCIONAL, SOCIAL Y POLÍTICO

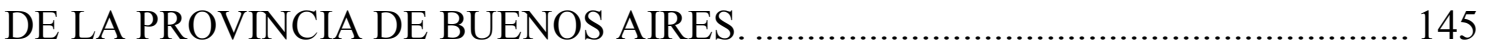

1. Estructura jurídica y capacidad institucional .................................................... 145

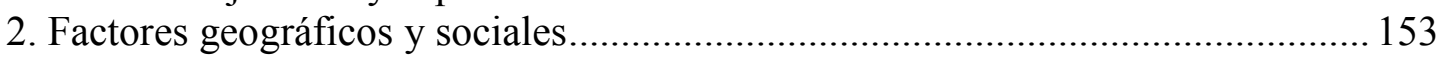

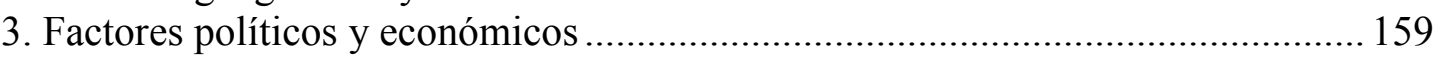

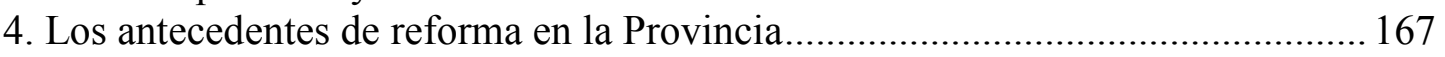




\section{CAPÍTULO VI. LAS DIRECTRICES DEL GOBERNADOR Y LAS ÁREAS CON}

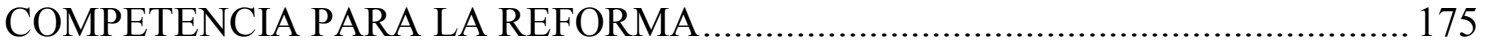

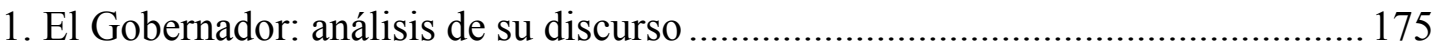

2. La Secretaría para la Modernización del Estado.............................................. 183

3. Jefatura de Gabinete y Ministerio de Gobierno ..................................................... 186

4. Secretaría General de la Gobernación................................................................. 189

a) Competencias de las Subsecretarías de la Secretaría General dentro del Decreto $\mathrm{N}^{\circ}$

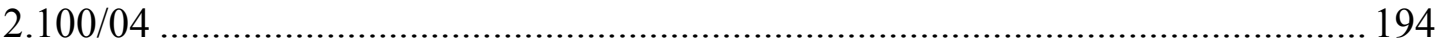

b) Competencia del Consejo de Gobierno Electrónico (Decreto No $1.824 / 02$ ) ........ 200

c) El poder relativo de las Subsecretarías .............................................................. 202

CAPÍTULO VII. LOS PLANES (explícitos e implícitos) DE MODERNIZACIÓN DE

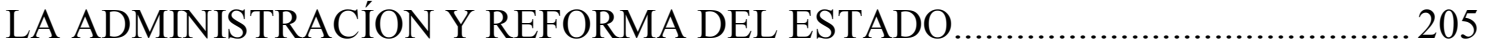

1. El Plan Rector de Modernización ........................................................................ 205

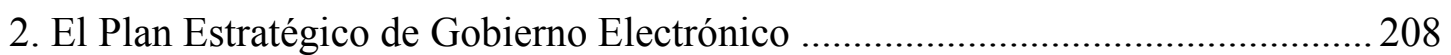

3. El Plan Trienal de la Gestión Pública ................................................................... 216

4. La Subsecretaría de Gestión Tecnológica y Administrativa................................... 220

CAPÍTULO VIII. ESTUDIO DE CASOS I - SECRETARÍA DE MODERNIZACIÓN

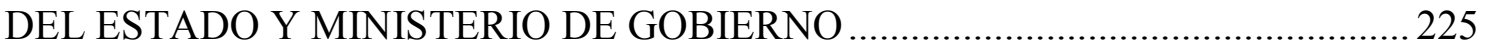

1. Acciones de la Secretaría para la Modernización del Estado .............................. 225

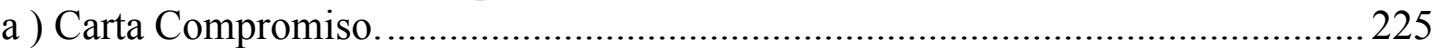

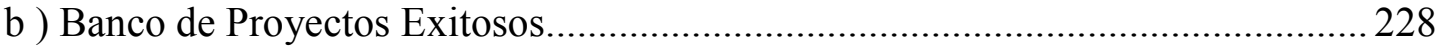

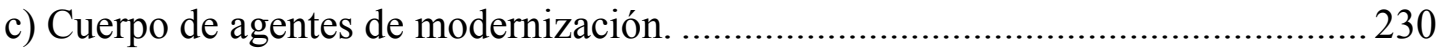

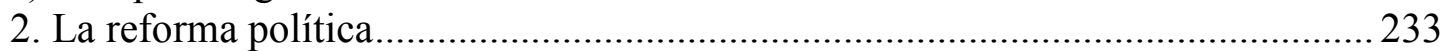

3. El voto electrónico: experiencia en la Provincia de Buenos Aires ....................... 237

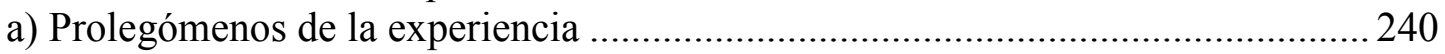

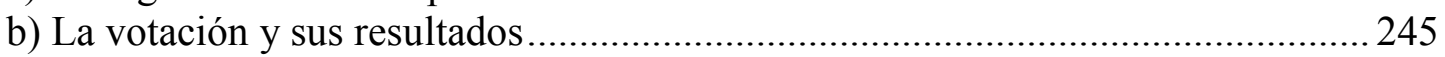

4. Otras acciones emprendidas por Ministerio de Gobierno.................................... 250

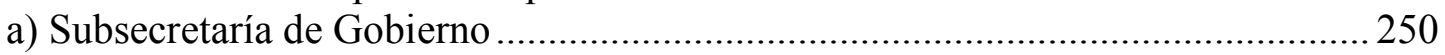

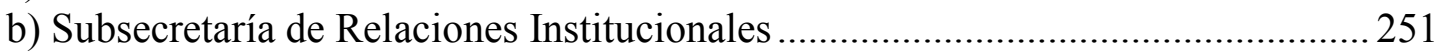

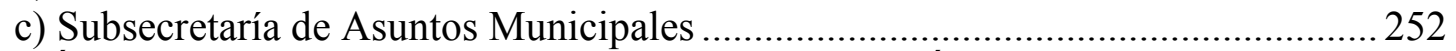

CAPÍTULO IX. ESTUDIO DE CASOS II - SECRETARÍA EJECUTIVA DE

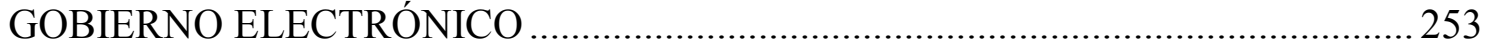

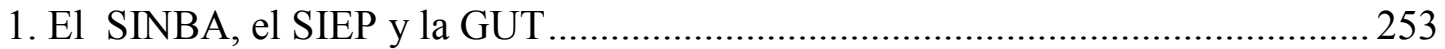

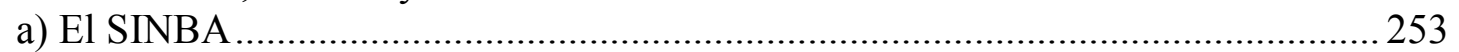

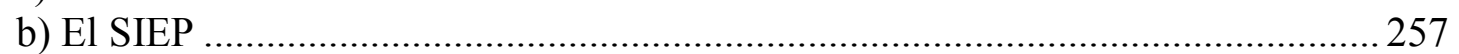

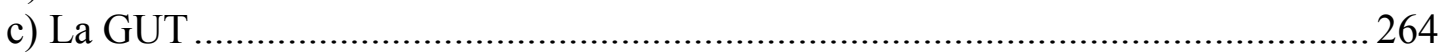

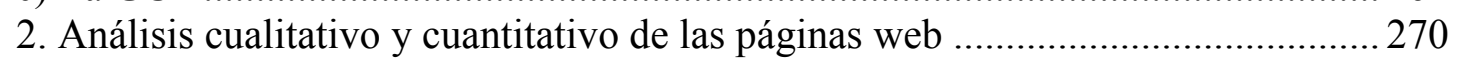

3. Transparencia y rendición de cuentas de los funcionarios a través de las TIC..... 292

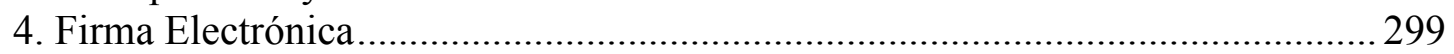

CAPÍTULO X. ESTUDIO DE CASOS III - SUBSECRETARÍA DE GESTIÓN

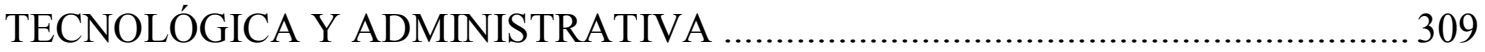

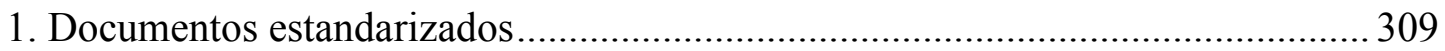

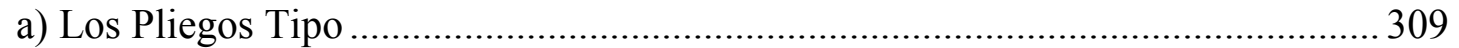

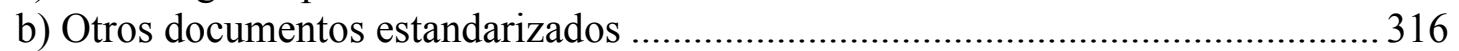

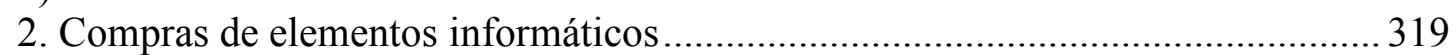

3. La Red Única Provincial de Comunicaciones de Datos .......................................... 324

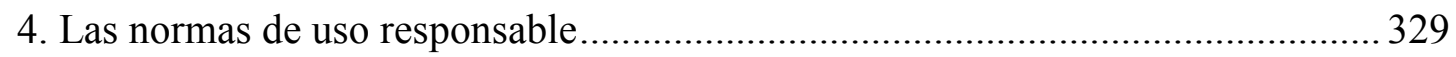




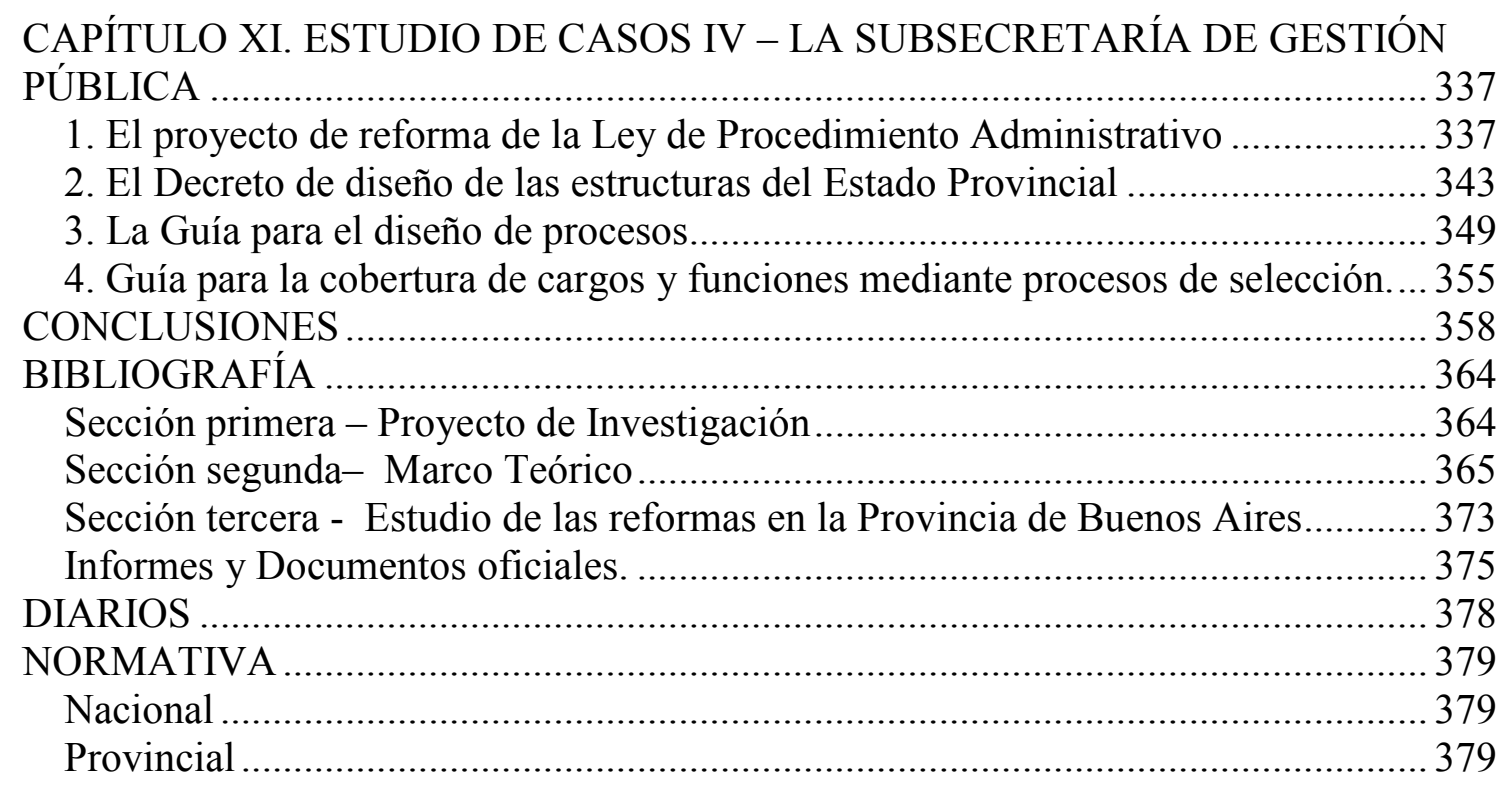


Dedicatoria

A Lorenzo, que no estaba

y ahora es 


\section{Resumen}

La tesis investiga las políticas de reformas administrativas y de modernización del Estado durante los años 2002-2007 propiciadas por el gobierno de la Provincia de Buenos Aires. Buscará dar respuesta a un conjunto de interrogantes claves que se platean a partir de ese proceso, desde los aspectos más teóricos e ideológicos hasta llegar a los aspectos prácticos, concretos, los resultados y la explicación de esos resultados. Así, preguntas tales como por qué reformar los aparatos Estatales aparece junto a preguntas vinculadas a los resultados efectivos de las políticas implementadas. Y es que no se puede, si se pretende realizar un análisis integral y multidimensional, soslayar la faz de diseño, ejecución y control de la política implementada.

Para ello se han estudiado los objetivos centrales trazados por el gobernador en materia de reforma del Estado y las diversas áreas con competencia para ello a lo largo de su gobierno: Secretaría para la Modernización del Estado y su Plan Rector de Modernización; Secretaría Ejecutiva de Gobierno Electrónico y el Plan Estratégico de Gobierno Electrónico; Subsecretaría de Gestión Pública y el Plan Trienal de la Gestión Pública, y analizaremos también el caso de la Subsecretaría Tecnológica y Administrativa con competencia en la temática para descubrir, implícitamente de las reformas propiciadas, un plan en sus acciones.

Durante su desarrollo podremos comprobar que no hubo coordinación en materia de reforma de la Administración Pública ya que no existió una visión armónica entre los distintos actores involucrados con competencia en la materia.

\section{Palabras Clave}

Administración Pública - Buenos Aires - Burocracia - Estado - modernización Reforma del Estado 


\section{Presentación}

La presente tesis para obtener el grado de Doctor en Ciencias Jurídicas de la Universidad Nacional de La Plata constituye una tesis complementaria a otra tesis presentada para obtener el título de Doctor en Ciencia Política, en la Facultad de Ciencias Sociales de la Universidad del Salvador, tesis que fue defendida en 2006.

Que sea complementaria no significa que no sea original. Por el contrario, entiendo que esta tesis completa, amplía y mejora la anterior. Y si no lo hace, al menos demuestra una continuidad en la preocupación de este tesista en ciertas problemáticas y ángulos de la investigación.

El estudio de las políticas de Gobierno Electrónico realizadas durante la gestión provincial del ex gobernador Felipe Solá (que fue el tema de aquella tesis) generaron la necesidad de investigar, desde otro ángulo, todas las políticas de reforma del Estado (y de la propia Administración) que estaban involucradas en aquél período analizado. Es decir, se cambió el foco, se pasó de estudiar una micro-política a una macro-política; varió no sólo la problemática sino nuestro objeto de estudio. En consecuencia nuestra hipótesis de partida en el presente trabajo es, también, una derivación de los resultados de la anterior; más aún, esos hallazgos generaron la exigencia de avanzar en el conocimiento profundizando en las políticas de reforma estatal.

Quien quiera tomarse el tiempo de leer la tesis anterior y compararla con ésta podrá comprobar que algunos datos que aquí aparecen están tomados de aquella (reelaboración y/o reinterpretación mediante). Esto significa una confirmación de lo que por entonces se había analizado pero también, y como veremos en los resultados y las conclusiones, que puesto en un contexto mayor, aquellos resultados y conclusiones alcanzan otra dimensión: lo que entonces parecía grave, aquí puede no serlo; lo que allí señalaba como una omisión, aquí puede ser visto como una decisión de otros actores que no había analizado; en definitiva, la política de gobierno electrónico que allí había abordado como objeto de estudio aquí se convierte en un elemento más, muy menor por cierto, de otro mucho mayor.

Estudiar políticas de un tiempo pasado, pero cercano en el tiempo, tiene muchas ventajas: examinar una gestión política que ya no existe nos permite distanciarnos un poco más de las acciones y estudiar sine ire et studio. Pero si bien la gestión ha finalizado, no los actores que la integraron y es en este contexto que se nos puede criticar por qué no seguir la serie un poco más allá para descubrir continuidades y quiebres pues estos podrían explicarnos decisiones (y omisiones) durante el período de estudio. Pero (otro pero más...) los equipos que se conforman en un gobierno pueden "pensar" distinto no sólo si lo hacen en forma individual; también piensan distinto (individualmente y en conjunto) cuando cambia el contexto. Por ello el análisis del contexto jurídico, social, económico y político del período en estudio juega un rol central.

¿Es esta una tesis jurídica? Sí, sin lugar a dudas. Aún cuando el análisis de la norma ocupe un rol de igual nivel que el sociológico, político e institucional, no es porque desprecie su valor. Por el contrario, de la lectura de la tesis se vislumbra la norma en toda su dimensión (dada por los actores que la crean, interpretan, aplican y/o hacen cumplir, esto es, que la hacen "viva") y no sólo como un elemento dado por El Legislador. Cómo ésta es mero formalismo de la decisión; cómo la realidad la desborda; cómo se transforma en letra muerta; cómo expresa objetivos deseados aunque no 
necesariamente realizables; cómo es buscada por algunos actores para modificar el estado de cosas y es desdeñada por otros por cristalizar ciertas formas de actuación; cómo legitima jurídicamente algunas decisiones y cómo no legitima necesariamente otras. Resulta evidente, a esta altura del conocimiento, que a la norma jurídica no la estudiamos sólo desde la norma jurídica y que debemos recurrir a otros procedimientos y herramientas hermenéuticas de análisis si queremos intentar realizar un estudio profundo de las causas y consecuencias.

Haré, antes de continuar, un detalle del contenido de los capítulos de la tesis y sus objetivos. Pero antes, quisiera aclarar que pese a reconocer que el proyecto de tesis no la integra, la he incorporado como Sección Primera pues el jurado (y mucho menos sus eventuales lectores) no suele tener al alcance de la mano cuáles fueron los objetivos generales, cuáles las hipótesis, cuál el estado del arte que, bien o mal, guiaron su elaboración. Por ello, la tesis propiamente dicha comienza en la Sección Segunda con el Marco Teórico, mientras que la Sección Tercera, estudia el caso concreto de reforma de la Administración Pública en la Provincia. Cada capítulo se estructura en cuatro secciones. Finalizo con un apartado de Conclusiones.

Capítulo 1. Si bien no puede confundirse la reforma del Estado con la reforma de la Administración Pública, en tanto la primera observa, describe y analiza las funciones estatales en el contexto de los grandes cambios históricos-ideológicos que legitiman la relación de mando y obediencia mientras que la segunda analiza las estructuras institucionales que ejecutan esas funciones, lo cierto es que no son independientes. Muy por el contrario, cómo la Administración Pública cumpla sus funciones, va a depender de para qué tipo de Estado lo haga. De allí la necesidad de estudiar a este último en el contexto actual de las reformas de la Administración Pública que se impulsan.

Resulta válido invertir la lógica de análisis de Aguilar Villanueva, para quien bajo toda teoría de la gestión pública ha de encontrarse siempre una cierta visión del Estado que responda por ella; aquí trataremos de ver con qué Estado estamos tratando para discurrir luego qué gestión pública les es aplicable.

Ahora bien, como señala Portinaro es muy común encontrar en la literatura de los últimos años, interrogantes acerca del poder del Estado, su futuro y su compleja acción de gobierno así como su capacidad de integración social. Se ha vuelto casi un leit motiv hablar de crisis, ocaso o más aún, del fin del Estado por la pérdida de poderes y funciones de los aparatos estatales.

La descripción del Estado que predomina hoy es la de un Estado débil, que ha perdido irremediablemente su soberanía en medio de la sociedad compleja. No es la intención de este capítulo dar cuenta de cómo, en esas afirmaciones, se esconden posiciones antipolíticas o que pretenden desplazar o hacer compartir la decisión política con otros actores (sean éstos, el tercer sector, las empresas o la sociedad civil) que no responden a la lógica de la responsabilidad democrática de validar el ejercicio o la renovación del poder mediante elecciones periódicas libres.

Resulta evidente que la producción de resultados justifica la existencia de cualquier institución pero no resulta obvio cuáles deben ser esos "productos" en una institución pública. Éstos se encuentran orientados por el modelo Estatal legitimado. Y este modelo ha cambiado (y mucho) en los últimos dos siglos.

Por ello, a muy grandes rasgos, en la primera Sección del primer capítulo veremos los síntomas de la crisis del Estado actual no sin antes indagar acerca de su génesis. En la segunda Sección, trataremos el acrecentamiento de las funciones del Estado liberal hasta 
la crisis del Estado social y su crítica/crisis desde una visión politológica. En la tercera Sección, desde una visión del derecho constitucional, se describe el crecimiento de las funciones estatales y la regulación, como nuevo modelo de intervención. Por último, trataremos el problema de la gobernabilidad y el debate conceptual. Veremos, en efecto, cómo el discurso de la crisis del Estado se traslada a la crisis de gobernabilidad.

Capítulo 2. Toda propuesta de reforma institucional no se basa ni en la situación real ni en las normas vigentes sino en ciertos criterios y valores deseables: qué es adecuado y quiénes deben hacerlo para lograr un estado de cosas buscado.

En el Segundo Capítulo, en la primera y segunda Sección, se realizará una conceptualización y comparación de las reformas del Estado de primera generación con las de segunda generación. Las primeras están fundadas en el Consenso de Washington y se las vinculadas con la transformación estructural de las funciones estatales. Legitimadas por la profunda situación de emergencia financiera y económica, por la deslegitimación de los modelos desarrollistas-autoritarios y por el colapso de los modelos socialistas de Europa del Este, el modelo neoliberal fue casi único en los esquemas de reforma. La República Argentina no fue ajena a la ola de "modernizaciones" que se dieron en todo Latinoamérica. Por ello, veremos ese proceso de reforma contextualizado en nuestra realidad.

Como ha dicho Zeller, el proceso de Reforma Estatal en un sentido integral comprende la dimensión política y la dimensión de los aparatos estatales. Este proceso en ambos niveles del Estado debe comprenderse -además- como una forma de resolución de la crisis política, económica y estatal que afectaron a la sociedad en las décadas de los años 70 y 80 .

A través de normas de "emergencia" se generaron facultades de policía extraordinarias que se le otorgaron al Estado, en particular al Poder Ejecutivo, con competencias para implementar las reformas que se consideran necesarias para superar situaciones consideradas excepcionales y de gravedad institucional más allá de las que podría realizar en tiempos de "normalidad". Estas normas restringieron, modificaron o limitaron los derechos constitucionales aunque la facultad nunca llegó a su desconocimiento o eliminación.

Hay en el debate actual distintas opciones de modelos de Estado que van asociados a diferentes concepciones de la gestión pública. Los temas recurrentes en las agendas de reforma han buscado modificar la capacidad institucional del Estado a través de una reestructuración organizativa, de la creación de la carrera pública profesional, de la desburocratización de normas y procedimientos y de la aplicación de las TIC en la gestión pública. Pero los objetivos son distintos.

Las de "Segunda Generación" estarían destinadas a la mejora del funcionamiento eficiente de las organizaciones estatales. En este caso, el fracaso de los resultados de la reforma de primera generación impulsó este cambio de perspectivas. Sin embargo, como veremos en la tercera Sección de este Capítulo, la Nueva Gestión Pública también logró abrirse paso entre las políticas de reforma. En la cuarta Sección de ese Segundo Capítulo veremos las políticas de Gobierno Electrónico, y desde la gestión de Obama, las de Open Government, como un nuevo intento en este proceso de reformas.

Capítulo 3. Como señaláramos, en el Capítulo primero se hizo una breve referencia a la crisis del modelo estatal y cómo esa crisis del Estado, como forma de organización 
política, se traslada a la crisis en la forma de gestionar analizada, ahora, como crisis de los gobiernos o de gobernabilidad.

Veremos en este capítulo, en su primera Sección, los aspectos teóricos relacionados con el gobierno y la administración, con especial énfasis en la organización legalburocrático y el modelo latinoamericano (segunda Sección).

Advertiremos que el concepto de administración, ya sea público o privado, está ligado al de eficiencia, relegando a un nivel secundario las referencias a los modernos objetivos de responsabilidad y rendición de cuentas.

En la tercera Sección analizaremos a la tecnocracia como un modelo de gestión con pretensión neutralizadora de lo político y cómo la lógica de eficiencia técnica pretende suplantar a la lógica de la decisión política.

En el marco de las demandas de mejoramiento de la calidad democrática (accountability) que se abordan en la cuarta Sección, finalizaremos con el estudio de los tipos de propuestas que existen para modificar las administraciones públicas y las naturales resistencias organizacionales.

Capítulo 4. Ante el colapso del modelo burocrático a finales de los años ochenta, los países de la OCDE propusieron reconsiderar la relación entre el administrador y el administrado considerando a la Administración como un servicio cuyo cliente es el público. Dichas políticas pusieron su acento en la necesidad de una modernización estructural del Estado a través de procesos de privatización, de la liberalización de una economía doméstica reorientada al exterior y de la gestión pública de los recursos.

En el ámbito latinoamericano, las propuestas de reforma han surgido desde el Centro Latinoamericano de Administración para el Desarrollo, más conocido como CLAD. E1 CLAD es un organismo público internacional, de carácter intergubernamental. Se constituyó en el año 1972 bajo la iniciativa de los gobiernos de México, Perú y Venezuela y su creación fue recomendada por la Asamblea General de las Naciones Unidas (Resolución 2802 - XXVI) con la idea de establecer una entidad regional que tuviera como eje de su actividad la modernización de las administraciones públicas como factor estratégico en el proceso de desarrollo económico y social.

Su misión es promover el análisis y el intercambio de experiencias y conocimientos en torno a la reforma del Estado y la modernización de la Administración Pública, mediante la organización de reuniones internacionales especializadas, la publicación de obras, la prestación de servicios de documentación e información, la realización de estudios e investigaciones y la ejecución de actividades de cooperación técnica entre sus países miembros y proveniente de otras regiones.

Institucionalmente es la secretaría técnica permanente de las Conferencias Iberoamericanas de Ministros de Administración Pública y Reforma del Estado que se realizan en el marco de las Cumbres Iberoamericanas de Jefes de Estado y de Gobierno. Bajo su propuesta, los Ministros de Administración Pública y Reforma del Estado han aprobado en las Cumbres la "Carta Iberoamericana de la Función Pública" en Bolivia en 2003, el "Código Iberoamericano de Buen Gobierno", en Uruguay, en 2006, la "Carta Iberoamericana de Gobierno Electrónico", en Chile, en 2007, la "Carta Iberoamericana de Calidad en la Gestión Pública", en El Salvador, en 2008 y la "Carta Iberoamericana de Participación Ciudadana", en Portugal, en 2009, entre otros documentos internacionales. Uno de estos documentos es el titulado "Gestión Pública Iberoamericana para el siglo XXI", en República Dominicana, en 2010 que, junto con el documento inicial "Una Nueva Gestión Pública para América Latina" elaborado en 
1998, marcan la línea doctrinaria de estado actual de la Administración Pública de América Latina y las principales líneas para su reforma.

Los documentos buscan la construcción de códigos deontológicos o de conducta que guíen el ejercicio correcto de la gestión pública y las orientaciones que en ellos se encuentran son críticas al modelo implantado desde el Consenso de Washington.

Siendo que estos documentos se constituyen en un horizonte hacia el cual los gobiernos de la región han pretendido reformar sus administraciones, corresponde exponer en este Capítulo los más representativos.

Capítulo 5. Iniciamos, en este Capítulo, la Tercera Sección de la tesis, aplicando el conocimiento teórico para el análisis del caso bajo estudio. En este Capítulo pretendemos dar cuenta del contexto jurídico, político, institucional de la Provincia de Buenos Aires que condiciona el accionar de los actores. En la primera Sección, se describe la estructura jurídica y capacidad institucional de la Provincia. Se inicia con un desarrollo de las estructuras y capacidades institucionales del Poder Ejecutivo, analizando las leyes ministeriales, empleo público provincial y su capacitación así como la distribución presupuestaria. Así, se advierten las distintas dimensiones de los Ministerios. En la Sección segunda se describen los factores geográficos y sociales de la Provincia: se analiza la distribución de la población, su crecimiento poblacional, nivel de instrucción y alfabetismo pero también se identifica cuáles son los principales problemas de la población.

La tercera Sección, analiza la evolución de los partidos políticos en la Provincia y la imbricación del destino político de la Provincia de Buenos Aires sobre el contexto nacional y de éste sobre aquél. Pero también se analiza el contexto económico: producto bruto geográfico, índice de desarrollo humano, Necesidades Básicas Insatisfechas, porcentaje de hogares en estado de pobreza e indigencia.

Por último, la cuarta Sección analiza los antecedentes de reforma en la Administración pública bonaerense, dando cuenta de los resultados de la reforma del Estado de primera generación; pero además, se da cuenta del contexto de crisis que precedió al inicio de la gestión.

Capítulo 6. Comenzamos el Capítulo sexto identificando cuáles fueron las directrices de reforma del Estado y de la Administración Pública según la visión del entonces Gobernador. Será importante detectar las orientaciones de la máxima autoridad para corroborar si estas directrices fueron seguidas por las áreas encargadas de llevarlas adelante.

Pero además realizaremos un análisis del discurso del gobernador para contextualizar si esa preocupación ocupó realmente un aspecto central de la agenda. Identificaremos, en las Secciones siguientes, las competencias jurídicas de las áreas que tuvieron acciones propias en materia de reforma: Secretaría para la Modernización del Estado (Sección segunda); Jefatura de Gabinete y Ministerio de Gobierno (Sección Tercera) y Secretaría General de la Gobernación (Cuarta Sección). Respecto de esta última, se analizan las competencias de las Subsecretarías de la Secretaría General dentro del Decreto $N^{\circ} 2.100 / 04$ y del Consejo de Gobierno Electrónico (Decreto N ${ }^{o} 1.824 / 02$ ), señalándose, por último, el poder relativo de las Subsecretarías.

Capítulo 7. El presente Capítulo de la Tesis describen los Planes que, en materia de reforma de la Administración Pública bonaerense en el período de estudio (2002-2007), 
fueron diseñados por la Secretaría para la Modernización del Estado: "Plan Rector de Modernización" (Sección Primera), la Secretaría Ejecutiva de Gobierno Electrónico: Plan Estratégico de Gobierno Electrónico (Sección Segunda) y la Subsecretaría de Gestión Pública: Plan Trienal de la Gestión Pública (Sección Tercera). Analizaremos también el caso de la Subsecretaría Tecnológica y Administrativa para descubrir, implícitamente, una línea coherente de acción (Sección Cuarta).

Se inicia así, a partir de los distintos actores que coparticiparon en el proceso de rediseño del Estado y la Administración, el estudio en general de los programas, planes y propuestas para llevarlo adelante. El estudio de las políticas concretas, está reservado a los cuatro capítulos subsiguientes, una reservado para cada área.

La comparación general nos permitirá ya descubrir, al menos en el plano teórico, las coherencias o incoherencias internas habidas en el seno de la misma organización y destacar a qué corriente teórica adscriben.

Capítulo 8. Como anunciamos en la síntesis del capítulo anterior, iniciamos en este Capítulo el estudio concreto de las acciones de reforma de la Administración y modernización del Estado a través del estudio, en este caso, de las acciones de la Secretaría de Modernización del Estado y del Ministerio de Gobierno. Así, dentro de la Sección primera, estudiamos las normas relacionadas con "Carta Compromiso"; "Banco de Proyectos Exitosos" y "Cuerpo de agentes de modernización". Aclaramos desde ya que el análisis es normativo sin perjuicio identificamos algunas acciones y proyectos específicos como derivaciones de aquellas. La Segunda Sección, titulada "La reforma política", se detiene tanto en el análisis de la Ley de internas abiertas, simultáneas y obligatorias como en el Programa Reforma Política.

La tercera sección trata los aspectos vinculados al voto electrónico con un análisis pormenorizado en la experiencia en la Provincia de Buenos Aires durante el período 2003. Finaliza el capítulo con una descripción de otras acciones emprendidas por Ministerio de Gobierno, entre ellas, de la Subsecretaría de Gobierno, la Subsecretaría de Relaciones Institucionales y la Subsecretaría de Asuntos Municipales.

Capítulo 9. El Capítulo indaga las acciones emprendidas por la Secretaría Ejecutiva de Gobierno Electrónico. Esta Capítulo es una síntesis de la tesis anterior. En él analizamos los proyectos del Sistema Informático Normativo Bonaerense (SINBA), Sistema Integrado de Emisión y Pagos No Impositivos (SIEP) y la Guía Única de Trámites (GUT) como parte de la primera Sección. Seguidamente, en la segunda Sección, analizamos desde el punto de vista cualitativo y cuantitativo las páginas web de los organismos oficiales a fin de corroborar su adecuación (o no) a las políticas institucionales de diseño. En la tercera Sección se aborda, el vínculo entre transparencia y rendición de cuentas de los funcionarios a través de las TIC en la Provincia. A través de un ensayo se intentó poner a prueba la asociación positiva entre ambos valores. La última Sección describe los vaivenes en el proceso de aprobación de la Firma Electrónica en la Provincia de Buenos Aires.

Capítulo 10. La Subsecretaría de Gestión Tecnológica y Administrativa no diseñó un plan explícito en materia de reforma de la Administración Pública del Estado bonaerense a pesar de haber sido, dentro de los límites de su competencia, un actor central de los cambios globales que estamos analizando. A pesar de ello, los principios de las reformas aplicadas pueden deducirse de los propios actos impulsados. Veremos 
cómo de esos principios se desprende la pretensión, así como la necesidad, de una significativa transformación y fortalecimiento de las instituciones. En este anteúltimo Capítulo, nos detenemos, en primer lugar, en una innovación en materia de contrataciones públicas: el proceso de creación de los pliegos tipo y otros documentos estandarizados. En la segunda Sección, veremos cómo mediante la aplicación de esos elementos estandarizados, pero sobre todo con el proceso de compra unificada, se realizó la compra de elementos informáticos. Ello nos permitirá analizar, como un logro, el menor valor por la compra unificada a la par de la mayor concentración de poder de la Subsecretaría y por otro lado cómo han adquirido los diferentes Organismos de la Administración en cantidades globales y relativas según presupuesto y cantidad de empleados. En tercer lugar, veremos el proceso de licitación de la Red Única de Comunicación de Datos, el proceso licitatorio más grande de la gestión del gobernador. Por último, estudiaremos el caso de la reforma en materia de usos permitidos de elementos informáticos, no sólo por la innovación que significó permitir que éstos fueran utilizados por los empleados para un uso personal, disminuyendo así la brecha digital, sino también por el proceso de sanción que dio cuenta de los debates internos por visiones contrapuestas entre distintos actores y cómo este se resolvió a través de un proceso colaborativo.

Capítulo 11. El último Capítulo analiza las acciones de la otra área con competencia en materia de reforma: la Subsecretaría de Gestión Pública. En este caso, analizamos las políticas que identificamos, por su contenido, como centrales para el objeto de la tesis: el Estado y la Administración Pública deseada, aún cuando reconocemos que las acciones de la Subsecretaría, sobre todo en materia de capacitación, han sido muy buenas. Así, en la Sección primera, se estudia el proyecto de reforma de la Ley de Procedimiento Administrativo. En segundo lugar, el Decreto de diseño de las estructuras del Estado Provincial. La tercera Sección analiza la Guía para el diseño de procesos y finalizamos con el estudio de la Guía para la cobertura de cargos y funciones mediante procesos de selección. Todas estas acciones han sido llevadas adelante por la Dirección Provincial de Gestión Pública. Aún cuando resultan importantes otras acciones de áreas dependientes de la Subsecretaría, como las acciones de capacitación llevadas adelante por el I.P.A.P., hemos seleccionados esas políticas por ser representativas de los cambios pretendidos en la forma de organización y Estado.

Además de pasar por la mirada (indulgente, por cierto) de los Directores, alguno de los Capítulos de esta tesis ya han sido sometidos a evaluación y puestos a consideración de la "Comunidad Científica" (si es que ella existe) a través de su publicación en Revistas Científicas, Jornadas y grupos de investigación. Casi toda mi producción en estos últimos años, por un principio de "economía de esfuerzos" ha estado orientada a ello.

Así, he publicado "El gobierno y la administración en Julien Freund après une lecture de Max Weber" en Corbetta Juan Carlos y Ricardo Sebastián Piana (Comp.), 2010, Julien Freund. El valor de lo politico, Ed. Prometeo, Buenos Aires; "Las Cartas Iberomericanas para una gestión pública de calidad. Orientaciones y buenas prácticas" en Revista Aportes para la Integración Latinoamericana Año XVI, No24 /junio 2011; “¿Por qué hay que regular la participación? Las lecciones de la Carta Iberoamericana de Participación en la Gestión Pública para la generación de proyectos sustentables" en 
Manuel Cienfuegos Mateo, Wilson N. Fernández y Noemí B. Mellado (Eds. y Dirs.), 2012, Desafios del desarrollo de la infraestructura regional para el medio ambiente, la cohesión social y la gobernabilidad del MERCOSUR, Montevideo; y "De las políticas de Gobierno Electrónico a las de Open Government. La reforma dentro de la reforma" en Noemí B. Mellado (Ed. y Dir.), 2012 Instituciones, comercio y cooperación monetaria en la integración sudamericana: sus efectos sobre la gobernabilidad regional. Editorial Lerner, Córdoba.

Participé con una ponencia, embrionaria de esta tesis, titulada "Análisis de las distintas estrategias de reforma de la gestión pública en la provincia de Buenos Aires (20022007)" en las V Jornadas de Sociología de la Universidad Nacional de La Plata realizadas los días 10, 11 y 12 de diciembre 2008 y, dos años más tarde, con "La Carta Iberoamericana de Participación Ciudadana en la Gestión Pública" en la VI Jornadas de Sociología de la Universidad Nacional de La Plata realizadas los días 8 y 9 de diciembre 2010 .

Esta difusión previa no hace perder su originalidad pues una tesis no es un trabajo secreto sino que debe contrastarse (validarse mediante la falsación, diría un metodólogo popperiano) y no hay contrastación sino es mediante su difusión, discusión $\mathrm{y}$ retroalimentación de los colegas.

La Bibliografía se ha agrupado según las Secciones. Ello busca facilitar al lector la identificación de los libros, informes y diarios que le han dado sustento teórico, metodológico.

Los agradecimientos... a todos. Todos han ayudado, de una u otra manera, a ser quien soy. Esta tesis es un reflejo, no representativo, claro está, de quien soy. 
SECCIÓN PRIMERA - PROYECTO DE INVESTIGACIÓN 


\section{PRIMERA PARTE - PRESENTACIÓN DEL TEMA Y DEL PROBLEMA}

Los cambios en la administración de los asuntos públicos suelen traer aparejados transformaciones normativas y organizativas que buscan legitimar su accionar, obtener recursos y viabilizar la implementación de nuevas políticas. Algunas modificaciones requieren cambios significativos en las estructura organizacional junto con la creación de nuevos roles y la desaparición de otros, la redesignación de áreas con otros nombres que expresen mejor los propósitos perseguidos e incluso la fusión o separación de distintos ámbitos de acuerdo con los intereses particulares del momento y del grupo político a cargo (Camou, 2005).

La propuesta plantea investigar las políticas de reformas administrativas durante los años 2002-2007 propiciadas por el gobierno de la Provincia de Buenos Aires. Varias razones justifican la selección.

En primer lugar, y como dimensión temporal, se propone estudiar un período finalizado. A diferencia del gobierno nacional, cuya continuidad, con matices, desde 2003 a la fecha es clara, se propone evaluar las políticas durante una gestión ya cerrada. Si bien el ex gobernador cumple desde la Cámara de Diputados un rol preponderante dentro de la oposición justicialista al gobierno, no tiene, desde ese ámbito, competencia en las políticas que se proponen investigar.

En segundo lugar, la relevancia de la unidad de análisis. Debe considerarse que es la Provincia con mayor población, aporte al PBI nacional y la segunda en extensión territorial. Además cuenta con sectores de población bien diferenciados, tanto en lo geográfico como en lo socioeconómico y es por ello, representativa del contexto nacional.

No es necesario, en nuestro contexto, resaltar la importancia de la Provincia de Buenos Aires en cuanto a su población, producción y superficie1. Sí, tal vez, su carácter representativo de las propias diferencias que existen en todo el país: geográficamente ocupa menos del $10 \%$ del territorio nacional, pero su población, que alcanza los 15.625.084 habitantes según el censo 2010, tiene el 38,94\%. Además, en ella puede verse reproducida la desigual distribución de la población: en el conurbano, que ocupa una superficie de $3.630 \mathrm{Km}^{2}$, esto es, un porcentaje de $1,2 \%$ respecto de la superficie total, habita el $63 \%$ de su población. Por ello, al igual que de la Argentina, de la Provincia de Buenos Aires puede decirse que es un Estado macrocefálico.

En términos políticos, más allá del fenómeno de subrepresentación medida en cantidad de diputados nacionales que aporta al Congreso sobre cantidad de población

\footnotetext{
${ }^{1}$ Desde el punto de vista económico se constituye en la Provincia de mayor peso relativo en cuanto al tamaño de su economía, siendo, por otro lado, la que posee mayor grado de diversificación productiva. La Provincia de Buenos Aires es la segunda provincia en extensión territorial: tiene una superficie de $307.571 \mathrm{Km}^{2}$, lo cual representa un $8,26 \%$ respecto del total del país. Sin embargo, el Producto Bruto Geográfico es de aproximadamente, el $35,5 \%$ del total nacional. Los últimos datos son de la Dirección Provincial de Estadística, del 2006. http://www.ec.gba.gov.ar/Estadistica/pbg/pbg3.html Fecha de Consulta: $1 / 12 / 10$.
} 
(Reynoso, 2005) $)^{2}$, su número en términos absolutos no es nada despreciable: 35 diputados nacionales en cada elección. ${ }^{3}$ Por otro lado, esa magnitud poblacional hace que, como puede advertirse cada vez con más fuerza, las estrategias nacionales se "jueguen" en el territorio bonaerense ${ }^{4}$.

El tema a estudiar tiene, además, singular trascendencia. Desde el retorno a la democracia hemos comprendido que el proceso de legitimación de los gobiernos requiere algo más que elecciones limpias, periódicas y plurales. Hay que conservar esa legitimidad arquitectónicamente: el gobierno debe demostrar que tiene una capacidad probada para dar respuesta a las demandas y expectativas sociales creadas. Pero también hay que conservar esa legitimidad horizontalmente: haciendo a los actores copartícipes de la gestión y de los procesos de decisión en un esquema de participación democrática.

Más allá de la reciente -y bienvenida- emergencia de estudios político-sociales a nivel subnacional, el análisis de las políticas de reforma del Estado y de la Administración Pública en la provincia de Buenos Aires tiene un importante valor empírico, tanto por la representatividad señalada más arriba como por las políticas que estudiaremos y los resultados a los que esperamos arribar.

En efecto, a diferencia de otras jurisdicciones, se han detectado áreas y planes específicos de reforma durante el período en estudio. Las conclusiones a las que arribaremos serán teóricamente relevantes y demostrativas de las diferentes políticas de reforma que se dan en nuestros Estados. Justamente, y como conjeturamos en la hipótesis, se han dado políticas contradictorias en materia de reforma de la Administración y es por ello que el estudio de esta problemática es relevante en sí misma.

Nuestra investigación buscará dar respuesta a un conjunto de interrogantes claves que se platean a partir del proceso de modernización del Estado y de la Administración Pública en la Provincia de Buenos Aires:

- ¿Por qué reformar los aparatos Estatales?

- ¿Cuál es la concepción del Gobernador sobre la organización del Estado, de la Administración Pública y su funcionamiento?

- ¿Qué políticas de reforma de la Administración Pública se han llevado adelante?

\footnotetext{
2 Según la investigación referenciada, el distrito de Buenos Aires está subrepresentado en aproximadamente un $9,5 \%$ en su magnitud de distrito.

${ }^{3}$ Es decir, los 70 diputados elegidos por la Provincia de Buenos Aires, ocupan poco más del $27 \%$ del total de la Cámara baja.

${ }^{4} \mathrm{Su}$ peso específico en el contexto nacional la hace estar presente en cualquier de los grandes acontecimientos nacionales. Buenos Aires no fue ajena a los clivajes de la política nacional de los últimos años. Más aún, algunos de ellos acaecieron antes en la provincia, como lo fue la ruptura Solá-Duhalde, que la ruptura en la Nación, Kirchner-Duhalde. Por ello, si bien es cierto que la hegemonía ininterrumpida del Partido Justicialista en la provincia, desde el año 1987 hasta la actualidad, expresa un electorado significativamente fiel, en buena medida cautivo (Camou, 2005), el ex gobernador Solá no gozó de los beneficios de la hegemonía del partido, pues pese a contar con mayoría formal en ambas Cámaras, la disciplina partidaria se encontró en crisis como consecuencia de la ruptura que señalamos más arriba. En materia económica, la provincia tampoco fue ajena a la gravedad de la crisis económica y social desatada en el país a partir de diciembre de 2001: fue en ese contexto de crisis económica y social generalizada que asumió la gestión del ex gobernador Felipe Solá en enero de 2002.
} 
- ¿Bajo qué concepción teórica se inscribieron las políticas de modernización de la Administración Pública bonaerense?

- ¿Existió una única línea teórica y de acción? ¿Son compatibles las políticas de modernización y reforma impulsadas?

- ¿Cuál ha sido el resultado de las políticas de modernización a través del uso de las TIC?

- ¿Quiénes han intervenido - más allá de las competencias formales-en el proceso de formulación e implementación de dichas políticas?

A través de la investigación intentaremos dar una respuesta a esas preguntas que surgen del análisis de la situación en la Provincia de Buenos Aires en materia de modernización de la Administración Pública durante los años 2002-2007.

\section{SEGUNDA PARTE - ESTADO DE LA CUESTIÓN}

El Estado, como la comunidad política superior de la modernidad, es un fenómeno complejo y puede ser estudiado desde distintos niveles. Según Alford y Friedland (1991) hay tres perspectivas teóricas para estudiarlo. En primer lugar, se deben observar las relaciones contradictorias del Estado entre sus aspectos capitalista, burocrático y democrático. Estas dimensiones lo constituyen en el nivel social. En segundo lugar, el Estado puede ser visto como compuesto por redes organizacionales, observando sus estructuras, que difieren en su capacidad política y legal para controlar recursos internos y externos, los aspectos presupuestarios, el personal que integra su estructura y los apoyos políticos que puedan existir. En tercer lugar, el Estado es también un ámbito en el que se definen decisiones sobre las que los distintos grupos tratan de influir. Los hechos resultantes pueden ser diversos y dependen de los intereses en disputa y de las capacidades que estos grupos puedan desplegar.

Nos detendremos, en esta investigación, en la segunda de las perspectivas anotadas más arriba. Es que en los últimos años el Estado ha sufrido una profunda metamorfosis en su rol frente a la sociedad, en su organización interna, en el perfil de su personal y en la composición de su presupuesto. Estas transformaciones han modificado sus funciones fiscales, funcionales y de poder con las instancias estatales subnacionales, con el mercado, con las organizaciones sociales y con actores del contexto internacional (Oszlak, 2000).

La gran mayoría de los autores hablan indistintamente de reforma del Estado y de la Administración Pública, sin embargo, mientras la primera observa, describe y analiza las funciones estatales en el contexto de los grandes cambios históricosideológicos que legitiman la relación de mando y obediencia, la segunda analiza las estructuras institucionales que ejecutas esas funciones; esto es, mientras la primera 
estudia qué hace el Estado, la segunda, cómo lo hace ${ }^{5}$, o como lo ha dicho Hintze (2001:1), "las decisiones sobre el qué hacer se refieren a las relaciones entre el Estado y la sociedad y las organizativas a cómo el aparato administrativo hace lo que hace". Lo cierto es que, como veremos, la reforma de la administración en nuestros países, ha implicado una verdadera reforma del Estado: el achicamiento y aplastamiento de la pirámide; recorte de sueldos y jubilaciones; privatizaciones y transferencias al sector privado han implicado, modificaciones en el ámbito social, político y económico.

Como ha señalado Oszlak en varios de sus trabajos, es necesario efectuar una verdadera reestructuración organizativa del Estado. Una estructura bien diseñada debe reflejar, implícitamente, un esquema racional de diferenciación, especialización e integración que prevea una óptima asignación de responsabilidades y recursos ${ }^{7}$.

Durante las últimas décadas se han aplicado distintos mecanismos para la reforma del Estado y de la Administración Pública. Pero como bien sostiene Groisman (1991:16),

... la reforma administrativa suele asociarse al concepto de modernización que es utilizado con cierta ligereza. Tiene una connotación positiva en cuanto está asociado a la idea de progreso, de adaptación a los fenómenos contemporáneos, de recepción de nuevas técnicas, adelantos y descubrimientos. Pero entraña la posibilidad de convertirse en una noción ambigua o encubridora, de amparar la moda o de sobrevalorar la función técnica frente a la política.

De ahí la necesidad de encuadrar las acciones que se han implementado en estos últimos años independientemente de su rótulo.

En verdad, las políticas de reforma del Estado y de la Administración Pública se adscriben a teorías más generales sobre la modernización ${ }^{8}$. Sin embargo, no existe una noción clara del concepto de modernización pese ser una de las temáticas claves de las

\footnotetext{
${ }^{5}$ En ese sentido, nuestro estudio estará limitado al análisis de las reformas administrativas. No obstante, el análisis de la reforma del Estado aparecerá constantemente porque necesariamente la Administración refleja un cierto tipo de Estado.

6 Agrega el mismo autor: "En este segundo nivel se concentran las llamadas reformas de segunda generación o reformas "hacia dentro", que tienen que ver con la las tecnologías de gestión y también con la eficiencia y la eficacia institucionales" (Hintze 2001:1). De una forma similar, Blautman ha dicho que mientras que la Reforma del Estado implicaría cambios estructurales en el ámbito social, político y económico, la Reforma Administrativa produciría modificaciones, sustancialmente en las formas de gestión del aparato público (Blutman, 1998). Echebarria Ariznabarreta (2000), por su parte, distingue las reformas institucionales, que son las que afectan el diseño y funcionamiento de las instituciones de las reformas sustanciales que afectan el contenido de la acción pública, redefiniendo su finalidad, objetivos y alcance

${ }^{7}$ Sin embargo, la realidad nos indica que las estructuras son creadas en función de las personas; por la necesidad de ubicar a alguien en una posición de alta responsabilidad por reubicar funcionarios políticos caídos en desgracia o "jerarquizar" personal cuando la estructura establece un techo a la carrera o el nivel de remuneración es magro. Sin embargo, hay que conseguir que el tamaño, esquema de división del trabajo y asignación de competencias y recursos, se ajusten a la misión que la organización debe cumplir, teniendo en cuenta un conjunto de metas y resultados deseables a lograr en el tiempo.

${ }^{8}$ En efecto, estos temas derivan en posicionamientos epistemológicos más profundos que nos excusamos de ahondar por ser material para una discusión filosófica que excede el tema de esta investigación.
} 
ciencias jurídicas y sociales a diferencia del concepto modernidad sobre el que existe una abundante (aunque no siempre coincidente) bibliografía.

Conceptualizaciones tan amplias como las que aparecen en el Diccionario de Política dirigido por Bobbio, Matteucci y Pasquino (1982) ${ }^{9}$ hasta los estudios de los trastornos sociales que producirían los procesos de anomia generados por los problemas de adaptación a las condiciones sociales industriales ${ }^{10}$, pasando por los estudios de eficiencia y eficacia económica en matriz de producción económica, todos ellos hacen referencia a la modernización desde distintas ópticas y matices.

De forma amplia la modernización ...

consiste en un cambio cada vez más acelerado e intenso de todas las estrcuturas sociales. Nuevas tecnologías, nuevos grupos -ascendentes y descendentes-, nuevos problemas, nuevas potencialidades, son el producto de la modernización. Como si se tratara del dibujo de una espiral, los parámetros de las situaciones posteriores son cambiados por los resultados de la actividad derivada de las situaciones anteriores. (Bouza-Brey, 1999:77).

Como agrega el autor citado más arriba, necesariamente el proceso de modernización va asociado al de secularización, puesto que si todo puede (o parece ser) modificado por la acción humana, lo sagrado, lo inmutable, los mitos se desvanecen.

Respecto al concepto de reforma, Julien Freund (1968) ha puesto de relieve la relación entre este concepto y el de revolución. La revolución adquiere un significado nuevo en la literatura política italiana de los siglos XIV y XV, en que la rivoltura o rivoluzione fue empleada como el primer equivalente de los trastornos negativos que la Edad Media llamaba seditio o rebellio, y más tarde, movimientos positivos de la reformatio, renovatio o restitutio. Y agrega:

Así, la literatura política italiana utiliza preferentemente el término [revolución] para designar la empresa que consiste en liberar una colectividad de un tirano para restablecer el antiguo orden. Los conceptos de reformatio, renovatio o restitutio contienen, asimismo, la idea de una vuelta a lo «verdaderamente antiguo» (Freund, 1968:720).

Hay, consecuentemente, asociado al concepto de reforma, tanto la idea de retorno como la de progreso. Sólo con la Ilustración y su fe constante en el poder de la razón humana se asociará la reforma sólo al progreso. En efecto, la idea de progreso es esencial para el pensamiento iluminista: supone la historia como un proceso en que los

\footnotetext{
${ }^{9}$ Entiende a la modernización como aquel conjunto de modificaciones operadas en las esferas política, económica y social que vienen caracterizando los dos últimos siglos.

${ }^{10}$ Ya estudiados por Durkheim.
} 
hombres alcanzan, lenta pero inexorablemente, una dirección definida y deseable y que ello será indefinidamente para gozar, en el término, de la felicidad. ${ }^{11}$

Ahora bien, si nos centramos en el uso que sobre estos conceptos se han hecho en los últimos años, resulta evidente que se espera que los científicos sociales no sólo comprendan este proceso de modernización y reforma, pero también que lo conduzcan y dirijan. En la práctica, la modernización requiere la capacidad de cada gobierno para aprender de situaciones y encontrar atajos a la modernidad, es decir, planificar comportamientos estratégicos (Guerreiro Ramos, 2008) ${ }^{12}$.

Según Fleury (1999) el proceso de reforma del Estado, y de redefinición de sus relaciones con la sociedad, es un proceso eminentemente político, a través del cual se están reconfigurando las relaciones de poder en las sociedades latinoamericanas. Para Oszlak (1999) la reforma administrativa es un esfuerzo sistemático y masivo orientado hacia la transformación de ciertas características del aparato del Estado, con la intención de dotarlo de mayor eficiencia y eficacia. La reforma Estatal apareció como un dispositivo, mecanismo y herramienta para reinventar el Estado, o, como dice Zeller, una forma de resolución de la crisis política, económica y estatal que afectaron a la sociedad en las décadas de los años `70 y ` 80 (Zeller, 1997).

La crisis de la deuda desató en los '80 un largo y desigual proceso de reformas estructurales ante la insuficiencia de las tradicionales políticas de ajuste y estabilización para ofrecer respuesta a la crisis. Muchas de de estas reformas estructurales eran a la vez reformas del Estado, ya porque afectaban el papel del Estado en relación con la economía y sus funciones sociales (Paramio, 2002). Buscaron reducir las dimensiones del sector público, incluyendo a menudo las de la propia administración, y que el mercado se encargara de la provisión de un buen número de bienes públicos que anteriormente suministraba el Estado.

La mala imagen de la burocracia, la corrupción, el clientelismo y nepotismo, la falta de una carrera civil administrativa y de transparencia, el déficit en los controles

\footnotetext{
11 Pero este progreso debería ser obra exclusiva del hombre y de su naturaleza social, sin ningún factor externo, pues en caso contrario, la idea de progreso se confundiría con la de Providencia.

${ }^{12}$ Guerreiro Ramos (2008) identifica dos grandes corrientes sobre la modernización de los Estados. Para una de ellas, hay una ley de la necesidad histórica que obliga a cada sociedad a tratar de llegar a la fase que han alcanzado los llamados países desarrollados. Las que no han llegado, se representan a sí mismas como "en desarrollo", a la espera de alcanzar la imagen de un futuro deseable que tiene como arquetipo, más o menos identificado, la etapa actual de desarrollo de Europa occidental, Japón y los Estados Unidos. En esta visión, más determinista, se advierten "barreras para el desarrollo" o "pre-requisitos de la modernización". Por el contrario, la otra corriente entiende que la "modernidad" no está, precisamente, ubicada en algún lugar del mundo ni tiene que ser identificada con un arquetipo; cada nación, sea cual fuere su configuración actual, siempre tiene la oportunidad de modernizarse según su propio esquema. En esta última posición se advierte una concepción de la realidad histórica y social que es el resultado de una tensión permanente entre posibilidades objetivas y la elección humana. Así, dado que para el primer caso se supone que hay una trayectoria histórica de los acontecimientos que se define como un resultado de un juego de causas absolutamente necesarias, sus partidarios creen que es posible obtener un conocimiento racional global de este curso de los acontecimientos. Por el contrario, la otra posición, al admitir que las causas no son absolutamente necesarias y que las elecciones humanas están siempre en interacción con factores objetivos para que los acontecimientos se produzcan, afirma que nuestra capacidad de comprensión de la realidad está siempre limitada por restricciones contextuales, es decir, sólo podemos comprender la realidad por prueba y error de forma tal que asume que la comprensión de la realidad exige un compromiso de participación en ella. En esta última tesis, se inscribía el sociólogo y político brasilero.
} 
públicos, legitimaron en América Latina las reformas iniciales, especialmente, las consignas de la Nueva Gestión Pública asociadas al control de la gestión pública.

Las privatizaciones pretendieron introducir los beneficios de la disminución en el costo y aumento de la calidad gracias a la competencia; mejora de la eficiencia en la prestación de servicios y en la asignación de recursos; inversión de recursos privados y disminución del gasto público. Los proyectos han pretendido optimizar la calidad en la prestación de servicios públicos haciendo más eficiente la distribución del gasto público siempre con miras a lograr el tan ansiado equilibrio fiscal.

Muchas de sus consignas en cuanto al diseño del Estado nos son conocidas: achicamiento del Estado, privatizaciones, disciplina fiscal y reducción de costos. En cuanto al diseño institucional, todos los proyectos de modernización del Estado han tenido a la reforma administrativa como uno de sus ejes centrales.

Pese a una década de reformas, continuaron los mismos vicios que se creían superar. En materia de personal, la falta de evaluación de desempeño "igualó" al personal en los incentivos salariales, y además, hubo reducciones de sueldos y un achatamiento de la curva salarial y de los salarios promedio. Por otro lado, el ingreso irrestricto de personal y la crisis presupuestaria, reprodujo el congelamiento de las vacantes y la habilitación de unos pocos puestos de trabajo a los que se accedió sin concurso (nepotismo político). En materia de gastos, pese al desprendimiento de funciones, privatizaciones y políticas de restricción de personal, los gastos de la Administración Pública Nacional, Provincial y Municipal aumentaron sin que los ciudadanos percibieran que ese incremento se haya trasladado a una mejora en la calidad de los servicios que presta.

Cuando el optimismo inicial sobre los resultados inmediatos de ese nuevo modelo se desvaneció y se comenzó a prestar mayor atención al marco institucional y a las condiciones sociales como precondiciones para un crecimiento económico duradero a medio y largo plazo, se difundió el uso de la expresión de reformas de segunda generación para hacer referencias a aquellos cambios institucionales precisos para que las diferentes economías nacionales pudieran atraer la inversión.

Las llamadas reformas de segunda generación, a diferencia de las de primera generación, apuntan a la reestructuración organizativa del aparato administrativo, al rediseño de las plantas de personal estatal, a la desburocratización de normas, procesos y trámites administrativos, a la implantación de sistemas de carrera administrativa basados en el mérito, a la capacitación y desarrollo permanente del personal y al mejoramiento de los sistemas de información y sus soportes computacionales (Oszlak, 2003).

Por ello se ha dicho que luego de las reformas estructurales de primera generación, los procesos de "modernización" de la gestión pública buscaron introducir nuevas lógicas en la forma de actuación de las instituciones gubernamentales haciendo énfasis en la ampliación de la capacidad institucional y en la eficacia de la acción estatal para el buen funcionamiento de los mercados (López, 2005).

Si bien la naturaleza y la velocidad de las innovaciones suelen ir más lentas que lo que el paradigma vigente entiende por "buen gobierno", lo cierto es que no se advierten tampoco hoy los resultados esperados. 
Los procesos de reforma y modernización democrática deben contribuir a legitimar los gobiernos. La necesidad de un cambio surge impostergable cuando los resultados de la democracia en América Latina están revelando una crisis en los modelos institucionales que hace peligrar la gobernabilidad democrática.

Argentina es, tal vez, el país en el que se han producido las transformaciones más radicales en la configuración, tamaño y papel del estado nacional, todo ello, en menos de una década, la de los '90. Tiene hoy uno de los aparatos estatales de nivel nacional más pequeños del mundo, al menos en relación a su población y PBI. Las reformas de segunda generación, que debían modificar este estado de situación, frente a la gran desconfianza que generaron las reformas estructurales de los ' 90 , han estado en un segundo plano en la agenda del Estado.

En cuanto a los estudios sobre la provincia de Buenos Aires, el vacío teórico es sorprendente. A pesar de este nuevo interés por los estudios locales, el análisis de la reforma del Estado y de la Administración pública provincial, desde la perspectiva que aquí propiciamos, es evidente. Es cierto que desde el derecho público provincial se estudian las instituciones que forman el cuerpo del Estado bonaerense, pero su estudio está más enfocado al análisis de las competencias constitucionales y legales de los organismos e instituciones, sus equilibrios y controles. El estudio de los proyectos, en este caso de la reforma del Estado y la Administración bonaerense, desde la fase de su diseño, aprobación, ejecución y control, ha quedado circunscripto, casi con exclusividad, a los informes o anuarios de los propios organismos de la Administración Provincial $^{13}$. Salvo el caso del estudio de Antonio Camou (2005) desde la Facultad de Humanidades y Ciencias de la Educación de la UNLP, aunque co-financiado por la CIC y la entonces Subsecretaría de la Gestión Pública de la Provincia, no hemos detectado otros estudios similares.

\section{TERCERA PARTE - HIPÓTESIS, OBJETIVOS Y METODOLOGÍA}

\section{Hipótesis}

Nuestra hipótesis central sostiene que no hubo coordinación en materia de reforma de la Administración Pública ya que no existió una visión armónica entre los distintos actores involucrados con competencia en la materia. Entendemos que:

- más allá de las fuertes críticas a la organización burocrática, se ha instalado una concepción de la reforma sostenida en las bases teóricas de la Nueva Gestión Pública con pocos procesos innovadores;

- no se han creado esquemas participativos y que las politicas de reforma están asociadas a mejorar la eficacia de los servicios actuales;

- siguiendo la distinción que al respecto realiza Camou (2001) podrán advertirse, al menos, tres visiones de la gobernabilidad dentro de una misma gestión: una visión relacionada con la eficacia (realismo político) en el primer Secretario de Modernización y luego Ministro de Gobierno,

\footnotetext{
${ }^{13}$ Ellos serán nuestro principal insumo documental junto con las leyes, decretos y expedientes.
} 
Cr. Florencio Randazzo; otra visión relacionada con la legitimidad (tradición del buen gobierno) en la entonces Subsecretaria de Gestión Pública y otra con el orden (estabilidad del sistema) en la Subsecretaría de Gestión Tecnológica y Administrativa.

- las experiencias exitosas de modernización están asociadas a la innovación y exploración, siendo central para ese éxito la detección de las necesidades reales y concretas.

\section{Objetivos}

Se plantea como objetivo general estudiar las políticas de reforma de la administración pública en Provincia de Buenos Aires durante el período 2002-2007. Como objetivos específicos se pretende:

- Identificar planes, proyectos, programas y normas de reforma de la administración y áreas con competencia;

- Estudiar en profundidad el Plan Rector de Modernización del Estado, el Plan Estratégico de Gobierno Electrónico y el Plan Trienal de la Gestión Pública 2004-2007, destacando objetivos y resultados e identificando la corriente en la cual se inscriben.

- Analizar el contenido de los planes, proyectos, programas y normas identificados;

- Detectar, sobre la base de la información obtenida, orientaciones técnicas y/o ideológicas de las políticas.

\section{Metodología}

Es posible distinguir dos niveles de análisis: a) Macro-organizacional: consistente en reformas constitucionales, cambios en las leyes de ministerios, planes de gobierno (de desarrollo, de seguridad, de privatización, etc.) ${ }^{14} \mathrm{y}$, b) Microorganizacional: hace referencia a las medidas explícitas de ordenamiento $\mathrm{y}$ racionalización de órganos de la administración central, empresas estatales, organismos descentralizados, proyectos de capacitación y/o profesionalización de los agentes públicos, etc. (conf. Zeller, 2007) ${ }^{15}$. Nuestra investigación, como hemos adelantado, se centrará, principalmente, en este último.

Trataremos de dar respuesta en esta investigación a las preguntas planteadas y contrastar las hipótesis elaboradas a través de un diseño de investigación descriptivo y a medida que se desarrolla se tratará de buscar un grado mayor de profundización, tratando de dar explicación al fenómeno estudiado. Para ello se tomarán críticamente los

\footnotetext{
14 En este grupo se nuclearán también todas aquellas medidas orientadas a una "refuncionalización" del aparato estatal - Reforma del Estado, corrimiento de las fronteras' entre éste y la sociedad.

15 Dentro de este nivel correspondería a las Reformas Administrativas, es decir, hacia el interior del propio aparato estatal - aunque no por ello inocuas para la sociedad.
} 
conceptos y los presupuestos desarrollados por la teoría actualmente existente, tomando las principales notas de cada uno de los modelos teóricos de reforma a fin de identificar las acciones concretas implementadas más allá de lo discursivo.

Si bien nuestra unidad de análisis es más controlable y estable que las unidades nacionales, no dejan de existir problemáticas en el estudio relacionadas con la ausencia de indicadores específicos y estándares para las unidades subnacionales. Para salvar ese vacío metodológico, se combinarán técnicas cuantitativas y cualitativas de análisis.

Teniendo en cuenta que las reformas de primera generación han generado como resultados cambios en la organización interna del Estado, en el perfil de su personal y en la composición de su presupuesto, será necesario analizar estos tres aspectos a fin de contrastar nuestra hipótesis principal.

Atento a que las políticas de reforma del Estado comprenden tanto la dimensión política, jurídica y la dimensión de los aparatos estatales, como bien advierte Zeller (2007) una estrategia posible para conocer la política de reforma estatal en su conjunto podría ser relevar y sistematizar el marco normativo que inicia el ciclo de formulación e implementación de las políticas públicas, pero esta fuente de datos también presenta numerosos problemas:

a) las normas pueden no estar vigentes, o por efectos de su reglamentación ser de alcance parcial, o modificadas por otras normas posteriores.

b) la norma, nada nos dice de su real grado de implementación.

c) tampoco la norma nos dice nada acerca de los resultados y en especial de los impactos de las políticas.

Por ello, recomienda - y adherimos además del necesario análisis jurídico - el análisis focal de cada política específica (Zeller, 2007:17). Así, un primer aspecto estará dado por la identificación de las políticas de reforma impulsadas por las áreas con competencia para ello, el contexto institucional y su resultado. Para analizar las políticas de reforma en la Provincia de Buenos Aires, estimamos adecuado replicar, como punto de partida, una serie de seis interrogantes básicos que el CLAD y el BID utilizaron en un conjunto de estudios. Estos interrogantes serán disparadores de la investigación y no pretenden agotar los ejes de la evaluación (López, 2005). Estas preguntas-guías de investigación son las siguientes:

- ¿Cuáles son los cambios que han sido introducidos?

- ¿Cuáles fueron los argumentos para introducir los cambios?

- ¿Cuáles son los contextos específicos y generales en los que tienen lugar los cambios?

- ¿Cómo se implementaron los cambios?

- ¿Qué sucedió en la práctica?

- ¿Cuál fue el mejoramiento institucional? 
Se analizará la evolución en la organización del Estado a través de sus estructuras y organigramas. Será importante destacar, siguiendo a Camou (2005) qué organismos de los estudiados con competencia en materia de reforma administrativa poseen una estructura sólida y cuáles son más permeables a los cambios políticos y crisis económicas. En segundo lugar, se analizará la composición, distribución por organismo, perfil y evolución del personal en la provincia. Por último, se estudiará la composición del presupuesto, su evolución y la distribución de recursos entre los distintos rubros.

Por tanto, es necesario utilizar una diversidad de técnicas, estrategias y abordajes, tales como:

- Realizar un seguimiento de las competencias y estructuras organizativas de algunos organismos en el período en estudio, destacando sus variaciones.

- Realizar el seguimiento en la implantación de algunas políticas de modernización, reforma del Estado y de gobierno electrónico -las más representativas para los respectivos Planes, abordándolas como estudio de caso-, desde el diseño hasta su sanción, pasando por las modificaciones que existieron en la etapa de aprobación administrativa.

- Recopilar todo el material documental publicado por los organismos con competencia en la materia durante todo el período de estudio para analizar su contenido y resaltar las modificaciones observadas.

- Describir las oficinas públicas donde trabajan los actores para observar dónde trabajaron/trabajan, cuántos eran/son y la disposición de los despachos y realizar entrevistas -entrevistas abiertas- a los funcionarios y empleados de entonces, en la medida de lo posible.

- Realizar un análisis de la normativa para determinar objetivos esperados, innovaciones, metas a alcanzar y descripción de los procesos involucrados.

- $\quad$ Siguiendo a los pioneros del análisis crítico del discurso, realizar un análisis cuantitativo de los discursos del Gobernador con una selección temática -identificando palabras y temas recurrentes- (Van Dijk, 1989 y 1997; Calsamiglia et al., 2002) a fin de identificar sus concepciones, valores y principales preocupaciones. La elaboración de un mapa semántico podrá coadyuvar a la identificación de las preocupaciones principales y asociaciones.

- Relevar, a partir del Directorio del Estado, la información disponible de los funcionarios de toda la Administración Provincial, identificar quiénes cuentan con dirección de correo electrónico, enviar correos electrónicos de prueba para analizar la existencia o no de respuesta y velocidad y deducir el interés y la motivación de su uso.

- Comparar las inversiones en materia de tecnologías -software y hardware- de los organismos provinciales a fin de detectar qué organismos realizan uso intensivo de las nuevas tecnologías.

Con este análisis exploratorio de las experiencias de modernización y reforma de la Administración Pública, se pretende aplicar una visión integrada de las diferentes experiencias, seleccionando alguna de ellas como casos testigo e identificándolas en el entorno en donde surgen para detectar factores condicionantes y facilitadores. 
En efecto, deberemos detenernos en el estudio de los factores condicionantes del éxito de las políticas de reforma y modernización, entendido como el conjunto de parámetros políticos, económicos, administrativos, sociales y culturales que favorecen, potencian, acotan, restringen o inhiben la inserción, los recursos, los procesos, los productos, los resultados y los impactos de las reformas en el contexto en estudio. Será necesario conocer y evaluar aquellos aspectos que condicionan y/o facilitan su diseño, las capacidades del gobierno para su implementación y los condicionantes.

Sólo así, combinando técnicas, estrategias y abordajes, será posible construir un enfoque metodológico integrador que evite caer en reduccionismos, simplificaciones o visiones sesgadas desde lo organizacional, lo político o lo jurídico, reconociendo la complejidad del fenómeno en estudio.

Esta combinación nos permitirá conocer las condiciones de partida para el éxito de las políticas innovativas en la gestión, a la vez que nos habilitará lograr profundización y alcanzar un grado explicativo en el estudio de estas políticas en el gobierno de la Provincia de Buenos Aires.

\section{Recursos, etapas y plazos}

Se destaca que para la realización del trabajo de investigación se cuentan con los recursos bibliográficos y herramientas tecnológicas necesarios. Será necesario elaborar entrevistas a informantes claves.

Se han definido como etapas las siguientes:

- Exploratoria: recopilación de la información de fuentes secundarias y relevamiento del material bibliográfico. También se relevará el material periodístico.

- Elaboración conceptual: permitirá profundizar el marco teórico y reformular el sistema de hipótesis, con el fin de orientar el trabajo de investigación.

- Análisis del discurso de los actores involucrados y de la documentación normativa y planes. Para ello, tomaremos como fuente la información disponible por Internet y la información pública, documentos e informes que pueda ser recabada.

- Entrevistas semiestructuradas a informantes calificados.

- Análisis de los datos obtenidos.

- Elaboración del informe

- Corrección final del trabajo

- Presentación y defensa. 
Se prevé la elaboración de la tesis en hasta dos años, sin perjuicio de lo cual se aclara que una parte importante del marco teórico ya se ha comenzado a elaborar y varias normas, informes y documentación también ya ha sido identificada y recopilada. 
SECCIÓN SEGUNDA - MARCO TEÓRICO 


\section{CAPÍTULO I. DE LA CRISIS DEL ESTADO A LA DE GOBERNABILIDAD}

\section{La crisis del Estado actual}

Una de las notas características del Estado, como forma política de la modernidad, ha sido, en el interior de su esfera, adueñarse de todo el poder político y oponerse a las formas de poder que tienen origen privado (de orden feudal o confesional) y hacia el exterior, constituirse como una unidad territorial de fronteras netamente definidas, aunque no definitivas con tendencia a constituir la colectividad que vive en sociedad cerrada (Freund, 1968). ¿Pero cómo definirlo?

La gran mayoría de los autores se ven en la necesidad de enumerar, e incluso de clasificar, la gran cantidad de elementos diversos que contiene la palabra Estado para encontrar una definición comprensiva (Portinaro, 2003).

Para una importante tradición de la sociología política, sobre todo de base posmarxista, el Estado puede ser abordado por las relaciones de poder, intereses y significaciones respaldados por actores que forman parte de la sociedad (Lagroye, 1991; Poulantzas, 1990). Desde esta visión, superadora ciertamente de una visión decimonónica que separa sociedad y Estado, el Estado es una red compleja y altamente institucionalizada de la sociedad, en la que se expresan el conjunto de conflictos y correlaciones de poder que se desarrollan entre los actores políticamente relevantes quienes tienen capacidad de influir, incidir o determinar políticas estructuradas en y a través del Estado.

Otra tradición, más clásica pero cada vez menos alejada de la anterior, lo caracteriza como poder político, como complejo institucional organizado, como monopolio de la fuerza pública, como jurisdicción territorial del derecho. El Estado es más que una simple institución, pues exige un marco constitucional normativo, en el interior del cual el poder da su impulso a las demás instituciones, leyes, reglamentos. Tampoco puede confundirse con las normas jurídicas ${ }^{16}$ pues más allá de su contenido, es "una realidad subordinada a la voluntad política y no a las normas jurídicas" (Freund, 1968:703). Menos aún puede confundirse, como lo hizo la teoría del Estado decimonónica, el Estado con la política: el Estado presupone lo político; es una modalidad histórica de una esencia.

Por otro lado, la construcción de cada Estado (State Building) se hizo de manera distinta según los países, en diferente clima histórico e ideológico, con toda clase de transiciones, acuerdos y clivajes. En el curso de los seiscientos años que corren desde el siglo XIV de lo que conocemos como Estado, éste ha asumido formas muy distintas aunque contiene un hilo conductor que lo permite diferenciar de otras formas de organización política (Fioravanti, 2004).

Vistos en la necesidad de adoptar una definición ideal-típica, una conceptualización, ya clásica, pero fecunda es la de Max Weber (1999 [1922]:43-44):

\footnotetext{
${ }^{16}$ Sabemos que Kelsen (1988) hace depender el Estado de su propia hipótesis, planteada como una norma original y fundamental de donde proceden todas las demás normas, de manera que aquél aparece como el sistema de las normas jurídicas realmente en vigor.
} 
Por Estado debe entenderse un instituto político de actividad continuada, cuando y en la medida en que su cuadro administrativo mantenga con éxito la pretensión del monopolio legítimo de la coerción física para el mantenimiento del orden vigente.

Portinaro en Estado (2003) ha desmenuzado esta definición. Así, el Estado es, ante todo, empresa, en tanto asociación provista de un aparato administrativo que obra continuadamente en pos de un fin; y es una empresa institucional porque sus ordenamientos son impuestos a todos quienes presentan determinadas características (por ejemplo, nacimiento y residencia); y es empresa institucional de carácter político en tanto la validez de sus ordenamientos está garantizada dentro de un territorio determinado mediante el ejercicio real o potencial de la coerción física; pero recién cuando este ejercicio se halla monopolizado por el aparato administrativo y es legitimado perdurablemente por la población, ese grupo político de carácter institucional puede llamarse Estado.

Ahora bien, sociólogos, politólogos y juristas italianos actuales como Poggi (1997), Matteucci (1998) Grossi (2003) o Fioravanti (2004) señalan, al describir la evolución histórico-institucional del Estado ( $\mathrm{y}$ en contra de la teoría del Estado decimonónica) que en su génesis, lejos está éste de pretender y/o ejercer el monopolio del poder. Recientes publicaciones norteamericanas, como la que citamos más abajo, coinciden con esta perspectiva. ${ }^{17}$

En efecto, Gianfranco Poggi (1997) ha puesto de manifiesto cómo el proceso de transformación del sistema feudal al sistema estatal tiene un interregno a partir del siglo XIII hasta la formación de los gobiernos absolutistas, que define como Sändestaat y que hace referencia a "la organización política de los estados", formato nuevo, distinto al feudal pero también al estatal, como el necesario eslabón, un paso entre uno y otro. Los Stände - las asambleas, parlamentos, dietas, cuerpos de los distintos estados [órdenes] y otros organismos característicos de fines de la Edad Media - fueron las más significativas de esas estructuras. Estas estructuras se presentaban ante el gobernante territorial como preparados para asociarse con él en los aspectos del gobierno que se entendían como característicamente públicos y generales. ${ }^{18} \mathrm{Y}$ agrega que con posterioridad, en los hechos, la soberanía se vio limitada siempre en lo externo, por el equilibrio del poder y la "constitución materialmente jerárquica" de cualquier sistema internacional, que circunscribe los márgenes de maniobra de cada actor, y en lo interior, por las leyes fundamentales, por la resistencia de los estamentos y por las asambleas representativas. ${ }^{19}$

\footnotetext{
${ }^{17}$ Por ello, como veremos más abajo, no es la soberanía la nota característica del Estado y la crisis de éste no sea consecuencia de la crisis de aquella.

${ }^{18}$ Según el sociólogo de la Universidad de Trento, como la complejidad de los intereses políticos de las ciudades no podía encontrar expresión únicamente en sus maniobras entre las fuerzas dominantes en el medio político existente, tenían que generarse nuevas estructuras que les dieran, además de autonomía política, el derecho a participar efectiva y permanentemente en el manejo del sistema más general de gobierno.

${ }_{19}$ Adviértase que Jean Bodin (1997), teórico de la soberanía, en 1576 reconocía límites a la soberanía y califica de inderogables ciertas leyes que atañen al Estado y fundación del reino (leges imperii).
} 
Por su lado, Fioravanti (2004) señala que en el origen de la forma política estatal los señores territoriales ejercitaban importantes poderes de imperium y que no es el elemento de la soberanía la nota características del Estado, sino, más bien, la conciencia de la existencia de un territorio que gobernar y defender en su conjunto según reglas fijas y compartidas aún cuando exista una pluridad de potestades dotadas de imperium, una pluridad de vínculos y obligaciones. Así, Fioravanti (2004:15) señala que

\begin{abstract}
... tenemos «Estado» porque tenemos una realidad territorial gobernada cada vez más en su conjunto, y cada vez de manera más institucionalizada, según reglas escritas que fijan el lugar de cada uno. Este es el sentido fundamental de la transformación a la que asistimos en el paso de la edad media a la moderna, y éste es el carácter del Estado moderno europeo que es posible captar en su origen: el Estado como gobierno de un territorio, que actúa de manera cada vez más disciplinada y reglada, con la intención de reunir las fuerzas operativas sobre ese territorio, de reconducirlas a una prospectiva común (el destacado es del original).
\end{abstract}

En el libro Realities of Representation. State Building in Early Modern Europe and European America, Maija Jansson (2007), de la Universidad de Yale, coincide en apuntar el rol central de las asambleas -y la representación como presupuesto implícitocomo componentes críticos del proceso de creación de los Estados, destacando la tensión existente entre las monarquías y estas instituciones. Expresamente:

These assemblies were a critical component of state building
in the seventeenth and eighteenth centuries and in many
instances formed the foundations of institutions that still
prevail. [...] Representative assemblies of this kind existed in
virtually every part of Latin Christendom from the end of the
twelfth century. During the sixteenth and seventeenth centurias
they were dissolved, recalled, reinvented and reshaped by the
experiences of absolute monarchy, civil war and revolution.
Throughout these centuries, however, the idea of
representation was never lost. It emerged as a lynchpin of
enlightenment political thought and eighteenth-century
constitutionalism (Jansson, 2007:2-3).

El Estado es un proyecto de organización política. Con esto, queremos destacar el trascendental valor de la razón y la planificación involucrados en su evolución a diferencia de otras formas históricas donde el pragmatismo, la tradición o la impronta de una élite tuvieron un aspecto central. Más precisamente, es un producto de la racionalización progresiva de una estructura política ya existente, es producto de la modernización.

El diagnóstico del fin del Estado se renovó en las décadas siguientes a la Segunda Guerra Mundial. Martin van Creveld, en un magnífico trabajo titulado The Rise and Decline of the State (1999) ha dicho que, considerados individualmente, hay buenas razones para pensar que los Estados pronto no serán capaces para controlar y 
proteger la vida política, militar, económica, social y cultural de sus ciudadanos de la forma que ha sido hasta hoy en día. Y agrega (1999:vii):

The state, which since the middle of the seventeenth century has been the most important and most characteristic of all modern institutions, is in decline. From Western Europe to Africa, either voluntarily or involuntarily, many existing states are either combining into larger communities or falling apart. Regardless of whether they fall apart or combine, already now many of their functions are being taken over by a variety of organizations which, whatever their precise nature, are not states.

Se habla de ocaso o de fin del Estado-nación en el sentido de que este sujeto no aparece más en grado de controlar los flujos de recursos, las cuatro "I" que fluyen desde más allá de sus límites -industria, individuos, inversiones, informaciones-: los Estados-nación tradicionales se han convertido ahora en unidades de negocio artificiosas, o directamente inadmisibles, en una economía global. Aparentemente, Economía y Estado han consumado su divorcio, por lo que se enfrentan, sin un poder institucional realmente capaz de mediación, "naciones sin riqueza" y "riquezas sin naciones" (Portinaro, 2003).

Es cierto que la globalización ha afectado aquellos supuestos que aparecen como esenciales, genéticos a la forma política estatal. El fenómeno de la globalización ya había planteado un desplazamiento del locus político del Estado Nacional hacia la comunidad internacional. Se ha afirmado el fin del territorio nacional como espacio definitorio de las realidades sociales como uno de los elementos de una globalización favorecida por las nuevas Tecnologías de la Información y las Comunicaciones (Beck, 1998).

El fenómeno posmoderno del "no-lugar" estudiado por Marc Auge (2000) puede, a través de las nuevas tecnologías, afectar el ámbito territorial de actuación del Estado y de sus lealtades implícitas. Mientras la organización política de la modernidad ha forjado su existencia en torno a comunidades políticas territoriales, en la era de las telecomunicaciones, las relaciones sociales no tendrían ya su fundamento en la relación cara-a-cara. En esta nueva era de la globalización basada en mercados abiertos y de libre intercambio, los usuarios, gracias a Internet, pueden comunicarse sin la mediación de un Estado que es calificado como ineficiente, caro y lento. El lugar común por excelencia de socialización, la ciudad, pierde dicha función por lo que es natural que en el futuro se generen otros tipos de lealtades. ${ }^{20}$

La globalización también genera reacciones y existen, mucho más que antaño, obstáculos insalvables para este proceso que incluyen, no sólo los nacionalismos y las xenofobias, sino también las organizaciones regionales políticas y comerciales que, defensivamente, se cierran cada vez más en su propio bloque. Este es un salvavidas de plomo para los Estados pues si es cierto que deben unirse en bloque para sobrevivir, lo hace a costa de ceder competencias a favor de una institución o líder regional.

20 En igual sentido, Vidal Jiménez (2001) entiende que el fenómeno del no-lugar supone una desterritorialización y desurbanización de la vida humana, donde no se convive, sólo se co-existe. 
Coincidimos con el planteo de Giddens (s/f), quien se muestra equidistante de planteos hiperglobalizadores o escépticos de la globalización. Según su opinión, estamos al principio del proceso de globalización y no al final. Este proceso tiene numerosas causas, entre las que destaca el impacto de la tecnología sobre los sistemas de mercado a escala mundial, a la vez que de la desaparición de la Unión Soviética. Pero a su vez, esta última etapa es el conjunto de cambios de mayor trascendencia que están sucediendo actualmente en el mundo. No ha avanzado tanto como dicen los hiperglobalizadores, ni lo impulsan puramente los imperativos económicos del mercado, pero de todos modos es el fenómeno más importante de nuestro tiempo. Y agrega:

La globalización no es sólo una serie de influencias, sino una compleja serie de transformaciones estructurales que afectan a la economía, la política y la cultura. Es necesario comprenderlas adecuadamente si pretendemos afrontarlas y beneficiarnos de ellas. La globalización no se refiere sólo al mercado global y a la expansión de la 'economía ingrávida' (la economía de la información mundial). Dice relación con un proceso de cambio en el papel del Estado y, al mismo tiempo, introduce muchas modificaciones en la vida cotidiana, incluidas las que afectan a la familia. La globalización tira hacia arriba, más allá del Estado-nación —el Estado pierde el control de ciertos procesos de toma de decisiones en los que antes era más poderoso. Pero también empuja hacia abajo, presionando en favor de un mayor grado de autonomía local por debajo del nivel estatal - las fuerzas globalizadoras ayudan a promover la descentralización de la que habla Novak. Al mismo tiempo, la globalización presiona hacia los lados. Produce nuevas regiones y alianzas que pueden traspasar las fronteras nacionales, fenómeno que ha sido analizado muy bien por Keniche Ohmae (Giddens, 1999:37).

Este puede parecer un esquema de Estado mínimo si tenemos en cuenta la delegación de funciones, pero ciertamente no es una reedición del modelo estatal liberal cuyo modelo veremos más adelante. Como ha dicho Sartori (1992) por mucho tiempo, liberalismo y democracia formaron parte de una simbiosis, pero hoy asistimos a algo más que a un mero achicamiento del Estado o al desprendimiento de funciones públicas para su gestión por empresas privadas: nos enfrentamos a una fuerte despolitización, a un achicamiento de la res publicae, lo cual implicará una menor calidad de democracia, una democracia menos participativa. Y en ello, la lógica de una Sociedad de la Información y el Conocimiento técnica tiene una gran responsabilidad.

La caracterización del mundo actual y de la Sociedad de la Información y el Conocimiento encierra muchas contradicciones. Se ha afirmado que la Sociedad de la Información y el Conocimiento crea nuevas oportunidades sociales: se generan nuevas alternativas educativas; existen consumidores más responsables e informados; aumentan los beneficios económicos al incrementarse la eficiencia por una mejora en la captación, procesamiento y difusión de la información y el conocimiento. También la Sociedad de la Información y el Conocimiento permitiría reforzar las libertades políticas al posibilitar un mayor conocimiento de las políticas y de los procesos públicos de toma de 
decisiones, lo cual conduciría, a su vez, a generar mayor eficiencia y eficacia administrativa (Gascó, 2004). ${ }^{21}$

Pero no existen estudios comparados que aporten un sustento empírico como para generalizar esos beneficios. Las iniciativas que pregonan que es inevitable el tránsito de la sociedad industrial a una sociedad de la información en la cual los ciudadanos, a partir del uso de servicios de telecomunicaciones, vivenciarán la mejora de distintos aspectos de su vida cotidiana, son parte de un creciente y asimétrico proceso de interdependencia internacional asociada a ideas y práctica neoliberales para las cuales es necesario garantizar el mercado libre y desregulado (do Couto Bemfica et al., $2005)^{22}$

La libertad de Internet aparece cuestionada por el simple hecho de su topología: existe un alto grado de concentración de los flujos de información en unos pocos sitios o nodos de la red altamente conectados - Yahoo, Amazon, Google, CNN-, lo que provoca una manifiesta invisibilidad del resto; por contraste, el núcleo central, donde se encuentran las páginas más consultadas, puede ser alcanzado desde cualquier punto y es visible para todos (Porras, 2005).

Si bien es cierto que Internet ha democratizado la información, no es menos cierto que la contrapartida es el control casi absoluto que puede ejercerse como quedó demostrado tras los atentados del 11 de septiembre: EE.UU. directamente eliminó miles de páginas web y espió millones de correos electrónicos.

Entre los grandes actores de la política internacional, el Estado se nos aparece como el que presenta mayores dificultades: los protagonistas son, por una parte, los mercados $\mathrm{y}$, por otra, parecen ser las organizaciones transnacionales, en un heterogéneo recorrido que va desde las opiniones públicas, los movimientos por la paz, ecologistas, las organizaciones terroristas y la macrocriminalidad organizada, etc.

Por un lado, la desterritorialización de la riqueza y la consecuente pérdida de control del Estado sobre la economía - de la soberanía monetaria y crediticia al control del factor trabajo, pasando por el drenaje fiscal- parece ser una de las causas. La separación del mando político y el económico constituye el estado de tensión característico de la situación presente de la democracia capitalista. Por otro lado, la imposibilidad de hacer frente a desafíos trasnacionales como los que tienen que ver con los terremotos en los mercados de acciones, las presiones migratorias o las emergencias ecológicas constituyen fenómenos irreversibles en el mundo contemporáneo que dan muestras de la imposibilidad de resolver este tipo de fenómenos en el marco de las fronteras políticas nacionales (Portinaro, 2003).

En la era de la globalización y de la digitalización, el poder de los Estados ya no se apoya de manera predominante en su extensión territorial y en la densidad de población, sino en recursos a-territoriales, como el capital y el saber tecnológico, por lo que ya no tiene mucho sentido atribuir a un Estado definido territorialmente las

\footnotetext{
21 Varios autores señalan, como veremos más adelante, las oportunidades que ofrecen las TIC para acentuar la participación política y la comunicación horizontal entre los ciudadanos.

${ }^{22}$ Señalan también estos autores que muchas de estas posiciones positivas se apoyan en las concepciones desarrolladas entre finales de los ' $60 \mathrm{y}$ comienzo de los ' 70 , reproduciendo un discurso determinista, según el cual, el desarrollo tecnológico es un proceso inevitable y autónomo en relación con la dinámica socioeconómica y política (do Couto Bemfica et al., 2005).
} 
funciones tradicionalmente asignadas a los sistemas políticos; tales funciones podrían ser asumidas con mayor flexibilidad por gobiernos no territoriales.

Cierto es que la red de límites externos hoy se ha vuelto más densa. Pero si se considera que desde siempre la soberanía estatal ha funcionado como reguladora de complejos dispositivos de apertura y clausura, de inclusión y exclusión, advertimos que tal lógica de funcionamiento del poder soberano no ha cambiado estructuralmente; han cambiado, más bien, sus modalidades de funcionamiento así como también han cambiado las configuraciones de poder a las que da origen.

Según Portinaro (2003) lo seriamente amenazado no parece ser el Estado, sino el Estado de derecho como complejo de instituciones orientadas a garantizar que los ciudadanos puedan gozar de los derechos fundamentales: la era de los derechos se revela como la era de los conflictos en torno a los derechos y de la sobrecarga institucional por la tutela y el cumplimiento de los derechos - sobrecarga que termina por paralizar al Estado y a sus políticas-. En este sentido, la síntesis moderna de Estado, derecho y constitución se ha resquebrajado y si bien no parece seriamente en peligro la supervivencia de los Estados, sí resulta claramente amenazada aquella modalidad de democracia ciudadana, de política de la sociedad civil, que sigue siendo aún hoy la promesa no cumplida del proyecto político de la modernidad.

Aún cuando el Estado, como fenómeno histórico, está ciertamente condenado a desaparecer, creemos, junto a los autores de la corriente italiana que estamos siguiendo en este apartado, que la crisis del Estado no es crisis del Estado como forma de organización, como continente, sino de uno de sus formas de organizarse, esto es, es crisis de contenido, de cómo distribuir recursos, de ejercer el poder y de legitimarse. En tanto que crisis de contenido, ésta puede aparecer a primera vista como crisis terminal y definitiva, pero el Estado ha sabido adaptarse - y muy bien - desde sus inicios a la fecha adoptando distintas formas. Es por ello que veremos en el próximo apartado una de esas crisis de forma, la del estado liberal al social y su crisis.

\section{Del Estado liberal al Estado Social y su crisis}

La palabra "crisis" ha comenzado a perder su significado. Vivimos en una constante crisis del sistema democrático, crisis del Estado, crisis del sistema de representación, crisis de los partidos políticos, crisis económica y social. Algunos, buscando retomar ese sentido, distinguen las verdaderas crisis de las situaciones "dramática ma non seriosa" (Posada Carbó, 1994).

Pero cuando se trata de la crisis del sistema democrático, la necesidad de superarla surge como impostergable cuando sus resultados están revelando una fragilidad en los modelos institucionales que hace peligrar la gobernabilidad del sistema político.

Es recién en el transcurso del siglo XIX al siglo XX, cuando el Estado se configura como una organización política fundada en la doctrina liberal, encarnando el clásico modelo liberal propugnado por Adam Smith $(1958[1776])^{23}$.

\footnotetext{
${ }^{23}$ Según ese clásico modelo liberal, el Estado tenía que cumplir con tres funciones básicas y no más que ellas: 1) el deber de proteger a la sociedad de la invasión de violencia por otros Estados, 2) la obligación
} 
Si bien el liberalismo, como ideología, no es original, logró mantener un núcleo de principios entrelazados a su filosofía y que proyectaron un cuerpo institucional específico al que se denominó Estado liberal, cuya definida concreción se materializó entre comienzos del siglo XIX y la primera guerra mundial (1914 - 1918) (vid. Vallespín, 1991; Burdeau, 1983) ${ }^{24}$.

El Estado liberal proviene de los resultados políticos, económicos y sociales, de las tres grandes revoluciones: la Gloriosa Revolución de 1688 en Gran Bretaña, la Revolución Norteamericana de 1776 (una doble revolución, en verdad, independentista y republicana) y la Revolución Francesa de 1789, que inauguran las tres grandes corrientes del pensamiento liberal, que hicieron posible el surgimiento del sistema político capitalista y el ascenso de la burguesía principalmente asentada en los centros urbanos: comerciantes, manufactureros, banqueros, funcionarios administrativos en su mayoría abogados, médicos e intelectuales (Kühnl, 1971). Las consecuencias políticas de la nueva situación se plantearon en términos irreductibles; ya que las críticas, y el accionar de la burguesía se concentraron en una férrea oposición al Estado absolutista y la nobleza; provocando la ruptura del poder predominante de la aristocracia, la mayoría de las veces por medios violentos.

Con otra calificación que atiende a la mayor o menor expansión del Estado frente a la sociedad, Bobbio, en Estado, gobierno y sociedad (1989) clasifica la evolución del Estado entre Estado feudal, Estado estamental, Estado absoluto y Estado representativo que dura hasta hoy e identifica a este último como ...

... el resultado de un compromiso entre el poder del príncipe cuyo principio de legitimidad es la tradición y el poder de los representantes del pueblo (donde por "pueblo" se entiende inicialmente a la clase burguesa), cuyo principio de legitimidad es el consenso (Bobbio, 1989:162).

Y coincide, con lo que afirmábamos más arriba acerca del desarrollo del modelo de Estado actual con la visión político-liberal, al afirmar que en el centro de este cambio está el descubrimiento y la afirmación de los derechos naturales del individuo, de derechos que todo individuo tiene por naturaleza y por ley, y que, precisamente porque son originarios y no adquiridos, todo individuo puede hacer valer contra el Estado recurriendo incluso al remedio extremo de la desobediencia civil y de la resistencia.

Aún cuando las bases ideológicas ya estaban sentadas tiempo atrás, la nueva estructura sólo pudo darse una vez consolidado el proceso de monopolización de funciones ${ }^{25}$ de esta forma de organización política de la modernidad ${ }^{26}$ que compitió con otras desde fines del siglo XIII (Portinaro, 2003).

de establecer una correcta administración de justicia, y 3) la obligación de realizar obras públicas y proveer de servicios con poco incentivo económico.

${ }^{24}$ El liberalismo, en tanto idea - fuerza, tuvo fuerza innovadora y eficacia para quebrar la cosmovisión imperante; rompió con la tradición para enaltecer a la Razón como su propia identidad; a la vez que la burguesía adquirió plena conciencia de su protagonismo.

${ }^{25}$ Como veremos a lo largo de esta tesis, el aparato burocrático cumplió una función esencial en ese proceso de monopolización.

${ }^{26}$ Como señala Heller (1992), la nueva palabra "Estado" designa certeramente una cosa totalmente nueva porque, a partir del Renacimiento y en el continente europeo, las poliarquías, que hasta entonces tenían un 
En el Estado liberal clásico no hubo una verdadera preocupación por la participación estatal en la economía, ya sea directa o por cualquier forma de indirecta. Todas las acciones fueron en función del mercado, en el que los agentes privados, por normas y principios propios, son los responsables de la ejecución de las políticas económicas y sociales relacionadas.

Pero este tipo de Estado, definido por la administración de un poder de policía limitado, se vio desbordado en sus funciones en su conjunto. Lo que ha ocurrido desde la segunda década del siglo $\mathrm{XX}^{27}$ fue una completa extensión de las estructuras, instituciones, funciones y responsabilidades, principalmente económicas, del Estado.

Los cambios eran necesarios ya que los problemas económicos y sociales causados por el modelo liberal clásico no eran viables a medio y largo plazo. La excesiva concentración del capital en manos de unos pocos operadores, la monopolización de los distintos sectores, el cierre de muchas empresas incapaces de competir de los mercados sin control estatal, el aumento de la degradación de las condiciones de trabajo y de los salarios de trabajadores (con el aumento del desempleo masivo) fueron algunas de las consecuencias de este período.

La emergencia del Estado de Bienestar no fue dada por una única causa, sino que fue producto de una gran variedad de factores heterogéneos. Sin que la enumeración sea exhaustiva ni el orden implique mayor importancia, podemos establecer como causas que justificaron el paso de un modelo a otro a: a) la quiebra del modelo liberalracionalista, b) el progreso de la industria y de la estratificación social, c) el movimiento reformista socialdemócrata, d) el socialismo cristiano, e) el advenimiento de la Constitución de Weimar, f) los grandes sindicatos industriales, g) la necesidad de contrarrestar el marxismo, h) la crisis de 1929.

En verdad, el mercado autorregulado no es capaz de registrar y satisfacer ciertas necesidades materiales y morales que además son fundamentales tanto para los individuos en cuanto tales como para la colectividad. El Estado liberal deja al "libre" trabajador prácticamente indefenso frente a las exigencias impersonales del mercado y expuesto a todos los golpes de las fluctuaciones económicas (Pellicani, 1986). Es por ello que las primeras reformas estuvieron orientadas en torno a las problemáticas laborales: seguros obligatorios, leyes sobre protección del trabajo, salarios mínimos, expansión de los servicios sanitarios y educativos a la clase trabajadora, el reconocimiento de los sindicatos, etc.

La crisis económica que sucedió al final de la Primera Guerra Mundial, la aparición de los principios democráticos y el crecimiento demográfico de la población y

carácter impreciso en lo territorial y cuya coherencia era floja e intermitente, se convierten en unidades de poder continuas y reciamente organizadas, con un sólo ejército que era, además, permanente; una única y competente jerarquía de funcionarios y un orden jurídico unitario, imponiendo además a los súbditos el deber de obediencia con carácter general.

${ }^{27}$ Ciertamente pueden detectarse antecedentes muy anteriores a lo que configurará el tipo de Estado de Bienestar. Históricamente, la experiencia dada con las agencias reguladoras fue iniciada en los años 80 del siglo XX en los Estados Unidos de América, pero los antecedentes de agencias reguladoras federales en los EE.UU. se remontan a 1887, año de nacimiento de la Comisión Interestatal de Comercio. Por el contrario, y a pesar de que el modelo se dio primero en Europa occidental, en cuanto a las agencias reguladoras, en Europa se dieron sólo un poco menos de 100 años más tarde: en Francia, en 1978 se introdujo en la Administración Pública el concepto de "autoridades independientes " con la creación de la Commission Nationale de l'Informatique et des libertes para promover la liberalización del comercio y antes de introducir la competencia en mercados monopolizados por las empresas estatales. 
su concentración en los centros urbanos obligaron, más que la ideología, a pensar en un nuevo modelo de actuación del Estado en la economía, aún desde una visión liberal, para hacer más eficaz la empresa y al propio mercado.

El modelo de Estado asistencial fue consecuencia del compromiso político entre los principios del mercado (eficiencia, cálculo riguroso de los costos y de los importes, libre circulación de las mercancías, etc.) y las exigencias de justicia social avanzadas del movimiento obrero europeo. Sin embargo, estas reformas se plantearon según diferentes, tiempos y modalidades en los países ${ }^{28}$.

Uno de estos modelos de intervencionismo estatal fue el conocido New Deal (1933-1939). Como consecuencia, EE.UU. se encontró con la creación de un número significativo de nuevas agencias reguladoras, a fin de recuperar su economía. Esta amplia reforma, generó un nuevo modelo de acción del Estado en la economía que se basa en dos preocupaciones fundamentales: en primer lugar, la creación de órganos ajenos al debate político; la segunda, generar información suficiente en los mercados organizándolos de una manera compatible con los intereses generales y el respeto de los consumidores.

En 1942, en los Estados Unidos existían unas doscientas instituciones privadas y públicas especializadas en el estudio y planificación de los problemas que surgirían en la posguerra. Un órgano del Estado era, por ejemplo, la Oficina de Planeamiento de los Recursos Nacionales a la que el presidente Roosevelt, por su importancia, le había encargado la misión de analizar los planes necesarios referidos a las políticas públicas y privadas para implementar en la posguerra. En Inglaterra, se organizó un comité presidido por el economista William Henry Beveridge en 1942, para trabajar en un informe exhaustivo acerca de los problemas de la seguridad social de 1945 en adelante. Conocido como el "Plan Beveridge", fue la base de las reformas sociales que encaró el gobierno laborista de Clement Atlee. En estos modelos de planificación, se intenta el reordenamiento económico de la sociedad $\mathrm{y}$, simultáneamente, su reordenamiento social.

El Estado de bienestar, intervencionista, al rechazar la idea de la autosuficiencia de la regulación del mercado, buscó propiciar la actividad económica a través de la adaptación de los sectores económicos y la acción directa. Se propuso una acción más dinámica e intervencionista del Estado en varios sectores importantes no afectados por el modelo liberal clásico: no sólo protege las fuerzas del mercado y la libertad de iniciativa, sino también busca mejorar la calidad de vida de la población y crear otros medios de participación social y de acceso, tanto en el plano económico como político.

La consolidación de los derechos sociales y la preocupación con el Estado visto como un conductor y formulador del interés público son el centro del modelo intervencionista de Estado en la economía. Pero el Estado de Bienestar no fue visto como una carga a la economía, sino como un estabilizador interno de los ciclos económicos y políticos que evitaba que la economía cayese en recesiones.

Desde esta posición, el desarrollo económico ya no se regula exclusivamente por los mecanismos espontáneos del mercado, sino también, y en ciertos casos sobre todo, por las intervenciones económicas y sociales del Estado que se han concretado, según Pellicani (1986) esencialmente en los siguientes puntos:

\footnotetext{
${ }^{28}$ En verdad, el primer modelo es autoritario; es el modelo de Bismarck.
} 
- expansión progresiva de los servicios públicos como la escuela, la casa, la asistencia médica;

- introducción de un sistema fiscal basado en el principio de la tasación progresiva;

- institucionalización de una disciplina del trabajo orgánica dirigida a tutelar los derechos de los obreros y a mitigar su condición de inferioridad frente a los empleadores;

- redistribución de la riqueza para garantizar a todos los ciudadanos un rédito mínimo;

- erogación a todos los trabajadores ancianos de una pensión para asegurar un rédito de seguridad aún después de la cesación de la relación de trabajo;

- persecución del objetivo del pleno empleo con el fin de garantizar a todos los ciudadanos un trabajo, y por lo tanto una fuente de rédito.

El Estado contemporáneo comenzó a intervenir en la economía, principalmente a través de dos mecanismos muy pertinentes a esta nueva configuración estatal: el uso de las herramientas de adjudicación del contrato de trabajo en la economía o los servicios públicos, así como su poder de policía que retoma con fuerza desde los tiempos de Estado liberal, cuando se servía sólo de esta manera.

El Estado, en su carácter de interventor activo en la vida social y económica, dada la necesidad de reestructurar la economía, generó una demanda de participación política de las clases marginadas y a su vez la adopción de compromisos para aliviar los antagonismos sociales y organizar mejor el crecimiento demográfico combinado con el crecimiento urbano desenfrenado.

El modelo de Estado de Bienestar fue eficiente durante casi cincuenta años para resolver las crisis cíclicas de las economías que afectaban la estabilidad política de los respectivos gobiernos. Pero también, el modelo se fue profundizando y terminó no solo interviniendo en los mecanismos del mercado sino también en las relaciones sociales en aspectos irrelevantes.

En este contexto histórico, ya en la mitad final de los años 70 y principios de los 80 del siglo XX, el modelo del Estado del Bienestar comienza a disminuir. El Estado de Bienestar no satisfacía las numerosas tareas y actividades que se había propuesto, teniendo en cuenta el alto gasto social relacionado con la seguridad, los servicios básicos la educación, la salud, y en consonancia con los demás servicios que dicho modelo se había autoimpuesto.

Esa concepción fue fundada, desde el comienzo de los años 70 del siglo pasado, por la doctrina formulada por la teoría económica de la Escuela de Chicago. Para ella, los fracasos del gobierno coexisten con las deficiencias del mercado, sobrepujándolos, llegando a la conclusión de que la reglamentación sólo pretende proteger los intereses de la industria regulada en un círculo vicioso, no promoviendo el bienestar ${ }^{29}$.

\footnotetext{
${ }^{29}$ Para los teóricos de la Escuela de Chicago como Stigier, Posner y Peltzman, las tareas centrales de la teoría de la regulación económica no justifican quién va a recibir los beneficios o soportar la carga de la
} 
Las críticas más conocidas son las corrientes políticas neoliberales. Se pone el acento en la fuerte carga fiscal y normativa del Estado de Bienestar que produciría un desincentivo para la inversión o bien, en muchos casos, una sobrecarga de demanda económica y una sobrecarga en la demanda política, lo que tendería a tornar al sistema como ingobernable. Pero además, y como producto de una experiencia en la práctica de la lucha y legislación protectora del trabajo, muchos sindicatos pretendieron $-\mathrm{y}$ algunas veces obtuvieron - incrementos salariales superiores a los incrementos en la productividad con lo que los incentivos para mejorar eran muy débiles. Otra gran crítica fue que los sistemas de seguro de desempleo y seguros sociales no estaban pensados a gran escala ni que una parte de la población los tomara como medio de vida, con lo que el sistema de valores del capitalismo estaba evidentemente dañado ${ }^{30}$. Además, el modelo de Estado de Bienestar no pudo resolver la tensión de la inminente crisis fiscal.

En definitiva, según la visión neoliberal, el Estado asistencial corroe en sus raíces las estructuras y los valores de la sociedad libre desarrollando una peligrosa tendencia hacia la burocratización de la vida colectiva y hacia la reglamentación: toda intervención del Estado en el mercado es una amenaza a la libertad individual y una peligrosa concesión al colectivismo ${ }^{31}$.

Aún cuando las críticas neoliberales fueron más visibles, lo cierto es que también el pensamiento de izquierda, como el de Offe (1990) y Habermas (1986), criticó el desarrollo del Estado de Bienestar como un mero paliativo a las consecuencias negativas del desarrollo capitalista. Según estas visiones, la política del Welfare State y de la programación económica no es más que una racionalización del sistema capitalista y un modo disfrazado para consolidar el dominio de clase de la burguesía.

Pero lo cierto es que, más allá de la discusión ideológica del modelo, la internacionalización o globalización puso en cuestión a la autonomía de las regulaciones nacionales, desde mediados de los 70 y entró en conflicto con la gestión estatal. La crisis fue rápida y mundial y, a partir de 1971-73, apareció la recesión con inflación. La interdependencia había penetrado con profundidad los mecanismos nacionales y había tornado a los países medianos más permeables a los shocks externos (Aglietta y Orléan, 1990).

El movimiento mundial que siguió en esta cadena de acontecimientos implicó la disminución del Estado de Bienestar. Este fenómeno mantiene una relación íntima con el fenómeno de la globalización económica, que no es más que la expansión del mercado (del capitalismo) en todos los ámbitos de cada una de las empresas (y también casi todas las empresas) o, lo que es lo mismo, del crecimiento del espacio privado en detrimento del Estado del Bienestar. Este cambio de opinión acerca de lo "espacial" merece ser ampliado: la disminución del Estado de Bienestar en el decenio de $1980 \mathrm{y}$ en el siguiente decenio, por la influencia ejercida por situación internacional, se refleja en

regulación (Pignataro de Oliveira et all., 2008). La medida reglamentaria se ve en este espectro, como resultado de la interacción de los intereses privados a fin de maximizar los beneficios, es decir, protege a la competitividad para obtener apoyo político, lo que lleva, por lo tanto, el dilema entre el interés público y el surgimiento de una reglamentación del comercio.

${ }^{30}$ Esta misma crítica, desde otra visión ideológica, también la señalaba Offe (1990).

${ }^{31}$ Otras explicaciones se dieron para justificar la necesidad de cambiar el modelo de intervención estatal, además de la cuestión de sus altos costos: escasez de recursos públicos, el endeudamiento progresivo del Estado, la ineficiencia administrativa, la lentitud, el exceso de burocracia y la corrupción, estos últimos, centrales para esta tesis. 
las privatizaciones, reducción de las cargas fiscales y desestatización del espacio público.

El lema fue retomar los límites de actuación del Estado, entregando los beneficios de la iniciativa a los privados y retrayendo sus funciones a las ya tradicionalmente conocidas: seguridad y orden. Para "justificar" una nueva concepción liberal del Estado, era necesario, generar nuevas estructuras de seguridad y viabilidad económica, en un marco jurídico e institucional.

En este nuevo contexto, a pesar de la reticencia de algunos países y regiones, la masa ideológica en las relaciones internacionales sugiere la retracción del Estado como agente del mercado, como Estado empresario. La idea central es que los sectores y actividades económicas llevadas a cabo hasta ahora por el Estado, en virtud del monopolio estatal o no, volviesen a ser, preferentemente, dirigidas exclusivamente por iniciativa privada, de acuerdo con las reglas del mercado o, como máximo, que se rijan por medio de estructuras reguladoras especializadas. ${ }^{32}$

Entre las nuevas perspectivas aplicadas por los cambios administrativos en la forma de la acción estatal de la política económica neoliberal, la nueva máxima es, en términos generales, reducir el tamaño del Estado, la revisión de sus funciones y propósitos.

Sectores y actividades económicas, e incluso los servicios públicos originalmente realizados por el Estado, fueron cedidos al ejercicio del sector privado, en un nuevo escenario con peculiaridades jurídicas e institucionales. Los contratos de concesión, permisos, autorizaciones, y regímenes especiales y privatización de los monopolios estatales pasaron a formar parte de esta nueva realidad.

Pero mientras que en los Estados desarrollados se planteó el pasaje de un Estado "weberiano" a un modelo "flexible", en América Latina los problemas eran otros: la "transición democrática", la falta de consolidación de estructuras weberianas, la (in)existencia de modelos de bienestar, la recurrencia de las crisis económica, los procesos de "desarrollo".

Es en este contexto que en América Latina en la década de los 90 se aplicó la reforma del Estado, caracterizada por la desestatización de funciones y privatización de los monopolios estatales con el fin de mejorar la prestación de los servicios públicos y un mejor desempeño en la economía.

Pero no hay, ni teórica ni pragmáticamente un único modelo y esquema de reforma. Así, por ejemplo, Echebarria Ariznabarreta (2000), identifica cuatro modelos: 1. Garantista: en donde prevalecen los ideales de libertad y justicia, 2. Eficientista: en donde prevalece la racionalidad económica y "managerialista", 3. Contractualista: se ofrece pautas antiburocráticas sin perder de vista la racionalidad económica, 4. Servicial: cuyo objetivo es la gestión, el aprendizaje y la participación.

Como veremos más adelante, desde fines de los '90 opera un nuevo cambio de paradigma apoyado por un modelo político cuyos vectores son la eficiencia y la racionalidad de la actividad reguladora del Estado con un fuerte acento en la cultura organizacional y la tecnología como herramientas y factores para el cambio.

\footnotetext{
32 En algunos casos y en sectores específicos, se admitió la posibilidad del actuar del Estado conjuntamente con el sector privado, en una situación en la que el Estado es un actor más, en igualdad, con las empresas privadas.
} 


\section{El constitucionalismo como principio legitimador}

El Constitucionalismo ha sido un movimiento histórico-político, de carácter doctrinario, que en razón de sus principios y de sus finalidades postula que el Estado debe ser "Estado de Derecho". Como ha dicho Loewenstein (1964), el constitucionalismo, como producto del pensamiento racionalista y mecanicista de los siglos XVII y XVIII, no fue sino la revolución contra el tradicional poder místico en la creencia de que por medio de instituciones racionales es posible, sino eliminar, al menos neutralizar los elementos irracionales de la dinámica política.

El constitucionalismo creó el entendimiento de que es necesario, por medio de la ley, contener y definir el poder político del Estado ya que había llegado a una capacidad y libertad exagerada, incluso peligrosa. Este constitucionalismo impuso límites al Estado, formulados por la ley para el control de sus funciones, buscando asegurar la libertad de los ciudadanos, no sólo súbditos.

Elementos tales como la soberanía popular, gobierno representativo, la subordinación del poder a la ley y legalidad de la administración, la protección de la propiedad y la libertad de la ciudadanía, pasan a ser la base de moderna Constitucionalismo.

El Estado, por lo tanto, se ha constituido con arreglo a la Constitución, y no más allá, amparado en valores sin ninguna conexión con lo divino. Su origen está en el poder de la colectividad y fuera de toda fundamentación sobrenatural del poder. En esta primera tesis, la idea de origen del poder estatal, es el principio de la soberanía popular, poder este legítimamente capaz de dar vida al propio Estado.

Pero los procesos de cambio que ocurren en las sociedades modernas cuyos Estados se basan en el vínculo constitucional formal, también se relacionan necesariamente con las fuerzas del mercado y su contexto económico y social. En todas las constituciones aparece, más o menos plasmada, pero aparece, la mediación del Estado en las relaciones entre el capital y las fuerzas del trabajo ${ }^{33}$.

En efecto, la idea originaria del constitucionalismo moderno es la Constitución del Estado liberal de origen burgués, la clase social que pasó a ocupar el poder en Europa con la caída de la monarquía absoluta. La idea fundamental de esta nueva organización del poder estatal radicó en la reducción de las actividades y tareas estatales que no garanticen la libertad y la seguridad, básicamente. En esta primera visión liberal, de organización capitalista, tuvo una connotación bastante clara acerca de la separación entre el Estado y la sociedad, pero, mientras la administración del orden público y la policía están en manos del Estado, la economía sólo requiere la autorregulación mercado.

Evidentemente, los derechos de la primera generación tuvieron un carácter más formal que material. No existía necesidad de (ni justificación para) garantizar los derechos ni medios para reconocer la intervención dentro de la sociedad y de la economía, porque era un modelo de Estado comprometido con las libertades necesarias para el funcionamiento del capitalismo. Es el Estado de la primera generación de

\footnotetext{
${ }^{33}$ La evolución del derecho constitucional registra las variaciones en el sistema de producción capitalista y las respuestas ideológicas, políticas y jurídicas que de esas variaciones se derivan.
} 
derechos: derechos de las libertades civiles y derechos políticos (participación política restringida). Con esta orientación liberal, las funciones estatales tienen un carácter negativo; no pretenden realizar políticas públicas de intervención social y económica.

Esta relación (ideológica-normativa) entre capital y fuerzas de trabajo, plasmada por escrito desde las revoluciones americana y francesa del siglo XVIII es, de hecho, la gran cuestión que da apoyo al debate teórico sobre los límites y las funciones del Estado. $^{34}$

A partir de la visión de Montesquieu que derivaría en el régimen presidencialista, las actividades estatales fueron divididas en tres campos separados, cada uno de ellos asignados a un cuerpo de magistrados: el ejecutivo al Presidente, el legislativo al Congreso y el judicial a los Tribunales. En este sistema de separación funcional por división subjetiva de las atribuciones, cada uno de estos campos se concedió al respectivo detentador del poder con autonomía y monopolio de acción, no pudiendo ser violado este ámbito por ninguno de los otros detentadores del poder. ${ }^{35}$

Dado que los diferentes detentadores del poder son mantenidos aisladamente unos de otros se deberían producir bloqueos entre ellos, y, como consecuencia de esto, debería ser temida constantemente una paralización de todo el aparato estatal. Sin embargo, como se era absolutamente consciente de que un asilamiento rígido de las funciones conduciría necesariamente a bloqueos permanentes entre los diferentes detentadores del poder, paralizando así el proceso político, se exigió que en ciertos "puntos de contactos", exactamente determinados, los detentadores del poder independientes sean coordinados para que sólo, a través de su cooperación, alcance validez constitucional la específica actividad estatal asignada al correspondiente detentador del poder (Corbetta y Piana, 2005) ${ }^{36}$.

Este derecho constitucional experimentó cambios en su sistema de paradigmas, cuando el Estado pasó por sus cambios fundamentales que ocurrieron a lo largo del siglo XX. Durante la transición entre los modelos de Estado liberal y social, el cambio de enfoque en el tratamiento de la fuerzas del mercado es un factor determinante para el análisis del alcance constitucional de las funciones del Estado.

Como ya señalamos, un icono de este cambio de dirección fue la constitución de Weimar de 1919. En este momento la Constitución procura tomar acciones positivas en

\footnotetext{
${ }^{34}$ La constitución es necesariamente limitada por la situación histórica real. Debido a su carácter normativo, es, a su manera, la realidad social y política que la rodea.

${ }^{35}$ Véase el ya clásico, pero aún interesante trabajo de Zippelius, Reinhold, 1998. Teoría general del Estado. Ed. Porrúa, México.

${ }^{36}$ Cuando el gobierno y el parlamento son prácticamente autónomos, como ocurre en el presidencialismo, existe más independencia y menor interdependencia. Sin embargo, la propia lógica de la dinámica política implica que la independencia de los poderes no puede ser total. Es que la estructura del sistema presidencialista implica una interdependencia por coordinación. En su totalidad, el mecanismo del poder se presenta, por lo tanto, como interdependencia de los diversos detentadores del poder por coordinación. En efecto, la división clásica en funciones separadas de gobierno, legislación y judicial está superada tanto por la teoría como por la realidad. Loewenstein (1964) ha propuesto una versión más realista aplicando una nueva división tripartita: determinación de la decisión, ejecución de la decisión y control político.
} 
la economía y en las relaciones de trabajo y del capital, no sólo con las libertades civiles y políticas $^{37}$.

El constitucionalismo social se caracterizó por agregar a los clásicos derechos individuales - civiles y políticos - los llamados derechos sociales, a la vez que limitó el derecho de propiedad reglamentando su ejercicio en función social. Las normas consagran que el orden social se sustenta en el trabajo, fundamento y base de la organización del Estado; que el capital industrial surge del esfuerzo humano y quienes participan con su esfuerzo tienen derecho al goce de una vida digna; que todos los seres humanos tienen, sin distinción de ningún tipo, el derecho de perseguir su bienestar material y su desarrollo espiritual en condiciones de libertad y dignidad en el orden espiritual, social, económico y cultural, esto es, la realización plena de su personalidad humana ${ }^{38}$.

Aparece, por lo tanto, la economía como una cuestión de Estado, no solamente de mercado. Fue notable el aumento en la producción de normas jurídicas de las diversas jerarquías de poder para disciplinar el aspecto económico. Debido al marco político-ideológico propiciador de esos cambios, la Constitución trajo nuevos conceptos y valores: son derechos de nueva generación, con una clara preocupación por el llamado a la igualdad de derechos.

El constitucionalismo social no reniega de los postulados anteriores sino que sigue siendo válida la limitación del poder y el sometimiento de los gobernantes y gobernados al principio de legalidad, sólo que adiciona un régimen de derechos sociales orientado a cumplir las metas de la justicia distributiva, partiendo entonces, no sólo del supuesto liberal de la libertad, sino que además aspira a la igualdad de oportunidades reales.

El Estado adquiere, pues, una verdadera responsabilidad en el establecimiento de los derechos económicos, sociales, políticos y culturales en un sentido amplio, con actuación (positiva) hacia la sociedad. Ya no es más un simple observador de las acciones del mercado; ahora aparecerá conectado directamente en la intervención en la economía, en diversos grados de intervencionismo, según los experimentos históricos, directrices e ideologías que se dieron en muchos Estados.

El resultado de la consolidación del Estado de Bienestar, además del crecimiento de las estructuras orgánicas, especialmente administrativas, fue, sobre todo, el desplazamiento del centro de gravedad del poder estatal del órgano legislativo hacia el Ejecutivo y, cuanto más complejo, hacia la Administración Pública a través de su tecnocracia. En efecto, la reproducción descontrolada de estructuras, organismos y Ministerios, producto de las nuevas competencias de los Estados, se aceleró ya que el Estado de Bienestar, naturalmente, necesitó de una mayor estructura organizacional y

\footnotetext{
${ }^{37}$ Entre las Constituciones de este tipo, además de la alemana de Weimar, pueden citarse la de México de 1917, la de Finlandia de 1919, la de Austria de 1920, la de Checoslovaquia de 1920, la de Yugoslavia de 1921, la de Polonia de 1921, la de España - republicana - de 1931.

${ }^{38}$ En algunos casos, las Constituciones que se sujetaban a los nuevos principios, incluían también alguna modificación en la estructura de los órganos estatales (v. g.: la creación del Consejo Económico - con el carácter de representación funcional - en la Constitución de Weimar).
} 
ésta no podía sino estar en el Poder Ejecutivo, único órgano de actuación continua en un mundo cada vez más dinámico. ${ }^{39}$

Esta compleja red de estructuras burocráticas superpuestas, organismos sin funciones y obsoletos, controles ineficientes y baja productividad condujo - según las críticas que veremos más adelante - a que el sistema se desvíe hacia la evasión de la responsabilidad a la vez que a la sumisión dogmática a criterios de los superiores.

Pero más allá de las políticas de recortes de las funciones y del propio Estado según el modelo neoliberal que ya se expuso, una nueva vuelta del péndulo se da con los cambios de funciones que el modelo de acción del Estado ha tenido durante los últimos años, especialmente después de las modificaciones constitucionales, legislativas, políticas e ideológicas ocurridos desde mediados de los '90 en casi todo Latinoamérica.

Según algunos autores, la forma hacia la que habría tendido el Estado actual, luego de la crisis del Estado social y superada la ideología neoliberal, sería el Estado con fuerte acento en la reglamentación (conf. Portinaro, 2003; Stråth, 2003). Este modelo surge como pretensión intermedia entre el exceso y la variedad de tareas del Estado de Bienestar y las limitaciones de la visión neoliberal.

Resulta un dato de la realidad que ha cambiado la forma de actuar el Estado en los últimos diez años: el Estado asume el papel de regulador, de supervisión y planificación de determinadas actividades y servicios. Se sostiene que el director de la política pública, es el Poder Ejecutivo pero ya no es el único. En efecto, el Estado ya no es el único agente inductor, responsable de los derechos fundamentales, habida cuenta de las nuevas formas de participación ciudadana en la economía, en los servicios públicos y, en términos más generales, en todo el proceso de diseño, ejecución y control de la política pública.

En verdad, la democracia contemporánea del último cuarto de siglo y comienzos del presente es un fenómeno totalmente nuevo. Globalización, tecnologías, amenaza de guerra nuclear, la ideología del "fin de las ideologías", megaciudades, terrorismo, choque cultural, migraciones, etc., han modificado el contexto de la democracia. Aun cuando compartamos el postulado básico según el cual el demos gobierna (o debe gobernar), la complejidad del mundo actual ha puesto en crisis todos los otros supuestos (Corbetta y Piana, 2009).

Como ha dicho Sartori, todas las democracias modernas son, sin duda y en la práctica, democracias representativas, es decir, sistemas políticos democráticos que giran en torno a la transmisión representativa del poder (Sartori, 1999). Pero agrega:

[...] ni la representación ni la democracia representativa en su conjunto pueden operar debidamente frente a una cultura que devalúa los valores y cuyo grito de batalla ha sido, en los últimos cuarenta años, el antielitismo, el rebajamiento de la élite. No nos equivoquemos: devaluando la meritocracia no conseguimos sino

\footnotetext{
${ }^{39}$ La teoría administrativa clásica define a la estructura organizacional como la forma en que las tareas de trabajo son divididas, agrupadas y coordinadas. Posteriormente, se amplió el concepto resaltando la necesidad de la adecuación de la división del trabajo y la coordinación de tareas a determinados factores contingenciales a situacionales, tales como el poder, la tecnología, y el ambiente.
} 
demeritocracia; devaluando la selección no conseguimos sino la selección de lo malo, y devaluando la igualdad en función de los méritos no conseguimos sino la igualdad en el demérito (Sartori, 1999:5).

Según Robert Dahl (Vallespín et al., 1999) incluso en los países democráticos (en los que las instituciones democráticas están bien establecidas desde hace tiempo y en las que existe una cultura política democrática fuerte), a los ciudadanos les resulta claramente difícil ejercer un control decisivo sobre las decisiones clave en política exterior.

Desde el retorno a la democracia hemos comprendido que el proceso de legitimación de los gobiernos requiere algo más que constituciones escritas y elecciones limpias, periódicas y plurales. Los procesos de reforma y modernización democrática deben contribuir a legitimar los gobiernos. La necesidad de un cambio surge impostergable cuando los resultados de la democracia en América Latina están revelando una crisis en los modelos institucionales que hace peligrar la gobernabilidad democrática.

\section{La gobernabilidad}

Señala Portinaro (2003) una de las grandes paradojas de la crisis del Estado: si bien es cierto que los Estados ya no se encuentran a la altura de los desafíos y las obligaciones trasnacionales con los que se enfrentan, por el otro lado, las instituciones internacionales que deberían reemplazarlos en el desempeño de estas obligaciones, como la ONU, en realidad son instituciones incompletas, carentes del poder que les permitiría llevar a cabo aquellas políticas que los Estados ya no están en condiciones de emprender. En ausencia de otra forma de organización política que lo reemplace, los discursos sobre la crisis del Estado se han trasladado a la crisis de gobernabilidad.

En la actualidad, la crítica contra las instituciones y las prácticas de la democracia liberal de partidos se ha hecho más fuerte; crítica que alcanza inclusive a los países anglosajones y a los nórdicos. Se trata de un fenómeno psicosocial complejo, pues aun reconociendo que la democracia es insustituible, un número creciente de ciudadanos se desentiende de la democracia realmente existente, en diferentes grados y niveles de aborrecimiento.

Este fenómeno, conocido como desafección a la democracia, no es teórico ni de principios sino práctico y cotidiano. Más que una crítica contra la idea de la democracia misma, se revela como falta de compromiso con sus sentidos profundos. El ciudadano, acostumbrado a vivir en democracia, opta por eludir el cumplimiento de una buena parte de sus deberes ciudadanos y deja de sentir la necesidad de usar los derechos políticos conquistados. Y si continúa participando en los procesos electorales, lo hace a pesar del sistema (Rubio Carracedo, 2000; Tusell, 1994).

La crisis generalizada del modelo democrático liberal, ha llevado a decir a Laporta (2000) que todo aquello que suene a representación electoral, a actividades de partido o a militancia política registra una cierta atmósfera de descalificación implícita o explícita. No es que la desconfianza ciudadana vire de unos a otros gobernantes o 
partidos, sino que recae específicamente sobre las instituciones representativas y los partidos políticos, núcleos centrales del modelo de la democracia moderna.

Varias son las causas que pueden explicar este fenómeno. Mucho se ha escrito acerca de las consecuencias negativas que el fin de la Guerra Fría ha tenido para las democracias occidentales: sin un modelo adversario con el cual medirse y contrastarse, se desvanecen los incentivos para mejorar y los logros se relativizan.

La crisis no deja de ser paradójica, pues se revela en el preciso momento en que ha obtenido una victoria irreversible. Como señala Subirats (2002) nunca en la historia de la humanidad se había conocido una extensión tan amplia de reglas y de mecanismos de representación plural, de participación y de control, que históricamente han ido conformando el concepto de la democracia moderna. Y sin embargo, continúa existiendo una insatisfacción creciente en cuanto a su funcionamiento.

Otro conjunto de factores que pueden dar cuenta de la desafección a la democracia pueden agruparse en torno a lo que Bobbio (2000) llamó las "promesas incumplidas": formalismo, distanciamiento, burocracia, opacidad y asimetría conspiran contra la necesidad de una democracia eficaz y eficiente y propician los movimientos autoritarios que prometen $-\mathrm{y}$ a veces logran - resultados a corto plazo.

Todo el proceso democrático está expuesto al constante desafío de producir legitimidad. La distinción entre legitimidad de origen y legitimidad de ejercicio pone en evidencia que en un sistema democrático no es suficiente el acceso a los cargos públicos a través de elecciones limpias y plurales. Por ello, si bien parte de la crisis tiene origen en el diseño institucional, una gran responsabilidad recae sobre el ejercicio de la representación y la mediación de los partidos políticos.

La crisis de representación afecta la piedra angular de la actual democracia de partidos. No sólo es la naturaleza oligárquica del proceso de definición de la oferta electoral, sino también el congelamiento burocrático de unas élites representativas cada vez más alejadas del sentimiento popular ${ }^{40}$ (Conf. Blanco Valdés, 1996).

Esa insatisfacción por el monopolio representativo de los partidos políticos ha derivado en el fortalecimiento de estructuras paralelas, como las ONGs, que defendiendo intereses sectoriales, desprecian la política. Sin articulación de intereses, el ámbito público pierde espacio y se vacía de contenido.

Insistimos, no es una crisis que afecte a los fundamentos y al ideal en que se basa y ni siquiera se trata de una crisis de las instituciones democráticas concretas, aunque algunas deban ser reformadas ${ }^{41}$. Lo que se advierte fundamentalmente es un descenso de la confianza del ciudadano en la forma de operar y en el rendimiento de las

\footnotetext{
40 Ese estancamiento no es sólo producto de la natural aspiración a conservar y mantener el poder. Es también favorecida por la ausencia de legislación que limite la permanencia y acumulación de cargos internos en el partido y en las bancas legislativas, factor que ha contribuido a la generalización de algunos de los vicios más nefastos de la profesionalización política. El "Estado invisible", esto es, sometido a los poderes de una burocracia partidaria contribuye no sólo a la ineficacia del sistema sino también a ampliar esa desafección.

${ }^{41}$ Sin embargo, si este proceso se extendiera más aún, la propia democracia como sistema legitimador de la relación mando-obediencia podría verse afectada. En efecto, sin participación en el debate público no hay pueblo y sin pueblo no puede haber gobierno del pueblo.
} 
instituciones representativas, que produce como contrapartida, su retraimiento al ámbito privado $^{42}$.

El Estado requiere de una teoría que explique el cambio de espíritu del Estado de Bienestar, que abarca una gran variedad de funciones y propicia el monopolio estatal por un nuevo tipo de Estado, regulador y promotor. La crisis aparece hoy como crisis de gobernabilidad y por ello, tal vez, las teorías sobre la gobernanza pública puedan ayudar a esta nueva Teoría del Estado.

Como señala Vallespín (2003), la globalización afecta, sin lugar a dudas la gobernabilidad del sistema político: sin entrar a discutir si esta crisis se funda en las contradicciones del Estado de Bienestar del capitalismo tardío, vista como crisis de legitimidad por Habermas y Offe o en torno a la idea del gobierno sobrecargado, por los autores del informe encargado por la Comisión Trilateral, King, Huntington y Nordhaus, vista como crisis por sobrecarga, lo cierto es que se advierten como problemáticas: a) un poder fragmentado; b) mayores expectativas y mayores demandas; c) nuevas necesidades y nuevos derechos, y d) una menor deferencia ciudadana a la autoridad.

El abordaje de la cuestión de la gestión de los asuntos públicos no es algo nuevo pero su concepto es muy controvertido. En efecto, no hay un único concepto de gobernanza pública ni de gobernabilidad; más bien, un número de diferentes puntos de partida para la nueva estructuración de las relaciones entre el Estado y sus instituciones en los niveles federal, provincial y municipal, por un lado, y las organizaciones privadas, con y sin ánimo de lucro y con la sociedad civil (sujetos colectivos e individuales), por el otro.

Sin embargo, los debates sobre las cuestiones relativas a la gobernanza son numerosas, y cada vez más a lo largo de los años, porque la gestión de los asuntos públicos se refleja en un criterio de evaluación muy potente para administración pública. Sin duda, la cuestión de la gestión pública no sólo aporta un enfoque multidisciplinario y del tratamiento a los ciudadanos por las Administraciones Públicas; también por medio de él, se puede evaluar y considerar los medios de búsqueda de mejoras en la eficacia y la protección de los derechos fundamentales, especialmente el derecho al desarrollo.

$\mathrm{Su}$ significado original contenía una asociación con el debate político del desarrollo, en el cual el término se utiliza para referirse a la política de desarrollo que orientaban algunos supuestos o elementos estructurales - como la gestión, las responsabilidades, la transparencia y la legalidad del sector público - considerados como necesarios para el desarrollo de todas las sociedades.

El origen del problema de gobernanza está vinculado con la gobernanza local, concebido a inicios de la década de 1980 y otro lado con la gobernanza empresarial, desarrollada a finales de 1980. Pero sus orígenes se sitúan en la obra de Crozier, Hungtinton y Watanuki (1975), donde se plantea la necesidad de superar el desajuste entre demandas sociales en expansión, la crisis financiera y de eficiencia del sector público que caracterizó a la década de los 70 .

\footnotetext{
42 Por ello resulta necesario repensar el funcionamiento estatal hacia formas que impliquen el compromiso e involucramiento de los diversos actores públicos, estatales y no estatales, de forma de lograr más legitimidad en las políticas relativas al espacio público que resulta necesario recuperar.
} 
Aunque el conjunto de ideas que incluye la gestión pública es complejo, hay que destacar la vaguedad conceptual de su aplicación práctica. Es imprescindible que la definición funcional no recaiga en conceptos tan vagos. Así, fueron presentados definiciones por organismos y organizaciones internacionales, como por institutos que se ocupan de la cuestión, buscando que las definiciones sean más parametrizadas.

Pese a que en las ciencias sociales los estudios vienen haciendo un uso frecuente del término, la palabra gobernabilidad, recién ingresa al Diccionario de la Real Academia Española en su edición de 2001, como "cualidad de gobernable", en su primera acepción y como "gobernanza", en su segunda acepción. Esta última, más consolidada en su uso junto al adjetivo gobernable ("que puede ser gobernado"), refiere al "arte o manera de gobernar que se propone como objetivo el logro de un desarrollo económico, social e institucional duradero, promoviendo un sano equilibrio entre el Estado, la sociedad civil y el mercado de la economía", por un lado, y a la "acción y efecto de gobernar o gobernarse".

En verdad, como señalábamos, el concepto de gobernabilidad entra en la escena de las ciencias sociales desde mediados de los años setenta, junto con la crisis de las economías desarrolladas, y en América Latina, junto con los procesos que comenzaron a desarrollarse durante las décadas de los setenta y ochenta: el proceso de crisis, ajuste y reestructuración económica; el agotamiento del modelo del Estado interventor y su consiguiente redefinición en términos de la Reforma del Estado; y el cambiante itinerario de las transiciones y consolidaciones democráticas (Camou, 2001).

No hay consenso en cuanto al concepto, pues en él confluyen varias tradiciones o modos de ver la política. Como sostiene Antonio Camou (2001), a quien seguimos en esta tesis, la gobernabilidad puede ser vista como: a) eficacia; b) legitimidad; y c) estabilidad.

La primera visión es propia del realismo político, para quien el problema central de la política pasa por el ejercicio eficaz/eficiente del poder y en este sentido, la gobernabilidad es una propiedad de los sistemas políticos definida por su capacidad para alcanzar objetivos prefijados (eficacia) al menor costo posible (eficiencia).

La noción de gobernabilidad asociada a la de legitimidad, proviene de otra antigua tradición del pensamiento político, asociada a la búsqueda de la mejor forma de gobierno y del bienestar general (hoy hablamos de buen gobierno y derechos humanos). Desde esta perspectiva, la gobernabilidad refiere al problema de la calidad de la acción gubernamental.

La última, asociada a la estabilidad, también encuentra su origen en una antigua tradición vinculada a la primera y que ha centrado su atención en el problema del orden político, en otras palabras, en la cuestión de la estabilidad entendida como la previsible capacidad del sistema para durar (sobrevivir) en el tiempo, superando o adaptándose a los desafíos que provienen del ambiente.

Así, el concepto de gobernabilidad es esencialmente complejo y puede vincularse tanto a la legitimidad del sistema político, a su capacidad de dar respuesta como a su estabilidad.

Desde un aspecto cualitativo, puede hacer referencia tanto a la calidad del desempeño gubernamental a través del tiempo (gobernabilidad-legitimidad), como a la cualidad de un sistema sociopolítico para gobernarse a sí mismo (gobernabilidad- 
estabilidad). Ahora bien, el aspecto cualitativo no puede desprenderse de su dimensión cuantitativa representada por la efectividad y eficiencia de las acciones de gobierno (gobernabilidad-eficacia), lo cual revela, por su parte, un ajuste entre las necesidades y los recursos del gobierno.

El concepto contiene además una faz estructural y otra dinámica. En efecto, no puede hablarse de gobernabilidad sin hacer referencia a las instituciones y a los actores en ellas involucrados. Desde esta perspectiva, es necesario evaluar, en la dimensión estructural, el diseño comunicacional del sistema, y en la dimensión dinámica, las relaciones y compromisos institucionales realmente existentes.

Desde otra perspectiva, la gobernabilidad expresa la capacidad de regulación y re-encauzamiento del conflicto y en este sentido, la gobernabilidad democrática implica la asignación de capacidades diferenciadas de acción y de veto a distintos actores sociales según su grado de representatividad dentro del sistema democrático. La capacidad aparece entonces como un elemento clave pues revela la solvencia de los gobernantes para tomar las decisiones apropiadas frente a los desafíos sociales.

Teniendo en cuenta ese concepto complejo de gobernabilidad, la gobernanza se plantea como el sistema de orientación política y su modo de tomar decisiones y lograr consensos. Es por ello que la buena gobernabilidad requiere de altos niveles de credibilidad. Hay que conservar esa legitimidad arquitectónicamente: el gobierno debe demostrar que tiene una capacidad probada para dar respuesta a las demandas y expectativas sociales creadas. Pero también hay que conservar esa legitimidad horizontalmente: haciendo a los actores copartícipes de la gestión y de los procesos de decisión en un esquema de participación democrática.

Puede decirse que gobernanza pública es una nueva generación de reformas administrativas y del Estado, que tiene por objeto una eficaz, transparente y compartida acción pública, llevada a cabo por el Estado, las empresas y la sociedad civil, para aportar soluciones innovadoras a los problemas sociales y para la creación de oportunidades y posibilidades de desarrollo de un futuro sostenible para todos los ciudadanos (Bovaird, 2005). O, en otras palabras, la gestión pública observa la forma en que las partes involucradas en el conjunto de la sociedad interactúan entre sí para influir en las cuestiones de la política pública. Por lo tanto, la gestión de los asuntos públicos no sólo es la acción del Estado, por ejemplo, en la economía sino también de la participación de las empresas, los usuarios y de toda la sociedad civil, organizada o no, en ese ámbito.

En vista de ello, Tony Bovaird (2005), aseguró que las normas, estructuras y procesos de una buena administración pública, que marcan los principios de la gobernanza pública, son: a) conquista de decisión democrática; b) compromiso de los ciudadanos; c) tratamiento justo y honesto de los ciudadanos; d) sustentabilidad y coherencia de las políticas; e) capacidad de trabajar en conjunto; f) transparencia; g) inclusión social e igualdad (de oportunidades, de costos, de utilización, de accesos y de resultados); h) respecto a la diversidad; i) responsabilidad; j) respecto a los derechos del otro; k) respeto al Estado de Derecho; 1) capacidad de trabajar en un ambiente global.

Para garantizar una mayor presencia en el área de gobierno de la administración pública es necesario impulsar (y cumplir) las leyes sobre transparencia, libertad de información, medidas para luchar contra la corrupción y programas para la igualdad de 
oportunidades. Son necesarias también las normas sobre la gestión de la participación de los agentes en la Administración y sobre la sostenibilidad de las políticas públicas.

Sin embargo, la eficacia potencial de la legislación, en sí misma, es limitada, por lo que otros mecanismos deben integrar la gobernanza. Tal vez, el principal requisito es el que apunta a la existencia de confianza y respeto de las reglas de juego entre los diferentes actores en el dominio público, lo que lo hace lograr un entorno en el que la fiabilidad y la seguridad estén presentes y sea un objetivo crucial de toda Administración Pública.

En este sentido, y siendo que el valor del aparato institucional público depende de la percepción de la sociedad sobre su capacidad institucional para satisfacer necesidades (v.g. garantizar de la equidad, el desarrollo y la gobernabilidad) ${ }^{43}$, resulta natural que los gobiernos de la región hayan querido reformar cómo hacen lo que hacen, y redefinir qué es lo que deben hacer.

${ }^{43}$ Conf. Oszlak, 1997. 


\section{CAPÍTULO II. LA REFORMA DEL ESTADO}

\section{Reforma del Estado de primera generación: achicar el Estado}

Se ha dicho que un sistema administrativo sobrecargado resulta demasiado "pesado" para dar rápida y eficiente respuesta a las complejas demandas del mundo actual. Se reclama un cambio sustancial en la forma de gestionar la cosa pública, una extensión de la democracia de las organizaciones para permitir una expansión del bienestar, creando una creciente presión para obtener más y mejores servicios públicos (Olías de Lima, 2001).

Desde la OCDE se han propuesto diversos mecanismos cuasi competitivos de mercado, definidos como aquellos instrumentos de gestión o diseños organizativos públicos en los que está presente, al menos, una característica significativa de los mercados: competencia, uso de señales de precio, toma de decisiones descentralizada y dispersa e incentivos monetarios.

Con el auge del neoliberalismo, desde fines de los ' 80 y durante toda la década del '90, se aplicaron en los Estados latinoamericanos programas de reforma más o menos ambiciosos, cuyo rasgo principal fue la reducción del aparato estatal. En estas políticas sobresalieron consideraciones de tipo jurídico y financiero y se impulsaron acciones de desregulación, descentralización, privatización, tercerización $\mathrm{y}$ achicamiento de las dotaciones de personal. Ahora bien, resulta necesario distinguir, con la mayoría de los autores las políticas de reforma que se dieron en esos años de las que surgieron a mediados de los noventa y luego.

Como señala Zeller en su Introducción al libro Marco conceptual metodológico para el estudio de las políticas públicas,

... pasaron a denominarse así como reformas de "Primera Generación" aquellas vinculadas con la transformación estructural de los roles estatales, mientras que las destinadas a la mejora del funcionamiento de las instituciones estatales se conceptualizaron como de "Segunda Generación" (Zeller, 2007 b:3).

En las reformas de primera generación -o hacia fuera según Oszlak (2003)- el Estado deja de hacer "algo" (v.g. producir bienes, prestar servicios, regular el comportamiento de ciertos actores), siendo reemplazado en su ejecución por un tercero (incluyendo a la "mano invisible" del mercado). El Estado prescinde totalmente de una proporción de prestadores estatales (v.g. empleados públicos), sin que nadie los reemplace. Hay procesos de reducción de la dotación de personal, a cambio de contraprestaciones materiales bajo la forma de indemnizaciones por retiro voluntario, jubilación anticipada. Pero son también parte de un proceso de "reestructuración" del Estado.

Estas reformas estuvieron influenciadas por el denominado "Consenso de Washington", por las políticas de los organismos multilaterales y por experiencias de países desarrollados. Estos objetivos en la transformación del Estado fueron impulsados 
y apoyados por los organismos multilaterales de crédito (FMI y BIRF) y por organismos internacionales como el CLAD ${ }^{44}$, en América Latina (Zeller, 2007). ${ }^{45}$

En este tipo de reformas, predominan consideraciones de tipo jurídico y financiero. Resulta mucho más sencillo lograr reformas irreversibles cuando su objeto es minimizar el Estado. Las reformas orientadas a lograr menos Estado suponen una reducción de su intervención en diversos planos de su relación con la sociedad (renunciamiento a continuar desempeñando los roles implícitos en las responsabilidades transferidas a otros actores sociales o estatales). Por ello, pueden denominarse como verdaderas reformas del Estado porque afectan sus funciones, marcos de competencia, relaciones público-privado y actores legitimados en el proceso de decisión, ejecución y control de las políticas públicas.

Desde el punto de vista jurídico, las reformas de primera generación implicaron la creación de nuevos marcos regulatorios, la suscripción de contratos de concesión, la contratación de servicios de terceros, la eliminación de regulaciones, la supresión de organismos reguladores, la finalización de contratos laborales y la prohibición del reingreso a la función pública durante períodos determinados.

Desde el punto de vista económico, implicaron ingresos por ventas de empresas, cancelaciones y recuperación de deuda pública, cobranzas de canon de concesionarios, pago a contratistas de servicios tercerizados, actualización de tarifas de servicios públicos, transferencias de partidas presupuestarias a gobiernos subnacionales, indemnizaciones por retiros voluntarios, supresión de aranceles y derechos en organismos de regulación anteriores a la desregulación.

Aunque no figuró explícitamente en el decálogo de recomendaciones del "Consenso de Washington" (Williamson 1990), la descentralización ocupó un rol central en la lógica de las reformas y condicionalidades impuestas por varios organismos financieros multilaterales ${ }^{46}$. Como ha señalado Vilas (2003:3),

En la lógica del "Consenso de Washington" la descentralización aparece como un instrumento de ordenamiento de las cuentas públicas. Busca coadyuvar al superávit fiscal primario del estado central, vía transferencias de actividades y responsabilidades a unidades político-territoriales subnacionales: provincias, departamentos, municipios, u otras. Descentralización implica en consecuencia reducción de las erogaciones fiscales del estado nacional o central.

\footnotetext{
44 Aunque con distintas perspectivas, como veremos más adelante. "No casualmente, fueron los países que en 1974 impulsaron la creación del CLAD (Centro Latinoamericano de Administración para el Desarrollo), lo cual significó una importante contribución a la generación e intercambio de conocimientos y experiencias en torno a la reforma administrativa" (Oszlak, 1999: 83-84).

${ }^{45}$ En el caso argentino, estas transformaciones se realizaron en el contexto de crisis fiscales profundas y recurrentes. Tal situación facilitó la implementación de políticas de ajuste fiscal, pero a su vez, limitó los cambios referidos a la denominada "modernización administrativa" y al fortalecimiento de la eficiencia de sus recursos humanos.

${ }^{46}$ Con motivo de la aplicación de las políticas de descentralización, los gobiernos locales han debido hacerse cargo de nuevas responsabilidades y administrar un aparato institucional mucho más denso y extendido, sin haber adquirido las capacidades de gestión requeridas, lo cual se tradujo en altos grados de ineficiencia en el cumplimiento de los programas de gobierno.
} 
¿Cómo se dio este proceso en Argentina? No es la intención de este trabajo remontarnos al período de reformas del Estado previas al retorno de la democracia, aunque muchas de las reformas posteriores replicaron la matriz de aquellas ${ }^{47}$.

La crisis del Estado, marcada por los desajustes sobrepuestos y no resueltos, originados principalmente en las políticas desarrolladas durante los veinte años anteriores, constituyó uno de los principales problemas para el régimen democrático argentino durante la década del 80 . Esos problemas son conocidos y muchos de ellos no han podido ser superados: Estado burocrático con dosis de autoritarismo, crisis de la deuda externa e interna, del sistema previsional y laboral, de las empresas públicas, del sistema educativo y del sistema de salud.

Si bien el gobierno radical (1983-1989) tuvo por objetivo primordial democratizar las estructuras de gobierno, el modelo económico heredado, basado en el mercado interno, planteó la necesidad de la reforma estatal y de la reformulación de las políticas públicas. Es así que inició -a partir de la vigencia del Plan Austral ${ }^{48}$ - políticas de reforma estatal basadas en los acuerdos de Argentina con el Fondo Monetario Internacional y el Banco Mundial en Berlín, en el año 1986.

La declaración en estado de emergencia económica del sistema previsional, en 1986, da cuenta de la grave perturbación económica en el área previsional. El sistema nacional de jubilaciones, en ese entonces, un régimen de reparto puro comenzaba a evidenciar serias dificultades en su funcionamiento, que derivaron en un paulatino y constante deterioro del nivel de las prestaciones. En este marco, el Poder Ejecutivo declara, por Decreto $\mathrm{N}^{\mathrm{o}} 2196 / 86$, en estado de emergencia económica el sistema previsional con el objetivo de suspender la ejecución de sentencias en contra del Estado por el incumplimiento del pago de haberes que, según la ley vigente, debían cubrir entre el $70 \%$ y el $82 \%$ del salario 49 .

Pero el verdadero ciclo de emergencia ininterrumpida, se inicia con la ley de emergencia económica de 1989, que se continúa en el año 2000, y nuevamente en el año 2002 aún vigente con modificaciones ${ }^{50}$.

En efecto, durante los gobiernos de Menem (1989-1999), se sentaron las bases de una profunda reforma estatal que más que los aspectos cuantitativos, se centró en cambios en las funciones del Estado a través de procesos identificados como de "modernización". Estas políticas estuvieron ancladas en las concepciones y

\footnotetext{
${ }^{47}$ Durante la Dictadura Militar, la crisis de la deuda externa de 1982, el sistema cambiario, las altas tasas de inflación y sistemas de ajuste inflacionario derivaron en políticas de nacionalización de la deuda externa; crisis provisionales y de las obras sociales, regímenes de promoción industrial y subsidios a empresas; endeudamiento de las empresas públicas; juicios laborales de empleados estatales y de empresas públicas y las originadas en la vulneración de los derechos humanos. Pero es llamativo observar que la mayor parte de estas cuestiones recién se contemplaron en las leyes de emergencia de 1989 y en la de Consolidación de la Deuda de 1991.

${ }^{48}$ Con el Plan Austral, dictado en 1985, se declaró la emergencia del sistema previsional y financiero y suscribió la Ley de Coparticipación Federal de Impuestos, que es base de la actualmente vigente.

49 De hecho y desde el reinicio del régimen democrático y en todos los gobiernos sucedidos desde entonces, se han dictado y/o prorrogado leyes de emergencia, originados en la cuestión fiscal, con el objetivo de equilibrar las cuentas públicas.

50 En verdad las Administraciones Públicas latinoamericanas estaban, al momento de aplicarse estas políticas de reforma, en pleno proceso por conseguir instituciones plenamente weberianas. La consecuencia de todo esto "... no es unas instituciones postburocráticas sino unas instituciones preburocráticas en las que predomina el clientelismo y la inseguridad jurídica” (Ramió, 2002:2).
} 
fundamentos del denominado "Consenso de Washington" del año 1989 e impulsadas, a través de fondos otorgados con condicionalidades, por los organismos multilaterales (FMI, BM y BID).

Durante la década del '90 se produjo una profundización de las llamadas políticas de ajuste estructural, poniendo fin definitivamente al modo de articulación social y estatal vigente en la República Argentina desde la década del '30 (Esteso y Cao, 2001).

A este período se corresponde la primera Ley de Reforma del Estado -Ley $\mathrm{N}^{\circ}$ 23.696- y la Ley de Emergencia Económica -Ley $\mathrm{N}^{\circ} 23.697-$, bases jurídicas para la primera Reforma del Estado Nacional ${ }^{51}$. La primera de ellas, ley ómnibus, abarcaba desde el régimen de privatizaciones hasta la organización administrativa pasando por los contratos y pasivos del sector público nacional, dando inicio a una de las transformaciones más radicales del Estado Nacional en cuanto a su configuración, tamaño y papel (Oszlak, 2000).

En líneas generales, las Leyes de Emergencia Económica y de Reforma del Estado de 1989 buscaron la descentralización de funciones en los niveles de los estados federales, la transferencia de funciones a las Provincias, la apertura económica abandonando las actividades de gestión económica, la desregulación de los mercados económicos y las profesiones. Pero también, esas mismas leyes contenían previsiones referentes a la formulación de políticas administrativas de modernización en la gestión y en los recursos humanos (Zeller, 2007) ${ }^{52}$.

Como consecuencia de estas políticas, los servicios de educación, salud y ciertos planes sociales se transfirieron a las provincias. Así, por ejemplo, a partir del 10 de enero de 1992, los servicios educativos administrados en forma directa por el Ministerio de Cultura y Educación y por el Consejo Nacional de Educación Técnica, conjuntamente con las facultades y funciones sobre los establecimientos privados, fueron reconocidos como "cuestiones locales". Posteriormente se transfirieron las escuelas superiores normales e institutos superiores estatales y la supervisión de los privados. ${ }^{53}$

Durante la primera presidencia de Menem esa política de apertura general, comercial y financiera, la desregulación que limitó la intervención estatal en la formación de precios (Decreto $\left.\mathrm{N}^{\mathrm{o}} 2284 / 91\right)^{54}$ y las privatizaciones y concesiones de las empresas públicas nacionales, modificaron abruptamente el esquema de funcionamiento

\footnotetext{
${ }^{51}$ Con las últimas leyes de emergencia, se abre un nuevo ciclo económico y de reforma estatal. Estas leyes buscaron tratar los sistemas impositivos, las deudas públicas, las regulaciones financieras, los mercados y regulaciones laborales y las privatizaciones de las empresas públicas. Cada una de estas leyes requirió un gran número de normas reglamentarias, que reglamentaron las distintas temáticas tratadas en los fundamentos y objetivos de las mismas.

${ }^{52}$ Las principales leyes de emergencia han sido normas "ómnibus" que legislaron distintos temas en forma simultánea (desde el tratamiento de deudas hasta el reordenamiento de la estructura estatal y de las políticas económicas).

${ }_{53}$ Dicha transferencia fue realizada a través de las Leyes $N^{\circ} 24.049$, No 24.061 y el Decreto $N^{\circ}$ 964/92. El personal docente, técnico, administrativo y de servicios generales que se desempeñaba en los servicios transferidos también fue transferido a las administraciones provinciales o municipales.

${ }^{54}$ Caben mencionar diversos decretos aplicables en materia de desregulación, tales como los Decretos $\mathrm{N}^{\mathrm{o}}$ 817/92, 958/92, 1493/92, 1494/92, 1813/92, 2293/92 y 1187/93, aplicables sobre la explotación pesquera, de transporte terrestre de carga y pasajeros, de reorganización portuaria, la navegación marítima y fluvial, de correos y permisionarios postales, sector minero, comercio minorista, entre otros.
} 
de un sistema económico protegido desde la segunda guerra mundial que permitió el desarrollo de algunas economías regionales. ${ }^{55}$

En este nuevo esquema, cuyas líneas directrices se establecieron en la Cumbre de las Américas de Santiago de Chile en 1996, se incorporan a la agenda temas sustantivos como la educación, la salud, la calidad de los servicios públicos, la seguridad humana y la gestión de justicia. No era ya la lógica del Estado mínimo sino la del su rol en dichas áreas sensibles. El supuesto ideológico era-sigue siendo- que sólo con la lógica de la empresa privada pueden romperse los obstáculos institucionales e introducirse criterios de eficiencia y efectividad en el sector público.

Pero ese esquema de Estado mínimo tampoco fue capaz de superar los problemas fiscales y de superávit ${ }^{56}$. La implementación de estas reformas estructurales solo se concretaron en forma limitada: la crisis fiscal y estatal marcó la agenda de la reorganización del Estado y de sus políticas, subordinada a la necesidad de restablecer el valor de la moneda, el equilibrio fiscal y superar la cesación de pagos de la deuda estatal (Zeller, 2007).

Como consecuencia de las políticas de reforma de primera generación, el Estado Nacional renunció a continuar desempeñando el papel de prestador directo de bienes y servicios y se desprendió de los servicios educativos (con excepción de la enseñanza superior), que transfirió a las provincias junto con los de salud. Eliminó un gran número de organismos y unidades estatales a cargo de funciones reguladoras de la actividad económica. Perdió el 70 \% de su personal y devolvió al mercado laboral (así como a la inactividad privada) a más de 100.000 empleados públicos (Oszlak, 2003).

Pero la minimización del Estado ha terminado siendo, como afirma Oszlak (2003:14) la "continuación del Estado por otros medios" ya que si bien, a partir de los años "90 las políticas de descentralización de servicios de salud y educación, y la descentralización parcial de servicios de acción social redujeron el aparato estatal nacional, implicaron, por otro lado, la correspondiente expansión de las administraciones provinciales.

Las administraciones provinciales, relativamente sencillas, en pocos años se vieron con un cúmulo de funciones que transformaron su fisonomía sin recibir la correspondiente capacitación para asumir esas nuevas tareas.

Más aún, el fracaso en los objetivos propuestos por estas reformas de primera generación se puso de manifiesto cuando en el período 1990-1999 no sólo hubo crecimiento en el Gasto público consolidado en los tres niveles ${ }^{57}$, sino $-y$ muy especialmente- cuando se advirtió que el Gasto público del Estado Nacional, pese al

\footnotetext{
${ }^{55}$ En el caso argentino, la apertura ya comienza con el gobierno militar de 1976, pero no adquirió el grado de apertura que la política económica del menemismo. La industria automotriz fue una de las pocas excepciones a la política de apertura.

${ }^{56}$ Sidicaro (2003) ha sostenido que a la pérdida de capacidades de gestión burocrática se sumaron todos los efectos de las arbitrariedades, caza de brujas y clientelismos, que en las condiciones de obsecuencia y de terror imperante deterioraron aún más los distintos niveles de la administración pública.

${ }^{57}$ En 1990, el gasto público consolidado en los tres niveles era de 61.949 millones de dólares mientras que en 1999, fue de 97.595 millones de dólares, lo cual supone un crecimiento del 57,5\% en el período.
} 
desprendimiento de funciones, privatizaciones y políticas de restricción de personal, aumentó un $31,8 \%{ }^{58}$

Por ello, sobre todo luego de la reforma constitucional de 1994, se inicia poco a poco en Argentina la llamada segunda Reforma del Estado Nacional, que se proponía profundizar, desde una nueva perspectiva y otros objetivos, las políticas de modernización y reforma administrativa.

\section{Reforma del Estado de segunda generación: Conceptos}

Como hemos dicho, existe una fuerte demanda social sobre el Estado para obtener mejores servicios, transparencia en el uso del gasto público, calidad en las prestaciones y mejores controles en las nuevas regulaciones de los servicios públicos privatizados.

En este nuevo proceso -y reflexión- sobre las "reformas del Estado", que se han querido distinguir como de "segunda generación", se continúa atendiendo al Estado como relación de dominación o como conjunto heterogéneo de aparatos organizacionales, pero se pone especial énfasis en los intrincados procesos de construcción institucional en el marco de los desafíos de la gestión pública. Estos procesos son los que pueden atentar contra los procesos de reforma.

Es por ello que en el programa de las reformas de segunda generación predominan consideraciones con un trasfondo tecnológico y cultural; se dice que la irreversibilidad es condición del éxito o fracaso de la empresa de las reformas estatales y se entiende que la intención política de la reforma, formalizada en un instrumento jurídico, es insuficiente para producir el cambio. La frase de Crozier (1995) es ya clásica: no se cambia la administración pública por decreto.

Una de las principales herramientas consiste en la incorporación de nuevas tecnologías de gestión (nuevas formas de administrar lo público) y en la búsqueda de cambios en la lógica de la cultura organizacional. El éxito depende en gran medida de que las premisas valorativas en que se fundan las nuevas tecnologías de gestión consigan permear la cultura político-administrativa vigente. serían:

Los objetivos, en términos generales, de la reforma de segunda generación

- reforzar funciones del Estado, sobre todo las de control;

- rediseño organizativo del aparato administrativo;

- desburocratización de normas, procesos y trámites administrativos;

- implantación de sistemas de carrera administrativa basados en el mérito;

\footnotetext{
${ }^{58}$ De 38.755 millones de dólares en 1990, pasó a 51.074 millones de dólares en 1999. Parece evidente que cuando las administraciones utilizaron como herramientas de reforma los principios del derecho administrativo, siguieron la propia lógica de la burocracia (Gascó, 2004). Sin embargo, la rigidez normativa, aunque no fue un elemento de dinamismo y flexibilidad para la reforma, no fue la única causa de su fracaso.
} 
- capacitación y desarrollo permanente del personal y rediseño de las plantas de personal estatal;

- mejoramiento de los sistemas de información y sus soportes computacionales.

Coincide Camou (2005:35) cuando afirma que

En ese trayecto se han enlistado en los últimos tiempos una serie de reformas pendientes para el posajuste, a saber: la reforma laboral, la reforma fiscal, la reforma crediticia, los desafíos de la integración comercial, un nuevo empuje a la productividad agrícola, la articulación de los imperativos del desarrollo sobre bases regionales, etc. En el plano social, por su parte, aparece como prioridad la compensación de los efectos negativos del libre juego del mercado mediante una política activa de gerencia del desarrollo social y combate a la pobreza, poniendo énfasis en la centralidad del empleo como mecanismo disparador de las capacidades individuales para progresar socialmente, o dicho de otra manera, como vía regia de vinculación entre el crecimiento económico y el bienestar social. Finalmente, desde una perspectiva política, el fortalecimiento democrático e institucional del Estado ha sido puesto en el primer plano. [...] De este modo, eficiencia, calidad, equidad y responsabilidad pública aparecen como cuatro principios rectores de la nueva agenda de la reforma estatal.

En esta nueva perspectiva de diseño del funcionamiento del aparato Estatal, la mejora de la calidad institucional aparece como un eje central, en especial, en las funciones que reaparecen como indelegables (justicia, seguridad, salud, educación) y un mayor/mejor control en los marcos regulatorios de los servicios privatizados y aún del sector privado.

Según Naím, citado por Oszlak (1999), los instrumentos típicos de esta etapa incluyen la reforma de legislación y prácticas laborales; la reforma del servicio civil; la reestructuración del gobierno, especialmente ministerios de índole social; la renovación del sistema judicial; la actualización de capacidades regulatorias; la conversión y reestructuración sectorial; las privatizaciones «complejas»; el desarrollo de la capacidad de promoción de exportaciones; y la reestructuración de relaciones entre los estados y el gobierno federal.

Pero,

[...] la experiencia ha permitido comprobar que los objetivos y contenidos de la segunda reforma difieren de contexto en contexto y dependen, a menudo, del alcance que haya tenido la primera. A la inespecificidad de su contenido se agrega su confusión conceptual. No se advierte, por ejemplo, un intento de diferenciación entre lo que son principios o valores de la reforma, lo que son nuevos roles implícitos y lo que son instrumentos de cambio. El ya clásico decálogo propuesto por Gaebler/Osborne, empleado muchas veces como enunciado de las reformas de segunda generación, se refiere fundamentalmente a principios y valores que deben orientar la 
«reinvención del gobierno», sin alusión a etapas. Aunque en su mayoría estos principios contienen supuestos instrumentales, no delimitan el papel del Estado ni conducen unívocamente a un programa de acción (Oszlak, 1999:87).

Las políticas de reformas sin un claro plan de acción (el cómo) han dado lugar a consecuencias no deseadas (Oszlak, 1999 b:3):

- $\quad$ La tendencia natural de la Administración Pública a la cariocinesis estructural continuaría hasta alcanzar extremos que volverían a plantear la reestructuración como decisión inevitable.

- $\quad$ El ingreso irrestricto de personal y la crisis presupuestaria a la que contribuiría, llevaría a un congelamiento de las vacantes y a la habilitación de unos pocos puestos de trabajo a los que se accedería sin concurso, a través de mecanismos de nepotismo político.

- La falta de evaluación de desempeño igualaría al personal respecto de los incentivos salariales, pero la creciente masa salarial producida por el ingreso irrestricto y la promoción automática podría ocasionar reducciones de sueldos y un achatamiento de la curva salarial y los salarios promedio.

- La falta de incentivos materiales efectivos y la automaticidad del ascenso, conducirían a la devaluación de los escalafones y a la renuncia a asumir mayores responsabilidades, dada la escasa diferencia salarial implícita en la promoción.

- La pirámide estructural se transformaría en un poliedro irregular raleado en su base y la composición de la planta de personal acabaría mostrando excesos de agentes no (o semi-) especializados y falencias de recursos humanos altamente calificados.

En efecto, resulta mucho más difícil lograr reformas irreversibles cuando su objeto es mejorar el Estado; cuando hay contradicción entre la racionalidad técnica en que se fundan (v.g. mérito, responsabilidad, capacidad, equidad, transparencia) y la racionalidad política que interfiere su efectiva aplicación (v.g. privilegios, discrecionalidad, nepotismo, búsqueda de rentas) (Conf. Oszlak, 2000). Y en este sentido, es una reforma pendiente. ${ }^{59}$

Las denominadas reformas de "Segunda Generación" se iniciaron a nivel nacional en el período 1995-1999. La sanción de la reforma constitucional de 1994 marcó un hito en la reforma del Estado sobre todo por los cambios institucionales, en el de los derechos civiles y en el sistema de gobierno que introdujo, muchos de los cuales no lograron cumplir sus objetivos pero que, sin dudas, modificó el mapa político. En el

\footnotetext{
${ }^{59}$ Este carácter de reforme pendiente es, justamente, el que ha impulsado a algunos a plantear una nueva etapa de reforma. Así, por ejemplo, Daniel García Delgado (2006:4) sostiene que "Luego de la hegemonía pensamiento único, de la desarticulación del Estado, de su cesión de competencias al mercado, de transferencia de responsabilidades sociales a la sociedad civil y a los gobiernos provinciales y locales sin los recursos necesarios, era imprescindible una etapa de reconstrucción del mismo. A diferencia de la orientación de las reformas del Estado de segunda generación, el Estado requiere no sólo de una gestión transparente, auditable, ni tampoco se reduce a una buena administración, sino también debe considerárselo como garante del bien común, centro de articulaciones sociales e impulsor de un proyecto colectivo y transformador".
} 
plano institucional, aparecen órganos extra-poder (Consejo de la Magistratura y Ministerio Público), la Jefatura de Gabinete de Ministros con la pretensión de separar la jefatura política de la administrativa del país y la autonomía de la Ciudad de Buenos Aires.

La Segunda Reforma en Argentina abarcó tanto la reforma impositiva, destinada a mejorar la recaudación y a obtener recursos genuinos para cubrir el déficit del sistema previsional y pagar los servicios de la deuda, como la reforma de las estructuras estatales, dirigida a "modernizar" la gestión de los programas públicos (Zeller, 2007).

La reforma incidió en diversos niveles del aparato estatal: en la Administración Pública Nacional, en el Sistema de Seguridad Social y en los estados provinciales y municipales. Los objetivos principales declamados de la segunda etapa del proceso de reorganización fueron: formular políticas públicas eficaces; satisfacer demandas sociales; armonizar los conflictos; redistribuir la riqueza y desarrollar la equidad; prestar sus servicios con calidad para los usuarios; invertir en infraestructuras básicas, como promotor de desarrollo; desempeñar eficientemente sus funciones de recaudación; proveer los servicios colectivos o de apropiación colectiva: seguridad, justicia, defensa; atender la cobertura de los servicios sociales básicos: salud, educación, acción social, cultura; velar por la protección del medio ambiente.

Se procuró reorganizar la estructura ministerial del Ejecutivo; se estableció una nueva reducción del personal permanente mediante la supresión de algunas áreas y el retiro voluntario; se formuló la necesidad de modificar el Estatuto Jurídico Básico, que regulaba la relación contractual laboral general de los empleados públicos ${ }^{60}$.

Estas reformas se fundamentaron en la necesidad de la aplicación de los programas organizacionales del sector de las empresas privadas y en el New Public Mangement cuyas bases teóricas veremos más adelante.

Así, en 1996 se sancionó la Ley $N^{\circ} 24.629$ que siguiendo los lineamientos que pautaban el nuevo modelo de Reforma del Estado, apuntaban a incorporar criterios de eficacia y eficiencia. Se puso una fuerte carga en la reorganización institucional y así se eliminaban $y / o$ reorganizaban organismos a través de la fusión; se reducían o transformaban instituciones y se introducían criterios propios de la empresa privada, tales como la competitividad entre sus agentes a través de sistemas de premios a la productividad e incentivos.

Se delegó en el Poder Ejecutivo Nacional las facultades para:

- centralizar, fusionar, transferir a las provincias - previo acuerdo-, reorganizar o suprimir, parcialmente, organismos descentralizados creados por ley;

- disponer la supresión total de organismos descentralizados creados por ley sólo cuando se asegure el cumplimiento de las funciones esenciales del Estado que pudiesen estar atendidas por dichos organismos y no impliquen la eliminación de funciones o roles que tengan directa incidencia en el desarrollo regional o comunitario;

\footnotetext{
${ }^{60}$ Junto a esta reforma, se establecía la reforma de gran parte de los sistemas de carrera existentes.
} 
- disponer la supresión de recursos propios de la Administración Central a su cargo o de afectaciones especificas establecidas por ley salvo aquellas afectaciones destinadas a las provincias o a financiar gastos de seguridad social;

- proceder a la privatización de actividades relacionadas con la prestación de servicios periféricos y la gestión de producción de obras o bienes que se encuentren a cargo de las jurisdicciones o entidades de la Administración Central, sin que esto implique la declinación de servicios esenciales y en la medida que se logre una mayor eficiencia en su realización, mejores servicios a los usuarios o a la comunidad, con una disminución de sus costos o una mejor asignación de los recursos públicos destinados a estos fines.

Por otra parte, para generar más empleos se daba prioridad a las Pymes y a los micro emprendimientos, otorgando mayor preferencia a aquellas integradas por personal que se hubiera acogido a programas de retiro voluntario.

Esta fase de reformas se plasmó en un profuso y extenso marco normativo que debía dar apoyo a la reforma: por medio del Decreto $\mathrm{N}^{\circ}$ 558/96 se creó, en el ámbito de la Jefatura de Gabinete de Ministros, la Unidad de Reforma y Modernización del Estado (URME) que debía culminar la primera etapa del Programa de Reforma y elaborar el Programa de Modernización del Estado. El Decreto determinaba, asimismo, la creación de la Unidad de Coordinación con las Provincias que asistió en los programas de reforma. Se estableció, en el ámbito del Ministerio de Trabajo y Seguridad Social, el Fondo de Reconversión Laboral del Sector Público Nacional y se disolvió el Comité Ejecutivo de Contralor de la Reforma Administrativa (CECRA) creado en 1990. Por otro lado, en junio de 1996 y a través del Decreto $N^{\circ}$ 660/96, se dispuso la reducción de las estructuras del nivel de conducción política y la redistribución de organismos según sus finalidades y principales competencias. Se suprimieron 18 secretarías, 42 subsecretarías y se fusionaron y transformaron diversos organismos y estructuras superiores. $^{61}$

En lo económico, el equilibrio fiscal fue uno de los grandes objetivos. En 1999 se sancionó la Ley 25.152 de Regulación de la Administración de los Recursos Públicos (Ley de Solvencia Fiscal). Esta norma marca un tercer momento en la reforma y/o modernización administrativa, tanto en materia de macro como de microreforma. Establece como requisito el equilibrio fiscal y la creación del denominado Fondo Anticíclico, conformado por fondos de los superávits fiscales. Un aspecto relevante de esta ley es la promulgación legal de los programas de modernización administrativa. También procura que estas reformas se apliquen en los estados provinciales.

\footnotetext{
${ }^{61}$ En 1990, se había introducido la llamada "regla de tres": ningún Ministerio debía tener más de tres Secretarías, ninguna Secretaría debía tener más de tres Subsecretarías, ninguna de éstas debía contar con más de tres Direcciones Generales y así sucesivamente. Lo cierto es que al producirse el retorno a la democracia, se crearon 32 Secretarías de Estado y 63 Subsecretarías, totalizando 95 unidades. Pero en 1989, y pese a las reformas sucesivas, el número había crecido a un total de 150 entre Secretarías y Subsecretarías. Pese a que sucesivas normas "correctivas" intentaron, con suerte variada, contener una tendencia natural a la multiplicación de unidades organizacionales, en los años siguientes surgieron reestructuraciones "celulares", elevando la cantidad al punto de alcanzar casi 200 Secretarías y Subsecretarías cuando ya se había reducido sustancialmente el papel del estado nacional y rebajado considerablemente la dotación de su personal.
} 
El gobierno de la Alianza continuó con estas políticas haciendo hincapié en la modernización administrativa, sobre todo con la Ley $\mathrm{N}^{\mathrm{o}} 25.233$ de Ministerios, que aumentó su número, y Decreto $\mathrm{N}^{\mathrm{o}} 103 / 01$ de Modernización de la Administración Pública. Se creó la "Oficina Anticorrupción” y se sancionó en 2000 la Ley No 25.246 Unidad de Información Financiera. ${ }^{62}$

Pero nuevos problemas fiscales unidos a la creciente deslegitimación del aparato estatal, hicieron que buenos planes de modernización desde lo teórico, como el que se implementaba con la Decisión Administrativa $N^{0}$ 123/2000 de Solvencia Fiscal y Calidad de la Gestión Pública y el Decreto $N^{\circ} 103 / 01$, quedaran relegados a un segundo $-\mathrm{y}$ hasta un tercer- plano ante la crisis de 2001-2002. ${ }^{63}$

La crisis de 2001 provocó una crisis tanto institucional como económica que terminó abruptamente el Plan de Convertibilidad y generó una nueva crisis de la deuda estatal y privada luego de la salida anticipada del gobierno de De la Rúa.

El gobierno de transición, asumido por Duhalde, dicta el Decreto $N^{\circ} 357 / 2002$ de modificación de la estructura ministerial y se crea el Consejo de Políticas Sociales y el período del ex presidente Kirchner iniciado en mayo del 2003, mediante la sanción de una nueva Ley de Emergencia Económica, reorienta la política económica y monetaria, consagrando un mayor intervencionismo o regulación estatal y reformulando la organización estatal hacia el fomento de las políticas sociales, de infraestuctura y de participación estatal en las empresas productivas y de servicios (Zeller, 2007).

También en 2003 el Gobierno modifica la estructura ministerial y crea el Ministerio de Planificación Federal, Inversión y Servicios Públicos e incorpora nuevas funciones a la Jefatura de Gabinete de Ministros. Si bien se mantienen legalmente los programas del Plan de Modernización se incorporan algunas nuevas medidas. Así, se establece que las universidades públicas tendrán prioridad en las actividades de consultoría contratadas eventualmente por el Estado y se fomenta el acceso a la información pública.

En definitiva, la aplicación de los procesos de reformas generaron resultados también disvaliosos: en primer lugar, el Estado mantuvo estructuras de control social que le permitieron mantener alianzas estratégicas, programas asistencialistas y políticas clientelares; en segundo lugar, la organización política del Estado tuvo pocas modificaciones con la reforma constitucional de 1994 pues ni se limitó el presidencialismo ni el papel hegemónico del Poder Ejecutivo; y en tercer lugar, el contenido rector fue fiscalista - recaudar para afrontar los pagos externos-, en lugar de acentuar la transparencia, equidad y mayor eficiencia en la gestión ${ }^{64}$.

\section{La Nueva Gestión Pública}

\footnotetext{
${ }^{62}$ También son relevantes la sanción de otras leyes: se aprueba la Ley $\mathrm{N}^{\mathrm{o}} 25.326$ de Protección de los Datos Personales (2000), Ley N 25.506 de Firma Digital (2001) y Ley N 25.467 de Ciencia, Tecnología e Innovación (2001).

${ }^{63}$ Esas normas fundamentaban la aplicación de programas como "gestión por resultados", de "calidad de los servicios a ciudadanos", "planeamiento estratégico" y "gobierno electrónico".

${ }^{64}$ Más críticas al período pueden leerse en Oszlak, 2000.
} 
Dentro de los varios intentos de modificación del funcionamiento de las administraciones públicas merecen destacarse las diversas doctrinas -no siempre coherentes entre sí- que agrupadas bajo el nombre de New Public Managment o Nueva Gestión Pública (NGP) procuraron producir, desde la década de los ochenta, importantes modificaciones en la lógica del funcionamiento burocrático sin llegar a confundirse -aún cuando encuentren una misma crítica y compartan puntos- con las políticas de reforma de primera generación.

El ideario de la Nueva Gestión Pública se ha difundido enérgicamente a nivel mundial como eje central para el cambio y la modernización de las administraciones públicas, en países con tradiciones institucionales tan disímiles como Estados Unidos, Suecia, Gran Bretaña, Francia, Australia, incluyendo los de la propia región de América Latina aunque el resultado concreto de su aplicación ha adquirido escasa difusión (López, 2005). Pero es Estados Unidos el principal país promotor del modelo para la nueva gerencia pública, a partir de la importante difusión alcanzada por la conocida obra Reinvención del Gobierno, de Osborne y Gaebler (1994) y sus principios de la modernización, denominados por las "Cinco R": "Reestructuración", "Reingeniería", "Reinvención", "Realineación” y "Reconceptualización"65.

La Nueva Gestión Pública, como reacción a la Administración pública tradicional, ha buscado construir modelos de organización más flexibles a través de: 1) la desregulación, descentralización y delegación de funciones ${ }^{66}$; 2) la desagregación de las áreas de competencia en agencias gubernamentales promoviendo su competencia y rivalidad y 3) la flexibilidad laboral (véase Heeks, 2001).

Estas nuevas teorías organizacionales hablan de "gestión" al intentar poner el acento en las reglas y decisiones necesarias para incentivar y coordinar acciones. Ahora bien, el carácter público añade una cualificación específica a esa gestión de acciones: los fines comunes de bien público que deben seguir esas acciones, condicionadas no sólo por las propias limitaciones del entorno administrativo, sino también por las decisiones políticas.

Las consignas "posburocráticos" resultan sumamente atrayentes: su ejercicio conduciría a un gobierno más económico y eficiente, con servicios de mayor calidad y programas más eficaces, y además, simultáneamente, introduce cambios como la ampliación del control político, mayor libertad a los gerentes públicos para que lleven a

\footnotetext{
${ }^{65}$ Para Fleury (1999) la búsqueda de soluciones para la crónica crisis de gobernabilidad de América Latina encontró apoyo y fuente de inspiración teórica en las corrientes del neoinstitucionalismo y en las teorías de la economía conocidas como public choice y Principal-Agente. A partir de ese cuerpo teórico se diseñaron las estrategias de reforma institucional para la región, en áreas tan distintas como las reformas judiciales, las de seguridad social, los servicios sociales, etc. Además, esa experiencia internacional en reforma del aparato administrativo del Estado fue también ampliamente difundida en la región, a través de una laboriosa acción de consultores internacionales, ingleses y neocelandeses especialmente, intensificando el debate sobre la necesidad de las reformas y la apropiación local de instrumentos innovadores en el campo de la gerencia pública.

${ }^{66}$ Es necesario distinguir claramente cada concepto pues suelen ser confundidos. Existe desregulación cuando se eliminan controles inútiles, superpuestos o que no agregan valor al proceso administrativo. Existe descentralización cuando se otorga funciones y responsabilidades a los niveles intermedios y/o inferiores de las administraciones rompiendo la lógica de la centralización en la cúspide de la pirámide. Existe delegación cuando se distinguen y separan las tareas de planificación, definición, diseño y control de políticas, reservadas a responsables políticos, de las tareas operativas rutinarias o bien reservándolas a los funcionarios de línea o bien privatizándolas.
} 
cabo su gestión, mayor transparencia gubernamental, postulados éstos que nadie podría renegar. Además, los principios y técnicas que configuran el "management público" se presentaron como un conjunto de iniciativas aplicables a todo tipo de organizaciones y caracterizadas por su "neutralidad política".

Un giro copernicano llevaría a cambiar al Estado como centro del sistema por el ciudadano, visto ahora como un cliente al que se le presta servicios. Se pensó que la legitimidad del Estado no estaría dada por su estructura institucional sino por su capacidad de prestar bienes y servicios. Ello haría necesario una administración con énfasis en los resultados y la satisfacción del ciudadano-cliente, lo que requería incorporar parámetros de medición de desempeño ${ }^{67}$.

Estos criterios "privatistas" de satisfacción del ciudadano-cliente fueron tomados de criterios y corrientes de gestión por resultados aplicados a las empresas. La Nueva Gestión Pública se planteó la necesidad de tomar iguales criterios de calidad al interior del Estado. Como ha señalado Hinzte (2003:1):

\begin{abstract}
Así como, entre otras, la corriente de la calidad total expresó de manera descollante, en las organizaciones del mercado, una "ideología de los procesos", en el campo estatal las corrientes de la "Nueva gestión pública" se abocaron con entusiasmo a la apología de la orientación a resultados y las relaciones contractuales referidas a éstos al interior y exterior de las organizaciones públicas. Max Weber devino en respetada pero perimida figura del pasado y sus ideas sobre la burocracia, en lastres de los que ya era hora de desembarazarse.
\end{abstract}

Se pretende que las burocracias obtengan mayor flexibilidad e inteligencia para actuar, sin perder el control de legalidad. Se sostiene que pasando del control de los recursos de los procesos a un nuevo criterio de control a través de evaluación de resultados, será posible planear el uso de los recursos y dirigir el gasto de esos recursos para obtener determinados resultados (Arellano Gault, 2001).

Pareciera que el acento puesto en el control es totalmente nuevo y propio de una visión gerencial del Estado, cuando en realidad es tan antiguo como la administración misma. Lo que sí es nuevo, es la

... tendencia a considerar el control de la gestión pública, sobre todo en la parte presupuestaria, como una suerte de competencia técnica pura, donde aplicando ciertas metodologías de control, se solucionarían cuestiones claves como son, entre otras, la distribución de los recursos, las responsabilidades de ejecución y el logro de las metas planteadas en un cierto período de tiempo establecido (Cleary, 2006:2).

\footnotetext{
${ }^{67}$ Se impulsó un cambio en la lógica normativa y regulatoria del Estado por otra centrada en la prestación de servicios, de la que las políticas de Gobierno Electrónico (en su primera fase) son un claro ejemplo. La estructura organizacional, antes que en el cumplimiento de los procedimientos y las tareas de control debía estar orientada a los resultados, buscándose con ello no sólo niveles de efíciencia sino también asignación de recursos y recompensas ligadas a dichos resultados. En este esquema, las TIC podían ayudar a la máxima descentralización sin pérdidas de control o de responsabilidad.
} 
Se señala que la Nueva Gestión Pública es una colección de ideas valores y creencias prestados de diferentes escuelas del pensamiento y de diferentes corrientes administrativas (Conf. Vargas Hernández, 1999).

Dos grandes corrientes integran la Nueva Gestión Pública. Tal vez la más conocida de ellas sea el Gerencialismo cuya impronta está dada por la incorporación en el ámbito público de la lógica del mundo empresario y gerencial.

Uno de los principios sobre el que se ha trabajado con mayor insistencia desde esta visión es "dejar que los gestores gestionen" buscando incrementar la responsabilidad de los cargos técnicos, por un lado, delegando más poder de decisión basado en la satisfacción del cliente, por el otro.

Podemos reseñar algunos de los principios que orientaban las reformas administrativas. Tal vez el principal estaba dado por la separación entre la política y la administración, entre el ámbito de planificación, decisión, control y evaluación, del ámbito de gestión, vinculada a un sistema de rendición de cuentas con una clara asignación de responsabilidades por las acciones.

En este esquema, la rendición de cuentas administrativa ha sido definida como

... el proceso mediante el cual quien se haya hecho cargo de algún asunto debe hacerse responsable e informar, ante quien tenga derecho a exigirlo, sobre tres aspectos: 1) los productos (y, eventualmente, resultados) logrados y/o, 2) los recursos utilizados para ello y/o 3) las actividades mediante las cuales se utilizaron los recursos. De acuerdo a la naturaleza de los procesos y los términos de las relaciones entre quienes deban rendir cuentas y los que puedan exigirla, pueden identificarse, dos modalidades extremas: a) la rendición de cuentas por el logro de productos [...] y b) por la ejecución de procesos. Por convención, llamaremos a la primera, genéricamente, "rendición de cuentas por resultados" (Hintze, 2003).

Este sistema de rendiciones de cuentas implica, a su vez, la evaluación del rendimiento mediante una definición previa y cuantitativa de metas, objetivos e indicadores de éxito ${ }^{68}$.

De acuerdo con sus enunciados y con la orientación adoptada hoy en día por gran número de países, la «reinvención» del gobierno supone la búsqueda de mayor efectividad en la acción estatal, lo cual, según esta visión, podría lograrse reuniendo las siguientes condiciones: guiarse por una misión; orientarse por resultados; tener una orientación empresaria (ganar en lugar de gastar); tener capacidad de anticipación; estar descentralizado; orientarse hacia el mercado; servir al cliente; cumplir un papel «catalítico».

Las "Carta Compromiso", son una herramienta de esta esquema. Las primeras tienen su origen en Gran Bretaña, en 1991, para los principales servicios públicos

\footnotetext{
${ }^{68}$ Formaba también parte de esa agenda de reforma - y de allí su confusión con las políticas de reforma de Segunda Generación - el control y la participación ciudadana, la rendición de cuentas y la descentralización, la reforma de la justicia, la creación o mejoramiento de la carrera civil, etc.
} 
estableciendo las normas de calidad y los sistemas de reclamos para los usuarios en caso de incumplimiento de los niveles de servicio fijados.

\begin{abstract}
Asimismo, a finales de los '90 se impulsaron las "Cartas de Servicios". Estas cartas tuvieron lugar en Portugal, Francia y España, entre otros países. Se instrumentaron diferentes propuestas en materia de mejora de la calidad de los servicios públicos y de fortalecimiento de las capacidades de los ciudadanos para ejercer sus derechos como usuarios de los servicios. Entre sus características principales, se destacan: - Enfoque del ciudadano como sujeto de derechos a recibir servicios públicos. - Incorporación de mecanismos de participación ciudadana. (Del Giorgio Solfa, Federico y otros, 2009:17)
\end{abstract}

Por su parte, los modelos de gestión por resultados inducen a que las organizaciones públicas establezcan sus objetivos, se responsabilicen por los mismos y jerarquicen sus procedimientos en torno al logro de los resultados, mejorando sus capacidades institucionales. En efecto, la gestión por resultados busca que la administración de los recursos se centre en el cumplimiento de las acciones estratégicas determinadas en un plan de gobierno preestablecido y para un determinado período, de manera tal que permita "gerenciar" y evaluar las acciones de las distintas organizaciones del Estado.

Las ideas de descentralización, también propiciadas por estas políticas, tendían a la agencialización. Como consecuencia directa de esa organización flexible y de la distinción de la dimensión política de la administrativa, se promovió la delegación de muchas de las funciones de gestión de servicios públicos en agencias públicas, mixtas o en empresas privadas.

Se buscaba romper con las estructuras compactas y piramidales de la administración por unidades independientes y autogestionables. Se pretendía que la competencia propia del sector privado se diera entre dichas agencias del sector público, competencia que sería impulsada mediante premios y castigos en las asignaciones de recursos conforme a los niveles de eficiencia alcanzados. Ello implicaría introducir rivalidades hacia dentro del sector público y de flexibilidad laboral nunca antes vistos en las administraciones públicas latinoamericanas.

Pero como mencionamos más arriba, no todas las doctrinas de la Nueva Gestión Pública son coherentes entre sí. La teoría de la Elección Pública (Public Choice), cuyas referencias prácticas encontramos en Gran Bretaña y el Commonwealth, parte también de una fuerte crítica al funcionamiento de la burocracia pero promueve, por el contrario, la centralización, la coordinación y el control para devolverle el poder a los decisores elegidos democráticamente. Conforme a esta posición, el gobierno estaría fuertemente condicionado por la obligación de dar cuentas al electorado. Esta accountability electoral, impulsa a que el nivel político ejerza un fuerte control sobre los niveles burocráticos.

Esta posición, que tiene su origen en teorías económicas, supone la decisión racional del ciudadano y su voto orientado a maximizar beneficios. Si los niveles políticos pueden ser "castigados" por el electorado por la ineficacia en el nivel de respuestas de la administración, es necesario que ese nivel político recupere la gestión 
de las políticas, lo cual supone centralización en la toma de decisiones, coordinación en las acciones y, por sobre todo, control de la gestión para promover la eficacia.

Con la ampliación de incumbencias se promueve la coordinación en la gestión de las políticas. ${ }^{69}$ Para ejercer un mejor control, se impulsa la reducción de los escalones intermedios de la pirámide burocrática acercando así los niveles de decisión y gestión de políticas, se terceriza o privatizan actividades públicas o bien, finalmente, se eligen discrecionalmente candidatos de confianza para ocupar determinados cargos.

Así, esta otra visión, aboga por la reducción del poder de la burocracia, repolitizar la administración y reforzar la incidencia de las autoridades electas no sólo en el terreno de la formulación sino en la implementación de políticas, a través de nuevos criterios de centralización, coordinación y control.

Como se ha señalado, la maximización de beneficios no parece estar orientada al interés general sino al del propio político aún cuando supone que ambos coinciden (conf. Fernández Santos et al., 2008).

Esta perspectiva también lleva la lógica de la empresa privada al ámbito público pues tanto gobernantes como gobernados son vistos como sujetos racionales que pretenden maximizar sus beneficios. De un lado, los políticos conservando el poder, del otro, los ciudadanos obteniendo un nivel de vida más alto. Coincidiendo ambos intereses, el electorado establece un pacto por el cual "mantiene" la confianza en el gobernante y le conserva su poder político en cuanto este "conserve y amplíe" su poder económico.

Nuevamente, el acento es puesto en el control, la privatización y la reducción de la estructura de la administración. Así, con esta tendencia, aunque por distintos caminos, llegamos a similares diseños de reforma sobre la administración.

\section{De las políticas de Gobierno Electrónico a las de Open Government}

Una nueva etapa en los procesos de reforma se da con las políticas de Gobierno Electrónico impulsadas desde fines de los 90, pero especialmente, desde 2002.

"Gobierno Electrónico" y "Administración Electrónica" son utilizados como sinónimos en la gran mayoría de documentos que tratan esta temática; el primero es más utilizado en Latinoamérica y el segundo en España aunque las dimensiones de los conceptos son distintas, como veremos más adelante.

Existen varias definiciones acerca de lo que debe entenderse por Gobierno o Administración Electrónica; en realidad tantas como autores, informes y normas se refieran a este nuevo concepto. Ello nos enfrenta a un primer problema de tipo conceptual.

Como se ha señalado:

\footnotetext{
${ }^{69}$ Se pretende ampliar las incumbencias horizontalmente, con lo que son más las temáticas que cada agente tiene a su cargo, y verticalmente, con lo que gana tanto en poder, como en confianza empowerment-. Obviamente, esto también conlleva, en la práctica, la creación agentes más polivalentes facilitando la tan ansiada flexibilización laboral.
} 
No es que no se haya escrito sobre estos temas, todo lo contrario. Tal vez se ha escrito demasiado. Ríos de bits y tinta inundan temas como Gobierno Electrónico, Sociedad de la Información y el Conocimiento y Brecha Digital. Pero lo abundante no quiere decir "bueno". En general, se trata de simples "recetas" sobre el uso de TIC basadas en otras tantas "recetas", una especie de publicidad de uso por fuera de las campañas de las compañías privadas. Esa sobreabundancia de actividad sobre el teclado termina siendo finalmente redituable sólo para unos pocos que apuntan al "mero consumo" de tecnología, con promesas que se asemejan a nuevos espejitos de colores donde la gente ve reflejadas torpemente sus esperanzas de gobiernos mejores, sociedades mejores, vidas mejores. Puro fetichismo, lejano a reflexiones genuinas sobre lo que sirve o no, lo que podría ser pertinente para resolver muchos de los problemas reales que aquejan a nuestros países. Quizás esto suceda porque arremeter seriamente sobre estos temas es mucho más trabajoso y no produce el dinero fácil que se obtiene cuando se adoptan discursos de los organismos de financiamiento internacional y se replican sus políticas sin innovación ni exploración ni adaptación a las realidades locales (Kaufman, 2007: 12-13).

No hay que remontarse mucho en el tiempo para rastrear el origen del concepto de Gobierno Electrónico, que nace de la mano de la New Public Managment (Nueva Gestión Pública) en la década de los '90. A excepción de algunos estudios académicos anteriores y de los anuncios en la campaña presidencial de los EE.UU. que llevara a Bill Clinton a la Casa Blanca, el concepto hace su aparición en la escena pública con el primer informe del ex vicepresidente Al Gore en 1993, en el marco de la Government Performance and Results Act (Ley sobre el Rendimiento y los Resultados del Gobierno) del mismo año donde puede leerse:

In the future, the concept of electronic government can go beyond transferring money and other benefits by issuing plastic, "smart" benefit cards. With a computer chip in the card, participants could receive public assistance benefits, enroll in training programs, receive veterans services, or pay for day care. The card would contain information about participants' financial positions and would separately track their benefit accounts - thus minimizing fraud. Electronic government will be fairer, more secure, more responsive to the customer, and more efficient than our present paper based systems (The National Performance Review. Chapter 4 Cutting Back to Basics. Step 4: Reengineering Programs to Cut Costs, 1993).

Las primeras políticas de Gobierno Electrónico hacen su aparición en este contexto. Por ello, no es casualidad que poco más adelante en ese mismo informe, pueda leerse que "Las oportunidades abundan para disminuir los costos operativos con el uso de las tecnologías de las telecomunicaciones" (traducción del autor).

El concepto Gobierno Electrónico fue creciendo acompañado por otros nuevos conceptos, como el de "e-governance", impulsando la transformación del sector público en torno a la "marquetización" de servicios gubernamentales en agencias 
gubernamentales externas (Norris, 2003).

Sin embargo, ese concepto original, asociado a la eficiencia gubernamental, fue permeable a otros usos y finalidades. De la mano de las facilidades de las tecnologías de la información y las comunicaciones, las nociones de transparencia, participación ciudadana y rendición de cuentas fueron ocupando un espacio central en la conceptualización del Gobierno Electrónico. Hoy, la idea de accountability (término que incluye tanto la obligación de rendir cuentas como la responsabilidad gubernamental hacia el electorado) es clave para reconstruir el concepto de Gobierno Electrónico.

¿Cómo definir al Gobierno Electrónico? Resulta difícil encontrar un concepto válido de Gobierno Electrónico; en primer lugar por la novedad del fenómeno, pero sobre todo, y más importante, porque se ha generalizado a partir de políticas deseadas antes que concretas (Criado Grande et al., 2002) ${ }^{70}$.

A modo de ejemplo de esta complejidad conceptual, veremos algunas definiciones $u$ objetivos institucionales que plantea el Gobierno Electrónico para organismos internacionales:

Para la OCDE (1998) el Gobierno Electrónico era visto como la aplicación de tecnologías basadas en Internet para actividades comerciales y no comerciales en el seno de las administraciones públicas. Más recientemente,

Se espera que el Gobierno Electrónico mejore el funcionamiento de la Administración Pública y su relación con el ciudadano. La buena noticia es que las tecnologías de la información y las comunicaciones (TIC) ofrecen una serie de herramientas para alcanzar la promesa del Gobierno Electrónico (OCDE, 2005; traducción del autor).

Para el BID (2003:19), "Desde un punto de vista tecnológico, el Gobierno Electrónico (...) es la capacidad que ofrecen las TIC para desarrollar y ofrecer información y servicios públicos a través de medios telemáticos, habitualmente Internet".

Desde el Banco Mundial, el Gobierno Electrónico refiere al uso por parte de las agencias gubernamentales de las TIC, que tienen la capacidad de transformar las relaciones con el ciudadano, las empresas y otras agencias gubernamentales. Entre los servicios que pueden brindarse, se señalan desde la mejora de la distribución de servicios gubernamentales al ciudadano hasta la interacción con las empresas y la industria, pasando por "empoderar" al ciudadano mediante el acceso a la información o la creación de una gestión pública más eficiente:

\footnotetext{
${ }^{70}$ Algunas definiciones ponen el acento en las TIC como un medio de interconexión entre gobierno y ciudadanos, empresas u otros gobiernos, medio que tendría consecuencias cualitativamente distintas a los medios de relacionamiento tradicionales. Muchas conceptualizaciones se concentran en los servicios. Otras en los fines. Algunas definiciones combinan los medios (TIC y reforma de la administración) y fines (mejores servicios). La definición del Gartner Group, que pone su acento en el cambio y la transformación institucional y en la articulación de consensos, fue muy utilizada a comienzos del 2000. Por último, otras ponen su acento en la gobernabilidad.
} 
«E-Government» refers to the use by government agencies of information technologies (such as Wide Area Networks, the Internet, and mobile computing) that have the ability to transform relations with citizens, businesses, and other arms of government. These technologies can serve a variety of different ends: better delivery of government services to citizens, improved interactions with business and industry, citizen empowerment through access to information, or more efficient government management. The resulting benefits can be less corruption, increased transparency, greater convenience, revenue growth, and/or cost reductions. Banco Mundial. http://go.worldbank.org/M1JHE0Z280. Ubicado el 01/03/08.

En el Plan de Acción de la Cumbre Mundial sobre la Sociedad de la Información (2004) se señala que las estrategias nacionales de Gobierno Electrónico deben tener como fines que "la administración pública sea más transparente, eficaz y democrática" (Punto 13, inciso g) y más adelante que las aplicaciones TIC pueden apoyar el desarrollo sostenible en la administración pública, los negocios, la educación y capacitación, la salud, el empleo, el medio ambiente, la agricultura y la ciencia en el marco de ciberestrategias nacionales para lo cual se han de tomar, entre otras medidas, las siguientes (Punto 15 - Gobierno Electrónico):

a) Aplicar estrategias de gobierno electrónico centradas en aplicaciones encaminadas a la innovación y a promover la transparencia en las administraciones públicas y los procesos democráticos, mejorando la eficiencia y fortaleciendo las relaciones con los ciudadanos.

b) Concebir a todos los niveles iniciativas y servicios nacionales de gobierno electrónico que se adapten a las necesidades de los ciudadanos y empresarios, con el fin de lograr una distribución más eficaz de los recursos y los bienes públicos.

c) Apoyar las iniciativas de cooperación internacional en la esfera del gobierno electrónico, con el fin de mejorar la transparencia, responsabilidad y eficacia en todos los niveles de gobierno.

En el 2003 la comunicación de la Comisión de la Unión Europea al Consejo y al Parlamento europeo refiere a la administración electrónica como el uso de las TIC en las administraciones públicas combinadas con los cambios organizativos y nuevas aptitudes encaminadas a mejorar los servicios públicos y los procesos democráticos, y reforzar el apoyo a las políticas públicas ("El papel de la administración electrónica en el futuro de Europa").

Sin adoptar una nueva definición, y en el marco del plan i2010 - "A European Information Society for growth and employment", la Unión Europea estableció en 2006 que los Estados miembros esperan que la administración electrónica contribuya a que los usuarios estén más satisfechos de los servicios públicos y alivie considerablemente la carga administrativa impuesta a empresas y ciudadanos para 2010 y que con ella el sector público conseguirá una mejora considerable de la eficiencia y un incremento de la transparencia y de la rendición de cuentas mediante un uso innovador de las TIC para 2010 ("Plan de acción sobre administración electrónica i2010: Acelerar la 
administración electrónica en Europa en beneficio de todos").

El nuevo Plan de Acción Europeo 2015, sobre la base de la Declaración de Malmö de los Ministros responsables de las acciones de Gobierno Electrónico, estableció que

... para 2015 las Administraciones Públicas europeas serán reconocidas por ser abiertas, flexibles y colaborativas en sus relaciones con los ciudadanos y las empresas. Ellas usan el Gobierno Electrónico para aumentar su eficiencia y efectividad y para mejorar constantemente sus servicios públicos en una forma que atiende las diferentes necesidades de los usuarios y maximiza el valor público, lo que coadyuva la transición de Europa a un liderazgo a la economía del conocimiento (UE, 2010; la traducción es propia).

Por fin, la Carta Iberoamericana de Gobierno Electrónico, aprobada en 2007, entiende las expresiones "Gobierno Electrónico" y "Administración Electrónica" como sinónimos y ambas son consideradas como ...

[...] el uso de las TIC en los órganos de la Administración para mejorar la información y los servicios ofrecidos a los ciudadanos, orientar la eficacia y eficiencia de la gestión pública e incrementar sustantivamente la transparencia del sector público y la participación de los ciudadanos (Punto 3 - Concepto de Gobierno Electrónico).

Sin pretender definir al Gobierno Electrónico, entendemos que tiene un carácter multidimensional y que el concepto engloba por lo menos los siguientes elementos: a) TIC; b) relación entre actores públicos y privados; c) prestación de servicios; d) optimización y modernización; y e) gobernabilidad. En efecto, no es posible hablar de Gobierno Electrónico sin incluir, al menos, la mejora de la eficacia y eficiencia de la gestión gubernamental, una amplia/transparente relación del gobierno con los distintos actores sociales y una nueva legitimidad (Piana, 2007).

No podemos cerrar este punto sin mencionar las distintas corrientes actualmente en debate. Conceptos como el de Gov 2.0, que propenden, para el ámbito público, la aplicación de las interacciones sociales de la Web 2.0, Wiki Gov, entendido como gobierno abierto y participativo que permitiría "editar" las decisiones gubernamentales o más radicales como el de We-Goverment (una traducción un poco literal pero comprensiva del efecto buscado podría ser nosotros gobernamos $-\mathrm{y}$ no los representantes-) parecen haber desplazado al concepto de Gobierno Electrónico por pasado de moda.

El concepto de Open Gov o Gobierno Abierto es, quizá, el que ha tomado más fuerza en estos últimos años a partir de la iniciativa del actual presidente de los Estados Unidos, que no se centra ya en los aspectos tecnológicos (aunque la tecnología sí importa), sino en la participación, rendición de cuentas y la apertura-disponibilidad de la información pública ${ }^{71}$.

${ }^{71}$ El Gobierno de Barack Obama aprobó a inicios de 2009 la Iniciativa Open Government como un 
Directamente relacionado en su origen con el de libertad de acceso a la información (Freedom Of Information) este concepto y sus significados abrevan de distintas fuentes tecnológicas: el de open data, software libre, open source, wikipedias, etc., incluyendo el de gobierno electrónico, ciertamente. Pero como mencionáramos más arriba, el concepto de Open Gov es mucho más amplio: transparencia, colaboración y participación, como ya vimos, pero también, responsabilidad y rendición de cuentas (accountability), asociación público-privado (public-private partnership), transversalidad; implicación y empoderamiento ciudadano.

Resulta obvio que tales postulados no son nuevos sino que están presentes en cualquier teoría de la democracia participativa. En efecto, la participación en el debate político no es, ciertamente, un fenómeno de la modernidad. La participación ciudadana ocupa, cada vez más, un aspecto fundamental del debate de la democracia mientras que otros elementos, antaño centrales, como la representación, los partidos políticos o la idea del bien común, son menos relevantes (ver, entre otros, Dahl, 1989; Sartori, 1989, Barber, 1984, Offe, 1988, Dworkin, 2006; Schmitter, 1994, entre muchos otros).

En definitiva, si bien el concepto de Gobierno Abierto es claramente positivo y demuestra una creciente preocupación por hacer al gobierno más democrático, preferimos mantener el concepto de Gobierno Electrónico para referirnos al uso de las tecnologías como eje de la transformación del Estado y las políticas públicas en torno a un sistema político más abierto y participativo donde el ciudadano y sus problemas sean el eje y centro de las políticas. Es que -como veremos más adelante- si el Gobierno Electrónico no busca esos fines, será una mera automatización de procesos, sin nada innovador, sin generar verdaderos procesos de cambio, sin alterar la lógica de poder y de cómo se hacen las cosas.

El origen del término es anglosajón: electronic government o más bien, egovernment o e-gov; pero la palabra gobierno en inglés no tiene un significado equivalente al español "gobierno", sino que podría asociarse más bien al de "régimen político", esto es, un concepto mucho más amplio que el de gobierno. El alemán elektronische Regierung (régimen electrónico) es también un concepto amplio.

¿Qué implicancia puede tener ello? Distintos ángulos de análisis se desprenden de cada uno de esas perspectivas. Desde la acepción más amplia, nos interesará problematizar cómo las TIC influyen en la estructura del poder del Estado actual, abriéndose dos grandes áreas de estudio: el Gobierno Electrónico, propiamente dicho, y la Participación Electrónica; con la primera, estudiamos cómo los órganos o personas legitimados definen políticas de Administración Electrónica y cómo utilizan las TIC para informarse, comunicarse, legitimarse y tomar sus decisiones (fenómeno de la tecnocracia); cuando estudiamos la Participación Electrónica, estudiamos cómo las TIC influyen en la vida cotidiana de los ciudadanos o meros usuarios para efectuar pedidos, controlar o influir en la decisión política de quienes tienen la responsabilidad para tomarla (responsabilidad adquirida en elecciones públicas abiertas, transparentes y

esfuerzo de su administración para crear niveles de apertura en el gobierno sin precedentes. La iniciativa, está basada en tres principios o postulados, que tradicimos y resumimos: El Gobierno debe ser transparente. La transparencia promueve la rendición de cuentas y provee información a los ciudadanos acerca de lo que su gobierno está haciendo. El gobierno debe ser participativo. El compromiso público potencia la efectividad del gobierno y mejora la calidad de sus decisiones. El gobierno debe ser colaborativo. La colaboración promueve activamente la participación de los ciudadanos en la labor de su gobierno. Ver más información en http://www.whitehouse.gov/open/about. Fecha de consulta: 13/01/11. 
participativas), cuyos temas principales son los de la democracia electrónica y la ciudadanía electrónica (e-democracy y e-citizenship). Desde la Administración Electrónica, por último, problematizamos aspectos relacionados con la implementación de políticas públicas utilizando medios electrónicos.

El concepto genérico de Gobierno Electrónico puede ser desagregado, al menos, en dos campos de acción, según el uso de TIC esté dado hacia dentro de la administración pública, Back Office, o hacia los otros actores que, de una u otra manera, se relacionan con ella a través de la pantalla, Front Office (Reilly, 2004).

Dentro del Back Office se incluyen aquellos programas, acciones e iniciativas relacionadas con la aplicación de las TIC a la organización y a los procedimientos internos a la Administración Pública (Gascó, 2004). Dentro de esta línea de acción caben incluir todos aquellos procesos que, utilizando las TIC, apoyen las acciones propias del gobierno, desde el uso de las PC, su interconexión a Extranets o la creación de una Intranet corporativa, la digitalización de la correspondencia, la creación de un sistema de seguimiento de expedientes y hasta la creación de mecanismos para el uso de la información pública para mejorar el proceso de toma de decisión. Especial referencia debe hacerse en esta línea a las acciones tendientes a la capacitación de los recursos humanos y a aquellas que tienden al rediseño organizacional, la gestión de las compras públicas y la administración financiera del Estado (Araya Dujisin, 2004).

Por su parte, dentro del concepto del Front Office se hace referencia a aquellas iniciativas en las cuales las TIC son aplicadas para brindar servicios y mejorar el relacionamiento con los actores externos a la Administración. Se busca crear una nueva interacción entre las Administración y otros actores, ya sean ciudadanos, organizaciones civiles o empresas. Estos tipos de iniciativas apuntan a mejorar el relacionamiento y la velocidad de la acción. Cabe incluir programas relacionados con el acceso a la información pública, la prestación de servicios y transacciones en línea hasta los procesos de mejora de la calidad democrática mediante la utilización de las $\mathrm{TIC}^{72}$.

Ahora bien, sin dejar de considerar la importancia de la distinción, lo cierto es que para la implantación efectiva del Gobierno Electrónico no pueden escindirse las acciones entre uno y otro campo de acción. Es que lo que se encuentra detrás de la pantalla, la reorganización administrativa, es un reflejo de lo que se ofrece, de lo que se muestra por la pantalla (Front Office). Es por ello que no podrá haber nunca ventanilla única, es decir, punto único de entrada, con organización burocrática.

Ahora bien, más allá de las vertientes ideológicas que sustentaron su emergencia, ¿cuáles son las precondiciones sociales, culturales, políticas y legales que

\footnotetext{
${ }^{72}$ De la combinación efectiva de ambos aspectos, surge lo que se ha denominado e-gobernanza, concepto que incluye aquellas acciones que se apoyan en el soporte digital para la elaboración de políticas públicas, toma de decisiones, participación activa en la elaboración de las políticas, gestión y evaluación de los resultados. En efecto, estos procesos son dinamizadores de la elaboración de las políticas públicas al generar mayor participación, mayor control y cogestión. Pero no puede dejar de considerarse aquellas actividades que tienden a establecer una conexión entre ambas esferas, esto es, aquellos programas que buscan incentivar y crear las condiciones de acceso, uso y apropiación de las TIC, pues no podría pensarse en un Gobierno Electrónico sin conectividad y acceso a Internet. En efecto, los servicios que presta el Estado son monopólicos y deben ser accesibles a toda la población; sus destinatarios son cautivos y debe garantizar ecuanimidad, integridad y transparencia en todos sus actos además de responsabilidad y seguridad (Cárdenas Rincón y Cubillos Velandia, 2002 y Tesoro et al., 2002). De ahí que las políticas de conectividad deben estar en la base de todo programa.
} 
determinan o condicionan la existencia o grado de desarrollo del Gobierno Electrónico?. Estas precondiciones, mucho más que las tecnológicas, producen serios obstáculos o vallas infranqueables a la implementación de las políticas de Gobierno Electrónico. Como veremos, muchas de ellas suponen la existencia de un verdadero desarrollo de una Sociedad de la Información y el Conocimiento.

Una sociedad civil democrática, abierta e inclusiva, parece ser la primera precondición. La participación es otro factor fundamental, claro que ello también supone una opinión pública formada e interesada en la cosa pública, que tenga la creencia de poder cambiar las cosas o de que, al menos, su voz será oída.

La dimensión cultural aparece como otro de los grandes condicionantes de la acción. En efecto, sin perjuicio de la existencia de una base normativa, muchas de las acciones encuentran una barrera en nuestra "forma de ser", en nuestros "hábitos sociales" y las políticas de Gobierno Electrónico son un claro ejemplo de ello, sobre todo en lo que se refiere a la resistencia organizacional o apropiación ciudadana de las TIC más allá de las políticas oficiales. Por ello, una sociedad y una organización abierta a los cambios -y no me refiero a las modas tecnológicas- también es una precondición del desarrollo de las políticas de Gobierno Electrónico.

Ciertamente que las políticas de Gobierno Electrónico en Estados autoritarios son "pour la gallerie", para los medios internacionales, para los organismos de crédito o para una selecta minoría. Pero sin llegar a ese extremo, un gobierno que no rinda cuenta de sus acciones, que no sea transparente, que no sea responsable de los resultados de sus acciones u omisiones, no ofrece ningún incentivo para que la ciudadanía utilice las TIC como forma alternativa -a veces principal- de comunicación con sus políticos.

Por último, las condiciones legales se manifiestan como otra de las precondiciones. En efecto, sin el desarrollo de un derecho de las telecomunicaciones, que reconozca la firma digital como equivalente a la ológrafa, la protección de los derechos intelectuales y de las inversiones en infraestructura, es difícil pensar en el desarrollo del Gobierno Electrónico. Además, y como es inevitable que el desarrollo tecnológico sea más rápido que el legal, para la necesaria seguridad jurídica que requiere cualquier inversión, se precisa revalorizar la figura del juez como intérprete de los principios generales del derecho para aplicarlos a las novedosas problemáticas que se planteen. 


\section{CAPÍTULO III. LA ORGANIZACIÓN ESTATAL}

\section{Gobierno y Administración}

Como sostiene Fioravanti, la noción de gobierno está íntimamente relacionada con el inicio del Estado como forma de asociación política. Así:

En una primera aproximación, se puede decir que el Estado moderno europeo comienza a existir a partir del siglo XIII, cuando se hace cada vez más evidente y visible cierta tendencia a la organización del gobierno de los múltiples territorios presentes en Europa. La noción de la que hablamos puede precisarse en el gobierno del territorio (Fioravanti, 2004:14).

De allí la importancia de vincular los aspectos de la forma política con su gestión. Pero el gobierno y la administración, ambos como estructuras sociales formales, racionalmente organizadas comparten ciertas notas características. Como ha sostenido Merton (1960), toda estructura social formal implica normas de actividad claras en las que, idealmente, cada serie de acciones está funcionalmente relacionada con los propósitos de la organización. Señala que:

En esa organización está unificada una serie de empleos, de posiciones jerarquizadas, a los que son inherentes numerosas obligaciones y privilegios estrictamente definidos por reglas limitadas y específicas. Cada uno de los empleos contiene una zona de competencia y de responsabilidad que le son atribuidas. La autoridad, el poder de control que se deriva de una posición reconocida, interesa al empleo y no a la persona particular que desempeña el papel oficial. La acción oficial suele tener lugar dentro del entramado de reglas preexistentes de la organización. ... La reglamentación o formulismo se manifiesta mediante un ritual social más o menos complicado que simboliza y apoya el orden minucioso de los diferentes empleos. Tal formulismo, que está unificado con la distribución de autoridad dentro del sistema, sirve para reducir al mínimo la fricción restringiendo en gran medida el contacto (oficial) a modos que están definidos previamente por las reglas de la organización. De esa manera se crean la facilidad de calcular la conducta de los demás y un conjunto estable de expectativas mutuas. Además, el formulismo facilita la interacción de los ocupantes de los empleos a pesar de sus actitudes privadas (quizá hostiles) de uno para otro. De este modo, el subordinado está protegido contra la acción arbitraria de su superior, ya que los actos de ambos están limitados por una serie de reglas mutuamente reconocidas. Ordenaciones específicas de procedimientos fomentan la objetividad y restringen el "rápido paso del impulso a la acción" (Merton, 1960:201) 
Esta descripción cabe tanto para el gobierno como para la administración; de allí que la teoría de la administración no nos pueda dar una clave para la distinción conceptual. Pero tampoco la distinción podemos encontrarla desde el derecho habida cuenta que desde el proceso de constitucionalización del poder, el constitucionalismo propugna la limitación de la discrecionalidad de la decisión política basado en la necesidad de evitar la decisión arbitraria, libre. Si bien desde el derecho administrativo se reconoce mayor grado de discrecionalidad al gobierno ${ }^{73}$, lo cierto es que el criterio de gradación tampoco resulta muy preciso ya que resulta imposible establecer parámetros claros que permitan conocer, de antemano, cuándo la discrecionalidad deja de ser tal y se convierte en arbitrariedad o ilegalidad.

Entre la Administración y los particulares existe un esquema de subordinación que se caracteriza, desde el punto de vista del derecho, por el régimen exorbitante del derecho privado integrado por la prerrogativa y la garantía. Como explica Cassagne (2000), mientras la figura de la prerrogativa se fundamenta en los requerimientos del bien común, porque las exigencias de la comunidad (justicia legal o general) se basan en la idea de servicio para satisfacer en forma directa el bien de cada uno de los componentes; la presencia de las garantías tiende a asegurar la realización del bien común mediante el reconocimiento de la posición que los individuos tienen en el seno de la comunidad dando participación a cada uno de ellos en la distribución del bien común.

Todo este conjunto de derechos y deberes está regulado en forma directa por el Derecho Administrativo, rama del derecho que define el equilibrio entre el poder estatal que persigue el interés de todos y los derechos de las personas. Marienhoff (2003:60) lo define como el

conjunto de normas y de principios de Derecho Público interno que tiene por objeto la organización y el funcionamiento de la administración pública así como la regulación de las relaciones interorgánicas, interadministrativas y las de las entidades administrativas con los administrados (Marienhoff, 2003:60)

Pero cierto es que dichas normas y principios no forman un verdadero sistema coherente, sino tan solo un conjunto de normas jurídicas positivas, de principios de derecho público y de reglas jurisprudenciales, frecuentemente asistemáticas.

Al decir de Gordillo (2003- V7) a diferencia de otras ramas del derecho positivo, el derecho administrativo no se halla completamente legislado y por ello debe recurrirse frecuentemente a elaboraciones jurisprudenciales o a principios constitucionales o de derecho supranacional para configurar una institución de derecho administrativo.

Es por ello que debemos recurrir a otros criterios de distinción. En efecto, aunque históricamente se ha intentado separar las funciones políticas y administrativas, lo cierto es que en toda organización administrativa subyace una determinada concepción política porque que esa pretendida relación jerárquica entre las esferas

\footnotetext{
${ }^{73}$ A través de la doctrina del acto del príncipe, por ejemplo (ver Gordillo, 2003, II-5, entre tantos otros).
} 
políticas y administrativas es difusa. La visión clásica de la Administración Pública suponía la existencia de dos lógicas dentro del Estado, una visión política y otra visión administrativa. Mientras la esfera política diseña las políticas públicas y sus prioridades, la administración la ejecuta técnicamente (Clearly, 2006). Pero el nacimiento del Estado moderno es inseparable del nacimiento de una estructura burocrática capaz de administrar sus recursos (Heller, 1992; Peters, 1999) y, como veremos, tanto el gobierno como la administración tienen esferas libres de actuación.

El triángulo de Matus (1987), base de su teoría, tal vez puede ayudarnos a comprender esta diferencia desde la acción: gobernar exige articular constantemente tres variables, proyecto de gobierno, capacidad del gobierno y gobernabilidad del sistema cada una de las cuales, en un sistema triangular, depende de las otras.

Es claro, en la exposición del economista chileno que,

El proyecto de Gobierno se refiere al contenido propositivo de los proyectos de acción que un actor se propone realizar para alcanzar sus objetivos, la discusión sobre los proyectos de gobierno versa sobre las reformas políticas al estilo de desarrollo, la política económica, etc., que parecen pertinentes al caso y al grado de gobernabilidad del sistema. Lógicamente el contenido propositivo es producto no sólo de las circunstancias e intereses del actor que gobierna sino además de su capacidad de gobernar, incluido su capacidad para profundizar en la explicación de la realidad, y proponer imaginativa y eficazmente respuestas y anticipaciones (Matus, 1987:74).

Así, no es posible gobernar sin un proyecto de gobierno el que no se reduce, evidentemente, a las competencias por el marco normativo ni a las rutinas administrativas ${ }^{74}$.

En efecto, un cuerpo político sólo tiene razón de ser si se propone metas políticas y para alcanzarlas es indispensable -según Julien Freund (1968) a quien seguimos principalmente en este apartado por la claridad de su exposición desde el punto de vista politológico- que haya un gobierno, esto es, "un aparato de mando que ordene, coordine, rectifique, aliente y proteja. No existe un Estado si no es organizado,

\footnotetext{
${ }^{74}$ Los otros lados de los vértices del triángulo son definido de la forma que sigue: "Gobernabilidad del sistema es una relación entre las variables que controla un actor en el proceso de gobierno, ponderadas por su valor o peso en relación a la acción de dicho actor. Mientras más variables decisivas controla, mayor es su libertad de acción y mayor es para él la gobernabilidad del sistema. Mientras menos variables controla, menor será su libertad de acción, y menos es la gobernabilidad del sistema" (Matus, 1987:75) y "La capacidad de conducción o dirección se refiere al acervo de técnicas, métodos, destrezas, habilidades y experiencias de un actor y su equipo de gobierno para conducir el proceso social hacia objetivos declarados, dadas la gobernabilidad del sistema y el contenido propositivo del Proyecto de Gobierno. El dominio de técnicas potentes de planificación es una de las variables más importantes en la determinación de la capacidad de un equipo de gobierno. Cuando hablamos de teorías, técnicas y métodos de planificación nos referimos, por consiguiente, a alterar o mejorar la capacidad de gobierno. La capacidad de gobierno se expresa en capacidad de dirección, de gerencia y de administración y control." (Matus, 1987:75).
} 
estructurado según el principio jerárquico del mando" (Freund, 1965:269) ${ }^{75}$. Dado que una de las tareas de la política es organizarse a sí misma y a la colectividad, debe fortalecer el orden con formas e instituciones transformando “... el mando en gobierno, es decir, en un consentimiento basado en la razón, la utilidad y el sentido del bien común" (Freund, 1968:316).

Lo arbitrario forma parte misma de la decisión política por cuanto la orientación de la acción concreta depende del discernimiento, apreciación y decisiones del individuo que ostenta el poder (Conf. Freund, 1968:140). Si la tarea política aparece claramente delimitada ${ }^{76}$ en el interior de la unidad política ${ }^{77}$ estableciendo el orden, la paz y tranquilidad, resulta necesario un gobierno capaz de realizarlo. El gobierno establece, consecuentemente, la orientación política general y es por ello la instancia reguladora del orden por excelencia ( $V i d$. Molina, 2000:170).

Con el gobierno se logra racionalizar el poder, esto es, el gobierno reglamenta y organiza el poder ${ }^{78}$. Al convertirse en gobierno, el mando se despersonaliza y se transforma en función. El carácter imperativo, personal y directo de la decisión, se manifiesta por la impasibilidad de leyes e instituciones; el mando deja de ser prerrogativa de un individuo para reflejarse a través del aparato gubernamental e integrarse mejor en el tejido social; la fuerza implícita se ampara en el armazón jurídico. Pero también, con el gobierno, la obediencia se vuelve más flexible, impersonal, blanda y desentendida ya que la responsabilidad se diluye en una aparente neutralidad (Conf. Freund, 1968: 316-317).

Pero la pretendida neutralidad del gobierno, explica Freund, es ficción porque, en tanto parte del poder, se sustenta en ciertas capas y clases sociales. Pero es una ficción necesaria para evitar conflictos y/o alteraciones del orden. Con la legalidad el gobierno se compromete a obrar de conformidad con la ley, pero también la legalidad es una ficción pues ésta se apoya en supuestos formales: que el gobierno es neutral; que sus actos son oficiales; que su procedimiento es siempre regular ${ }^{79}$.

Freund señala algunas consecuencias de la racionalización del mando con el gobierno. En primer lugar, el mando procura perpetuarse en el orden que ha creado y sobrevivir a la persona que ostenta el poder mediante una reglamentación de la sucesión $^{80}$. En segundo lugar, funcionalizándose e institucionalizándose, el poder toma

\footnotetext{
${ }^{75}$ Más adelante Freund (1968:319) señala que "La configuración específica del gobierno se presenta como un mando jurídicamente institucionalizado, reforzado por convenciones constitucionales que regulan su continuidad, su organización interna y sus relaciones de estructuración, explícitas con el conjunto de la colectividad".

${ }^{76}$ Podríamos decir, exorcizada de otras pretensiones no políticas como hacer el hombre bueno, héroe o santo.

${ }^{77}$ Hacia el exterior la actividad será la defensa, debilitando al adversario, bloqueándolo o atrincherándolo (Conf. Freund, 1968:44).

78 Aclara, sin embargo, que la función no es exclusiva y esta función organizadora la comparte con otras instituciones.

${ }^{79}$ Freund ve en la ley no más que una herramienta al servicio de los fines de la política y de allí que, si la ley puede ser desobedecida por los súbditos, tanto más por el gobierno - aunque nunca directamente para no develar la ficción - cuando las circunstancias de la orientación política lo requieren.

${ }^{80}$ Como señala Freund, la consecuencia de establecer un principio de sucesión no es menor porque es uno de los factores esenciales de la estabilidad política y de la concordia interior ya que la cohesión, continuidad y regularidad suprime uno de los principales motivos del miedo que se dan, especialmente, en las sucesiones de gobierno.
} 
la forma de un aparato en el seno del cual reina la especialización, como veremos con más detalle con respecto a la administración pública.

El siguiente cuadro aclarará la posición de Freund respecto de la diferenciación entre poder y gobierno ${ }^{81}$.

\section{- Poder}

- Saca su fuerza del soporte oscuro y difuso de capas y clases sociales

- Es informe, a menudo desconcertante

- Es difuso pues está en los sindicatos, en la prensa, en los salones, en los laboratorios científicos y también en el gobierno.

- Es la potencia indistinta de grupos y de capas o clases diferentes

- Gobierno

- Encuentra su fuerza en su forma y su institución misma, es decir, en la legalidad

- Es un edificio claramente estructurado

- Tiene un lugar y ocupa edificios oficiales y se sabe quién lo representa

- Está, en principio, para cualquier miembro de la colectividad y no representa a nadie individualmente

Ahora bien, Freund distingue dos tipos de decisiones que contribuyen a crear el orden imperativo de la sociedad. Por un lado, las de carácter puramente reguladoras, de policía, de administración, de represión y sanción frente a situaciones concretas, particulares y variables en lo económico o social; por el otro, aquellas que, por su carácter, pretenden perdurar en el tiempo y regular la vida colectiva global. Ellas son verdaderamente constructoras del orden: son las instituciones, costumbres y cultura que, en cuanto tales, condicionan la unidad misma de la colectividad. ${ }^{82}$ Se refleja en estas últimas una cierta visión filosófica sobre lo que tendría que ser la sociedad, las relaciones entre el individuo y la colectividad, las representaciones morales, una idea del derecho, de la justicia, de la libertad, de la disciplina, etc. y, en tanto conforman el estilo de vida de una sociedad imponen un dique contra las decisiones que les sean contrarias. Las primeras son similares en casi todos los países mientras que las segundas hacen que cada unidad política sea única.

Si bien las primeras son, evidentemente, más superficiales, Freund no reniega su importancia. Más aún, según Freund, el orden público está conformado por la amalgama de ambos tipos de disposiciones (Freund, 1968:270). Pero son las primeras las que

\footnotetext{
${ }^{81}$ Ver Freund, 1965, punto 59. Poder y Gobierno.

82 Entre los ejemplos de este tipo de decisiones, Freund enumera las siguientes: aquellas disposiciones que definen el régimen privado propio de la colectividad, su sistema económico y social, las relaciones entre la Iglesia y el Estado, la doctrina escolar, la organización general de la administración, etc. (Freund, 1968: 269).
} 
otorgan mayor previsibilidad al mando político y, consecuentemente, obtienen mayor adhesión.

Conforme la evolución de las formas históricas, el mando político no se ejerce directamente sino que "utiliza el conducto del aparato administrativo y burocrático o la fuerza que representan los partidarios que se adhieren a los objetivos del mando, o también se apoya en una o varias capas o clases sociales" (Freund, 1968:130) ${ }^{83}$ y la ley es su instrumento. En efecto, el gobierno, como poseedor del monopolio de la violencia legítima, es el guardián de la legalidad ${ }^{84}$.

Como consecuencia de la racionalización del mando con el gobierno, aquél se funcionaliza y especializa. Siguiendo a Weber, Freund afirma que el mando estuvo siempre asistido por personas entregadas a su causa, servidores privados o consejeros benévolos o bien remunerados pero que:

... las necesidades de la división del trabajo, resultantes de la complejidad de problemas y su acrecentamiento numérico, como consecuencia de la extensión del control estatal a esferas de actividad cada vez más numerosas, así como la extensión territorial de las colectividades políticas modernas, han llevado al gobierno a rodearse de una administración cada vez más amplia, sometida a la legalidad general y racionalizada funcionalmente en virtud de tareas precisas (Freund, 1968:318).

A través de la administración, el gobierno garantiza el orden, orienta la economía, administra la justicia, coordina las distintas actividades de un país; controla, reforma, adapta, acumula expedientes y archivos como si quisiera también proteger nuestro pasado; garantiza las libertades individuales por medio de códigos, estatutos, privilegios, capitulares y formularios y agrega: "Sus movimientos son lentos, ya que tiene que respetar las formas. ... Para controlar las manifestaciones o combatir los motines, tiene su policía; para castigar los crímenes tiene sus prisiones o campos" (Freund, 1968:320).

Para Freund, la administración pública es el brazo del mando que, en las administraciones burocráticas, tiene a la norma como elemento técnico. Esto último implica que cualquier decisión política llega a la colectividad casi exclusivamente por conducto de las leyes pero ello no significa que la ley tenga una superioridad axiológica o lógica sobre lo político e insiste: "Lo político sigue siendo soberano en relación con el derecho, tanto en ese sistema como en cualquier otro, y la legalidad es sólo una técnica

\footnotetext{
${ }^{83}$ En el mismo parágrafo, también afirma que "Vivimos en Estados fuertemente organizados desde hace mucho tiempo, caracterizados por la continuidad de la legalidad y de la administración y fundados sobre constituciones que, en principio, son directa o indirectamente la expresión de la voluntad popular soberana" (Freund, 1968:130).

${ }^{84}$ Esta última es definida por el autor lorenés como “... el sistema de las normas, de las reglas, de las convenciones y costumbres, que permite al gobierno extender su autoridad, a la vez, sobre la colectividad en su conjunto y sobre cada uno de sus miembros indistintamente, a fin de establecer una coherencia en las relaciones exteriores entre los individuos y las agrupaciones" (Freund, 1968:325).
} 
reguladora más apropiada a las condiciones racionales de las sociedades modernas". (Freund, 1968:415).

Si bien la administración está estrechamente vinculada a las normas ${ }^{85}$, no es su mera ejecutora sino que posee, como el gobierno, discrecionalidad. Señala expresamente: "Su papel, en efecto, consiste en ejecutar y aplicar las decisiones de la autoridad política, pero adaptándolas a situaciones concretas y corrigiendo el rigor que proviene de su generalidad y de su racionalismo, si llegara el caso" (Freund, 1968:299). Es que el puro legalismo la convertiría en una administración tiránica, inhumana e injusta. Para escapar de las normas generales, que no contemplan los casos particulares, es necesario pues, que la administración posea flexibilidad en la interpretación y ejecución de la ley.

Pero si la administración, como resultado del proceso de racionalización e institucionalización del poder se sitúa claramente en la esfera de la relación mando y obediencia, también influye en la órbita de la relación público y privado. En efecto, el estatuto de los funcionarios públicos está sometido a una regulación especial (pública) en relación con su empleador, el Estado y en cuanto a sus funciones, están orientadas hacia la búsqueda del bien público. Además, la administración ha sido uno de los principales artífices del crecimiento de los servicios públicos durante el Estado de Bienestar luego de la Segunda Guerra Mundial pero con un proceso inverso y paralelo de privatización del espacio público consecuente con el fenómeno de la despolitización de esos ámbitos. Aún cuando somos testigos de un notable proceso de transferencia de funciones públicas a organismos privados o no estatales, sin embargo Freund (1968) aclara que la gestión administrativa siempre es acto público.

\section{Organización burocrática y algunas notas sobre el modelo latinoamericano}

Como hemos visto más arriba, el Estado se consolida como producto de un doble proceso de concentración de funciones y división de tareas que requiere de un aparato especializado para la recaudación, guerra, administración de justicia, etc. (Conf. Mayntz, 1985). Tan asociado se encuentra el nacimiento del Estado con el de la administración que es posible identificar las administraciones públicas más consolidadas en aquellos Estados que tuvieron gobiernos monárquicos absolutos. Ahora bien, si bien la administración pública no es un fenómeno único de la Europa moderna, la nota de la legalidad administrativa, que debe ser vista desde este ángulo del análisis como un factor fundamental para la homogeneización social en la categoría de súbdito y luego de ciudadano, sí es propia de nuestra contemporaneidad.

Según Weber (1999), la preponderancia del tipo de dominación legalista ha ido a la par con el desarrollo de una administración burocrática, técnicamente racional y administrada por especialistas. En este caso, la Administración es burocrática y como modelo más puro de la dominación legal, tal vez, es el más claro resultante de la identificación del tipo de dominación que equipara la legitimidad con la legalidad o en términos de Weber, la dominación de carácter racional que "descansa en la creencia en

\footnotetext{
${ }^{85}$ Como veremos a propósito de la administración burocrática, ésta está basada exclusivamente en normas.
} 
la legalidad de ordenaciones estatuidas y de los derechos de mando de los llamados por esas ordenaciones a ejercer la autoridad (autoridad legal)" (Weber, 1999:172).

La burocracia es un sistema objetivo de gestión y administración que busca la eficacia en la respuesta y eficiencia en la utilización de los recursos necesarios para llegar a ella. Como sostiene Kliksberg (1975), los escritos tradicionalistas dan primacía al concepto de la eficiencia o productividad como valor central, relegando a un nivel secundario las referencias a los modernos objetivos de responsabilidad y agrega:

El objetivo de eficiencia tiene además en el tradicionalismo acentuados tonos de inmediatez. Se trata de obtener la mayor eficiencia, a corto plazo, y ello llega a hacer perder de vista, incluso, el mismo objetivo de eficiencia a largo plazo, en el tiempo (Kliksberg, 1975:102).

En su faz ideal es un sistema altamente racionalizado y de máxima eficiencia técnica, que pretende alcanzar resultados con precisión, rapidez, expertisse, la discreción y óptima eficacia (Weber, 1999; Merton, 1960; García Pelayo, 1982). El modelo burocrático, que aún hoy pretenden seguir muchas Administraciones Públicas en nuestra región, se caracteriza por la asignación de funciones y competencias con arreglo a leyes, normas o reglas administrativas.

Bajo este sistema de organización, las reglas son técnicas, objetivas e impersonales y el procedimiento es formal y escrito, todo ello en procura de la objetividad y racionalidad. Consecuentemente, los deberes y los derechos, así como las actividades, se encuentran predeterminados independientemente de las aptitudes o capacidades específicas de las personas en el cargo. Se supone que las funciones han sido previamente distribuidas en virtud de una capacidad objetivamente demostrada.

Como otra derivación de estos principios se establece un sistema piramidal de mando y obediencia, con sistemas de control escalonados, ya sea por inspección de la autoridad superior o bien por apelación del perjudicado hasta llegar a la cúspide máxima de poder. Conforme a este modelo, la distribución de tareas contribuiría a la legitimidad racional del sistema a la vez que a una mayor productividad.

La obediencia también está mediatizada por la ley y así, se obedecen las ordenaciones impersonales y objetivas legalmente estatuidas y sólo a las personas por ellas designadas, en méritos éstas de la legalidad formal de sus disposiciones dentro del círculo de su competencia (Conf. Weber, 1999) ${ }^{86}$.

La formación profesional es uno de los rasgos principales del modelo no sólo por el carácter de asalariado del personal, sino especialmente porque normalmente sólo participa en el cuadro administrativo el calificado profesionalmente para ello mediante pruebas realizadas con éxito; los llamados 'funcionarios' en la terminología de Weber. En este sentido, la labor es formalista: sine ira et studio, sometida tan sólo a la presión del deber estricto; 'sin acepción de personas', formalmente igual para todos, es decir, para todo interesado que se encuentre en igual situación de hecho (Weber, 1999:179).

\footnotetext{
${ }^{86}$ Por otro lado, como señaló Merton (1960:202) "El carácter general de las reglas requiere el uso constante de la categorización, por la cual los problemas y los casos particulares se clasifican a base de criterios definidos y son tratados en consecuencia."
} 
En principio, el empleo burocrático supone la expectativa de la tenencia vitalicia del cargo y la ausencia de factores perturbadores que puedan reducir el tamaño de la organización, eleva así al máximo la seguridad vocacional (conf. Merton, 1960).

El expediente administrativo es otro de los rasgos del tipo ideal que hace que la oficina sea la médula de toda forma moderna en la actividad de las asociaciones y el procedimiento escrito su instrumento.

Las Administraciones Públicas se han caracterizado también por su ritualismo: realización de tareas operativas rutinarias, unidades de gran dimensión, procedimientos y sistemas de comunicación muy formalizados, proliferación de reglas y un poder de decisión limitado por una extensa red escalonada de jerarquías. ${ }^{87}$

En síntesis,

Las categorías fundamentales de la dominación legal son, pues: 1. Un ejercicio continuado, sujeto a ley, de funciones, dentro de; 2 . Una competencia, que significa: a) un ámbito de deberes y servicios objetivamente limitado en virtud de una distribución de funciones, b) con la atribución de los poderes necesarios para su realización, y c) con fijación estricta de los medios coactivos eventualmente admisibles y el supuesto previo de su aplicación. Una actividad establecida de esa suerte se llama 'magistratura' o 'autoridad' (Weber, 1999:174).

Pueden apuntarse, al menos, dos grandes modelos o tradiciones administrativas. El europeo continental o napoleónico, por un lado y el inglés y norteamericano, por el otro.

El primer modelo nos es conocido y reconoce casi todas las notas apuntadas más arriba. Sólo para cabe destacar que este modelo se inició en Francia ya en el siglo XVI con una creación progresiva de una administración fuertemente jerarquizada, centralista y profesionalista con división territorial ${ }^{88}$ aunque es ciertamente con Napoleón y la división ministerial y su organización del funcionariado en cuerpos que este tipo se consolida y "exporta" al resto del continente (conf. Sanz, 1999).

El modelo anglosajón reconoce dos subtipos aunque su nota común es su origen más tardío y flexibilidad. El modelo de administración pública inglés, que tomarán muchas de los Estados de Commonwealth, es de una administración descentralizada, residual y desprofesionalizada. En efecto, la aristocracia inglesa realizaba, de forma no remunerada, muchas de las funciones que en ese momento estaban realizando la incipiente organización burocrática en Francia. Un gran poder local, poco control centro-periferia, lo diferencia, notablemente del proceso de concentración de poder y de funciones que estaba ocurriendo del otro lado del Canal de la Mancha. Es recién a mediados del siglo XIX y como consecuencia de la democratización creciente del Parlamento, que este esquema comienza a transformarse, concentrado y dividido

87 En este esquema organizativo, el sector público debe diferenciarse claramente del sector privado discurriendo cada uno por caminos distintos, tanto en cuanto a su continuidad, estructura, personal, ascensos, ética de actuación, velocidades de respuesta, competencias para actuar.

${ }^{88}$ En Alemania, y como producto de su federalismo, esta división territorial será también política con lo que, como en los estados federales, su complejiza el sistema con un doble (triple o cuádruple como en España) nivel de administraciones públicas. 
ministerialmente en funciones, para dar lugar a una de los modelos de administración pública más cerrados, profesionalistas y elitistas que actualmente existen. El proceso de industrialización, completó el proceso añadiendo a las clásicas funciones liberales, las de regulación económica. El norteamericano, por su parte, aún cuando heredó algunas de las notas de aquél, los propios antecedentes federales y presidencialistas modificaron el modelo que adquiere, así, una mayor fragmentación administrativa institucional y territorial, por un lado, una administración más ligada al gobierno y permeable, por su menor profesionalización, a la cooptación de los lobbies. Por último, la jerarquización más que legal, está dada por el control financiero del centro sobre los Estados de la federación ${ }^{89}$.

Si observamos la estabilidad política y administrativa del sistema político notamos que mientras que en el caso de los modelos anglosajones, su estabilidad promueve una continuidad que no admite bruscos cambios políticos, en los Estados de la Europa continental -donde han existido frecuentes rupturas y transformaciones en sus sistemas políticos- el elemento de continuidad han sido justamente las administraciones públicas. En esos casos, los sistemas administrativos han adquirido un valor político propio como garantes de la continuidad, los que les han permitido ser más autónomos e independientes del sistema político.

Otro elemento que distingue a uno y otro modelo es el tipo de vinculación que se da entre los ámbitos públicos y privados, ya que mientras que el modelo anglosajón se encuentra más abierto al pluralismo y a la participación como consecuencia de una sociedad independiente del Estado, por el contrario, encontramos en los modelos continentales un claro intervensionismo estatal. Ello ha derivado en relaciones ambiguas entre una sociedad que reclama más intervención del Estado para su desarrollo pero que se queja de sus amplias estructuras y del poder que goza.

Ahora bien, este esquema ritualista que representó un gran avance frente a los modelos de administración propios de los estados absolutistas (conf. Pastori, 1982), estaba pensado para funcionar sobre la base de un sistema político cerrado, en un ambiente estable y con participación política limitada. Con demandas simples, las tareas rutinarias tienen buenos resultados y las actividades de control son sencillas. Pero con la apertura política y las nuevas demandas provenientes de sectores antes excluidos, el sistema burocrático respondió creando nuevos organismos específicos y nuevas estructuras superiores de control.

Por la propia configuración rígida y fragmentada de este tipo de organizaciones piramidales, la comunicación se hace lenta y la innovación casi imposible; las bajas retribuciones económicas y el desprestigio de la actividad pública genera gran inestabilidad en los empleados y poco incentivo para el progreso, reproduciendo el inmovilismo y los bajos incentivos para el cambio institucional.

Freund (1984) advierte también contra la intensión de la burocracia de regular todos los aspectos de la vida a través de las leyes. Las leyes - sostiene - deben regular los aspectos esenciales de la vida social; no deben entrar en los detalles de las costumbres porque se enfrentan al fenómeno de la burocracia que consiste en un sistema que quiere, por fuerza de la ley, transformar a menudo arbitrariamente, nuestras formas

\footnotetext{
${ }^{89}$ De todas formas, actualmente, casi todos los modelos han ido tendiendo hacia las notas del modelo europeo continental con sus matices.
} 
de vida ${ }^{90}$. Otra de las características apuntada por el sociólogo norteamericano Merton del proceso de burocratización está dada por la desvinculación creciente entre los medios de producción, el conocimiento y el trabajador. ${ }^{91}$

La infraestructura institucional, con políticas centralizadoras de poder, planeamiento, gestión y gasto, están evidentemente pensadas para afrontar situaciones normales y previsibles. Si las burocracias han de caracterizarse por su previsibilidad y observancia a las reglas, es imposible que se adapten a las circunstancias especiales o novedosas. Cuando operan en un ambiente dinámico y complejo o cuando se las utiliza para dar respuesta a nuevas demandas o a nuevos actores sociales, sus respuestas son disfuncionales. En ese contexto, el ritualismo y el celo por las normas de atribución de competencias se vuelven un serio obstáculo.

Debe tenerse presente que los nuevos desafíos, por su complejidad o carácter difuso, requieren el abordaje no sólo interdisciplinario sino interdepartamental y sabemos que los procesos gubernamentales que requieren la participación de dos o más organismos obtienen bajísimos niveles de eficacia, además de un alto costo. Los resultados no podrían ser otros cuando los procesos no están automatizados y tienen al papel y al expediente administrativo como instrumentos de integración.

En ese contexto, el ritualismo y el celo por las normas de atribución de competencias se vuelven un serio obstáculo. Y esta propia insolvencia las hace posicionarse erróneamente ante los nuevos problemas. Los output del sistema suelen ser respuestas a demandas acumuladas con lo que el sistema político pierde su capacidad y velocidad de renovación y, consecuentemente, de estar alerta frente a los nuevos desafíos, fenómeno este que ha sido definido como obsolescencia gubernamental. La obsolescencia gubernamental se presenta cuando los rendimientos de la acción de gobierno no sólo se rezagan frente a los cambios sociales y políticos, sino que hay un deterioro en los indicadores del bienestar social e individual; cuando los ciudadanos no son tomados en cuenta en términos de corresponsabilidad y cuando el Estado carece de respuestas oportunas para enfrentar lo previsto y más aún, la incertidumbre y las contingencias (Dror, 1990).

Según Merton (1960:203) "Una flexibilidad insuficiente en la aplicación de destrezas dará por resultado desajustes más o menos graves en un ambiente modificado". Este mismo autor resume el proceso de la siguiente manera:

1) Una burocracia eficaz exige seguridad en las reacciones y una estricta observancia de las reglas; 2) Esta observancia de las reglas lleva a hacerlas absolutas; ya no se consideran relativas a un conjunto

\footnotetext{
${ }^{90}$ Según este autor, el riesgo no está en la pretensión de regulación de todas las relaciones sociales sino en la degradación positivista de este ordenamiento pues bajo una aparente coherencia de principios constitucionales se advierte el puro decisionismo de leyes a medida.

91 "Un número cada vez mayor de individuos descubren que para trabajar tienen que ser empleados. Para trabajar, hay que tener instrumentos y equipo. $Y$ de instrumentos y equipo solo se dispone, y esto cada vez más, en la burocracia, privada o pública. En consecuencia, se tiene que ser empleado por la burocracia para tener acceso a los instrumentos a fin de trabajar para vivir. En este sentido la burocratización trae consigo la separación, de los individuos de los medios de producción, como en la empresa capitalista moderna o en la empresa comunista del Estado (de la variedad de mediados de siglo $X X)$, así como en el ejército posfeudal la burocratización produjo la separación completa de los medios de destrucción." (Merton, 1960: 202-203).
} 
de propósitos; 3) Esto impide la rápida adaptación en circunstancias especiales no claramente previstas por quienes redactaron las reglas generales; 4) Así, los mismos elementos que conducen a la eficacia en general producen ineficacia en casos específicos (Merton, 1960:206).

Así, la capacidad de acción queda atada por una estructura normativa rígida y legalista que deja atrás otros valores como los de la eficiencia, adecuación o velocidad. En este modelo, más cuantitativo que cualitativo, las respuestas no pueden ser rápidas ni orientadas a la calidad (Gascó, 2004).

Este bajo nivel de respuesta, unido a la creciente complejidad, demuestra una insolvencia en la capacidad de gobernar que genera frustraciones, desconfianzas, incertidumbre y finalmente, deslegitiman a todo el sistema político. Ya Habermas (1986) puso el acento en la baja legitimidad de las instituciones públicas como consecuencia de la sobrecarga de demandas sociales. Este autor menciona que esa baja de legitimidad es el producto conjunto de una crisis de gestión administrativa del sistema y de una crisis de apoyo político de los ciudadanos a los gobiernos. La ingobernabilidad sería entonces la suma de una crisis de entrada y de una crisis de salida.

Como es fácil observar, y éste es un presupuesto esencial en las justificaciones sobre la necesidad de la reforma del Estado, se entiende que la mejora de los resultados (productos que el Estado otorga a la sociedad) depende de la mejora de los procesos (que tramita la Administración).

Sin embargo, antes de continuar con el discurso sobre la ineficacia de la gestión burocrática, es necesario analizar cuáles son/deberían ser los objetivos institucionales de una administración pública para luego hacer su evaluación institucional.

Como se ha señalado, la capacidad institucional parece hallarse sujeta a una suerte de ley de hierro pues requiere un equilibrio entre a) la disponibilidad de capacidad de trabajo por parte de los recursos humanos, b) la disponibilidad de potencial de uso adecuado de los recursos materiales y c) la disponibilidad de capacidad de articulación de los anteriores para producir valor para el entorno y la propia organización (conf. Hintze, 2011).

Si bien la evaluación de la capacidad institucional puede enfocarse al qué (lo que producen), al cómo (la forma en que lo hacen) o al con qué (los recursos), es difícil establecer criterios de evaluación en instituciones públicas (conf. Przeworski, 1998).

Aún cuando parezca una verdad de Perogrullo, uno de los requisitos de la gobernanza es garantizar un mínimo de satisfacción real de las demandas, lo que configura el elemento de la eficacia. Ahora bien, en este punto existe una importante diferencia entre la eficacia privada y pública que no muchos informes de organismos internacionales y teóricos advierten ${ }^{92}$.

Ciertamente, los gobiernos deben actuar eficientemente, esto es, obtener resultados al menor coste económico y social posible, pero mientras que las empresas privadas deben privilegiar la rentabilidad y, por lo tanto, la eficiencia es uno de los principales criterios para su evaluación, no parece ser lo mismo en una institución

\footnotetext{
92 Recordemos, grosso modo, que eficiencia significa aprovechar los recursos, y eficacia cumplir con los objetivos propuestos con independencia de los recursos utilizados.
} 
pública. Mientras algunos autores reclaman la medición y evaluación de los resultados institucionales a partir del criterio de la eficiencia, en verdad, la capacidad institucional pública (y consecuentemente su legitimidad) se encuentra más asociada a la correspondencia entre lo reclamado/deseado por el ciudadano y la respuesta que a los costes de su resolución, esto es, a la eficacia y no a la eficiencia. En este sentido, la medición y evaluación de un organismo público está ligada al bienestar general y la equidad alcanzadas ${ }^{93}$.

Ahora bien, pese a todo lo que podemos decir acerca de las deficiencias de las administraciones de corte napoleónico, lo cierto es que la burocracia tradicional, especialmente en América Latina, nunca ha logrado los niveles del tipo ideal weberiano. Procedimientos clientelares, ausencia de carrera y de funcionariado profesional en los niveles medios y elevados son comunes en las administraciones latinoamericanas y no se corresponden al tipo de burocracia europea continental.

A la propia estructura deficitaria del sistema político, se suma la corrupción como un agravante. Ella afecta y corroe a todos los niveles de la estructura administrativa por lo que no es un problema del diseño estructural sino más bien un problema social.

Sin perjuicio de ello, el modelo burocrático en nuestra región tuvo sus innegables logros: dar visos de continuidad al Estado frente a los incesantes cambios políticos que se han dado en la región. Aunque parezca contradictorio, sus principales defectos han sido sus méritos: su organicidad jerárquica, su estabilidad y sus resistencias a los cambios. ${ }^{94}$

Ahora bien, en contextos estatales teñidos por la inestabilidad política, donde se gobierna con la excepcionalidad normativa, las administraciones públicas latinoamericanas se enfrentan a una evidente crisis en su capacidad de respuesta a las demandas sociales. Existe una sobrecarga cuantitativa y cualitativa de demandas que no puede ser satisfecha. 95 Pero como veremos, esta no es la única "explicación" / "justificación" para su reforma.

\section{La tecnocracia}

Es cierto que ya Max Weber (1999) señalaba que la administración burocrática significa dominación gracias al saber pues éste representa su carácter racional fundamental y especifico, pero el fenómeno de la tecnocracia implica algo más que saber técnico.

\footnotetext{
93 Como sostiene Rivera Urrutia (2003:83): "En fuerte contraste con el dominio del comercio, la gobernabilidad debe asegurar que ningún derecho básico se imponga a los otros y en consecuencia el gobierno debe buscar respuestas equilibradas y establecer puentes entre demandas contradictorias".

${ }^{94} \mathrm{Sin}$ dejar de reconocer la justicia de muchas de las críticas a las Administraciones públicas, lo cierto es que las burocracias no son sino un reflejo de la propia sociedad. Y en este sentido, no existe burocracia más resistente a la apertura democrática y al cambio que aquella que surge en sistemas políticos clientelares.

${ }^{95}$ Las grandilocuentes campañas de los partidos políticos suelen generar más expectativas de cambios en el sistema, pero por lo general nunca llegan a cumplirse. Por otra parte, nuevos tipos de demanda imponen a los gobiernos mayores limitaciones y controles. Todo ello genera, por un lado, aumento de las demandas y por el otro lado, restricciones a la salida de los insumos.
} 
La creciente tecnificación de la política, la sociedad y la cultura, hace retomar viejos/nuevos problemas relacionados con el poder tecnocrático. Si resulta cierta la afirmación que sostiene que el pensamiento tecnocrático constituye una concepción del poder y de la sociedad que está estrechamente unida a los momentos de transición hacia otros modelos sociales y productivos (Valencia, 1995), es que tenemos que preguntarnos quién está liderando este cambio hacia la Sociedad de la Información y el Conocimiento.

Al paradigma de la complejidad, como uno de los fenómenos más notorios de la sociedad moderna, se suma el supuesto que afirma que la relación de poder debe estar liderada por aquellos que sean capaces de comprender y aprehender esa realidad compleja. Ese es el presupuesto de todo pensamiento y legitimación del poder tecnocrático: una determinada concepción de la relación saber-poder por la cual serán los que saben los que ejercerán el poder. Esa relación se complementa, a su vez, por la supuesta preeminencia de la ciencia y técnica en la búsqueda de soluciones eficaces a los problemas sociales y económicos.

Fisichella (1982) afirma que el término tecnocracia es uno de los términos más ambiguos de las ciencias sociales, no sólo por la identidad de los actores, sino también por su alcance histórico, la naturaleza de ese conocimiento y su posición social.

Ciertamente que es un fenómeno observable en las sociedades industriales desarrolladas contemporáneas, pero los desarrollos teóricos de Platon, Bacon, SaintSimon, Comte, o más modernos como los de Veblen, Burnham, Galbraith e incluso Bell, ponen de manifiesto que el problema no es nuevo. Sin perjuicio de ello, el fenómeno está estrechamente relacionado con la modernidad. Como ha sostenido el professor brasilero Luiz Carlos Bresser-Pereira (1990) en la reedición de un clásico suyo en lengua inglesa:

Technobureaucratism represents the crystallization of rationalistic ideas and actions which define the modern world. It is the sum total of the whole technological, economic and social revolution which has been taking place throughout the world since the Commercial Revolution and especially since the Industrial Revolution within the framework of an utilitarian rationalism (1990:191).

El primer postulado de la ideología tecnocrática es que, no sería, de hecho, ideología. Según esta cosmovisión, las ideologías, cualesquiera que sean - liberalismo o el intervencionismo, el nacionalismo o el colonialismo, el totalitarismo, el espiritismo, el igualitarismo, el fascismo - son emocionales e irracionales, manifestando intereses y pasiones. Su segundo supuesto, tal vez el más conocido, es que el comportamiento político ya no es viable en el mundo de hoy con los avances de la ciencia y la tecnología pues con sus criterios sería posible gobernar los asuntos públicos. Así, la administración no es una cuestión política, sino técnica.

Ahora bien, suponer la mayor importancia de la ciencia y la técnica para la solución de los problemas sociales y económicos no anula la política pero sí la discusión y el diálogo para la resolución de los problemas. Por ello, el pensamiento tecnocrático no es un pensamiento del diálogo. La concepción tecnocrática de lo político es una concepción que desprecia la política real como ámbito de la 
incompetencia, de la arbitrariedad, de la corrupción y, por qué no, del populismo de los políticos que por acceder al poder reniegan de los principios de la eficacia y eficiencia de la gestión (Fisichella, 1982). Esa pretensión de sustituir el lenguaje político por una koiné tecnológica, elimina el diálogo, vacía de contenido a lo político.

La idea, en sí misma, de la tecnoburocracia, supone que puede existir un conocimiento especial que no tiene el común y que está restringido a ciertos científicos o burócratas. Esta diferencia es la base misma, a su vez, de la obediencia a la orden (conf. Lukes, 1988). Como bien señala Valencia (1995), la visión tecnocrática no sólo supone una visión elitista del poder, sino también una subordinación de los fines a los medios, pues mientras aquellos descansan en ideales, éstos se sustentan en la verdad absoluta y objetiva de la ciencia. De ahí el menor lugar de la política y la necesidad de dejar el manejo de los medios a los expertos.

El tecnócrata viene a representar el establecimiento de la lógica dirigida al incremento de la eficiencia y bienestar social. El técnico profesional asume tareas de decisión buscando impulsar la rentabilidad y racionalidad económica. ${ }^{96}$

Sostenía Meynaud (1968) que la tecnocracia bajo ninguno de los regímenes contemporáneos ha logrado asegurarse el control de la acción gubernativa. Tampoco podría decirse que constituya una verdadera élite en el sentido de grupo social coherente que deliberadamente aspira a tomar el poder político. Estos planteos, lógicos en los años 60 y 70, sin embargo, no invalidan la actual preocupación existente. En efecto, el problema de la tecnocracia se acentúa cuando se yuxtapone con el actual proceso de despolitización que supone la desafección a la democracia. La tecnocracia no aspira a la dirección política sencillamente porque reniega de ella. Pero tecnificado cuestiones esencialmente políticas, esto es, llevándolas del ámbito del debate político a una supuesta certeza técnica, llegamos al mismo punto.

La tecnología opera sobre el sistema político de varias formas, entre ellas, adaptando el proceso de decisión a las exigencias y posibilidades tecnológicas, exigencias y necesidades definidas por las estructuras técnicas. Se produce así una práctica de decisión y gestión más vinculada a criterios técnicos que jurídicos (GarcíaPelayo, 1982).

Freund advierte que en la eficiencia técnica de la decisión propiciada por la ideología de la tecnocracia, se esconde una ideología anti-decisionista. En efecto, la visión técnica que pretende neutralización de la política esconde iguales consecuencias:

... Detrás de esta concepción cooperativa de la obediencia se disimula el viejo sueño de la Humanidad, de una política no-política. Del mismo modo que antiguamente se creía poder atenuar la singularidad y la resolución de una decisión política subordinándola sucesivamente a normas religiosas, éticas o económicas, se pone hoy en día la esperanza en una organización técnico-científica. A pesar de la importancia actual de la corriente tecnocrática, no hay posibilidad en que llegue a suplantar un día la voluntad propiamente política (Freund, 1968 , nota 95).

\footnotetext{
${ }^{96}$ Consecuente con esta lógica, son los procesos de selección y ascenso de la tecnocracia. El reclutamiento meritocrático es visto como una mejora a los azarosos procesos de selección de los partidos políticos.
} 
Es un hecho evidente que las decisiones políticas fundamentales son tomadas por un número relativamente pequeño de personas. Normalmente, las decisiones políticas se han apoyado en un conocimiento experto, en las directrices elaboradas por técnicos. El proceso de tecnocratización no es nuevo pues la lógica del funcionario especializado se encuentra ya implícita en el modelo del Estado de Bienestar. Lo que sí es nuevo es el grado con que se pretende convertir en cuestiones administrativastécnicas aspectos esencialmente políticos: si todo puede planearse, definirse, gestionarse y ejecutarse según pautas técnicas, el espacio para la política es nulo.

La pretendida neutralización de la política no ha podido revertir el hecho de que, a pesar de la racionalización técnica, el crecimiento de las atribuciones del poder hace que el ciudadano dependa mucho más del Estado que antes. Y sin embargo vivimos, según Freund, atrapados por ideologías que pretenden neutralizar la política. Como señala expresamente:

El común objetivo del liberalismo y del socialismo es cercar la política para dejar campo libre a las reformas sociales espontáneas o dirigidas. De hecho, tal vez nunca como en nuestros días el imperio de la política haya sido tan amplio ni tan inquietante... (Freund, 1968:36).

En efecto, como nunca antes en la historia, los desarrollos de la técnica han llegado a casi todos los sectores de la población. Vivimos rodeados de los progresos de la electrónica y muchos de esos usos nos son naturales aunque incomprensibles en cuanto a su funcionamiento lo que da a quienes logran dominar esa técnica un velo de superioridad.

Como una consecuencia necesaria de todo ello, muchos de los temas esencialmente políticos de la Sociedad de la Información y el Conocimiento son definidos como aspectos técnicos y por lo tanto, no debatibles.

La tecnocracia, como sistema de gestión y dirección de la política sustentada sobre una concepción técnica de las cosas, condiciona y puede determinar la toma de decisiones al nivel político, aunque se autodefina como apolítica. Teniendo en cuenta que la legalidad técnica se impone con mucha más fuerza que la legalidad normativa, hay que destacar que no estamos sólo frente a una racionalidad técnica limitada al ámbito tecnológico sino más bien, ante un logos tecnológico que tiene al hombre mismo como uno de los elementos que debe someterse a su lógica y legalidad.

Esta "intelligentsia" nos somete a una nueva forma de tutela a pesar de que no puede defenderse la idea de que las élites técnicas gocen de un conocimiento moral superior o un conocimiento más elevado respecto a lo que constituya el interés público.

Esa alta idea y valor que tiene de su conocimiento técnico hace del tecnócrata, al igual que del burócrata, un sujeto no abierto a los cambios. Por el contrario, la política, al decir de Matus, requiere "el conductor (que) dirige un proceso hacia objetivos que elige y cambia según las circunstancias...” (Matus,1987:73)

Así aunque no estemos frente a una élite tecnocrática, nadie puede dudar que en la Sociedad de la Información, los nuevos científicos, técnicos y productores de 
servicios de la Economía Digital, tienen cada vez más influencia en las cuestiones políticas.

Por ello, resulta entonces necesario encontrar algún modelo de reforma incremental cuyos principios y presupuestos propicien la coparticipación de todos los actores involucrados en ella a fin de modificar las lógicas de funcionamiento institucional que se quieren modificar. Las TIC pueden ser herramientas fundamentales para el funcionamiento de modelos de organización en red que propicien la participación.

\section{Los actuales modelos de reforma administrativa y las resistencias a las propuestas de cambio}

Los modelos de reformas aplicados en las administraciones en Latinoamérica no han sido similares y no han llevado a una convergencia de resultados. Sin embargo, en términos generales, ese mismo Estado interventor modificó gradualmente sus competencias trasladando muchas de ellas, aún las históricas, al sector privado. Ese mismo Estado, antes centralizador, pasó a descentralizar y desconcentrar funciones básicas en los niveles inferiores de su organización territorial (Oszlak, 2000).

Los procesos de reforma que se inspiraron en las consignas de la Nueva Gestión Pública fallaron en la comprensión acerca de las diferencias existentes entre el Estado y las empresas privadas en cuanto a las distintas funciones y relaciones que tienen con la ciudadanía (Rivera Urrutia, 2003). La pretensión de reformar un Estado burocrático por un Estado moderno basado en los principios de la empresa privada estaba condenada a fallar.

Por un lado, los resultados no deseados. La flexibilización administrativa, si bien puede conducir a hacer operativos los principios de economía, eficacia y eficiencia, en ámbitos administrativos como el latinoamericano, condujeron a resultados disfuncionales. En efecto, en instituciones débiles, la discrecionalidad en el nivel político puede acarrear arbitrariedad en la gestión ${ }^{97}$.

Por otro lado, las resistencias. Las mayores resistencias se encontraron en la flexibilización institucional. Las instituciones cuentan con una estructura de incentivos formales, racionales y normativos que enmarcan la interacción de sus participantes,

\footnotetext{
97 En el ámbito latinoamericano, se señala que la informalidad de las instituciones es una nota característica (O'Donnell, 1997, entre otros). Ahora bien, esta afirmación nos lleva a otro debate sobre qué es lo que distingue las formales de las informales. Uno de los criterios para distinguir la formalidad e informalidad de las instituciones es el grado de codificación que ellas tienen, entendida la codificación como procedimientos que reducen la ambigüedad de los comportamientos esperados o debidos. Una norma, según este argumento, sería formal si distintas personas atribuyen un mismo significado a ese comportamiento esperado o debido mediante procedimientos que promueven la aceptación (y validez) de esas condiciones (Tylor, 1995). Para otros, "las instituciones formales son aquellas asociadas con mecanismos externos de imposición como la supervisión y la sanción a cargos de terceros, mientras que las instituciones informales generalmente están caracterizadas por la falta de sanciones externas" (Knight 2002 conf. traducción de Leiras, 2004) o sanciones auto-impuestas (self-enforcing). Finalmente, algunos señalan que las instituciones informales son "reglas socialmente compartidas, usualmente no escritas, que son creadas, comunicadas e impuestas fuera de los canales oficialmente sancionados" (Helmke y Levitsky 2003:11-12).
} 
incentivos que orientan y limitan el comportamiento de los actores. Esos incentivos pueden estar determinados por los recursos disponibles, las normas que regulan su uso y los objetivos que se plantean, pero este esquema relacional además de estar constituido por un marco normativo y regulativo es, esencialmente, un esquema cognitivo que, con cierto carácter simbólico, proporciona significado al comportamiento de los agentes. Este actuar con un significado se desarrolla a partir de la cultura organizativa, las estructuras formales e informales y las rutinas y procesos.

Existe en nuestras administraciones desconfianza en torno a la factibilidad de una rápida combinación entre los valores de la Nueva Gestión Pública y los valores de la administración pública tradicional.

En efecto, existen ciertos aspectos que hacen, sino directamente inviable, dudosa la aplicabilidad de las técnicas y acciones de la visión privada al ámbito público. El primero de ellos es la imposibilidad de que sea el mercado el mecanismo de asignación de recursos pues siempre ello depende de un proceso político. En segundo lugar, las administraciones públicas no perderán su calidad de instrumentos de los poderes públicos, y por ello, su politicidad. En tercer lugar, no sólo los distintos valores de uno y otro ámbito sino la imposibilidad de medir en términos de eficacia económica la agregación de valores públicos que se dan en el ámbito de las administraciones públicas.

Los defensores de la Nueva Gestión Pública señalan que los magros resultados alcanzados en Latinoamérica se deben a que la incorporación de las técnicas del management no fue acompañada con la "recreación" de mecanismos que hubieran favorecido el desarrollo de una nueva "cultura de la responsabilidad", capaz de reordenar la interrelación entre funciones políticas y administrativas, en lugar de sustituir la supervisión de burócratas y políticos por el control a través de principios de mercado.

Desde otra posición se ha dicho que ...

Trasladar esa lógica (empresarial) al sector público presenta claras insuficiencias, ante la necesidad de observar valores colectivos y atender la exigencia de colaboración interinstitucional, imprescindible en la gestión de numerosas políticas públicas (Echebarría y Mendoza, 1999:40-41).

También se afirma que uno de los orígenes del mal funcionamiento de las técnicas de la Nueva Gestión Pública en el ámbito latinoamericano es la falta de formalidad y respeto a las normas que impera en la cultura administrativa de la región donde ni siquiera se ha logrado alcanzar los postulados de la organización burocrática weberiana.

Para Ramió (2001:22)

en la mayoría de los países latinos no es nada evidente, a diferencia de los países anglosajones, que estemos experimentando la transformación de un modelo burocrático hacia un modelo postburocrático debido a que, quizás, nunca hemos disfrutado de unas administraciones realmente burocráticas que respeten los parámetros 
weberianos. Nuestras construcciones burocráticas han sido sólo parciales en el sentido que han combinado una sobreburocratización estructural con una infraburocratización del comportamiento.

Las iniciativas que han pretendido aplicarse en América Latina no han incluido una reflexión sobre las particularidades de su Administración pública y por ello, en realidad, la transición hacia el nuevo paradigma se ha materializado en la adopción de determinadas pautas de carácter gerencial que han puesto de relieve la dimensión tecnocrática de la reforma. Al no tener en cuenta la vigencia de pautas culturales poco permeables a la aceptación de los nuevos criterios, muchos de los proyectos iniciados en países como Bolivia, Uruguay, Venezuela, Chile, Nicaragua o Argentina han quedado frustrados. Y es que, en definitiva, los cambios a los que han apuntado las políticas y las decisiones adoptadas, entre las que se encuentran las relacionadas con los proyectos de gobierno electrónico, no han conseguido resolver el conflicto subyacente entre la racionalidad técnica en que se han fundado y las condiciones (instituciones, diríamos nosotros) culturales y políticas del medio en que han pretendido ser implantadas (Gascó, 2010).

Como bien advierte Arellano Gault (2001), la Nueva Gestión Pública presupone una institucionalidad técnica del comportamiento burocrático con poco espacio para la ambigüedad. Y sin embargo, no hay elemento más político en los procesos de decisión pública que la operacionalización de la decisión política ya que esta supone un amplio margen de libertad y decisión que abarca desde su diseño, distribución, control hasta su ejecución. No obstante los postulados de la Nueva Gestión Pública, la variable política no desaparece: en toda política de reforma existe un complejo proceso de adaptación, negociaciones complejas y aprendizaje. Por ello afirma el mismo autor en otro de sus trabajos que la Nueva Gestión Pública es en realidad una doctrina, una ideología y una estrategia de sobre-simplificación discursiva que cae cerca de extremos casi grotescos (Arellano Gault, 2003) ${ }^{98}$.

La supuesta neutralización de las administraciones sobre un modelo de corte científico y de racionalidad técnica que el gerencialismo propicia, es un supuesto teórico difícilmente contrastable. Las prácticas reales demuestran que las administraciones tienen un fuerte elemento de cultura política y organizacional, el cual es necesario apreciar a fin de institucionalizar cualquier proceso de reforma.

En las reformas hacia adentro del Estado, los condicionamientos políticos son mucho más determinantes que en las reformas hacia fuera y suelen convertirse en factores explicativos de su fracaso. Por ello, para poder comprender cabalmente las causas de las resistencias organizacionales en los procesos de reforma, resulta esencial introducir la vertiente del análisis institucioanlista.

La institución puede ser definida como el conjunto de valores, normas, reglas, rutinas y procesos que estructuran las relaciones entre los agentes que la integran al establecer aquellos parámetros de lo que se considera aceptable a partir de las relaciones entre roles a seguir y situaciones definidas (March et al., 1997).

\footnotetext{
${ }^{98}$ Además, en las administraciones públicas de corte europeo continental el elemento político ha sido un factor estabilizador de la continuidad frente a los golpes de Estado y cambios de gobierno, incluidas también las latinoamericanas.
} 
Toda institución cuenta con unos valores que la caracterizan con apoyos informales basados en una aceptación implícita por parte de los actores. Las normas y reglas, junto a su sistema de sanciones, establecen un régimen institucional. Estas estructuras son el reflejo formal de las instituciones porque establecen la importancia y el rango otorgado a determinados actores o ámbitos de actuación y suelen utilizarse como indicador de su vigencia y difusión.

Las instituciones cuentan con una estructura de incentivos formales, racionales y normativos que enmarcan la interacción de sus participantes, incentivos que orientan y limitan el comportamiento de los actores. Esos incentivos pueden estar determinados por los recursos disponibles, las normas que regulan su uso y los objetivos que se plantean, pero este esquema relacional además de estar constituido por un marco normativo y regulativo es, esencialmente, un esquema cognitivo que, con cierto carácter simbólico, proporciona significado al comportamiento de los agentes. Este actuar con un significado se desarrolla a partir de la cultura organizativa, las estructuras formales e informales y las rutinas y procesos.

Una institución crea significados y condiciona el comportamiento de los agentes al aportar una determinada cosmovisión y al distinguir lo debido, lo incorrecto, lo posible y lo equivocado. ${ }^{99}$ Este tipo de significaciones determinan el accionar de los agentes a partir de sus responsabilidades institucionales y relacionales con el resto de actores, es decir, aquello que se espera, como apropiado, de su rol. Este rol de cada uno de los agentes de la institución constituye el límite real, más allá de los formales, de las instituciones.

Por ello se han visto a las instituciones no sólo como las estructuras normativas que utilizan los actores para desarrollar sus planes, actividades y estrategias, sino como reglas de juego configuradoras de la propia visión que los actores desarrollan en su ámbito de actuación (Criado Grande et al. 2002 y Salvador, 2002). La importancia de la cultura institucional se revela en el hecho de que los valores que ésta transmite suelen ser más persistentes que los formalmente establecidos, llegando incluso a alterar su interpretación y aplicación efectiva.

En materia de utilización intensiva de las tecnologías en materia de reformas, debe señalarse que hay una inherente oposición entre tecnología y cultura. El grado de compatibilidad necesaria entre las tecnologías centrales y las de gestión plantean fuertes condicionamientos al desempeño y contribuyen a homogeneizar los patrones estructurales y funcionales de aquéllas organizaciones que operan con tecnologías similares.

La cultura ejerce una influencia homogeneizante sobre el comportamiento burocrático. Los modos de percibir y categorizar la realidad, las creencias acerca de la eficacia de ciertos instrumentos para lograr objetivos, los criterios de legitimidad prevalecientes, las actitudes hacia la autoridad o las orientaciones hacia el tiempo, son elementos que concurren a tornar más homogéneas las percepciones interpersonales (Oszlak y Felder, 1998).

Cada cultura tiene su propia visión sobre cómo deben comportarse los funcionarios públicos y la legitimidad de sus roles está fuertemente determinada por

\footnotetext{
${ }^{99}$ Cuestiones tales como el modelo de administración referencial, la ideología dominante, los lemas de atención a los ciudadanos o las modas organizativas son algunos claros ejemplos elementos que pueden configurar una cosmovisión acerca del funcionamiento de la Administración Pública.
} 
esta cultura. El nepotismo, la venalidad, el ausentismo son propias de ciertas culturas burocráticas.

Las influencias homogeneizadoras de la cultura tienden a convertirse en restricciones organizacionales, es decir, factores que retardan o interfieren la acción organizacional bajo normas de racionalidad.

La estabilidad es uno de los rasgos distintivos de toda institución. En este sentido, las estructuras y rutinas tienden a la estabilidad o cambian con más lentitud pues existe en ellas una resistencia natural al cambio ${ }^{100}$ (DiMaggio y Powell, 1999).

Por ello, los procesos de reforma pueden fallar cuando las organizaciones replican arreglos y fórmulas institucionales ya aceptadas y consolidadas. La falta de comprensión de los cambios atenta contra la profundidad de la reforma y así, muchos de los procesos exitosos de reforma que se han intentado trasladar desde los llamados países desarrollados fallan cuando se intentan implantar en las administraciones de la región: no son semejantes las instituciones políticas, ni las condiciones económicas, ni las lealtades de la administración.

Para que los cambios se conviertan en institución y las instituciones efectivamente en constreñidoras y direccionadoras de la actividad de los agentes implicados, los cambios deben contar con cierto grado de estabilidad. Por ello resulta necesario introducir cambios limitados, asentarlos e incorporarlos a la lógica del funcionamiento para, con posterioridad, continuar con el proceso de reforma.

Ante la incertidumbre que pueden generar las estrategias de exploración y experimentación y con la intención de legitimar las reformas, muchas veces se opta por recurrir a estrategias y políticas ya probadas en el pasado por la misma organización o por otras organizaciones referenciales. Las estrategias de mimetismo, transferencia o réplica, definidas por DiMaggio y Powell (1999) como "isomorfismo institucional", tienden a buscar rápidos resultados y a legitimar a la institución. ${ }^{101}$ Son políticas de reforma que demandan menor inversión, exigen menos apoyo y resultan menos riesgosas, pero los resultados no suelen ser sustentables en el tiempo. Con ello se consigue que la institución tenga un margen de aceptación hasta que con el tiempo y ante la ausencia de resultados concretos, se inicie un nuevo proceso de reforma. ${ }^{102}$

Muchas veces los proyectos exitosos que se pretenden implementar en nuestra región que vienen "enlatados" y financiados por organismos de crédito ${ }^{103}$; casi nunca

100 Esta estabilidad no siempre se halla condicionada por la estabilidad del sistema global en el que se asientan. Hemos ya mencionado el caso de las burocracias latinoamericanas, las cuales han sido estables en el contexto de sistemas políticos muy inestables.

101 Es necesario destacar que DiMaggio y Powell (1999) y varios autores que siguen su conceptualización, distinguen tres tipos de isomorfismo institucional: a) coercitivo, como resultado de recomendaciones, ayudas financieras condicionadas o presiones formales e informales ejercidas por otras organizaciones para que se reproduzcan las estructuras y las pautas de funcionamiento; b) mimético, como resultado de procesos de imitación de casos líderes que configuran ejemplos a seguir; c) Presión normativa, que refiere al impacto de ciertas agrupaciones profesionales que intercambian conocimientos, definen aquello que consideran 'buenas prácticas' y favorecen su rápida extensión.

102 Se suelen evaluar los resultados en los alcanzados por el modelo referencial y no los resultados de la propia organización reformada. Con ello puede la organización reformada alcanzar cierta legitimidad que la pone a resguardo de las críticas.

${ }_{103}$ Las poblaciones de las naciones periféricas están continuamente expuestas a la influencia de los niveles de vida prevalecientes en los países desarrollados, que tratan de conseguirlo también. Este hecho está en la raíz de una de las principales características de muchas naciones en desarrollo: el desequilibrio 
ponen el acento en nuestras peculiaridades, idiosincrasias y necesidades. No se explora ni se innova. Se piensa que la legitimidad de origen de ese proyecto derivará en el éxito de su implantación en otro contexto, soslayando los necesarios acuerdos previos que requiere la implementación de toda política de Estado. En ese sentido, no puede pensarse que el traslado de procesos de modernización foráneos pueda conducir a similares resultados en regiones culturalmente diferentes. El desajuste entre las pautas formales y normativas de funcionamiento de las instituciones y lo que efectivamente ocurre dentro de la organización es una respuesta lógica.

Se evaden así estrategias de reforma que, partiendo de una previa exploración de los de equilibrios existentes entre valores, normas, reglas y procesos, puedan introducir cambios que alcancen niveles razonables de efectividad (Criado Grande et al., 2002).

Para las actuales administraciones, basadas en una cultura de jerarquía piramidal, las propuestas de agencialización de las oficinas públicas propiciadas por la Nueva Gestión Pública, implicaban, muchas veces, salirse del reparto del poder. Estar fuera de la estructura conduce a estar fuera del juego político, fuera de las asignaciones de recursos, fuera de la carrera de ascensos.

Por otro lado, la política y el poder institucional están en el Estado por lo que transferir los principios de la empresa privada al Estado es vaciarlo de contenido. El Estado se legitima no sólo por los resultados, también por la transparencia, participación, equidad y calidad (Bañón y Carrillo Barroso, 1997).

En definitiva, las administraciones, junto con los parlamentos y los partidos políticos, son instituciones que deben articular intereses y dar respuestas equilibradas frente a las múltiples demandas contrapuestas de la sociedad civil. La estructura administrativa sigue y seguirá siendo un intermediario irremplazable entre los funcionarios políticos y la sociedad, tal vez la más capacitada para transformar las vagas demandas sociales, con el auxilio de las reglas administrativas, en demandas concretas, ciertas y factibles (Fountain, 2001). De allí que deban acompañar los cambios sociales, a través de su reforma, si no quieren distanciarse cada vez más de la sociedad.

Ahora bien, ¿cuál es el modelo de reforma sobre el cuál la más moderna teoría está trabajando? Los modelos de unidades ejecutoras, estructuras matriciales, por proyecto y transversales que abundaron a fines de los ' 90 han sido superados por el modelo de las redes administrativas sustentados en las tecnologías.

Las redes administrativas pueden ser definidas como estructuras de comunicación horizontal y abierta entre diferentes organismos interdependientes, organismos que pueden ser públicos o privados. Al ser una comunicación abierta, las interconexiones pueden ir más allá de los canales legal y formalmente establecidos.

Como ha señalado Rodal (2003), desde el punto de vista organizacional, la red permite crear estructuras de comunicación que facilitan y optimizan los flujos de información y que resuelven numerosos problemas técnicos y sociales en el lugar donde se aplican.

En este modelo de organización, el Estado no es el único actor y por ello no es el carácter público o privado de las unidades que conforman la red lo que define su naturaleza administrativa sino más bien su fin. Se ha dicho, en este sentido, que es

entre las aspiraciones del pueblo y la capacidad del sistema de económico y de producción para cumplir con ellas, tanto cuantitativas como cualitativas. Vid. Guerreiro Ramos (2008). 
posible ver las redes como un modelo de intermediación de intereses o como una nueva forma de "governance" en la cual el estado, si bien es un actor relevante (quizá el más importante), ya no ocupa un papel central (Girard, 2002).

Cuantas más conectividades tenga la red, más gana. Al contrario del esquema burocrático, en el que la suma de estructuras torna más pesado al sistema al hacer crecer a una pirámide ya de por sí sobrecargada, en una red, las conexiones con otros organismos, con otras redes, no implican aditamentos en la estructura original, sino simplemente, nuevas conectividades. Ello hace crecer el valor de una red pues la red gana en información y en utilidad cuando es mayor el número de los que están conectados o asociados, ya que la propia conectividad produce nuevos conocimientos y recursos que se multiplican de forma geométrica en nuevas direcciones. Así, uno de los activos más importantes de la estructura en red son los actores que la conforman, actores que distribuyen y comparten sus informaciones, recursos y capacidades.

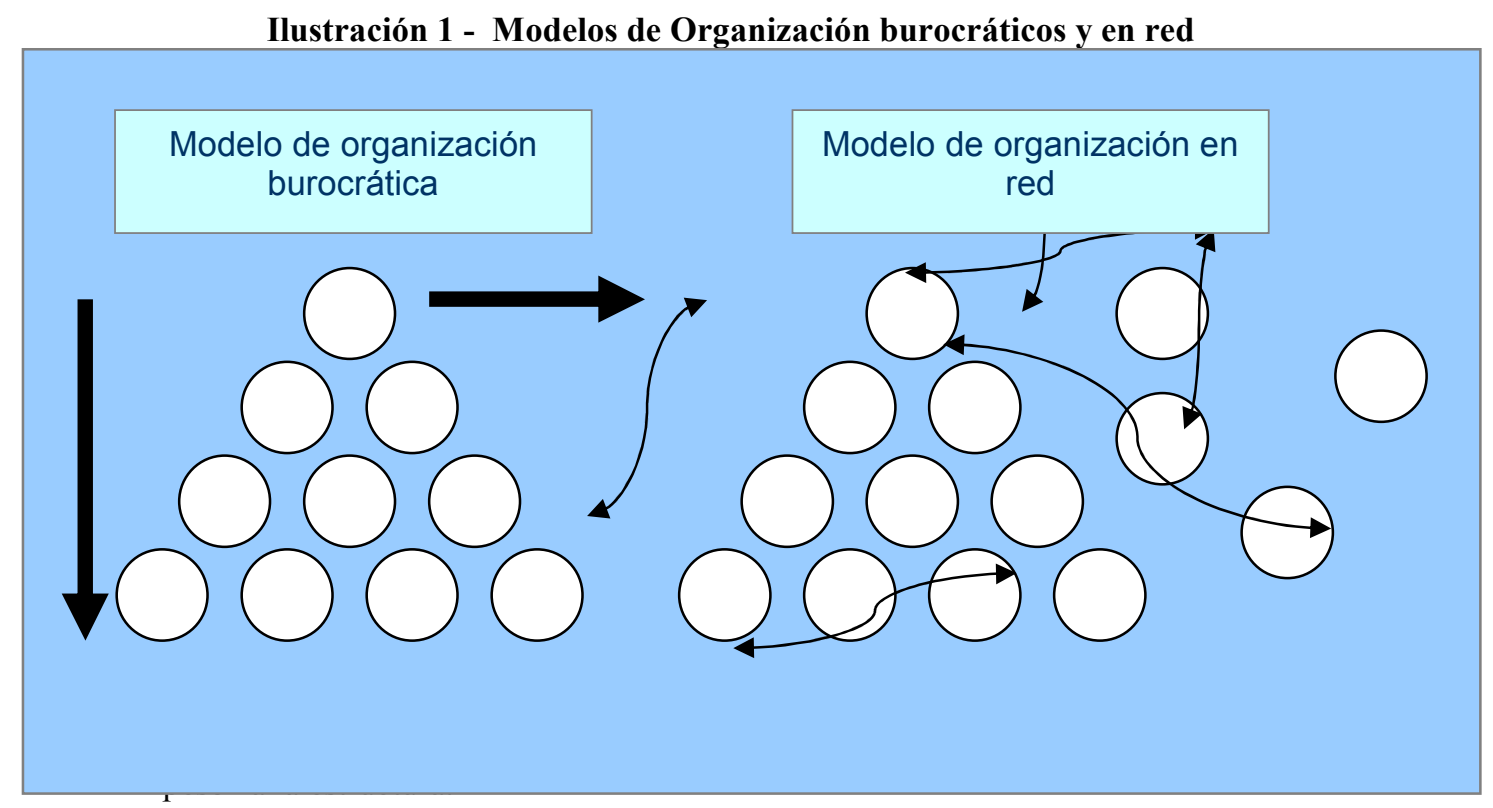

Una red no está conformada sólo por los actores y los recursos que se comparten: existen reglas, que si bien son ambiguas y no está claro quién debe aplicarlas, orientan el comportamiento y posicionamiento de los actores y sugieren qué está permitido y qué no está permitido, además de indicar qué acción está interconectada con qué posición y qué costes y beneficios están asociados con determinados comportamientos. Estas reglas informales generan ciertas percepciones acerca del rol que ocupa cada uno de los miembros de la red y cuáles son las reglas de juego; ellas son las que permiten dar sustentabilidad a la red más allá de los actores que la integran.

Así, las redes no se sustentan en una relación jerárquica entre sus diferentes unidades, sino en la confianza y consenso, confianza que implica coordinación horizontal entre los varios actores que la conforman. La confianza no es espontánea y tiene que ser sostenida. Por ello uno de los mayores problemas de las redes es asegurar su permanencia. En efecto, la subsistencia dependerá de que los procesos 
comunicacionales puedan establecerse de forma continua, estable y duradera, pero si es cierto que las redes son redes que conectan personas, la persistencia de la red dependerá muchas veces de vínculos informales entre personas antes que entre instituciones (Börzel, 1997).

Las TIC como ninguna otra herramienta pueden ayudar a consolidar la confianza. Niklas Luhmann (1996) ya había dicho que el establecimiento de la confianza requiere de volúmenes de información suficientes que posibiliten a la sociedad reducir la incertidumbre con la que intuye el futuro. El esquema de la organización en red sobre base tecnológica puede superar ese estado de incertidumbre. Aportando más información es posible generar una confianza que permita a los actores participar de manera directa o indirecta en las políticas públicas, siendo, consecuentemente, más responsables por su mayor participación en las decisiones que se toman (León y Ramírez, 2003) ${ }^{104}$.

Sólo con una red interconectada es posible lograr el esperado esquema de descentralización. Esta política descentralizadora debe contar con un previo aprendizaje acerca de los beneficios del trabajo en coordinación antes que en subordinación. Debe resaltarse que si bien con el trabajo en coordinación se gana en responsabilidad también se gana en autoría: no existen más subordinaciones sino coautoría entre el nivel de gestión y el nivel de diagramación.

En efecto, es necesario no sólo modificar las bases institucionales sino, y especialmente, modificar las interacciones entre las instituciones. De otra forma, las reformas encontrarán fuertes reacciones, barreras y resistencias, tanto sociales, corporativas, legislativas, procedimentales, como interorganizativas, siendo la tecnológica la menos importante (Criado Grande y Ramilo Araujo, 2001).

Las TIC podían ayudar a la máxima descentralización sin pérdidas de control o de responsabilidad ${ }^{105}$. Las innovaciones a través de políticas de Gobierno Electrónico imponen ciertas pautas organizacionales radicalmente novedosas para las actuales administraciones públicas. Tomando el paradigma de la economía de redes, los proyectos de Gobierno Electrónico podrán impulsar cambios basados en los principios de descentralización coordinada, apertura en red y creación de confianza ${ }^{106}$.

Por su parte, la introducción efectiva de los principios de información y participación implícitos en toda política de Gobierno Electrónico crean los cambios

\footnotetext{
${ }^{104}$ Para Subirats (2002), coincidieron en el tiempo y en sus expectativas, nuevos gestores públicos con ganas de implementar en las administraciones públicas sistemas de gestión más próximos a los que se estaban dando en el campo privado, con políticos que buscaban renovadas formas de legitimación en una mejora de la capacidad de prestar servicio de las administraciones y la creciente accesibilidad y potencial transformador de las TIC. En este sentido, las estrategias de "cartas de servicios"-citizen charts- o de "calidad total" fueron un modelo estereotipado a seguir. Por otro lado, las dinámicas de "aplanamiento" de estructuras o de descentralización de la gestión, buscando proximidad, mayor personalización del servicio, encontraron en las TIC las herramientas necesarias para evitar procesos de desgobierno y de elusión de responsabilidades.

${ }^{105}$ Justamente, el concepto de e-governance fue creciendo acompañado por otros nuevos conceptos que impulsaban la transformación del sector público en torno a la "marquetización" de servicios gubernamentales en agencia gubernamentales externas (Norris, 2003).

${ }_{106}$ Las políticas de participación en el diseño de la gestión de las políticas públicas, incluyendo a sus destinatarios, es además de una estrategia eficiente para lograr mayor legitimidad en la reforma, también fundamental para obtener compromiso en la política de reforma y vencer la resistencia organizacional al cambio.
} 
situacionales necesarios para dar origen a dinámicas de cambio institucional con carácter incremental, siguiendo lógicas de innovación limitada. Con una correcta combinación de nuevas ideas, asociadas a la introducción de las TIC y sus presupuestos, con las reglas, valores y procesos existentes, será posible introducir ese tipo de innovaciones. Esta lógica, coherente con la idea de estabilidad y persistencia de las instituciones, reconoce la posibilidad de introducir oportunidades para la innovación pero también reconoce los límites institucionales para el cambio.

Desde esta posición nos acercamos al enfoque del análisis de las redes de actores que afirma que las políticas se elaboran en procesos complejos de interacción entre un amplio número de actores interdependientes que, como tales, podrán realizar políticas sobre la base de la cooperación.

La incorporación inteligente de las TIC, en una organización en red, generará una redefinición de tareas y de procesos, un cambio en el modelo burocrático. Una política exitosa cambiará la estructura de ejercicio del poder y el funcionamiento democrático. Es por ello que en un modelo de organización en red ya no hay actores que se limitan a crear demandas y otros a dar respuestas porque todos coparticipan en la política plenaria.

Ahora bien, si los núcleos de esa red no tienen poder de decisión, si no se cambia la lógica de la estructura piramidal, la implantación de una red en las actuales administraciones públicas, sólo podría funcionar en los niveles medios; sería más un ámbito de debate que un espacio de decisión y gestión. Es necesario, consecuentemente, que los vínculos de las redes lleguen/involucren también al más alto nivel.

Por último, pero no menos importante, es necesario también establecer los límites reales de los modelos de organización en red en las estructuras públicas. Los principios de legalidad, racionalidad y mando-obediencia implícitos en la organización burocrática son esenciales al Estado de Derecho y por ello no pueden ser eliminados sin socavar la base de la forma estatal.

Las redes son sistemas de comunicación horizontales y abiertos. A través de ellas, es posible gestionar proyectos de carácter transversal que requieren la formación de equipos con integrantes de varias áreas de la organización y un doble flujo de autoridad, el tradicional, vertical desde el punto de vista jerárquico, al que se suma uno horizontal desde el punto de vista técnico, pero la organización en red no puede reemplazar a las formas actuales de organización de las administraciones públicas.

La red es, entonces, el modelo de reforma de tercera generación que bajo el nuevo paradigma del Gobierno Abierto, contribuirá a acelerar la dinámica del sistema político, permitiendo que muchos actores participen interactuando, según el caso, tanto como generadores de inputs como de outputs, de demandas y de productos. 


\section{CAPÍTULO IV. LOS PARADIGMAS DEL BUEN GOBIERNO A TRAVÉS DE LAS CÁRTAS Y CÓDIGOS DEL CONSEJO LATINOAMERICANO DE ADMINISTRACIÓN PÚBLICA}

\section{El Código Iberoamericano de Buen Gobierno}

El Código Iberoamericano de Buen Gobierno fue aprobado en Montevideo el 23 de junio de 2006. Participaron de su suscripción diecisiete países de la Región.

Está destinado y sus consignas son de aplicación para los Presidentes de República, Vicepresidentes, Presidentes de Gobierno o de Consejo de Ministros, Primeros Ministros, Jefes de gabinete de ministros, ministros, secretarios de Estado o equivalentes, y, en general, todos los altos cargos del Poder Ejecutivo.

Se señala en su Preámbulo que el fundamento del Código es el principio de la dignidad de la persona humana y como valores esenciales de desarrollo los de la libertad y autonomía del ser humano y su esencial igualdad intrínseca.

La estructura del Código cuenta con un Preámbulo donde se establecen los lineamientos teóricos y principales orientaciones. El Código tiene 42 artículos divididos en cinco apartados. Su primer apartado, titulado Fundamentos, establece el ámbito de aplicación, principios básicos y valores del buen gobierno así como su definición. El segundo apartado, Reglas vinculadas a la naturaleza democrática del gobierno, detalla acciones necesarias del Poder Ejecutivo hacia el buen gobierno, operacionalizando, a través de ejemplos, principios mínimos del buen gobierno democrático. El siguiente apartado, hace lo propio con la ética gubernamental y el cuarto con la gestión pública. El último apartado, Cumplimiento del Código, refiere a su aplicación.

Como veremos, se advierte en su articulado un foco de atención en los problemas del Estado de Derecho y, en contrapartida, poco desarrollo de los problemas relacionados con la buena gestión y distribución de los recursos (Conf. García Delgado, 2006).

\subsection{Preámbulo}

La inspiración del Código reconoce estar inserta en dos tradiciones diversas aunque complementarias:

- Búsqueda de una ética universal fruto de un consenso en los principios y valores básicos de la convivencia global: el respeto a la soberanía, al derecho internacional, la no injerencia en los asuntos internos de otros Estados, la tolerancia, la convivencia pacífica, la solidaridad y la cooperación (pluralidad cultural y social de los pueblos);

- Tendencias universales promotoras de la construcción de códigos deontológicos o de conducta que guien el ejercicio correcto de las 
diversas prácticas profesionales ${ }^{107}$.

Se señala la necesidad de ...

... acercar a representantes y representados y de la conveniencia de facilitar la unión de gobierno y ciudadanía en un proyecto mutuamente compartido de desarrollo y justicia, movidos por el deseo de promover gobiernos sostenidos por la confianza generalizada y el respeto a las instituciones democráticas ... (Preámbulo).

Se sostiene que el fundamento del Código es el principio de la dignidad de la persona humana y como valores esenciales de desarrollo los de la libertad y autonomía del ser humano y su esencial igualdad intrínseca. Un buen gobierno, reconoce, respeta y promueve todos los derechos humanos -civiles, políticos, sociales, culturales y económicos-, en su naturaleza interdependiente y universalidad.

Uno de los objetivos del Código enunciado en el Preámbulo es el de dignificar socialmente el servicio público de forma tal que sus integrantes sientan el orgullo de realizar una labor esencial para su comunidad, promoviendo en la actuación gubernamental el interés general. ${ }^{108}$ Es por ello que se declara inaceptable un Gobierno que ampare y facilite la corrupción; que dificulte el escrutinio público sobre su toma de decisiones; que no tome en cuenta las necesidades de sus ciudadanos o que actúe en forma irresponsable y que no rinda cuentas.

\subsection{Fundamentos}

Luego de establecer el ámbito personal de aplicación del Código, en su artículo segundo define como principios básicos el respeto y reconocimiento de la dignidad de la persona humana; la búsqueda permanente del interés general; la aceptación explícita del gobierno del pueblo y la igualdad política de todos los ciudadanos y los pueblos; y el respeto y promoción de las instituciones del Estado de Derecho y la justicia social.

El siguiente artículo define ciertos valores que, a diferencia de los principios, no aparecían detallados en el Preámbulo. Explícitamente reconoce como valores del buen gobierno:

- Objetividad, tolerancia e integridad,

- responsabilidad, credibilidad, e imparcialidad,

- dedicación al servicio, transparencia, ejemplaridad y austeridad,

- accesibilidad,

- eficacia,

- igualdad de género

\footnotetext{
107 Es, sin embargo sobre esta última sobre la que se apoya la política del CLAD para sugerir buenas prácticas institucionales, aunque, claro está, con la firma de los ministros del área.

108 Reconoce el Código el abuso de los recursos públicos para fines de interés partidista o particular.
} 
- protección de la diversidad étnica y cultural, así como del medio ambiente

Por último, el Capítulo cierra con la caracterización o Concepto de buen gobierno:

\begin{abstract}
Aquél que busca y promueve el interés general, la participación ciudadana, la equidad, la inclusión social y la lucha contra la pobreza, respetando todos los derechos humanos, los valores y procedimientos de la democracia y el Estado de Derecho.
\end{abstract}

Vemos entonces abrirse en la definición tres grandes líneas: interés general, como objetivo último de toda acción de gobierno; participación ciudadana como procedimiento (democrático) para la toma de decisión; e inclusión, como necesario complemento de la participación, para que todos efectivamente puedan ser parte del proceso. Pese a esta apertura, como ya hemos visto, el Código se articula en tres tipos de reglas de conducta, las vinculadas a la naturaleza democrática del gobierno, a la ética gubernamental y a la gestión pública.

\title{
1.3. Reglas vinculadas a la naturaleza democrática del gobierno
}

Destacamos alguna de las reglas con que el Código busca que los Poderes Ejecutivos de la Región orienten sus acciones hacia el buen gobierno y que hacen a la democracia. Así, detalla que el Poder Ejecutivo:

1. Promoverá, reconocerá y protegerá los derechos humanos y las libertades de los ciudadanos y los pueblos, evitando toda actuación que pueda producir discriminación por razón de nacimiento, etnia, sexo, religión, opinión o cualquier otra condición o circunstancia personal o social que atente contra la dignidad humana.

2. Perseguirá la satisfacción de los intereses generales de los ciudadanos y los pueblos, y sus decisiones y actuaciones se fundamentarán en consideraciones objetivas orientadas hacia el interés común, al margen de cualquier otro factor que exprese posiciones personales, familiares, corporativas, clientelares o cualesquiera otras que puedan colisionar.

3. Impulsará y garantizará el debate político con transparencia y los mecanismos de información y participación para el desarrollo de dicho debate.

4. Se someterá a la ley y al Derecho, y promoverá y respetará la independencia e imparcialidad del Poder Judicial, colaborando activamente en sus actividades investigadoras.

5. Procurará que las Cortes Supremas o Tribunales Constitucionales sean ocupados por juristas de trayectoria, honestidad probada e independencia acreditada. 
6. Respetará la independencia y asegurará los medios materiales, personales e informativos necesarios para que los tribunales y órganos electorales desempeñen eficaz e imparcialmente su función.

7. Asegurará la imparcialidad y objetividad de las actuaciones públicas y la profesionalidad de los empleados públicos, combatiendo, entre otras, las prácticas clientelares, nepotistas y patrimonialistas.

8. Promoverá la igualdad de derechos, oportunidades y trato entre hombres y mujeres, removiendo sus obstáculos y combatirá la pobreza y la exclusión social y cultural.

9. Promoverá normas de financiamiento político que garanticen la igualdad, resguarden la independencia de sus decisiones en los cargos a los que acceden, limiten razonablemente los gastos de campaña, aseguren la transparencia de ingresos y gastos, sancionen equitativa y eficazmente los incumplimientos y protejan las actividades investigadoras de los órganos de control.

\subsection{Reglas vinculadas a la ética gubernamental}

En cuanto a las reglas relacionadas con la ética gubernamental, destacamos las siguientes que señalan que los miembros del Poder Ejecutivo:

1. Evitarán el uso abusivo del poder, en especial los privilegios informativos, reguladores y competenciales para perseguir a personas, instituciones o empresas que actúen en el marco de la legalidad.

2. Se abstendrán de toda actividad privada que pueda constituir un conflicto de intereses con su cargo público, entendiéndose que existe conflicto cuando los altos cargos intervienen en las decisiones relacionadas con asuntos en los que real o aparentemente, de acuerdo a criterios razonables, confluyan a la vez, o puedan confluir en el futuro, intereses de su puesto público e intereses privados propios, de familiares directos, o intereses compartidos con terceras personas.

3. Se someterán a las condiciones y exigencias previstas para el resto de los ciudadanos en las operaciones financieras, obligaciones patrimoniales o negocios jurídicos que realicen, sin propiciar ni admitir favoritismos.

4. No aceptarán ningún trato de favor o situación que implique privilegio o ventaja injustificada.

5. Rechazarán cualquier regalo, favor o servicio, personal o familiar, en condiciones ventajosas que, más allá de los usos habituales, sociales y de cortesía, puedan condicionar el desempeño de sus funciones.

6. No influirán en la agilización o resolución de trámite o procedimiento administrativo sin justa causa y, en ningún caso, cuando ello comporte un privilegio e impedirán el tráfico de influencias.

7. Se responsabilizarán por las decisiones y actuaciones propias; y asumirán 
las responsabilidades ante los superiores y no las derivarán hacia los subordinados sin causa objetiva.

8. Ejercerán sus competencias de acuerdo a los principios de buena fe y dedicación al servicio público.

9. Evitarán todo uso indebido de la información que conozcan por razón del cargo.

10. Se comprometerán a que el desempeño de cargos en órganos ejecutivos de dirección de partidos políticos, o en asociaciones y fundaciones, en ningún caso menoscabará o comprometerá el ejercicio eficaz e imparcial de sus funciones.

\subsection{Reglas vinculadas a la gestión pública} Ejecutivo:

Por último y en lo que hace a la gestión pública, los miembros del Poder

1. Actuarán de acuerdo con los principios de legalidad, eficacia, celeridad, equidad y eficiencia y vigilarán siempre la consecución del interés general y el cumplimiento de los objetivos del Estado.

2. Garantizarán que la gestión pública tenga un enfoque centrado en el ciudadano.

3. Garantizarán el ejercicio del derecho de los ciudadanos y de los pueblos a la información sobre el funcionamiento de los servicios públicos que tengan encomendados, con las especificaciones que establezcan las leyes.

4. Serán accesibles, en el desempeño de sus cargos, a la ciudadanía y a los pueblos, y atenderán eficazmente y contestarán oportuna y fundadamente a todos los escritos, solicitudes y reclamaciones que aquéllos realicen.

5. Procurarán, en el ejercicio de sus funciones, que su desempeño sea una efectiva referencia de ejemplaridad en la actuación de los empleados públicos.

6. Administrarán los recursos materiales y financieros del Estado con austeridad, evitando cualquier tipo de uso impropio.

7. Protegerán el patrimonio cultural y el medio ambiente en el marco de sus competencias.

8. Garantizarán la integridad, conservación y permanencia de los documentos y archivos oficiales.

9. Promoverán la creación, la mejora de la calidad y el uso compartido de estadísticas, bases de datos, portales de gobierno en línea y, en general, todo aquello que facilite la labor interna y el mejor acceso.

10. Fomentarán la participación en la formulación, implantación y evaluación de las políticas públicas.

11. Promoverán la evaluación permanente de sus políticas y programas para asegurar el rendimiento y la eficacia. 
12. Promoverán y garantizarán políticas y programas de carrera, capacitación y formación que contribuyan a la profesionalización de la administración pública.

13. Promoverán una administración receptiva y accesible, y la utilización de un lenguaje administrativo claro y comprensible para todas las personas y los pueblos.

14. Garantizarán la protección de los datos personales, y la adecuada clasificación, registro y archivo de los documentos oficiales, reconociendo, además, el derecho de cada ciudadano a conocer y actualizar los datos personales que obren en poder del Estado.

\subsection{Algunas reflexiones finales}

Seguimos en estas reflexiones finales del Código Iberoamericano de Buen Gobierno el excelente y profundo comentario realizado por García Delgado quien señala que el código es "impulsor de un necesario proceso para comenzar a homogenizar, compartir o consensuar los criterios que deben guiar una buena gestión del Estado en los países de la región" aunque también reconoce que "es un conjunto de consideraciones sobre principios y normas, que tratan de articular racionalidad instrumental, ética y modernización al que se hace dificil no suscribir." (2006:1).

En efecto, como hemos podido ver, muchas o casi todas estas reglas ya están en las Constituciones políticas de los Estados o sus normas positivas. Hay poca innovación o operacionalización en las normas. Tal vez, lo más novedoso sea pretensión de establecer límites a las facultades discrecionales del Ejecutivo, como en los casos de nombramientos de jueces o funcionarios, o en las reglas de ética, donde hay consideraciones acerca de las causales de incompatibilidad de la función pública con la actividad privada que en muchas legislaciones no está muy detallado o, en ese mismo ámbito, el de la ética, el de asumir la responsabilidad de las acciones y no derivarla, sin causa objetiva, a terceros o inferiores.

Como también señala García Delgado (2006), la relación de la ciudadanía parece circunscribirse al gobierno, dejando de lado la distinción entre Estado, régimen y gobierno muy cara a los sistemas políticos presidenciales latinoamericanos. En este sentido, no sólo se vacía al Estado como proyecto colectivo sino que se corre el riesgo de equiparar el gobierno con la buena administración. Muy por el contrario, las normas de ética, transparencia y gobernanza deben trasuntar todo el complejo Estado-régimengobierno-ciudadanía.

Es por ello, entendemos, un error que muchas de las normas se circunscriban al Poder Ejecutivo. Si bien es cierto que el Poder Ejecutivo es, sobre todo en el marco del presidencialismo fuerte que caracteriza al modelo latinoamericano, quien debe cargar con mayores responsabilidades para implementar las acciones que el Código propicia para alcanzar el buen gobierno, lo cierto es que esas consignas, en la medida que correspondan, también deberían ser aplicables y aplicadas por los Poderes Legislativo y Judicial así como por los órganos constitucionales creados fuera de la órbita de los poderes clásicos y también por la sociedad, que padece, pero también ampara, utiliza y convive con la corrupción, la falta de transparencia y los favoritismos. Por otro lado, situar la responsabilidad del estado de cosas que es necesario cambiar para lograr el 
buen gobierno sólo en cabeza de los más altos cargos del Ejecutivo es desconocer la responsabilidad que le cabe a los cuerpos intermedios y empleados de las Administraciones. Aún cuando su responsabilidad y capacidad de acción sea mucho menor, no por ello puede ignorarse el rol central que juega en la ejecución de las políticas de reforma de la Administración Pública.

Coincidimos con el autor que venimos siguiendo en el déficit del Código acerca de la perspectiva histórica y regional, tanto por la creciente interdependencia de los Estados a partir de su integración regional como de su necesidad de insertarse

No coincidimos, en cambio, con la crítica que realiza García Delgado (2006) a la ética pública planteada en el Código. En contra del enfoque deontológico, procedimental, basado en códigos, control y obediencia a estándares universales y regulación de las conductas funcionariales por los ciudadanos con el que identifica correctamente la línea que sigue el Código, propone él una ética teleológica, sustantiva, distributiva, dialógica, que plantee también la ética en términos de proyecto colectivo, donde los fines, los intereses y las prioridades que se fijan o concertan son decisivas para la equidad que se desea lograr. Es cierto que la ética pública no puede involucrar sólo al Estado pero la definición de la orientación de la acción política, aún cuando se trate de políticas erróneas y que deriven en desgobierno, se discuten en otro ámbito, el político. Las orientaciones del Estado se mueven en el ámbito de la participación política, el voto, la decisión, el control, el consenso, etc. que, en un sistema democrático, también supone la puesta en común de una orientación última de la cosa pública que revela las valoraciones éticas del pueblo. De otra forma, eliminamos la política por la ética y reintroducimos en el espacio público los criterios absolutos de la ética que no pueden generar sino división y violencia.

Se puede advertir una visión neoinstitucionalista en el Código pues las problemáticas están más centradas en la falta de capacidad institucional y no en las orientaciones de la gestión de la cosa pública que son, en definitiva, las que condicionan la fortaleza, transparencia y apertura de las instituciones. En efecto, el "Estado mínimo" no puede ser considerado una causa de las políticas del neoliberalismo sino todo lo contrario.

\section{La Carta Iberoamericana de Gobierno Electrónico}

La Carta Iberoamericana de Gobierno Electrónico fue aprobada durante la IX Conferencia Iberoamericana de Ministros de Administración Pública y Reforma del Estado, en Pucón, Chile, durante el año 2007 y adoptada por la XVII Cumbre Iberoamericana de Jefes de Estado y de Gobierno, Santiago de Chile en noviembre de ese mismo año.

La Carta es resultado del consenso alcanzado por los representantes de los gobiernos iberoamericanos en busca de definir un nuevo paradigma en cuanto al uso de las tecnologías de la información y las comunicaciones (TIC), como herramientas coadyuvantes de la mejora de la gestión pública, proponiendo un conjunto de conceptos, valores y orientaciones que facilitan dicho objetivo. Sus enunciados sirven como orientaciones de utilidad para el diseño, implantación, desarrollo y consolidación de las TIC como herramientas coadyuvantes de la mejora de la gestión pública. 
Como decíamos, el documento contiene un conjunto de conceptos, valores, orientaciones y principios. La principal orientación gira en torno al reconocimiento del derecho de los ciudadanos a relacionarse electrónicamente con el Estado y la correlativa responsabilidad de los gobiernos en proveer las herramientas necesarias para satisfacer ese derecho y por ello se subraya que la perspectiva desde la que se tiene que abordar el empleo de las TIC en la gestión pública que es la del ciudadano y sus derechos. ${ }^{109}$ Este cambio de paradigma crea una oportunidad para que la sociedad sea la dinamizadora del Gobierno Electrónico y no una simple destinataria.

La estructura de la Carta es la siguiente: consta de un preámbulo y tres capítulos. En el Preámbulo se anuncian los antecedentes en cuanto a acuerdos internacionales, se fijan las grandes líneas que enmarcan el texto, centradas fundamentalmente a la Sociedad de la Información y el Conocimiento, la brecha, la participación y el fortalecimiento de la democracia; $y$, finalmente, se propicia la traducción de estos enunciados y principios en acciones concretas, mediante mecánicas participativas.

El Capítulo Primero tiene por título "Finalidad y Ámbito de la Carta”. Define, en primer término, los Objetivos. Sigue con un listado de Finalidades y después con algunos Conceptos. Tal el caso de Gobierno Electrónico y Administración Electrónica donde se reconoce que se trata de términos iguales para la comprensión de la Carta, por mencionar un ejemplo. A continuación enumera una serie de Principios.

En el Capítulo Segundo se dedica al "Derecho al Gobierno Electrónico". Menciona el de relacionarse electrónicamente tanto en la relación ciudadano a gobierno (C2G) como en la de gobierno a ciudadano (G2C), los efectos en cuanto derechos de esa relación, los instrumentos del Gobierno Electrónico, la seguridad, las direcciones electrónicas, los sitios electrónicos, los criterios para determinar el régimen de documentos y archivos electrónicos, las consecuencias del Gobierno Electrónico sobre el Derecho Administrativo y la protección de datos personales.

El Capítulo Tercero, "Condiciones Generales para el Establecimiento y Desarrollo del Gobierno Electrónico", se dedica a contemplar las medidas complementarias necesarias para producir el tránsito de los sistemas actuales a otros más integrados donde se contemplen la interoperabilidad en sus distintos niveles: locales, nacionales, regionales e internacionales. Continúa con la preparación de las Administraciones Públicas, la planificación de Gobierno Electrónico con participación multisectorial, la usabilidad de los sistemas, la inclusión digital, la integración de procesos y servicios, las políticas de promoción de contenidos $\mathrm{y}$, finalmente, el despliegue de las infraestructuras telecomunicativas.

\subsection{Preámbulo}

Si realizamos un análisis pormenorizado de la Carta, sobre todo en su Preámbulo, advertiremos que us afirmaciones, como en todo preámbulo, son tanto consideraciones fácticas, valores deseados como objetivos a alcanzar ${ }^{110}$.

\footnotetext{
109 Se entiende por ciudadano, para la Carta según una visión amplia, cualquier persona natural o jurídica que tenga que relacionarse con una Administración Pública y se encuentre en territorio del país o posea el derecho a hacerlo aunque esté fuera de dicho país.

${ }^{110}$ Una de las primeras afirmaciones es la sostiene que el mundo contemporáneo está caracterizado por las profundas transformaciones originadas en el desarrollo y difusión de las TIC en la sociedad, pero que el
} 
La Carta Iberoamericana reconoce el derecho de acceso electrónico a las Administraciones Públicas. Se pretende, por un lado, reconocer a los ciudadanos un derecho que les facilite su participación en la gestión pública y sus relaciones con las Administraciones Públicas y que contribuya también a hacer éstas más transparentes y respetuosas con el principio de igualdad, a la vez que más eficaces y eficientes y, por el otro, como objetivo estratégico e indirecto, el de promover la construcción de una sociedad de información y conocimiento, inclusiva, centrada en las personas y orientada al desarrollo.

En ese marco, se establece, desde el propio Preámbulo, el derecho del ciudadano a conocer, con la facilidad que implican los medios electrónicos, lo que está haciendo la Administración, tornándola más transparente $\mathrm{y}$, por ello mismo, más controlable para luchar contra la corrupción y generar confianza en los ciudadanos. Tienen también los ciudadanos el derecho de promover la inclusión y la igualdad de oportunidades de forma que todos los ciudadanos puedan acceder, cualquiera que sea su situación territorial o social, a los beneficios que procura la sociedad del conocimiento. Otro de los derechos, clásicos desde este tipo de perspectiva, es la de participar activamente emitiendo opiniones, sugerencias y en general en el seguimiento de toma de decisiones, así como sobre el tipo de servicios que el Estado provee y el modo de suministrarlo.

Los redactores de la Carta, suscripta por los Estados Iberoamericanos, instan a la cooperación, coordinación e interoperabilidad internacional. Así, solicitan a los Estados que, en la construcción de la Sociedad de la Información y el Conocimiento, eviten adoptar medidas y decisiones unilaterales contrarias al Derecho Internacional, realizando acciones tendentes a contribuir a la plena consecución del desarrollo económico y social de la población de los países afectados y al bienestar de sus ciudadanos.

En concordancia con la orientación política-ideológica del CLAD, contraria al neoliberalismo, la Carta reconoce el rol insustituible que le corresponde a los Estados en estas materias, para garantizar la universalización a toda la población y la continuidad de los servicios electrónicos y el fortalecimiento de la democracia.

\subsection{Capitulo Primero - Finalidad y Ámbito de la Carta}

La Carta establece, como uno de sus primeros objetivos, el "de determinar las bases conceptuales y los componentes que constituyen el Gobierno Electrónico" para Iberoamérica. Si bien establecer un objetivo conceptual, como primer objetivo, podría parecer superfluo en un documento orientativo para las políticas públicas, sin embargo, teniendo en cuenta la gran cantidad de definiciones y orientaciones (muchas de ellas contradictorias) que se han dado en la literatura a lo largo de los recientes años en esta nueva materia, hacen necesario establecer una definición mínima para cerrar el debate

caso de América Latina está dado por el mantenimiento de profundas desigualdades sociales, desigualdad que se traslada a su uso y aprovechamiento. Más aún, dado que la información y el conocimiento constituyen factores esenciales de la productividad y el desarrollo humano - continúa el Preámbulo - es necesaria la concentración de esfuerzos para evitar la profundización de las desigualdades, facilitar la inclusión y fortalecer la cohesión social.Otro de los presupuestos fuertes, por sus consecuencias, es el que sostiene son las barreras que el espacio y el tiempo ponen entre los ciudadanos y sus Administraciones las que alejan al ciudadano del interés por la cosa pública. Consecuencia lógica de ello (no explicitada) sería que las TIC pueden modificar ese estado de cosas. 
en torno a este concepto.

El segundo de los objetivos está relacionado con la "definición de los contenidos del derecho de los ciudadanos a relacionarse de forma electrónica" con sus Gobiernos y Administraciones Públicas.

El tercer objetivo es el de "conformar un marco genérico de principios rectores, políticas y mecanismos de gestión" llamado a constituir un lenguaje común sobre el Gobierno Electrónico en los países de la comunidad iberoamericana. Por último, se menciona, como objetivo de la Carta, el de "servir como orientación para el diseño, regulación, implantación, desarrollo, mejora y consolidación de modelos nacionales de Gobierno Electrónico en la gestión pública".

Entre las finalidades explícitas establecidas en el Punto $2^{111}$ de la Carta se enumeran las siguientes:

a. Aproximar los Gobiernos y sus respectivas Administraciones a los ciudadanos $[\ldots]$.

b. Incrementar la calidad de los servicios y productos públicos que el Estado tiene que suministrar a los ciudadanos al mejorar la eficiencia, la eficacia y una mayor transparencia $[\ldots]$.

c. Contribuir a que los países iberoamericanos accedan en plenitud a la Sociedad de la Información y el Conocimiento mediante el impulso que, para la misma, supone el efectivo establecimiento del Gobierno Electrónico [...].

d. Coadyuvar en la consolidación de la gobernabilidad democrática, mediante la legitimación efectiva de los Gobiernos y sus Administraciones que comporta el potencial democratizador del Gobierno Electrónico.

e. Optimizar, con ocasión de la implantación del Gobierno Electrónico, los modos de organización y de funcionamiento de los Gobiernos y sus Administraciones, simplificando trámites y procedimientos.

f. Fomentar el uso de los medios electrónicos en los demás ámbitos de la sociedad a través de la percepción de la utilidad que presentan en la Administración Pública.

g. Sensibilizar a las Administraciones para que ofrezcan sus servicios y se interconecten con la ciudadanía a través de estrategias de múltiples canales de acceso.

h. Desarrollar en la implementación del Gobierno Electrónico, acciones que apunten a generar información para que redunden en conocimiento social, con el objetivo de aumentar la competitividad y mejorar el posicionamiento de cada comunidad [...] (Punto 2 - Finalidades - Carta Iberoamericana de Gobierno Electrónico).

La Carta Iberoamericana de Gobierno Electrónico, entiende las expresiones

111 Usaremos indistintamente Punto / Párrafo / Epígrafe para referir e identificar los párrafos numerados de la Carta. 
Gobierno Electrónico y Administración Electrónica como sinónimos; el primero es más utilizado en Latinoamérica y el segundo en España. Para la Carta ambos conceptos son considerados como:

[...] el uso de las TIC en los órganos de la Administración para mejorar la información y los servicios ofrecidos a los ciudadanos, orientar la eficacia y eficiencia de la gestión pública e incrementar sustantivamente la transparencia del sector público y la participación de los ciudadanos (Punto 3 - Concepto de Gobierno Electrónico Carta Iberoamericana de Gobierno Electrónico).

Sin embargo, conceptualmente son distintos. En efecto, mientras que el concepto gobierno comprende "... el conjunto de los órganos a los que institucionalmente les está confiado el ejercicio del poder" (Levi, 1986:710), el de administración denota “... el conjunto de actividades directamente preordenadas para la concreta persecución de las tareas y de los fines que se consideran de interés público o común en una colectividad o en un ordenamiento estatal" (Gozzi, 1986:12). Es decir, el primero incluye al segundo pero no a la inversa.

Según la Carta, el Gobierno Electrónico se propone la satisfacción de las necesidades así como contribuir al desarrollo de la sociedad, por lo que -entiendejamás podrá consistir en una simple respuesta a las ofertas tecnológicas que provienen del mercado. Por ello, -continúa- aquél se encuentra indisolublemente vinculado a la consolidación de la gobernabilidad democrática, y tiene que estar orientado a facilitar y mejorar la participación de los ciudadanos en el debate público y en la formulación de la política en general o de las políticas públicas sectoriales, entre otros medios, a través de consultas participativas de los ciudadanos (Conf. Punto 4 de la Carta).

Más adelante, en el Punto 24 - Interoperabilidad de Servicios, se señala que el Gobierno Electrónico constituye la oportunidad de dar respuesta plena al reto de conseguir una gestión pública más eficiente y de establecer pautas de colaboración entre Administraciones Públicas.

Los Principios de la Carta, que se encuentran enumerados en el Epígrafe $6^{\circ}$, son los de igualdad, legalidad, conservación, transparencia y accesibilidad, proporcionalidad, responsabilidad y adecuación tecnológica con los que deben interpretarse y complementarse todos los derechos, principios y exigencias establecidos en su texto.

Respecto al primer principio, el de igualdad, se subraya que en ningún caso el uso de medios electrónicos puede implicar la existencia de restricciones $\mathrm{o}$ discriminaciones para los ciudadanos que se relacionen con las Administraciones Públicas por medios no electrónicos, tanto respecto al acceso a la prestación de servicios públicos como respecto a cualquier actuación o procedimiento administrativo. ${ }^{112}$

En cuanto al principio de legalidad la Carta adopta el paralelismo o igualdad de garantías previstas en los modos tradicionales de relación del ciudadano con el Gobierno y la Administración. Así, las garantías de los trámites electrónicos deben ser las mismas que las que se reconocen en formato papel o presencial aún cuando aquellos

112 Como también se aclara, ello no es óbice para que los gobiernos dicten medidas dirigidas a incentivar la utilización de los medios electrónicos. 
supongan un simplificación general en las transacciones. Además, la Carta agrega:

\begin{abstract}
El principio de legalidad también comprende el respeto a la privacidad, por lo que el uso de comunicaciones electrónicas comporta la sujeción de todas las Administraciones Públicas a la observancia de las normas en materia de protección de datos personales (Punto 6, b - Principios del Gobierno Electrónico - Carta Iberoamericana de Gobierno Electrónico).
\end{abstract}

Respecto del principio de conservación se señala la necesidad de garantizar que las comunicaciones y documentos electrónicos se conserven en las mismas condiciones que por los medios tradicionales. En cuanto al principio de transparencia y accesibilidad se garantiza que la información de las Administraciones Públicas y el conocimiento de los servicios por medios electrónicos se hagan en un lenguaje comprensible según el perfil del destinatario.

La accesibilidad Web se refiere a la capacidad de acceso a la Web y a sus contenidos por parte de todas las personas, con prescindencia de toda eventual limitación. ${ }^{113}$

Es muy importante que entre los principios se resalte que los requerimientos de seguridad sean adecuados a la naturaleza de la relación que se establezca con la Administración (principio de proporcionalidad) pues permite diseñar políticas adecuadas al tipo de trámite ${ }^{114}$ así como el de responsabilidad de forma tal que la Administración y el Gobierno respondan por sus actos realizados por medios electrónicos de la misma manera que los realizados por medios tradicionales.

Por último, el principio de adecuación tecnológica establece que las administraciones elegirán las tecnologías más adecuadas para satisfacer sus necesidades, recomendándose el uso de estándares abiertos y de software libre en razón de la seguridad, sostenibilidad a largo plazo y para prevenir que el conocimiento público no

\footnotetext{
113 Las limitaciones pueden ser a) visuales (desde la baja visión o el daltonismo hasta la ceguera total), b) motrices (dificultad o imposibilidad de usar las manos), c) auditivas (sordera o deficiencias auditivas), d) cognitivas (dificultades de aprendizaje o discapacidades que afecten a la memoria, la atención, o las habilidades lógicas), e) técnicas (insuficiente familiaridad con las TIC), o f) ambientales (restricciones en la atención visual o auditiva emergentes del contexto de uso). Se señala que cuando los sitios Web están diseñados con una adecuada concepción de la accesibilidad, todos los potenciales usuarios podrían acceder -en condiciones de igualdad- a sus contenidos y servicios. Esta condición resulta esencial para que las prestaciones de Gobierno Electrónico puedan cumplir con su imperativo de llegar a todas las personas. En materia de accesibilidad Web es común hacer referencia a las Pautas de Accesibilidad al Contenido en la Web (WCAC) -que el Consorcio World Wide Web (W3C) creó en 1998- y que indican cómo crear sitios Web para que todas las personas puedan acceder a sus contenidos. Dado que muchas personas con discapacidad utilizan software o dispositivos especiales de accesibilidad asistida para poder acceder al contenido, es necesario que ese contenido sea compatible con las ayudas técnicas. OEA (2008). "Editorial", Boletín Foro e-Gobierno, n ${ }^{\circ}$ 35, Junio 2008. Disponible en línea en: http://www.educoas.org/RestrictedSites/curso1/Newsletter-Junio08/Editorial35.html Fecha de Consulta: 23/01/10.

114 En este sentido, resulta disfuncional y oneroso establecer sistemas de firma electrónica, avanzada o no, para trámites sencillos como pedir turnos o solicitar certificaciones.
} 
sea privatizado. ${ }^{115}$

\subsection{Capítulo Segundo - Derecho al Gobierno Electrónico}

La Carta establece el derecho de los ciudadanos a relacionarse electrónicamente con sus Gobiernos y Administraciones Públicas de forma tan amplia como lo permita la naturaleza del trámite y pretensión de que se trate. Según la Carta, ello supone que las Administraciones estén interrelacionadas entre sí a fin de simplificar los procedimientos y que cuenten con leyes de acceso a la información pública.

Los detalles de este derecho de amplio alcance están enumerados en el Punto 9 de la Carta e incluyen las facultades de:

- Dirigir por vía electrónica todo tipo de escritos, recursos, reclamaciones y quejas como si se hubieran realizado por medios tradicionales así como utilizar documentos administrativos electrónicos en las mismas condiciones.

- Realizar todo tipo de pagos, presentar y liquidar impuestos y cualquier otra clase de obligaciones.

- Recibir notificaciones cuando tal medio sea aceptado por el ciudadano o cuando así lo solicite.

- Acceder a la información administrativa general con igual grado de fiabilidad que la que es objeto de anuncio en diarios o boletines oficiales.

- Acceder a los expedientes para conocer su estado.

- Acceder a información pública de alto valor agregado que sirva para aumentar la competitividad.

- Evitar la presentación reiterada ante la Administración de documentos que ya obren en poder de la misma o de otra, especialmente si son electrónicos ${ }^{116}$.

Este último derecho, el evitar el requerimiento de documentación ya obrante en la Administración, a su vez presupone dos principios fundamentales existentes en todo plan de Gobierno Electrónico: "Simplificación Registral" y "Ventanilla única", íntimamente relacionados entre sí y que debieron tener un mayor desarrollo en la Carta. Según el primero, si alguien ya ha entregado cierta información al Estado, éste no debería volver a pedirla, salvo que sea preciso actualizarla, obviamente. ${ }^{117}$ El principio

\footnotetext{
115 Dentro de este principio se comprende el del uso de distintos medios electrónicos como son: el computador, la televisión digital terrestre, los mensajes SMS en teléfonos celulares, entre otros, sin perjuicio de la eventual imposición del empleo en determinados casos de aquellos medios concretos que se adecuen a la naturaleza del trámite o comunicación de que se trate.

116 Lo que supone, bien aclara la Carta, acciones de interoperatibilidad y simplificación registral que se encuentran tratadas más adelante.

117 Esto implicaría que cuando un ciudadano se identifica ante un organismo público (y se autentica presentando su documento de identidad, por ejemplo) su domicilio ya debería ser conocido por el
} 
de Ventanilla Única supone que el Estado, idealmente en su sentido más amplio, debe presentarse ante la sociedad como una única entidad, independiente de su estructura interna y sus divisiones políticas o territoriales. Bajo este principio, el Estado asume él mismo el costo de su complejidad y distribución política, jurisdiccional y administrativa y se muestra como uno solo. ${ }^{118}$

Para lograr el ejercicio efectivo de este derecho, la Carta enumera, a su vez, algunas herramientas, instrumentos o regulaciones del Gobierno Electrónico. Una de las primeras es la identificación de los ciudadanos, Administraciones, funcionarios y agentes así como la autenticidad de los documentos electrónicos, equipos y sistemas. Otro punto es la necesidad de que las direcciones electrónicas de las Administraciones Públicas estén accesibles para todos los ciudadanos y, como su complemento, la regulación y establecimiento de registros electrónicos a los que los ciudadanos puedan dirigir sus comunicaciones electrónicas (con confirmación de su recepción). El siguiente ítem que menciona la Carta, el régimen de los documentos y archivos electrónicos, es regulado más adelante.

Uno de los puntos transcendentales en cualquier política de Gobierno Electrónico es de la Seguridad y ello no sólo por cuanto la seguridad jurídica y física es necesaria para las operaciones y transacciones de todo tipo sino porque aquella aporta el elemento de confiabilidad necesario en tanto los documentos electrónicos son elementos intangibles. Respecto a esta problemática, la Carta establece que los Estados iberoamericanos aprobarán las normas jurídicas y técnicas necesarias para que los ciudadanos y las Administraciones Públicas en sus relaciones electrónicas puedan tener seguridad y confianza, tanto en lo que se refiere a la identidad de la persona, órgano o institución que se comunica, como en lo que se refiere a la autenticidad e integridad del contenido de la comunicación, así como, consecuentemente, en la imposibilidad de ser repudiada por el emisor. ${ }^{119}$

La autenticidad e integridad de la comunicación recibida, elementos esenciales para la firma electrónica avanzada (según legislación europea) o digital (según legislación argentina):

[...] consiste en que se corresponde con la originalmente remitida sin que sus contenidos hayan podido ser alterados, expresando por tanto la voluntad, opinión, alegatos, y otros contenidos sustentados por la persona que la remite por medios electrónicos (Punto 11, segundo párrafo - Seguridad del Gobierno Electrónico - Carta Iberoamericana de Gobierno Electrónico).

Un tema también clave para establecer un verdadero acceso a la información y para garantizar la comunicación, poco regulado hasta el momento, es el de las

organismo y a lo sumo le debería preguntar si no ha cambiado. Lo mismo debería pasar con todos los datos que el Estado administra de la sociedad, ya sean personas o empresas.

118 Cuando uno quiere registrar a su hijo en la escuela, poco le importa si ésta depende del municipio, del gobierno provincial o del nacional o si el registro civil depende del Ministerio del Interior de la Nación o de otro provincial o si los impuestos son tasas municipales, rentas estaduales o tributos federales.

119 El punto reitera que los Estados también establecerán sistemas alternativos a la firma electrónica cuando la naturaleza del trámite lo aconseje. 
direcciones electrónicas de las Administraciones Públicas. La Carta establece que "los Estados iberoamericanos regularán sobre las direcciones electrónicas de las Administraciones Públicas garantizando que los ciudadanos las puedan conocer con facilidad" (Epígrafe 13, segundo párrafo de la Carta). Para asegurar este derecho, la Carta recomienda elaborar estándares comunes evitando el uso de siglas teniendo en cuenta el uso intuitivo de la navegación en Internet. Por último, también para facilitar la localización de esas direcciones y desde la perspectiva del ciudadano, las mismas deberían estar elaboradas en función de los temas atendidos por cada Institución que puedan ser objeto de búsqueda y localización por los ciudadanos. Consecuentemente, no se recomienda seguir la práctica habitual de las administraciones de colocar el nombre de sus organismos en la Web.

Se establece que las Administraciones Públicas serán responsables de la integridad, veracidad y calidad de los datos, servicios e informaciones en sus sitios electrónicos y portales. Además, para evitar el phishing recomienda que los sitios electrónicos estén dotados de los sistemas de firma electrónica que identifiquen a su titular y garanticen la comunicación segura con los mismos.

Las Administraciones son responsables de la información que publican, debiendo aclarar cuál es el órgano responsable de los mismos y de su puesta al día ${ }^{120}$ y es por ello que en los sitios electrónicos no podrán figurar avisos de exención de responsabilidad por su contenido. Caso contrario - agrega la Carta - esos sitios o direcciones no podrán considerarse una sede electrónica, ni formará parte del sistema de Gobierno Electrónico " $y$ asi deberá figurar con caracteres relevantes en todas sus páginas" (Punto 14 de la Carta).

Como hemos visto, la Carta define al Gobierno Electrónico como el uso de las TIC en los órganos de la Administración para mejorar la información y los servicios ofrecidos a los ciudadanos, orientar la eficacia y eficiencia de la gestión pública e incrementar sustantivamente la transparencia del sector público y la participación de los ciudadanos (Punto 3 - Concepto de Gobierno Electrónico). Ahora, agrega que además implica que los ciudadanos puedan relacionarse con las Administraciones Públicas en todo momento, así como que puedan recibir de forma automática la confirmación de la recepción de tales comunicaciones. Este último aspecto es el que destaca el Punto 15 de la Carta con el título Registros Electrónicos. Es allí donde se establece que tal confirmación se hará mediante copia autenticada, realizada automáticamente, de las comunicaciones y documentos presentados, en su caso, en los que constará la fecha y hora de presentación. Se recomienda a los Estados que notifiquen a los ciudadanos, a través de los registros electrónicos, sus resoluciones y decisiones, siempre que los mismos hayan consentido esta forma de notificación. Se establece, por último, que deberán regular...

[...] sobre los registros electrónicos y su régimen jurídico, de forma que se garanticen la seguridad y autenticidad de las comunicaciones, así como la forma de acreditar la fecha y hora en que se han realizado, que en todo caso serán automáticas (Punto 15 - Registros

\footnotetext{
120 También constará la norma que autoriza la creación del sitio y el contenido de tal norma así como los mecanismos y sistemas que permiten el establecimiento de comunicaciones seguras cuando éstas sean necesarias.
} 
Electrónicos - Carta Iberoamericana de Gobierno Electrónico).

En el Punto siguiente, el 16, la Carta regula el Régimen de los documentos y archivos electrónicos sobre la base del principio de equivalencia de validez de los documentos electrónicos con los documentos en papel. Para ello se recomienda el establecimiento de normas que regulen la conservación y gestión de los datos de forma que se que se garantice la integridad, autenticidad, mantenimiento y conservación sin posibilidades de manipulación o alteración indebida. ${ }^{121}$

Como consecuencia del principio de igualdad establecido en el Epígrafe $6^{\circ}-$ Principios del Gobierno Electrónico y que hemos desarrollado más arriba, en el Punto 17 de la Carta - Consecuencias del Gobierno Electrónico sobre el procedimiento administrativo, se establece que los Estados deberán prever que puede haber quienes quieran relacionarse con medios electrónicos y quienes no lo deseen en un mismo expediente por lo que ello obligará a reconocer el derecho de ambos y permitir la concurrencia de modos de acceso. Se reitera el derecho de que en todo caso los ciudadanos deberán poder conocer por medios electrónicos el estado de tramitación de los expedientes y se agrega que el acceso al expediente podrá hacerse por comparecencia en la oficina pública o, en su caso, a un expediente electrónico. Se aclara, a renglón seguido, el acceso al expediente en la oficina pública no implica per se su acceso en formato papel; es decir, para aquellos que no estén familiarizados con las TIC, o no quieran emplearlas desde sus propios domicilios $u$ oficinas, las Administraciones deberán facilitar y poner a su disposición aparatos, equipos y personal de apoyo preparado para acceder electrónicamente desde dichas oficinas públicas o acreditar su identidad personalmente para remitir sus escritos por medios electrónicos desde la propia oficina pública de información. Consecuencia de todo ello, se consagran las oficinas únicas de atención y de acceso por múltiples canales.

Por último, aún cuando implique la reproducción del derecho de habeas data consagrado constitucionalmente en varias constituciones iberoamericanas, la Carta establece el derecho a la Protección de datos personales (Punto 18). En ese marco se reconoce el derecho de todo ciudadano de solicitar ante los organismos competentes la actualización, la rectificación o la destrucción de aquellos datos contenidos en registros electrónicos oficiales o privados, si fuesen erróneos o afectasen ilegítimamente sus derechos y se reitera que este derecho requiere, como otros de la Carta, que se garantice el acceso a la información y a los datos que sobre sí mismo o sobre sus bienes consten en esos registros oficiales o privados.

\subsection{Capítulo Tercero - Condiciones Generales para el Establecimiento y Desarrollo del Gobierno Electrónico}

La Carta es explicita, en su último capítulo, acerca de cuáles son las condiciones para el establecimiento y desarrollo del Gobierno Electrónico.

En primer lugar, en su Epígrafe 19, reconoce que los Estados deben tener en cuenta los problemas del tránsito hacia un sistema integral de Gobierno Electrónico para

121 El Punto agrega la necesidad de que las Administraciones aseguraren que los documentos electrónicos sean accesibles $\mathrm{y}$, cuando fuere necesario, traspasados a otros formatos y soportes de forma que permanezcan siempre accesibles 
lo que tomarán las medidas necesarias para resolverlos, entre las que destaca las de interoperabilidad e integración entre diversas jurisdicciones, por un lado, y el componente formativo, por el otro. En efecto, este derecho a emplear medios electrónicos ...

[...] exige un tiempo de preparación de las Administraciones públicas. La eficacia en este punto no es incompatible con el realismo acerca de los tiempos y las exigencias de planificación para el establecimiento del Gobierno Electrónico con criterios de flexibilidad no incompatible con la certidumbre y el compromiso sobre fechas de implantación del Gobierno electrónico (Punto 20 - Preparación de las Administraciones Públicas - Carta Iberoamericana de Gobierno Electrónico).

Esto último implica, entre otras cosas, desarrollar metodologías de planificación específicas (que incluyan la evaluación y el monitoreo), generar estrategias de gestión y producción de información pública y gestionar redes, basadas en modelos de gestión de conocimiento. Es por ello que la planificación ocupa otro ítem importante en la Carta. Se establece que una vez definido el objetivo, es preciso determinar los plazos de ejecución teniendo en cuenta los costos-beneficios así como las estrategias y metodologías necesarias para la implementación, entre las que destaca las de gestión y producción de información pública y de gestión de redes. La Carta insiste en el factor tiempo y agrega que los "Estados deberían asumir compromisos de calendarios en que concreten fechas de implantación sucesiva de servicios" (Punto 21 - Planificación del Gobierno Electrónico - Carta Iberoamericana de Gobierno Electrónico). ${ }^{122}$

En cuanto a la integración jurisdiccional, se sugiere la creación de instancias interdepartamentales e intersectoriales así como "una instancia con presencia de agentes sociales y de la Administración Pública que permita conocer la opinión de los agentes sociales y les permita participar en el desarrollo del Gobierno Electrónico" (Punto 21 - Planificación del Gobierno Electrónico - Carta Iberoamericana de Gobierno Electrónico). Llama la atención que como una de las posibles estrategias institucionales aparezca en última instancia la creación de autoridades responsables del desarrollo y consolidación del Gobierno Electrónico a las que les atribuye y especifica como función la jefatura rectora de la información y de la comunicación gubernamental de alto nivel.

En el Epígrafe 23 - Las transformaciones de las Administraciones Públicas la Carta Iberoamericana de Gobierno Electrónico recomienda a los Estados acordar nuevos marcos regulatorios en lo que hace a los desarrollos propios de sistemas o sus adaptaciones como capital estatal intangible. Agrega la necesidad de establecer mecanismos de transferencia y sistemas de apoyo en lo que hace una referencia más para la integración interjurisdiccional. En materia de recursos humanos, sugiere se establezcan programas de adaptación de los empleados públicos a los nuevos sistemas de Gobierno Electrónico, promoviendo su profesionalización, garantizando la sostenibilidad en el tiempo de la ejecución de los procesos electrónicos. Se agrega la necesidad de adaptar las reglas de procedimiento a las posibilidades que ofrecen las

122 Como una de las posibles estrategias, la Carta menciona la posibilidad de otorgar algunos beneficios por ejemplo en materia tributaria y aduanera. 
comunicaciones electrónicas. Su último inciso, sugiere, sin caracterizarlos, la adopción de nuevos modelos de gestión en la Administración Pública que fomenten la mejora continua de los procesos y la constante innovación.

Un punto significativo de la Carta, que ya hemos visto referenciado en otros epígrafes, es el de la Interoperabilidad de servicios desarrollados en los Puntos 24 y 25 y que es encuadrada en el marco del establecimiento de una gestión pública más eficiente y colaborativa. La interoperabilidad no sólo es tecnológica, también semántica, organizativa, legal y regional, estas últimas de difícil implementación. ${ }^{123}$ Se recomienda que todas las Administraciones Públicas, cualquiera que fuere su nivel y con independencia del respeto a su autonomía, ${ }^{124}$ dispongan las medidas necesarias, entre las que destaca los acuerdos, para que se establezcan sistemas que sean interoperables.

En el siguiente Epígrafe, el 26, se hace referencia a la Usabilidad de sistemas y programas. La primera referencia es a la necesidad de que los sistemas y programas deben ser de uso fácil y agrega que tienen que estar disponibles, accesibles y ser manejables intuitivamente por el ciudadano. Respecto a la producción de contenidos a través de sitios Web u otros medios electrónicos ....

[...] deberán incorporarse mecánicas de personalización de sectores específicos para seleccionar los lenguajes utilizados, identificando permanentemente los perfiles de usuarios y sus correspondientes necesidades de información y servicios, poniendo especial atención en la inclusión de personas con discapacidades. También se deberá utilizar un lenguaje simple, directo, evitando el uso de siglas (Punto 26 - Usabilidad de sistemas y programas - Carta Iberoamericana de Gobierno Electrónico).

El siguiente tema, Inclusión digital e infoalfabetización es uno de los más desarrollados y ocupa tres puntos, del 27 al 29. Al reconocer al ciudadano el derecho de relacionarse por vía electrónica con las administraciones públicas, la Carta promueve la inclusión y la igualdad de oportunidades con prescindencia de la situación territorial o social, así como la construcción de una Sociedad de la Información y el Conocimiento inclusiva, centrada en las personas, orientada al desarrollo, la multiculturalidad y el conocimiento entre los pueblos. Así, en primer lugar, se establece explícitamente la necesidad de que los Estados deban establecer políticas, estrategias y programas de

\footnotetext{
123 Como hemos dicho, la interoperabilidad aparece referenciada en varios puntos de la Carta. La interoperabilidad tecnológica la encontramos en el Epígrafe 6, g) referido a la adecuación tecnológica y a la garantía de múltiples medios de acceso; en el Punto 19, de Medidas Complementarias cuando menciona el tránsito de los sistemas actuales a un sistema integrado; y en el Párrafo 23 sobre transferencias y sistemas de apoyo. La interoperabilidad organizativa, aparece en los Objetivos (Párrafo 1, ítems c) y d); y en el Párrafo 7 que menciona la simplificación de procedimientos. La interoperabilidad semántica, que supone la interconexión entre tecnologías y sistemas de información, esto es, la Gestión de Datos, se encuentra en los Objetivos, Párrafo 1, c) cuando señala la construcción de un lenguaje común y en los Principios, Párrafo 6, d), que invoca la necesidad de lenguajes comprensibles. La interoperabilidad transfronteriza aparece también en el Párrafo 9 y en el 25.

124 Esta cooperación no debe limitarse hacia dentro de los Estado; también debe ser regional, una interoperabilidad transfronteriza. Así, señala la Carta expresamente: "En especial se tratará de lograr un estándar común de interoperatibilidad entre todos los países iberoamericanos" (Punto 24 Interoperabilidad de servicios- Carta Iberoamericana de Gobierno Electrónico).
} 
inclusión digital, para combatir la infoexclusión, reduciendo la brecha digital ya sea por razones geográficas o sociales, eliminando las barreras existentes para el acceso a los servicios electrónicos y promoviendo una cultura ciudadana sobre el Gobierno Electrónico.

Un punto especial tratado por la Carta es la problemática por la exclusión de etnias y comunidades indígenas para lo cual se cree indispensable generar políticas activas que les permitan acceder, participar y beneficiarse de los servicios electrónicos, mediante la incorporación de los lenguajes que dichos grupos utilizan para comunicarse en los medios electrónicos. Se reconoce, a su vez, que esa exclusión no sólo es cuestión de los lenguajes de grupos étnicos y se va un paso más allá al indicar a los Estado la necesidad de habilitar y apoyar los espacios de producción de contenidos culturales propios con el objetivo de posibilitar la equidad, la multiculturalidad y el respeto a la diversidad. Y agrega, más adelante:

La preparación de los ciudadanos y la transformación de la cultura social son fundamentales para una más rápida implantación del Gobierno Electrónico y de la sociedad de la información y el conocimiento. En ese sentido los Estados deben promover y planificar la formación de los ciudadanos a este respecto. La pieza fundamental es la educación de las nuevas generaciones desde la más temprana edad (Punto 29 - Inclusión digital e infoalfabetización Carta Iberoamericana de Gobierno Electrónico).

Recomienda a los Estados nacionales a que induzcan tanto a los gobiernos municipales e intermedios como al sector privado y a las comunidades organizadas para que creen y mantengan espacios públicos que cuenten con medios electrónicos de libre acceso sin desechar los espacios privados ya generados, operando asociativamente sobre estos desarrollos. ${ }^{125}$

La superación de la brecha digital también implica formación y en este sentido la Carta recomienda la transformación de la cultura social en lo que respecta al Gobierno Electrónico a través de un proceso de formación ciudadana e infoalfabetización que estimule su acceso, participación y utilización como elemento fundamental de ese proceso de preparación de la ciudadanía.

Uno de los últimos puntos de la Carta refiere, nuevamente, a la Integración de procesos y servicios. Para poner el foco en el ciudadano y no en la tecnología, la Carta recomienda que los Estados Iberoamericanos orienten el Gobierno Electrónico a ofrecer servicios públicos integrados, así como propender a una mayor integración de sus procesos internos. Y explícitamente se señalan como políticas a impulsar las siguientes:

a. Desarrollo de portales únicos. Debido a que la proliferación de portales dificulta la utilización del Gobierno Electrónico por parte de la población, se sugiere la construcción de portales únicos que

\footnotetext{
125 Se señala la posibilidad de establecer lugares de acceso público en bibliotecas públicas, municipalidades, ONG's, locutorios privados subvencionados, en los que se permita la utilización libre de medios electrónicos.
} 
agrupen diversos servicios electrónicos para incrementar el acceso universal a los servicios electrónicos.

b. Combinación de medios. Es importante reconocer que el Gobierno Electrónico al servicio del ciudadano se complementa con otros tipos de medios y mecanismos no electrónicos. Por ello, en la relación entre la Administración Pública y el ciudadano es preciso combinar puntos únicos de contacto presencial con puntos virtuales, de manera de utilizar los primeros para asegurar el acceso y la simplicidad en la utilización de los segundos (Punto 30 - Integración de procesos y servicios - Carta Iberoamericana de Gobierno Electrónico).

El último punto de la Carta, el 31, identificado como El despliegue de las infraestructuras, establece como una de las condiciones para la universalización del Gobierno Electrónico, el despliegue de infraestructuras regionales que sean capaces de dar soporte a las velocidades de transmisión necesarias para que el acceso al Gobierno Electrónico constituya una posibilidad real y sin retardos. En ese marco, el acceso a la banda ancha, es señalada también como una condición necesaria.

Determina que es responsabilidad de cada Estado determinar cuál es la solución tecnológica más conveniente ${ }^{126}$ y el rol que corresponderá a la iniciativa privada y a los mercados y el correlativo poder que se reservan los propios Estados, ya sea como reguladores o como prestadores de servicios en sus diversas modalidades. En todo caso, finaliza, "a los Estados corresponde asegurar el mantenimiento de obligaciones de servicio público o de servicio universal incluso en un escenario de competencia".

\section{La Carta Iberoamericana de Calidad en la Gestión Pública}

La Carta Iberoamericana de Calidad en la Gestión Pública fue aprobada por la X Conferencia Iberoamericana de Ministros de Administración Pública y Reforma del Estado San Salvador, El Salvador, en junio de 2008 y adoptada por la XVIII Cumbre Iberoamericana de Jefes de Estado y de Gobierno, celebrada también en San Salvador, El Salvador, en octubre de 2008.

La Carta se estructura en cinco Capítulos donde se desarrollan 69 epígrafes precedidos por un Preámbulo. En el primero de ello, se establece la Finalidad de la Carta y Noción de Calidad en la Gestión Pública y en el Capítulo segundo, se desarrollan los "Principios inspiradores de una gestión pública de calidad". Especial interés tiene el Capítulo tercero donde se establecen los "Derechos y deberes de los ciudadanos para una gestión pública de calidad". En el anteúltimo Capítulo se pautan "Orientaciones, acciones e instrumentos para formular políticas y estrategias de calidad en la gestión pública", finalizando con uno titulado "Consideraciones finales acerca de la eficacia de la Carta".

El contenido de la Carta es finalista pues, según allí se indica, "una gestión pública se orientará a la calidad cuando se encuentre referenciada a los fines y propósitos últimos de un Gobierno democrático" y éste es asociado, en la Carta, a la

\footnotetext{
126 Hacemos notar que más arriba, en el Punto 6, la Carta se había pronunciado expresamente a favor del software libre.
} 
gestión pública centrada en el servicio al ciudadano, por un lado, y a una gestión pública para resultados (Punto 3). Más aún, entre los principios inspiradores de la Carta, aparece la asociación de la función pública como un servicio público.

\subsection{Preámbulo}

La Carta Iberoamericana vincula la calidad en la gestión pública con dos propósitos fundamentales de un buen gobierno democrático:

- toda gestión pública debe estar referenciada a la satisfacción del ciudadano, ya sea como usuario o beneficiario de servicios y programas públicos, o como legítimo participante en el proceso formulación, ejecución y control de las políticas públicas bajo el principio de corresponsabilidad social;

- la gestión pública tiene que orientarse para resultados, por lo que debe sujetarse a diversos controles sobre sus acciones, suponiendo entre otras modalidades la responsabilización del ejercicio de la autoridad pública por medio del control social y rendición periódica de cuentas.

La Carta promueve el establecimiento de un enfoque común acerca de las nociones de calidad y de excelencia en la gestión pública y del derecho de los ciudadanos a una gestión pública de calidad, estableciéndose unos contenidos mínimos que podrían ser incrementados por los ordenamientos jurídicos nacionales. A este último propósito, la Carta lo identifica como empoderamiento del ciudadano.

\subsection{Finalidad de la Carta y noción de Calidad en la Gestión Pública}

En su premier artículo, la Carta denfine su Objeto en tres incisos que son, esencialmente, pedagógicos pues buscan promover un enfoque común sobre la calidad y la excelencia en la gestión pública, que integre las distintas perspectivas políticas y técnicas (inciso a); conformar un cuerpo de principios y orientaciones que sirvan de referencia en la formulación de políticas, planes, modelos y mecanismos que permitan la mejora continua de la calidad de su gestión pública (inciso b) y proponer la adopción de instrumentos que incentiven la mejora de la calidad en la gestión pública, que sean flexibles y adaptables a los diferentes entornos de las Administraciones Públicas iberoamericanas y a sus diversas formas organizativas (inciso c).

El concepto de calidad es desarrollado en el Punto 2 de la Carta, la que ...

Constituye una cultura transformadora que impulsa a la Administración Pública a su mejora permanente para satisfacer cabalmente las necesidades y expectativas de la ciudadanía con justicia, equidad, objetividad y eficiencia en el uso de los recursos públicos.

La calidad en la gestión pública debe medirse en función de la capacidad para satisfacer oportuna y adecuadamente las necesidades y expectativas de los ciudadanos, de acuerdo a metas preestablecidas alineadas con los fines y propósitos superiores de la Administración Pública y de acuerdo a resultados cuantificables que tengan en cuenta el interés y las necesidades de la sociedad. [...] cobran especial importancia todas las partes interesadas en sus diferentes formas de relación, así como la sostenibilidad y la corresponsabilidad social. 
La calidad en la gestión pública puede y debe ser constantemente mejorada, buscando elevarla a niveles de excelencia, es decir obtener resultados sostenibles, con tendencias crecientes de mejora, y que tales resultados se comparen favorablemente con los más destacados referentes nacionales e internacionales.

Para el buen gobierno, la formulación de políticas públicas deben ser convenientes a toda la sociedad, dentro de parámetros equilibrados de racionalidad política, técnica y económica y "tiene sentido si su fin último es alcanzar una sociedad del bienestar, con justicia y equidad, garantizando el desarrollo de la persona y el respeto a su dignidad, la cohesión social y la garantía del cumplimiento efectivo e integral de los derechos humanos" (Punto 3).

\subsection{Principios inspiradores de una gestión pública de calidad}

La preferencia de las Administraciones Públicas están en la satisfacción de las necesidades y expectativas de los ciudadanos. Ello supone, también, maximizar la creación de valor público y éste "responder al principio de gestión para resultados" (Punto 4). Por su parte y como integrante del principio de servicio público, se señala la necesidad de optimizar la dirección efectiva e integrada del proceso de creación de valor público para asegurar la máxima eficacia, eficiencia y efectividad de su desempeño.

Otro de los principios desarrollados en este punto es el de legitimidad democrática como garantía y protección de las libertades públicas. Si bien se afirma que proviene de la elección popular de las autoridades políticas y de la participación y control de la ciudadanía sobre los asuntos públicos, también es su fuente "el ejercicio independiente de una función pública profesional, seleccionada bajo los principios de igualdad, mérito y capacidad, al servicio de un programa de gobierno resultante del proceso democrático".

Por su parte, según el principio de transparencia, las Administraciones Públicas deben ser abiertas al escrutinio público, tolerantes a la crítica y permeables a las propuestas de mejora y de cambio provenientes de la ciudadanía. Como parte del principio de legalidad, que supone el sometimiento al Estado de Derecho, su racionalidad y objetividad, se afirma que la calidad requiere la formalización de los enfoques, modelos, acciones e instrumentos de calidad, mediante la adopción de normas jurídicas.

Otro de los principios es el de coordinación y cooperación buscando, entre otros, que las Administraciones Públicas, a pesar de la asignación de competencias, relaciones e instancias entre las reparticiones, presten servicios de forma integral al ciudadano, especialmente, en modelos descentralizados y con diferenciación competencial a nivel territorial. Completan el título los principios de ética pública ${ }^{127}$, de acceso universal ${ }^{128}$,

\footnotetext{
127 ... "orientan, tales como la vocación de servicio público, la probidad, la honradez, la buena fe, la confianza mutua, la solidaridad y la corresponsabilidad social, la transparencia, la dedicación al trabajo, el respeto a las personas, la escrupulosidad en el manejo de los recursos públicos y la preeminencia del Interés público sobre el privado" Punto 9.

${ }^{128}$ Hace referencia, más que a las dificultades de acceso por incapacidades físicas, a las dificultades de tiempo y espacio: ... "comprende el esfuerzo por lograr la universalización y el más amplio y fácil acceso espacial y temporal de los ciudadanos a servicios públicos de igual calidad, con independencia de la ubicación geográfica de los ciudadanos y del momento". Punto 10.
} 
continuidad en la prestación de servicios e imparcialidad $^{129}$.

Resulta conveniente desarrollar los principios de eficacia y de eficiencia entendiéndose por el primero que es la consecución de los objetivos, metas y estándares orientados a la satisfacción de las necesidades y expectativas del ciudadano mientras el segundo sería la optimización de los resultados alcanzados por la Administración Pública con relación a los recursos disponibles e invertidos en su consecución. Por su parte, el de economía busca la utilización racional de los recursos públicos (Puntos 13 a $15)$.

Finalmente, sostiene la Carta el principio de responsabilización, central para la teoría de la democracia, indicando que es, por un lado, la rendición de cuentas por el desempeño de las autoridades frente a los ciudadanos, y control social sobre la gestión pública, por el otro. Relacionado con éste, se encuentra el de evaluación permanente y mejora continua.

\subsection{Derechos y deberes de los ciudadanos para una gestión pública de calidad}

Según la Carta, forman parte del derecho a una gestión pública de calidad los siguientes:

a. Acceder a cualquier servicio público o prestación a que tengan derecho, recibiendo una atención y asistencia ágil, oportuna $\mathrm{y}$ adecuada.

b. Solicitar y obtener información pública de interés general, en especial, resultados de la gestión pública y al desempeño de los órganos y entes de la Administración Pública, completa, veraz y actualizada. [...]

c. Conocer el esquema de organización de la Administración Pública, los servicios y prestaciones que ofrecen y los requisitos, condiciones, trámites y procedimientos administrativos y medios para acceder a ellos.

d. Identificar a las autoridades, funcionarios públicos encargados de las prestaciones o servicios públicos [...].

e. Presentar con facilidad las peticiones, solicitudes o reclamos a los órganos y entes de la Administración Pública, así como recibir oportuna y adecuada respuesta a tales peticiones o solicitudes [...]

f. Participar en el ciclo de diseño y mejora del servicio, así como a presentar propuestas de transformación e innovación [...]

i. Exigir un trato respetuoso y deferente por las autoridades y funcionarios públicos [...].

j. Participar en la formación de las políticas públicas de conformidad con la ley nacional, así como en las evaluaciones del desempeño de los órganos y entes de la Administración Pública y conocer sobre su resultado (Punto 18).

Por parte de los ciudadanos, estos contribuirán al sostenimiento de los costes, darán un trato respetuoso y conforme a principios éticos a los funcionarios y autoridades públicas, realizarán un uso adecuado de los bienes y servicios públicos y participarán en el ciclo de formulación, ejecución, evaluación y control de las políticas públicas (Punto 19).

129 ... "sin discriminación por motivos tales como el género, edad, raza, ideología, religión, nivel económico, situación social o localización geográfica" Punto 12. 
3.5 Orientaciones, acciones e instrumentos para formular politicas y estrategias de calidad en la gestión pública

El ante último capítulo, el más extenso de la Carta, con dos Secciones en su haber, refiere a las orientaciones, acciones e instrumentos para formular políticas y estrategias de calidad en la gestión pública. Propone nueves ejes u orientaciones estratégicas, que resumimos:

1. Para una gestión pública al servicio de la ciudadanía: "La capacidad de innovar y adaptarse continuamente a los requerimientos sociales permitirá a la Administración Pública incrementar la credibilidad y confianza de los ciudadanos sobre las diversas prestaciones y variados servicios que suministra" (Punto 24).

2. Hacia una gestión pública para resultados: "Para la objetiva determinación de resultados, se requiere analizar la evolución del desempeño y el nivel de alcance de las metas, trazadas con sistemas de información para el seguimiento, evaluación y control rigurosos y oportunos, que fundamenten la toma de decisiones y medidas correctivas.[...] requiere la implementación de sistemas de monitoreo, medición y control que permitan un adecuado control, y la toma de decisiones" (Punto 26).

3. Compromiso social y ambiental: "Los órganos y entes de la Administración Pública, en su compromiso de servir a la sociedad, promoverán esfuerzos para contribuir al desarrollo social, económico y ambiental de forma sostenible, además de sus atribuciones legales, siempre que no sean incompatibles con las mismas" (Punto 27).

4. Responsabilidad directiva, liderazgo y constancia de objetivos: "La gestión pública de calidad exige una alta cualificación de los directivos [...] deberán rendir cuentas y someterse a control por los resultados obtenidos, e impulsar activamente el cambio, definiendo visión, misión, objetivos y metas, de conformidad con la ley. [...] y motivar a los funcionarios públicos, apoyándolos, facultándolos y otorgándoles el reconocimiento merecido" (Punto 28).

5. Gestión por procesos: "los procesos constituyen una secuencia ordenada de actividades, interrelacionadas, para crear valor añadido[...] basada en datos y evidencias, definiendo objetivos, metas y compromisos a alcanzar. [...] La gestión por procesos en la Administración Pública debe tener en cuenta que el ciudadano es el eje fundamental de la intervención pública [...]" (Puntos 30 y 31).

6. Desarrollo de capacidades de los empleados públicos: "[...] el éxito de una Administración Pública depende del conocimiento, habilidades, creatividad innovadora, motivación y compromiso de sus autoridades, directivos y demás funcionarios públicos. [...] Para el desarrollo de capacidades resulta de gran importancia [...] elaborar normas éticas que proporcionen pautas de comportamiento a los funcionarios públicos, orientadas al servicio público; establecer un sistema de profesionalización de la Función Pública; incorporar programas de capacitación en gestión de calidad [...]" (Puntos 32 y 33);

7. Participación de los empleados públicos para la mejora de la calidad de la gestión;

8. Proceso continuo de aprendizaje, innovación y mejora de la calidad; 
9. Relaciones de colaboración y cooperación orientadas a la mejora de la calidad: "Las Administraciones Públicas identificarán aquellas organizaciones públicas o privadas con las cuales colaborar y cooperar, con el propósito de: a. Acercar el servicio a la ciudadanía. b. Crear sinergias y mejorar la coordinación y coherencia de la gestión pública. c. Mejorar la eficacia, eficiencia y economía de los servicios públicos. d. Mejorar la calidad de los servicios. e. Compartir las mejores prácticas, generar aprendizaje y la gestión del conocimiento" (Punto 36).

La siguiente Sección, dentro del mismo Capítulo, titulada Acciones e instrumentos para la calidad en la gestión pública, recomienda algunas acciones, técnicas e instrumentos básicos de calidad, en los que los órganos y entes públicos pueden apoyarse para la implementación de la calidad en la gestión pública.

Así, por ejemplo, recomienda como modelo la dirección estratégica que supone un enfoque flexible, que se anticipa y adapta a las necesidades de la sociedad (Punto 38) y que se basa en el "ciclo de mejora: establecimiento de objetivos y planificación, desarrollo de forma sistemática y a través de procesos de las actuaciones planificadas, comprobación de los resultados obtenidos con respecto a los objetivos establecidos y adaptación continua de la planificación estratégica" (Punto 39).

El uso de técnicas de prospectiva y estudio del entorno general y específico junto con la realización de encuestas de opinión son estrategias que permiten identificar necesidades, expectativas y retos de la sociedad (Puntos 40 y 41).

Un punto en la Carta que se desarrollará con profundidad en la Carta Iberoamericana de participación ciudadana en la gestión pública pero que tiene poco desarrollo aquí, es el de participación. Sólo se recomienda a las Administraciones desarrollar mecanismos de participación ciudadana, a lo largo de todo el ciclo de las políticas públicas, ya sea a través de comités consultivos, grupos de trabajo, foros, encuentros, jornadas de intercambio de experiencias con otras instituciones $o$ Administraciones Públicas y actividades similares.

Un punto que sí tiene más desarrollo es el de la "gestión por procesos" que implicaría, según la Carta en el Punto 45, el desarrollo de algunas de las actuaciones siguientes:

a. La identificación de los requerimientos, necesidades y expectativas, de los diferentes destinatarios de las prestaciones y servicios públicos, así como de otros posibles grupos de interés.

b. La identificación de todos los procesos necesarios para la prestación del servicio público y la adecuada gestión de la organización: procesos clave u operativos, de apoyo a la gestión y estratégicos; lo que se denomina mapa de procesos.

c. La definición del objetivo de cada uno de los procesos, así como de los beneficios que aporta a los grupos de interés a los que va dirigido. d. La definición secuencial detallada y precisa de las diferentes actividades que componen el proceso o procedimiento concreto, para el cumplimiento de los diferentes requerimientos, y en su caso su diagrama.

e. La definición de las obligaciones, así como de las autoridades y directivos encargados.

f. La definición de indicadores que permitan la medición y control del desarrollo de la marcha adecuada del proceso.

g. La definición y desarrollo de un sistema de gestión que permita el 
seguimiento, evaluación y mejora continua de la calidad de los procesos, y la prestación del servicio.

h. La implantación de sistemas de gestión normalizados o estandarizados.

La constitución de equipos internos ad hoc para la ejecución de proyectos aparece en la Carta. Señala que "Tendrán encomendadas tareas de identificación, análisis y resolución de aspectos susceptibles de ser mejorados, para la óptima orientación a resultados y a la satisfacción de los usuarios" (Punto 46).

Un gran desafío que propugna la carta es la mejora de la normatividad a través de un marco normativo sencillo que facilite la eficacia, eficiencia, agilidad y adaptabilidad de los procesos y procedimientos.

Otro de los puntos que trata son las Cartas Compromiso o Cartas de Servicios al Ciudadano que, según se señala, son documentos públicos con los cuales un "ente público expresa sus compromisos asumidos en la prestación del servicio, especificando plazos de ejecución" ó "estándares de calidad" ó "mecanismos de participación ciudadana" que deben complementarse con un sistema de seguimiento y evaluación del cumplimiento de los compromisos y revisión (Puntos 47 y 48).

Otros de los instrumentos para la calidad en la gestión pública recomendados es la generación de mecanismos adecuados para la comunicación y la difusión de información relevante para los ciudadanos ${ }^{130}$.

En el Punto 52 y ss. recomienda adoptar, como hábito sistemático, mecanismos de evaluación de la eficacia, eficiencia y efectividad, es el seguimiento a través de indicadores, la revisión del cumplimiento de los objetivos y planes establecidos, entre otros, generando estándares de calidad como punto para la medición. Los resultados de estas evaluaciones servirán, según la Carta, para medir avances e identificar puntos críticos en la gestión pública.

Todo ello debe complementarse con la generación de "procesos sistemáticos y organizados para obtener información a través de sugerencias, quejas y reclamos de los ciudadanos [...] y la capacidad de escucha y de respuesta efectiva y eficaz" $\mathrm{y}$ mecanismos que permitan, a los funcionarios, aportar sugerencias (Puntos 56 y 60).

Pero tal vez el punto central que la Carta trata en esta Sección, es la gestión del conocimiento que requiere, como rutina organizativa, el desarrollo de procesos sistemáticos para captar e incorporar, generar, adaptar y difundir la información y el conocimiento adquirido estableciendo protocolos para la creación, validación y difusión del conocimiento que generen valor. Ello puede plasmarse en repositorios de información, mecanismos de intercambio de experiencias y redes de acceso $\mathrm{o}$ interconexión que permitan la identificación de las mejores prácticas.

\subsection{Consideraciones finales de la Carta}

El último punto de la Carta refiere a la necesidad de planificación a corto, mediano y largo plazo, teniendo en cuenta que los cambios sustanciales y sostenibles se lograrán en el largo plazo (Punto 61).

$\mathrm{Y}$ se añade, una exigencia que ya estaba anticipada, que "la estrategia de

\footnotetext{
130 "Entre los posibles instrumentos, se pueden contemplar los siguientes: formularios, guias de servicios, publicaciones, folletos divulgativos, hojas de instrucciones, circulares, páginas de información sobre la organización y sus servicios ubicadas en Internet, puntos automáticos de información y consulta, u otros medios" (Punto 49).
} 
calidad tiene que ser anticipativa y adaptativa, siempre atenta a los cambios del entorno dinámico, lo que dotará a los órganos y entes públicos de mayor capacidad de respuesta" (Punto 63).

\section{La Carta Iberoamericana de Participación Ciudadana}

La Carta Iberoamericana de Participación Ciudadana en la Gestión Pública fue aprobada por la XI Conferencia Iberoamericana de Ministros de Administración Pública y Reforma del Estado en Lisboa, Portugal, en 2009 y adoptada por la XIX Cumbre Iberoamericana de Jefes de Estado y de Gobierno, celebrada en Estoril, Portugal, en diciembre de ese mismo año.

Consta de un Preámbulo y Seis Capítulos con un total de cincuenta (50) epígrafes y una Consideración Final relacionada con el compromiso de los Estados iberoamericanos de promover la participación ciudadana en la gestión pública siguiendo las pautas de orientación contenidas en la Carta. El Capítulo primero define el Objeto, fundamentos y principios de la participación ciudadana en la gestión pública seguido por otro referente a la Participación ciudadana en el proceso de formación de las políticas públicas. En el tercero se habla de las Formas de participación y en el Capítulo Cuarto sobre La participación como organización y proceso. El anteúltimo capítulo refiere al Acceso a la información pública para la participación ciudadana y el Sexto a la Evaluación del proceso de participación en la gestión pública.

4.1. Objeto, fundamentos y principios de la participación ciudadana en la gestión pública

El concepto de participación ciudadana en la gestión pública que adopta la Carta está vinculado al "proceso de construcción social de las políticas públicas que, conforme al interés general de la sociedad democrática, canaliza, da respuesta o amplía los derechos económicos, sociales, culturales, políticos y civiles de las personas, y los derechos de las organizaciones o grupos en que se integran, así como los de las comunidades y pueblos indígenas" (epígrafe 2), el que debe ser complementado con lo establecido en el Preámbulo donde se lo desagrega el derecho genérico de las personas a participar colectiva e individualmente en la gestión pública con los derechos de información, participación, asociación y expresión sobre lo público en la busca de una democracia plena (ver también epígrafe 3 ).

Uno de los objetivos definidos en la Carta es el de definir los contenidos básicos del derecho de los ciudadanos y las ciudadanas a participar en la gestión pública (epígrafe 1, punto b).

El vínculo entre la democracia y la participación es resaltado varias veces en la Carta y ocupa específicamente los Puntos 3 a 5. En concreto se establece que [...]

La participación ciudadana en la gestión pública es consustancial a la democracia. Los principios democráticos de la representación política deben complementarse con mecanismos de participación de la ciudadanía en la gestión pública, que permitan expandir y profundizar la democracia y su gobernabilidad.

La participación ciudadana en la gestión pública refuerza la posición activa de los ciudadanos y las ciudadanas como miembros de sus 
comunidades, permite la expresión y defensa de sus intereses, el aprovechamiento de sus experiencias y la potenciación de sus capacidades, contribuyendo de esta manera a mejorar la calidad de vida de la población.

Asimismo, fomenta una nueva cultura, en la que la ciudadanía va adquiriendo una mayor disposición a informarse acerca de los asuntos públicos, a cooperar y a respetar la diversidad social y cultural, a interactuar dentro de ella y a favorecer la comprensión intercultural.

Desde el punto de vista de los gobiernos la participación ciudadana en la gestión pública ayuda a abordar los conflictos y a propiciar acuerdos, así como a aumentar la legitimidad y efectividad de las decisiones.

También establece la Carta que la participación ciudadana en la gestión pública, cualquiera fuere su objeto, debe combinar formas orgánicas con formas procedimentales. Se añade, además, que el objeto es tender a la institucionalización de la participación como a la modificación de los equilibrios de poder a favor de aquellos que se encuentren subrepresentados en los circuitos de decisiones. La Carta no efectúa distinciones según el derecho a participar sea ejercido (o reclamado) en forma individual o colectiva. Esta última, supone, el derecho de organizarse en colectivos sociales y organizaciones representativas (epígrafe 35 i).

Queda establecido en el epígrafe 6 el doble vínculo existente de la participación ciudadana en la gestión como derecho activo exigible a los poderes públicos por los ciudadanos y las ciudadanas y su contraparte, esto es, ser una responsabilidad cívica (corresponsabilidad social, según se lo define más adelante en el epígrafe 10), punto que se desarrolla en el epígrafe 39.

Finalmente, cierra la Sección con un listado de principios aplicables a la participación, entre los que se destacan los de igualdad y la autonomía; el primero de ellos, en tanto ese derecho es de cada ciudadano y ciudadana por lo cual los Estados iberoamericanos deben establecer las garantías necesarias para que cualquier derecho sea ejercido en igualdad de condiciones; el segundo, autonomía, por cuanto ese derecho debe ejercerse con total autonomía o libertad ${ }^{131}$. Complementan, entre otros, los constitucionalización, institucionalización, gratuidad y corresponsabilidad social.

\subsection{La participación como organización y proceso}

Un aspecto esencial que aparece en la Carta es la necedad de regulación de la participación. En su epígrafe 20, reconoce que la participación en la gestión pública puede adoptar distintas formas. Así, habrá pluridad de formas según el objeto de la participación: si se la ejerce sobre la toma de decisiones públicas, sobre la actividad administrativa o sobre la evaluación de sus resultados. También, será distinta si este derecho se ejerce en forma individual o en forma colectiva. La participación puede canalizarse a través de procedimientos, instancias o ambos. Tendrá, por último, variantes según los tipos de sujetos sociales sobre quienes recae la política pública.

\footnotetext{
131 Así, por ejemplo, cuando los destinatarios son los pueblos indígenas, la Carta establece que su participación deberá darse de acuerdo a sus normas, prácticas, procedimientos, gestión e institucionalidad propia, "conforme a sus cosmovisiones, en armonía con la comunidad y la naturaleza" (epígrafe 19), que "se estructuren y definan sus propias fórmulas de representación interna" (epígrafe 22 inciso f), que deberá llevarse a cabo "mediante procedimientos apropiados" (epígrafe 35 inciso e), etc.
} 
Los componentes básicos del derecho de participación ciudadana en la gestión pública aparecen desarrollados en el Punto 35. Allí se consigna la necesidad de que los ordenamientos jurídicos estatales reconozcan a todos los habitantes el derecho genérico de participación ciudadana en la gestión pública y garanticen su ejercicio efectivo. Y, en una enumeración mínima (no taxativa), se detallan en diez incisos diferentes los derechos participativos en la gestión pública que hemos agrupado temáticamente para mejor comprensión incluyendo otros que parecen desperdigados todo a lo largo de la Carta.

Respecto del derecho de intervenir en las distintas fases de la proceso de formación de políticas públicas, el más genérico de la enumeración, aparece en primer lugar (epígrafe 35 inciso a), se encuentra íntimamente vinculado con el de ser informado expresamente sobre el derecho de participación ciudadana en la gestión pública, sus contenidos, las formas y procedimientos para su ejercicio y los entes y órganos de la respectiva Administración Pública competente con la que se pueden relacionar para participar (inciso g del mismo epígrafe).

En el epígrafe 38 aparece otro de los principios generales: el derecho a reclamar derechos a través de acciones ciudadanas de interés público. Se establece que los Estados iberoamericanos consagrarán jurídicamente el derecho a reclamar derechos, a través de acciones ciudadanas de interés público. Entre esas acciones, menciona el derecho de petición (que es establecida en la propia Carta), la acción popular, la acción de amparo o tutela y la acción de cumplimiento.

Por su parte, el derecho a la presentación de solicitudes, proyectos y propuestas $y$ de recibir respuesta, comprende el de presentarlas en el ámbito competencial de los entes y órganos públicos de los diferentes ámbitos territoriales, así como el recibir las respuesta ${ }^{132}$.

Se reconoce el derecho de participar, a través del trámite que sea previsto, en la elaboración, modificación y revisión de los proyectos normativos y disposiciones de carácter general que les afecten, en particular a determinados colectivos sociales (epígrafe 35 inciso d) ${ }^{133}$.

Según el epígrafe 35 inciso f) es un derecho el solicitar y obtener información pública necesaria, referida a la gestión pública, que sea completa, oportuna, veraz y actualizada. Este derecho es instrumental pues, como veremos, aparece como un prerrequisito para poder ejercer útil y eficazmente el derecho de participar.

La Carta consagra que el derecho genérico de participación ciudadana en la gestión pública incluye el de denunciar ante las autoridades competentes cuando se perciba la obstaculización del ejercicio de la participación, de conformidad con el ordenamiento jurídico nacional (epígrafe 35 inciso $\mathrm{h}$ ).

Siguiendo la línea de lo ya establecido por la Carta Iberoamericana de Gobierno Electrónico, se sostiene en el epígrafe 36 que la aplicación de las tecnologías de información y comunicación a los procesos de participación ciudadana en la gestión pública posibilita el desarrollo del derecho ciudadano a relacionarse y comunicarse electrónicamente con sus Gobiernos y Administraciones Públicas, sin que esto generar

\footnotetext{
132 Ésta debe ser no sólo oportuna y adecuada sino también debe respetar la dignidad de la persona (epígrafe 35 inciso b). Como se aclara a renglón seguido, este derecho es independiente, esto es, no se superpone con el derecho de ejercer recursos administrativos o judiciales.

${ }^{133}$ En el caso de que esas normas y decisiones afecten a los pueblos indígenas, el inciso siguiente, establece además de la participación en su elaboración, modificación y revisión, el derecho a ser consultados previamente, ambas, consulta y participación, mediante procedimientos apropiados.
} 
restricciones para aquellos que usen medios tradicionales. Para la efectivización de este derecho, los Estados iberoamericanos promoverán el acceso universal a las tecnologías de información y comunicación, facilitando la participación, especialmente, de los pueblos indígenas $\mathrm{y}$ grupos poblacionales marginados y culturalmente diversos (epígrafe 37).

En el epígrafe 35 inciso i) aparece consagrado el derecho de organizarse en colectivos sociales y organizaciones representativas de los ciudadanos y las ciudadanas, y conformar redes sociales, con miras a potenciar la capacidad de incidencia sobre la gestión pública.

El último inciso del epígrafe 35 señala el derecho de "Seguir, medir y evaluar la gestión pública y sus resultados, de conformidad con las necesidades y ópticas de la ciudadanía, de los colectivos sociales y pueblos indígenas". En el epígrafe 16 se señala, además, que es un derecho de la ciudadanía medir y evaluar los resultados e impactos de las políticas públicas y se afirma que ello facilitará la intervención independiente de la sociedad en el seguimiento, evaluación y su control.

Los derechos a la participación en la gestión pública (así como su ejercicio) suponen, por su parte, la responsabilidad de los ciudadanos y organizaciones colectivas. Como señala la Carta en su epígrafe 39, el derecho de participación conlleva responsabilidades cívicas. Así, esa responsabilidad cívica implica:

- Conocer y hacer un uso adecuado de los mecanismos de participación.

- Informarse sobre los aspectos de interés público así como sobre las competencias asignadas a la entidad pública a la cual se dirija.

- Escuchar las razones presentadas por los representantes de la Administración Pública $\mathrm{y}$, en los casos de ser necesaria la contra argumentación, hacerlo de acuerdo a razones que obedezcan a la mayor objetividad posible y mediante una actitud de diálogo.

- Respetar y propiciar decisiones públicas que prioricen el interés general de la sociedad.

- Intervenir en los procesos de evaluación de la participación ciudadana, así como de sus actuaciones, de manera que permita aprendizajes para su mejora.

Todo derecho supone una garantía para su ejercicio. En su epígrafe 22, la Carta señala que para garantizar la participación individual y colectiva las Administraciones Públicas propiciarán medidas tendientes a posibilitar el acceso a información de interés genera; difundir los canales de comunicación abierta y permanente con cada área de la Administración; su vinculación con la ciudadanía con su sola condición de tal; la respuesta en tiempo y forma adecuada a toda consulta, solicitud o propuesta presentada; la provisión de mecanismos participativos especiales para incluir a todo ciudadano y ciudadana que tenga dificultades para comunicarse con la Administración, o limitaciones para acceder a los mecanismos de participación ordinarios; la gestión transparente de intereses a instancias de colectivos ciudadanos para manifestar reclamos, propuestas o consultas en el marco de las políticas y normas vigentes.

Para finalizar, es importante señalar que la Carta recomienda a las Administraciones Públicas procurar que los diferentes contenidos del derecho a la participación en la gestión pública sean jerarquizados a través de su 
constitucionalización, regulando los mecanismos, procedimientos y garantías que requiere (epígrafe 10 inciso a).

\subsection{El acceso a la información pública como presupuesto de la participación y control.}

La mayor participación requiere la generación de canales de participación; requiere del establecimiento de regulaciones que determinen los derechos, obligaciones y responsabilidades, tanto de los ciudadanos como de los funcionarios, tanto unos como otros, proactivos., con vocación civil para el cambio.

Pero es también necesario brindar los instrumentos necesarios que posibiliten esa participación. El acceso a la información pública es uno de los requisitos necesarios para el ejercicio del derecho de participación en la gestión pública en sus distintas formas que debe enmarcarse en otro de los principios generales que debe orientar la gestión pública: el principio de transparencia.

Justamente, es por ello que la Carta Iberoamericana dedica un Capítulo especial a este recaudo, que ha recibido amplia recepción en las Constituciones latinoamericanas, y lo reconoce como sustento de la participación, señalando, también, como principios que el acceso y la entrega de la información debe estar encuadrada en los de relevancia, exigibilidad, accesibilidad, oportunidad, veracidad, sencillez, comprensibilidad y máxima divulgación.

En su epígrafe 40, la Carta Iberoamericana de Gestión en la Participación Ciudadana en la Gestión Pública señala que "El acceso a la información es un derecho que sustenta el adecuado funcionamiento de la democracia puesto que es condición para garantizar otros derechos y, en particular, el de participación ciudadana en la gestión pública" y a continuación (epígrafe 41) establece las condiciones de su efectividad y el principio de su gratuidad.

Referente al punto de la gratuidad en el proceso de participación, la Carta establece que cuando hubieren tasas y precios para la recepción de la información solicitada, las normas que los establecen así como condiciones de su dispensa deberán hacerse conocer.

Vinculado con el control, la Carta señala que los Estados pondrán a disposición, sin que necesariamente medie solicitud, información actualizada referida a la ejecución y resultados de las políticas públicas así como información relativa a los servicios y prestaciones que ofrecen y los requisitos, condiciones, trámites y plazos de los procedimientos administrativos y los medios para acceder a ellos, todo ello para facilitar la participación ciudadana y el control del manejo de la cosa pública (epígrafes 44 a 46). 
SECCIÓN TERCERA - ESTUDIO DE LAS REFORMAS DEL ESTADO EN LA PROVINCIA DE BUENOS AIRES 


\section{CAPÍTULO V. CONTEXTO JURÍDICO-INSTITUCIONAL, SOCIAL Y POLÍTICO DE LA PROVINCIA DE BUENOS AIRES.}

\section{Estructura jurídica y capacidad institucional}

La Provincia tiene su propia Constitución y dicta sus propias leyes a través del sistema bicameral -con el acuerdo de las dos Cámaras- promulgadas por el Poder Ejecutivo. Tuvo su primera Constitución en 1854, reformada en 1868. La Constitución Provincial vigente fue dictada en 1934 y fue reformada en 1994.

La provincia está dividida políticamente en 135 partidos o municipios. Lezama, el municipio 135, aún está en proceso de normalización aunque ya eligió sus autoridades por el voto democrático. La autonomía municipal es relativa atento a que no gozan de la facultad de dictarse su propia constitución local -derecho constituyente de tercer grado-. Aunque los municipios tienen un Poder Ejecutivo y Concejo Deliberante elegidos democráticamente y una justicia de faltas administrativa, su funcionamiento se encuentra reglado por una norma provincial, la Ley Orgánica de las Municipalidades, Decreto-Ley $N^{\circ} 6.769 / 58$.

Conforme lo establece la Constitución Provincial cada uno de los partidos en que se divide la Provincia, constituirá un distrito electoral y los distritos electorales serán agrupados en secciones electorales (artículo 61 de la Constitución Provincial).

La Provincia se halla dividida en 8 secciones electorales, según la siguiente distribución: ${ }^{134}$

\footnotetext{
134 Sección Capital: La Plata. Sección Primera: Campana, San Fernando, Pilar, Escobar, Tigre, Luján, Mercedes, Suipacha, Navarro, Lobos, Gral. Las Heras, Gral. Rodríguez, Marcos Paz, Merlo, Morón, 3 de Febrero, Gral. San Martín, Vicente López, San Isidro, Hurlingham, Ituzaingo, Malvinas Argentinas, J. C. Paz, San Miguel. Sección Segunda: Colón, Pergamino, San Nicolás, Ramallo, San Pedro, Baradero, Zárate, Exaltación de la Cruz, San Andrés de Giles, San Antonio de Areco, Carmen de Areco, Salto, Rojas, Bartolomé Mitre, Capitán Sarmiento. Sección Tercera: La Matanza, Berisso, Ensenada, Lanús, Lanús Este, Florencio Varela, Cañuelas, Banfield, Punta Indio, Avellaneda, Lomas de Zamora, Quilmes, Alte. Brown, Berazategui, Pte. Perón, Esteban Echeverría, Ezeiza, San Vicente, Brandsen. Sección Cuarta: Gral. Villegas, F. Ameghino, Gral. Pinto, Leandro N. Alem, Gral. Arenales, Junín, Chacabuco, Chivilcoy, Alberti, Bragado, 9 de Julio, Carlos Casares, H. Yrigoyen, Pehuajó, Trenque Lauquen, Rivadavia, Carlos Tejedor, Lincoln, Gral. Viamonte. Sección Quinta: Lezama, Chascomús, Gral. Paz, Monte, Gral. Belgrano, Las Flores, Rauch, Tandil, Necochea, San Cayetano, Lobería, Gral. Alvarado, Balcarce, Gral. Pueyrredón, Mar Chiquita, Ayacucho, Pila, Gral. Guido, Maipú, Gral. Madariaga, Villa Gesell, Pinamar, Partido de la Costa, Gral. Lavalle, Tordillo, Dolores, Castelli. Sección Sexta: Pellegrini, Tres Lomas, Saliqueló, Guaminí, Daireaux, Gral. La Madrid, Laprida, Benito Juárez, González Chaves, Tres Arroyos, Cnel. Pringles, Cnel. Dorrego, Monte Hermoso, Cnel. Rosales, Bahía Blanca, Tornquist, Cnel Suárez, Saavedra, Adolfo Alsina, Puán, Villarino, Patagones. Sección Séptima: 25 de Mayo, roque Pérez, Saladillo, Gral. Alvear, Bolívar, Tapalqué, Azul, Olavarría.
} 
Cuadro 1 - Cantidad y porcentaje de población por sección electoral

\begin{tabular}{|c|c|r|r|r|}
$\begin{array}{l}\text { Secciones } \\
\text { electorales }\end{array}$ & $\begin{array}{l}\text { Cantidad de } \\
\text { municipios }\end{array}$ & $\begin{array}{l}\text { Porcentaje sobre } \\
\text { el total de } \\
\text { municipios }\end{array}$ & Población & \multicolumn{2}{|l|}{$\begin{array}{l}\text { Porcentaje sobre el } \\
\text { total de población }\end{array}$} \\
\hline I & 24 & 17,91 & 4.821 .349 & 34,89 \\
\hline II & 15 & 11,19 & 646.780 & 4,68 \\
\hline III & 19 & 14,18 & 5.022 .571 & 4,35 \\
\hline IV & 19 & 14,18 & 563.224 & 8,66 \\
\hline V & 27 & 19,40 & 1.196 .411 & 5,10 \\
\hline VI & 22 & 16,42 & 704.178 & 2,12 \\
\hline VII & 8 & 5,97 & 292.748 & 4,14 \\
\hline VIII & 1 & 0,75 & 571.416 & $\mathbf{1 0 0 , 0 0}$ \\
\hline Totales & $\mathbf{1 3 4}$ & $\mathbf{1 0 0 , 0 0}$ & $\mathbf{1 3 . 8 1 8 . 6 7 7}$ & \\
\hline
\end{tabular}

Fuente: Elaboración propia sobre la base de los datos del Ministerio del Interior.

El tipo de lista es cerrada y bloqueada y la fórmula electoral empleada es la de representación proporcional por cociente electoral a los restos más numerosos.

La Constitución de la Provincia de Buenos Aires, siguiendo el modelo de otras constituciones provinciales, ha otorgado jerarquía constitucional a diversos organismos e instituciones de naturaleza administrativa. Además de regular el funcionamiento de los tres poderes clásicos, ha establecido el régimen de nombramientos, incompatibilidades y residencia de los empleados y funcionarios públicos (artículos 52, 53 y 54 de la Constitución Provincial) y la creación de algunos organismos administrativos, técnicos y de control.

El sistema de control también está estructurado y cristalizado en la Constitución y así se establece la figura del Fiscal de Estado (artículo 155) junto con las figuras del Tesorero y Subtesorero y del Contador y Subcontador de la Provincia (artículo 156), así como la organización del Tribunal de Cuentas (Capítulo VII de la Constitución) ${ }^{135}$.

En el artículo 147 de la Constitución se establece que el despacho de los negocios administrativos de la Provincia estará a cargo de dos o más ministros secretarios, y que una ley especial deslindará los ramos y las funciones adscriptas al despacho de cada uno de los ministerios.

Durante el período en estudio, el Gobierno Bonaerense propició tres leyes de Ministerios. La primera, la Ley $\mathrm{N}^{\mathrm{o}}$ 12.856, que fuera sancionada en febrero de 2002, modificó la mayoría de los artículos de la Ley entonces vigente -Ley $\mathrm{N}^{\mathrm{o}} 12.355$ de 1999-. Esta Ley tuvo otra importante modificación con la sanción de la Ley $\mathrm{N}^{\mathrm{o}} 12.928$, y fue finalmente derogada en su totalidad por la última Ley de Ministerios de la gestión, la Ley $\mathrm{N}^{\mathrm{o}} 13.175 .{ }^{136}$ Esta última Ley de Ministerios estableció que el Poder Ejecutivo Provincial contará con la asistencia de las siguientes carteras:

\footnotetext{
135 La Asesoría General de Gobierno no tiene rango constitucional pero es una institución con antecedentes desde la Colonia.

${ }^{136}$ La Ley No 12.999 , que también modificó la Ley de Ministerios, sólo incorporó como Secretaría a la de Turismo y Deportes, pero no modificó la estructura ni competencias de los demás Ministerios y Secretarías.
} 
1. Ministerio de Gobierno

2. Ministerio de Economía

3. Ministerio de Justicia

4. Ministerio de Seguridad

5. Ministerio de Asuntos Agrarios

6. Ministerio de la Producción

7. Ministerio de Salud

8. Ministerio de Infraestructura, Vivienda y Servicios Públicos

9. Ministerio de Desarrollo Humano

10. Ministerio de Trabajo

Además de ello, el Gobernador era asistido por cinco Secretarías:
11. Secretaría General
12. Secretaría de Prensa y Comunicación Social
13. Secretaría de Derechos Humanos
14. Secretaría de Turismo y Deporte
15. Secretaría de Política Ambiental

La Dirección General de Cultura y Educación, al ser un área directamente creada por la Constitución Provincial ostenta la categoría de Organismo de la Constitución, conjuntamente con el Consejo de la Magistratura, la Contaduría General, el Honorable Tribunal de Cuentas, el Fiscal de Estado, la Tesorería General y la Honorable Junta Electoral, aunque aquella es, en verdad un Ministerio. ${ }^{137}$

Pese a la igualdad jurídica de los Ministerios y Secretarías, la distribución del presupuesto es un indicador de los ejes centrales tanto de la gestión como del poder de cada cartera.

\begin{tabular}{|l|r|}
\hline \multicolumn{2}{|c|}{ Cuadro 2 - Presupuesto 2006 - Administración Central } \\
\hline Organismo & Monto \\
\hline CONSEJO MAGISTRATURA & 2.204 .460 \\
\hline JUNTA ELECTORAL & 2.635 .730 \\
\hline SEC. DD.HH. & 6.057 .700 \\
\hline JEFATURA DE GABINETE & 7.777 .940 \\
\hline TESORERIA GENERAL & 8.090 .680 \\
\hline ASESORIA GENERAL & 17.058 .780 \\
\hline
\end{tabular}

\footnotetext{
${ }^{137}$ Según la Constitución provincial, la organización del gobierno y la administración del sistema cultural y educativo están a cargo de una Dirección General de Cultura y Educación, autárquica y con rango de ministerio (artículo 201), cuyo Director, es designado por el Poder Ejecutivo con acuerdo del Senado por cuatro años en su mandato. A diferencia de este caso, para la designación de los otros Ministros no se precisa acuerdo del Senado.
} 


\begin{tabular}{|l|r|}
\hline CONTADURIA GENERAL & 20.017 .300 \\
\hline FISCALIA & 25.631 .940 \\
\hline MIN. DE TRABAJO & 35.786 .000 \\
\hline TRIBUNAL DE CUENTAS & 36.735 .600 \\
\hline MIN. DE ASUNTOS AGRARIOS & 41.022 .180 \\
\hline MIN. DE LA PRODUCCION & 82.554 .935 \\
\hline MIN. DE GOBIERNO & 83.793 .100 \\
\hline GOBERNACION & 212.947 .980 \\
\hline MIN. PUBLICO & 297.994 .490 \\
\hline MIN. DE ECONOMIA & 506.929 .419 \\
\hline MIN. DE JUSTICIA & 541.353 .000 \\
\hline MIN. DE SALUD & 563.303 .233 \\
\hline MIN. INFRAESTRUCTURA & 684.154 .270 \\
\hline PODER JUDICIAL & 685.653 .900 \\
\hline HOSPITALES & 1.072 .868 .700 \\
\hline MIN. DE DESARROLLO HUMANO & 1.132 .590 .400 \\
\hline MIN. DE SEGURIDAD & 1.893 .916 .300 \\
\hline TOTAL ADMINISTRACIÓN CENTRAL & $\mathbf{\$ 7 . 9 6 1 . 0 7 8 . 0 3 7}$ \\
\hline Dirección General de Cultura y Educación & $\mathbf{\$ 7 . 1 9 0 . 1 0 5 . 6 7 3}$ \\
\hline
\end{tabular}

Fuente: Elaboración propia sobre la base de los datos de la Ley de Presupuesto 2006.

El presupuesto de la Dirección General de Cultura y Educación es el más alto que recibe los organismos del Estado, alcanzando los \$ 7.190.105.673, esto es, un poco menos que la suma de toda la Administración Central de la Provincia, aunque menor que el pago que insumió la deuda pública del Estado bonaerense. ${ }^{138}$

Un análisis rápido de los números muestra que los ejes centrales de la administración giran en torno a la educación, la seguridad, gastos en salud y políticas y planes sociales a través del entonces Ministerio de Desarrollo Humano.

Así, la clasificación por finalidad y función muestra que el $60 \%$ del gasto se asignó a Educación, Seguridad, Salud y Acción Social considerando, ahora, pago de deuda (Longo, 2005). ${ }^{139}$

La Ley de Ministerios establecía la organización y el funcionamiento de las carteras ministeriales y secretarias, las que tienen rango ministerial. Si bien en la Administración centralizada, a cada unidad orgánica le corresponde un cargo ocupado por una persona física (agente) con un determinado nivel en el escalafón (director provincial, director, subdirector, jefe de departamento) conjuntamente con los niveles de conducción superior (ministro-secretario, oficial mayor-subsecretario), las organizaciones no orgánicas están muchas veces a cargo de agentes a los que la norma de creación les otorga rango o remuneración equivalente. ${ }^{140}$

\footnotetext{
138 La cifra, según el presupuesto 2006, era de \$ 8.056.624.099.

139 Si a ello se suman las transferencias a Municipios y otras organizaciones, el porcentaje asciende al $73 \%$. El gasto en personal crecerá $11,6 \%$ respecto de este año, a partir del impacto salarial de los aumentos ya otorgados.

${ }^{140}$ Por ejemplo, el Consejo de Gobierno Electrónico tenía a un Secretario Ejecutivo con rango equivalente a Subsecretario.
} 
Cada uno de los organismos cuenta con una muy distinta apertura en cuanto a su organización. El Organismo con más compleja organización era (y es) el Ministerio de Seguridad, que debía manejar a las fuerzas de seguridad y contaba entonces con más de 45.000 agentes.

Debemos destacar que ciertos organismos se encuentran autorizados por Ley para aprobar su propia estructura orgánico-funcional, con lo cual no hay homogeneidad en los criterios organizacionales. ${ }^{141}$

La composición por Jurisdicción del empleo público provincial alcanzada en 2007 puede ser un buen indicador de la complejidad del Estado bonaerense ${ }^{142}$.

Cuadro 3 - Composición del empleo público

\begin{tabular}{|l|r|r|r|}
\hline Organismo & Permanente & Temporaria & \multicolumn{1}{c|}{ Total } \\
\hline Gobernación & 1.386 & 694 & 2.080 \\
\hline Instituto Cultural & 1.145 & 980 & 2.125 \\
\hline C.I.C & 308 & 414 & 722 \\
\hline Jefatura de Gabinete & 99 & 23 & 122 \\
\hline Secretaría DD.HH. & 9 & 37 & 46 \\
\hline Mrio. De Trabajo & 732 & 200 & 932 \\
\hline I.P.S & 475 & 251 & 726 \\
\hline Mrio. De Desarrollo Humano & 3.582 & 1.138 & 4.720 \\
\hline Mrio. De Justicia & 106 & 70 & 176 \\
\hline Servicio Penitenciario & 13.036 & 670 & 13.706 \\
\hline Patronato de liberados & 654 & 46 & 700 \\
\hline Mrio. De Seguridad & 45.721 & 574 & 46.295 \\
\hline Policía & 45.530 & 0 & 45.530 \\
\hline Caja de Retiros, J y Pens. & 87 & 0 & 87 \\
\hline Mrio. De Gobierno & 2.029 & 568 & 2.597 \\
\hline Mrio. De Economía & 4.009 & 745 & 4.754 \\
\hline Inst. Pcial. Lot y Casino & 1.914 & 1.182 & 3.096 \\
\hline M.I.S.V.P & 1.239 & 367 & 1.606 \\
\hline U.E.P Ferroviario Pcial & 1.034 & 893 & 1.927 \\
\hline O.C.E.B.A & 90 & 17 & 107 \\
\hline O.R.A.B & 187 & 2 & 189 \\
\hline Autoridad del Agua & 880 & 0 & 880 \\
\hline Dcción de la Vialidad & 1.680 & 17 & 1.697 \\
\hline S.P.A.R. & 43 & 69 & 560 \\
\hline Instituto de la Vivienda & 495 & 65 & \\
\hline
\end{tabular}

141 Para la Fiscalía de Estado dicha facultad se encuentra contemplada en el artículo 43 in fine del Decreto Ley $\mathrm{N}^{\circ} 7.543 / 69$ (según redacción de la Ley $\mathrm{N}^{\circ} 12.748$ ), que establece que el Fiscal de Estado aprobará la estructura orgánica funcional y el plantel básico. Esta facultad no es extensiva a la Contaduría General de la Provincia, ya que las atribuciones conferidas al Contador General se limitan a proponer al Poder Ejecutivo, por intermedio del Ministro de Economía, su estructura, plantel básico y asignación de funciones. Lo mismo sucede en relación a la Tesorería General de la Provincia. La Policía de la provincia de Buenos Aires también tenía facultades para aprobar su estructura, las que surgen de una interpretación de las atribuciones relativas a la coordinación contemplada en el artículo 21 de la Ley $\mathrm{N}^{\circ} 12.155$, y la reglamentación de dicho artículo por el Decreto $N^{\circ}$ 61/99. La Dirección General de Cultura y Educación, por su parte, tiene sus facultades delegadas con relación a la estructura orgánica según surgen del artículo 33 de la Ley $N^{\circ} 11.612$ (Conf. Randazzo, 2004).

142 Para 2010, a partir de las creaciones de cargos propuestas por el Ejecutivo provincial, la totalidad de cargos en la Provincia son de 323.790 de planta permanente y de 81.917 de planta temporaria en los organismos centralizados. A estos números, hay que sumar 16.672 cargos de planta permanente y 1.729 de temporarios en los organismos descentralizados. 


\begin{tabular}{|l|r|r|r|}
\hline Mrio. De Salud & 31.931 & 10.588 & 42.519 \\
\hline I.O.M.A & 1.611 & 719 & 2.330 \\
\hline Mrio. De Asuntos Agrarios & 947 & 68 & 1.015 \\
\hline CORFO Rio Colorado & 137 & 1 & 138 \\
\hline Mrio. De Producción & 430 & 154 & 584 \\
\hline Fiscalía de Estado & 395 & 86 & 481 \\
\hline E. A. Río Santiago & 1.755 & 568 & 2.323 \\
\hline Tesorería Gral. de la Pcia. & 131 & 3 & 134 \\
\hline Contaduría Gral. de la Pcia. & 296 & 97 & 393 \\
\hline H. T. de Cuentas & 363 & 43 & 406 \\
\hline D. G. de Cultura y Educación & 139.863 & 75.658 & 215.521 \\
\hline Junta Electoral & 64 & 0 & 64 \\
\hline TOTAL GENERAL & $\mathbf{3 0 3 . 8 2 8}$ & $\mathbf{9 6 . 9 3 8}$ & $\mathbf{4 0 0 . 7 6 6}$ \\
\hline
\end{tabular}

Fuente: Dpto. de Estadística. Dcción. Pcial. de Personal y Subsec. Gestión Pública. Plan Trienal 2004-2007 sobre la base de datos aportados por la Dirección Provincial de Personal.

Según los datos del Indec, 2001, sobre el total de la población mayor de 14 años ocupada en la Provincia, el $19 \%$ se desempeña en el sector público en planta permanente, mientras que el $52 \%$ trabaja en el sector privado y el otro $29 \%$ lo hace en otras condiciones. La relación cantidad de empleados públicos/habitantes, que alcanza a 27,7 empleados públicos cada 1000 habitantes durante el período de estudio, es una proporción baja en comparación con otras Provincias. ${ }^{143}$

Sin embargo es preocupante la cantidad de empleados no regularizados. La cantidad de empleados en "planta transitoria" durante el período, que alcanza casi un $30 \%$, es reflejo de las sucesivas crisis económicas y leyes que suspendieron la incorporación de nuevo personal en la planta estable, personal que, entre otros aspectos, no tiene estabilidad ni derecho a la agremiación. Aunque no hay datos precisos por la dispersión de la información, esa cifra se eleva si incluimos al personal que presta actividades en el ámbito público bajo la modalidad de contrato de servicio, locación de obra y prácticas rentadas, los cuales tienen un menor grado -o casi nulo- de derechos laborales, dependiendo del tipo de contrato.

Sin adentrarnos en el análisis de las consecuencias más profundas, lo cierto es que este personal sin estabilidad, que debe renovarse año a año, tiene naturalmente otro tipo de compromiso con la Administración Pública. En términos generales, la necesidad de renovar el contrato y justificar su permanencia, hace que trabajen en forma más intensiva que la planta estable pero el compromiso con el Estado es mucho menor, con el cual no se sienten identificados sino con el funcionario que los incorporó.

Es importante destacar el nivel de estudio alcanzado por ese personal permanente y transitorio. Si bien aún no hay estadísticas específicas, la ex Subsecretaría de Gestión Pública hace suyos los porcentajes de Nación. En este sentido, informa que

\footnotetext{
143 Por ejemplo, La Rioja tiene una proporción de 85/1000 empleados por habitantes y Santa Cruz 86/1000. Estos datos no se encuentran actualizados; en verdad, en el período actual, se ha señalado un crecimiento del empleo público. Sin embargo, si consideramos la Ley de Presupuesto 2012, Ley $\mathrm{N}^{\circ}$ 14.331, con un total de 352.805 cargos en la Planta Permanente y 86.836 en la Planta Temporaria, sumados a los creados (4.072), nos da un solo un crecimiento de un punto $(28,19$ empleados públicos cada mil habitantes).
} 
el personal profesional con estudios superiores -universitarios y terciarios-, no llega a un tercio del total.

Cuadro 4 - Nivel de estudios alcanzado en porcentaje

\begin{tabular}{|l|l|}
\hline Nivel primario & $40 \%$ \\
\hline Nivel secundario & $32 \%$ \\
\hline Nivel terciario & $7 \%$ \\
\hline Nivel universitario & $20 \%$ \\
\hline Sin instrucción & $1 \%$ \\
\hline
\end{tabular}

Fuente: Ministerio de Economía Nación.

Esa baja cifra se torna más preocupante si advertimos que gran parte de los profesionales no tiene estabilidad y que son constantemente "expulsados" al ámbito privado por los bajos salarios, la falta de incentivos y la ausencia de una carrera administrativa.

De acuerdo a un muestreo preliminar que informó la entonces Subsecretaría de Gestión Pública, de los datos preliminares sobre escolarización sobre 177.177 agentes, el $41 \%$ de ellos no completaron el secundario. Dentro de ese grupo, 5.949 tenían primario incompleto. Por su parte, cerca de un tercio de los empleados tiene el secundario completo y el $26 \%$ acredita poseer estudios superiores. ${ }^{144}$

De todas formas, el porcentaje de empleados con estudios terciarios y universitarios es alto si tenemos en cuenta los datos más arriba expresados, esto es, que en la Provincia, sólo el 4\% de la población tiene estudios terciarios completos y el 4\% estudios universitarios completos ${ }^{145}$.

Hemos visto que los distintos Ministerios y Secretarías del Poder Ejecutivo bonaerense presentan muy diversos grados de apertura institucional y composición de empleo. Dentro del gabinete del Poder Ejecutivo Provincial, también suelen observarse problemas de articulación entre distintas áreas que llevan a una descoordinación intersectorial que tiene evidente impacto en el diseño y la implementación de las políticas públicas.

En parte, esta situación puede explicarse por un esquema de distribución de responsabilidades de gestión, a nivel del Ejecutivo provincial, en función de líneas partidarias del oficialismo que luego trasladan sus conflictos a la dinámica de diseño e implementación de políticas públicas en el gobierno. En otros casos, se puede adjudicar al desconocimiento de lo que se está haciendo en cada área, a la falta de mecanismos institucionalizados de articulación y a la existencia de

\footnotetext{
144 Lo curioso es que la Ley $\mathrm{N}^{\circ} 10.430$ que rige el ingreso del personal administrativo establece que se deberá acreditar estudio secundario para aspirar a formar parte del plantel de personal en la Provincia, con algunas excepciones. De los 390.000 empleados provinciales, 207.546 son docentes, los que, al tener estudios completos, no fueron considerados en la muestra. Para ampliar la información, ver Diario EL DIA, "Estatales: el 41\% no terminó el secundario", 12 de noviembre de 2005.

${ }^{145}$ Veremos este dato con más profundidad en el punto siguiente de este Capítulo.
} 
visiones diferentes en función de las distintas atribuciones que tienen los distintos organismos (Camou, 2005:37).

Pero por otro lado, como el mismo estudio que citáramos más arriba ha podido demostrar, los organismos bonaerenses que atienden problemas de tipo social, como Salud, Acción Social y Trabajo, son estructuralmente más permeables a diferentes dinámicas de poder, mientras que otras áreas presentan una plasticidad estructural menos flexible a las características del poder político, como por ejemplo el área de Economía, cuyo accionar atraviesa e influye en todas las demás. En ese sentido, se demostró que mientas el Ministerio de Economía permanece relativamente inmutable en su estructura durante más de diez años, el área de acción social tuvo muchas configuraciones estructurales distintas. Más aún, del gasto agregado de la Administración Pública Provincial, el Ministerio de Economía incrementó su gasto menos de la mitad de aquél, mientras Acción Social lo hizo en casi el doble.

Gráfico 1 - Evolución de los gastos Min. Economía y Acc. Social

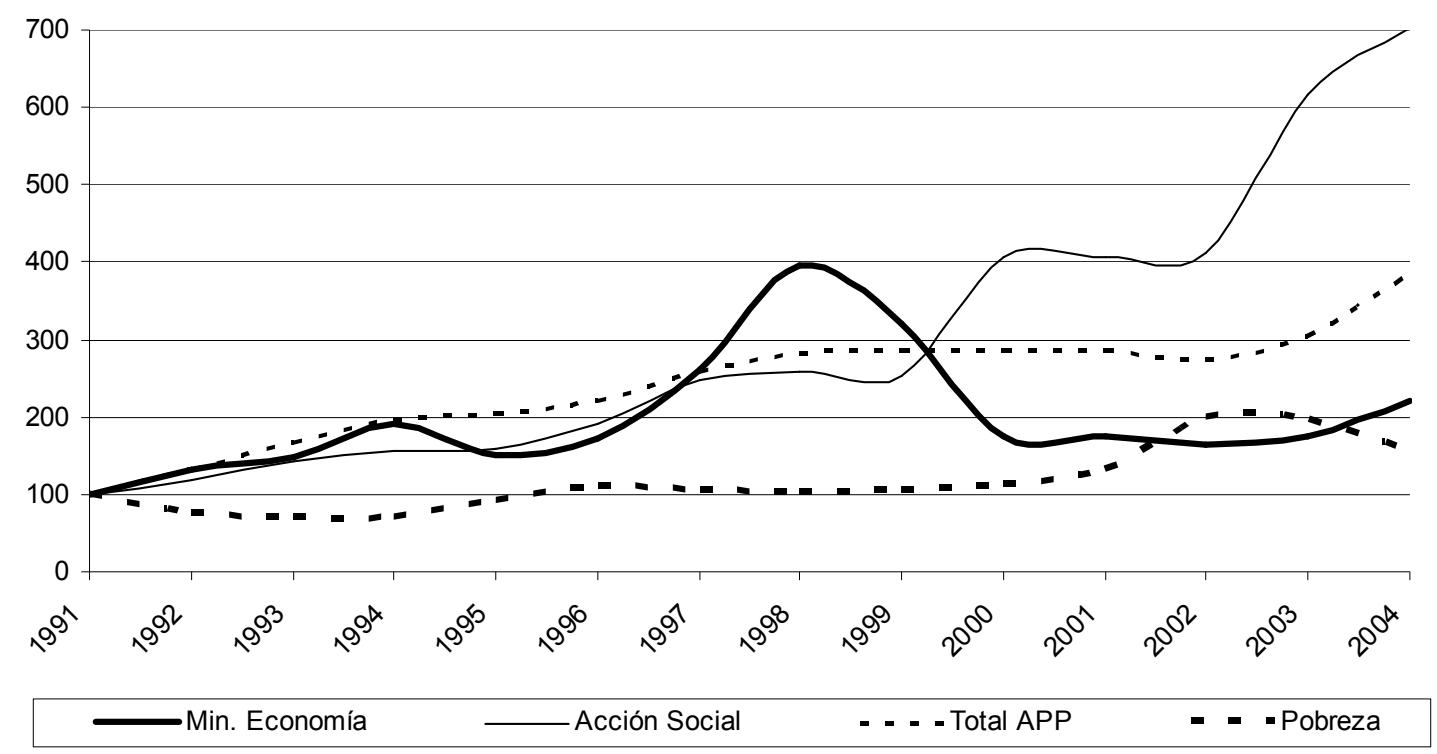

Fuente: Camou (2005).

Nota: Ejecución presupuestaria y pobreza, base $1991=100$.

Del gráfico puede observarse que entre 1991 y 1994 no existe relación entre la evolución de la pobreza y los gastos del Estado provincial destinados a atenderla. Pero a partir de 1995 el gasto social sigue, con retardo de un año, la evolución de la situación social, tomando la forma de una sobrerreacción cuando la pobreza se incrementa. Desde el año 2000, resulta notoria la incapacidad del Estado provincial de atender las necesidades emergentes del drástico empeoramiento de la situación social y desde 2003 la pobreza disminuye mientras el gasto en acción social aumenta (Camou, 2005). Sin embargo, es importante también destacar cómo el gasto del Ministerio de Economía permaneció inmutable pese a las crisis económicas. 


\section{Factores geográficos y sociales}

La Provincia de Buenos Aires es el Estado de mayor importancia de la República Argentina en cuanto a su población, producción y superficie, siendo un caso representativo de las propias diferencias que existen en todo el país. Es la segunda Provincia en extensión territorial: tiene una superficie de $307.571 \mathrm{Km}^{2}$, lo cual representa un $8,26 \%$ respecto del total del país. Pero representando geográficamente menos del 10\% del territorio nacional, su población, totaliza 15.594.428 de habitantes según datos del censo 2010 , esto es, casi un $40 \%$ del total nacional ${ }^{146}$.

Decíamos que la Provincia es representativa de las diferencias que existen en todo el país, pues en ella también puede verse reproducida la desigual distribución de la población. En el conurbano, que ocupa una superficie de $3.630 \mathrm{Km}^{2}$, esto es, un porcentaje de $1,2 \%$ respecto de su superficie total, habita el $63,55 \%$ de su población (9.910.282 hab.). Por ello, al igual que la Argentina, de la Provincia de Buenos Aires puede decirse que es un Estado macrocefálico.

Atento al período temporal bajo estudio (2002-2007), utilizaremos los (pocos) datos existentes correspondientes a esos años sin perjuicio de lo cual, y cuando resulte necesario para una mejor contextualización, utilizaremos datos jurídicos, sociales y económicos correspondientes a la gestión provincial subsiguiente.

Sostiene el Informe sobre Desarrollo Humano de la Provincia de Buenos Aires de 2003, que de los 14 municipios con mayor ritmo de crecimiento en el período intercensal 1999-2001, 9 pertenecen al tercer cordón. ${ }^{147}$

\section{Cuadro 5 - Distribución de la población de la Provincia de Buenos Aires entre 1991 y 2001}

\begin{tabular}{|l|l|l|l|c|}
\hline Lugar & \multicolumn{1}{l}{$\begin{array}{l}\text { Población } \\
\text { 1991 }\end{array}$} & $\begin{array}{l}\text { Población } \\
\mathbf{2 0 0 1}\end{array}$ & $\begin{array}{l}\text { Variación } \\
\text { absoluta }\end{array}$ & Variación porcentual \\
\hline $\begin{array}{l}\text { Total Tercer } \\
\text { cordón }\end{array}$ & 1.402 .669 & 1.700 .796 & 298.127 & $21,3 \%$ \\
\hline $\begin{array}{l}\text { Interior } \\
\text { Provincial }\end{array}$ & 3.239 .681 & 3.441 .970 & 202.289 & $6,2 \%$ \\
\hline $\begin{array}{l}\text { Conurbano } \\
\text { (24 partidos) }\end{array}$ & 7.952 .624 & 8.684 .437 & 731.813 & $9,2 \%$ \\
\hline Total & $\mathbf{1 2 . 5 9 4 . 9 7 4}$ & $\mathbf{1 3 . 8 2 7 . 2 0 3}$ & $\mathbf{1 . 2 3 2 . 2 2 9}$ & $\mathbf{9 , 8 \%}$ \\
\hline
\end{tabular}

Fuente: Informe sobre Desarrollo Humano de la Provincia de Buenos Aires, 2003.

\footnotetext{
${ }^{146}$ Ello representa un pequeño aumento en el porcentaje atento a que en 2001 representaba el 38,13\% de la población total de Argentina para pasar a 38,90\% en 2011.

${ }_{147}$ Los partidos que tuvieron un mayor ritmo de crecimiento en el período intercensal 1999-2001 en el Conurbano fueron los más alejados de la Capital Federal: Ezeiza (58\%), Florencio Varela (37\%) y Moreno (32\%). El ritmo de crecimiento de los tres cordones del Conurbano "se asocia muy fuertemente a los períodos en que se produjeron las migraciones: como demuestra un estudio del INDEC publicado en 1999, los partidos más cercanos a la Capital Federal muestran bajo crecimiento y alto porcentaje de población no nativa de la Provincia y de más de 65 años de edad (Avellaneda. General San Martín, Lanús, Morón, San Isidro, Tres de Febrero y Vicente López): son quienes han migrado hace varias décadas" (Informe sobre Desarrollo Humano en la Provincia de Buenos Aires, 2003:43).
} 
Sin embargo, esta tendencia parece haber disminuido durante el período bajo análisis (2002-2007). En estos años sólo crecieron el doble de la media provincial (4,20\%), seis municipios del Conurbano, ninguno del Primer Cordón, sino del Segundo Cordón (Ezeiza, Florencio Varela, y José C. Paz) y Tercer Cordón (Escobar, Pte. Perón y San Vicente), registrándose importantes aumentos en los Municipios del Interior (Gral. Madariaga, 83\%; Coronel Rosales, 61,85\%, Gral. Las Heras, 19,28\%, Pinamar, $13,88 \%$, etc.).

Cuadro 6 - Crecimiento poblacional Buenos Aires - selección municipios del interior al $1^{\circ}$ de julio de cada año

\begin{tabular}{|c|c|c|c|c|c|c|}
\hline Municipio /Año & 2002 & 2003 & 2004 & 2005 & 2006 & 2007 \\
\hline CAÑUELAS & 43.639 & 44.445 & 45.252 & 46.079 & 46.948 & 47.845 \\
\hline $\begin{array}{l}\text { CORONEL } \\
\text { PRINGLES }\end{array}$ & 16.626 & 24.159 & 24.243 & 24.328 & 24.417 & 24.511 \\
\hline $\begin{array}{l}\text { CORONEL } \\
\text { ROSALES }\end{array}$ & 24.076 & 62.321 & 62.510 & 62.703 & 62.904 & 63.112 \\
\hline ESCOBAR & 183.207 & 187.094 & 190.981 & 194.966 & 199.154 & 203.480 \\
\hline $\begin{array}{l}\text { EXALTACION DE } \\
\text { LA CRUZ }\end{array}$ & 24.758 & 25.303 & 25.849 & 26.409 & 26.996 & 27.603 \\
\hline EZEIZA & 122.415 & 125.755 & 129.099 & 132.524 & 136.124 & 139.844 \\
\hline $\begin{array}{l}\text { FLORENCIO } \\
\text { VARELA }\end{array}$ & 359.693 & 367.116 & 374.546 & 382.161 & 390.163 & 398.433 \\
\hline $\begin{array}{l}\text { GENERAL LAS } \\
\text { HERAS }\end{array}$ & 11.112 & 13.160 & 13.303 & 13.451 & 13.606 & 13.767 \\
\hline $\begin{array}{l}\text { GENERAL } \\
\text { MADARIAGA }\end{array}$ & 3.097 & 18.649 & 18.763 & 18.881 & 19.004 & 19.132 \\
\hline $\begin{array}{l}\text { GENERAL } \\
\text { RODRIGUEZ }\end{array}$ & 69.912 & 71.440 & 72.968 & 74.534 & 76.180 & 77.881 \\
\hline JOSE C. PAZ & 236.450 & 239.981 & 243.514 & 247.136 & 250.941 & 254.872 \\
\hline LA COSTA & 62.237 & 63.916 & 65.596 & 67.317 & 69.124 & 70.992 \\
\hline MARCOS PAZ & 44.904 & 45.904 & 46.925 & 47.969 & 49.026 & 50.106 \\
\hline MONTE HERMOSO & 5.067 & 5.171 & 5.275 & 5.381 & 5.493 & 5.608 \\
\hline MORENO & 394.969 & 402.517 & 410.068 & 417.835 & 426.065 & 434.572 \\
\hline PILAR & 239.084 & 245.781 & 252.483 & 259.350 & 266.566 & 274.022 \\
\hline PINAMAR & 18.266 & 18.831 & 19.396 & 19.975 & 20.584 & 21.212 \\
\hline $\begin{array}{l}\text { PRESIDENTE } \\
\text { PERON }\end{array}$ & 61.714 & 63.162 & 64.611 & 66.096 & 67.656 & 69.268 \\
\hline SAN VICENTE & 45.468 & 46.253 & 47.039 & 47.843 & 48.690 & 49.563 \\
\hline VILLA GESELL & 25.859 & 26.557 & 27.257 & 27.973 & 28.725 & 29.504 \\
\hline
\end{tabular}

$\begin{array}{lllllll}\text { Total Provincia } & \quad 14.290 .241 & 14.410 .581 & 14.530 .996 & 14.654 .379 & 14.784 .007 & 14.917 .940\end{array}$

Fuente: Elaboración propia sobre la base del Anuario Demográfico de la Provincia de Buenos Aires 2007. http://www.ec.gba.gov.ar/Estadistica/Anuario2006/1demografia/Poblacion\%201.1.1.xls.

Fecha de Consulta: 03/04/12. 
Estos datos se confirman cuando comparamos el crecimiento intercensal 20012010 del Interior (crecimiento del 9,53\%) respecto de los 24 municipios del Conurbano $(12,37 \%)$ lo cual demuestra una recuperación del crecimiento de Interior frente al Conurbano.

\section{Imagen - 1- Distribución Población Provincia Buenos Aires}

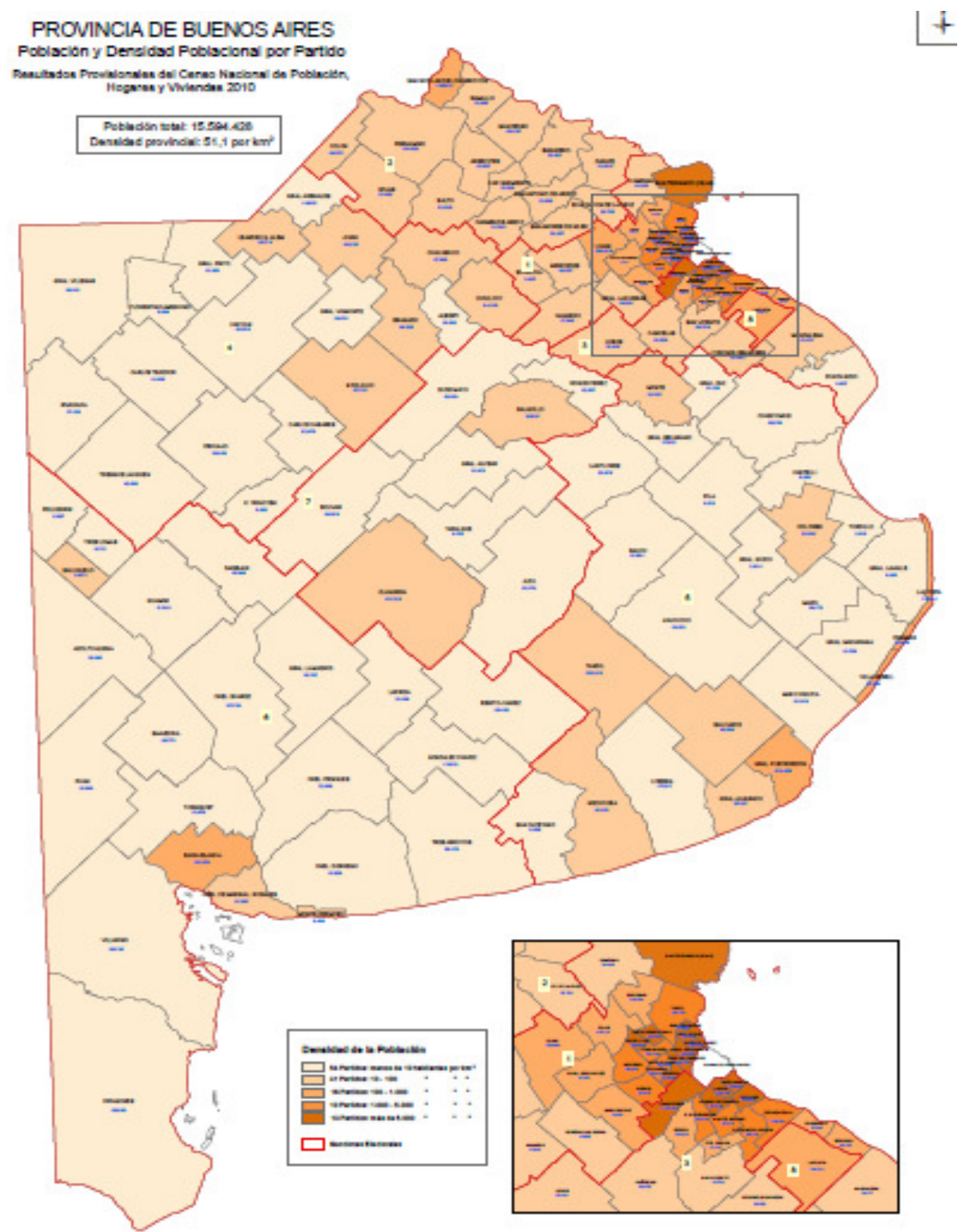

Fuente: Dirección Provincial de Estadística.

http://www.ec.gba.gov.ar/Estadistica/Provincia2010 naranja.pdf

Fecha de Consulta: 03/04/12

El $62 \%$ de la población tiene entre 15 y 64 años de edad. Un $27 \%$ constituye el grupo etario de 0 a 14 años, mientras que el sector pasivo, de más de 65 años representa, consecuentemente, el 11\% del total. Según el INDEC, en 2003, el $40 \%$ de los hogares se ubica en la franja 25 a 44 años y el $43 \%$ en la franja de 45 a 64 años. 
Entre los muchos estudios acerca de los factores que más preocupaban a los bonaerenses durante el período de estudio, la inseguridad, la desocupación y los problemas económicos se encontraban en todos los casos como los problemas más acuciantes. ${ }^{148}$

Pero resulta interesante adentrarnos también en otros aspectos que revelen los problemas comunes que condicionan la calidad de vida de las personas. En este marco, las encuestas que centran sus cuestionarios en la noción de "vida cotidiana", resultan especialmente importantes para conocer en qué aspectos está fallando la Administración Pública y dónde podría intervenir directamente. En este sentido, resulta relevante rescatar los datos alcanzados en la encuesta realizada por la Universidad Nacional del Sur, en la ciudad de Bahía Blanca, en 2001 distribuida en todas las edades y en todos los niveles socioeconómicos. ${ }^{149}$

En dicho estudio, entre los problemas que los encuestados perciben que más afectan su vida cotidiana, no sólo se vieron reflejados los problemas de la desocupación -el más alto con $62 \%$ - y de la inseguridad pública, la delincuencia y/o violencia con el $40 \%$, sino también el problema de la corrupción en el gobierno, con el $40 \%$ de las respuestas, con lo que la transparencia aparece como una de las soluciones estratégicas claves para el mejoramiento de la calidad de vida. Otra falla importante del aparato gubernamental aparece en el mal funcionamiento de la justicia, los altos impuestos y la poca calidad del servicio educativo. ${ }^{150}$

Cuadro 7 - Problemas de la vida cotidiana que más afecta la situación
personal del entrevistado
\begin{tabular}{|l|c|}
\hline Desocupación & $62 \%$ \\
\hline Inseguridad pública, la delincuencia y/o violencia & $40 \%$, \\
\hline Corrupción en el gobierno & $40 \%$ \\
\hline Estancamiento, recesión & $20 \%$ \\
\hline Salarios insuficientes o bajos & $23 \%$ \\
\hline Mal funcionamiento de la justicia & $16 \%$ \\
\hline Altos impuestos & $16 \%$ \\
\hline Contaminación ambiental & $15 \%$ \\
\hline Caída del poder adquisitivo, pobreza & $13 \%$ \\
\hline
\end{tabular}

\footnotetext{
${ }^{148}$ Dichas preocupaciones no han cedido; la desocupación, producto de la recuperación económica ha disminuido, pero no baja, según informes del CEOP, del 10\%.

149 Siguiendo a Agnes Heller (1987), se definió a la vida cotidiana como el conjunto de actividades que caracterizan la reproducción de los hombres particulares, los cuales crean la posibilidad de la reproducción social, delimitando como áreas de la vida cotidiana las siguientes dimensiones: a) económico-laboral, b) familiar-reproductiva, c) educativa, d) política y e) status o clase social. Los resultados de dicha investigación se hallan expuestos en el Informe sobre Desarrollo Humano de la Provincia de Buenos Aires de 2002.

150 Las respuestas fueron espontáneas y no más de tres. La carencia o poca calidad en las prestaciones del sistema de salud, trasgresión a los derechos humanos, evasión impositiva, tráfico y consumo de drogas, individualismo o falta de solidaridad y poca representatividad de los partidos políticos fueron otros problemas que aparecieron con una frecuencia menor al $10 \%$. Con preguntas guiadas, pudo corroborarse que se consideraba a la educación como el factor que más influye en la posibilidad de ascenso social. Así, las respuestas privilegian a la educación con el $93 \%$ como la mejor herencia que se le puede dejar a los hijos y el $89 \%$ afirmó que el acceso a la educación aumenta las posibilidades de acceder a mejores puestos de trabajo. Cuando se introdujo el tema de la política y su influencia en la vida cotidiana, comenzando por identificar si el entrevistado considera que la misma influye o no en aquélla, el $81 \%$ de los encuestados afirma que la política afecta su vida cotidiana.
} 


\begin{tabular}{|l|c|}
\hline Situación de los jubilados & $11 \%$ \\
\hline Carencia o poca calidad del servicio educativo & $10 \%$ \\
\hline
\end{tabular}

Fuente: Universidad Nacional del Sur, 2001 sobre Ciudad de Bahía Blanca, tomado del Informe sobre Desarrollo Humano de la Provincia de Buenos Aires, 2002.

Dichos indicadores no se modificaron luego de la crisis económica de 2002. Así, según el Informe Latinobarómetro, en 2005, la cantidad percibida de funcionarios públicos corruptos en Argentina era de 74\%, uno de los más altos en América Latina. En 2007, a la pregunta "¿Ha sabido Ud, o algún pariente de algún acto de corrupción en los últimos doce meses?" el 23\% declara que sí mientras que los dos años anteriores el porcentaje se mantenía estable en $14 \%{ }^{151}$.

A fines de 2005, según el Centro de Estudios de Opinión Pública, sobre una muestra de 1.000 personas a nivel nacional, de un puntaje de 1 a 10 , posibilidad de una caída en los niveles generales de corrupción sólo alcanzó 5,2 puntos. ${ }^{152}$

Según el Informe del Barómetro Global de la Corrupción de Transparency International (2005) la corrupción afecta fuertemente a los partidos políticos. Más del $51 \%$ de los entrevistados cree que la corrupción afecta la vida política y confirma que la mayoría cree que la corrupción se mantuvo (39\%) y que se mantendrá en iguales niveles los próximos tres años $(43 \%) .{ }^{153} \mathrm{La}$ "percepción" en materia de corrupción es una pesada carga para la democracia argentina. Según el mismo informe, año 2007, el porcentaje de encuestados que declaran haber pagado un soborno para obtener un servicio se encontraba en el cuarto cuantil (5\%), pero los partidos políticos son considerados corruptos por más de cuatro de cada cinco entrevistados en Argentina ${ }^{154}$.

Son importantes y reveladores también los datos consignados en el Informe sobre el Desarrollo Humano en la Provincia de Buenos Aires 2004-2005 ya que se centró en los jóvenes de la Provincia. Según el citado Informe, de acuerdo a la encuesta

${ }^{151}$ Y si bien desde año 2003 hasta la crisis del 2007, ha crecido como nunca antes en democracia, la inseguridad se ha consolidado como tema central de las elecciones celebradas en 2011 . No es que no se crezca sino que las desigualdades están en la velocidad en que los distintos sectores sociales crecen. En 2011, disminuye en casi todo los países la percepción de que se gobierna para todo el pueblo; pero aún dentro de un mismo bloque, como el MEROCUR, con gobiernos políticamente alineados y sin grandes cambios en la conducción de los partidos, aunque sí en sus líderes, la diferencia es notable: mientras que en Argentina y Uruguay aumenta esa percepción en 12 puntos porcentuales, en Brasil cae 16\% y en Paraguay 4\%. Y sin embargo, la percepción personal de "satisfacción con la vida" tiene un promedio en la Región del 72\% y en los países del MERCOSUR no baja del 75\% llegando en Brasil, al 82\%. En Brasil, sólo el $45 \%$ cree que la democracia es preferible a cualquier otra forma de gobierno en cualquier circunstancia; en Uruguay, el 75\% lo considera como la única opción. Los problemas-reto de la democracia en la región siguen asociados a la corrupción pero dentro del MERCOSUR son variadas las preocupaciones: si bien en todos la corrupción es el más importante, el segundo más importante es la transparencia del Estado en Argentina y Paraguay, garantizar la justicia social en Brasil y Uruguay (Informe Latinobarómetro, 2011).

152 Diario CLARÍN, "Más tiempo libre, la meta de los argentinos para 2006”, 31 de diciembre de 2005. Un informe de la consultora D'Alessio IROL señalaba en diciembre de 2003 que la corrupción es la principal asignatura pendiente de la democracia (72\%); un año más tarde, la misma consultora indicaba que la mitad de los consultados cree que el nivel de corrupción de la clase política es igual al de cinco años atrás. Las encuestas fueron realizadas a través del portal Clarín.com e involucraron 14.960 y 22.752 respuestas respectivamente.

${ }^{153}$ La base de la encuesta fue hecha en la república Argentina sobre 1.000 casos.

${ }^{154}$ Fuente: http://www.transparency.org/content/download/27458/413669/file/GCB 2007 report_esp 0212-2007.pdf. Fecha de Consulta: 08/07/11. 
realizada entre jóvenes bonaerenses, el 23\% de los encuestados afirmó tener elevado nivel de participación en al menos una de las cuatro categorías presentadas -parroquias o asociaciones religiosas, clubes, centros culturales o vecinales, micro emprendimientos, partidos políticos o gremios-. Extrapolando este dato al conjunto de la población de entre 18 y 29 años, eso significa que hay aproximadamente 650.000 jóvenes participantes sociales activos en toda la Provincia de Buenos Aires. Pero ...

\begin{abstract}
Solamente una décima parte de los 650.000 jóvenes mencionados participa activamente en la política partidaria: apenas 70.000, un número de todas maneras inquietante. Recién una vez explicado que ésta es la única forma legítima de cambio social relevante (para bien o para mal), algunos reconocieron que la participación política puede ser una condición necesaria para influir sobre los cambios sociales. Igual, menos del 3\% de los jóvenes manifiesta tener vocación política (Informe sobre el Desarrollo Humano en la Provincia de Buenos Aires 2004-2005:53).
\end{abstract}

Según los resultados de la encuesta del mismo Informe, un $48 \%$ de los jóvenes bonaerenses no posee un proyecto laboral de largo plazo.

Es interesante también destacar la cantidad de organizaciones que tienen sede en la Provincia de Buenos Aires y la naturaleza de su actividad. La mayoría de las organizaciones, para obtener forma y reconocimiento jurídico legal, deben cumplimentar su inscripción obligatoria en la Dirección de Personas Jurídicas del entonces Ministerio de Justicia de la Provincia de Buenos Aires. Según esa Dirección, existía un registro aproximado de 23.000 organizaciones, aunque ese registro no se encuentra totalmente actualizado.

Para comparar el nivel de asociatividad, a nivel nacional, el banco de datos más importante lo constituye el Centro Nacional de Organizaciones de la Comunidad (CENOC), dependiente del entonces Ministerio nacional de Desarrollo Social y Medio Ambiente. El CENOC registra entidades de todo el país en forma voluntaria y sin exigencias de la forma jurídico-legal que cada una de ellas posea, aunque sí sistematiza la información distinguiendo, entre otras, cantidad de organizaciones, desagregadas por provincia y municipio, tipo de organización, modo de intervención, población objetivo, área temática y tema específico.

Respecto a la cantidad de organizaciones inscriptas y a su distribución geográfica, al primer semestre del 2001, se observa un total en todo el país de 7.202. En la Provincia, la cantidad de ONG's suman un total de 1.788 , de las cuales 588 son del interior, mientras que 1.200 lo son del Gran Buenos Aires.

En el interior de la Provincia de Buenos Aires, el 49\% de las organizaciones son asociaciones civiles. En segundo lugar, aparecen los grupos comunitarios (11\%). En un porcentaje que no alcanza el $10 \%$ se destacan las sociedades de fomento y las fundaciones. En el Gran Buenos Aires, un 31\% corresponde a asociaciones civiles, mientras que los grupos comunitarios representan el 15\%. Las sociedades de fomento y los centros de jubilados alcanzan el $9 \%$.

En relación a las áreas temáticas abordadas por las organizaciones del interior de la Provincia, más de la mitad (57\%) aborda el área social/humana, siguen las de educación (28\%) y salud (23\%). Las que se dedican a temas relacionados con trabajo, 
cultura, deportes y recreación rondan el 14\% respectivamente. Más de la mitad de las organizaciones del Gran Buenos Aires (58\%) trabaja en el área social/humana. De ellas, el $25 \%$ aborda temáticas vinculadas a la educación, alrededor del $19 \%$ se dedica a la cultura y a salud y el 10\% se ocupa del área trabajo.

El modo de intervención se refiere a las modalidades en que las organizaciones actúan sobre una realidad concreta. La mitad de las organizaciones del interior de la Provincia actúa en actividades vinculadas a la atención primaria. Alrededor del $32 \%$ lo hace en capacitación y rondan el $20 \%$ las dedicadas a la difusión, asesoramiento y desarrollo local, respectivamente. No llegan a alcanzar el $10 \%$ aquellas cuya modalidad de intervención se refiere a la asistencia técnica (9\%) y financiera (7\%). El 39\% de las organizaciones del Gran Buenos Aires, interviene en temas de atención primaria; el $28 \%$ lo hace en capacitación. Alrededor del 20\% aborda la difusión (23\%) y la promoción humana $(21 \%){ }^{155}$

En materia de educación, si bien menos del 2\% del total de la población es analfabeta y pese a la importancia que los ciudadanos le asignan a la educación como factor de promoción social y ascenso social, los datos del Indec de 2003 muestran un bajo índice de estudios terciaros y universitarios ${ }^{156}$.

Cuadro 8 - Alfabetismo Provincia de Buenos Aires

\begin{tabular}{|l|c|}
\cline { 2 - 2 } \multicolumn{1}{c|}{} & Porcentaje \\
\hline Analfabetizados & $98,4 \%$ \\
\hline
\end{tabular}

Fuente: Elaboración propia sobre la base de los datos de Indec, 2003.

Nota: Total Provincial de 10 años o más, 11.400.404 habitantes.

Cuadro 9 - Nivel de instrucción alcanzado en Provincia de Buenos Aires distribuido según el lugar

\begin{tabular}{|l|c|c|c|}
$\begin{array}{c}\text { NIVEL DE INSTRUCCIÓN } \\
\text { ALCANZADO }\end{array}$ & CONURBANO & $\begin{array}{c}\text { RESTO DE } \\
\text { LA } \\
\text { PROVINCIA }\end{array}$ & $\begin{array}{c}\text { TOTAL } \\
\text { PROVINCIAL }\end{array}$ \\
\hline Sin instrucción & & $3 \%$ & $3 \%$ \\
\hline Primario incompleto & $3 \%$ & $13 \%$ & $12 \%$ \\
\hline Primario completo & $12 \%$ & $32 \%$ & $31 \%$ \\
\hline Secundario incompleto & $31 \%$ & $20 \%$ & $22 \%$ \\
\hline Secundario completo & $23 \%$ & $15 \%$ & $16 \%$ \\
\hline Superior no universitario incompleto & $17 \%$ & $2 \%$ & $2 \%$ \\
\hline Superior no universitario completo & $2 \%$ & $5 \%$ & $4 \%$ \\
\hline Superior universitario incompleto & $4 \%$ & $5 \%$ & $5 \%$ \\
\hline Superior universitario completo & $5 \%$ & $4 \%$ & $4 \%$ \\
\hline Total & $3 \%$ & $100 \%$ & $100 \%$ \\
\hline
\end{tabular}

Fuente: Indec, 2003.

\section{Factores políticos y económicos}

\footnotetext{
${ }^{155}$ Cabe aclarar que muchas organizaciones intervienen con más de una modalidad.

${ }^{156}$ Lamentablemente, estos datos aún no se encuentran actualizados por el Censo 2010.
} 
Ha señalado Ollier (2011) una peculiar imbricación, con referencia al caso de la Provincia de Buenos Aires, de las instancias nacional y provincial, tanto por el rol preponderante de esta Provincia en la política nacional como del impacto decisivo de la política nacional en su territorio pero también por un natural proceso de cooperación entre ambas jurisdicciones. En efecto, su carácter des/estabilizador sobre la nación se evidencia no sólo en los resultados electorales provinciales, sino más bien, últimamente, por la búsqueda del gobierno nacional en "decidir" los candidatos a los cargos provinciales. Se advierte en las últimas décadas la "nacionalización" de los discursos, políticas y acciones de la Provincia. Por último, aunque menos evidente, ambas Jurisdicciones entablan distintos procesos colaborativos que reconocen esta tensión relacional.

La hegemonía ininterrumpida del Partido Justicialista en la Provincia de Buenos Aires desde el año 1987 hasta la actualidad, expresa un electorado significativamente fiel, en buena medida cautivo. En esta estructura territorial, los actores políticos de peso son pocos (Camou, 2005). En verdad, si se analiza todo el período desde el retorno a la democracia (1983-2010), éste describe la declinación del Partido radical y la creciente hegemonía del peronismo, por un lado, y por otro, la irrupción local de una tendencia global: el debilitamiento del rol del partido tradicional y el crecimiento personalista de las figuras extrapartidarias.

Luego de la gobernación radical de Alejandro Armendáriz, el Partido Justicialista ocupó el Poder Ejecutivo cuando, en 1987, Antonio Cafiero ganó las elecciones con el $46 \%$ de los votos superando a la Unión Cívica Radical en siete puntos porcentuales. En 1991, Eduardo Duhalde asumió la gobernación con el 47,7\% de los votos y fue reelecto, luego de la reforma de la Constitución Provincial en 1994 en 1995 con el 56,7\% de los sufragios. En 1999, pese a haber perdido las elecciones de diputados de 1997, volvió a ganar el Partido Justicialista la gobernación con el 48,3\% de los votos con Carlos Ruckauf contra el 41,4\% para la Alianza (UCR y FREPASO $)^{157}$. Finalmente en 2003 ganó las elecciones el Partido Justicialista nuevamente encabezado por Felipe Solá $(43,30 \%)$ con un amplio margen respecto de los otros partidos que se presentaron a las elecciones ${ }^{158}$.

Como es sabido, el exgobernador Solá ingresó en el cargo como consecuencia de la renuncia, en plena crisis, del gobernador Ruckauf que, a pedido del presidente Duhalde, asume en la Cancillería argentina. Pero no es tan conocido por qué es que el ex secretario de Agricultura, Ganadería, Pesca y Alimentación, durante casi todo el gobierno de Menem, asume la vicegobernación en la fórmula Ruckauf- Solá que compite con Meijide-Posse.

En verdad, cuando en 1999 Duhalde finaliza su mandato, varios intendentes del Conurbano se proponían designar a otro candidato en lugar del candidato del

\footnotetext{
${ }^{157}$ Debe destacarse que, la adhesión de Ruckauf a la postulación de Cavallo a la presidencia, le "sumó" al primero de casi $8,8 \%$.

${ }^{158} \mathrm{Si}$ bien fuera del período bajo estudio, debe consignarse que el 28 de octubre de 2007, en las elecciones a Gobernador y Vicegobernador, la lista del "Frente para la Victoria", encabezada por la fórmula Daniel Scioli-Alberto Balestrini, se impuso con el apoyo del $48,24 \%$ de los votantes. En la elección provincial 2011, el Frente para la Victoria con la fórmula Scioli-Mariotto, llegó al 55,18\% de los votos, con una diferencia de casi 30 puntos porcentuales respecto de la segunda fórmula. Ver http://www.juntaelectoral.gba.gov.ar/mapa resultado/resumenes/2011 totprovincia.pdf. Fecha de Consulta: 03/04/12.
} 
gobernador: Carlos Ruckauf. La corriente Nuevo Espacio Bonarense, liderada desde 1998 por Felipe Solá, contaba con ...

... la simpatía de los intendentes de Avellaneda (Álvarez de Olivera), Quilmes (Scarabino), San Martín (Pandolfi) y San Fernando (Amiero). Sumados los intendentes de Hurlingam (J.J. Álvarez), Moreno (West), José C. Paz (Glaría) y La Matanza (Cossi), constituyen el Grupo Bauen, con la tarea de enfrentar la postulación de Ruckauf. ... En una hábil maniobra, Duhalde desarma a sus rivales, proponiendo a Solá como compañero de fórmula de Ruckauf (Ollier, 2011: 183-184).

En esas elecciones de 1999 aunque en el interior de la Provincia el poder del PJ disminuye en base al poder local de los intendentes de la UCR, más allá de los nombres y líneas internas, el PJ no cuenta con una fuerza política opositora que limite sus políticas, encontrando más bien el partido gobernante sus frenos y contrapesos en el poder de los intendentes del conurbano y de algunos legisladores del propio partido.

Como sostiene Camou (2005:37) en su informe:

... durante la primera etapa de la gestión Ruckauf cuando el PJ no tenía mayoría propia en la Legislatura, la Alianza votó la mayoría de los proyectos de ley del Poder Ejecutivo, aunque en algunos casos luego de largas negociaciones. De igual manera, cuando luego de 1997 el PJ perdió la mayoría y la presidencia en la Cámara de Diputados, no disminuyó el porcentaje de proyectos presentados por el Ejecutivo aprobados por la Legislatura. En este sentido, se reconoce la existencia de una oposición que -en líneas generales- no obstaculizó la gobernabilidad de la provincia.

Según Godio, en el primer período el Gobernador Solá “carecía entonces de poder político propio y dependía de la fuerza del propio presidente Duhalde, quien controlaba al Partido Justicialista en esa provincia" y agrega

Debe advertirse que si bien el soporte de los gobernadores al presidente introducía la anomalía de un sistema de relaciones político-institucionales entre los Poderes Ejecutivo y Legislativo, que son los principales órganos de decisión política del régimen democrático. Debe señalarse que, aunque todavía débilmente, se manifiestan entonces voces discordantes dentro del propio Partido Justicialista ... (Godio, 2003:79-80).

El ex gobernador Solá validó su mandato en 2003 con la fórmula SoláGiannettasio. Duhalde, entonces en ejercicio de la presidencia, se involucró de manera personal y directa en la continuidad de Solá (conf. Rodríguez y Rodríguez Blanco, 2004). 
Si bien el oficialismo en las Cámaras obtuvo un fuerte triunfo ${ }^{159}$ el gobierno de Solá no gozó de los beneficios de contar con mayoría legislativa: la disciplina partidaria se encontró en crisis y existieron conflictos en la relación entre el Poder Ejecutivo y el Poder Legislativo como consecuencia de la lucha por el liderazgo.

Es que si bien la base electoral de la provincia contribuyó decisivamente al triunfo de Néstor Kirchner en 2003, propiciado en ese entonces por Eduardo Duhalde, la atomización territorial del peronismo bonaerense se dio por la inexistencia de un liderazgo indiscutido dentro del PJ.

La exigua diferencia que separó las candidaturas de Chiche Duhalde y Felipe Solá fue leída como la expresión del estado de relaciones de fuerza imperante entre sectores, que aún amparados bajo el mismo paraguas partidario, se iban posicionando en veredas cada vez más diferenciadas. Pero también, la distribución de las preferencias electorales reafirmó, en sintonía con los comicios anteriores, el proceso de debilitamiento de las lealtades partidarias mediante, por un lado, el desarrollo de un procedimiento de trasvasamiento no tutelado de votos y la multidimensionalidad del espacio político, procesos reflejados en las distribución de los votos a los diferentes candidatos entre las elecciones presidenciales y las legislativas; y por el otro, a través del importante corte de boletas constando en distintos municipios de la provincia para los cargos legislativos (Rodríguez, 2006:113).

Legislativo.

El propio ex gobernador Solá, sufrió los embates de la futura fractura en el

\begin{abstract}
A fines de 2004 la división en el bloque de legisladores oficialistas bonaerenses, dejando en minoría a los partidarios del Gobernador F. Solá, aliado del Presidente, y la negativa a incluir en la aprobación del presupuesto provincial la delegación de poderes en el ejecutivo tal como sucedía en el ámbito nacional, dieron la tónica de un conflicto creciente que preanunciaba la ruptura que se produciría para las elecciones legislativas de 2005. Luego de que esa ruptura se produjera, el oficialismo se encontró en minoría en varias oportunidades, al menos durante el segundo semestre de 2005 y hasta que se produjo la renovación parlamentaria (Cheresky, 2006:48).
\end{abstract}

En efecto, previendo las tensiones que se generarían en elecciones legislativas de 2005 (que derivaron en la ruptura Duhalde-Kirchner), Solá lanzó en diciembre de 2004 su línea interna contando con la adhesión de 51 de los 76 intendentes, demostrando con ello la desarticulación del dominio territorial de Duhalde. Esta situación de tensión se agravó luego de la ruptura Duhalde-Kirchner y repercutió en el gobierno bonaerense que no logró una inserción territorial propia.

159 En Diputados obtuvo 28 de los 46 cargos en disputa y en Senadores 19 de los 23. Ver: http://towsa.com/andy/totalpais/buenosaires/index.html. Fecha de Consulta: 19/07/11. 
Estas incoherencias, que se advierten en el gabinete del entonces gobernador Solá, más en la primera etapa y el final ${ }^{160}$, podrían dar cuenta, como veremos más adelante, de las distintas visiones e incoherencias sobre el tipo de Estado, de reforma y de modernización que se propiciaban en el gobierno provincial.

La existencia de estas divisiones internas que se plasman sobre todo en la Cámara de Diputados generaron una relación entre el Poder Ejecutivo y el Poder Legislativo de delicados equilibrios, que se puso de manifiesto en la necesidad de realizar permanentes negociaciones en el ámbito de la labor legislativa y en las modificaciones realizadas a las leyes antes de ser aprobadas.

Desde entonces, y hasta la fecha, la Nación impulsó políticas de relacionamiento (y apoyo económico) directo con los municipios.

La creación de los Aportes del Tesoro de la Nación (ATN) representó la aparición de una herramienta que permite al poder central efectuar asignaciones de fondos a las provincias y municipios en forma discrecional. [...] a partir del recambio presidencial no será el gobierno de la provincia de Buenos Aires el que decida en qué zonas del conurbano se harán más obras cloacales o cuáles serán los pueblos de la provincia beneficiados de una eventual nueva ruta. [...] El mensaje de la presidencia a las intendencias es claro. No se preocupen por lo que recauden o el gobierno de vuestras provincias les otorguen. La chequera del poder central estará disponible en forma directa para las necesidades de los intendentes (sin que ellos deban recurrir a sus gobernadores), siempre y cuando -claro está- se pongan a disposición del Poder Ejecutivo Provincial y de la "Caja Rosada". Este sistema fue el que le permitió al ex presidente [Kirchner] convertirse en el excluyente líder territorial de la provincia. El gobernador Felipe Solá había dado pelea al principio del mandato por retener el poder de decisión y ser el interlocutor obligado de los intendentes. Pero el poder central quebró esa lógica con un método de recaudación que le permitió retener sin coparticipación la mayor parte de los ingresos y decidir él mismo el destino de las obras y las inversiones estatales (Cafferata, 2008:137139).

Respecto a los aspectos económicos, los vaivenes no fueron menores.

La Provincia se constituye en la de más peso relativo en cuanto al tamaño de su economía, siendo, por otro lado, la que posee mayor grado de diversificación productiva. El Producto Bruto Geográfico, durante el período de estudio fue, relativamente estable.

\section{Cuadro 10 - Producto Bruto Geográfico en millones de pesos, a precios constantes de 1993. Provincia de Buenos Aires - Período 2002-2006}

\footnotetext{
${ }^{160}$ Piénsese por ejemplo, en la vicegobernadora Giannettasio o Mariano West, ministro de Desarrollo Humano y Trabajo, respaldados por Duhalde, y el progresivo espacio que van ocupando el movimiento piquetero dentro de su gabinete (Conf. Quiroga, 2006) que llegó a ocupar la Secretaría de Derechos Humanos, con Edgardo Binstock y la vicejefatura de Gabinete, a cargo de Emilio Pérsico.
} 


\begin{tabular}{|l|r|r|r|r|r|}
\hline & $\mathbf{2 0 0 2}(*)$ & $\mathbf{2 0 0 3}(*)$ & $\mathbf{2 0 0 4}(*)$ & $\mathbf{2 0 0 5}(*)$ & $\mathbf{2 0 0 6}(*)$ \\
\hline PBG a precios de mercado (aproximados) & 79.996 & 88.314 & 98.262 & 108.078 & 117.290 \\
\hline PBG a precios de productor & 73.758 & 80.845 & 89.443 & 98.344 & 106.339 \\
\hline
\end{tabular}

Fuente: Dirección Provincial de Estadística. (*) Dato Provisorio.

En el año 1996, el sector primario de la Provincia, constituido fundamentalmente por su actividad agropecuaria, generaba el $6 \%$ del valor agregado por la oferta total de bienes y servicios. El sector secundario aportaba otro $42 \%$ y el $52 \%$ de la actividad económica global restante corresponde a los servicios financieros, de transporte y comunicaciones, comercio, turismo y gobierno.

El conurbano bonaerense presenta una gran concentración de población y de actividades industriales, comerciales y de servicios. Según los datos aportados por la propia Provincia, el cinturón noreste de la Provincia se ha especializado en el cultivo de maíz y soja, mientras que en el centro oeste y sureste predomina la producción de trigo, girasol y maíz. En la zona correspondiente al Gran Buenos Aires y la ribera del río Paraná, destaca la producción intensiva de frutas y hortalizas (papa, ajo, cebolla, naranjas, limones, mandarinas y pomelos). La producción de ganadería de Buenos Aires continúa siendo fuerte ${ }^{161}$.

La actividad industrial se concentra principalmente en el cinturón del Gran Buenos Aires, el área más urbanizada y de mayor concentración económica, y se extiende en todo el frente fluvial Paraná-del Plata. En este sector están representadas todas las actividades industriales del país, que en orden de importancia son: alimenticia $(19 \%)$; química (13\%); petroquímica y refinería (12\%); automotriz (11\%) y metalmecánica $(5 \%)$.

Otros polos industriales se ubican en Bahía Blanca, con industrias alimentarias y petroquímicas; en Mar del Plata, centro de la industria pesquera y albergue de canteras; en Tandil, con industrias lácteas y metalúrgicas; en Olavarría, como centro cementero; en San Nicolás, centro siderúrgico y en Zárate-Campana, con industrias petroquímicas y destilerías.

Algunos datos pueden darnos cuenta de la situación socioeconómica de caída y recuperación de la Provincia en el período estudiado. La participación de la construcción fue entre el $2,7 \%$ y el $6,5 \%$ entre 2002 y 2006. La tasa de empleo pasó del $34 \%$ al $42,5 \%$ entre 2002 y 2009 mientras que la tasa de desocupación era del $20 \%$ en 2002 y se ubicaba en el $8 \%$ en 2010 con una caída del subempleo del $18 \%$ al $10 \%$ entre 2003 y 2009. Por su parte, en 2003, el 61,3\% las personas estaba en condición de pobreza. Hoy, se mejoró (lejos de ser óptimo, por cierto) al 14,5\% según datos de 2009 . Hubo una caída en la cantidad de personas en condición de indigencia de 31,8\% a 3,6\% entre 2003 y 2009. También mejoró la tasa de repitencia en la escuela primaria total de $4,9 \%$ a $4,6 \%$ entre 2002 y 2008 y la tasa de abandono anual en la escuela primaria total de $2,1 \%$ a $1,7 \%$ en igual período. Aumentó la cantidad de hogares con cobertura de

\footnotetext{
161 Según el Informe de Gestión 2002-2003 elaborado por la Jefatura de Gabinete (2003) había en esa fecha 48.063.368 de cabezas de ganado bovino, 12.395.839 de cabezas de ganado ovino, 2.120.089 de cabezas de ganado porcino y 4.021.917 de ganado caprino. http://www.lib.utexas.edu/benson/lagovdocs/argentina/buenosaires/memoria-gestion-gobernacion-0203.pdf. Fecha de Consulta: 01/07/11.
} 
agua corriente de $68 \%$ a $71 \%$ entre 2006 y 2009 y aumentó el porcentaje de hogares con cobertura de cloacas del $54 \%$ al $63 \%$ entre 2006 y $2009^{162}$.

Sin embargo, el contexto social sigue siendo preocupante. Algunos índices pueden darnos cuenta de la magnitud de la crisis en la Provincia de Buenos Aires. El índice de Desarrollo Humano corrobora la representatividad de la Provincia de Buenos Aires en los números globales que tiene la República Argentina. Pero se advierte también, que el comparado del último decenio da muestras de un deterioro general con un mayor porcentual en la caída de la Provincia de Buenos Aires.

\begin{tabular}{|c|c|c|c|c|c|}
\hline Total & $\begin{array}{c}\text { Índice de } \\
\text { esperanza de } \\
\text { vida }\end{array}$ & $\begin{array}{l}\text { Índice de } \\
\text { educación }\end{array}$ & $\begin{array}{l}\text { Índice de } \\
\text { ingresos }\end{array}$ & $\begin{array}{c}\text { Índice de } \\
\text { desarrollo } \\
\text { humano } 2001\end{array}$ & $\begin{array}{c}\text { Índice de } \\
\text { desarrollo } \\
\text { humano } 2010\end{array}$ \\
\hline $\begin{array}{l}\text { Provincia de } \\
\text { Buenos Aires }\end{array}$ & 0,843 & 0,943 & 0,668 & 0,854 & 0,818 \\
\hline Argentina & 0,841 & 0,962 & 0,686 & 0,853 & $\mathbf{0 , 8 3 0}$ \\
\hline
\end{tabular}

Fuente: Elaboración propia a partir de los informes de Desarrollo Humano 2004 y el Informe sobre el Desarrollo Humano en la Provincia de Buenos Aires 2004-2005 e Informe Nacional sobre Desarrollo Humano 2010, Desarrollo humano en Argentina: trayectos y nuevos desafíos, 2010.

Según los datos de la Dirección Provincial de Estadísticas, aún hoy el porcentaje de población con Necesidades Básicas Insatisfechas (NBI) permanece alto y su predominio continúa concentrándose en los partidos del Conurbano bonaerense. ${ }^{163}$

De acuerdo a los últimos datos publicados por la Dirección Provincial de Estadísticas, cerca del 16\% de la población de la Provincia vive en hogares con NBI. El porcentaje de población en hogares con NBI es ligeramente inferior al registrado en 1991 (17\%) y claramente inferior al de 1980 (24\%). En comparación, en el Tercer Cordón es donde resulta ligeramente mayor la proporción de población en hogares con NBI dentro del Conurbano. En el Interior, ese porcentaje históricamente ha sido y continúa siendo sensiblemente menor $(10 \%)$.

\begin{tabular}{|c|c|c|c|c|c|c|}
\hline & \multicolumn{6}{|c|}{ Cuadro 12 - necesidades básicas insatisfechas } \\
\hline & \multicolumn{2}{|c|}{1980} & \multicolumn{2}{|c|}{1991} & \multicolumn{2}{|c|}{2001} \\
\hline & $\begin{array}{c}\text { millones de } \\
\text { personas }\end{array}$ & NBI \% & $\begin{array}{c}\text { millones de } \\
\text { personas }\end{array}$ & NBI \% & $\begin{array}{c}\text { millones de } \\
\text { personas }\end{array}$ & NBI \% \\
\hline Total del país & 27,4 & 27,7 & 32,2 & 19,9 & 35,9 & 17,7 \\
\hline Total Provincia & 10,7 & 24,2 & 12,5 & 17,0 & 13,7 & 15,8 \\
\hline Partidos del Conurbano & 6,8 & 26,6 & 7,9 & 18,9 & 8,6 & 17,6 \\
\hline
\end{tabular}

\footnotetext{
162 Todos estos datos han sido tomados del Plan de Regionalización, 2011. Se encuentran disponibles en la Web: http://www.regionalizacionba.com.ar/index.htm. Fecha de Consulta: 06/01/12.

${ }_{163}$ Se considera población con NBI a aquella en la que está presente al menos uno de los siguientes indicadores de privación: 1.- Habita viviendas con más de 3 personas por cuarto -hacinamiento crítico-; 2.- Habita en una vivienda de tipo inconveniente -vivienda precaria u otro tipo-; 3.- Habita en viviendas que no tienen retrete o tienen retrete sin descarga de agua; 4.- Forma parte de Hogares que tienen algún niño en edad escolar que no asiste a la escuela ó 5.-Forma parte de Hogares que tienen 4 ó más personas por miembro ocupado y en los cuales el jefe tiene bajo nivel de educación -sólo asistió dos años o menos al nivel primario-.
} 


\begin{tabular}{|l|c|c|c|c|c|c|}
\hline Interior Provincia & 3,9 & 20,4 & 4,6 & 13,9 & 5,1 & 12,7 \\
\hline
\end{tabular}

Fuente: Dirección Provincial de Estadísticas.

http://www.ec.gba.gov.ar/Estadistica/anuario2002/nav.htm

Los datos que surgen de la medición de pobreza se encuentran más actualizados. Utilizando el método de la "línea de pobreza"164, la Encuesta Permanente de Hogares del Indec señala que se han producido bajas sustanciales en el porcentaje de hogares y personas en estado de pobreza. La zona de la Provincia con mayor reducción de esos índices es el Conurbano bonaerense, históricamente la zona más afectada.

\begin{tabular}{|c|c|c|c|c|c|}
\hline \multicolumn{6}{|c|}{ Cuadro 13 - Porcentaje de hogares en estado de pobreza } \\
\hline & $\begin{array}{c}\text { 1er sem. } \\
2003\end{array}$ & $\begin{array}{c}2 \text { do sem. } \\
2003\end{array}$ & $\begin{array}{c}\text { 1er sem. } \\
2004\end{array}$ & $\begin{array}{c}\text { 2do sem. } \\
2004\end{array}$ & $\begin{array}{c}\text { Variación } \\
\text { puntos }\end{array}$ \\
\hline Conurbano & 51,1 & 43,2 & 39,8 & 34,7 & $-16,4$ \\
\hline Gran La Plata & 29,9 & 24,4 & 24,0 & 20,4 & $-9,5$ \\
\hline Mar del Plata-Batán & 30,6 & 27,5 & 18,9 & 21,1 & $-9,5$ \\
\hline Bahía Blanca - Cerri & 32,1 & 28,8 & 31,0 & 25,2 & $-6,9$ \\
\hline
\end{tabular}

Fuente: Dirección Provincial de Estadísticas.

http://www.ec.gba.gov.ar/Estadistica/pdf/ephc3.pdf

Cuadro 14 - Porcentaje de personas en estado de pobreza

\begin{tabular}{|c|c|c|c|c|c|}
\hline & $\begin{array}{c}\text { 1er sem. } \\
2003\end{array}$ & $\begin{array}{c}\text { 2do sem. } \\
2003\end{array}$ & $\begin{array}{c}\text { 1er sem. } \\
2004\end{array}$ & $\begin{array}{c}\text { 2do sem. } \\
2004\end{array}$ & $\begin{array}{c}\text { Variación } \\
\text { puntos }\end{array}$ \\
\hline Conurbano & 61,3 & 53,5 & 50,9 & 44,4 & $-16,9$ \\
\hline Gran La Plata & 40,0 & 34,1 & 32,5 & 29,3 & $-10,7$ \\
\hline Mar del Plata - Batán & 39,9 & 34,8 & 22,6 & 29,6 & $-10,3$ \\
\hline Bahía Blanca - Cerri & 40,8 & 36,9 & 39,1 & 31,3 & $-9,5$ \\
\hline
\end{tabular}

Fuente: Dirección Provincial de Estadísticas.

http://www.ec.gba.gov.ar/Estadistica/pdf/ephc3.pdf

En estado de indigencia ${ }^{165}$, esto es, hogares que no cuentan con ingresos suficientes como para cubrir una canasta básica de alimentos capaz de satisfacer un umbral mínimo de necesidades energéticas y proteicas, si bien puede verse una importante disminución entre el primer semestre de 2003 y el segundo semestre de 2004, el pico de casi $32 \%$ de personas indigentes en el conurbano bonaerense no hace sino revelar la profundidad de la consecuencia de la crisis de 2002.

Cuadro 15 - Porcentaje de hogares indigentes

$\begin{array}{ccccc}\text { 1er sem. } & 2 \text { do sem. } & \text { 1er sem. } & \text { 2do sem. } & \text { Variación } \\ 2003 & 2003 & 2004 & 2004 & \text { puntos }\end{array}$

164 Este método consiste en establecer, a partir de los ingresos de los hogares, si éstos tienen capacidad de satisfacer por medio de la compra de bienes y servicios un conjunto de necesidades tanto alimentarias como no alimentarias - entre ellas: vestimenta, transporte, salud, vivienda, educación, etc. - consideradas esenciales.

165 Estos hogares constituyen un subgrupo dentro del conjunto de los hogares situados debajo de la línea de pobreza. 


\begin{tabular}{|l|c|c|c|c|c|}
\hline Conurbano & 24,5 & 18,2 & 13,6 & 12,9 & $\mathbf{- 1 1 , 6}$ \\
\hline Gran La Plata & 11,4 & 10,1 & 9,6 & 6,6 & $\mathbf{- 4 , 8}$ \\
\hline Mar del Plata - Batán & 14,9 & 12,5 & 7,5 & 6,2 & $\mathbf{- 8 , 7}$ \\
\hline Bahía Blanca - Cerri & 14,6 & 10,9 & 11,3 & 8,0 & $\mathbf{- 6 , 6}$ \\
\hline
\end{tabular}

Fuente: Dirección Provincial de Estadísticas.

www.ec.gba.gov.ar/Estadistica/prensa/pobreza.pdf

\begin{tabular}{|c|c|c|c|c|c|}
\hline \multicolumn{6}{|c|}{ Cuadro 16 - Porcentaje de personas en estado de indigencia } \\
\hline & $\begin{array}{c}\text { 1er sem. } \\
2003\end{array}$ & $\begin{array}{c}\text { 2do sem. } \\
2003\end{array}$ & $\begin{array}{c}\text { 1er sem. } \\
2004\end{array}$ & $\begin{array}{c}\text { 2do sem. } \\
2004\end{array}$ & $\begin{array}{c}\text { Variación } \\
\text { puntos }\end{array}$ \\
\hline Conurbano & 31,8 & 22,9 & 18,2 & 16,9 & $-14,9$ \\
\hline Gran La Plata & 157 & 14,3 & 13,6 & 9,6 & $-6,1$ \\
\hline Mar del Plata-Batán & 19,5 & 15,5 & 9,4 & 9,1 & $-10,4$ \\
\hline Bahía Blanca - Cerri & 19,4 & 14,0 & 16,2 & 10,6 & $-8,8$ \\
\hline
\end{tabular}

Fuente: Dirección Provincial de Estadísticas.

http://www.ec.gba.gov.ar/Estadistica/pdf/ephc3.pdf.

Fecha de Consulta: 03/04/12.

En una de las últimas publicaciones de la Dirección Provincial de Estadísticas, referida a la incidencia de la indigencia en los hogares, que cubre la serie 2004-2008, se advierte una mejoría en este índice.

Cuadro 17 - Incidencia de la Indigencia en los hogares

2004

2005

2006

2007

2008

\begin{tabular}{|l|r|r|r|r|r|}
\hline Gran La Plata & 6,6 & 4,7 & 4,5 & 1,9 & 3,3 \\
\hline Bahía Blanca - Cerri & 8,0 & 7,4 & 5,2 & - & 3,6 \\
\hline Partidos del GBA & 12,9 & 9,1 & 7,3 & 5,1 & 3,6 \\
\hline Mar del Plata - Batán & 6,2 & 8,6 & 5,6 & 3,2 & 2,3 \\
\hline
\end{tabular}

Fuente: Dirección Provincial de Estadísticas.

http://www.ec.gba.gov.ar/Estadistica/anuario $\% 202008 / 2$ condicionesdevida/Pobreza $\% 2$ $\underline{02.26 . x l s}$

Fecha de Consulta: 03/04/12.

Si se considera que Buenos Aires es la región más fértil no sólo de Argentina, sino también de América Latina y que tiene el 33\% de la superficie cultivada del país, con más de 10 millones de hectáreas, la existencia de hogares por debajo de la línea de indigencia es un hecho revelador de la desigual distribución de la riqueza.

\section{Los antecedentes de reforma en la Provincia}

La Provincia de Buenos Aires no fue ajena al proceso de reforma $\mathrm{y}$ privatizaciones que se dieron en la década de los ' 90 . Con la Ley $\mathrm{N}^{\mathrm{o}} 11.184$ de Reconversión Administrativa, sancionada en 1991, la Provincia de Buenos Aires se dio su propia Ley de reforma del Estado, siguiendo el modelo del Estado Nacional, aunque 
con dimensiones mucho más acotadas y con menor jerarquía en la agenda pública (Randazzo, 2004). ${ }^{166}$

Dicha ley autorizó al Poder Ejecutivo a la intervención de entes o empresas del Estado Provincial para racionalizar sus estructuras administrativas; optimizar recursos y servicios; disponer su transferencia al sector privado y fijar una política de compromisos con el Poder Ejecutivo a través de "contratos programa".

Por el artículo $8^{\circ}$ de la Ley $\mathrm{N}^{\circ} 11.184$ se facultó al Poder Ejecutivo a crear entes autárquicos institucionales que absorban, total o parcialmente, competencias de órganos de la Administración Central, con lo que puede confirmarse que la Administración centralizada fue vista como un disvalor.

Se lo autorizó, asimismo, a reubicar cargos de igual o superior jerarquía y agrupamiento al personal comprendido o reasignar su destino. ${ }^{167}$

Según el Cr. Gustavo Longo, entonces Responsable Ejecutivo de la Unidad de Coordinación de Programas de Innovación de la Provincia, la ineficacia de ese tipo de políticas se reflejó ante el hecho de que el promedio de cambios, solamente a nivel de Ministerios en los últimos doce años fue de 4,5 por año, con las implicancias que acarrea en los niveles inferiores y la carga administrativa relacionada con los cambios de programas presupuestarios (Longo, 2005).

Fue también en el marco de dichas políticas que el Gobierno Nacional en 1993 transfirió a la Provincia el manejo de las redes ferroviarias de transporte de pasajeros para su posterior privatización. ${ }^{168}$

Ese fue el comienzo de una serie de medidas en igual sentido: 1997 privatización de ESEBA ${ }^{169}$ y privatización de OSBA en 1999. Como consecuencia de ello, se crearon organismos reguladores y de control.

Se inició también un proceso de transferencia de la ejecución del llamado gasto social, que comprendió desde los establecimientos de salud y educación hasta la gestión de algunos fondos nacionales (FONAV, FEDEI, entre otros).

Durante el período 1991-1999 se desarrollaron otras reformas en el Gobierno provincial. El Decreto $N^{\circ}$ 18/91 estableció nuevos criterios para el diseño y aprobación de estructuras organizativas y creó el Consejo Asesor de la Reforma del Estado y Procedimientos Administrativos (CAREPA). A partir de 1996 se comienza con la modalidad de programación presupuestaria para la formulación del Presupuesto General de la Provincia. ${ }^{170}$

La gravedad de la crisis económica y social desatada en el país a partir de diciembre de 2001 derivó en la declarada emergencia pública que produjo profundas modificaciones en la economía de la Nación. La Provincia se vio afectada por los

\footnotetext{
166 La Ley $\mathrm{N}^{\circ} 11.184$ fue prorrogada por el término de un año mediante la Ley $\mathrm{N}^{\circ} 11.369$ y por la Ley $\mathrm{N}^{\circ} 11.489$, por otro período.

167 Se preveía la prescindibilidad de los agentes con una indemnización equivalente a la prevista en el artículo 247 de la Ley Nacional de Contrato de Trabajo -Ley $\mathrm{N}^{\circ} 20.744$ - y un régimen de jubilación de excepción, un régimen de pasividad anticipada y un sistema de retiro voluntario.

168 Un año después se trasfirió Astilleros Río Santiago, pero la privatización no pudo concretarse.

169 La concesión fue rescindida por los incumplimientos del concesionario Azurix, creándose Aguas Bonaerenses S.A. cuyo capital social corresponde en propiedad al Estado Provincial y a los trabajadores sanitarios.

170 Otra importante medida tendiente a la reducción de gastos fue el congelamiento de vacantes.
} 
efectos de la crisis: fue en ese contexto de crisis económica y social generalizada que pocos meses después asumió la gestión del entonces gobernador Felipe Solá.

En efecto, si bien la crisis tuvo su epicentro en los episodios de diciembre de 2001, era un proceso que muchos meses antes había producido resquebrajamientos en el Estado. Así, para fines de junio de 2001 durante el mandato del entonces Gobernador Ruckauf, la Legislatura Provincial había dictado la Ley $\mathrm{N}^{\mathrm{o}} 12.727$ por la cual se declaraba "en estado de emergencia administrativa, económica y financiera" al Estado Provincial, la prestación de servicios y la ejecución de los contratos a cargo del sector público provincial centralizado, descentralizado, organismos autónomos y autárquicos de la constitución, comprendiendo también a los Poderes Legislativo y Judicial y a todos los entes en los que el Estado Provincial se encuentre asociado con uno o varios municipios.

Pero el proceso fue complejo. Conjuntamente con la crisis nacional de 2001, el Poder Ejecutivo, todavía a cargo de Carlos Ruckauf, dictó el Decreto $N^{0} 1.960 / 01$, complementado con el Decreto $\mathrm{N}^{\mathrm{o}} 1.966 / 01$, por conducto del cual se declaró el estado de emergencia de la situación económico financiera del Estado y se establecieron los mecanismos de bonos con los cuales la Provincia iba a hacer frente a sus obligaciones. Dicho acto fue notificado a la Honorable Cámara de Diputados y al Honorable Senado, con fecha 17 de julio de 2001.

Pero el Ejecutivo, envió su proyecto de Ley en medio de cuestionamientos sobre la legalidad de la medida y ante la emergencia planteada y frente al rápido devenir de los acontecimientos, la Legislatura aprobó su propia Ley de emergencia, la Ley $\mathrm{N}^{\mathrm{o}}$ 12.727, que luego fuera modificada y ampliada por sucesivas leyes: Leyes $\mathrm{N}^{\mathrm{o}} 12.774$, $12.775,12.789,12.836$ y $12.845,13.242$ y 13.850 .

Lo cierto es que el propio Poder Ejecutivo había presionado a la Legislatura para la sanción de la Ley cuando el decreto que establecía este estado de excepción, fue notificado a la Suprema Corte de Justicia para implementarlo en su rol de Superintendente del Poder Judicial, y ésta, en lo que constituye un primer antecedente de declaración de inconstitucionalidad de oficio en la Provincia de Buenos Aires, lo anuló $^{171}$.

Por la mencionada Ley provincial de emergencia, el Poder Ejecutivo quedó autorizado a renegociar todos sus contratos, siempre y cuando el cocontratante aceptase una serie de condiciones que se allí se especifican. También se autorizó a rescindir cualquier tipo de convenio que genere obligaciones a cargo del Estado provincial, salvo las relaciones de empleo público, indemnizando sólo el daño emergente. Más aún, el art. 4 posibilitó la modificación de “... la naturaleza del contrato por otra que resulte más conveniente, desde el punto de vista financiero, a los intereses de la Provincia."

También se autorizó al Poder Ejecutivo a disponer la rescisión de contratos que generaran obligaciones a cargo del Estado Provincial, cualquiera fuera su naturaleza y

\footnotetext{
${ }^{171}$ Como ha sostenido Botassi (2002:1), dicha ley resultó inconstitucional por desconocer los derechos adquiridos, en especial los sueldos y jubilaciones recortados en porcentajes confiscatorios por la emergencia avanzando contra facultades propias del Poder Judicial, como el levantamiento de las medidas cautelares contra el Fisco. Pero además, por cuanto fue dictada sin que existan los presupuestos jurídicos que legitimarían dictar ese tipo de norma, en especial, la emergencia ajena a la voluntad de los gobernantes.
} 
objeto y se lo facultó a renegociar los contratos y a modificar la naturaleza del contrato por otra que resultara financieramente más conveniente a la Provincia.

En base a esta autorización, por medio del Decreto $N^{\circ} 2.040 / 01$ se rescindieron todos los contratos de locación de obra o servicio suscriptos por dependencias de la Administración Pública Provincial centralizada o descentralizada, Organismos autárquicos y Organismos de la Constitución. Sin embargo, autorizó a los titulares de esos organismos a decidir, mediante resolución fundada, la continuidad de la contratación hasta la fecha de vencimiento, cuando la obra servicio resultare indispensable.

Tal vez lo más conocido de la Ley fue la emisión de dos tipos de letras de tesorería: los "patacones" que se entregarían a empleados públicos y jubilados ${ }^{172}$ y los "bonos de cancelación de obligaciones de la Provincia de Buenos Aires" con los que se pagarían créditos de proveedores y contratistas. En materia de política salarial del sector público, esta ley de emergencia dispuso la reducción de las retribuciones brutas totales, mensuales, normales, habituales regulares y permanentes y el sueldo anual complementario del personal de la totalidad de los organismos provinciales. ${ }^{173}$ Pero además, por el Capítulo V de la Ley se redujo las retribuciones mensuales, el aguinaldo y los haberes previsionales del personal de la totalidad de los organismos provinciales, excluyendo únicamente a los jueces, miembros del Ministerio Público y empleados del Banco de la Provincia de Buenos Aires en forma retroactiva en una escala creciente según los montos de doce categorías de haberes. ${ }^{174}$

El 29 de enero de 2002 la provincia se declaró en default: la deuda pública ascendía a 7800 millones de pesos, y el déficit, a 2500 millones. El presupuesto preveía un recorte de entre 1500 y 2000 millones de pesos respecto de lo presupuestado en 2001, que había ascendido a 10.300 millones $^{175}$.

Otero:

Como lo describía el Ministro de Economía de la gestión de Solá, Gerardo

La provincia de Buenos Aires en la crisis del 2001 soportaba una

\footnotetext{
172 Por ser una "cuasi" o "pseudo" moneda, el eufemismo salvó la evidente inconstitucionalidad de la norma.

173 La planilla establecía porcentajes de reducción progresivamente crecientes para los sueldos superiores a los mil doscientos pesos aplicables sobre el excedente a dicha cifra.

174 Por su artículo $7^{\circ}$ se aprobó la emisión de Letras de Tesorería para Cancelación de Obligaciones, denominadas "Patacón” y "Bonos de Cancelación de Obligaciones de la Provincia de Buenos Aires" y por su artículo $9^{\circ}$ se autorizó al Poder Ejecutivo al pago de haberes y otras retribuciones personales con Pesos y/o "Patacones" y/o "LECOP", disponiéndose en forma expresa su obligatoriedad para Magistrados, miembros del Poder Judicial y del Ministerio Público, Legisladores, miembros del Poder Ejecutivo Provincial y titulares de los Organismos de la Constitución, entidades autárquicas, organismos descentralizados, autónomos, de previsión y asistencia social y en general de todo organismo público que se encuentre bajo la órbita del Estado Provincial y funcionarios, empleados, agentes públicos y becarios de los tres poderes del Estado Provincial, así como a todo aquel que perteneciera a cualquiera de los organismos. Más allá de la buena recepción de los patacones por el comercio, debida entre otras cosas por la caída de las ventas, lo cierto es que quienes debía cambiar la cuasi moneda por pesos perdían hasta un $15 \%$.

${ }^{175}$ Ver, Diario LA NACION, "El Ministerio de Economía bonaerense ya tiene nuevo titular", 19 de febrero de 2002. http://www.lanacion.com.ar/375203-el-ministerio-de-economia-bonaerense-ya-tienenuevo-titular
} 
caída de la recaudación del 50\%, producto del largo proceso recesivo; había incertidumbre sobre las posibilidades y la fecha de pago de los salarios de los agentes políticos; el atraso en los pagos a proveedores y contratistas era de 120 días; la deuda flotante superaba los $\$ 1000$ millones y los fondos destinados a los comedores escolares sufrían una demora de más de 60 días. Esto provocaba graves problemas en la prestación de servicios. La deuda con los municipios por garantía de coparticipación, alcanzaba los $\$ 85$ millones y la coparticipación Municipal por juegos de azar tenía un atraso de 9 meses. El déficit de 2001 fue de $\$ 3.200$ millones, la misma cifra equivalente en dólares. Con este panorama, el gobernador Felipe Solá se puso al frente de la provincia y con él, quienes integramos su gabinete, iniciamos una ardua tarea que exigía mantener $\mathrm{y}$, en lo posible, mejorar las prestaciones con cada vez más escasos recursos. Sin financiamiento externo, con el gobierno nacional exigido en asegurar la continuidad institucional y el drama social de millones de bonaerenses golpeando las puertas de las reparticiones provinciales y de los municipios, hubo que multiplicar esfuerzos y agudizar la creatividad para sostener una situación que se hacía impredecible... ("Desde la incertidumbre a las finazas sustentables", Noticias de Economía nº 66, cit. por Randazzo, 2004).

Las medidas de emergencia produjeron fuertes cuestionamientos por parte de los sindicatos y empleados estatales. La Corte, integrada por conjueces, rechazó la acción declarando la constitucionalidad de la norma de emergencia, aunque puso límites en cuanto a su extensión.

En efecto, pese a que originalmente la Ley preveía que el estado de emergencia tuviera vigencia por el período de un año, el artículo 51 de la Ley $\mathrm{N}^{\circ} 13.002$ la prorrogó hasta el 31 de diciembre del 2003, habiendo sido a su vez prorrogado anteriormente por el Decreto $\mathrm{N}^{\circ} 1.465 / 02$ en virtud de la autorización conferida por la Ley $\mathrm{N}^{\circ} 12.774$. Por último, la Ley $\mathrm{N}^{\mathrm{o}} 13.154$ prorrogó la emergencia desde el $1^{\circ}$ de enero de 2004 hasta el 31 de diciembre de ese año. Sin embargo, la Corte en un caso particular no autorizó la quita salarial más allá del primer semestre de 2003 por lo que el Ejecutivo Provincial se vio obligado a devolver los importes deducidos durante el segundo semestre de ese año para evitar una catarata de juicios en su contra.

Ese panorama también fue fuente de profundos conflictos sociales, pues la caída de la convertibilidad implicó, entre otras cosas, transferencias de ingresos desde un sector de la sociedad hacia otro, modificaciones en los precios relativos, pérdidas y ganancias y disminución del poder adquisitivo de los salarios. Según el entonces Subsecretario de Gestión Tecnológica y Administrativa de la Secretaría General de la Gobernación, ese situación ...

minó la capacidad operativa, la seguridad jurídica y la credibilidad misma de las instituciones y fue en ese contexto que se inició la presente gestión la que, a pesar de la urgencia de los problemas que se presentaban, siempre pretendió contar con una estrategia de mediano plazo, que orientara las decisiones más allá de atender la emergencia (Deniro, 2005:1). 
También en el marco de la Ley de Emergencia, y a nivel del Ejecutivo, el Decreto $\mathrm{N}^{\circ} 29 / 02$ estableció diversas medidas destinadas a la contención del gasto público en los distintos rubros; entre ellos, se restringió el uso de los vehículos oficiales, con o sin chofer, a funcionarios con jerarquía no menor a Ministros del Poder Ejecutivo; se suspendieron los viajes al exterior, autorizando a la Secretaría General de la Gobernación a establecer excepciones puntuales por Resolución fundada. Asimismo, se suspendió la suscripción y edición de publicaciones, y se limitó el uso de celulares a funcionarios de rango equivalente o superior a Subsecretario.

Con igual espíritu, y a través del Decreto $\mathrm{N}^{\circ} 159 / 02$, se establecieron las Unidades Retributivas por Productividad y Eficiencia (URPE), de carácter no remunerativo ni bonificable, tendientes a reemplazar sistema de compensación salarial que se había arraigado profundamente en la Provincia a través de viáticos y horas extras.

Esa política de emergencia y contención del gasto público, acompañada por los logros del gobierno nacional, tuvo sus frutos. Según la Memoria de Gestión de la Provincia de Buenos Aires para el período 2002-2003,

El gobierno respondió con una fuerte política de asistencia social y puso énfasis en mantener la consistencia en el frente fiscal y monetario a fin de estabilizar las variables nominales, lo que se logró en el segundo semestre del año 2002, cuando se comenzaron a advertir los primeros síntomas de reactivación en los sectores transables de la economía (Jefatura de Gabinete, 2003:13).

En el presupuesto del 2002 se redujo el gasto total, pese a la inflación, en \$ 540.000 .000 que corresponden a gasto primario y $\$ 310.000 .000$ de pesos de intereses de la deuda. Por su parte, los gastos en personal cayeron $\$ 340.000 .000$ millones de pesos sin producir despidos. El aumento de la recaudación en el 2002 implicó un aumento de $\$ 765.000 .000$ millones de pesos más que en el año anterior, lo que implicó un incremento del $20 \%$.

Las transferencias a los municipios se incrementaron en $\$ 200.000 .000$, y el atraso de la coparticipación municipal por juegos de azar se redujo en cinco meses. La deuda flotante disminuyó en $\$ 700.000 .000$, y la reducción del déficit fue de $\$$ 3.200 .000 .000 a $\$ 1.270 .000 .000$, una disminución del $56 \%$ que sobrepasó la meta comprometida en los acuerdos con el gobierno nacional (Randazzo, 2004).

El gasto público total en 2005 alcanzó aproximadamente los 17.160 millones de pesos. Ello implicó un aumento en el gasto total del 31,7\% en el 2005 respecto del 2004. Los factores que más incidieron, según el Ministerio de Economía local, fueron los aumentos salariales y los aumentos de precios de bienes y servicios, que representan aproximadamente un $53 \%$ de los gastos corrientes. ${ }^{176}$

Respecto de los gastos de capital, que principalmente incluyen a las inversiones de largo plazo, se previó que aumentaran un $96,6 \%$, aunque su incidencia en los gastos totales no pasa el $10 \%$ contra el $90 \%$ que representan los gastos corrientes, esto es, aquellos necesarios para el funcionamiento habitual del Estado, constituido

176 Las transferencias corrientes, fuertemente influidas por la coparticipación a municipios, rondan el $23 \%$ del total. Los bienes y servicios insumen alrededor del $13 \%$ del total del presupuesto. 
principalmente por erogaciones en remuneraciones y servicios tales como energía eléctrica, combustible, comunicaciones, transporte. ${ }^{177}$

Para el 2006 se proyectaron erogaciones totales por 22.418 millones de pesos, de las cuales 21.620 millones son gasto primario. El resto se destina al pago de intereses de la deuda, lo cual representó unos 3.000 millones de pesos más que en 2005. En cuanto a los recursos propios por impuestos provinciales, para el 2006 se estimaron en 12.452 millones, un $16,1 \%$ superior a lo recaudado en $2005 .^{178}$

La Provincia, ha reclamado un aumento en el porcentaje de recursos que percibe de la Nación en concepto de coparticipación al sentirse "discriminada": generando el $33 \%$ del total de ingresos en el país, tiene el 38\% de la población, producía el 34,5\% del total de exportaciones, tenía al $34 \%$ de la población con NBI del país, pero recibía aproximadamente el $20 \%$ del $57,66 \%$ de la masa de los recursos coparticipables. ${ }^{179}$

177 De todas formas es necesario destacar que el gasto en inversiones pasó de representar el 6,3\% al 9,3\% del gasto total.

178 El 2005 cerró con una mejora del $21,3 \%$ en ingresos tributarios y del $11 \%$ respecto a la meta de \$106.834 millones previstos en el Presupuesto del año anterior. Hoy por Ingresos Brutos se estima una recaudación de 6.781 millones de pesos, basado en la mayor actividad económica y en la profundización de las medidas para el control de la evasión impositiva. Los datos son de la Contaduría General de la Provincia. Dirección de Análisis e Investigación Económica Financiera. Ver en http://www.cgp.gba.gov.ar/Presupuestaria/ http://www.cgp.gba.gov.ar/Presupuestaria/EstadosComparativos.aspx. Fecha de Consulta: 03/04/12.

179 Muchos reclamos de este tipo fueron sostenidos por diferentes miembros del Gabinete del entonces Gobernador Solá, aún luego de su ruptura con el duhaldismo y su alianza electoral con el Presidente Kirchner. El Jefe de Gabinete era uno de los más arduos defensores de esta batalla. En este sentido ha dicho que "Durante el ejercicio 2001, la provincia percibió 3.506 millones de pesos, monto muy inferior al que hubiera recibido si los recursos se hubiesen distribuido según indicadores objetivos: la pérdida es del orden de 2.400 millones de pesos si la variable escogida es la población y del orden de 1.800 millones de pesos si fuera por el aporte al PBG. La situación se agrava teniendo en cuenta que, en materia de derechos a la exportación que no resultan coparticipables, la provincia de Buenos Aires aporta aproximadamente el 40\% sobre el total de dicho tributo" (Randazzo, 2004:52). 


\section{CAPÍTULO VI. LAS DIRECTRICES DEL GOBERNADOR Y LAS ÁREAS CON COMPETENCIA PARA LA REFORMA}

\section{El Gobernador: análisis de su discurso}

Dado que el liderazgo aparece como un factor crítico para el éxito de cualquier proceso de modernización y transformación organizacional, éste debe ser claro y fuerte, no sólo en el nivel técnico sino, especialmente, en el máximo nivel político pues sin la iniciativa constante de las máximas autoridades es difícil vencer los naturales obstáculos y resistencias organizacionales.

Es por ello que luego de haber descripto brevemente el contexto político, social y económico del gobierno bajo análisis, corresponde ahora analizar ahora al actor principal de este proceso: el gobernador.

Cuando asumió su gestión, el ex gobernador Solá expresó un fuerte compromiso con la modernización del Estado. En el discurso de apertura de sesiones legislativas, pronunciado el $1^{\circ}$ de marzo de 2002, el gobernador Felipe Solá manifestó que:

La Modernización del Estado provincial debe tener un solo objetivo. Ese objetivo es que el Estado, en lugar de alejar a los hombres que la gente elige para representarlos y conducirlos, léase los políticos; en lugar de alejarlos de la gente común que utiliza como puede los servicios cotidianos de ese Estado y requiere que ese Estado sea ágil, eficiente, justo, moderno; debe acercarlos. En lugar de alejarlos; acercarlos (Subsecretaría de la Gestión Pública, 2004-a:10).

El sistema de modernización del Estado Provincial contiene tres lineamientos básicos. En primer lugar tomaremos medidas que mejoren la calidad del servicio a los ciudadanos. La descentralización, desconcentración y regionalización de muchas acciones del poder central, dará mayor eficacia y transparencia a los actos de gobierno. ... Modernizar los instrumentos de administración financiera, facilitar el modelo de gobierno electrónico, reordenar la carrera administrativa y los sistemas informáticos, readecuar la ley de coparticipación, reestructurar las múltiples regionalizaciones provinciales, son algunos de los temas que seguramente esta Honorable Legislatura deberá abordar y cuyo aporte será esencial para enriquecerlos. ... La Reforma Política debe tener como prioritaria expresión una Reforma del Estado. ... El Estado bonaerense debe necesariamente adecuar sus estructuras para prestar mejores servicios a sus ciudadanos. ... Por eso no queremos un Estado gendarme ni ausente, sino un Estado Inteligente, que sea capaz de dar respuestas a las necesidades de los vecinos, con rapidez y eficiencia (Subsecretaría de la Gestión Pública, 2004-a:10-11; el destacado es nuestro). 
Además de estas declaraciones específicas, el Gobernador señaló en varias ocasiones aspectos relevantes sobre la materia, en especial, en los actos donde se aprobaron o presentaron proyectos de modernización o nombraron funcionarios.

Así, en el discurso de la asunción del Secretario para la Modernización del Estado, Cr. Florencio Randazzo, en febrero de 2002, el Gobernador expresó que el objetivo de la política de modernización debía estar focalizado más en la reforma política que en la eficientización de la gestión.

En la presentación del "Plan Rector de Modernización"180 que elaborara el Poder Ejecutivo a través de la Secretaría de Modernización del Estado, estando todavía a cargo del Cr. Florencio Randazzo, el ex gobernador Solá manifestó:

Me pregunto de quién es el Estado, y creo que las respuestas podrían ser una teórica y otra real. El Estado debería ser lo mejor de todos, debería ser el lugar donde la población depositara su confianza y sintiera que allí está radicada su defensa.

En realidad, para la gente el Estado es, en un sentido lejano, de los políticos que lo usan como forma de vida, como sostén de su actividad, como lugar donde ejercitar su poder cuando lo tienen. Y en términos de mayor cercanía, de los empleados, quienes atienden a la gente o la desatienden.

Si Argentina, sus provincias, quieren ser honestas con la gente, con el pueblo, tienen que reformar el Estado. Y para reformar el estado tienen que asumir todos los costos de reformar el estado, y tienen que asumir distinto tipo de costos. Porque si reformar el estado es solamente hacer ajuste fiscales, si reformar el estado es simplemente concluir que el consenso de Washington tenía razón y todo el tema es el déficit fiscal cuando es uno de los grandes temas pero no el único, entonces reformaremos rápido y con costos para algunos, no para todos, el Estado.

Reformar es mucho más que eso. En primer lugar no hacerse el zonzo con el déficit fiscal, pero además de eso es darlo vuelta como un guante $\mathrm{y}$ hacerlo transparente $\mathrm{y}$ eficiente. Es imposible hacerlo eficiente si no es transparente, y es imposible que sea transparente si quienes están en el estado tienen cosas que ocultar en el ropero. Y está lleno de funcionarios con cosas que ocultar en el ropero, sean funcionarios de línea, históricos o nuevos, propios de una gestión. (Subsecretaría de la Gestión Pública, 2004:7-8).

Esa reconstrucción, ese nuevo compromiso, ese nuevo modelo de gestión no implicaba, en la concepción del Poder Ejecutivo una nueva "refundación" del Estado.

Porque no hay memoria institucional, se rompe la relación y el vínculo histórico que puede haber entre el Estado y la gente, si se tiene esa actitud de "antes de mí todo fue malo, con mi llegada todo fue distinto", y por algo vivimos en un país donde casi todos los movimientos nuevos tienen la palabra transformación, renovación, reforma; es decir, todo el mundo viene a cambiar y modificar -y si es

${ }^{180}$ La presentación del Plan fue hecha el 15 de abril de 2003. 
posible en 180 grados- lo que encontró. Ese es un pecado de juventud y soberbia muy fuerte. $Y$ en esta aproximación yo no creo o por lo menos creo parcialmente, que a veces tiene sentido y otras veces no (Subsecretaría de la Gestión Pública, 2004-a:6).

Sin embargo, pocos meses después de creada la Secretaría para la Modernización del Estado, en una presentación sobre la estrategia para la modernización del Estado, se sostenía que para lograr un Estado inteligente, impulsor de políticas que propendan al bien común, la reforma debe apoyarse en tres pilares: reformas en los modelos de gestión; reformas en los sistemas transversales y el Gobierno Electrónico.

En agosto de 2002 se sancionó el Decreto $\mathrm{N}^{\mathrm{o}} 1.824 / 02$ que aprobara, por su artículo primero, el Plan Estratégico de Gobierno Electrónico en la Provincia de Buenos Aires. Se dictó cuando estaba al frente de la Secretaría de Modernización el Dr. Hugo Franco con el pase a Jefe de Gabinete de Florencio Randazzo. Se define el proyecto de gobierno electrónico como parte del proceso de reforma del Estado orientado a mejorar la cantidad y calidad de los servicios (Conf. Secretaría para la Modernización del Estado, 2002).

En el seminario sobre Reforma Administrativa, Política y Económica del Estado Provincial, realizado en Tigre en diciembre de 2002 sostuvo que "La necesidad de la reforma del Estado no es una necesidad de modernización solamente. Tiene muchísimo, también, de democratización" (Subsecretaría de la Gestión Pública, 2004a:5; el destacado también es nuestro).

Esa concepción fue sostenida un año más tarde, en 2003, en el discurso de apertura de las sesiones legislativas cuando sostuvo que:

\begin{abstract}
Estoy convencido que no habrá reforma del Estado sin una verdadera reforma política. Aquella que transparente y legitime la relación de los ciudadanos con la política y sus dirigentes. Entendemos que es una condición necesaria, pero no suficiente. No nos reconciliará automáticamente con la sociedad, pero, seguramente, evitará el divorcio definitivo (Subsecretaría de la Gestión Pública, 2004-a:4).
\end{abstract}

Pero un nuevo cambio se advierte cuando la Secretaría para la Modernización del Estado pasa a ser una Subsecretaría de la Secretaría General de la Gobernación, en un primer momento con el nombre de Subsecretaría de la Función Pública, y luego como Subsecretaría de la Gestión Pública, entonces a cargo de la Ing. Agr. Claudia Bernazza.

Desde allí se impulsa el Plan Trienal de la Gestión Pública 2004-2007. La nueva consigna no era cambiar el Estado sino recuperarlo. Se partía del siguiente supuesto: el Estado refleja los valores y la concepción que la sociedad tiene del mismo; el modelo economico había producido el desmantelamiento del Estado de los '90 con funestas 
consecuencias; refortaleciendo el Estado sería posible reconstituir el tejido social y relegitimar, consecuentemente, al Estado ${ }^{181}$.

Ahora bien, ¿cuál era la concepción del ex gobernador sobre la organización del Estado y su funcionamiento? Una remisión a sus discursos públicos ${ }^{182}$ permite identificar su posición:

Ese Estado debe estar fortalecido aún frente a la reducción global de sus gastos, que es inevitable. La otra parte es enemiga de todo crecimiento privado y sólo se piensa a sí misma. Es egoísta, pequeña, rapaz y está envejecida. Concibe una realidad que ya fue. Es el Estado burocrático, el de las oficinas que trabajan para su propia reproducción vegetativa, el de las prebendas que estamos atacando, el que maltrata a los jubilados cuando quieren hacer trámites o cobrar, el que impide la inscripción de industrias, comercios, barrios o productos nuevos, el que nos imposibilita cobrar impuestos, el que hace de las huelgas una rutina (Discurso Apertura Sesiones Legislativas, 01/03/02).

En la consideración pública, el Estado aparece sobredimensionado, burocrático, lento, y como un lugar que sólo se mira a sí mismo y con prácticas cotidianas no claras. Mi gobierno se propone cambiarlo y no voy a aflojar en esto. [...] Ya hemos sufrido las experiencias tanto del estatismo como de la indiferencia y la inacción de un Estado ausente mientras se desmantelaba y concentraba lo poco que quedaba del aparato productivo. Es necesario - lo he decidido - un nuevo compromiso del Estado Provincial con los protagonistas de la producción bonaerense, que sólo se logra a partir de un profundo conocimiento de sus necesidades. (Discurso Apertura Sesiones Legislativas, 01/03/03).

Es cierto que los aspectos relacionados con la reforma del Estado y de la Administración Pública no suelen ser un tema de la "agenda"; pero, como veremos el gobernador había hecho de la "burocracia" uno de sus mayores enemigos.

\section{Cuadro 18 - Discursos del gobernador sobre la palabra "burocracia"}

\section{Burocracia}

Una parte del Estado es socia clara de ese crecimiento: es la parte más legitima y defendible de lo que administramos, el Estado que educa, vigila, previene, investiga, cura, brinda justicia, da crédito, promociona y promueve a los bonaerenses. (...) La otra parte es enemiga de todo crecimiento privado y solo se piensa a sí misma. Es egoísta, pequeña, rapaz y está envejecida. Concibe una realidad que ya fue. Es el Estado burocrático, el de las oficinas que trabajan para su propia reproducción vegetativa; el de las prebendas que estamos atacando; el que maltrata a los jubilados cuando quieren hacer tramites ó cobrar, el que impide la inscripción de industrias, comercios, barrios ó productos nuevos, el que nos imposibilita

181 Así, por ejemplo: "En función de la experiencia, podemos afirmar que difícilmente exista una demanda social de reforma del Estado, por lo cual es interesante trabajar sobre cuestiones específicas que pueden generar un alto grado de legitimidad social, como, por ejemplo, mejorar la seguridad o la educación, aspectos que no tienen mucha relación con una reforma integral, pero que favorecen el inicio de un proceso mayor a partir de ganar la aprobación de la población" (Longo, 2005:14-15).

182 La selección está tomada del documento elaborado por la Subsecretaría de la Gestión Pública, 2004a, págs. 11, 2, 2, 2-3, respectivamente y los destacados nos pertenecen. 
cobrar impuestos, el que hace de las huelgas una rutina.

Apertura del $130^{\circ}$ período legislativo, $1^{\circ}$ de marzo de 2002.

Todo lo que sea gris, burocrático, cobarde, mediocre y rutinario hoy atenta directamente con la posibilidad de que las instituciones sirvan al pueblo en medio de una crisis fenomenal del país para poder apostar a un futuro mejor en el área institucional.

Jornadas provinciales sobre justicia penal democrática y crisis económica, 20 de abril de 2002.

En esta Provincia inmensa no hay otra posibilidad que no sea descentralizar, no hay ninguna posibilidad que no sea hacerse fuerte en La Plata; ¿qué va a tener que vencer uno? A la burocracia de La Plata. En la ciudad de La Plata se vive del Estado provincial, no tengan la menor duda; menos que antes, pero se vive del Estado provincial.

Seminario sobre reforma administrativa, política y económica del Estado provincial, 07 de diciembre de 2002.

Es entender cómo funciona el aparato provincial, y cómo el aparato provincial a lo largo del tiempo ha ido desviando los objetivos para los cuales fue creado cualquier aparato provincial; ha ido desviando los objetivos para hacerlos cada vez más débiles y para hacerlos cada vez más burocrático-dependientes.

Seminario sobre reforma administrativa, política y económica del Estado provincial, 07 de diciembre de 2002.

Esa Argentina que nos duele tiene responsables, unos más, otros menos, las responsabilidades son diferentes de acuerdo a las obligaciones. ¿Cómo se supera eso? Yo he dado un ejemplo de abajo hacia arriba: por ejemplo, los veteranos de Malvinas de Campana deben ser los que más viviendas han logrado construir, lo han hecho porque han tenido constancia y fe y porque no se dejaron vencer por los obstáculos o las burocracias.

$119^{\circ}$ Aniversario de la creación del Partido de Campana-entrega de boletos de compraventa y actas de tenencia, 6 de julio de 2004.

Porque el principal enemigo de un gobierno es el aislamiento, el aislamiento pro burócrata que crea la posibilidad de creer que nadie se va a dar cuenta si uno es un corrupto, el aislamiento que crea una mala clase politica, el protegerse entre nosotros, los que hacemos la misma profesión de políticos mientras los demás somos giles que militan.

Lanzamiento movimiento "Evita", 17 de noviembre de 2005

Es decir, el crédito se moldea según la demanda y no la demanda se acomoda al diseño de los tecnócratas o peor aún de los burócratas, que son los que actúan cuando los políticos nos distraemos.

Apertura del $134^{\circ}$ período de sesiones ordinarias en la Legislatura de la Provincia de Buenos Aires, $\mathbf{1}^{\circ}$ de marzo de 2006.

Nuestro gobierno decidió que entregar un DNI no puede ser una tortura burocrática para quien lo solicita. Tiene que ser un trámite rápido.

Apertura del $134^{\circ}$ período de sesiones ordinarias en la Legislatura de la Provincia de Buenos Aires, $1^{\circ}$ de marzo de 2006.

Fuente: Elaboración propia.

Dicha afirmación se confirma, trazando un mapa conceptual sobre la "burocracia". 
Gráfico 2 - Mapa conceptual sobre la "burocracia"

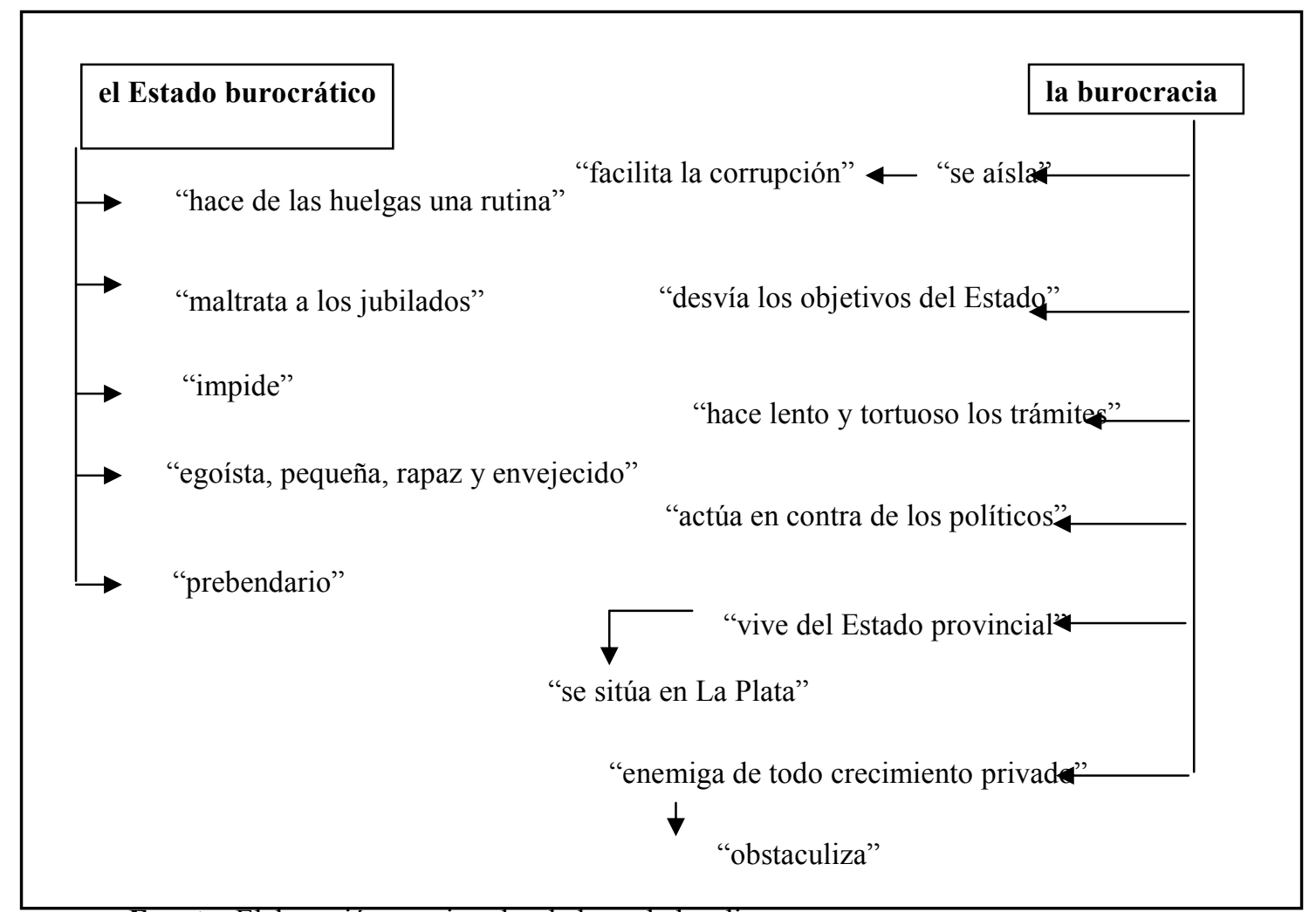

Fuente: Elaboración propia sobre la base de los discursos.

Se advierte, entonces una cierta continuidad en el discurso. Sin embargo, la temática de la reforma del Estado y de la gestión ¿fue un tema verdaderamente prioritario en la agenda diaria del ex gobernador? La realización de un estudio cuantitativo sobre la repetición de ciertas palabras claves en los discursos del entonces gobernador de la Provincia podrá arrojar luz al respecto.

Para dilucidar este aspecto y analizar sus afirmaciones en el contexto general de los discursos y relativizar estas declaraciones, se realizó un análisis cuantitativo semántico de los discursos del ex gobernador, con una selección temática, identificando palabras y temas recurrentes a fin de detectar las verdaderas preocupaciones de la máxima figura política de la provincia. Para ello, se analizó la totalidad de los discursos del Gobernador cargados en la página web de la entonces Secretaría de Prensa y Comunicación Social. ${ }^{183}$ Habiéndose seleccionado 57 palabras claves, el estudio dio como resultado una baja exposición al público de los temas relacionados con la reforma del Estado y de la gestión. ${ }^{184}$

\footnotetext{
183 Esa gran base de datos, incluye desde el discurso de asunción al inicio de su gestión, el 3 de enero de 2002, hasta el 7 de diciembre de 2007. En esos seis años, fueron registrados más de 768 discursos públicos del Gobernador. La cantidad de palabras de la base de datos así obtenida fue de más de 1.263 .000 palabras.

184 Para la selección de las palabras clave se tuvo en cuenta los discursos de asunción del cargo y los discursos de apertura de las sesiones hasta 2006, donde el gobernante define su programa y preferencias en la gestión de gobierno; es un acto frente a otro poder del Estado, de alto contenido y simbolismo político, además de alta exposición mediática.
} 
En efecto, agrupando todos los temas/palabras claves usualmente asociados a la problemática de la reforma de la gestión ${ }^{185}$, éstas no superan el 3\% de la frecuencia de las otras palabras clave, donde, la política, el poder, la seguridad, el Estado ocuparon un lugar central. ${ }^{186}$

Cuadro 19 - Cant. y porc. palabras clave de los discursos del gobernador

\begin{tabular}{|l|r|r|}
\hline PALABRAS & CANTIDAD & \multicolumn{2}{|c|}{ PORCENTAJE } \\
\hline sociedad del conocimiento & 1 & 0,003 \\
\hline ineficacia & 2 & 0,007 \\
\hline gobierno electrónico & 4 & 0,013 \\
\hline gestión pública & 8 & 0,027 \\
\hline tecnocracia & 12 & 0,040 \\
\hline informática & 12 & 0,040 \\
\hline función pública & 15 & 0,050 \\
\hline ineficiencia & 20 & 0,067 \\
\hline terrorismo & 28 & 0,093 \\
\hline modernización & 34 & 0,11 \\
\hline consenso & 35 & 0,12 \\
\hline conflicto & 35 & 0,12 \\
\hline burocracia & 45 & 0,15 \\
\hline legitimidad & 49 & 0,16 \\
\hline eficacia & 58 & 0,19 \\
\hline transparencia & 81 & 0,27 \\
\hline emergencia & 105 & 0,35 \\
\hline corrupción & 137 & 0,46 \\
\hline tecnología & 169 & 0,56 \\
\hline eficiencia & 177 & 0,59 \\
\hline delito & 178 & 0,59 \\
\hline ética & 189 & 0,63 \\
\hline descentralización & 234 & 0,78 \\
\hline democracia & 235 & 0,78 \\
\hline protesta & 237 & 0,79 \\
\hline campo & 311 & 1,04 \\
\hline impuesto & 323 & 1,08 \\
\hline confianza & 325 & 1,08 \\
\hline derechos humanos & 327 & 1,09 \\
\hline delincuencia/delincuente & 344 & 1,15 \\
\hline recuperación & 354 & 1,18 \\
\hline empleo & 384 & 1,28 \\
\hline
\end{tabular}

185 Las palabras fueron: sociedad del conocimiento, ineficacia, gobierno electrónico, gestión pública, tecnocracia, informática, función pública, ineficiencia, modernización, burocracia, eficacia, transparencia, tecnología, eficiencia y descentralización.

${ }^{186}$ Las otras categorías están dadas por los siguientes rótulos y contenidos: a) poder y política (autoridad, poder, unidad, política, Estado); b) educación, empleo y salud (ciencia, empleo, cultura, educación, trabajo, salud); c) democracia (legitimidad, corrupción, ética, democracia, confianza, justicia, pueblo, derechos humanos, consenso); d) producción, economía y desarrollo (campo, impuesto, recuperación, desarrollo, economía, producción, industria, crecimiento); e) seguridad (delito, delincuencia/delincuente, seguridad); f) crisis (terrorismo, problemas, crisis, conflicto, emergencia, protesta); g) otros temas (jóvenes/juventud, necesidades, sociedad, esperanza, fe). 


\begin{tabular}{|l|r|r|}
\hline autoridad & 384 & 1,28 \\
\hline desarrollo & 400 & 1,33 \\
\hline crisis & 413 & 1,38 \\
\hline jóvenes/juventud & 433 & 1,44 \\
\hline economía & 450 & 1,50 \\
\hline necesidades & 559 & 1,86 \\
\hline producción & 580 & 1,93 \\
\hline sociedad & 613 & 2,04 \\
\hline ciencia & 694 & 2,31 \\
\hline esperanza / fe & 706 & 2,35 \\
\hline cultura & 749 & 2,49 \\
\hline industria & 819 & 2,73 \\
\hline educación & 883 & 2,94 \\
\hline responsabilidad & 935 & 3,11 \\
\hline justicia & 938 & 3,12 \\
\hline crecimiento & 1010 & 3,36 \\
\hline poder & 1095 & 3,65 \\
\hline seguridad & 1164 & 3,88 \\
\hline unidad & 1276 & 4,25 \\
\hline pueblo & 1573 & 5,24 \\
\hline salud & 1640 & 5,46 \\
\hline problemas & 1755 & 5,85 \\
\hline política & 2003 & 6,67 \\
\hline trabajo & 2030 & 6,76 \\
\hline Estado & 2451 & 8,16 \\
\hline TOTAL & $\mathbf{3 0 0 2 1}$ & $\mathbf{1 0 0}$ \\
\hline
\end{tabular}

Fuente: Elaboración propia

Gráfico 3 - Nubes de palabras del discursos del Gobernador

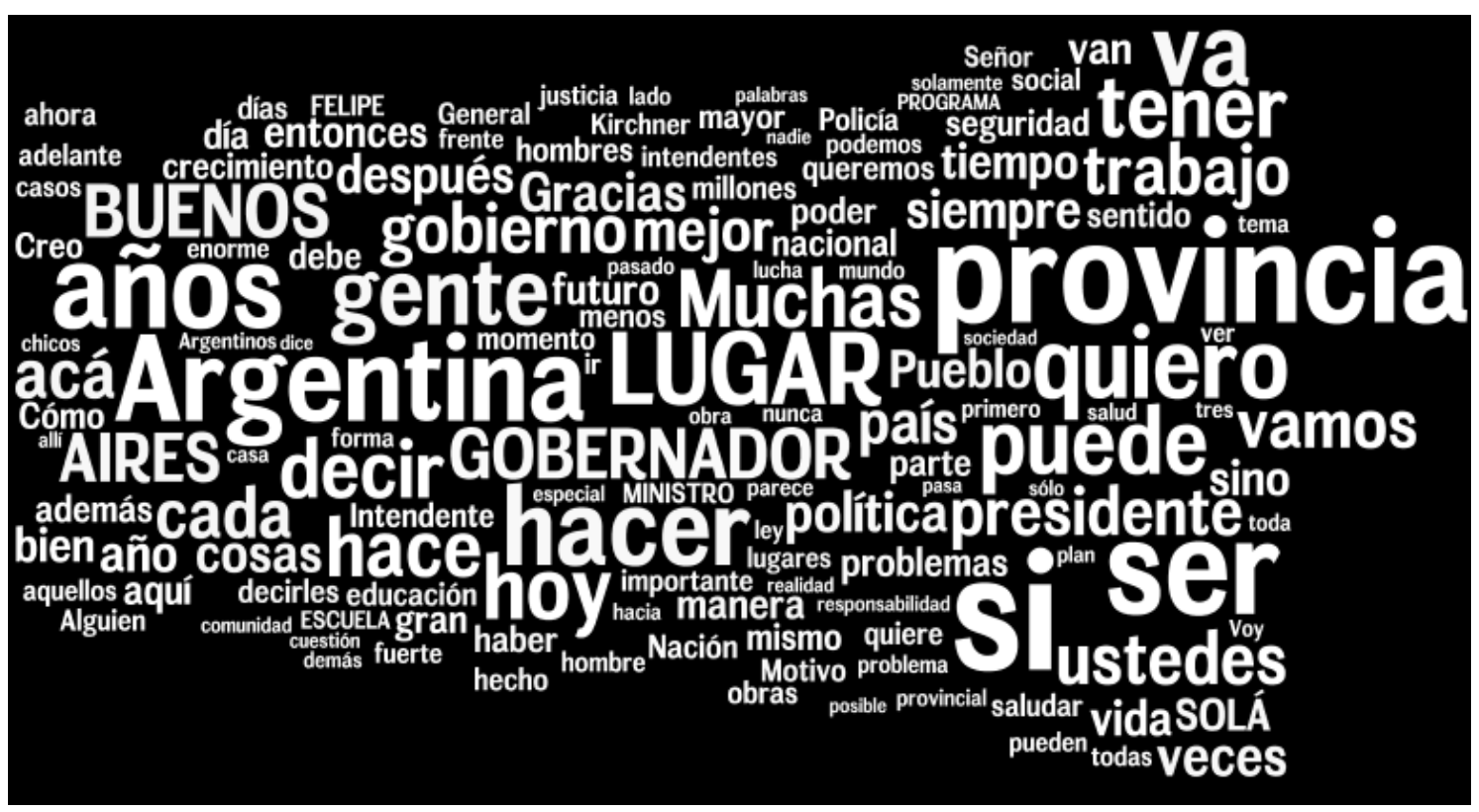

Fuente: Elaboración propia utilizando el sistema disponible en http://www.wordle.net/ 
Gráfico 4 - Temas del discurso del ex gobernador Solá

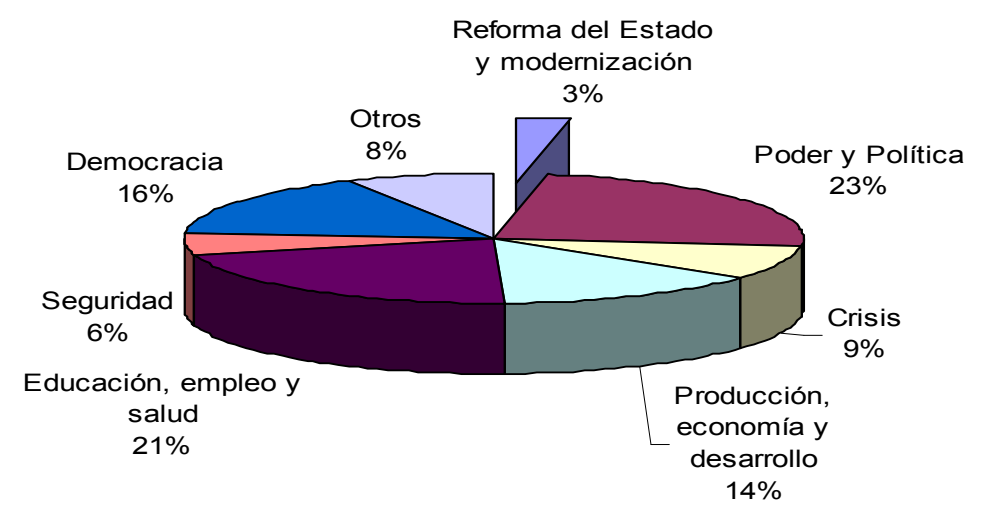

Fuente: Elaboración propia sobre la base de los discursos cargados en la página web de la ex Secretaría de Prensa y Comunicación Social.

Pero, más allá de este panorama global, uno de los objetivos de la tesis es realizar un análisis particular en aquellas áreas cuya misión y rol institucional esté vinculado y/u orientado a los procesos de reforma: la Secretaría para la Modernización del Estado, la Secretaría General de la Gobernación y la Jefatura de Gabinete y el Ministerio de Gobierno ${ }^{187}$.

Como veremos estas áreas son unidades de conducción que marcan una orientación política y técnica sobre cómo otras áreas responsables de producción (sea de productos internos o externos a la administración) deben hacerlo.

Analizaremos por ello, las competencias y funciones de éstas áreas para la reforma del Estado y la Administración Pública bonaerense. Será parte de las conclusiones analizar la concordancia (o no) de estas misiones, junto con el análisis de los Planes y Programas de reforma con los objetivos buscados por la cabeza del ejecutivo.

\section{La Secretaría para la Modernización del Estado}

Con la Ley de Ministerio, Ley No 12.856 y la creación con rango de Secretaría de Estado del área de Modernización, el Gobierno bonaerense parecía otorgar a la política de reforma una importancia trascendental. Dicha normativa preveía como competencia de la Secretaría para la Modernización del Estado la elaboración de las

\footnotetext{
${ }^{187}$ Entendemos por misión y rol institucional a la finalidad institucional establecida, por un lado, y la efectivamente lograda, respectivamente (conf. Hintze, 2001). Será necesario mostrar series cronológicas ilustrativas de la evolución de las estructuras y competencias entre los diferentes organismos responsable de los procesos de reforma.
} 
propuestas de políticas informáticas y de gobierno electrónico, y coordinar con las áreas correspondientes su instrumentación progresiva (conf. artículo 28 de la Ley No 12.856).

El área fue creada por impulso del Cdor. Florencio Randazzo, luego, Jefe de Gabinete y posteriormente, Ministro de Gobierno de la gestión, quien asumió la "conducción política" de la línea interna, llamada "felipismo" conjuntamente con el entonces Secretario General de la Gobernación, Dr. José María González Fernández hasta su alejamiento en 2005 por cuestiones personales y de salud.

La entonces Ley de Ministerios atribuyó como competencias de la Secretaría para la Modernización del Estado, el ejercicio de las siguientes atribuciones:

1- Entender en la elaboración de propuestas de reformas macroestructurales de la Administración Pública Provincial.

2- Diseñar mecanismos técnico administrativos para la instrumentación de la gestión por resultados en las instituciones provinciales.

3- Elaborar propuestas de reestructuración de los sistemas administrativos de apoyo (administración financiera, recursos humanos, compras y contrataciones y capacitación) en coordinación con el Ministerio de Economía y la Secretaría General de la Gobernación.

4- Elaborar, en coordinación con la respectiva área institucional propuestas de descentralización a las Municipalidades de la prestación de servicios.

5- Elaborar propuestas de políticas informáticas y de gobierno electrónico y coordinar con las áreas correspondientes su instrumentación progresiva.

6- Elaborar propuestas de cambios necesarios en el marco jurídico para instrumentar reformas en la organización y sistemas administrativos públicos.

7- Elaborar informes periódicos de avances de la reforma.

8- Elaborar propuestas de reforma política.

Es dable destacar que la fundamentación de la Ley de Ministerios elevada al Congreso por el propio Poder Ejecutivo, se la llamaba "Secretaría para la Reforma del Estado" y se señalaba como responsabilidad la de elaborar políticas y propuestas de reforma y apoyar al gobernador en el proceso de transformación de la Administración Pública provincial y "se le asigna, además la responsabilidad de elaborar propuestas de reforma política, uno de los temas centrales que la dirigencia debe resolver" (el destacado no es del original).

La nueva Secretaría estableció un fuerte marco jurídico de intervención y centralización en los proyectos de modernización.

En efecto, por un lado, por Decreto de estructura de esa nueva Secretaría, Decreto $N^{0}$ 819/02, se emplazó al Instituto Provincial de la Administración Pública (I.P.A.P.), como organismo descentralizado dependiente de la Subsecretaría de la Función Pública en el ámbito de la Secretaría para la Modernización del Estado, transfiriéndose e incorporándose a la Secretaría para la Modernización del Estado, en lo pertinente y de conformidad a las competencias conferidas por la Ley $\mathrm{N}^{\mathrm{o}} 12.856 \mathrm{de}$ 
Ministerios las unidades orgánicas centralizadas y descentralizadas, las plantas del personal nominadas e innominadas, créditos presupuestarios, recursos económicos, financieros y materiales, y cuentas especiales que se correspondían con la Subsecretaría de la Función Pública de la Secretaría General de la Gobernación.

Por otro lado, y en ese mismo ámbito, se creó una Unidad de Coordinación Central para la Modernización del Estado, con carácter ad hoc conformada de manera permanente por el Secretario para la Modernización del Estado y el Responsable Ejecutivo de Proyectos que se integraría, en cada caso según la especificidad temática de los proyectos de reforma y modernización, con la autoridad máxima de los Ministerios y/o Secretarías con competencia e injerencia en la materia, pudiendo delegar tal representación, como así podrá cooptarse a especialistas o expertos invitados. Se aclaraba que todos los miembros integrantes y convocados actuarían en carácter ad honorem (conf. art. 11 Decreto $\mathrm{N}^{\mathrm{o}}$ 819/02).

El artículo siguiente establecía que dicha Unidad debía diseñar, coordinar, controlar $\mathrm{y}$ evaluar el Plan Estratégico Integrado para la transformación $\mathrm{y}$ modernización del Estado, con una definición de objetivos claros, precisos y de transparente interpretación "orientado hacia un cambio integral, sistemático y asistido y con un máximo aprovechamiento de los recursos humanos existentes".

El esquema organizativo se complementaba con la constitución en los organismos centralizados y descentralizados del Poder Ejecutivo Provincial de una Unidad para la Modernización del Estado, cuya conformación dependería de las temáticas, cuestiones, y/o especificidades de los proyectos de reforma y modernización que se determinen como prioritarios para el Estado Provincial.

La función de cada Unidad sectorial consistirá en el monitoreo de la ejecución de los proyectos, planes, programas y acciones que se hayan acordado para la Jurisdicción, debiendo reportar su accionar en la forma y modo que se establezca y se integrarán con aquellas autoridades, especialistas o expertos convocados al efecto (conf. art. 13 Decreto $N^{\circ} 819 / 02$ ).

Cada Unidad determinaría los mecanismos, estrategias y metodologías a seguir en cada dependencia y en función de los objetivos estratégicos asignados por el Poder Ejecutivo a través de la Unidad Central de Coordinación para la Modernización del Estado, contemplando el control de gestión necesario que asegure el cumplimiento de los proyectos, planes y programas y elaborando informes y reportando sobre el resultado alcanzado a la máxima autoridad del organismo y a la Unidad Central de Coordinación para la Modernización del Estado.

Otro Decreto, el No 2419/02, establecía la necesidad de sistematización de los resultados de los Programas vinculados, en general, al fortalecimiento institucional de la administración pública provincial y prever en lo futuro la intervención de la Secretaria de Modernización del Estado en el desarrollo de los mismos. Por ello se prescribía que las distintas jurisdicciones remitieran a la Secretaría para la Modernización del Estado los resultados de cualquier programa que contemple componentes de fortalecimiento institucional, régimen de recursos humanos y reforma de los sistemas administrativos y financieros de apoyo que se hubieran realizado en los últimos cinco (5) años, sin 
importar la fuente de financiamiento de los mismos (art. $1^{\circ}$ ) y que la Secretaría para la Modernización del Estado podría formar comisiones especiales para el análisis de las distintas problemáticas involucradas en el proceso de modernización del sector público provincial, invitando a expertos y representantes de Organizaciones no Gubernamentales y del sector privado a realizar propuestas de mejora y optimización en la gestión pública $\left(\operatorname{art} .2^{\circ}\right)$.

Por último, se dejaba sentado la intervención de la Secretaría para la Modernización del Estado, en forma previa, en la gestión de los programas que contemplen componentes de fortalecimiento institucional cualquiera fuera su fuente de financiamiento conjuntamente con la de todo proyecto normativo que directa $o$ indirectamente implique modificación de estructuras organizativas, dependencias funcionales o jerárquicas $\mathrm{o}$ de reorganización administrativa. Esta competencia constituiría el primer paso hacia la centralización en el diseño de las estructuras que se alcanzaría posteriormente con el Decreto $\mathrm{N}^{\mathrm{o}} 1322 / 05$.

Como veremos más adelante, pocos meses después se sanciona el Decreto $\mathrm{N}^{\mathrm{o}}$ 1.824/02 que aprobó, por su artículo primero, el Plan Estratégico de Gobierno Electrónico en el ámbito de la Secretaría de la Modernización.

\section{Jefatura de Gabinete y Ministerio de Gobierno}

La modificación de la Ley de Ministerios, Ley $\mathrm{N}^{\mathrm{0}}$ 12.928, de agosto de 2002, creó la Jefatura de Gabinete. Es especialmente importante para nuestro estudio comprobar las competencias de esta nueva área, con rango de Secretaría ministerial, pues la misma fue creada como iniciativa del entonces Secretario para la Modernización del Estado, quien pasó a ocupar ese cargo. Era esperable -y una consecuencia naturalque el nuevo "Ministerio" tuviera las incumbencias en materia de modernización y gobierno electrónico atento a ser el organismo, por principio, transversal y encargado de llevar adelante los proyectos y programas que involucran a toda la Administración Pública. Pero ello no sucedió. ${ }^{188}$

En el siguiente cuadro transcribimos las competencias de las dos últimas leyes de Ministerio de la gestión de Solá, donde podemos observar que no hubo grandes cambios.

Cuadro 20 - Competencias de Jefatura de Gabinete

188 En la Nación, la tanto el área de Gestión Pública, como la ONTI y Gobierno Electrónico, dependen de la estructura de la Jefatura de Gabinete de Ministros, por la naturaleza transversal de sus acciones. 


\begin{tabular}{|c|c|}
\hline 1. Coordinar las reuniones de Gabinete de Ministros. & $\begin{array}{l}\text { 1. Convocar y coordinar las reuniones de Gabinete de } \\
\text { Ministros. }\end{array}$ \\
\hline $\begin{array}{l}\text { 2. Ejercer todas aquellas funciones de coordinación } \\
\text { entre los diferentes Ministerios y Secretarías, que } \\
\text { sean necesarios para el cumplimiento de los } \\
\text { objetivos propuestos por el Poder Ejecutivo. }\end{array}$ & $\begin{array}{l}\text { 2. Ejercer todas aquellas funciones de coordinación } \\
\text { entre los diferentes Ministerios y Secretarías, que } \\
\text { sean necesarios para el cumplimiento de los objetivos } \\
\text { propuestos por el Poder Ejecutivo. }\end{array}$ \\
\hline \multirow[t]{2}{*}{$\begin{array}{l}\text { 3. Proponer la creación de Comisiones } \\
\text { interministeriales, o de cualquier nivel de } \\
\text { integración, que hagan a la mejor ejecución, } \\
\text { coordinación y control de gestión de los planes, } \\
\text { programas y proyectos emanados del Poder } \\
\text { Ejecutivo. }\end{array}$} & $\begin{array}{l}\text { 3. Proponer la creación de Comisiones } \\
\text { interministeriales, o de cualquier nivel de } \\
\text { integración, que hagan a la mejor ejecución, } \\
\text { coordinación y control de gestión de los planes, } \\
\text { programas y proyectos emanados del Poder } \\
\text { Ejecutivo. }\end{array}$ \\
\hline & $\begin{array}{l}\text { 4. Diseñar, coordinar y evaluar los programas } \\
\text { interministeriales, interorganizacionales e } \\
\text { interjurisdiccionales, en concurrencia con las } \\
\text { áreas con competencias afines. }\end{array}$ \\
\hline $\begin{array}{l}\text { 4. Atender las actividades relacionadas con el } \\
\text { protocolo en los actos oficiales, la organización y } \\
\text { coordinación de los actos, ceremonias y reuniones } \\
\text { que se lleven a cabo en la Gobernación. Organizar y } \\
\text { coordinar las audiencias del Sr. Gobernador y } \\
\text { atender a las delegaciones y personalidades que } \\
\text { concurran a entrevistarlo. }\end{array}$ & $\begin{array}{l}\text { 5. Atender las actividades relacionadas con el } \\
\text { protocolo en los actos oficiales, la organización y } \\
\text { coordinación de los actos, ceremonias y reuniones } \\
\text { que se lleven a cabo en la Gobernación. Organizar y } \\
\text { coordinar las audiencias del Sr. Gobernador y atender } \\
\text { a las delegaciones y personalidades que concurran a } \\
\text { entrevistarlo. }\end{array}$ \\
\hline $\begin{array}{l}\text { 5. Coordinar en las distintas Casas de la Provincia de } \\
\text { Buenos Aires radicadas o que se radiquen en } \\
\text { territorio argentino y en el exterior, la difusión y } \\
\text { promoción de los aspectos económicos, culturales, } \\
\text { históricos, científicos y turísticos y todo otro de } \\
\text { interés provincial, supervisando la participación en } \\
\text { ellas de las distintas áreas gubernamentales. }\end{array}$ & $\begin{array}{l}\text { 6. Coordinar en las distintas Casas de la Provincia de } \\
\text { Buenos Aires radicadas o que se radiquen en } \\
\text { territorio argentino y en el exterior, la difusión y } \\
\text { promoción de los aspectos económicos, culturales, } \\
\text { históricos, científicos y turísticos y todo otro de } \\
\text { interés provincial, supervisando la participación en } \\
\text { ellas de las distintas áreas gubernamentales. }\end{array}$ \\
\hline $\begin{array}{l}\text { 6. Ejercer el control de gestión de los distintos } \\
\text { planes, programas y acciones desarrolladas por las } \\
\text { distintas áreas de gobierno. }\end{array}$ & $\begin{array}{l}\text { 7. Ejercer el control de gestión de los distintos } \\
\text { planes, programas y acciones desarrolladas por las } \\
\text { distintas áreas de gobierno. }\end{array}$ \\
\hline $\begin{array}{l}\text { 7. Atender las actividades relacionadas con la } \\
\text { institucionalización del enlace entre el Gobierno }\end{array}$ & $\begin{array}{l}\text { 8. Atender las actividades relacionadas con la } \\
\text { institucionalización del enlace entre el Gobierno }\end{array}$ \\
\hline Provincial y la Jerarquía Eclesiástica de la Iglesia & Provincial y la Jerarquía Eclesiástica de la Iglesia \\
\hline $\begin{array}{l}\text { Católica y desarrollar un sistema de fluida y estrecha } \\
\text { comunicación entre dichos ámbitos. Actuar en lo } \\
\text { inherente a las relaciones del Gobierno Provincial } \\
\text { con todas las iglesias, confesiones y comunidades } \\
\text { religiosas que funcionan en su territorio. }\end{array}$ & $\begin{array}{l}\text { Católica y desarrollar un sistema de fluida y estrecha } \\
\text { comunicación entre dichos ámbitos. Actuar en lo } \\
\text { inherente a las relaciones del Gobierno Provincial } \\
\text { con todas las iglesias, confesiones y comunidades } \\
\text { religiosas que funcionan en su territorio. }\end{array}$ \\
\hline
\end{tabular}

Fuente: Elaboración propia.

Nota: En negritas, se indican las actividades transversales.

Las competencias de la Jefatura de Gabinete, sólo tangencialmente establecen funciones de coordinación, reforma y modernización.

Pero la iniciativa de reforma se trasladó, junto con el traspaso del funcionario, de la Jefatura de Gabinete, al Ministerio de Gobierno.

Veamos las competencias de la Ley de Ministerio vigente al momento de asumir Florencio Randazzo el Ministerio de Gobierno (2004-2007):

Ley No 13.175 - ARTÍCULO 16.- Le corresponde al Ministerio de Gobierno asistir al Gobernador de la Provincia en todo lo inherente a 
la determinación, ejecución y coordinación de las políticas relacionadas con el gobierno político y de aplicación a los Municipios, a las entidades intermedias y profesionales al ejercicio pleno de los principios, derechos y garantías constitucionales. En especial le compete:

1. Refrendar los actos administrativos de los organismos públicos.

2. Intervenir en las relaciones atinentes a las cuestiones de límites y aplicación de políticas complementarias, tratados y convenios; así como en aquellas que correspondan con el cuerpo consular.

3. Ejercer la Policía de culto.

4. Las relaciones con los municipios y con otras provincias en cuestiones limítrofes, evaluar y aconsejar sobre la creación de nuevos municipios o proponer la reunión o división de los existentes, así como participar y proyectar las propuestas de regionalización.

5. Intervenir en la dirección política relativa a la negociación de pactos, convenios, protocolos, tratados y cualquier otro acuerdo de la Provincia con el Estado Nacional, con los Estados Provinciales y con los Municipios, sin perjuicio y en concordancia con las competencias atribuidas a los restantes Departamentos de Estado.

6. Asistir en la determinación de pautas y criterios sociodemográficos con el fin de impulsar su inclusión en los planes y programas de desarrollo social, tecnológico, económico, ambiental y cultural, a partir de la ponderación de los indicadores macro y micro estructurales y de los diagnósticos de situación.

7. Asistir en la determinación y caracterización de la identidad cultural local, regional y territorial de la provincia, contemplando las corrientes migratorias internas y externas.

8. Proponer la política relacionada con la migración e inmigración.

9. Intervenir en la política demográfica provincial. Desarrollar proyecciones de variables socio-tecno-económico-ambiental y cultural relacionadas con el volumen de población, distribución, diversidad y de ordenamiento territorial y de infraestructura, y con el desarrollo local, regional y provincial.

10. Las relaciones con la Junta Electoral, las entidades, los partidos políticos y demás entes y reparticiones del gobierno provincial.

11. Intervenir en la custodia de los emblemas y símbolos provinciales y en la reglamentación de su uso, como así también en lo relativo a actos patrióticos y de homenaje.

12. Asesorar y proponer al Gobernador sobre feriados y asuetos administrativos.

13. El régimen institucional de todas las profesiones que se ejercen en el territorio de la Provincia, en especial las que se rigen por el derecho público y sus respectivas cajas previsionales, con independencia de la regulación referida a cada especialidad que la legislación atribuya a otras áreas.

14. Mantener ordenado y actualizado el registro central de las personas, realizando las funciones de inscripción del estado civil, de los hechos vitales, capacidad, identificación, paradero desconocido, estadística demográfica y domicilio de las personas, promoviendo las acciones judiciales necesarias, realizar la identificación personal y ordenar la modificación del contenido de los asientos de estadística.

15. Mantener actualizados: los Registros de las personas con paradero desconocido, de Infractores de Tránsito, y, del sistema de informática 
jurídico-legal necesario al registro organizado de las entidades profesionales y cumplimentar lo establecido en el convenio suscripto con el Sistema Nacional de Informática Jurídica.

16. Publicar los actos administrativos y judiciales emanados de los Poderes Ejecutivo, Legislativo y Judicial, los avisos provenientes de los Organismos Oficiales Nacionales, Provinciales y Municipales, Entes Autárquicos y Descentralizados y las publicaciones de entidades particulares que respondan a exigencias reglamentarias.

17. Organizar y aplicar el régimen notarial y designaciones de escribanos titulares, adscriptos y suplentes de registro.

18. Efectuar la planificación, programación, ejecución y control del ordenamiento urbano y territorial, coordinando acciones comunes con las jurisdicciones que correspondan y con los municipios.

19. Efectuar análisis y estudios para el dictado de normas relacionadas con el ordenamiento urbano y elaborar y proponer los proyectos pertinentes.

20. Colaborar y asesorar a los municipios sobre cuestiones vinculadas al desarrollo y equipamiento urbano, coordinando su accionar con otras áreas con competencias concurrentes.

21. Ejecutar el ordenamiento físico, urbano y regional del territorio, coordinando acciones con otras carteras ministeriales en la materia.

22. Intervenir en los procedimientos de regularización y acceso a la titularidad dominial en coordinación con otras autoridades de aplicación de las normas respectivas y organismos especiales, si los hubiere.

Como hemos visto, las competencias de la Ley de Ministerio no le atribuían competencias propias para la reforma administrativa, aunque sí política a la que, como hemos visto, al Gobernador situaba como central para la reforma del Estado.

\section{Secretaría General de la Gobernación}

Como detallaremos, la Secretaría General de la Gobernación fue el organismo que, según la última reforma ministerial de la gestión bajo análisis, poseería las competencias necesarias para el desarrollo de las políticas para la reforma administrativa. Un cuadro comparativo de esas responsabilidades dará cuenta de ello.

Cuadro 21 - Competencias de la Secretaría General de la Gobernación

\begin{tabular}{|l|l|l|}
\hline \multicolumn{1}{|c|}{ Ley N $\mathbf{N}^{\mathbf{0}} \mathbf{1 2 . 8 5 6}$} & \multicolumn{1}{c|}{ Ley N $\mathbf{N}^{\mathbf{0}} \mathbf{1 3 . 1 7 5}$} \\
\hline $\begin{array}{l}\text { 1- Coordinar las reuniones de } \\
\text { Gabinete de Ministros. }\end{array}$ & $\begin{array}{l}\text { Competencia de la Jefatura de } \\
\text { Gabinete }\end{array}$ & $\begin{array}{l}\text { Competencia de la Jefatura de } \\
\text { Gabinete }\end{array}$ \\
\hline $\begin{array}{l}\text { 2- Proponer la creación de } \\
\text { Comisiones Interministeriales, o } \\
\text { de cualquier nivel de } \\
\text { integración, que hagan a la } \\
\text { mejor ejecución, coordinación y } \\
\text { control de gestión de los planes, } \\
\text { programas y proyectos }\end{array}$ & $\begin{array}{l}\text { Competencia de la Jefatura de } \\
\text { Gabinete }\end{array}$ & $\begin{array}{l}\text { Competencia de la Jefatura de } \\
\text { Gabinete }\end{array}$ \\
\hline
\end{tabular}




\begin{tabular}{|c|c|c|}
\hline emanados del Poder Ejecutivo. & & \\
\hline $\begin{array}{l}\text { 3- Coordinar el despacho de los } \\
\text { actos de alcance general y } \\
\text { particular que se sometan a } \\
\text { consideración del Poder Ejecutivo. } \\
\text { Evaluar y en su caso elaborar los } \\
\text { proyectos de actos administrativos, } \\
\text { iniciativas y convenios. }\end{array}$ & $\begin{array}{l}\text { 1. Coordinar el despacho de los } \\
\text { actos de alcance general y } \\
\text { particular que se sometan a } \\
\text { consideración del Poder Ejecutivo. } \\
\text { Evaluar y en su caso elaborar, los } \\
\text { proyectos de actos administrativos, } \\
\text { iniciativas y convenios. }\end{array}$ & $\begin{array}{l}\text { 1. Coordinar el despacho de los } \\
\text { actos de alcance general y } \\
\text { particular que se sometan a } \\
\text { consideración del Poder Ejecutivo. } \\
\text { Evaluar y en su caso elaborar, los } \\
\text { proyectos de actos administrativos, } \\
\text { iniciativas y convenios. }\end{array}$ \\
\hline $\begin{array}{l}\text { 4- Elaborar, proponer, y ejecutar } \\
\text { planes, programas y proyectos en } \\
\text { materia de ordenamiento } \\
\text { legislativo. }\end{array}$ & $\begin{array}{l}\text { 2. Elaborar, proponer, y ejecutar } \\
\text { planes, programas y proyectos en } \\
\text { materia de ordenamiento } \\
\text { legislativo. }\end{array}$ & $\begin{array}{l}\text { 2. Elaborar, proponer, y ejecutar } \\
\text { planes, programas y proyectos en } \\
\text { materia de ordenamiento } \\
\text { legislativo. }\end{array}$ \\
\hline $\begin{array}{l}\text { - Dar trámite a los proyectos de } \\
\text { Ley sancionados por la } \\
\text { Legislatura, a los fines } \\
\text { establecidos en los artículos } 108, \\
109,110 \text { y } 111 \text { de la Constitución } \\
\text { de la Provincia de Buenos Aires. } \\
\end{array}$ & $\begin{array}{l}\text { 3. Dar trámite a los proyectos de } \\
\text { Ley sancionados por la } \\
\text { Legislatura, a los fines } \\
\text { establecidos en los artículos } 108, \\
109,110 \text { y } 111 \text { de la Constitución } \\
\text { de la Provincia de Buenos Aires. } \\
\end{array}$ & $\begin{array}{l}\text { 3. Dar trámite a los proyectos de } \\
\text { Ley sancionados por la } \\
\text { Legislatura, a los fines } \\
\text { establecidos en los artículos } 108, \\
109,110 \text { y } 111 \text { de la Constitución } \\
\text { de la Provincia de Buenos Aires. } \\
\end{array}$ \\
\hline $\begin{array}{l}\text { 6- Protocolizar, registrar y archivar } \\
\text { los actos dictados por el } \\
\text { Gobernador, y adoptar los } \\
\text { recaudos necesarios para la } \\
\text { publicación de los mismos. }\end{array}$ & $\begin{array}{l}\text { 4. Protocolizar, registrar y archivar } \\
\text { los actos dictados por el } \\
\text { Gobernador, y adoptar tos } \\
\text { recaudos necesarios para la } \\
\text { publicación de los mismos. }\end{array}$ & $\begin{array}{l}\text { 4. Protocolizar, registrar y archivar } \\
\text { los actos dictados por el } \\
\text { Gobernador, y adoptar los } \\
\text { recaudos necesarios para la } \\
\text { publicación de los mismos. }\end{array}$ \\
\hline $\begin{array}{l}\text { 7- Poner en conocimiento del } \\
\text { Gobernador los pedidos de } \\
\text { informe y/o explicaciones } \\
\text { formulados por la Legislatura } \\
\text { vinculados con las funciones o } \\
\text { atribuciones del Poder Ejecutivo } \\
\text { Provincial. }\end{array}$ & $\begin{array}{l}\text { 5. Poner en conocimiento del } \\
\text { Gobernador los pedidos de } \\
\text { informe y/o explicaciones } \\
\text { formulados por la Legislatura, } \\
\text { vinculados con las funciones o } \\
\text { atribuciones del Poder Ejecutivo } \\
\text { Provincial. }\end{array}$ & $\begin{array}{l}\text { 5. Poner en conocimiento del } \\
\text { Gobernador los pedidos de } \\
\text { informe y/o explicaciones } \\
\text { formulados por la Legislatura, } \\
\text { vinculados con las funciones o } \\
\text { atribuciones del Poder Ejecutivo } \\
\text { Provincial. }\end{array}$ \\
\hline $\begin{array}{l}\text { 8- Organizar y supervisar el } \\
\text { registro de la normativa que rige } \\
\text { las acciones de gobierno y la } \\
\text { administración pública en general. }\end{array}$ & $\begin{array}{l}\text { 6. Organizar y supervisar el } \\
\text { registro de la normativa que rigen } \\
\text { las acciones de gobierno y la } \\
\text { administración pública en general. }\end{array}$ & $\begin{array}{l}\text { 6. Organizar y supervisar el } \\
\text { registro de la normativa que rigen } \\
\text { las acciones de gobierno y la } \\
\text { administración pública en general, } \\
\text { coordinando su accionar con la } \\
\text { Asesoría General de Gobierno. }\end{array}$ \\
\hline $\begin{array}{l}\text { 9- Coordinar las iniciativas del } \\
\text { Poder Ejecutivo en materia de } \\
\text { legislación. }\end{array}$ & $\begin{array}{l}\text { 9. Coordinar las iniciativas del } \\
\text { Poder Ejecutivo en materia de } \\
\text { legislación. }\end{array}$ & $\begin{array}{l}\text { 10. Coordinar las iniciativas del } \\
\text { Poder Ejecutivo en materia de } \\
\text { legislación. }\end{array}$ \\
\hline & $\begin{array}{l}\text { 7. Elaborar, definir y ejecutar, } \\
\text { conforme las politicas emanadas } \\
\text { del Poder Ejecutivo, los } \\
\text { programas, proyectos y acciones } \\
\text { en materia de cooperación } \\
\text { internacional de la Provincia. }\end{array}$ & $\begin{array}{l}\text { 7. Elaborar, definir y ejecutar, } \\
\text { conforme las políticas emanadas } \\
\text { del Poder Ejecutivo, los } \\
\text { programas, proyectos y acciones } \\
\text { en materia de cooperación } \\
\text { internacional de la Provincia. }\end{array}$ \\
\hline & $\begin{array}{l}\text { 8. Generar y optimizar la } \\
\text { aplicación de los mecanismos } \\
\text { internacionales de cooperación } \\
\text { técnica y fortalecimiento } \\
\text { institucional, tanto bilaterales } \\
\text { como multilaterales; ejerciendo a } \\
\text { tal efecto, las relaciones } \\
\text { funcionales con los organismos } \\
\text { nacionales e internacionales con }\end{array}$ & $\begin{array}{l}\text { 8. Generar y optimizar la } \\
\text { aplicación de los mecanismos } \\
\text { internacionales de cooperación } \\
\text { técnica y fortalecimiento } \\
\text { institucional, tanto bilaterales } \\
\text { como multilaterales; ejerciendo a } \\
\text { tal efecto y en representación del } \\
\text { Poder Ejecutivo, las relaciones } \\
\text { funcionales con los organismos }\end{array}$ \\
\hline
\end{tabular}




\begin{tabular}{|c|c|c|}
\hline & competencia en la materia. & $\begin{array}{l}\text { nacionales e internacionales con } \\
\text { competencia en la materia. }\end{array}$ \\
\hline & & $\begin{array}{l}\text { 9. Coordinar con los organismos } \\
\text { y/o carteras provinciales la } \\
\text { ejecución y la aplicación de los } \\
\text { proyectos de cooperación, de } \\
\text { acuerdo a los fines a los que se } \\
\text { encuentren destinados. }\end{array}$ \\
\hline $\begin{array}{l}\text { 10- Diseñar, proponer, organizar, } \\
\text { supervisar y ejecutar, conforme a } \\
\text { las pautas que fije el Poder }\end{array}$ & $\begin{array}{l}\text { 10. Diseñar, proponer, organizar, } \\
\text { supervisar y ejecutar, conforme a } \\
\text { las pautas que fije el Poder }\end{array}$ & $\begin{array}{l}\text { 11. Diseñar, proponer, organizar, } \\
\text { supervisar y ejecutar, conforme a } \\
\text { las pautas que fije el Poder }\end{array}$ \\
\hline $\begin{array}{l}\text { Ejecutivo las políticas provinciales } \\
\text { sobre recursos humanos. }\end{array}$ & $\begin{array}{l}\text { Ejecutivo las políticas provinciales } \\
\text { sobre recursos humanos. }\end{array}$ & $\begin{array}{l}\text { Ejecutivo las políticas provinciales } \\
\text { sobre recursos humanos. }\end{array}$ \\
\hline $\begin{array}{l}\text { 11- Entender en la elaboración y } \\
\text { aplicación de la política salarial } \\
\text { del sector público, coordinando la } \\
\text { participación de otros ministerios } \\
\text { y organismos en cuanto } \\
\text { corresponda. }\end{array}$ & $\begin{array}{l}\text { 11. Entender en la elaboración y } \\
\text { aplicación de la política salarial } \\
\text { del sector público, coordinando la } \\
\text { participación de otros ministerios } \\
\text { y organismos en cuanto } \\
\text { corresponda. }\end{array}$ & $\begin{array}{l}\text { 12. Entender en la elaboración y } \\
\text { aplicación de la política salarial del } \\
\text { sector público, coordinando la } \\
\text { participación de otros ministerios y } \\
\text { organismos en cuanto corresponda. }\end{array}$ \\
\hline $\begin{array}{l}\text { 12- Organizar el sistema } \\
\text { provincial de informática, sin } \\
\text { perjuicio de las competencias que } \\
\text { sobre la materia tienen asignadas } \\
\text { las carteras ministeriales. }\end{array}$ & $\begin{array}{l}\text { 12. Organizar el sistema provincial } \\
\text { de informática, sin perjuicio de las } \\
\text { competencias que sobre la materia } \\
\text { tienen asignadas las carteras } \\
\text { ministeriales. }\end{array}$ & $\begin{array}{l}\text { 13. Organizar los sistemas } \\
\text { provinciales de informática y } \\
\text { comunicaciones, sin perjuicio de } \\
\text { las competencias que sobre la } \\
\text { materia tienen asignadas las } \\
\text { carteras ministeriales. }\end{array}$ \\
\hline \begin{tabular}{|l|} 
13- Programar y ejecutar la \\
difusión pública de los actos de \\
gobierno, manteniendo relación \\
con los servicios informativos de \\
los medios de comunicación. \\
\end{tabular} & $\begin{array}{l}\text { 13. Programar y ejecutar la } \\
\text { difusión pública de los actos de } \\
\text { gobierno, manteniendo relación } \\
\text { con los servicios informativos de } \\
\text { los medios }\end{array}$ & $\begin{array}{l}\text { Competencia de la Secretaría de } \\
\text { Prensa y Comunicación Social }\end{array}$ \\
\hline $\begin{array}{l}\text { 14- Organizar, programar e } \\
\text { implementar la prestación de los } \\
\text { servicios de apoyo necesarios para } \\
\text { la difusión de las distintas acciones } \\
\text { de gobierno. }\end{array}$ & $\begin{array}{l}\text { 14. Organizar, programar e } \\
\text { implementar la prestación de los } \\
\text { servicios de apoyo necesarios para } \\
\text { la difusión de las distintas acciones } \\
\text { de gobierno. }\end{array}$ & $\begin{array}{l}\text { Competencia de la Secretaría de } \\
\text { Prensa y Comunicación Social }\end{array}$ \\
\hline $\begin{array}{l}\text { 15- Coordinar y ejecutar las } \\
\text { actividades periodísticas y de } \\
\text { divulgación de la información } \\
\text { requerida por los distintos } \\
\text { organismos provinciales y } \\
\text { municipales. } \\
\end{array}$ & $\begin{array}{l}\text { 15. Coordinar y ejecutar las } \\
\text { actividades periodísticas y de } \\
\text { divulgación de la información } \\
\text { requerida por los distintos } \\
\text { organismos provinciales y } \\
\text { municipales. }\end{array}$ & $\begin{array}{l}\text { Competencia de la Secretaría de } \\
\text { Prensa y Comunicación Social }\end{array}$ \\
\hline $\begin{array}{l}\text { 16- Organizar, programar y } \\
\text { planificar el funcionamiento de la } \\
\text { emisora L.S.11 Radio Provincia de } \\
\text { Buenos Aires. Coordinar su } \\
\text { programación y elaborar y } \\
\text { proponer las medidas de } \\
\text { optimización que se consideren } \\
\text { acordes con las políticas a } \\
\text { implementar. }\end{array}$ & $\begin{array}{l}\text { 16. Organizar, programar y } \\
\text { planificar el funcionamiento de la } \\
\text { emisora L.S.11 Radio Provincia de } \\
\text { Buenos Aires. Coordinar su } \\
\text { programación y elaborar y } \\
\text { proponer las medidas de } \\
\text { optimización que se consideren } \\
\text { acordes con las políticas a } \\
\text { implementar. }\end{array}$ & $\begin{array}{l}\text { Competencia de la Secretaría de } \\
\text { Prensa y Comunicación Social }\end{array}$ \\
\hline $\begin{array}{l}\text { 17- Atender las actividades } \\
\text { relacionadas con el protocolo en } \\
\text { los actos oficiales, la organización } \\
\text { y coordinación de los actos, } \\
\text { ceremonias y reuniones que se } \\
\text { lleven a cabo en la Gobernación. }\end{array}$ & $\begin{array}{l}\text { Competencia de la Jefatura de } \\
\text { Gabinete }\end{array}$ & $\begin{array}{l}\text { Competencia de la Jefatura de } \\
\text { Gabinete }\end{array}$ \\
\hline
\end{tabular}




\begin{tabular}{|c|c|c|}
\hline $\begin{array}{l}\text { Organizar y coordinar las } \\
\text { audiencias del Sr. Gobernador y } \\
\text { atender a las delegaciones y } \\
\text { personalidades que concurran a } \\
\text { entrevistarlo. }\end{array}$ & & \\
\hline $\begin{array}{l}\text { 18- Programar, organizar, } \\
\text { implementar y fiscalizar el } \\
\text { funcionamiento de los servicios de } \\
\text { telecomunicación y radiodifusión, } \\
\text { interviniendo en la promoción y } \\
\text { expansión de sistemas, medios, } \\
\text { estaciones, redes y canales de } \\
\text { comunicación, y proponer las } \\
\text { reglamentaciones pertinentes. }\end{array}$ & $\begin{array}{l}\text { 17. Programar, organizar, } \\
\text { implementar y fiscalizar el } \\
\text { funcionamiento de los servicios de } \\
\text { telecomunicación y radiodifusión, } \\
\text { interviniendo en la promoción y } \\
\text { expansión de sistemas, medios, } \\
\text { estaciones, redes y canales de } \\
\text { comunicación, y proponer las } \\
\text { reglamentaciones pertinentes. }\end{array}$ & $\begin{array}{l}\text { Competencia de la Jefatura de } \\
\text { Gabinete }\end{array}$ \\
\hline $\begin{array}{l}\text { 19- Coordinar en las distintas } \\
\text { Casas de la Provincia de Buenos } \\
\text { Aires radicadas o que se radiquen } \\
\text { en territorio argentino y en el } \\
\text { exterior, la difusión y promoción } \\
\text { de los aspectos económicos, } \\
\text { culturales, histéricos, científicos y } \\
\text { turísticos y todo otro de interés } \\
\text { provincial, supervisando la } \\
\text { participación en ellas de las } \\
\text { distintas áreas gubernamentales. }\end{array}$ & $\begin{array}{l}\text { Competencia de la Jefatura de } \\
\text { Gabinete }\end{array}$ & $\begin{array}{l}\text { Competencia de la Jefatura de } \\
\text { Gabinete }\end{array}$ \\
\hline $\begin{array}{l}\text { 20- Atender las actividades } \\
\text { relacionadas con la } \\
\text { institucionalización del enlace } \\
\text { entre el Gobierno provincial y la } \\
\text { Jerarquía Eclesiástica de la Iglesia } \\
\text { Católica y desarrollar un sistema } \\
\text { de fluida y estrecha comunicación } \\
\text { entre ambos ámbitos. Actuar en lo } \\
\text { inherente a las relaciones del } \\
\text { Gobierno provincial con todas las } \\
\text { iglesias, confesiones y } \\
\text { comunidades religiosas que } \\
\text { funcionan en su territorio. }\end{array}$ & $\begin{array}{l}\text { Competencia de la Jefatura de } \\
\text { Gabinete }\end{array}$ & $\begin{array}{l}\text { Competencia de la Jefatura de } \\
\text { Gabinete }\end{array}$ \\
\hline \multirow[t]{3}{*}{$\begin{array}{l}\text { 21- Ejecutar las políticas que se } \\
\text { establezcan en materia de } \\
\text { aeronavegación, infraestructura } \\
\text { aeronáutica y servicios aéreos. } \\
\text { Organizar e implementar las } \\
\text { acciones para el desarrollo de los } \\
\text { servicios, los aeródromos } \\
\text { provinciales y los recursos } \\
\text { económicos, en coordinación con } \\
\text { las distintas jurisdicciones } \\
\text { involucradas }\end{array}$} & $\begin{array}{l}\text { 18. Ejecutar las políticas que se } \\
\text { establezcan en materia de } \\
\text { Aeronavegación, infraestructura } \\
\text { aeronáutica y servicios aéreos. } \\
\text { Organizar e implementar las } \\
\text { acciones para el desarrollo de los } \\
\text { servicios, los aeródromos } \\
\text { provinciales y los recursos } \\
\text { económicos, en coordinación con } \\
\text { las distintas jurisdicciones } \\
\text { involucradas. }\end{array}$ & $\begin{array}{l}\text { 14. Ejecutar las políticas que se } \\
\text { establezcan en materia de } \\
\text { aeronavegación, infraestructura } \\
\text { aeronáutica y servicios aéreos. } \\
\text { Organizar e implementar las } \\
\text { acciones para el desarrollo de los } \\
\text { servicios, los aeródromos } \\
\text { provinciales y los recursos } \\
\text { económicos, en coordinación con } \\
\text { las distintas jurisdicciones } \\
\text { involucradas. }\end{array}$ \\
\hline & & $\begin{array}{l}\text { 15. Confeccionar la agenda } \\
\text { sistémica del Poder Ejecutivo. }\end{array}$ \\
\hline & & $\begin{array}{l}\text { 16. Actuar como organismo rector } \\
\text { del poder ejecutivo, en materia } \\
\text { de: investigaciones cientificas y } \\
\text { tecnológicas, reforma y } \\
\text { modernización; relaciones con las }\end{array}$ \\
\hline
\end{tabular}




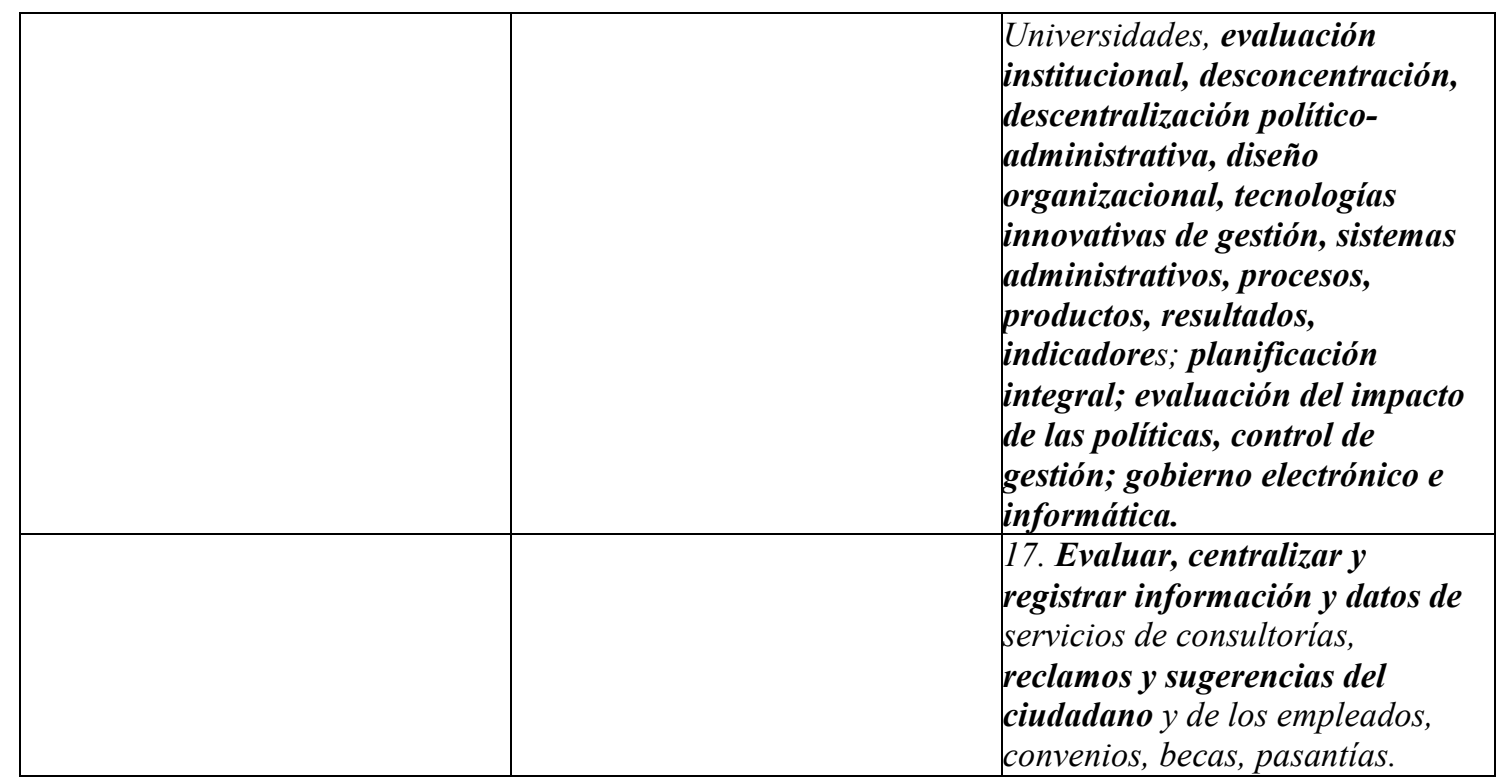

Fuente: Elaboración propia.

Nota: En cursiva, se indican las nuevas competencias. En negritas, las competencias para la reforma administrativa.

La última Ley de Ministerio, Ley $N^{\circ} 13.175$, al eliminar a la entonces Secretaría para la Modernización del Estado, incorporó alguna de sus competencias a la Secretaría General de la Gobernación. Consecuencia de ello, las funciones de la ex-Secretaría para la Modernización del Estado, pasaron a la Subsecretaría de la Gestión Pública (antes Función Pública), conjuntamente con el Instituto Provincial de la Administración Pública (I.P.A.P.) dentro de la Secretaría General conjuntamente con el Consejo de Gobierno Electrónico, creado por Decreto $\mathrm{N}^{\circ} 1.824 / 02$, que se incorpora a la estructura de la Secretaría General en virtud de su dependencia funcional de la ex Secretaría de Modernización del Estado. ${ }^{189}$

Si bien a primera vista puede parecer que ha perdido y ganado algunas competencias en virtud de la creación de la Jefatura de Gabinete y de la Secretaría de Prensa y Comunicación Social, lo cierto es que la Secretaría General de la Gobernación concentró entre sus funciones la administración tanto de la Secretaría de Prensa y Comunicación como de la Secretaría de Política Ambiental y de la Secretaría de Turismo y Deportes pues estas Secretarías carecían de Dirección General de Administración y, consecuentemente, fue la Secretaría General la que, por norma, absorbía estas competencias (Decreto $\mathrm{N}^{\mathrm{o}}$ 1.322/05 - Anexo 1. Punto 1.7. Acerca del Servicio Administrativo de Apoyo).

${ }^{189}$ Se creaba además, en su seno, la Agencia de Cooperación y Relaciones Internacionales. 


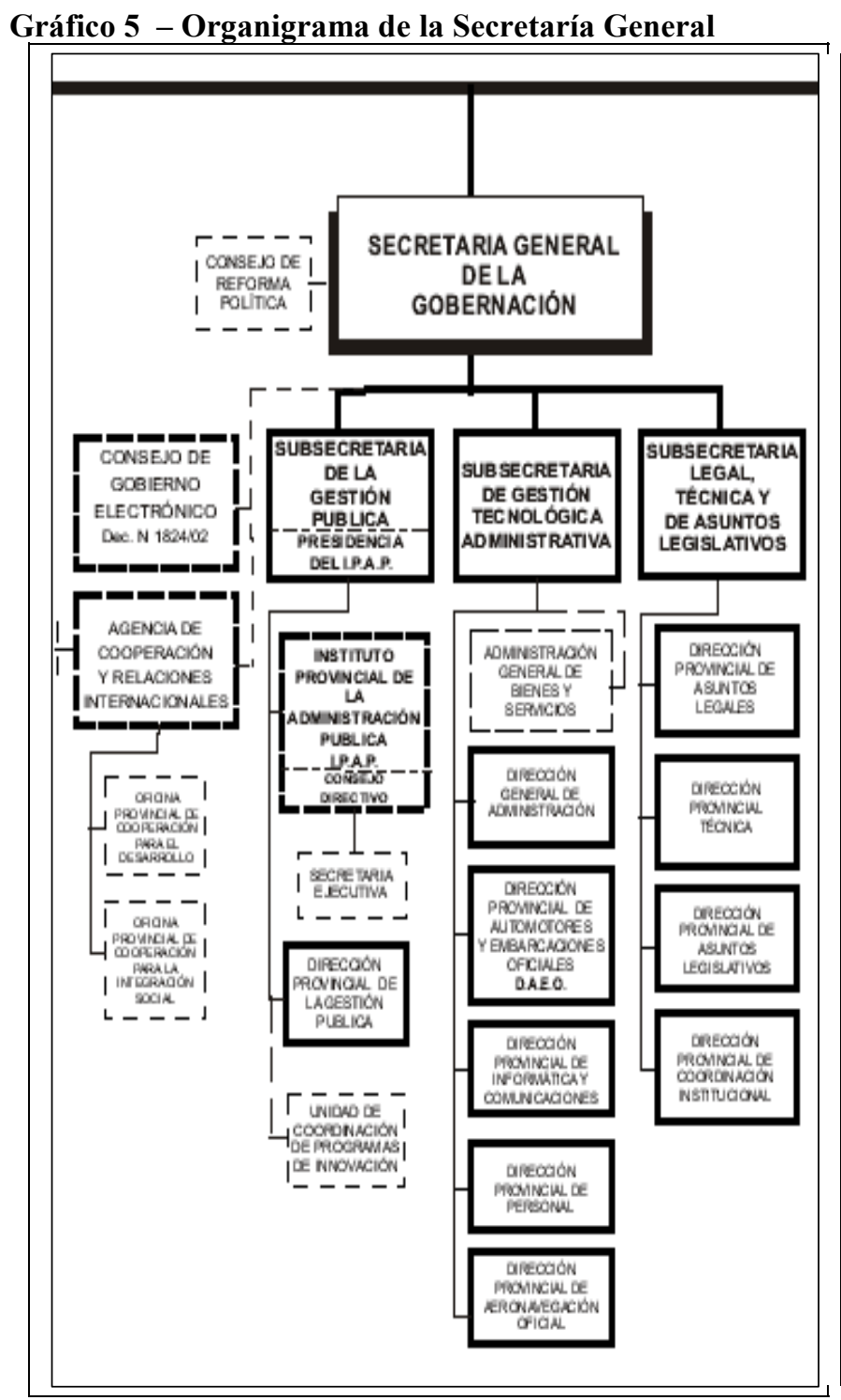

Por otra parte, el carácter transversal que la nueva Ley de Ministerios le otorgaba a la Secretaría General surgía del artículo 13 cuando expresamente establece que: "Los asuntos que, por su naturaleza deban ser atribuidos y resueltos por dos o más departamentos, serán refrendados con la firma de todos los Ministros que intervengan en ellos, previa intervención del Secretario General de la Gobernación".

Pero es dentro de la desagregación de competencias entre las distintas Subsecretarías de la Secretaría General que se advierten las competencias específicas para la reforma de la Administración Pública y del Estado.

a) Competencias de las Subsecretarías de la Secretaría General dentro del Decreto $N^{\circ}$ 2.100/04

El Decreto $\mathrm{N}^{\mathrm{o}} 2.100 / 04$ establecía los objetivos, competencias, misiones y funciones de las Subsecretarías de las Secretaría General y las Direcciones dependientes de éstas. Respecto a los objetivos y competencias del Consejo de Gobierno Electrónico, 
una verdadera Subsecretaría más, el Decreto se remite al Decreto de su creación $\mathrm{N}^{\mathrm{o}}$ $1.824 / 02$ que veremos más adelante.

En el siguiente cuadro comparativo, se transcriben las competencias de cada Subsecretaría de la Secretaría General de la Gobernación, destacando en negritas los objetivos vinculados con la reforma de la Administración Pública y del Estado.

Cuadro 22 - Competencias de las Subsecretarías de la General de la Gobernación

\begin{tabular}{|c|c|c|c|}
\hline SUBSECRETARÍA & SUBSECRETARIA & SUBSECRETARIA & AGENCIA \\
\hline LEGAL, TÉCNICA Y & DE GESTIÓN & DE LA GESTIÓN & COOPERACIÓN \\
\hline DE $\quad$ ASUNTOS & TECNOLÓGICA Y & PÚBLICA & RELACIONES \\
\hline LEGISLATIVOS & ADMINISTRATIVA & & $\begin{array}{l}\text { INTERNACIONA- } \\
\text { LES }\end{array}$ \\
\hline
\end{tabular}

\begin{tabular}{|c|c|c|c|}
\hline \multicolumn{4}{|c|}{\begin{tabular}{|c|} 
OBJETIVOS \\
\end{tabular}} \\
\hline $\begin{array}{l}\text { 1. Evaluar los aspectos } \\
\text { legales y técnicos de los } \\
\text { proyectos de actos } \\
\text { administrativos, de } \\
\text { alcance general y } \\
\text { particular y, en general, } \\
\text { de todo acto que se } \\
\text { someta a consideración } \\
\text { del Señor Gobernador y } \\
\text { del Secretario General } \\
\text { de la Gobernación, } \\
\text { llevando el despacho de } \\
\text { ambas autoridades. }\end{array}$ & $\begin{array}{l}\text { 1. Planificar y } \\
\text { coordinar, conforme } \\
\text { con las normas que fije } \\
\text { el Poder Ejecutivo, las } \\
\text { políticas r sobre } \\
\text { tecnologías de gestión } \\
\text { administrativa } \\
\text { organizativa, a ser } \\
\text { aplicadas en el ámbito } \\
\text { de su competencia y } \\
\text { proponer su desarrollo } \\
\text { en los distintos } \\
\text { organismos de la } \\
\text { Administración Pública } \\
\text { Provincial. }\end{array}$ & $\begin{array}{l}\text { 1. Diseñar y ejecutar } \\
\text { políticas relativas a la } \\
\text { recuperación } \\
\text { institucional } \\
\text { modernización }\end{array}$ & $\begin{array}{l}\text { 1. Asistir al Señor } \\
\text { Secretario General de } \\
\text { la Gobernación en } \\
\text { materia de relaciones } \\
\text { internacionales y } \\
\text { cooperación para el } \\
\text { desarrollo } \\
\text { Integración social y de } \\
\text { las normativas } \\
\text { relacionadas, para } \\
\text { generar así, una } \\
\text { mayor inserción de } \\
\text { la Provincia en el } \\
\text { contexto } \\
\text { internacional. }\end{array}$ \\
\hline $\begin{array}{lr}\text {. Elevar } & \text { a } \\
\text { consideración } & \text { y } \\
\text { conformidad del } & \text { los } \\
\text { Secretario General } & \text { actos } \\
\text { anteproyectos de action de } \\
\text { administrativos general y } \\
\text { alcance general, } \\
\text { particular y, en gene } \\
\text { de todo acto que se } \\
\text { promueva para la firma } \\
\text { del Señor Gobernador. }\end{array}$ & $\begin{array}{lr}\text { 2. Programar la } \\
\text { implantación } & \text { y } \\
\text { mantenimiento en las } \\
\text { distintas áreas de } \\
\text { gobierno, de un sistema } \\
\text { provincial de } \\
\text { informática de la } \\
\text { Administración } \\
\text { Pública Provincial, } \\
\text { coordinando r el } \\
\text { funcionamiento del } \\
\text { sistema en orden a los } \\
\text { requerimientos de los } \\
\text { organismos } \\
\text { dependencias del Poder } \\
\text { Ejecutivo. }\end{array}$ & 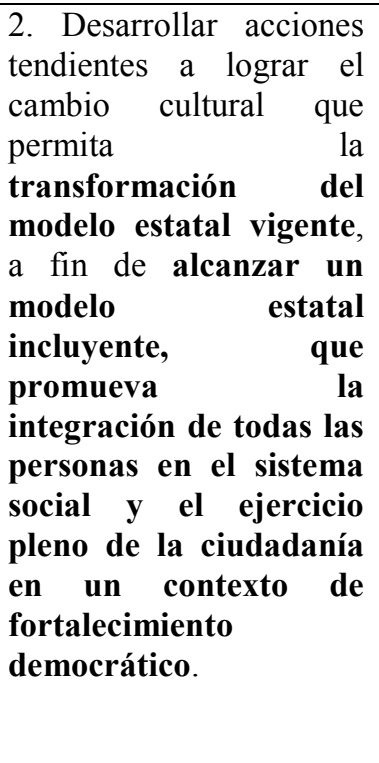 & $\begin{array}{l}\text { 2. Asistir al Señor } \\
\text { Secretario General de } \\
\text { la Gobernación en la } \\
\text { representación y el } \\
\text { ejercicio de las } \\
\text { relaciones funcionales } \\
\text { ante el Gobierno } \\
\text { Nacional y los } \\
\text { Organismos } \\
\text { Internacionales, de } \\
\text { orden público o } \\
\text { privado y las } \\
\text { Representaciones, en } \\
\text { los temas vinculados a } \\
\text { relaciones } \\
\text { internacionales } \\
\text { cooperación para el } \\
\text { desarrollo } \\
\text { integración social. }\end{array}$ \\
\hline $\begin{array}{l}\text { 3. Examinar que los } \\
\text { proyectos elevados al } \\
\text { Señor } \quad \text { Gobernador } \\
\text { cuenten con el requisito }\end{array}$ & $\begin{array}{lrr}3 . & \text { Coordinar } & \text { las } \\
\text { acciones para } & \text { el } \\
\text { desarrollo } & & \text { e } \\
\text { implantación del } & \text { plan }\end{array}$ & $\begin{array}{l}\text { 3. Actuar como órgano } \\
\text { asesor y de estimación } \\
\text { en los } r \text { procesos } \\
\text { institucionales }\end{array}$ & $\begin{array}{l}\text { 3. Participar, en la } \\
\text { coordinación de las } \\
\text { acciones de los } \\
\text { organismos técnicos }\end{array}$ \\
\hline
\end{tabular}




\begin{tabular}{|c|c|c|c|}
\hline $\begin{array}{llll}\text { establecido } & \text { por } & \text { el } \\
\text { artículo 145 } & \text { de } & \text { la } \\
\text { Constitución } & \text { de } & \text { la } \\
\text { Provincia de } & \text { Buenos } \\
\text { Aires. } & & & \end{array}$ & $\begin{array}{l}\text { estratégico y de acción } \\
\text { a llevarse a cabo por } \\
\text { la Unidad Gobierno } \\
\text { Electrónico juntamente } \\
\text { con las áreas } \\
\text { competentes en materia } \\
\text { de administración de las } \\
\text { distintas jurisdicciones } \\
\text { y organismos. }\end{array}$ & 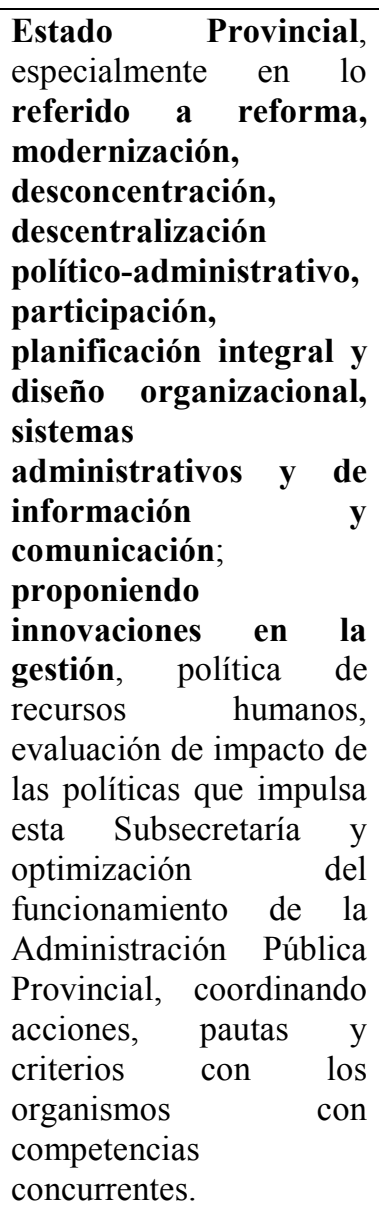 & $\begin{array}{l}\text { competentes de la } \\
\text { Administración } \\
\text { Provincial, en la } \\
\text { elaboración, } \\
\text { definición, } \\
\text { coordinación, } \\
\text { ejecución, } \\
\text { seguimiento } \\
\text { evaluación de las } \\
\text { estrategias, } \\
\text { programas, proyectos } \\
\text { y actividades en } \\
\text { materia de relaciones } \\
\text { internacionales } \\
\text { cooperación para el } \\
\text { desarrollo, así como } \\
\text { en lo pertinente a la } \\
\text { integración social. }\end{array}$ \\
\hline $\begin{array}{lr}\text { C. Coordinar } & \text { la } \\
\text { obtención } & \text { y } \\
\text { sistematización } & \text { del } \\
\text { asesoramiento que se } \\
\text { requiera para el } \\
\text { cumplimiento de las } \\
\text { funciones del Poder } \\
\text { Ejecutivo Provincial, así } \\
\text { como para el } \\
\text { establecimiento de } \\
\text { objetivos, políticas y } \\
\text { criterios de gestión. }\end{array}$ & 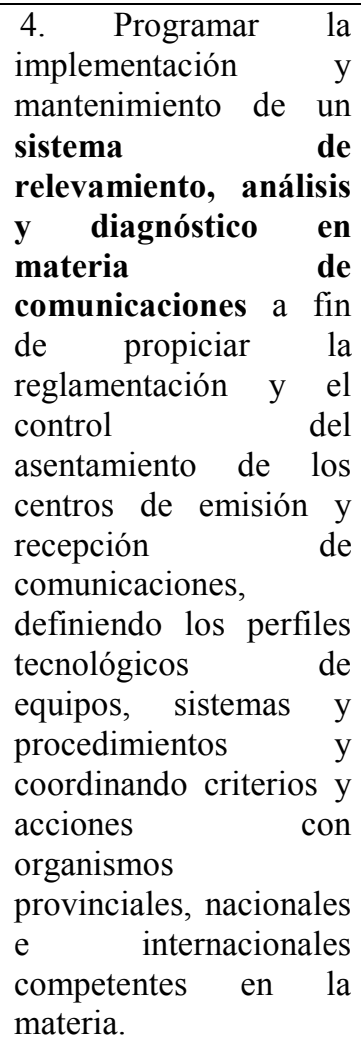 & $\begin{array}{lcr}\text { 4. Proponer } & \text { a } & \text { la } \\
\text { Secretaría General } & \text { el } \\
\text { desarrollo de } & \text { los } \\
\text { principios rectores, } & \text { recion } \\
\text { contribuyendo en } & \text { la } \\
\text { aplicación de } & \text { las } \\
\text { políticas diseñadas para } \\
\text { su aplicación. }\end{array}$ & $\begin{array}{l}\text { 4. Participar, en } \\
\text { coordinación con las } \\
\text { acciones de los } \\
\text { organismos técnicos } \\
\text { competentes de la } \\
\text { Administración } \\
\text { Provincial, en materia } \\
\text { de acuerdos } \\
\text { internacionales, } \\
\text { propiciando su activa } \\
\text { participación en el } \\
\text { área de competencia. }\end{array}$ \\
\hline $\begin{array}{lrr}\text { 5. Analizar } & \text { y } & \text { dar } \\
\text { intervención } & \text { a } & \text { los }\end{array}$ & $\begin{array}{ll}\text { 5. Proponer } & \text { acciones } \\
\text { tendientes } & \text { a la }\end{array}$ & $\begin{array}{l}\text { 5. Diseñar políticas que } \\
\text { favorezcan }\end{array}$ & $\begin{array}{l}\text { 5. Propiciar } \\
\text { participar en }\end{array}$ \\
\hline
\end{tabular}




\begin{tabular}{|c|c|c|c|}
\hline $\begin{array}{l}\text { organismos que resulten } \\
\text { competentes en razón de } \\
\text { la materia, de los } \\
\text { proyectos de ley } \\
\text { sancionados por la } \\
\text { Legislatura, a los fines } \\
\text { establecidos en los } \\
\text { artículos 108, 109, } 110 \text { y } \\
111 \text { de la Constitución } \\
\text { de la Provincia de } \\
\text { Buenos Aires. }\end{array}$ & 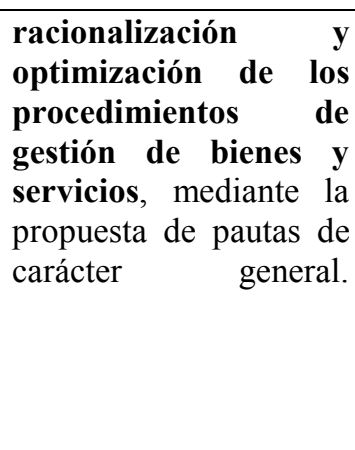 & $\begin{array}{l}\text { participación y el } \\
\text { compromiso } \\
\text { aportando metodologías } \\
\text { que permitan la } \\
\text { integración de los } \\
\text { actores sociales en la } \\
\text { planificación }\end{array}$ & $\begin{array}{l}\text { negociación } \\
\text { acuerdos } \\
\text { internacionales y de } \\
\text { cooperación sobre la } \\
\text { base de los } \\
\text { mecanismos } \\
\text { bilaterales, regionales } \\
\text { o multilaterales } \\
\text { destinados a la } \\
\text { desarrollo y a la } \\
\text { integración social. }\end{array}$ \\
\hline $\begin{array}{l}\text { 6. Analizar y evaluar, en } \\
\text { el marco de la } \\
\text { competencia asignada, } \\
\text { los anteproyectos de Ley } \\
\text { que como iniciativa del } \\
\text { Poder Ejecutivo, sean } \\
\text { elevados para su } \\
\text { remisión a la Honorable } \\
\text { Legislatura. }\end{array}$ & $\begin{array}{l}6 . \\
\text { administrar y coordinar, } \\
\text { la ejecución de las } \\
\text { políticas a ser aplicadas } \\
\text { sobre el parque } \\
\text { automotor y de } \\
\text { embarcaciones } \\
\text { oficiales, proponiendo } \\
\text { las acciones que } \\
\text { determinen su } \\
\text { adquisición, reemplazo, } \\
\text { configuración, } \\
\text { normalización } \\
\text { régimen de uso de } \\
\text { unidades. }\end{array}$ & $\begin{array}{l}\text { 6. Diseñar y ejecutar una } \\
\text { política de formación } \\
\text { de dirigentes sociales, } \\
\text { políticos y estatales, } \\
\text { acorde con el cambio } \\
\text { cultural promovido, a fin } \\
\text { de fortalecer el proyecto } \\
\text { de gobierno, las políticas } \\
\text { de Estado y la relación } \\
\text { de la Administración } \\
\text { Provincial con la } \\
\text { ciudadanía. }\end{array}$ & $\begin{array}{lr}\text { 6. Intervenir en la } \\
\text { preparación de la } \\
\text { documentación } \\
\text { necesaria para la } \\
\text { negociación, } \\
\text { celebración, } \\
\text { modificación u } \\
\text { actos otros } \\
\text { relativos jurídicos } \\
\text { convenios u } r \text { otros } \\
\text { instrumentos } \\
\text { internacionales de } & \text { su } \\
\text { competencia. }\end{array}$ \\
\hline $\begin{array}{l}\text { 7. Protocolizar, registrar } \\
\text { y archivar los actos } \\
\text { dictados por el } \\
\text { Gobernador y por el } \\
\text { Secretario General, así } \\
\text { como todos aquellos que } \\
\text { tramiten en el ámbito de } \\
\text { la Secretaría General, } \\
\text { arbitrando los medios } \\
\text { necesarios a los fines de } \\
\text { su publicación, por el } \\
\text { organismo competente. }\end{array}$ & $\begin{array}{l}\text { 7. Propiciar el dictado } \\
\text { de normas que permitan } \\
\text { la optimización de la } \\
\text { infraestructura física, } \\
\text { previendo el máximo } \\
\text { aprovechamiento de } \\
\text { edificios, instalaciones, } \\
\text { mobiliarios y equipos. }\end{array}$ & $\begin{array}{l}\text { 7. Promover el estudio y } \\
\text { diseño de sistemas de } \\
\text { carrera para } \\
\text { personal el } \\
\text { Administración Pública } \\
\text { Provincial. }\end{array}$ & $\begin{array}{lr}\text { 7. Asumir el rol } \\
\text { articulador en los } \\
\text { foros vinculados con } \\
\text { la cooperación técnica } \\
\text { y la asistencia al } \\
\text { desarrollo } \\
\text { integración social y en } \\
\text { la coordinación y } \\
\text { evaluación de las } \\
\text { acciones } \\
\text { cooperación } \\
\text { internacional. }\end{array}$ \\
\hline $\begin{array}{l}\text { 8. Protocolizar, registrar } \\
\text { y archivar los actos } \\
\text { dictados por los distintos } \\
\text { funcionarios, } \\
\text { ejercicio en de las } \\
\text { facultades delegadas por } \\
\text { el Señor Gobernador. }\end{array}$ & $\begin{array}{l}\text { 8. Coordinar la gestión } \\
\text { administrativa } \\
\text { contable y de los } \\
\text { recursos humanos, } \\
\text { materiales, informáticos } \\
\text { y financieros afectados } \\
\text { a las áreas dependientes } \\
\text { de la Secretaría } \\
\text { General, como así } \\
\text { también de las } \\
\text { Secretarías } \\
\text { dependen del Poder } \\
\text { Ejecutivo Provincial y } \\
\text { que no cuentan con } \\
\text { servicios } \\
\text { administrativos propios. }\end{array}$ & $\begin{array}{lr}\text { 8. Establecer } & \text { los } \\
\text { lineamientos, } & \\
\text { instrumentos } & \text { y } \\
\text { mecanismos necesarios } \\
\text { que aseguren el } \\
\text { desarrollo } & \text { y } \\
\text { funcionamiento eficaz } \\
\text { de la carrera } \\
\text { administrativa, } \\
\text { coordinando, con las } \\
\text { dependencias } \\
\text { involucradas, } \\
\text { implementación. }\end{array}$ & $\begin{array}{lr}\text { 8. Actuar } & \text { como } \\
\text { dependencia } & \\
\text { orientadora de los } \\
\text { organismos de orden } \\
\text { académico, r de } \\
\text { investigación } r y \\
\text { desarrollo, de las } \\
\text { instituciones privadas } \\
\text { y de los organismos } \\
\text { no gubernamentales, } \\
\text { en el área de su } \\
\text { competencia. }\end{array}$ \\
\hline $\begin{array}{lr}9 . \quad \text { Poner } & \text { en } \\
\text { conocimiento del } & \text { Señor } \\
\text { Gobernador, } & \mathrm{a} \\
\text { requerimiento } & \text { del }\end{array}$ & $\begin{array}{l}\text { 9. Elaborar los planes y } \\
\text { programas necesarios } \\
\text { para la aplicación de las } \\
\text { regulaciones que }\end{array}$ & $\begin{array}{lr}9 . \quad \text { Coordinar } & \text { con } \\
\text { organismos } & y \\
\text { dependencias } & \text { con } \\
\text { competencia e } & \text { injerencia }\end{array}$ & $\begin{array}{l}\text { 9. Actuar como } \\
\text { dependencia oferente } \\
\text { de cooperación } \\
\text { horizontal, }\end{array}$ \\
\hline
\end{tabular}




\begin{tabular}{|c|c|c|c|}
\hline $\begin{array}{l}\text { Secretario General, los } \\
\text { pedidos de informes y/o } \\
\text { explicaciones } \\
\text { formulados por el Poder } \\
\text { Legislativo, vinculados } \\
\text { con las funciones y/o } \\
\text { atribuciones del Poder } \\
\text { Ejecutivo Provincial. }\end{array}$ & $\begin{array}{l}\text { determinan las } \\
\text { relaciones entre la } \\
\text { Administración Pública } \\
\text { Provincial y sus } \\
\text { agentes, asegurando la } \\
\text { implementación y } \\
\text { mantenimiento de las } \\
\text { áreas encargadas de la } \\
\text { aplicación de normas } \\
\text { sobre disciplina, } \\
\text { correcto desempeño de } \\
\text { funciones } \\
\text { reconocimientos } \\
\text { fiscalización médica } \\
\text { laboral. }\end{array}$ & $\begin{array}{l}\text { en materia de desarrollo, } \\
\text { formación y capacitación } \\
\text { de recursos humanos } \\
\text { enmarcados } \\
\text { regímenes estatutarios } \\
\text { específicos, el diseño e } \\
\text { implementación de } \\
\text { acciones conjuntas que } \\
\text { conlleven a un mayor } \\
\text { aprovechamiento de los } \\
\text { recursos y a una } \\
\text { articulación entre los } \\
\text { diferentes sistemas de } \\
\text { carrera. }\end{array}$ & $\begin{array}{l}\text { coordinando con los } \\
\text { organismos y carteras } \\
\text { provinciales } \\
\text { competentes en cada } \\
\text { tema, para consolidar } \\
\text { así la presencia de la } \\
\text { provincia en el ámbito } \\
\text { internacional. }\end{array}$ \\
\hline $\begin{array}{l}10 . \text { Intervenir, a } \\
\text { requerimiento del } \\
\text { Secretario General y/o el } \\
\text { Señor Gobernador, con } \\
\text { los organismos } \\
\text { competentes, en lo } \\
\text { atinente a la elaboración } \\
\text { de anteproyectos de } \\
\text { leyes y/o actos } \\
\text { administrativos. }\end{array}$ & $\begin{array}{lr}\text { 10. Participar en la } \\
\text { definición de las } \\
\text { políticas salariales del } \\
\text { sector público, en } \\
\text { coordinación con las } \\
\text { distintas áreas con } \\
\text { competencia } \\
\text { concurrente. }\end{array}$ & $\begin{array}{l}\text { 10. Promover la } \\
\text { participación de los } \\
\text { organismos gremiales a } \\
\text { fin de desarrollar la } \\
\text { carrera administrativa. }\end{array}$ & $\begin{array}{l}\text { 10. Participar, en } \\
\text { coordinación con } \\
\text { otros organismos } \\
\text { técnicos competentes } \\
\text { de la administración } \\
\text { provincial, en eventos } \\
\text { internacionales, de } \\
\text { interés para la } \\
\text { Provincia, en materia } \\
\text { de relaciones } \\
\text { internacionales y } \\
\text { cooperación para el } \\
\text { desarrollo y la } \\
\text { integración social. }\end{array}$ \\
\hline $\begin{array}{lr}\text { 11. Elaborar los actos } \\
\text { administrativos } \\
\text { convenios } \\
\text { redacción le encomiende } \\
\text { el Secretario General y/o } \\
\text { el Señor Gobernador. }\end{array}$ & $\begin{array}{l}\text { 11. Coordinar } \\
\text { conjuntamente con la } \\
\text { Subsecretaría de la } \\
\text { Gestión Pública, el } \\
\text { proceso de } \\
\text { transformación } \\
\text { reforma del Estado, } \\
\text { así como el diseño de } \\
\text { las políticas que } \\
\text { permitan lo } \\
\text { perfeccionamiento y } \\
\text { organización de los } \\
\text { recursos humanos y la } \\
\text { aplicación de nuevas } \\
\text { tecnologías en la } \\
\text { Administración } \\
\text { Pública Provincial, de } \\
\text { conformidad con las } \\
\text { directivas emanadas de } \\
\text { la superioridad. }\end{array}$ & 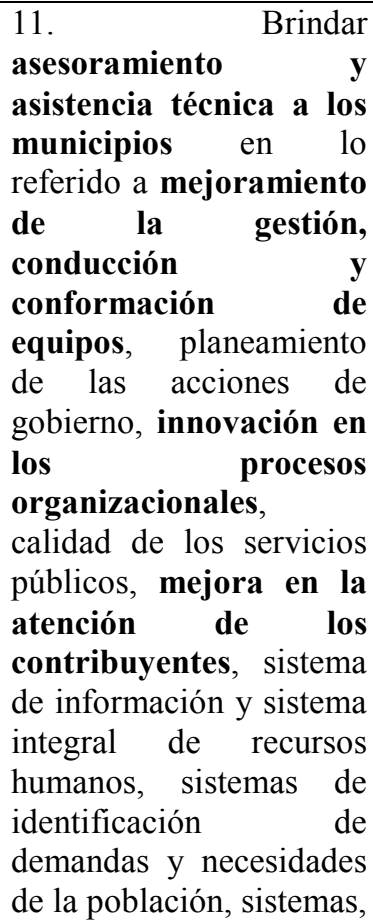 & $\begin{array}{l}\text { 11. Coordinar con los } \\
\text { organismos y carteras } \\
\text { provinciales } \\
\text { competentes, el } \\
\text { diseño, la gestión y la } \\
\text { evaluación de los } \\
\text { programas para el } \\
\text { desarrollo } \\
\text { integración social, } \\
\text { facilitando el acceso a } \\
\text { las diferentes fuentes } \\
\text { de cooperación } \\
\text { internacional. }\end{array}$ \\
\hline
\end{tabular}




\begin{tabular}{|c|c|c|c|}
\hline & & $\begin{array}{l}\text { criterios, alcances y } \\
\text { metodologías alternativas } \\
\text { para generar una efectiva } \\
\text { participación popular en } \\
\text { la gestión municipal, } \\
\text { coordinando pautas, } \\
\text { criterios y acciones con } \\
\text { las áreas competentes. }\end{array}$ & \\
\hline $\begin{array}{l}\text { 12. Instruir en el diseño } \\
\text { de planes, programas y } \\
\text { proyectos con objeto de } \\
\text { optimizar } \\
\text { ordenamiento } \\
\text { legislativo. }\end{array}$ & $\begin{array}{l}\text { 12. Programar la } \\
\text { implementación de } \\
\text { políticas que se } \\
\text { establezcan en materia } \\
\text { de aeronavegación, } \\
\text { infraestructura } \\
\text { aeronáutica y servicios } \\
\text { aéreos, coordinando las } \\
\text { acciones para el } \\
\text { desarrollo de dichos } \\
\text { servicios, los } \\
\text { aeródromos } \\
\text { provinciales y los } \\
\text { recursos económicos, } \\
\text { en concordancia con las } \\
\text { distintas jurisdicciones } \\
\text { involucradas, conforme } \\
\text { las directivas de la } \\
\text { Secretaría General. }\end{array}$ & $\begin{array}{l}\text { 12. Colaborar en el } \\
\text { cumplimiento de pautas } \\
\text { formales y técnicas } \\
\text { referidas a la } \\
\text { organización del Poder } \\
\text { Ejecutivo Provincial, la } \\
\text { carrera administrativa, la } \\
\text { aplicación a } \\
\text { instrumentación de } \\
\text { innovaciones de gestión } \\
\text { y la adecuación de la } \\
\text { gestión pública. }\end{array}$ & $\begin{array}{l}\text { 12. Participar en la } \\
\text { celebración r de } \\
\text { convenios bilaterales } \\
\text { con } r \text { Estados } \\
\text { Extranjeros referidos a } \\
\text { las competencias de } \\
\text { esta Agencia y de los } \\
\text { convenios que se } \\
\text { encuentran r en } \\
\text { vigencia, así como } \\
\text { también en los } \\
\text { programas emergentes } \\
\text { de su aplicación. }\end{array}$ \\
\hline $\begin{array}{lrr}\text { 13. Requerir } & \text { a } & \text { los } \\
\text { organismos de } & \text { la } \\
\text { Constitución } & \text { de } & \text { la } \\
\text { Provincia de } & \text { Buenos } \\
\text { Aires y a la } & \text { Asesoría } \\
\text { General de Gobierno, en } \\
\text { los casos en que } \\
\text { corresponda y lo estime } \\
\text { pertinente, aquellos } \\
\text { dictámenes que sean } \\
\text { necesarios para la firma } \\
\text { de los r actos } \\
\text { administrativos } \\
\text { Señor Gobernador y del } \\
\text { Señor reclario } \\
\text { General. Secretario }\end{array}$ & \begin{tabular}{llr} 
& \multicolumn{2}{c}{ 13. Asistir al Secretario } \\
General en & la \\
elaboración & & del \\
anteproyecto & & del \\
presupuesto & de & la \\
Jurisdicción. & & \\
\end{tabular} & $\begin{array}{l}\text { 13. Proponer, diseñar, } \\
\text { implementar y ejecutar } \\
\text { planes, programas y } \\
\text { acciones referidas al } \\
\text { mejoramiento de la } \\
\text { calidad de la gestión, la } \\
\text { atención de los } \\
\text { ciudadanos, r la } \\
\text { aplicación r de } \\
\text { tecnologías innovadoras } \\
\text { y mecanismos de } \\
\text { transparencia, } \\
\text { participación } \\
\text { ciudadana y control } \\
\text { social de la gestión } \\
\text { pública. }\end{array}$ & $\begin{array}{l}\text { 13. Participar en los } \\
\text { temas de competencia } \\
\text { de esta Agencia, en el } \\
\text { proceso de integración } \\
\text { de los países del } \\
\text { Mercado Común del } \\
\text { Sur (MERCOSUR). }\end{array}$ \\
\hline $\begin{array}{l}\text { 14. Mantener, a } \\
\text { requerimiento del } \\
\text { Secretario General, las } \\
\text { relaciones funcionales } \\
\text { del Poder Ejecutivo } \\
\text { Provincial con la } \\
\text { Asesoría General de } \\
\text { Gobierno, la Escribanía } \\
\text { General de Gobierno y } \\
\text { los Organismos de la } \\
\text { Constitución. }\end{array}$ & $\begin{array}{l}14 . \\
\text { programas vinculados a } \\
\text { su } \\
\text { específica y proyectar } \\
\text { los } \\
\text { administrativos } \\
\text { necesarios para la } \\
\text { puesta en marcha de los } \\
\text { mismos }\end{array}$ & $\begin{array}{l}\text { 14. Promover la } \\
\text { realización de estudios e } \\
\text { investigaciones básicas, } \\
\text { descriptivas y aplicadas } \\
\text { para la Administración } \\
\text { Pública Provincial y } \\
\text { Municipal, determinando } \\
\text { las prioridades, las } \\
\text { pautas y criterios. }\end{array}$ & $\begin{array}{lr}14 . \quad \text { Propiciar } & \text { y } \\
\text { ampliar acciones } \\
\text { tendientes }\end{array}$ \\
\hline $\begin{array}{l}\text { 15. Coordinar } \\
\text { implementar } \\
\text { programas y }\end{array}$ & & $\begin{array}{lrr}15 . & \text { Ejercer } & \text { las } \\
\text { atribuciones } & \text { y } & \text { funciones } \\
\text { inherentes } & \text { a } & \text { la }\end{array}$ & $\begin{array}{l}\text { 15. Afianzar la } \\
\text { identidad cultural, } \\
\text { social, económico- }\end{array}$ \\
\hline
\end{tabular}




\begin{tabular}{|c|c|c|}
\hline $\begin{array}{ll}\text { especiales que } & \text { le } \\
\text { encomiende } & \text { el } \\
\text { Secretario General. } & \end{array}$ & $\begin{array}{l}\text { Presidencia del Instituto } \\
\text { Provincial de la } \\
\text { Administración Pública } \\
\text { Provincial (I.P.A.P.). }\end{array}$ & $\begin{array}{l}\text { productiva } \\
\text { científica bonaerense } \\
\text { en el escenario } \\
\text { internacional, a } \\
\text { través de acciones de } \\
\text { intercambio y } \\
\text { articulación con otras } \\
\text { naciones y estados } \\
\text { regionales extranjeros. }\end{array}$ \\
\hline $\begin{array}{l}\text { 16. Asistir al Señor } \\
\text { Secretario General en los } \\
\text { asuntos relativos a su } \\
\text { competencia específica, } \\
\text { en especial los } \\
\text { vinculados a políticas de } \\
\text { interés para el Poder } \\
\text { Ejecutivo Provincial, } \\
\text { que le sean requeridos y } \\
\text { representarlo cuando así } \\
\text { se le encomiende. }\end{array}$ & $\begin{array}{l}\text { 16. Elaborar convenios } \\
\text { con instituciones } \\
\text { públicas y privadas sobre } \\
\text { los temas de competencia } \\
\text { de esta Subsecretaría. }\end{array}$ & $\begin{array}{lr}\text { 16. Propiciar } & \text { la } \\
\text { formación } & \text { y } \\
\text { capacitación } & \text { de } \\
\text { graduados } & \text { de } \\
\text { Universidades con } \\
\text { sede en la Provincia } \\
\text { de Buenos Aires, a } \\
\text { efectos que puedan } \\
\text { recibir formación y } \\
\text { perfeccionamiento en } \\
\text { Centros Académicos } \\
\text { de excelencia. }\end{array}$ \\
\hline $\begin{array}{l}17 . \quad \text { Confeccionar } \\
\text { programas vinculado } \\
\text { con sus competencias } \\
\text { específicas, elaborando y } \\
\text { proyectando las acciones } \\
\text { y los actos necesarios } \\
\text { para su funcionamiento } \\
\text { y el logro de los } \\
\text { objetivos determinados. }\end{array}$ & & \\
\hline $\begin{array}{l}18 . \quad \text { Brindar apoyo } \\
\text { técnico-legal, en todos } \\
\text { aquellos supuestos } \\
\text { requeridos por el Señor } \\
\text { Gobernador y el Señor } \\
\text { Secretario General. }\end{array}$ & & \\
\hline
\end{tabular}

Fuente: Elaboración propia.

Nota: En negritas, se indican las competencias vinculadas a la reforma de la

Administración Pública y del Estado.

\section{b) Competencia del Consejo de Gobierno Electrónico (Decreto $N^{o} 1.824 / 02$ )}

El gobierno electrónico, como materia de política pública, aparece por primera vez documentado en las competencias de la Secretaría para la Modernización del Estado en la Ley de Ministerios, Ley No 12.856 que crea esa Secretaría.

En agosto de 2002, se sancionó el Decreto $\mathrm{N}^{0} 1.824 / 02$ que aprobara, por su artículo primero, el Plan Estratégico de Gobierno Electrónico en la Provincia de Buenos Aires. Se dictó en el mismo mes de la sanción de la Ley de Ministerios que creaba la Secretaría de Modernización, a cargo en ese momento del Dr. Hugo Franco con la designación de Florencio Randazzo como Jefe de Gabinete.

Por su artículo segundo se creaba un organismo específico para llevar adelante la política de gobierno electrónico, el Consejo de Gobierno Electrónico para la Provincia de Buenos Aires, integrado por el Ministro de Economía, el Ministro de Gobierno, el 
Secretario General de la Gobernación y el Secretario para la Modernización del Estado $^{190}$.

Para la asistencia del Consejo se creó el cargo de Secretario Ejecutivo de Gobierno Electrónico, con rango de Subsecretario y dependencia funcional de la Secretaría para la Modernización del Estado.

Por último, se constituyó el Comité Ejecutivo Intersectorial de Gobierno Electrónico (CEIGE), con dependencia funcional directa del Consejo de Gobierno Electrónico, coordinado técnicamente por el Director Provincial de Informática e integrado por los máximos responsables de informática de las jurisdicciones del Poder Ejecutivo Provincial y un representante por la Secretaria para la Modernización del Estado. Expresamente se establecía que la constitución del CEIGE no demandaría aumento alguno en la planta de personal ni podría justificar ninguna forma directa $o$ indirecta de contratación de personal o consultoría individual: "Todas las necesidades de recursos humanos deberán ser atendidas por funcionarios o empleados de cada jurisdicción, quienes cumplirán sus cometidos como extensión o en sustitución transitoria de sus obligaciones habituales" (artículo $5^{\circ}$ in fine Decreto $\mathrm{N}^{\mathrm{o}} 1.824 / 02$ ).

¿Cómo se distribuían las competencias entre esos organismos?

Al Consejo de Gobierno Electrónico se le encomendaban las principales atribuciones, prioritariamente:

- Aprobar la "Guía Para la Implementación del Plan Estratégico de Gobierno Electrónico para la Provincia de Buenos Aires" y sus modificaciones.

- Coordinar las iniciativas del Plan Estratégico de Gobierno Electrónico.

- Aprobar el Plan de Acción General de Gobierno Electrónico y sus modificaciones, incluyendo las metas y objetivos generales, de conformidad con las directrices establecidas en el Plan Estratégico.

- Gestionar la disponibilidad de recursos económicos, técnicos, humanos y todo aquello que fuera necesario para concretar los proyectos incluidos en el Plan de Acción, facilitando las acciones interjurisdiccionales en todos sus niveles.

Al CEIGE, por su parte, se le encomendaba como principal función la de coordinación para la ejecución del Plan de Acción General de Gobierno Electrónico y de las iniciativas y proyectos de dicho plan. Expresamente se le encomendaba al CEIGE que "en aquellos proyectos que utilicen tecnologías de información y comunicaciones orientados al desarrollo del Gobierno Electrónico deberá seguir las pautas establecidas en el Plan Estratégico" (artículo $5^{\circ}$ Decreto No 1.824/02).

\footnotetext{
${ }^{190}$ Sin embargo, el loable fin de integrar al Organismo con la máxima jerarquía política quedaba inmediatamente desvirtuado con la posibilidad de designar funcionarios para que actúen en su representación (artículo $3^{\circ}$ Decreto $\mathrm{N}^{\circ} 1.824 / 02$ ).
} 
Gráfico 6 - Estructura institucional del Decreto $N^{0}$ 1.824/02

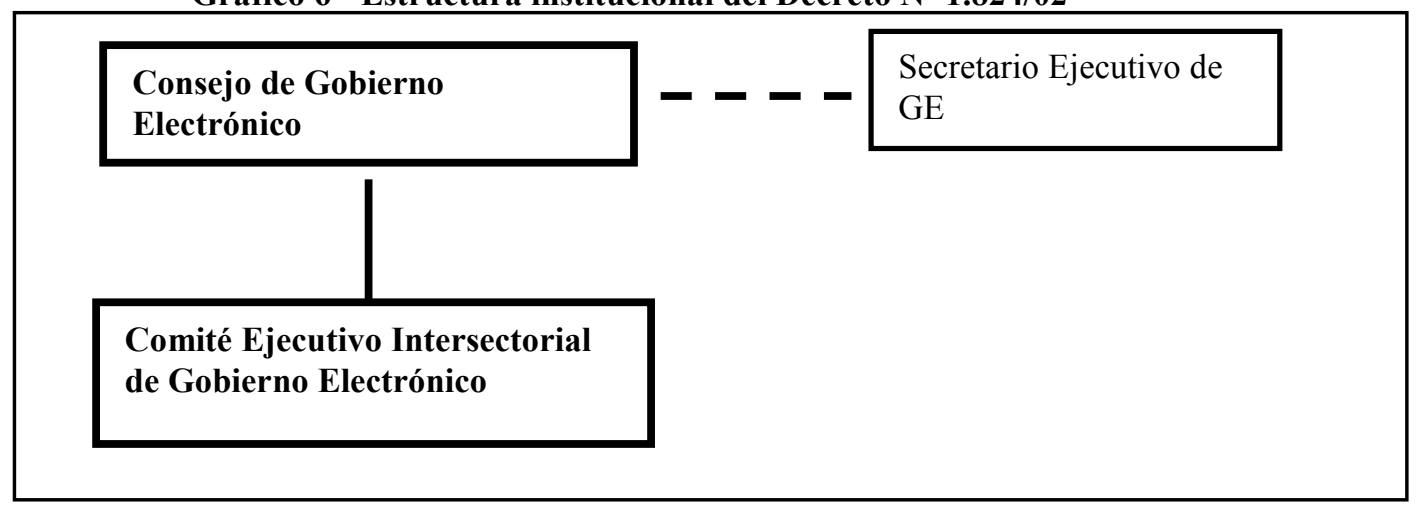

Fuente: Elaboración Propia.

En conclusión, en su organización, el Decreto preveía la creación de dos ámbitos distintos: uno político, el Consejo de Gobierno Electrónico, integrado por los Ministros más importantes, y otro técnico y de ejecución, el CEIGE, dependiente de aquél, e integrado por los directores informáticos de todas las jurisdicciones.

Más allá del Plan Estratégico, el Decreto ya establecía algunas acciones específicas para el CEIGE. Entre ellas se encomendaba

... aprobar la Guía para la Implementación del Plan Estratégico y el Plan de Acción, desarrollar la Política de Tecnología de la Información y las Comunicaciones, definiendo los criterios de propiedad y administración de la información y los recursos relacionados, establecer las pautas para la priorización y contratación de los proyectos referidos al área de Tecnologías de Información y Comunicaciones, enfatizando los patrones de economía, eficiencia, eficacia y reuso de recursos disponibles en la Administración Pública Provincial o en otros organismos del Sector Público, así como la propiedad intelectual y material del Estado provincial (artículo $7^{\circ}$ Decreto $\left.\mathrm{N}^{\mathrm{o}} 1.824 / 02\right)^{191}$.

Como señalamos más arriba, el Consejo Ejecutivo de Gobierno Electrónico pasó a depender de la Secretaría General de la Gobernación por Decreto N 2.100/04.

\section{c) El poder relativo de las Subsecretarías}

Todas las Subsecretarías tienen igual jerarquía dentro de la estructura de la Secretaría General, pero pese a sus capacidades jurídicas formales y específicas, las distintas Subsecretarías no tienen igualdad en las capacidades reales del ejercicio del poder y el control de los recursos.

\footnotetext{
${ }^{191}$ Otros lineamientos que se le imponía al CEIGE era la necesidad de registrar y mantener la propiedad intelectual de todas las aplicaciones que se desarrollen en la Provincia y la necesidad de promover la agregación de demanda para obtener mejores precios y condiciones de compra como manera de hacer más eficiente el uso de los recursos financieros disponibles.
} 
Tanto la Subsecretaría de Gestión Tecnológica y Administrativa, la Secretaría Ejecutiva de Gobierno Electrónico, cuyo Secretario tiene rango de Subsecretario aunque no la Secretaría Ejecutiva-, como la Subsecretaría de la Gestión Pública son las áreas de la Secretaría General de la Gobernación con competencias para el tema bajo estudio.

Las Subsecretarías de la Secretaría General de la Gobernación con más "peso" político fueron la de Gestión Tecnológica y Administrativa ${ }^{192}$ y la Legal, Técnica y de Asuntos Legislativos, dirigidas respectivamente por el Contador Luis Alfredo Deniro y la Abogada María López Outeda, quienes se desempeñaron desde el inicio de la gestión del Gobernador e incluso fueron señalados por algunos medios locales como posibles sucesores para el cargo de Secretario General de la Gobernación luego de la renuncia del primer Secretario, el Dr. José María González Fernández, cargo que finalmente ocupó hasta el fin de la gestión el Contador Ricardo Bozzani ${ }^{193}$. Otras de las Subsecretarías con peso, fue la Subsecretaría de la Gestión Pública, a cargo de la Ing. Arg. Claudia Bernazza, que llegó a ser una de las dirigentes más importantes de la llamada rama femenina del "felipismo".

Un buen indicador del peso relativo de los actores y del distinto poder entre las áreas es la capacidad operativa y de empleados de cada una de ellas ${ }^{194}$. Así, la Secretaría Ejecutiva de Gobierno Electrónico, entonces a cargo del Ingeniero Delfín Rabinovich, sólo contaba con la labor de 8 profesionales, incluyendo al Secretario Ejecutivo, de los cuales, 3 eran agentes de modernización del Estado. Contaba con una secretaria administrativa y un empleado administrativo ${ }^{195}$.

En cambio, de la Subsecretaría de Gestión Tecnológica y Administrativa, además del personal propio, dependían cinco Direcciones Provinciales junto con la Administración General de Bienes y Servicios. ${ }^{196}$ Ello implica no sólo manejo de más personal sino, por la composición de las Direcciones dependientes, el control de recursos estratégicos. Además, tenía a su cargo el control y la ejecución de los gastos de toda la Secretaría General por tratarse de una Subsecretaría con funciones administrativas jurisdiccional.

Otro indicador que puede ser revelador del distinto poder de las Subsecretarías es el simbólico, siguiendo el desarrollo que sobre la teoría de las organizaciones realiza Schein (2004), analizando, en ese caso, la ubicación de los despachos. Es sabido que su

\footnotetext{
${ }^{192}$ La Subsecretaría de Gestión Tecnológica y Administrativa cubría las tareas de administración, de personal, contables y de servicios técnicos y auxiliares en todas las Secretarías de Estado, además de la propia Secretaría General, con lo que su poder político y de coordinación era significativo. El Decreto que establece la apertura de dicha Subsecretaría es el Decreto $\mathrm{N}^{\circ}$ 2.935/04.

${ }^{193} \mathrm{http}: / / \mathrm{www}$. agencianova.com/nota.asp? $\mathrm{n}=20053$ 18\&id=21309\&id tiponota=5. Fecha de Consulta: 25/07/11.

${ }^{194}$ La capacidad de decisión, que es otro aspecto central de este indicador burocrático, será parte de los siguientes capítulos cuando analicemos las acciones propiamente dichas llevadas adelante por los diversos actores en su interrelación.

${ }^{195} \mathrm{La}$ composición del personal profesional era variada, pero ninguno pertenecía a la planta estable de la Secretaría Ejecutiva. Los agentes de modernización dependían de otra Subsecretaría, la de Gestión Pública, y consecuentemente pueden ser convocados a prestar sus servicios en otro proyecto. Tanto el cargo de Secretario Ejecutivo como el cargo de secretaria privada del Secretario Ejecutivo son políticos. Uno de los profesionales pertenecía al Min. de Salud. El otro profesional era contratado.

196 Las Direcciones eran: Dirección General de Administración, Dirección Provincial de Automotores y Embarcaciones Oficiales, Dirección Provincial de Informática y Comunicaciones, Dirección Provincial de Personal y Dirección Provincial de Aeronavegación Oficial.
} 
ubicación así como los espacios que ocupan son materia de recurrentes conflictos políticos y muestras de poder entre los integrantes de los poderes públicos. O como lo han dicho Blutman y Mendez Parnes (2003), existen manifestaciones visibles e invisibles que definen una cultura organizacional. No sólo cómo se visten las personas; también la forma en cómo se distribuye el espacio físico. El Poder Ejecutivo bonaerense no es la excepción.

Por cuestiones de espacio limitado, en la casa de Gobierno de la Provincia, ubicada en el centro de la ciudad de La Plata, sólo se hallan los despachos de los funcionarios más importantes de los siguientes organismos: Ministerio de Gobierno, Secretaría General, Secretaría de Prensa y Comunicación Social y de la Jefatura de Gabinete además del despacho del Gobernador. El resto de los funcionarios y personal administrativo se encontraba, principalmente, en el Centro Administrativo Gubernamental ubicado en las torres de calle 12 o en otras casas o edificios alquilados o propiedad de la Provincia.

Sólo la Subsecretaría de Gestión Tecnológica y Administrativa, la Subsecretaría de Legal, Técnica y de Asuntos Legislativos y la de Gestión Pública estaban situadas en uno de los lugares claves de la Casa de Gobierno. 


\section{CAPÍTULO VII. LOS PLANES (explícitos e implícitos) DE MODERNIZACIÓN DE LA ADMINISTRACÍON Y REFORMA DEL ESTADO}

\section{El Plan Rector de Modernización}

Como hemos señalado en el Capítulo anterior, cuando asumió la gestión el entonces Gobernador expresó un fuerte compromiso con la modernización del Estado. Una de las primeras políticas fue el diseño de su propia estructura ministerial: a poco menos de dos meses de la asunción en el cargo, a través de la Ley $\mathrm{N}^{\circ} 12.856$, se creó la Secretaría para la Modernización del Estado.

Es necesario detenerse en el "Plan Rector de Modernización" que se elaborara la Secretaría de Modernización del Estado, todavía a cargo del Cr. Florencio Randazzo, porque en él se advierten aspectos centrales de la concepción de la organización. La presentación del Plan fue hecha el 15 de abril de $2003^{197}$ y se advierten aspectos centrales de la concepción de la organización y la adscripción teórica a los postulados de la Nueva Gestión Pública.

El objetivo declarado era la "desburocratización de la administración pública", mediante la "simplificación de trámites administrativos" y la puesta en marcha de un "régimen de compras y contrataciones abreviado" y de "nuevas modalidades de licitación y selección". ${ }^{198}$

El Plan Rector de modernización se había estructurado como un anteproyecto de ley, pues muchas de las reformas requerían modificación de las leyes vigentes. ${ }^{199} \mathrm{El}$ proyecto contenía más de 120 artículos que modificaban varias leyes, tales como la de Contabilidad y de Empleo Público. En efecto, se pretendía modificar, por ejemplo, el régimen laboral del empleo público así como los mecanismos de licitación y contratación directa por parte del Estado, flexibilizando los controles y aumentando los montos de contratación.

Como contrapeso a estas "flexibilizaciones", se introducía el control ciudadano directo en las acciones de gobierno y la implementación de un régimen de acceso a la información administrativa. Ya no sería requisito para el acceso a la información demostrar el interés legítimo sino que el criterio sería el del interés simple. Por otra parte, y dentro del ámbito de la ética en el ejercicio de la función, se obligaba a todo funcionario a presentar una declaración jurada de bienes que debería actualizar todos los años, ya que, de lo contrario, sería inhabilitado para ejercer un nuevo cargo.

El documento está compuesto por un conjunto de programas, normas y procedimientos ...

\footnotetext{
197 Ese día dejaba el cargo de Secretario y asumía como Jefe de Gabinete, que entonces era, también, una Secretaría de Estado.

${ }^{198}$ Diario EL DIA, "Reforma administrativa en el Estado bonaerense", 11/04/03. http://www.eldia.com.ar/ediciones/20030411/elpais5.asp. Fecha de consulta: 05/10/11.

${ }_{199}$ Sin embargo, a más de un año de su elaboración, el anteproyecto no había sido presentado a la Legislatura porque, como manifestaba Randazzo (2004), se habían presentado muchas dificultades políticas.
} 
... destinados a instalar una administración de los recursos públicos orientada a los resultados y a la responsabilidad de los funcionarios frente a los mismos. Representa un nuevo modelo de gestión que se sustenta en la panificación y el control, la reforma de los sistemas administrativos, y en la transparencia, la participación y el control ciudadano en la gestión pública (Randazzo, 2004:58).

\section{Cuadro 23 - Plan Rector de Modernización}

\begin{tabular}{|c|c|}
\hline $\begin{array}{l}\text { PROGRAMA DE MODERNIZACIÓN } \\
\text { ADMNINISTRATIVA }\end{array}$ & $\begin{array}{l}\text { PROGRAMA DE TRANSPARENCIA Y } \\
\text { PARTICIPACIÓN CIUDADANA }\end{array}$ \\
\hline $\begin{array}{l}\text { - Desburocratización de la } \\
\text { Administración Pública Provincial }\end{array}$ & $\begin{array}{l}\text { Desburocratización de la } \\
\text { Administración Pública Provincial y } \\
\text { control social }\end{array}$ \\
\hline - Gestión de Recursos Humanos & $\begin{array}{l}\text { - Régimen de ética en el ejercicio de la } \\
\text { función pública administrativa }\end{array}$ \\
\hline - Nuevas Tecnologías de Gestión & $\begin{array}{l}\text { - Régimen de acceso a la información } \\
\text { administrativa }\end{array}$ \\
\hline - $\quad$ Proyecto de mejora de la Gestión & \\
\hline - $\quad$ Sistema de control interno & \\
\hline
\end{tabular}

Fuente: Elaboración propia sobre la base de Randazzo (2004)

Para el entonces Secretario para la Modernización, el Plan constituía un revolucionario proceso de cambio institucional al suponer una modificación del paradigma de gestión.

El Plan estaba estructurado en dos programas centrales con sus respectivos componentes; el primero de ellos asociado a la modernización Administrativa y el segundo a la Transparencia y de Participación Ciudadana.

- Programa de Modernización Administrativa: Este Programa consta de distintos componentes:

- Sistema de Control Interno;

- Gestión de Recursos Humanos;

- Proyectos para la mejora de la gestión;

- Desburocratización de la Administración Pública;

- Nuevas Tecnologías de Gestión.

Este Programa se integra por un conjunto de herramientas y técnicas de gestión de recursos humanos, financieros, físicos y tecnológicos destinados a fortalecer la capacidad administrativa y la eficacia institucional de 
la Administración Pública Provincial. El objetivo manifiesto era implementar una "gestión por resultados" y así lograr: mayor eficacia, eficiencia, economía y calidad en el cumplimiento de políticas, objetivos y metas; ordenamiento y control en el uso y disposición de los recursos públicos asignados. Entre los principales ejes se determina la responsabilidad administrativa de los funcionarios públicos, estableciéndose pautas específicas para cada gestión en particular y el control de su cumplimiento y se crea la obligación de rendir cuentas de los resultados de la gestión. Un sistema de control interno, con la creación de una auditoría interna, sistematizaría la información y tendría como autoridad de aplicación a la Jefatura de Gabinete.

Se contempla la "gestión por competencia", que flexibilizaría la selección, capacitación, evaluación y promoción de los agentes de la administración pública, y crearía un sistema de "gestión por resultados". Asimismo, se permitía la creación de "regímenes gerenciales", para lo cual se autoriza al Poder Ejecutivo a generar para el personal sin estabilidad "sistemas de selección por concursos" y modalidades de contratación distintas a las previstas en la Ley $\mathrm{N}^{\mathrm{o}} 10.430$.

- Programa de Transparencia y de Participación Ciudadana: Incluía un conjunto de herramientas destinadas a involucrar a los ciudadanos y las organizaciones de la sociedad civil en la formulación, la ejecución y el control de la gestión pública introduciendo normas y sistemas de transparencia ${ }^{200}$. Los componentes eran:

\section{- Régimen de Acceso a la información Administrativa; ${ }^{201}$ \\ - Régimen de la ética en el ejercicio de la Función Pública; \\ - Desburocratización de la Administración Pública Provincial y Control Social.}

Es necesario detenerse en dos componentes. Uno de ellos, el de desburocratización administrativa, es común a ambos programas. Otro de ellos, el de Nuevas Tecnologías de Gestión, en cuanto tiene implicancias sobre la Planificación.

\footnotetext{
${ }^{200}$ Este Programa de Transparencia y de Participación Ciudadana incluía la Declaración Jurada Obligatoria, que se actualizaría anualmente y al finalizar la gestión. La exigencia incluía al gobernador y vice, ministros, secretarios, subsecretarios y equivalentes, titulares de los organismos de la Constitución y funcionarios con rango no inferior al de director provincial. Los que no cumplimenten este requisito serán pasibles de sanciones hasta la "prohibición para ejercer nuevamente la función pública".

201 Es importante también señalar la posibilidad del Plan Rector para solicitar y recibir información relativa a cualquier documentación de carácter público (documentos, antecedentes, estudios, dictámenes, opiniones, datos estadísticos, y toda otra información vinculada a las entidades de la administración), flexibilizando los requisitos de acceso contenidos en la Ley $\mathrm{N}^{\circ} 12.475$.
} 
El componente de Nuevas Tecnologías de Gestión sería abordado a partir de las siguientes acciones: Planeamiento Estratégico; Presupuesto por Programas; Presupuesto Plurianual y Acuerdos Programa.

Por su parte, el componente de desburocratización administrativa se preveía instrumentar a partir de las siguientes acciones: Simplificación administrativa; Régimen de compras y contrataciones abreviado; Firma digital, expediente electrónico y sistema de compras y contrataciones digital y Guía Única de Trámites (GUT) ${ }^{202}$.

Se había elaborado una propuesta para modificar el diseño de estructuras organizativas en el marco de la gestión por resultados, incorporando criterios de flexibilidad y temporalidad.

¿Cuál es marco teórico que da sustento al Plan? La serie de "premios" y "castigos" que se otorgan a los Organismos, la competencia por los recursos, así como los compromisos-contratos que contiene el Plan Rector, son una clara muestra de la adscripción del Plan de modernización a las políticas de la Nueva Gestión Pública.

En efecto, el Plan Rector introduce el concepto de control interno dentro de una visión gerencial del funcionario. Según el Plan, existirían "gerentes públicos" sobre quienes recaerían la responsabilidad de administrar recursos públicos y garantizar resultados de gestión, tanto en términos de bienes y servicios brindados como en términos del impacto producido por éstos en la comunidad, debiendo responder por la responsabilidad asignada y por los resultados de la gestión.

Los "Acuerdos Programa" son otro ejemplo de la adscripción del Plan a las teorías de la Nueva Gestión Pública. Dentro del Plan, los Acuerdos Programa habían sido diseñados como herramientas mediante las cuales los organismos se comprometerían a alcanzar determinados resultados de gestión, teniendo como contrapartida el otorgamiento de una serie de flexibilidades en materia presupuestaria. Se preveía que los Acuerdos Programa fueran suscriptos por los titulares de organismos y de unidades ejecutoras de programas presupuestarios bajo la supervisión del Ministerio de Economía. Contra la elaboración de un compromiso de cumplimiento de políticas, objetivos y metas debidamente cuantificables y mensurables, se le otorgaría al organismo beneficios de naturaleza presupuestaria o la pérdida de las flexibilidades otorgadas ante su incumplimiento. Estas especies de "contratos" hacia dentro de la Administración son otro claro reflejo de las políticas de la Nueva Gestión Pública.

Pese al fuerte "posicionamiento" político del Plan y de la presentación del Proyecto, el plan no tuvo acogida legislativa.

\section{El Plan Estratégico de Gobierno Electrónico}

En agosto de 2002, a instancias del entonces Secretario de Modernización del Estado, Cr. Florencio Randazzo, se sancionó el Decreto N ${ }^{\circ} 1.824 / 02$ que aprobara, por

\footnotetext{
${ }^{202}$ Sin embargo, es necesario destacar que dentro del Plan Rector no hay referencias expresas al Gobierno Electrónico como una de sus áreas centrales. Si bien al momento de la presentación del Plan Rector ya se había sancionado el Decreto $\mathrm{N}^{\circ}$ 1.824/02 de Gobierno Electrónico, el Plan Rector agrupaba también áreas y acciones ya creadas o establecidas para darles marco legal y unificación dentro de una única política de Estado.
} 
su artículo primero, el Plan Estratégico de Gobierno Electrónico en la Provincia de Buenos Aires. Se dictó en el mismo mes de la sanción de la Ley de Ministerios que creaba la Secretaría de Modernización del Estado.

Debemos extraer del Plan los objetivos de esa política. Por ello, es importante resaltar alguno de los Considerandos del Decreto pues son reflejo de los valores y expectativas puestas por el Gobierno de la Provincia en el gobierno electrónico.

En primer lugar, se define el proyecto como parte del proceso de reforma del Estado orientado a "mejorar la cantidad y calidad de los servicios". Expresamente señala que

... el uso de estas tecnologías favorece la interacción entre los gobiernos, las empresas, las comunidades y los ciudadanos, mejora la transparencia y el control de los actos de gobierno, aumenta la eficiencia de los procesos administrativos, incrementa la eficacia de los programas de gobierno y su impacto final, y propicia la formulación e implementación de políticas de desarrollo económico regional, entre otros beneficios (Decreto $\mathrm{N}^{\mathrm{o}} 1.824 / 02$ ).

En otro de los Considerandos entiende que el uso de las TIC en el sector público ha creado una disciplina en sí misma, llamada Gobierno Electrónico. Se señala que el intercambio de información conducirá a introducir cambios significativos en el contenido del trabajo y la organización administrativa aunque también reconoce la necesidad de la capacitación de los recursos humanos y de acortar la brecha digital. expresa que

Por último dos párrafos más dan cuenta de los valores. En primer lugar, se ... el desarrollo del Gobierno Electrónico deberá asumirse, por los órganos de la administración, como un proceso indispensable, evolutivo, modular e incremental" y que "para el cumplimiento de los fines enunciados debe dotarse a la Provincia de un diseño institucional que, respetando el principio de descentralización como uno de los ejes rectores en el proceso de Modernización del Estado, permita a su vez una coordinación ágil entre las distintas jurisdicciones y organismos que integran el sector público provincial (Decreto $\mathrm{N}^{\circ} 1.824 / 02$ ).

Estos últimos Considerandos son sustanciales al señalarse el carácter incremental que debe tener dicho proceso de reforma y al condicionar los resultados a un diseño institucional descentralizado en cuanto a su ejecución pero centralizado en cuanto a la decisión.

El Decreto contiene un profuso Anexo de 33 páginas donde se establece el Plan Estratégico. Allí se afirma que los sitios de Internet de los organismos de la Provincia constituyen una demostración práctica de las actividades del sector público en la Web aunque se reconoce que sólo representan una pequeña muestra del potencial del gobierno electrónico. Se reconoce que la tecnología no es un fin en sí misma sino que "representa un medio, o herramienta, para concretar la visión de un Estado moderno, eficaz y eficiente".

En ese Anexo, nuevamente se sostiene que el Gobierno Electrónico se encuadra dentro de la Modernización del Estado aunque ahora, con más énfasis, se lo define como "una parte fundamental de la misma". 
Se puntualiza la misión del gobierno electrónico como el desarrollo de

... una plataforma tecnológica para satisfacer los requerimientos y responder a las necesidades de los habitantes, contribuyendo a crear una administración pública íntegra, eficaz y transparente, mediante el uso eficiente de la información, los recursos humanos, los procesos y la tecnología. De esta forma el gobierno electrónico se transformará en un canal ejemplar para la prestación de los servicios del Estado y se constituirá en el soporte y facilitador de la difusión e implantación de las políticas del Gobierno (Decreto $\mathrm{N}^{\circ} 1.824 / 02$ - Anexo pág. 10).

El objetivo es introducir nuevos y mejores servicios y rediseñar los procesos internos de la Administración Pública de manera integrada, simple, fácil de acceder y usar, flexible y adaptable. Deberá también permitir la integración de los sistemas de los diferentes servicios, compartir recursos e introducir el concepto de gestión pública basada en la responsabilidad de los funcionarios por los resultados y la utilización de los recursos del Estado (Decreto $\mathrm{N}^{\mathrm{o}}$ 1.824/02 - Anexo pág. 11).

Los Objetivos Generales del Plan son:

- Acercar la administración pública al habitante, haciéndola más accesible y transparente y brindando más y mejores servicios; recursos;

- $\quad$ Aumentar el impacto de los programas de Gobierno;

- Complementar el proceso de modernización mejorando la calidad y la eficiencia de los servicios del Estado mediante el uso de información, procesos y tecnología;

- Desarrollar aplicaciones verticales y transversales, sobre una infraestructura común, que solucionen temas y problemas específicos de los habitantes.

Los Objetivos específicos denunciados son:

- Desarrollar la estrategia de los portales de la provincia para:

- Difundir las actividades del gobierno provincial y sus dependencias;

- Informar a los habitantes sobre los servicios y trámites que presta la provincia y los requerimientos para realizarlos;

- Permitir a los habitantes requerir información, realizar trámites y pagar impuestos en forma remota;

- Habilitar nuevos canales de comunicación entre los ciudadanos y las autoridades políticas;

- Habilitar nuevos medios de participación ciudadana; 
- Contribuir a través de la TIC a la eficiencia y transparencia de la administración pública de la provincia reduciendo costos de gestión $\mathrm{y}$ permitiendo la difusión de los actos de gobierno;

- Promover el uso eficiente de la información, los procesos, los recursos humanos y la tecnología;

- Maximizar el aprovechamiento de las tecnologías y sistemas existentes en la Provincia y sus organismos

- Rediseñar los procesos de manera integrada y continua con foco en el habitante aplicando criterios de simplicidad, facilidad de acceso, punto único de contacto y flexibilidad;

- $\quad$ Facilitar y dar soporte a la difusión e implementación de las políticas de Estado, aumentando el impacto de los programas

- Servir de modelo para la prestación de servicios a través de distintos canales -delegaciones, agencias, kioscos, Call Centers, correo electrónico, oficinas municipales, etc.-;

- Contribuir a la eficiencia en el trabajo, la satisfacción laboral, la capacitación y la realización profesional de los empleados públicos provinciales.

Entre los beneficios esperados que se obtendrán mediante el uso de las TIC se señalan:

- Mejorar la calidad de los servicios que el Estado brinda a sus habitantes;

- Aumentar el impacto de los programas que ejecuta;

- $\quad$ Mejorar la eficiencia general de la administración provincial;

- $\quad$ Recuperar la legitimidad política y pública de sus organizaciones y de los empleados públicos;

- Integrar la información de la Provincia. ${ }^{203}$

El Plan identifica ciertas áreas estratégicas dentro de las cuales se llevarán adelante los proyectos. Se identifican seis áreas de trabajo seleccionadas por su carácter transversal y se las clasifican, a su vez, según tengan impacto directo o indirecto en los ciudadanos y las empresas.

Cuadro 24 - Áreas de impacto del Gobierno Electrónico

\begin{tabular}{|c|c|}
\hline Áreas de Impacto Directo & Áreas de Impacto Indirecto \\
\hline 1. Mejoras en la Calidad de los Servicios & 1. Tecnología de la Información \\
\hline \multirow[t]{3}{*}{ 2. Eficiencia en la Gestión } & 2. Gestión del Conocimiento \\
\hline & 3. Brecha Digital \\
\hline & 4. Infraestructura Legal del Gobierno Electrónico: \\
\hline
\end{tabular}

203 Se señala expresamente que "La información es propiedad de la Provincia y los organismos son responsables de administrarla y protegerla sin limitar el acceso a la misma por otros organismos de acuerdo a las leyes y normativa vigente" 


\section{Fuente: Elaboración propia.}

Resulta importante reseñar cada una de las áreas de trabajo propuestas.

En cuanto a la mejora en la calidad de los servicios sólo se menciona que todas las prestaciones que brindan los organismos de la Provincia deben incluir a todo tipo de "usuarios" (públicos o privados, individuales o colectivos).

Respecto las iniciativas que tiendan a la eficiencia en la gestión se identifican tres campos de acción que deberían reflejar el nuevo modelo de gestión orientado a resultados. Ellas son:

a) Administración de Recursos que incluyen los proyectos que tienen por objetivo transformar la gestión interna común de todos los organismos de la Administración Pública Provincial, sus sistemas de soporte y su relacionamiento: ${ }^{204}$

- Compras y Contrataciones,

- Gestión de Recursos Humanos,

- $\quad$ Gestión de Administración Financiera

- $\quad$ Seguimiento de Expedientes y

- $\quad$ Gestión de Gestión Documental.

b) Gestión Operativa Interna donde se engloban a los proyectos que tienen por objetivo transformar el Back Office y la eficiencia de sus tareas transaccionales:

- $\quad$ sistema de captura de DDJJ y de pagos,

- $\quad$ digitalización del catastro y tablero de control del área de Rentas

- $\quad$ Sistema Único de Acción Social del Ministerio de Desarrollo Humano y Trabajo.

c) Infraestructura donde se agrupan los proyectos que mejoren la actual infraestructura de tecnología provincial:

- completar Infraestructura de Ultima Milla de la Red Provincial de Comunicaciones,

- $\quad$ optimizar el gasto en comunicaciones y el uso de los recursos de TIC,

- $\quad$ soporte centralizado a Usuarios de dependencias provinciales en los Municipios,

\footnotetext{
204 El Plan realiza un diagnóstico respecto a los actuales sistemas de gestión afirmando que en la actualidad se desarrolla en un círculo vicioso donde se invierten recursos escasos en múltiples sistemas de soporte reduciendo la disponibilidad para desarrollo de proyectos orientados a mejorar la gestión sustantiva de las jurisdicciones. No se dispone de información homogénea, íntegra y válida para la toma de decisiones y la evaluación de resultados.
} 
- $\quad$ plataforma de aprendizaje a distancia para toda la Provincia

- $\quad$ estándares de equipamiento que agilicen el proceso de adquisición de TIC.

Dentro de las áreas estratégicas de impacto indirecto, el Plan señala aquellas acciones orientadas a consolidar la Tecnología de la Información como facilitador y soporte de la visión estratégica. Se anuncia como política necesaria dentro del área, la de coordinar acciones para el logro de los objetivos detallados, manteniendo un inventario de iniciativas y proyectos en materia de gobierno electrónico. Por último, se menciona la necesidad de establecer la infraestructura necesaria para la Firma Digital.

Otras de las áreas estratégicas de impacto indirecto, es la Gestión del Conocimiento. Dentro de esta área, las acciones deben tender a ordenar y gestionar la información y el conocimiento que posee la Provincia para lograr sinergias y difundir ideas, metodologías, prácticas y herramientas que contribuyan a optimizar la gestión. Se mencionan como objetivos promover el desarrollo de una organización aprendiente (sic), crear comunidades de práctica y afinidad en la Administración Pública Provincial y crear un reservorio de mejores prácticas de gestión y de lecciones aprendidas en los proyectos de modernización del Estado.

En cuanto al área de trabajo sobre Brecha Digital el Plan señala que esa es un área estratégica e indelegable del Estado para asegurar la equidad social en el acceso de todos los habitantes a los beneficios de la tecnología. Se subdividen las acciones dentro de "sub-áreas", entre ellas, accesibilidad, donde se incluyen acciones destinadas a mejorar la experiencia de la interacción con el Gobierno, eliminando las barreras creadas por las transacciones basadas en papel, a la provisión de acceso a toda la población cualquiera sea su condición económico-social y educativa y su lugar de residencia y a ampliar y mejorar el acceso a los servicios del Gobierno a través de la creación de una infraestructura pública con cobertura en todo el territorio provincial. Otra de las "sub-áreas" es la de capacitación donde deberán incluirse todas las acciones tendientes a proveer a todos los usuarios -externos e internos- los medios y canales adecuados para asegurar el acceso a la educación y capacitación en el uso de los servicios electrónicos y de las nuevas tecnologías.

Por último, es posible identificar el área de Infraestructura Legal del Gobierno Electrónico a la que define como Derechos Digitales. En ese marco, según el Plan, deberán llevarse a cabo todas las iniciativas orientadas a garantizar a los habitantes ciertos derechos, que emergen o son generados por el uso de las TIC. Si bien reconoce que esos derechos no necesariamente están explícitos en la legislación, afirma que es una responsabilidad del Gobierno su reconocimiento. Entre esos derechos menciona:

- $\quad$ Propiedad y protección de los datos y la información;

- Transparencia y auditabilidad;

- $\quad$ Protección de la privacidad;

- Capacidad de búsqueda y acceso a la información que el ciudadano considere de interés para él en cualquier medio digital o material;

- $\quad$ Accesibilidad para las personas con capacidades diferenciales;

- $\quad$ Seguridad de los activos frente a ataques externos; 
- $\quad$ Promover marcos regulatorios previsibles que propendan a la defensa de los derechos de los habitantes.

Ahora bien, ¿cuál sería la adscripción teórica del Pan Estratégico de Gobierno Electrónico? De la definición de Gobierno Electrónico dada por el Plan ${ }^{205}$ no podemos extraer una conclusión pues contiene todo los elementos de las definiciones doctrinarias:

- $\quad$ la tecnología como medio;

- fin: acceso ciudadano a los servicios gubernamentales, de las empresas y de los agentes estatales;

- consecuencias: transformar la función gubernamental introduciendo nuevos valores;

- $\quad$ Contexto: modernización del Estado.

Pero si retomamos nuevamente los objetivos del Plan, tanto generales como particulares y efectuamos una distinción según los objetivos de gobierno electrónico asociados a la eficacia y aquellos asociados a la participación, podremos advertir cuál es la visión implícita del Plan Estratégico sobre el gobierno electrónico.

\section{Cuadro 25 - Objetivos plan estratégico de Gobierno Electrónico}

\begin{tabular}{|c|c|c|}
\hline & $\begin{array}{l}\text { GE } \\
\text { Eficacia }\end{array}$ & $\begin{array}{l}\text { GE } \\
\text { Participación }\end{array}$ \\
\hline $\begin{array}{l}\text { 1. Acercar la administración pública al habitante, haciéndola } \\
\text { más accesible y transparente y brindando más y mejores servicios }\end{array}$ & $\mathbf{X}$ & $\mathbf{X}$ \\
\hline $\begin{array}{l}\text { 2. Implementar la gestión basada en responsabilidad por } \\
\text { resultados y recursos }\end{array}$ & $\mathbf{X}$ & \\
\hline 3. Aumentar el impacto de los programas de Gobierno & $\mathbf{X}$ & \\
\hline $\begin{array}{l}\text { 4. Complementar el proceso de modernización mejorando la } \\
\text { calidad y la eficiencia de los servicios del Estado mediante el uso de } \\
\text { información, procesos y tecnología }\end{array}$ & $\mathbf{X}$ & $\mathbf{X}$ \\
\hline $\begin{array}{l}\text { 5. Desarrollar aplicaciones verticales y transversales, sobre una } \\
\text { infraestructura común, que solucionen temas y problemas específicos } \\
\text { de los habitantes }\end{array}$ & & $\mathbf{X}$ \\
\hline $\begin{array}{l}\text { 6. Difundir las actividades del gobierno provincial y sus } \\
\text { dependencias }\end{array}$ & & $\mathbf{X}$ \\
\hline $\begin{array}{l}\text { 7. Informar a los habitantes sobre los servicios y trámites que } \\
\text { presta la provincia y los requerimientos para realizarlos }\end{array}$ & & $\mathbf{X}$ \\
\hline $\begin{array}{l}\text { 8. Permitir a los habitantes requerir información, realizar } \\
\text { trámites y pagar impuestos en forma remota }\end{array}$ & & $\mathbf{X}$ \\
\hline $\begin{array}{l}\text { 9. Habilitar nuevos canales de comunicación entre los } \\
\text { ciudadanos y las autoridades políticas }\end{array}$ & & $\mathbf{X}$ \\
\hline 10. Habilitar nuevos medios de participación ciudadana & & $\mathbf{X}$ \\
\hline
\end{tabular}

205 Se lo define como "el uso de la Tecnología en el marco de la Modernización del Estado, como medio para facilitar el acceso a los servicios gubernamentales en beneficio de los ciudadanos, las empresas y la productividad de los empleados públicos" cuyas implicancias transforman la función gubernamental introduciendo nuevos valores: la comunicación, la cooperación, la participación interactiva y el reconocimiento de la información como valor estratégico. 


\begin{tabular}{|c|c|c|}
\hline $\begin{array}{l}\text { 11. Contribuir a través de la TIC a la eficiencia y transparencia } \\
\text { de la administración pública de la provincia reduciendo costos de } \\
\text { gestión y permitiendo la difusión de los actos de gobierno }\end{array}$ & $\mathbf{X}$ & $\mathbf{X}$ \\
\hline $\begin{array}{l}\text { 12. Promover el uso eficiente de la información, los procesos, } \\
\text { los recursos humanos y la tecnología }\end{array}$ & $\mathbf{X}$ & \\
\hline $\begin{array}{l}\text { 13. Maximizar el aprovechamiento de las tecnologías y sistemas } \\
\text { existentes en la Provincia y sus organismos }\end{array}$ & $\mathbf{X}$ & \\
\hline $\begin{array}{l}\text { 14. Rediseñar los procesos de manera integrada y continua con } \\
\text { foco en el habitante aplicando criterios de simplicidad, facilidad de } \\
\text { acceso, punto único de contacto y flexibilidad }\end{array}$ & $\mathbf{X}$ & \\
\hline $\begin{array}{l}\text { 15. Facilitar y dar soporte a la difusión e implementación de las } \\
\text { políticas de Estado, aumentando el impacto de los programas }\end{array}$ & $\mathbf{X}$ & \\
\hline $\begin{array}{l}\text { 16. Servir de modelo para la prestación de servicios a través de } \\
\text { distintos canales (delegaciones, agencias, kioscos, call center, correo } \\
\text { electrónico, oficinas municipales, etc.) }\end{array}$ & $\mathbf{X}$ & \\
\hline $\begin{array}{l}\text { 17. Contribuir a la eficiencia en el trabajo, la satisfacción } \\
\text { laboral, la capacitación y la realización profesional de los empleados } \\
\text { públicos provinciales }\end{array}$ & $\mathbf{X}$ & \\
\hline TOTAL & 11 & 9 \\
\hline
\end{tabular}

Fuente: Elaboración propia.

Si bien del análisis de los objetivos generales y particulares no podemos advertir que exista un claro predominio de una visión sobre la otra, si ahora analizamos los beneficios que se esperan como consecuencia de la aplicación de las acciones necesarias para desarrollar los objetivos, sí podremos advertir la preeminencia de una visión sobre la otra.

Para clasificar en más o menos importante todos esos beneficios esperados y así poder determinar cuál de todos esos objetivos enunciados es más relevante, se efectuó un conteo para determinar cuántas veces aparece cada una de las palabras clave de los objetivos en el entendimiento de que cuantas más veces aparezca una palabra, más importante ésta será para el Plan.

Cuadro 26 - Cantidad palabras clave por objetivos PALABRAS CLAVE POR OBJETIVO CANTIDAD PALABRAS

\begin{tabular}{|l|c|}
\hline Mejorar la calidad de los servicios que el Estado brinda a sus habitantes; & 10 \\
\hline Aumentar el impacto de los programas que ejecuta; & 13 \\
\hline Mejorar la eficiencia general de la administración provincial; & 28 \\
\hline $\begin{array}{l}\text { Recuperar la legitimidad política y pública de sus organizaciones y de los } \\
\text { empleados públicos; }\end{array}$ & 2 \\
\hline Integrar la información de la Provincia & 22 \\
\hline TOTAL PALABRAS OBJETIVOS & $\mathbf{7 5}$ \\
\hline TOTAL PALABRAS PLAN & $\mathbf{6 . 3 8 8}$ \\
\hline
\end{tabular}

Fuente: Elaboración propia.

Nota: En negritas, se indican las palabras clave por cada objetivo buscadas. 
De ese simple análisis cuantitativo surge que los beneficios relacionados con una visión del gobierno electrónico asociada a la organización -eficiencia e integración de la información- acumulaban más de la mitad de las palabras clave (66\%) mientras que los objetivos relacionados con una visión del gobierno electrónico asociada a la participación -legitimidad y calidad-apenas representaban el 16\%.

\section{El Plan Trienal de la Gestión Pública}

Un cambio teórico-ideológico se advierte cuando la Secretaría para la Modernización del Estado pasa a ser una Subsecretaría dentro de la Secretaría General de la Gobernación, en un primer momento con el nombre de Subsecretaría de la Función Pública, y luego como Subsecretaría de la Gestión Pública, a cargo, en todo momento, de la Ing. Agr. Claudia Bernazza.

En rasgos generales, el Plan se estructuraba en tres componentes: a) fortalecimiento del Estado como proyecto político - social y como organización, aspectos que incluían la planificación estatal con enfoque estratégico, el diseño de la organización estatal y empleo público y carrera; b) modernización e innovaciones en el ámbito público (por ejemplo Carta Compromiso); y c) formación para el cambio cultural dentro del cual el rol del IPAP y sus cursos era el eje del componente.

La funcionaria definió prontamente la estrategia de la Subsecretaría que quedó plasmada en el Taller: "¿Qué Estado queremos?: Hacia un Plan Trienal de la Gestión Pública"206 organizado por la entonces Subsecretaría de la Función Pública en mayo de 2004 y que luego se plasmaría en el Documento $N^{0} 1$ "Conceptos y convicciones que guían el proceso de recuperación y modernización estatal", publicados luego en la página web de la Subsecretaría.

De dicho documento puede deducirse el viraje de las funciones e ideologías subyacentes, pues la modernización como tal deja de ser el aspecto central. En efecto, allí sostiene la Subsecretaria que:

\footnotetext{
... la apuesta fuerte de la Subsecretaría de la Gestión Pública es la de ser un organismo rector al servicio de la planificación y gestión estatal de la provincia de Buenos Aires, que sea capaz de orientar, acompañar y asistir al Estado provincial en el diseño de sus planes de acción, sus estructuras, sus procesos organizacionales y comunicacionales, como así también en el desarrollo de las bases para una carrera (tanto de los agentes como de los funcionarios) de la que hoy se carece (Subsecretaría de la Gestión Pública, 2004-b, Documento $\mathrm{N}^{\mathrm{o}}$ 1, págs. 14-15; el destacado es del original).
}

La gestión reconoció la necesidad de variar la política de modernización iniciada por el Cr. Randazzo:

\footnotetext{
${ }^{206} \mathrm{El}$ documento puede descargarse en: http://www.dpgp.sg.gba.gov.ar/html/Res_Bernazza/5.1_Resolucion_SSFP 5_04_Anexo_I_Plan_Trienal. doc. Fecha de Consulta: 23/07/11.
} 
En este marco, el nuevo órgano rector debe reformular sus líneas de acción en relación con la implementación de mecanismos que "mejoren" la gestión desde los sistemas de planificación, administrativos y de control (Subsecretaría de la Gestión Pública, 2004-c, Documento No 2, pág. 5; el destacado es del original).

... a poco de andar fue reformulado, no porque hubiese existido la necesidad de cambiar las líneas estratégicas, sino porque fue necesario establecer una direccionalidad, a partir de una concepción clara sobre la caracterización y el rol del Estado (Longo, 2005:8).

En efecto, se señalaba que el Plan de Modernización que se había diseñado al inicio de la gestión, en el año 2002, se había considerado al concepto de modernización como un proceso permanente de adaptación de las estructuras del sector público, con el fin de adecuarlas a las nuevas exigencias sociales y que en paralelo, se incorporó el concepto de reforma administrativa que, según esta Subsecretaría (Subsecretaría de la Gestión Pública, 2004-c), se transformó en un fin en sí mismo. Y se afirma:

La reforma administrativa, tal como fue concebida en la Argentina, y a partir de las experiencias, ha funcionado como un proceso básicamente normatizador, que se realiza de una sola vez, y que intenta mejorar aspectos relacionados con los sistemas administrativos de apoyo, o sistemas transversales, que inciden en el funcionamiento de toda la Administración Pública. Estos procesos han tenido su basamento en la necesidad de dotar de una mayor eficiencia a la administración, han operado fundamentalmente ante la necesidad de disminuir el gasto público, y en líneas generales se puede decir que no han logrado con éxito su cometido (Subsecretaría de la Gestión Pública, 2004-c, Documento $\mathrm{N}^{\circ}$ 2, pág. 5; el destacado es del original).

La nueva consigna no era cambiar el Estado sino recuperarlo. Se partía del siguiente supuesto: el Estado refleja los valores y la concepción que la sociedad tiene del mismo; la sociedad había producido el desmantelamiento del Estado de los ' 90 con funestas consecuencias; refortaleciendo el Estado sería posible reconstituir el tejido social y relegitimar, consecuentemente, al Estado. ${ }^{207}$

En la provincia de Buenos Aires, y durante el año 2003, comenzó a incorporarse, dentro del plan de modernización, el concepto de recuperación del Estado. Esto marca la necesidad de abrir el debate sobre cuestiones o aspectos de la gestión que los "nuevos mecanismos" dan por saldados, pero que si se profundiza en la gestión

\footnotetext{
207 Así, por ejemplo: "En función de la experiencia, podemos afirmar que difícilmente exista una demanda social de reforma del Estado, por lo cual es interesante trabajar sobre cuestiones especificas que pueden generar un alto grado de legitimidad social, como, por ejemplo, mejorar la seguridad o la educación, aspectos que no tienen mucha relación con una reforma integral, pero que favorecen el inicio de un proceso mayor a partir de ganar la aprobación de la población" (Longo, 2005:14-15)
} 
cotidiana de cada organismo no lo están. La conformación del Presupuesto, los problemas de financiamiento, los sistemas de información, las normas vigentes sobre procedimientos, los sistemas de carrera, las capacidades, y tantos otros aspectos de la administración, limitan un buen diseño, pero fundamentalmente una eficaz ejecución de las políticas públicas, y esto no será subsanado con mecanismos o proyectos puntuales relacionados estrictamente con nuevas técnicas de gestión, que si bien redundarán en beneficios de funcionamiento, no abordan en forma directa el problema, y peor aún, no son visualizados favorablemente por quienes se consideran sus beneficiarios. En este caso no se habla de un reemplazo de proyectos, sino de un orden de prioridades (Subsecretaría de la Gestión Pública, 2004-c, Documento No 2, págs. 5-6; el destacado es del original).

Pero, la Subsecretaría da un paso más al incorporar a partir de 2004, la innovación como concepto orientador de su accionar.

Surge como un concepto más específico, incluido dentro del marco general de la modernización, que refiere a proyectos "novedosos". Es necesario no caer en el facilismo de considerar que, por nuevo, es adecuado. En principio podríamos trabajar en algunas exigencias relacionados con ciertos atributos que el concepto de innovación debe tener, para que el mismo integre a todas las acciones que la Subsecretaría llevará adelante en su área específica Subsecretaría de la Gestión Pública, 2004-c, Documento Nº 2, pág. 6).

Así, las acciones de modernización del Estado son asociadas ahora a la innovación, descartando el término "reforma" por identificarlo a la concepción del Estado vigente en la década del '90. Se define la modernización como "una posibilidad de mejora continua de la capacidad de gestión... la mejora no será considerada como tal si no favorece la inclusión social" (Subsecretaría de la Gestión Pública, 2004-b, Documento $\mathrm{N}^{\mathrm{o}} 1$, pág. 20).

Vemos entonces que el cambio no fue meramente de nombre. La modernización iniciada por la entonces Secretaría para la Modernización del Estado continúa, asumido ahora por una Unidad de Coordinación de Programas de Innovación, pero como una de las tres grandes líneas de acción. Las otras dos líneas de acción eran:

- Fortalecimiento del Estado como proyecto político-social y como organización a cargo de la Dirección Provincial de la Gestión Pública; y,

- Formación para el cambio cultural asumida por el Instituto Provincial de la Administración Pública (IPAP), cuya Presidencia era ejercida por el titular de la Subsecretaría de la Gestión Pública.

Dentro de los principios básicos para el diseño del Programa de Fortalecimiento de la Calidad Institucional, la Subsecretaría (2004-c:9) sostiene que: 
- $\quad$ Ninguna mejora puede implementarse si no es por decisión de la propia organización.

- La innovación debe basarse, en primera instancia, en una optimización de los sistemas actuales.

- $\quad$ El impacto en los servicios brindados a la ciudadanía son los pilares que justifican un proceso de innovación.

- La mejora en la relación con los usuarios no se circunscribe solamente a las áreas de atención al público, sino que pone en juego a toda la organización.

- La innovación supone siempre un aumento de los mecanismos de comunicación y participación.

En cuanto a las acciones que el Plan Trienal 2004/2007 propicia, las que dan muestras de sus principales orientaciones, la Subsecretaría buscó focalizarse en aquellos proyectos que tengan impacto en el funcionamiento de los organismos de cara a la ciudadanía, y, en la medida de lo posible, que impacten transversal y positivamente en varios ámbitos de la Administración Pública. Entre las acciones de innovación propuestas por la Subsecretaría (2004-b) se señalan las siguientes:

- Establecimiento de un Programa de Fortalecimiento de la Calidad Institucional con el objetivo de sostener y apoyar aquellas propuestas de innovación que han resultado exitosas, y proponer las que puedan considerarse necesarias y viables.

- Creación de un Banco de Proyectos de Innovación (BPI) como espacio de registro y difusión de experiencias.

- $\quad$ Acompañamiento del Plan Estratégico de Gobierno Electrónico para la Provincia de Buenos Aires, aprobado por Decreto $\mathrm{N}^{0} 1.824 / 02$.

- Apoyo a los proyecto de mejora de los sistemas administrativos de apoyo (gestión de personal, compras y contrataciones) y al fortalecimiento de los sistemas de información y comunicación (digestos normativos y legales, directorios, legajos, servicios a través de Internet), y a las iniciativas y programas específicos del Plan Estratégico de Gobierno Electrónico (Sistema de Recursos Humanos, Infoleg), entre otras.

Por último, fueron considerados como mecanismos aptos para llevar adelante el proceso de modernización los siguientes:

- Carta Compromiso con el Ciudadano.

- Banco de experiencias exitosas. 
- Convenio con el Instituto Argentino de Normalización (IRAM) para la obtención de certificados de calidad y asistencia técnica para el desarrollo de programas.

- Cuerpo de Agentes de Modernización.

Resulta notorio, en efecto, que se modificó la concepción sobre la reforma del Estado y de la Administración.

\section{La Subsecretaría de Gestión Tecnológica y Administrativa}

La Subsecretaría de Gestión Tecnológica y Administrativa, dependiente de la Secretaría General de la Gobernación, a diferencia de las otras áreas arriba analizadas, no tuvo un plan o programa doctrinario ni fue explicitado en un documento oficial que sustentara sus acciones. A pesar de ello, se señaló en varios actos administrativos impulsados por esta Subsecretaría la existencia de un "plan de modernización del Estado". De ahí que debamos analizar su orientación a partir de los Considerandos de los Decretos propiciados desde esa área.

Para el Subsecretario, Cr. Luis Deniro (2005:8),

La implantación de todo nuevo modelo de gestión, requiere de una significativa transformación de las instituciones, en este caso las provinciales, incorporando nuevas prácticas y tecnologías (planificación estratégica, cambios estructurales, revisión y reformulación de procesos, identificación de productos, etc.) y debe estar acompañada por la reforma de los sistemas administrativos de apoyo, los que las atraviesan y condicionan.

La importancia del área, durante el período en estudio fue creciendo de menor a mayor de la mano del Subsecretario. Comenzó siendo una Dirección General de Administración y finalizó durante la gestión de Solá, como la Subsecretaría que controlaba la administración de la Unidad de Coordinación del Gobernador, de la Secretaría de Turismo y Deportes, de la Secretaría de Prensa y Comunicación Social y co-participando en la elaboración de los proyectos de la Secretaría Ejecutiva de Gobierno Electrónico; tuvo también la administración de la Secretaría de Política Ambiental y del Teatro Argentino, todo ello, además de la administración de la propia Secretaría General. ${ }^{208}$

Según se manifiesta en la ponencia presentada por el funcionario a cargo de esta Subsecretaría en el X Congreso Internacional del CLAD sobre la Reforma del Estado y de la Administración Pública, hizo falta combinar una fuerte dosis de racionalidad política con una sostenida interacción con los organismos a fortalecer o refuncionalizar,

\footnotetext{
208 Además, para tomar cuenta del peso propio de esta Subsecretaría, es preciso recordar que dependían de esta Subsecretaría Direcciones Provinciales trasversales a toda la gestión intra-adminsitración: Direcciones Provinciales de Aeronáutica, Personal de la Provincia, Informática y Comunicaciones, General de Administración, Bienes y Servicios y Automotores y Embarcaciones Oficiales.
} 
sobre la base de problemáticas concretas, objetivos claros y acciones determinadas (Deniro, 2005).

¿Cómo se tradujeron estos lineamientos en las normas? Ya señalamos que esta Subsecretaría no tuvo un plan explícito de acción y sin embargo es posible reconstruirlo a partir de las políticas propiciadas, en especial, analizando las consideraciones de los actos administrativos gestionadas por esta Subsecretaría que estén relacionados con la reforma de la Administración. Así, veremos en el siguiente Cuadro alguna de las consideraciones de los Decretos propiciados con indicación de la temática ${ }^{209}$ :

Cuadro 27 - Selección de párrafos de los Considerandos de los Decretos impulsados por la Subsecretaría de Gestión Tecnológica y Administrativa

Decreto $N^{0}$ 1204/03 que define la Red Única Provincial de Comunicación de Datos

Provincial de Comunicacion de Datos

Que no obstante ello, algunos Organismos Provinciales y Municipios aún cuentan con conexiones a redes independientes, situación que debe reverse definitivamente, no sólo porque generan recursos ociosos $e$ ineficaces que provocan, a la vez, múltiples e innecesarias erogaciones sino que, en honor a la coherencia que demanda la planificación impulsada por esta Administración Provincial en materia de Modernización del Estado, deviene imprescindible integrarlos a la Red Única Provincial de Comunicación de Datos;

Decreto $\mathrm{N}^{\mathbf{2}}$ 2.442/05 que aprueba el Régimen sobre el Uso Responsable de Elementos Informáticos

Que en este sentido, resulta fundamental establecer para todos los agentes de la Administración Pública Provincial un marco normativo único y claro sobre el Uso Responsable de los Elementos Informáticos que el Estado les brinda para mejorar su gestión y para generar las condiciones de su uso confiable, legal y eficiente;

Decreto $\mathrm{N}^{\mathbf{0}} 1.859 / 07$ que crea el sistema de Conjuntos Mínimos de Datos

Que esta Gestión de Gobierno impulsó en el año 2002 y a poco de asumir la administración de la Provincia de Buenos Aires, un proceso de reforma del Estado cuyos objetivos centrales fueron y son la mejora de la calidad de los servicios que brinda a sus habitantes, el aumento del impacto de los programas que ejecuta mejorando la eficacia en el uso de los recursos públicos, la optimización de la eficiencia general de la Administración Pública Provincial y la recuperación de la legitimidad política de las instituciones públicas;

Que para alcanzar los propósitos pretendidos
Decreto $\mathrm{N}^{\circ}$ 944/05 que aprueba el Contrato Tipo de Locación de Obra para la Administración Pública Provincial

Que atento a que se trata de un medio de contratación al que el Estado Provincial recurre en forma repetitiva, se estima oportuno y conveniente la aprobación de un modelo tipo de contrato de Locación de Obra para que, en el marco del actual Artículo 14 del Reglamento Contractual, se contribuya a evitar confusiones, dispendio de actividad administrativa y rechazos de proyectos de contrataciones;

Decreto $\mathbf{N}^{0}$ 3.578/06 de aprobación del Acuerdo Marco suscripto con la empresa Oracle Argentina S.A

Que de tal situación deriva la necesidad de encontrar soluciones integrales y homogéneas a los problemas de adquisición y uso de software con el mayor grado de beneficios para la Administración Pública Provincial;

Decreto $\mathrm{N}^{\mathbf{3}} 3.435 / 07$ para Contratar la provisión del servicio de acceso mediante vínculos de comunicación de datos de banda ancha fija y/o móvil con servicio de red privada virtual

Que, como ya se ha sostenido en oportunidad de impulsar otras medidas en el campo de las Nuevas Tecnologías de la Información y las Comunicaciones (TIC), para la construcción de una nueva gobernanza basada en la eficiencia y eficacia de las políticas implementadas, resulta necesario contar con una gestión pública que alcance altos niveles de credibilidad, capacidad de gobierno, liderazgo político y legitimidad y, en ese sentido, la Provincia se encuentra firmemente comprometida en el desarrollo de aquellos proyectos transversales que, incorporando nuevas prácticas y tecnologías,

209 Seleccionamos de los textos, párrafos completos de los aspectos vinculados a la reforma y al modelo Estatal. En todos los casos, el destacado no es del original. 


\begin{tabular}{l}
\hline resulta indispensable en primera instancia, \\
promover una adecuada coordinación intra \\
Administración Provincial con el objeto que la \\
información administrada alcance niveles de \\
oportunidad, seguridad y disponibilidad que \\
posibiliten su intercambio interno, respetando los \\
límites legales vigentes sobre confidencialidad de \\
los datos secretos y sensibles y contribuya de \\
manera sustancial, a la eficiencia y efectividad en \\
el desarrollo de los sistemas de información \\
provincial;
\end{tabular}

Decreto $\mathrm{N}^{\circ}$ 3.130/06 que aprueba el Acuerdo Marco con la empresa Nextel

Que esta Administración Gubernamental, en el marco del Plan de Modernización del Estado, viene desarrollando diversas acciones tendientes a promover el fortalecimiento de la gestión administrativa, politica que conlleva implícito el objetivo de simplificar todos los procesos $y$ procedimientos sobre los que se desarrollan $y$ basan las acciones administrativas transversales a todos los Organismos;

Decreto $\mathrm{N}^{\mathbf{0}} \mathbf{1 . 6 7 6 / 0 5}$ que crea el Pliego Único de Bases y Condiciones Generales y de los Pliegos Tipo de Bases y Condiciones Particulares por Tipo de Demanda

Que entonces, sobre la base de esa experiencia y sus resultados, cabe valorar e institucionalizar la modalidad de compra unificada, que implica la consolidación de la demanda común y de su trámite, pero mantiene desconcentrados el perfeccionamiento y cumplimiento del contrato, mediante la aprobación del Pliego Tipo de Bases y Condiciones para la Compra Unificada de Bienes e Insumos, incorporado en el Anexo III;

Que en tal sentido, en su redacción se buscó armonizar los requisitos formales, subjetivos y objetivos, de acuerdo al texto de los últimos avances en materia contractual, conforme a la letra de los Decretos $N^{o} 787 / 2004$ y 2698/2004, en pos de implementar un procedimiento claro $y$ transparente, dotado de la necesaria agilidad y eficiencia a fin de obtener una mayor y mejor concurrencia al llamado del Estado Provincial a efectuar ofertas, que paralelamente respete los principios de publicidad e igualdad;

Decreto reglamentario de la Ley $\mathbf{N}^{0}$ 13.727, Decreto $\mathbf{N}^{\mathbf{0}} 3.313 / 07$ para la creación de la base única de datos de vehículos y compactación de vehículos

Que ante esa situación (saturación de chatarra), promuevan la reforma de los sistemas administrativos y se constituyan en un efectivo apoyo $y$ sostén de todas las actividades de carácter sustantivo, para lo cual ha incorporado, como objetivo central de la agenda de reformas, la implantación coordinada de soluciones tecnológicas compatibles y soportables por una infraestructura común en los diferentes Organismos;

Que en el marco de las acciones que la Provincia se encuentra llevando adelante tendientes a planificar gastos, reducir costos y obtener mayores ventajas a través de mecanismos contractuales seguros $y$ políticas claras $\boldsymbol{y}$ uniformes que estimulen la competencia, resulta imprescindible que el Estado aproveche en su totalidad esas nuevas aplicaciones, dejando habilitada la posibilidad de admitir nuevas aplicaciones a través de estos accesos;

Decreto $\mathbf{N}^{\mathbf{0}}$ 3.687/06 que aprueba el Acuerdo celebrado con el Correo Oficial de la República Argentina S. A.

Que en el marco del Plan de Modernización del Estado Provincial, que conlleva implícito el objetivo de simplificar todos los procesos y procedimientos sobre los que se desarrollan y basan infinidad de acciones administrativas transversales a todas las jurisdicciones, cabe avanzar hacia el establecimiento de una relación única, adoptada en el máximo nivel ejecutivo, entre la Administración Pública Provincial y el Correo Oficial de la República Argentina S.A.;

Decreto $\mathbf{N}^{\mathbf{0}}$ 2.524/07 que aprueba el Acuerdo Marco suscripto con empresa Microsoft Licensing

Que en la inteligencia de profundizar y facilitar una mayor y mejor relación entre el Estado y la sociedad civil, esta Administración siempre priorizó la atención, adopción y desarrollo de toda herramienta y/o medio apto para la mejor consecución de tales fines;

Que de tal situación deriva la necesidad de encontrar soluciones integrales y homogéneas a los problemas de adquisición y uso de software, con el mayor grado de beneficios para la Administración Pública Provincial;

Decreto $\mathbf{N}^{\mathbf{2}} 2.455 / 05$ que aprueba el Régimen de Uso Responsable de Telefonía Celular

Que es objetivo primordial del Gobierno Provincial 
este Poder Ejecutivo tomó la decisión de dar una rápida y contundente respuesta, promoviendo la aplicación de un procedimiento específico, con la celeridad que el caso impone, que posibilite reducir drásticamente ese universo; la plena optimización del uso y del gasto derivado de la telefonía móvil, a efectos de lograr el máximo de eficiencia en la gestión de esas comunicaciones;

Que la Secretaría General de la Gobernación tiene la responsabilidad de generar acciones tendientes a la racionalización y optimización de los procedimientos de gestión de bienes y servicios, entre ellos, el de comunicaciones, mediante la propuesta de pautas de carácter general;

Fuente: Elaboración propia.

Nota: Las negritas no son de los originales.

Así, según hemos podido analizar, entre esos principios de desprenden los de eficacia mediante una mayor delegación de las competencias jurisdiccionales para la autorización y aprobación de las licitaciones públicas, privadas y las contrataciones directas, fortaleciendo la gestión de cada Ministerio, Secretaría u Organismo, pero

... teniendo presente que ello derivaba también en una mayor responsabilidad y compromiso de los funcionarios delegados, respecto de las políticas de Estado en materia de simplicidad de procesos y procedimientos, celeridad en la gestión y transparencia en su accionar (Deniro, 2005:6).

Otro de los principios orientadores de su gestión, como explícitamente los reconoce en el documento presentado en el CLAD es del economía de procesos y transparencia que se aplicó en la elaboración de los Pliegos Tipo.

Otro es el de participación mediante las Consultas Públicas ${ }^{210}$ como paso previo a la aprobación de los Pliego Tipo con el objeto de alcanzar la mayor transparencia, publicidad y participación igualitaria de los posibles oferentes. El de transparencia que, para la Subsecretaría bajo análisis, se alcanzó por haber adherido al Sistema de Identificación de Bienes y Servicios de Utilización Común del Gobierno Nacional; ello, permitió contar con una herramienta para administrar datos sobre precios, estableciéndose como paso previo a la adjudicación, la consulta de "precios referenciales o testigos" de los productos o servicios a contratar. Otro de los elementos que coadyuvaron a la transparencia fue la difusión de las contrataciones en el sitio Web de la Provincia, adoptando el principio general de gratuidad de los pliegos de bases y condiciones allí publicados.

En definitiva, como ha señalado el Subsecretario a cargo de la Subsecretaría de Gestión Tecnológica y Administrativa, el Cr. Luis Deniro, la agenda de esas reformas se centró en los siguientes tópicos:

- mejorar la calidad de los servicios que el Estado Provincial brinda a sus habitantes;

\footnotetext{
${ }^{210}$ Las consultas son mediante el mecanismo de su consulta pública no vinculante.
} 
- impulsar en los organismos provinciales, transformaciones institucionales internas que aumenten el impacto de los programas que ejecutan y mejoren la eficacia en el uso de los recursos públicos;

- desarrollar transformaciones transversales que apunten a producir cambios coordinados en los sistemas que atraviesan horizontalmente toda la Administración Provincial en sus modalidades de gestión y que se constituyan en el apoyo y sostén administrativo para todas las actividades de carácter sustantivo;

- dotar de soluciones tecnológicas compatibles a los diferentes organismos, coordinadas con ellos y soportadas por una infraestructura común;

- garantizar la accesibilidad pública a la información relativa a sus funciones, como al manejo y disponibilidad de los recursos de sector público.

Hizo falta combinar "una fuerte dosis de racionalidad política con una sostenida interacción con los organismos a fortalecer o refuncionalizar" (Deniro, 2005:5), sobre la base de problemáticas concretas, objetivos claros y acciones determinadas.

Si bien parece desprenderse de los conceptos vertidos en los actos administrativos propiciados un verdadero pragmatismo en las políticas propiciadas, en verdad, el norte de las acciones parece fundado en una fuerte preocupación por el reordenamiento del caos que la crisis de 2001 causó en la gestión administrativa. A través de la simplificación, concentración de competencias y unificación de criterios y/o actos administrativos, se puede advertir en esta Subsecretaría otra visión de la reforma del Estado y la Administración. 


\section{CAPÍTULO VIII. ESTUDIO DE CASOS I - SECRETARÍA DE MODERNIZACIÓN DEL ESTADO Y MINISTERIO DE GOBIERNO}

\section{Acciones de la Secretaría para la Modernización del Estado}

Como hemos señalado más arriba, la Secretaría para la Modernización del Estado, aprobada por Ley $N^{\circ} 12.856$ en el año 2002 fue creada a instancias del Cdor. Florencio Randazzo.

Hemos analizado en el Capítulo VII el Plan de Modernización presentado y cuál fue su resultado. El Plan de Gobierno Electrónico, también fue allí expuesto. Ambos fueron planificados por esta Secretaría aún cuando su ejecución no resultó viable, en el primer caso por la falta de apoyo legislativo y en el segundo, por la desaparición de la Secretaría y su traspaso a la Secretaría General de la Gobernación.

Describiremos, por ello ahora, sólo algunas de las acciones más relevantes de esta Secretaría así como del Ministerio de Gobierno, ambos ocupados por el Contador Randazzo y dejaremos para las conclusiones el análisis de su adecuación a los planes generales previstos por el área así como entre éstos con las políticas pretendidas por el Gobernador $^{211}$.

\section{a) Carta Compromiso.}

La Carta Compromiso, cuya Programa fue aprobado por Decreto $\mathrm{N}^{\circ} 47 / 03$, tiene como objetivo mejorar la relación entre los organismos que conforman la Administración Pública de la Provincia de Buenos Aires y los ciudadanos, fortalecer la confianza de los ciudadanos en los servicios públicos y mejorar su relación y percepción con respecto a los funcionarios y agentes públicos.

Según el Decreto de creación, el Programa se basa en los siguientes principios rectores:

a) Igualdad: el suministro de servicios públicos ha de regirse por el principio de igualdad de derechos de los usuarios. El acceso y las reglas que rigen las relaciones entre los usuarios y los prestadores de servicios públicos deberá garantizar condiciones de igualdad, sin discriminación de ningún tipo.

b) Continuidad: deberá garantizarse la continuidad de la prestación de los servicios considerados esenciales.

c) Participación: los usuarios y beneficiarios de servicios de atención al público deben contar con mecanismos de participación adecuados a cada caso, a fin de garantizar y proteger el derecho a una correcta prestación.

\footnotetext{
${ }^{211}$ Igual procedimiento utilizaremos en los capítulos subsiguientes cuando analicemos los casos de cada una de las Subsecretarías a cargo de la modernización de la administración pública y la reforma del Estado.
} 
d) Derecho a la información: los usuarios y beneficiarios de servicios comprendidos en el presente programa deben contar con la posibilidad de tener un efectivo acceso a la información en las condiciones que establece la normativa vigente.

e) Calidad: las organizaciones alcanzadas por el presente Programa deben tender en la medida de sus posibilidades a la efectiva satisfacción de los usuarios en la prestación de los servicios a su cargo, dando cuenta de las iniciativas que pongan en marcha a tal efecto.

f) Transparencia: Los organismos prestadores de servicios a los ciudadanos en tanto tales, deben realizar la publicidad de su gestión, en cuanto a dar a conocer qué puede razonablemente esperarse en cada caso, como garantía de efectividad y eficiencia en la asignación de sus recursos humanos, económicos y financieros.

Los organismos que se incorporen al Programa deberán comprometerse a informar a los usuarios sobre la naturaleza, contenido, características y formas de prestación de los servicios que brinda el organismo y los requerimientos para acceder a los mismos. Se comprometen, asimismo, a determinar los niveles o estándares de calidad actuales y las metas cuantificables para su desempeño futuro, previendo, para esto último, un sistema de monitoreo y evaluación del cumplimiento de los estándares sobre la base de un conjunto homogéneo de indicadores. Interesante es también el compromiso de dar amplia difusión de los resultados, en un lenguaje claro y accesible para el conjunto de la población así como el de establecer un sistema de quejas y reclamos, mecanismos de compensación por errores injustificados y/o incumplimiento de los compromisos y mecanismos de consulta a los usuarios acerca de los servicios que aquellos demanden, sus sugerencias y opiniones para la mejora de los mismos.

En el documento "Carta Compromiso con el Ciudadano de la Provincia de Buenos Aires" (2003:15), se describen los pasos a seguir para elaborar la Carta Compromiso:

... la planificación, la creación de un ambiente cooperativo, la consulta y testeo de los ciudadanos y del personal del organismo, la difusión y el monitoreo de la Carta Compromiso. En la etapa de planificación resulta fundamental, en primer lugar, lograr el apoyo de la Alta Dirección del organismo, que es el nivel donde deberá decidirse quién es el responsable de producir la Carta y los recursos necesarios para el desarrollo de todas las actividades. Una vez obtenido el apoyo, deberán adecuarse las tareas y elaborar el cronograma de trabajo para llevar adelante la labor. (...) Para una adecuada elaboración del documento es necesario testear y consultar en forma sistemática a los destinatarios de los servicios. Es importante tener en cuenta que las consultas a los ciudadanos deberán realizarse en una primera instancia en el proceso de elaboración de la Carta, de forma tal que puedan incorporar su visión y opiniones sobre los servicios en la fase más temprana. De la misma forma, es importante consultar e involucrar a los empleados que se desempeñan en la organización. Ellos son quienes deben participar en la formulación de 
los estándares de su Carta y, en general, los que están en la mejor posición para hacer sugerencias para su mejora. En este sentido, es conveniente recabar información de las distintas áreas de la organización y no sólo de aquellas con injerencia directa en la elaboración de la Carta.

El sistema es (pues aún continúa vigente) muy bueno, pero su complejidad, atenta a su implementación y difusión.

Hasta 2004, cuando detectamos la última publicación sobre el tema por parte del Organismo responsable sólo cuatro organismos iniciaron un proceso tendiente a elaborar una Carta, y dos lo finalizaron (conf. Subsecretaría de la Gestión Pública, 2004-c:7 $)^{212}$. Justamente, en 2004 se realizó una reunión para evaluar los resultados alcanzados hasta ese entonces con la Carta Compromiso, ya bajo la órbita de la entonces Subsecretaría de la Función Pública a cargo de la Ing. Claudia Bernazza.

Uno de los Organismos que participó de la reunión, fue el OCEBA (Organismo de Control de Energía Eléctrica de la Provincia de Buenos Aires) y el expositor fue su Presidente, el Ing. Jorge Alberto San Miguel. El funcionario señaló que las razones para la incorporación del Organismo al Programa Carta Compromiso con el Ciudadano, es componente ético, por un lado, y la necesidad de revertir la concepción de que los organismos públicos no defienden a los usuarios.

Los contenidos de la Carta Compromiso del OCEBA son,

- sobre el prestador:

○ descripción clara de los servicios ofrecidos por el organismo;

○ identificación del beneficiario;

- identificación de los responsables del servicio;

o descripción de las formas de acceso a los servicios;

○ enumeración de los derechos y obligaciones de los ciudadanos en relación con los servicios.

- Sobre la calidad:

○ estándares de calidad establecidos;

○ compromisos de mejora para el período anual;

○ información sobre formas de participación de la ciudadanía;

- participación de la ciudadanía;

- sistema de quejas y mecanismos de compensación implementado.

Este Organismo ya ha venido participando en otros proyectos del área, como el Banco de Proyectos Exitosos que derivó en el diseño de indicadores de control del servicio eléctrico, y esta práctica le otorgó un expertise para su participación en el programa de Carta Compromiso.

\footnotetext{
${ }^{212}$ Los cuatro Organismos fueron: OCEBA, Laboratorio Central, Casa de la Provincia e IPS. Sólo los dos primeros los iniciaron.
} 
El Presidente del OCEBA señaló como beneficios de la implementación:

- identificar claramente los destinatarios (mayor receptividad);

- promover una sensibilización en el organismo y motivación en los empleados al seleccionar un facilitador por área;

- identificar claramente los servicios que se brindan;

- sensibilidad en la atención: capacitación mediante cursos, orientar la organización para el cumplimiento de resultados, analizar las entradas en el 0800 .

Según el Presidente, todo esto significa un fortalecimiento en la institución pero implica también un proceso de transformación de la organización enfocado en el aprendizaje, receptividad (valorando la percepción de los ciudadanos); competencia (a través de la capacitación); comunicación interna y externa; participación y agilidad (descentralizando la solución de conflictos).

Se señaló como fortalezas del programa la transversalidad de los distintos temas, contar con un Plan Estratégico y el aprendizaje institucional. Entre las debilidades que la capacitación debe ser más profunda y la necesidad de señales de acompañamiento por parte del gobierno provincial (inexistentes según señaló el funcionario).

\section{b) Banco de Proyectos Exitosos.}

El Banco de Proyectos Exitosos de la Gestión Pública de la Provincia de Buenos Aires busca que incorporar, en un único repositorio los casos de éxito en la gestión pública de todos los organismos de la Administración Pública del orden provincial centralizada o descentralizada, entidades autárquicas y otras entidades donde el estado provincial tenga participación mayoritaria en el capital en la formación de las decisiones societarias, en forma individual o conjunta.

El Banco de Proyectos Exitosos, creado por el Decreto 2905/02, es un sistema de recepción, evaluación, registro, documentación y divulgación de los proyectos exitosos de gestión pública en las jurisdicciones de la Administración Pública Provincial (APP). Tiene como objetivo la difusión de instrumentos y tecnologías de gestión que se destaquen por el uso eficiente y eficaz de los recursos públicos con alto impacto en la población beneficiaria, de manera tal que puedan ser aprovechados por otros organismos públicos en el marco de la planificación de nuevos proyectos de gestión (Subsecretaría de la Gestión Pública, 2004-c:7).

Como se señala en el artículo "Banco de proyectos de innovación en la gestión pública de la Provincia de Buenos Aires" de Alicia Susana Doyle y Carmen Susana Lozano (s/f:2),

El BPE se basó en una iniciativa del Instituto Latinoamericano de Planificación Económica y Social para América Latina y El Caribe - 
ILPES-, cuyo objeto era asegurar que los países latinoamericanos y del Caribe dispusieran de una herramienta que les permitiera conocer experiencias y proyectos de los cuales aprender para incorporar enseñanzas en las nuevas acciones financiadas con recursos de inversión. El programa piloto se desarrolló en Colombia, en el año 2000 y en vista de los resultados obtenidos, fue replicado en varios países de América (Chile, Perú, Brasil).

¿Qué se considera por caso de éxito? Lo define el artículo $2^{\circ}$ del propio Decreto de creación del Banco:

ARTICULO $2^{\circ}$.- Entiéndese por casos exitosos las prácticas y experiencias de gestión ex-post que agregan valor al cumplimiento de las obligaciones legales y misiones propias de los organismos públicos, que reúnan las siguientes características:

a) Innovación, creatividad o adaptación de tecnologías administrativas en el proceso.

b) Efectos positivos significativos para el organismo y sus usuarios / beneficiarios.

c) Potencial de transferencia a otras entidades públicas.

d) Resultados verificables y susceptibles de medición.

e) Sustentabilidad en el tiempo.

Podrá tenerse en consideración otros criterios, en aquellos casos donde la particularidad del proyecto o experiencia lo requiera.

Para la generación del Banco, dependiente de la Secretaría para la Modernización del Estado -y luego de la Subsecretaría de la Gestión Pública con la disolución de esta Secretaría-se organizan concursos. Sí, expresamente, se señala que el caso inscripto en el Banco de Proyectos Exitosos de la Gestión Pública que haya obtenido el mayor puntaje de calificación, se hará merecedor al Premio Provincial de Alta Calidad en la Gestión Pública para el respectivo año. La evaluación estará a cargo de un Comité de Evaluación, cuyos miembros serán renovados anualmente y cumplirán sus funciones con carácter ad honorem.

Bajo la Secretaría para la Modernización del Estado se presentaron los siguientes proyectos ganadores:

Cuadro 28 - Proyectos ganadores Banco de Proyectos Exitosos 2003.

\begin{tabular}{|c|l|l|}
$\begin{array}{l}\text { No de } \\
\text { Orden }\end{array}$ & Organismo & Nombre de la experiencia \\
\hline 1 & $\begin{array}{l}\text { Jefatura de Gabinete, Dirección Provincial } \\
\text { de Casas de la Provincia de Buenos Aires }\end{array}$ & $\begin{array}{l}\text { Consideraciones hacia la calidad en la atención } \\
\text { y el mejor servicio al ciudadano }\end{array}$ \\
\hline 2 & $\begin{array}{l}\text { Ministerio de Salud, Dirección General de } \\
\text { Administración, Oficina de Control de } \\
\text { Gestión }\end{array}$ & \begin{tabular}{l} 
Catálogo VADEME \\
\hline 4
\end{tabular} \\
$\begin{array}{l}\text { Servicio Provincial de Agua Potable y y } \\
\text { Saneamiento Rural (SPAR) }\end{array}$ & $\begin{array}{l}\text { Estudio del estado sanitario de la población en } \\
\text { relación directa con el agua potable }\end{array}$ \\
\hline 5 & $\begin{array}{l}\text { Ministerio de Seguridad, Subsecretaría de } \\
\text { Planificación y Logística de Seguridad }\end{array}$ & $\begin{array}{l}\text { Sistema de recolección, procesamiento y } \\
\text { análisis de la información delictiva, mediante }\end{array}$ \\
\hline
\end{tabular}




\begin{tabular}{|c|c|c|}
\hline & & $\begin{array}{l}\text { el empleo de herramientas de análisis criminal } \\
\text { y sistemas de información geográfica (SIG) }\end{array}$ \\
\hline 6 & Ministerio de Salud & $\begin{array}{l}\text { Informatización del registro de Personas con } \\
\text { Discapacidad y Registro de Prestadores. Banco } \\
\text { Pcial. de datos en la temática de Discapacidad }\end{array}$ \\
\hline 7 & $\begin{array}{l}\text { Dirección general de Cultura y Educación } \\
\text { (DGCyE) }\end{array}$ & $\begin{array}{l}\text { "Sistema de información para la Gestión } \\
\text { Educativa: desarrollo e implementación de un } \\
\text { legajo de alumnos y del sistema de } \\
\text { Información Geográfico en Internet }\end{array}$ \\
\hline 8 & $\begin{array}{l}\text { Ministerio de Gobierno, Dirección } \\
\text { Provincial de Escuelas de Gobierno }\end{array}$ & programa Parlamentos Juveniles \\
\hline 9 & $\begin{array}{l}\text { Ministerio de Salud, Dirección de Salud } \\
\text { Mental }\end{array}$ & $\begin{array}{l}\text { Programa Malvinas - Programa de salud del } \\
\text { veterano de guerra bonaerense }\end{array}$ \\
\hline 10 & Instituto de Previsión Social & $\begin{array}{l}\text { "RUPA: Registro Único Permanente de } \\
\text { Afiliados }\end{array}$ \\
\hline
\end{tabular}

Fuente: http://www.dpgp.sg.gba.gov.ar/html/bpe2003.htm.

Fecha de Consulta: 4/1/12.

Con la transformación de la Secretaría para la Modernización del Estado en la Subsecretaria de la Gestión Pública (SSGP), en el año 2004 se decidió reformular el Banco creándose el Banco de Proyectos de Innovación (BPI) en la Gestión Pública. En él se extiende la convocatoria no sólo a experiencias ya realizadas sino también a ideas transformadoras del quehacer de la administración, para lo cual se invita a participar a ciudadanos y ONG. Se modificaron, como luego veremos, los objetivos buscados.

\title{
c) Cuerpo de agentes de modernización.
}

El cuerpo de Agentes de Modernización fue creado por el Decreto No 540/03 y

\begin{abstract}
tiene como objetivo principal la asistencia técnica a organismos para la implementación de procesos de modernización, a través de un equipo de agentes de la planta permanente de diferentes jurisdicciones de la Administración Pública Provincial, altamente capacitados en el conocimiento de normas y sistemas que rigen el funcionamiento de los organismos públicos provinciales y para la modernización de la APP con nuevas técnicas de gestión con criterios y visiones de enfoque estratégico (Subsecretaría de la Gestión Pública, 2004-c:7).
\end{abstract}

En los fundamentos del Decreto propiciado por la Secretaría de Modernización del Estado se señala la urgencia en la formación de funcionarios idóneos para las tareas de implementación del Plan de Modernización del Estado mediante la formación de agentes públicos que llevarán el nombre de Agentes de Modernización, los cuales han de desarrollar las tareas de asesoramiento en organismos a los que puedan ser destinados donde sus servicios sean más necesarios.

Se agrega que la formación profesional de los Agentes, mediante una enseñanza teórico-práctica cuidadosa e intensiva, permitirá el ejercicio de tal función, a través de la aprobación de los cursos específicos que han de preverse, garantizándose la transparencia y la objetividad en el sistema de selección para la inscripción a los mismos. Por último, se señala la conveniencia de que las posibilidades de formación se 
ofrezcan a los actuales agentes de la planta permanente de personal de la Administración Pública Provincial, lo que significará para los interesados un estímulo para su progreso profesional a la vez que beneficiará a la Administración al aprovechar su experiencia y conocimiento.

Importa transcribir del Decreto los siguientes artículos que dan cuenta de la filosofía del proyecto:

\begin{abstract}
ARTICULO $2^{\circ}$.- Los AGENTES DE MODERNIZACIÓN tendrán por objeto asistir y asesorar a la máxima autoridad y a los demás integrantes de las jurisdicciones y entidades de la Administración Pública Provincial a las que sean destinados, en la implementación del PLAN de MODERNIZACIÓN DEL ESTADO y a llevar a cabo todos los trámites concernientes al mismo. Asimismo, representarán a la SECRETARÍA PARA LA MODERNIZACIÓN DEL ESTADO en todo lo que respecta a la implementación del mencionado plan.
\end{abstract}

ARTÍCULO $4^{\circ}$.- $^{-} \mathrm{Se}$ designará a los AGENTES DE MODERNIZACIÓN entre el personal de la Planta Permanente de la Administración Pública Provincial que apruebe el Programa de Formación de Agentes de Modernización de carácter teórico y práctico, con sus evaluaciones correspondientes, que, a tales efectos, instrumente la SUBSECRETARÍA DE LA FUNCIÓN PÚBLICA de la SECRETARÍA PARA LA MODERNIZACIÓN DEL ESTADO.

ARTÍCULO $6^{\circ}$.- Los aspirantes a ser designados como AGENTES DE MODERNIZACIÓN deberán cumplir con el "PERFIL DEL AGENTE DE MODERNIZACIÓN" que como "Anexo I" forma parte del presente Decreto y aprobar el Programa de Formación de Agentes de Modernización.

ARTÍCULO $7^{\circ}$.- Los asistentes al Programa de Formación de Agentes de Modernización, continuarán revistando en sus jurisdicciones y organismos correspondientes, manteniendo sus agrupamientos escalafonarios pertinentes, con permiso especial con goce de haberes a partir de su admisión al mismo. Dicho permiso subsistirá mientras dure la condición de cursante del Programa de Formación de Agentes de Modernización.

ARTÍCULO $10^{\circ}$.- Las correspondientes designaciones como AGENTES DE MODERNIZACIÓN implicarán la adscripción funcional de los designados a la SECRETARÍA PARA LA MODERNIZACIÓN DEL ESTADO, manteniéndose los cargos de revista correspondientes.

Según señalan en un documento elaborado por funcionarios de la Unidad de Coordinación de Programas de Innovación del área de Gestión Pública de la Provincia que "El espíritu de la creación de la figura de Agentes de Modernización, es el de promover el aprendizaje organizacional como fortaleza fundamental de una gestión innovadora que consolida esta aplicación como práctica sustentable en el tiempo" (Besada et al., 2005:2). 
El anexo del Decreto destaca las principales funciones que se le asignarán a los agentes. Nuevamente, se destaca el espíritu de la orientación en la reforma que tuvo la entonces Secretaría para la Modernización del Estado:

a) Asistir en el diseño e implementación del Plan Estratégico y los planes operativos de las distintas áreas.

b) Asesorar en metodologías de análisis de la organización.

c) Asistir en la definición y composición de los Acuerdos Programa, asesorando en el diseño e implementación de los compromisos de resultados a asumir por las distintas áreas con el máximo nivel de la organización.

d) Asistir en la propuesta de alineación del presupuesto de la organización, su estructura organizativa y los Acuerdos Programa.

e) Colaborar en la definición del mapa de procesos organizacionales primarios y secundarios con la respectiva identificación de productos.

f) Asistir en la identificación de los indicadores y en el diseño e implementación del sistema de monitoreo de la gestión y de los resultados del Plan del organismo, de la Carta Compromiso con el Ciudadano, del Banco de Proyectos Exitosos, del Sistema de Participación Ciudadana y demás herramientas de gestión incorporadas al Plan de Modernización del Estado.

g) Asesorar en el diseño e implementación de sistemas de carrera, desarrollo del personal, identificación y evaluación de competencias enmarcados en el Plan de Modernización del Estado.

h) Colaborar en la preparación e instrumentación de Normas y de Procedimientos administrativos.

i) Participar en la informatización de procesos administrativos y productivos.

j) Colaborar en la detección de necesidades de capacitación surgidas de los nuevos perfiles de tareas y los requerimientos de los nuevos estándares de producción que demanda el Plan y articular con el INSTITUTO PROVINCIAL DE ADMINISTRACIÓN PÚBLICA, a través de los consejeros en los organismos, el plan de formación requerido.

k) Colaborar en actividades de capacitación para personal del organismo.

A los Agentes se les exigía dedicación exclusiva, y para postularse, no tener menos de treinta años de edad y tener cinco de antigüedad en la Administración Pública Provincial con título universitario o de estudios superiores que respondan a planes no inferiores a cuatro (4) años, preferentemente con formación de postgrado y especialización en áreas afines con la gestión pública. Se les requería experiencia laboral en conducción de personal y equipos de trabajo integrados por profesionales, administrativos y técnicos; en planificación y supervisión de planes sectoriales y conocimientos básicos de la normativa y procedimientos vigentes en la Provincia sobre 
presupuesto, contabilidad, compras y contrataciones, administración de bienes y administración de personal.

Sólo 14 agentes fueron designados en esta primera experiencia ${ }^{213}$. No es este el momento para el análisis de las acciones que realizaron ni de la falta de continuidad del programa $^{214}$ pero sí para destacar que recién en 2005 se estableció que a los designados como Agentes de Modernización, mientras ejerzan tal función, y sin perjuicio de la retribución que perciban de acuerdo a su situación de revista, recibirían un reconocimiento mensual no remunerativo, no bonificable, consistente en sumas de dinero hasta pesos un mil quinientos $(\$ 1.500)$, según determine la Autoridad de Aplicación de acuerdo al desempeño individual correspondiente y a cuyos efectos se la autoriza expresamente a realizar las erogaciones pertinentes de conformidad con las disposiciones vigentes (conf. Decreto $\mathrm{N}^{\mathrm{o}}$ 859/05).

La falta de dependencia de los agentes al Organismo convocante (que implicó que la Jurisdicción siempre los pudo "recuperar" en cualquier tiempo, la que, además, pagaba su sueldo), la falta de estabilidad del programa y de apoyo económico (sólo se contribuía con esa retribución no remunerativa) hizo que esta experiencia, más allá del buen trabajo técnico que cada uno de los agentes realizó, no haya tenido el éxito esperado.

\section{La reforma política}

La mayoría de los proyectos de reforma política propiciados por el Ejecutivo no tuvieron acompañamiento legislativo. Como hemos señalado más arriba, el período se caracterizó por una compleja relación entre los poderes políticos en la que, salvo proyectos circunstanciales, muy pocos proyectos del Ejecutivo fueron aprobados por las Cámaras.

Algunos de los proyectos son interesantes para su descripción, aunque, como decíamos más arriba, no lograron aprobación legislativa.

1. Reglamentación de las campañas electorales: El proyecto de reglamentación de las campañas electorales tuvo como finalidad dar respuesta a los compromisos asumidos por la provincia de Buenos Aires en el Acuerdo Federal con relación a los gastos de la propaganda y campañas electorales estableciendo un régimen integral de la temática.

2. Capacitación de los partidos políticos. Modificación del Decreto Ley $\mathrm{N}^{\circ}$ 9.889/82 Orgánica de los Partidos Políticos y Agrupaciones Municipales. Actividades de capacitación. Este proyecto tenía por objeto establecer que los partidos políticos deban destinar un porcentaje fijo de los aportes estatales que perciben a actividades de capacitación e investigación.

\footnotetext{
${ }^{213}$ Una segunda convocatoria, cerrada para quienes ya se habían presentado en la primera oportunidad y con formación en la abogacía y la contabilidad, se abrió con posterioridad para cubrir las vacantes que se produjeron con la "cooptación" de alguno de ellos por parte de las áreas donde realizaron funciones.

${ }^{214}$ Hoy han sido reemplazado por los "Expertos en Gestión Pública", programa aprobado por el Decreto $\mathrm{N}^{\mathrm{o}}$ 2.133/09. Ver http://www.sg.gba.gov.ar/conv gest pub/Decreto_2133-09.pdf Fecha de Consulta: $10 / 01 / 12$
} 
3. Modificación al régimen electoral. Se propuso un sistema mixto de magnitud fija y con ajuste de proporcionalidad que facilitara la personalización de las candidaturas, obligando a los partidos a proponer sus mejores candidatos para competir por el voto de los ciudadanos. El sistema propuesto buscaba combinar elementos de personalización, garantizando al mismo tiempo una representación equitativa para los distintos partidos a fin de facilitar, tanto la personalización y responsabilización de los candidatos frente a los electores como la equidad en la distribución de bancas de las distintas fuerzas políticas.

4. Creación de partidos seccionales. El proyecto contemplaba la creación de una nueva forma de asociación política que favorecería nuevos grados de participación de los independientes a nivel municipal y de la legislatura provincial.

5. Modificación de la Ley Electoral $N^{\circ}$ 5.109. Se propició establecer la modificación del régimen de cuocientes actualmente vigente en el artículo 109 de la Ley Electoral de la provincia de Buenos Aires y la sustitución del mismo por el régimen vigente en el Código Electoral Nacional (artículo 161).

6. Presupuesto participativo. Buscó dotar a la provincia de un marco que permita a cada municipio el desarrollo e implementación progresiva del régimen de presupuesto participativo, un mecanismo por el cual los ciudadanos, a través de su participación directa, asignan las prioridades en que deben ser invertidos los fondos del gobierno municipal destinado a inversiones. Ejecutivo?

Más allá de las propuestas legislativas, ¿cuáles fueron las acciones del

El Programa Rector de Reforma Política se creó en respuesta a la severa crisis político-institucional que profundizó los problemas de gobernabilidad, las desigualdades socioeconómicas y la fragmentación social. El Gobierno estableció un mecanismo basado en el diálogo y con ejes claves para una real transformación. Según se definieron en los documentos de trabajo del Ministerio, los cuatros ejes temáticos de la reforma política eran:

1. Sistema electoral y Voto Electrónico.

2. Régimen de Partidos Políticos.

3. Transparencia y Participación ciudadana.

4. Fortalecimiento del Estado y Descentralización de la gestión.

Según se señalaba, se buscaba incrementar la calidad democrática del sistema político provincial y de los partidos políticos y generar un genuino debate público.

El Programa fue aprobado por Decreto $N^{\circ} 1786 / 04$, orientado, según el propio texto de la norma, en mejorar la calidad del sistema político provincial e instrumentar un proceso de transformación del sistema político estableciendo la sistematización de las acciones y de los productos para lograrlo. 
Asimismo, se incentivó la creación del Consejo de Reforma Política de la Provincia de Buenos Aires, con el objetivo de formalizar un ámbito dentro del Ejecutivo Provincial, donde se definan los ejes de trabajo y los lineamientos relacionados con la reforma política.

Se definieron como pasos para la implementación del Programa Rector de Reforma Política los siguientes:

1.- Creación de la Mesa del Diálogo para la Reforma Política de la Provincia de Buenos Aires. Tuvo por objeto facilitar canales de participación $\mathrm{y}$ deliberación para todos los actores de la sociedad en el territorio de la provincia, como así también generar mecanismos efectivos de diálogo entre los actores políticos, sociales y los partidos políticos que permitan la construcción de consensos en torno a las metas y alcances de la reforma, posibilitando que toda la ciudadanía conozca las características del proceso y tome conocimiento de los contenidos específicos de la misma.

Estaba integrada por actores políticos, partidarios, instituciones intermedias, organizaciones no gubernamentales, instituciones religiosas, universidades y centros de estudios y organizaciones comunitarias.

Se dispuso la creación de un conjunto diferenciado de instancias de participación que asegure que todos los sectores interesados, puedan expresar sus ideas y opiniones de manera ordenada, respetando los criterios de pluralismo y tolerancia por las diferencias y contribuyendo a la formación de consensos a través de Mesas Provinciales y Mesas Regionales.

2.- Convenio con la Honorable Junta Electoral de la Provincia de Buenos Aires: Tuvo por objeto profundizar y mejorar los canales de comunicación y coordinación institucional existentes entre la Honorable Junta Electoral y el Poder Ejecutivo para la implementación de propuestas de reforma electoral, política y de voto electrónico en la Provincia de Buenos Aires.

3.- Mesas Sectoriales para la Reforma Política. Tuvieron por finalidad conocer la opinión de los distintos sectores de la comunidad respecto a la implementación de la Reforma Política.

4.- Audiencias Públicas. Su objetivo fue permitir y promover una efectiva participación ciudadana y confrontar de forma transparente las distintas opiniones, propuestas, experiencias y conocimientos existentes sobre el proceso de reforma política iniciado por la provincia. Fueron de carácter consultivo y no vinculante. Pudieron participar de ella todas las personas físicas o jurídicas, públicas o privadas, que tuvieran interés en hacerlo. 


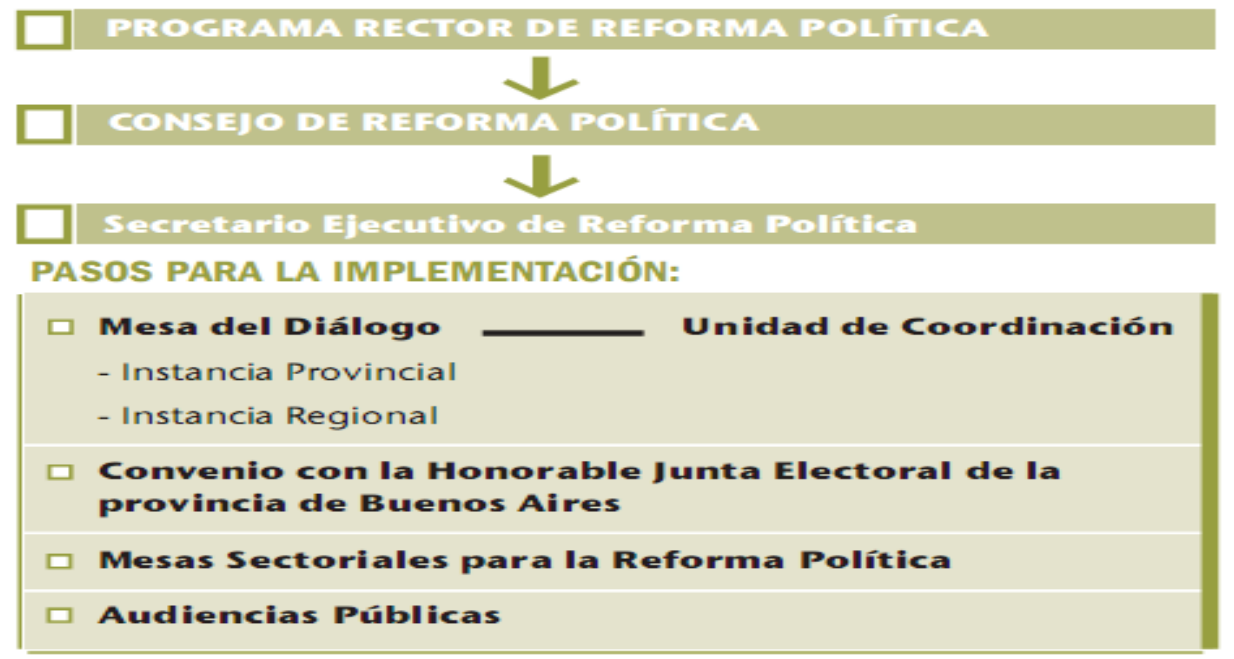

Fuente: Ministerio de Gobierno, 2006.

En el marco del informe de actividades realizadas por el Consejo de Reforma Política, se informaron las primeras coincidencias básicas detectadas, que se presentaron por eje temático:

1) Sistema electoral: Modificar la ley electoral para reemplazar el actual mecanismo de cociente electoral por el sistema D'Hondt en la asignación de bancas. Terminar con la sábana horizontal presentando cada categoría a elegir en una boleta independiente (Gobernador, Senadores, Diputados, Intendente, Concejales y Consejeros Escolares). Revisar la ley de cupo por género a fin de establecer una nueva proporción.

2) Voto electrónico: Definir las características centrales de un sistema de votación electrónico que cumpla con los requisitos de accesibilidad, confiabilidad, privacidad, seguridad, eficiencia comprobada y relación adecuada entre costo y prestación, tal como establece la Ley $\mathrm{N}^{\mathrm{o}} 13.082$.

3) Régimen de partidos: Modificar la Ley Orgánica de Partidos Políticos a fin de facilitar la constitución de agrupaciones municipales. Modificar la Ley Orgánica de Partidos Políticos para establecer un porcentaje mínimo de recursos que todo partido político deberá destinar a actividades de capacitación e investigación. Modificar la Ley Orgánica de Partidos Políticos para contemplar la creación de una nueva forma de asociación política: los partidos seccionales.

4) Participación y transparencia: Reglamentar los institutos de democracia semi-directa establecidos en el artículo 67 de la Constitución de la Provincia: consulta popular e iniciativa popular. Sancionar una ley de libre acceso a la información pública de toda la Provincia. Establecer el procedimiento para la realización de audiencias públicas convocadas por el Poder Ejecutivo y Legislativo. Incorporar la revocatoria de mandatos como mecanismo de participación y control ciudadano. 
5) Fortalecimiento del Estado y descentralización: Revisar la necesidad de implementar una reforma parcial de la Constitución a fin de establecer la autonomía municipal en la Provincia de Buenos Aires. Revisar la relación fiscal existente entre la provincia y los municipios a fin de hacerla más equilibrada.

En cuanto a los consensos alcanzados, se informaron los siguientes:

$$
\begin{aligned}
& \text { a- Iniciativa Popular. } \\
& \text { b- Consulta Popular } \\
& \text { c- Sistema D’Hont } \\
& \text { d- Defensor del Pueblo } \\
& \text { e- Acceso a la información pública. }{ }^{216}
\end{aligned}
$$

\section{El voto electrónico: experiencia en la Provincia de Buenos Aires}

Para el impulsor de la ley de voto electrónico, el entonces Ministro de Gobierno, Cr. Randazzo, “ ... la instauración del voto electrónico, es un capítulo especial dentro de la Reforma Política, porque constituye una herramienta modernizadora de los sistemas electorales y de la participación ciudadana" (Ministerio de Gobierno, 2005:8). Pero, como veremos más adelante, la Ley $N^{0} 13.082$ quedó sólo un poco más allá de las buenas intenciones pues sus objetivos iniciales se vieron limitados por la ausencia de una ley nacional que modificara el Código Nacional Electoral (Diéguez, Tula, Eyherabide, 2005). Por ello la experiencia fue sólo utilizada durante el período en estudio, tanto en 2003, 2005 como 2007, en ciertas mesas para extranjeros.

Dadas las "idas y vueltas" que tuvo la primera experiencia, nos detendremos en su análisis pues su estudio nos da cuenta de la improvisación existente en este tema a pesar de haber sido indicada por relevante para la reforma política como parte de la reforma del Estado.

Cuando el gobierno de Felipe Solá decidió realizar su "prueba piloto" con la utilización de urnas electrónicas existían grandes expectativas pues esa experiencia se constituían en el primer ensayo real en todo el país para aplicar un nuevo sistema de votación, moderno, rápido y eficaz, en el contexto de los reclamos por la reforma política y transparencia democrática.

El proyecto no sólo fue planteado como un intento de aggiornar el mecanismo de emisión del sufragio y el escrutinio sino que fue reconocido como "una de las piezas

\footnotetext{
215 Dicho instituto, introducido por la reforma de la Constitución Provincial de 1994, fue finalmente creado por la Ley $\mathrm{N}^{\circ} 13.834$ promulgada por Decreto $\mathrm{N}^{\circ} 1.380 / 08$ del 7/7/08 con un texto distinto al consensuado en este espacio.

${ }^{216}$ Si bien el derecho, establecido por la Constitución de la provincia de Buenos Aires en su artículo 12 inc. 4. y regulado desde el año 2000 por la Ley $\mathrm{N}^{\circ} 12.475$ y mediante Decreto $\mathrm{N}^{\circ} 2.549 / 04$, sólo se reconoce para el acceso a los documentos administrativos para toda persona física o jurídica que alegue interés legítimo en la misma. El debate giró en torno a un nuevo régimen legal de acceso.
} 
claves de la reforma política". Según el Gobernador, en Brasil el método "aumentó la concurrencia a votar y el voto positivo", ya que "la gente confía más en la electrónica que en los hombres". ${ }^{217}$

Desde un primer momento se anunció que

... con este sistema se evita el fraude tradicional, que puede surgir en la misma mesa entre autoridades y fiscales, porque cuando se cierra la máquina emite un ticket con los resultados de esa urna, el presidente de mesa retira el diskette y lo envía a la junta electoral ... garantiza la simplificación del trabajo de las autoridades de mesa, sencillez para el elector, confidencialidad y seguridad del voto (Diario EL DIA, "Voto electrónico: se firmó un convenio con Brasil", 31 de Julio de 2003).

Además, se agregaba que el famoso "robo de boletas" es imposible. ${ }^{218}$

La aplicación del sistema sería para las elecciones de 2003. Por medio del Decreto $N^{0} 43 / 03$, el entonces gobernador Solá convocó a elecciones el día 14 de septiembre de 2003 para renovar los cargos de gobernador, vicegobernador, senadores y diputados provinciales, intendentes municipales, concejales y consejeros escolares. En estas elecciones, las secciones II, III y VIII -Capital- debían elegir 23 senadores, mientras que la I, IV, V y VII, 46 diputados. ${ }^{219}$

Meses más tarde del dictado del Decreto $\mathrm{N}^{0} 43 / 03$, la Provincia adhirió al régimen de simultaneidad de elecciones, con lo que se sumaron a los comicios 35 diputados nacionales. ${ }^{220}$

El primer objetivo fue que la experiencia se realizase en algunos distritos en las elecciones del 14 de setiembre de 2003. Se esperaba utilizarlo en unos diez distritos bonaerenses del interior y del Conurbano, en los que votarían cerca de un millón de

217 Diario EL DIA, "Voto electrónico: se firmó un convenio con Brasil", 31 de Julio de 2003. Brasil es el icono en la aplicación del voto electrónico en América Latina ya que ha exportado en los últimos años su sistema de votación de registro electoral directo-RED- desde México hasta Argentina. Durante 2004, la experiencia de Venezuela fue la más difundida por los medios con motivo del referéndum revocatorio que definiría la continuidad del presidente Hugo Chávez. Brasil incorporó el voto electrónico en 1996 y en la actualidad su uso alcanza a la totalidad de sus habitantes. En las elecciones municipales realizadas el 3 de octubre de 2004 el padrón electoral estaba compuesto aproximadamente por 120 millones de electores habilitados. En esa oportunidad renovaron sus autoridades 5.562 municipios y los cargos de alcaldes y concejales a cubrir alcanzaron el altísimo número de 377.000. A pesar de la gran cantidad de puestos de votación (406.689) el 80\% de los resultados se obtuvieron en 50 minutos, resultado que difícilmente hubiera podido obtenerse de no haber estado todos los lugares de votación equipados por urnas electrónicas. El gobierno brasileño, por encargo del Tribunal Superior Electoral, desarrolla su propia tecnología.

218 Diario EL DIA, "Elecciones sin boletas ni urnas y sin variantes para la bronca”, 30 de enero de 2003.

219 Los senadores y diputados provinciales tienen un mandato por cuatro años, y son elegidos a través del sufragio directo conforme a la representación poblacional de los distritos donde son elegidos (artículos 70 y 78 de la Constitución Provincial).

${ }^{220}$ La ley de simultaneidad de elecciones es la Ley $\mathrm{N}^{\circ}$ 15.262. El Decreto de adhesión fue de julio de 2003, Decreto $\mathrm{N}^{\circ} 1.097 / 03$, mientas que el de llamado a elecciones fue de enero de ese mismo año. 
electores. La intención inicial era pedirle prestadas 420.000 urnas a Brasil mediante una gestión de la Organización de Estados Americanos (OEA). ${ }^{221}$

En una primera reunión con los funcionarios del Tribunal Superior Electoral (TSE), el organismo brasileño encargado de proveer las urnas, los funcionarios bonaerenses hicieron explícita la decisión política del gobernador Solá de que en las elecciones de setiembre se realizara efectivamente la experiencia piloto y que el proyecto que modificaba la ley Electoral para adaptar este sistema ya se encontraba en la Legislatura para su aprobación. Como veremos más abajo, ello estaba lejos de ser real.

Más adelante, se dijo que era necesario que el proyecto se aplique sólo en tres o cuatro distritos del interior con baja conflictividad política, por lo que se descartaban las comunas del Conurbano y se incluía a las ciudades de Junín y Bahía Blanca. Se mantenía la premisa de que la experiencia debía abarcar alrededor de un millón de electores sobre los casi nueve millones que integraban el padrón provincial. ${ }^{222}$

Finalmente, el Gobierno decidió que la experiencia tuviera un carácter de ensayo, de aplicación gradual y controlada. Por ello se estableció que la misma se hiciera en una sola circunscripción electoral, la VII sección electoral, ubicada en el centro de la Provincia, que comprende los Partidos de Tapalqué, Roque Pérez, Olavarría, Azul, 25 de Mayo, Saladillo, General Alvear y Bolívar.

Varios argumentos se han dado acerca del por qué de la elección de esos municipios (Tula et al., 2005). Entre ellos, los públicamente manifestados:

- $\quad$ el bajo nivel de conflictividad electoral registrado en los últimos veinte años;

- $\quad$ la extensión territorial y densidad sociodemográfica reducida, que facilita la logística y capacitación del sistema de voto electrónico;

- $\quad$ por tratarse de distritos que no superan los 150 mil habitantes;

- las características socioeconómicas, político-culturales y geográficas del electorado, que reflejarían una muestra proporcional y representativa de la totalidad de la población sociodemográfica bonaerense.

Sin embargo, recuérdese que en las intenciones iniciales se buscaba realizar la experiencia sobre un millón de votantes, mientras que la VII sección electoral sólo representa apenas un poco más del $2 \%$ del electorado bonaerense con lo que hay que descartar los argumentos anteriores.

Todo ello da la razón a quienes sostienen que las justificaciones fueron exclusivamente políticas. En efecto, debe tenerse en cuenta que de los ocho municipios que conforman la sección electoral, seis tenían administraciones radicales -Azul, Bolívar, Olavarría, Saladillo, 25 de Mayo y Roque Pérez- y solo dos eran intendencias justicialistas -General Alvear y Tapalqué-. Si bien es cierto que sólo dos municipios declararon de interés municipal esta iniciativa, ninguno de ellos era Justicialista -Roque Pérez y Saladillo-.

221 Diario EL DIA, "Avanzan las gestiones para poner en marcha el voto electrónico", 1 de marzo de 2003.

${ }^{222}$ Diario EL DIA "El voto electrónico se estrenará en setiembre", 21 de mayo de 2003. 
Como luego se manifestó en las elecciones de 2005, el Partido Justicialista estaba viviendo una de sus crisis por la lucha por el liderazgo y el acompañamiento del proyecto del Gobernador podría significar un pérdida en esa lucha por representar "la nueva" política frente a la política del "que se vayan todos". $\mathrm{Y}$ en ese marco, un proyecto como el del uso de tecnologías lo posicionaba al gobernador discursivamente como innovador.

\section{a) Prolegómenos de la experiencia}

Como veremos, los problemas centrales de la experiencia no se encontraron en la tecnología aplicada, ni en el cambio organizacional que requería la experiencia sino en las trabas jurídicas y políticas que existieron para que el proyecto se materialice. Y en estos, todos los actores políticos tuvieron responsabilidad.

Los problemas que se plantearon fueron varios. El primero, la falta de previsiones normativas al respecto. En verdad, el Poder Ejecutivo había enviado a la Legislatura un proyecto para modificar Ley Electoral Provincial, Ley $\mathrm{N}^{\circ} 5.109$, para introducir los cambios necesarios para la efectiva utilización del voto electrónico.

Dicho proyecto de ley pretendía introducir una variante al sistema tradicional, que quedase incluida en forma permanente en la ley electoral bonaerense. Sin embargo, estaba circunscripto a la autorización de la experiencia concreta pues contenía cierta direccionalidad al apuntar sólo al modelo brasileño.

El proyecto estuvo detenido varios meses pues existían resistencias no sólo en los partidos de la oposición sino también dentro de la propia bancada oficialista del Partido Justicialista. Según el Gobernador, el rechazo a este sistema se debía a que

... hay intereses muy claros y una vieja política tradicional que no quiere que haya cambios de ningún tipo ... No crean que es tan sencillo; hay intereses muy claros y hay una vieja política tradicional que no quiere que haya cambios de ningún tipo; que quiere seguir con el método puntero, repartir la boleta, etc." (Diario EL DIA, "Voto electrónico: dura pelea en la Provincia ", 19 de Junio de 2003).

Para el presidente de la bancada radical de la Cámara de Diputados, esa iniciativa respondía más a un capricho del Gobernador que a una modernización del Estado. Desde el Senado, los senadores de la Unión Cívica Radical, Alberto Conde y Carlos Pérez Gresia, solicitaron pedido de informes por una supuesta desinteligencia entre los proyectos del ejecutivo nacional y el ejecutivo provincial. ${ }^{223}$

Para el entonces senador Pérez Gresia, el proyecto que fue aprobado por Diputados no constituía un avance en el fortalecimiento de las instituciones provinciales, si no un retroceso. El proyecto del Poder Ejecutivo fue modificado en

223 Diario EL DIA "El jefe del bloque de diputados bonaerenses dice que "es un capricho del Gobernador", 19 de Junio de 2003. La Resolución N 9/03 del Ministerio del Interior de la Nación creaba un grupo de trabajo, presidido por el Director Nacional Electoral, cuyo objetivo era analizar el impacto de las TIC en los procesos electorales, tomándose 100 días para elaborar una propuesta y confeccionar un proyecto al respecto. Sin embargo, la objeción no era sustancial atento las competencias propias de cada uno de los ámbitos. 
Diputados y delegaba en el Poder Ejecutivo la reglamentación de casi todas las decisiones necesarias para implementar este sistema. ${ }^{224}$

Al ataque de la estructura partidaria de la UCR y la omisión de apoyo explícito del partido justicialista provincial, respondió el por entonces Secretario para la Modernización del Estado, Florencio Randazzo, quien asociaba el proyecto con la transparencia del sistema. Desde el Gobierno se asociaba la experiencia a la innovación y la transparencia, como un capítulo de la reforma política, de la "nueva política"; quienes se opusieran a él, se identificaban con la "vieja política", incluso los partidos políticos.

Lo cierto es que mucho del "enredo" jurídico que trababa la experiencia era responsabilidad propia de funcionarios que impulsaban el proyecto. En efecto, el 20 de mayo de 2003, es decir, al menos de cuatro meses de las elecciones, en declaraciones a un diario local, el Secretario para la Modernización del Estado, no tenía claro la necesidad o no de reformar el Código Electoral Nacional para aplicar el mecanismo en las elecciones bonaerenses. ${ }^{225}$

Sin embargo, la necesidad de la reforma del Código Electoral Nacional era clara desde que, como consecuencia del Decreto $\mathrm{N}^{\circ} 1.097 / 03$ de julio de 2003, las elecciones entre los cargos nacionales y provinciales se realizarían simultáneamente llevando a la aplicación de las normas federales. Las alternativas que ese funcionario tenía en estudio, demostraban la improvisación pues eran jurídica o políticamente inviables. Entre ellas, solicitar una "resolución" a la Cámara Electoral Nacional para que permita la elección por medio del voto electrónico de los diputados nacionales, lo cual implicaba tanto como darle al Poder Judicial funciones legislativas sobre las cuales el Congreso de la Nación tiene fuertes limitaciones conforme el artículo 77 in fine de la Constitución Nacional. La otra alternativa era presentar en el Congreso una "disposición transitoria" que posibilite la utilización de este mecanismo para la elección de legisladores nacionales en los distritos seleccionados, alternativa jurídicamente válida pero que, atento a la necesidad de contar con la mayoría absoluta del total de los miembros de las Cámaras, parecía políticamente inviable sin el consenso previo de todos los bloques mayoritarios.

Paralelamente, la Provincia de Buenos Aires suscribió, conjuntamente con el entonces ministro del Interior de la Nación, Aníbal Fernández y el entonces canciller Rafael Bielsa, un acuerdo de cooperación técnica con el presidente del Tribunal Superior Electoral de Brasil, Pedro Sepulveda Pertense. Se estableció que serían cedidas en préstamo sin costo, 1000 urnas electrónicas modelo 2000, 700 de las cuales debían ser utilizadas para el día de la elección y unas 250 para capacitación, el asesoramiento técnico y la provisión del software correspondiente. La Provincia debía hacerse cargo de los viáticos de los técnicos y funcionarios del Tribunal que debían trasladarse a la Provincia para la adaptación del software. Asimismo, se suscribieron acuerdos con Universidades con sede en el territorio de la Provincia de Buenos Aires para colaborar con la prueba piloto y con varias instituciones intermedias locales y ONG's especializadas. $^{226}$

\footnotetext{
224 Diario EL DIA, "Voto electrónico sí, cheque en blanco no", 15 de Julio de 2003.

225 Diario EL DIA, "El voto electrónico se estrenará en setiembre", 21 de mayo de 2003.

226 Las ONG's que participaron fueron: 1. Asociación Civil CONCIENCIA.; 2. Centro de Implementación de Políticas Públicas para la Equidad-CIPPEC-. y 3. Asociación Civil de Informática.
} 
Luego de una fuerte presión, el 15 de julio de 2003 se aprobó la Ley Provincial $\mathrm{N}^{\circ}$ 13.082, que modificó en veintitrés artículos de la Ley Electoral $\mathrm{N}^{\circ}$ 5.109. El proyecto del Gobernador, que había sufrido modificaciones en Diputados, fue aprobado sin modificaciones por la Cámara de Senadores para no retrasar más aún la sanción.

El radicalismo, finalmente, aunque no apoyó el proyecto mayoritario, votó el despacho de minoría que establecía el carácter excepcional de la experiencia atento a las incompatibilidades existentes con la legislación nacional y en algunos preceptos constitucionales. La presión por no quedar calificada como "vieja política" resultaba evidente pues aprobó el proyecto pese a reconocer, a su juicio, la existencia de incompatibilidades con preceptos constitucionales.

El proyecto, que se convirtió en la Ley Provincial $\mathrm{N}^{\circ}$ 13.082, modificó el capitulo XXVII de la Ley Electoral, otorgando amplias facultades al Poder Ejecutivo para organizar el voto electrónico. Los puntos centrales de la norma fueron:

- Artículo 149: autoriza al Poder Ejecutivo a implementar "total o parcial del sistema de voto electrónico en aquellos distritos electorales que considerara oportunos y pertinentes".

- Artículo 150: autoriza al Poder Ejecutivo a determinar el sistema que considere más adecuado para cada elección de acuerdo con ciertos parámetros de accesibilidad, confiabilidad, privacidad, seguridad, eficiencia comprobada y relación entre costo y prestación.

- Artículo 151: autoriza al Poder Ejecutivo a reglamentar otros artículos de la ley electoral siempre y cuando se trate de adecuar la normativa con los requerimientos específicos del tipo de voto electrónico seleccionado.

Faltaba aún, como luego se admitió, modificar el Código Electoral Nacional. El Gobierno provincial presentó en el Congreso Nacional dos iniciativas. Las modificaciones buscaban la habilitación de una cláusula de excepción para la Provincia y la habitación para que participara la Junta Electoral de la Provincial en la experiencia.

Randazzo apelaba al "espíritu de patriotismo" de los diputados nacionales radicales y los convocó a asumir su compromiso con la sociedad y dar un salto cualitativo, aprobando una ley que sin duda marcaría un hito en la historia llegando a identificarla con la ley Sáenz Peña y el voto femenino.

Es por eso que el funcionario, ahora con el cargo de Jefe de Gabinete, se reunió con los diputados de la comisión de Asuntos Constitucionales acompañado por la jueza de la Junta Electoral de la Provincia, Ana Bourimborde, para explicarles los alcances de la prueba piloto que el gobierno de Solá pretendía realizar, pidiéndosele celeridad

Las Instituciones Intermedias, por distrito, fueron: Bolívar: 1· Sociedad Italiana; $2 \cdot$ Biblioteca Popular Bernardino Rivadavia; 3· Fundación Futuro; 4· Cámara Comercial e Industrial; 5· Cooperativa Eléctrica; 6. Asociación Española de Socorros Mutuos; 7. Sociedad Rural. Roque Pérez: 1 Sociedad Rural; 2. Organización No Gubernamental "Roque Pérez Solidario". Azul: 1 - Instituto de Desarrollo Local. 25 de Mayo: 1· Instituto de Formación Docente $\mathrm{N}^{\circ} 28$. General Alvear: 1 A Asociación de Jubilados, Retirados y Pensionados "Raul L. Soria"; 2· Asociación Española de Socorros Mutuos, Social, Cultural y Deportiva; 3. Asociación de Bochas. Tapalqué: 1- Sociedad de Bomberos Voluntarios. Saladillo: 1- Centro de Investigaciones para el Desarrollo Humano. 
porque ya no había demasiado tiempo. A más tardar, las reformas debían ser aprobadas en una semana porque de lo contrario surgirían dificultades para la instrumentación. ${ }^{227}$

Pero ninguna de las iniciativas tuvo mejor suerte. El radicalismo no aportó el quórum necesario para el debate del proyecto. Los diputados nacionales del Partido Justicialista acusaban al radicalismo por la negativa a dar quórum para tratar el proyecto. Así, el diputado nacional Juan Carlos Correa, integrante de la Comisión de Asuntos Constitucionales, afirmó que ...

dijeron que no se oponen al proyecto pero creen que no es la oportunidad política de avanzar con el voto electrónico ... es un argumento infantil, porque en el fondo se ocultan detrás de la oportunidad, para no aprobar el proyecto". (Diario EL DIA "Al final, no se podrá estrenar en setiembre el voto electrónico", 14 de Agosto de 2003).

Según el diputado nacional Miguel Saredi, la experiencia del voto electrónico se cae definitivamente por la postura del bloque radical". Dijo Randazzo en declaraciones públicas ...

En una clara demostración de que es un partido en vías de extinción, en una sociedad que marcha inexorablemente a erradicar los viejos vicios de la política, el radicalismo decidió no respaldar está transformación que, indudablemente, de haberse concretado tal como estaba prevista hubiese sido el puntapié inicial en la reforma política bonaerense (Diario EL DIA, "Un atajo para probar el voto electrónico", 15 de Agosto de 2003).

Pero el fracaso, no fue solamente atribuible a los legisladores del radicalismo. Se escondía detrás una sórdida disputa en el peronismo bonaerense porque varios candidatos del oficialismo justicialista no querían que este sistema se aplique porque consideraban que reducía sus chances electorales. ${ }^{228}$

El Gobierno bonaerense fue también responsable del fracaso. En primer lugar, se apropió del proyecto con la intención mostrarse como uno de los pasos más importantes de la reforma política, excluyendo a los demás actores. Como consecuencia de ello, la modificación de las "reglas de juego" a pocos meses de las elecciones generaba más dudas y suspicacias que certezas. Más aún, manejando los tiempos por ser un proyecto propio, llegó a la instancia de pretender modificar el Código Electoral Nacional de una semana a otra. También había adherido a la simultaneidad de las elecciones, circunstancia que, desde ya, no sólo implicó que las elecciones se realicen el mismo día sino que se utilice la infraestructura del Estado Nacional, los padrones del Ministerio del Interior y las normas de la Nación. Todo ello revela la improvisación y la politización partidaria de la experiencia.

Sólo entonces, se apeló a una "solución" alternativa: el sistema sería utilizado con los residentes extranjeros que sólo eligen candidatos a cargos bonaerenses. Así,

227 Diario EL DIA, "Es auspicioso el avance del voto electrónico en nuestra provincia", 27 de Julio de 2003.

228 Diario EL DIA, "Naufraga en la Provincia el debut del voto electrónico". 9 de Agosto de 2003. 
salvando el escollo jurídico, se pondría poner en marcha el sistema con un padrón de 1.527 extranjeros inscriptos que residen en los distritos de Olavarría, Azul, Saladillo, Tapalqué, 25 de Mayo, General Alvear, Roque Pérez y Bolívar. ${ }^{229}$

Por otro lado, para "aprovechar" las urnas, se colocarían unas 500 urnas electrónicas en las escuelas en las que se realizaren los comicios con el sistema tradicional para que los electores voluntariamente probaran el sistema, antes o después de emitir el sufragio oficial ${ }^{230}$.

Así, a través del Decreto No 1443/03, del 15 de agosto de 2003, se dispuso que la prueba piloto se efectuara parcialmente, es decir, sólo para los electores extranjeros de la VII Sección Electoral de la Provincia.

Los funcionarios judiciales nacionales habían planteado serias objeciones. Se habían señalado varios "agujeros negros" si el voto electrónico se ponía en práctica con el sistema legal vigente, entre ellos, la inexistencia de un código secuenciado que sirva para determinar los pasos a seguir ante las dificultades que puedan aparecer el día de la elección. Se mencionaba, por ejemplo, que no estaba previsto cómo se debe actuar ante un caso de impugnación del voto, ni cómo proceder con las personas que tengan la numeración del Documento Nacional de Identidad diferente a la que aparece en el padrón, que según el Código podrían votar cuando la diferencia entre el padrón y el número real fuera de un número mientras que para habilitar el voto en las urnas electrónicas, deben ser iguales el padrón electrónico y el número real. Es decir, había reparos importantes desde el ámbito judicial ${ }^{231}$.

Respecto las elecciones experimentales con los ciudadanos argentinos con candidatos ficticios, se realizó una presentación a la Junta Nacional Electoral para llevar a cabo la votación experimental el 14 de septiembre en aquellos establecimientos habilitados de la VII Sección Electoral ${ }^{232}$, aún cuando, según los impulsores del

229 Nótese que del millón de votos originalmente previstos, ahora sólo se utilizarían el 0,15\%. Además, como para los extranjeros el voto es facultativo el éxito de estos comicios quedaba sujeto - en gran parte - a una fuerte campaña de difusión con el objetivo de lograr una amplia participación (Tula et al., 2005).

${ }^{230}$ Para evitar "confusiones", se había decidido utilizar listas "ficticias" que postularían, entre otros candidatos, a San Martín, Belgrano y Saavedra.

${ }^{231}$ Diario EL DIA, "La experiencia piloto en 8 distritos no se podría realizar. Hay reparos de la Justicia Electoral", 9 de Agosto de 2003.

${ }^{232}$ A menos de un mes de la celebración de los comicios provinciales, la Justicia federal se expidió a través del Acta 36 en la que se impedía la realización de la prueba piloto con voto electrónico. El 26 de agosto, la Junta Electoral Nacional, integrada por el presidente de la Cámara Federal de Apelaciones de La Plata, Leopoldo Schiffrin, el juez federal -con competencia electoral en la Provincia- Humberto Manuel Blanco y la secretaria electoral María Belén Vergarale, puso un nuevo freno al debut del voto electrónico con el padrón de extranjeros de ocho distritos y rechazó, incluso, la posibilidad de realizar una "prueba simulada" con este sistema con boletas de candidatos "ficticios". Según la Junta, el Gobierno provincial había solicitado hacia fines de agosto una presentación para solicitar autorización para realizar la "prueba piloto" con el padrón de extranjeros de la VII Sección Electoral, incluyendo la posibilidad de instrumentar este sistema con los ciudadanos argentinos, mediante una votación simulada con candidatos ficticios. El fallo sostuvo que "la Junta Electoral Nacional sólo puede tener en cuenta votos emitidos con arreglo a la ley federal que rige las elecciones, es decir, el Código Electoral Nacional ... la Junta Electoral Nacional debe computar todos los votos emitidos en la elección simultánea, y sólo puede hacerlo con el sistema de emisión que establece la ley nacional, no existe manera por la cual pudiera realizarse el escrutinio en forma legal si se accediera al pedido de análisis ...; en cuanto a la votación puramente experimental y sin valor de sufragio, corresponde señalar que la misma podría interferir el normal desarrollo de los comicios, por lo cual tampoco cabe hacer lugar a ese aspecto de la solicitud". 
proyecto, como los extranjeros sólo pueden votar a autoridades electivas provinciales, la administración de los comicios debía estar a cargo de la Junta Electoral Provincial (Tula et al., 2005).

A menos de una semana, aún la ciudadanía no sabía cómo iba a votar, pese a lo cual, las campañas de difusión continuaban. Finalmente, la Junta Nacional Electoral, reconoció la competencia de la Honorable Junta Electoral de la Provincia, única y exclusivamente respecto de los residentes extranjeros.

Con esa autorización, la Junta Electoral resolvió que las urnas electrónicas fueran remitidas a los jueces de paz y civiles de turno; se elevó la nómina del personal que se ocuparía de la capacitación y de la asistencia informática. Participaron como asistentes no sólo el personal de la Junta Electoral Provincial sino también docentes de la Universidad Nacional del Centro (UNCEN) y ONG's locales, coordinados por el personal de la Jefatura de Gabinete.

Por su parte, el Gobierno continuó y acrecentó la campaña de difusión e instrucción y se amplió la votación simulada a las ciudades de La Plata, Lomas de Zamora, Mercedes, Mar del Plata y Quilmes entre otras.

La organización y logística del acto electoral estuvo a cargo de la Jefatura de Gabinete, el Ministerio de Gobierno y la Honorable Junta Electoral de la Provincia de Buenos Aires en calidad de exclusiva autoridad de aplicación. Nótese que sin la asistencia del Poder Ejecutivo, la Honorable Junta Electoral de la Provincia, no podría haber liderado la experiencia. En efecto, si bien la Junta Electoral designó a auxiliares informáticos, ellos fueron nombrados por la Jefatura de Gabinete. ${ }^{233}$

\section{b) La votación y sus resultados}

Finalmente, y luego de los "enredos" que tuvo que sobrellevar el proyecto, el 14 de septiembre de 2003 votaron 306 ciudadanos extranjeros en las dieciocho mesas habilitadas de los ocho municipios de la VII Sección.

Señalan Tula, Diéguez, Eyhrabide (2005), que excepto Olavarría, en donde se utilizaron cuatro mesas electorales para los extranjeros -dos por cada sexo- en el resto de los municipios se abrieron sólo dos. Con ello, de las mil urnas electrónicas prestadas sólo se utilizaron dieciocho, esto es, el 1,8\%.

Treinta y ocho (38) minutos después del cierre de los comicios, se obtuvieron los datos del escrutinio.

Sin embargo, desde el Gobierno, se sostuvo que no hubo un pedido de autorización a la Junta Electoral Nacional sino una mera notificación. Se aclaraba que "... en ningún momento se pidió autorización para realizar la elección con el sistema de voto electrónico con el padrón de extranjeros, ya que no la necesitamos ... la Junta Electoral Nacional no tiene competencia para resolver sobre ese tema, debido a que no hay simultaneidad, ya que los extranjeros votan con un padrón especial elaborado por la Junta Electoral Provincial y con autoridades que también son designadas por este órgano". Por ello se presentó un recurso de reposición, sosteniendo que la competencia en el caso de los votantes extranjeros era competencia exclusiva y excluyente de la Honorable Junta Electoral de la provincia de Buenos Aires. Diario EL DIA, "Otro round con la Justicia por el voto electrónico", 6 de Septiembre de 2003.

233 Esos asistentes tenían por función permanecer en los establecimientos educativos durante toda la jornada electoral para salvar las dudas o superar los inconvenientes técnicos con las urnas electrónicas. Asimismo, los partidos políticos y las alianzas electorales intervinientes en los comicios podían disponer de un experto informático previamente acreditado como fiscal. 
De la experiencia no sólo participaron jóvenes, más acostumbrados a la tecnología, sino también personas mayores. ${ }^{234}$ En términos generales, los electores con más de 50 años demostraron más dificultades para practicar su voto frente a la urna electrónica —alrededor de 30 minutos - que los más jóvenes, que demoraron apenas unos 8 minutos. De todas formas, según los informes, no se observaron serios inconvenientes en la utilización del equipo.

Sí, en cambio, se advirtió cierta dificultad para marcar el número de la lista partidaria pues había números de listas muy próximos entre sí, lo que generó confusión. $^{235}$

Generó más confusión el hecho de que en algunos lugares de votación, los carteles con los datos en papel, que debían encontrarse de frente al elector para facilitar la votación, se ubicaron lejos de la urna. ${ }^{236}$

Según informó la Provincia, la participación de extranjeros en la Séptima Sección Electoral era en 2001 del 11\% del padrón y pasó al 23\% en 2003. Por ello, en los informes oficiales se pone el acento en el aumentó de la participación en un $120 \%$. Pero también los hechos señalan que, pese a la amplia difusión, sólo participaron poco más del $20 \%$ de los habilitados para hacerlo.

Cuadro 29 - Concurrencia electoral. Elecciones del 14 de septiembre de 2003

\begin{tabular}{|l|r|r|r|r|}
\hline Municipios & $\begin{array}{l}\text { Padrón de } \\
\text { Extranjeros }\end{array}$ & \multicolumn{2}{c}{$\begin{array}{l}\text { Cantidad de } \\
\text { Votantes }\end{array}$} & \multicolumn{2}{l|}{$\begin{array}{l}\text { Porcentaje de } \\
\text { Participación }\end{array}$} \\
\hline Tapalqué & 22 & 11 & 50 \\
\hline Roque Pérez & 34 & 12 & 35,3 \\
\hline Bolívar & 128 & 37 & 28,9 \\
\hline General Alvear & 25 & 7 & 28 \\
\hline Azul & 231 & 53 & 22,9 \\
\hline Saladillo & 130 & 28 & 21,5 \\
\hline 25 de Mayo & 127 & 22 & 17,3 \\
\hline Olavarría & 830 & 136 & 16,4 \\
\hline Total sección & $\mathbf{1 . 5 2 7}$ & $\mathbf{3 0 6}$ & $\mathbf{2 0}$ \\
\hline \multicolumn{2}{|c|}{ Fuente: Tula et al. (2005) } \\
\hline
\end{tabular}

El estudio del comportamiento sociológico del electorado que participó de la experiencia piloto, realizado por la Universidad del Salvador, arroja interesantes resultados.

El estudio se realizó por medio de una encuesta de opinión que se aplicó al universo de votantes extranjeros empadronados en la VII Sección Electoral a través de un cuestionario semi-estructurado de 14 preguntas, de respuestas espontáneas

\footnotetext{
234 Así, en Bolívar, Evaristo Reinaldo Sotelo, de 92 años fue el residente extranjero de mayor edad en votar. Pascual Ferro, nacido en 1915, fue el votante más rápido. En Roque Pérez Elena Catalina Torresi, de 90 años, votó por primera vez. En 25 de Mayo un residente de origen italiano, que no se había querido capacitar, se presentó a votar el día de la elección. El hombre de 82 años, recibió la explicación de las autoridades de mesa y pudo efectuar su voto sin inconvenientes ni demoras (Ministerio de Gobierno, 2003).

235 Por ejemplo, 503 RECREAR; 505 FREPOBO, 507 Izquierda Unida; 508 ARI.

236 Según Tula, Diéguez, Eyhrabide (2005), el hecho que el presidente de mesa pudiera otorgar o no más tiempo a través de su micro terminal, le otorgó al mucho poder respecto del elector.
} 
precodificadas y abiertas suministradas por la entonces Jefatura de Gabinete. Se relevaron datos del total de votantes extranjeros de la Séptima Sección que acudieron a los comicios. Se recabaron datos de 281 individuos (93\% del total efectivo) mientras que 20 personas se negaron a responder el cuestionario. ${ }^{237}$

En cuanto a las características de estos votantes pueden destacarse que más de la mitad eran hombres. Casi el $84 \%$ de la población que votó tenía más de 50 años. ${ }^{238}$

\section{Gráfico 7 - Participación según sexo}

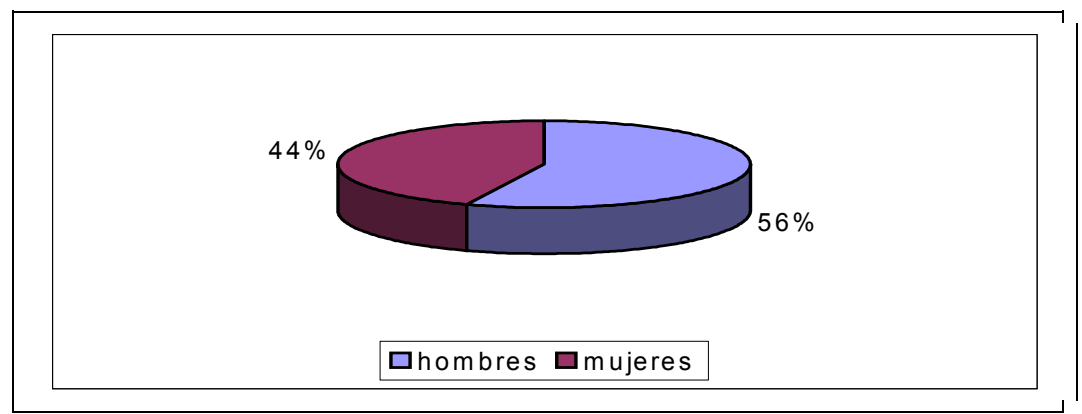

Fuente: Instituto de Investigaciones en Comunicación Social (2003)

Dos tercios del electorado (66\%) alcanzó el nivel primario, ya sea habiéndolo completado o no. Menos de un tercio (24\%) alcanzó el nivel secundario -en las mismas condiciones que el caso anterior- y sólo una mínima cantidad de ellos alcanzó el nivel terciario y universitario (7\%). Sólo un $2 \%$ no había concurrido a establecimiento educacional alguno.

La mayoría de los votantes eran jubilados o pensionados (30\%); la categoría siguiente es amas de casa (26\%), trabajadores por cuenta propia (24\%), asalariados en el sector privado $(10 \%)$, desocupados $(4 \%)$ y patrones $(4 \%)$. Una mínima proporción no declaró ocupación alguna $(2 \%)$.

En cuanto a los beneficios, mayormente el voto electrónico fue caracterizado como sencillo (32\%). En menor medida es calificado como rápido (29\%). El tercer lugar lo ocupan "Otras" (15\%). Entre la Opción "Otras", sólo el 17,4\% aparecen como negativas. También se lo caracteriza como seguro (13\%), transparente $(10 \%)$. Únicamente una muy pequeña proporción de encuestados no declaró opinión alguna sobre sus cualidades $(1 \%) .{ }^{239}$

\footnotetext{
237 Notamos que para la Universidad del Salvador la cantidad de votos fue de 302 mientras que la cantidad informada por la Justicia Electoral fue de 306.

238 Vinculado con la edad de los participantes, el $30 \%$ eran jubilados o pensionados, $26 \%$ amas de casa y $24,2 \%$ cuentapropistas.

${ }^{239}$ Respecto de las otras menciones, del total de ellas, la gran mayoría (80\%) son positivas y giran en torno de la calificación del sistema como "bueno", "lindo", "positivo", "evita fraude", "es moderno", etc. y le siguen los comentarios negativos (17\%), relacionados con la falta de práctica y los problemas de operatividad con el sistema. Marginalmente hubo menciones neutras (3\%) en torno de comentarios tales como "desconoce".
} 
Gráfico 8 - Cualidades del Voto Electrónico

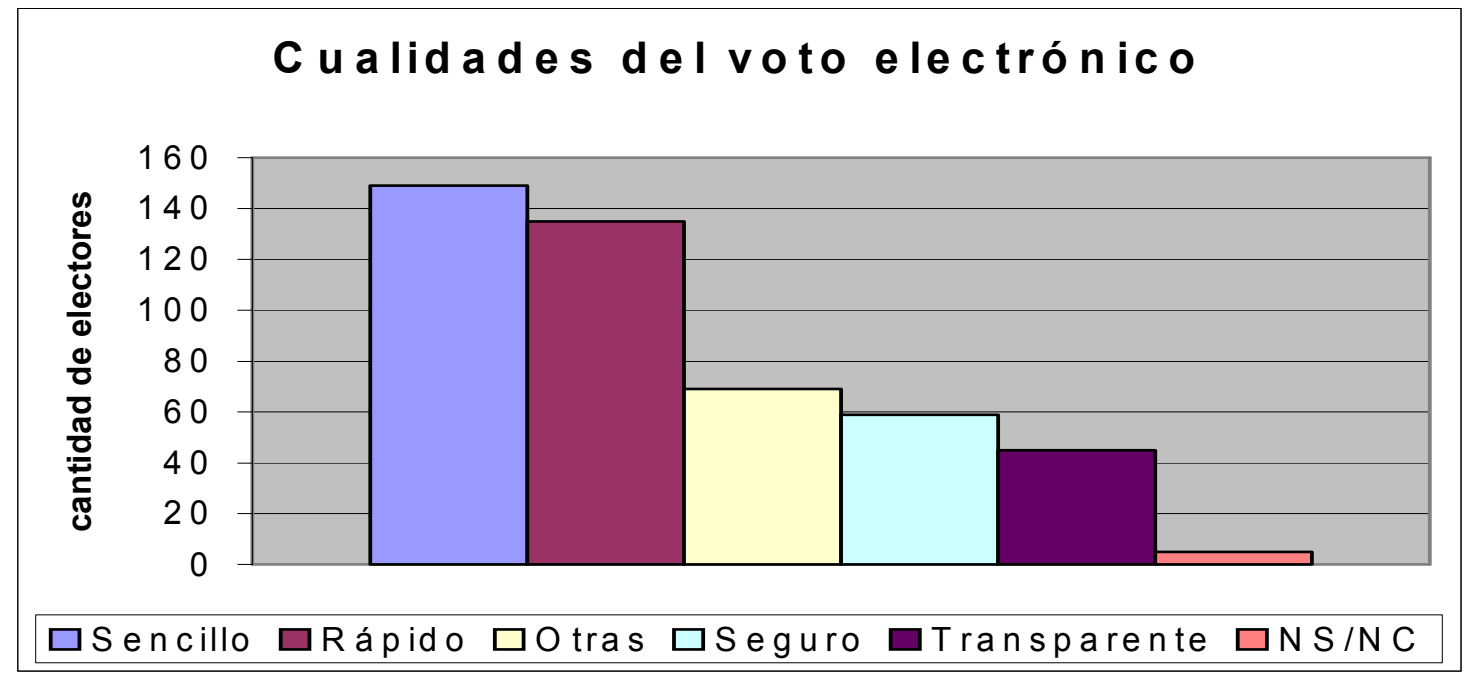

Fuente: Instituto de Investigaciones en Comunicación Social (2003)

Mayoritariamente no hubo problemas con el uso de la urna electrónica (89\%). Sólo el $11 \%$ de los participantes respondieron que sí tuvieron problemas con la mecánica del sistema. Entre las razones por las que se experimentaron dificultades, se menciona la necesidad de capacitación para poder manejar la urna, la cantidad de veces que hay que apretar la tecla verde y la necesidad de confirmar la elección. En segundo lugar aparece la presentación de listas en pantalla y otras menciones.

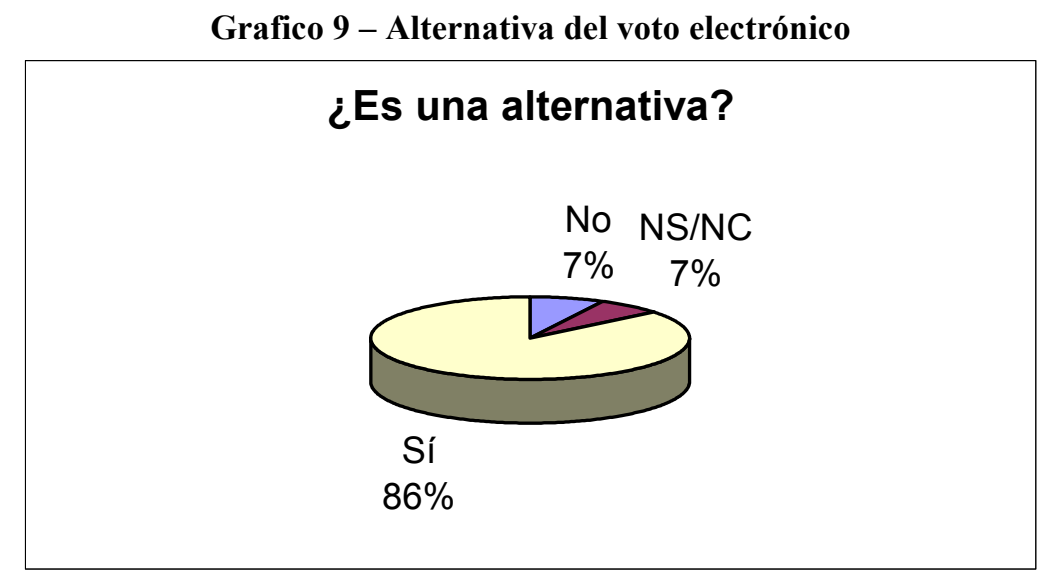

Fuente: Instituto de Investigaciones en Comunicación Social (2003)

La gran mayoría de los encuestados consideran que es una alternativa válida (86\%). Sólo una minoría menciona lo contrario (7\%). La misma cantidad de personas no expresan opinión alguna $(7 \%)$.

Entre los que consideraron el voto electrónico como alternativa apropiada al sistema electoral tradicional, al voto electrónico se le atribuye la cualidad de ser más ágil respecto del voto con papel (34\%), ser más eficiente $(25 \%)$, de optimizar el recuento y procesamiento de los votos $(17 \%)$, además de otras razones $(13 \%)$. En 
último lugar surge la percepción de que el sistema es más austero (10,5\%). Las no menciones fueron marginales $(0,5 \%)$.

La gran mayoría de los casos afirman que el sistema de voto electrónico contribuye a la reforma política (79\%). La cantidad de casos que afirman lo contrario llegan sólo al 8\%.

Estos datos, sin dudas, están relacionados con el tipo de participante sobre el cual se realizó la elección. Como afirma el Informe de la Universidad del Salvador, los resultados arrojan una gran coherencia en términos de sus variables socio demográficas. Coincide el Informe elaborado por la Jefatura de Gabinete cuando señala que

... el perfil de los encuestados así como las menciones guardan un alto grado de coherencia; no se identificaron sub grupos dentro del universo de votantes con tendencias significativamente distintas respecto de los resultados totales" (Jefatura de Gabinete, 2003:91).

Los resultaros, auspiciosos según el Gobierno provincial, derivaron en la continuidad del Proyecto. Durante 2004, no hubo comicios oficiales y se continúo con la difusión del voto electrónico. El gobernador Felipe Solá, creó el Programa de Voto Electrónico, con lo que ratificó su decisión de institucionalizar la nueva herramienta electoral.

En efecto, el 22 de junio de 2004 y por medio del Decreto $\mathrm{N}^{\circ} 1.329 / 04$, se creó el Programa de Voto Electrónico que tuvo como propósito explícito concientizar a la población sobre el cambio cultural relacionado con los métodos de votación, en busca de mayor transparencia y participación ciudadana. El principal objetivo anunciado fue la instauración progresiva del sistema en todo el territorio provincial, además de actuar como órgano orientador, asesor, ejecutor, supervisor, evaluador y de control en todo lo que respecta al voto electrónico en la Provincia de Buenos Aires. ${ }^{240}$

Sin embargo, el interés y la ambición originalmente puesta en el Programa de Voto Electrónico decayeron. El sistema de votación electrónica se utilizó nuevamente para la elección de 2005 y $2007^{241}$.

\footnotetext{
240 Se definieron otras acciones: - Impulsar y organizar todas las actividades necesarias para lograr una masiva difusión del nuevo sistema. - Promover y coordinar la participación efectiva de las universidades, centros de estudio, instituciones intermedias, asociaciones y fundaciones relacionadas con la materia, a fin de facilitar la interacción de todas las partes y actores relevantes para alcanzar la implementación del sistema. - Propiciar convenios de cooperación técnica y científica con Tribunales Electorales Nacionales y Provinciales, así como de otros países, que hayan o estén implementando este tipo de sistemas electorales de voto electrónico. - Relacionarse con la Honorable Junta Electoral de la provincia de Buenos Aires a fin de coordinar las acciones pertinentes para la aplicación de sistemas de voto electrónico al régimen electoral provincial, respetando el ámbito de competencias de cada jurisdicción y resguardando la independencia de los poderes constitucionales que representan.

${ }^{241}$ Pese a las promesas de reforma de la ley electoral nacional, no existieron nuevos proyectos de modificación por lo que en 2005 nuevamente fue utilizado sólo para el voto de extranjeros en los municipios de Berisso y General Pueyrredón en las elecciones legislativas. En este caso, se cambió el sistema utilizado (empresa española Indra que también hizo el recuento provisional) y pese a encontrarse habilitados para votar 12.100 electores en Mar del Plata y 900 en Berisso, sólo lo hicieron 1.445 y 186 respectivamente. Es decir, alcanzó a votar el 12 \% del padrón habilitado. En 2007, el sistema fue utilizad, también para mesas de extranjeros, en La Plata, Berisso, Almirante Brown y Bahía Blanca. En 2010, fue
} 


\section{Otras acciones emprendidas por Ministerio de Gobierno}

El Ministerio de Gobierno, bajo la conducción de Florencio Randazzo, informó como resultado de su gestión las siguientes acciones cuyo detalle es relevante para confirmar la orientación de la política de reforma:

\section{a) Subsecretaría de Gobierno}

a) Registro Provincial de las Personas:

- Capacitación para la recuperación y fortalecimiento del Registro de las Personas: Se estableció como una de las políticas prioritarias de la gestión capacitar al personal que presta servicios tanto en Sede Central como en las delegaciones del interior. Las actividades de capacitación involucraron temáticas propias del quehacer del Registro en lo administrativo y la atención del público, la planificación estratégica y auditoría interna y control de gestión. Se brindaron 1.198 horas de capacitación a través del Instituto Provincial de la Administración Pública (IPAP) y de la Universidad Nacional de La Plata (UNLP).

- Incorporación de tecnología y equipamiento. Se inició un proceso gradual de incorporación de equipamiento tecnológico que abarcará, en el mediano plazo, la totalidad de las Delegaciones del Registro. El mismo consistió en: -520 computadoras personales de última generación. -50 impresoras a chorro de tinta. -5 impresoras láser. La primera etapa abarcó 134 delegaciones cabecera, 5 delegaciones no cabecera, y 5 Centros Integrales de Documentación (CIDs).

- Conexión en red de Delegaciones. En una primera etapa, se conectaron en red las 134 delegaciones cabecera y los 5 CIDs, de los cuales 106 se encontraban grabando datos electrónicamente.

- Programa Integral de Conservación Preventiva y Restauración de los Archivos del Registro Provincial de las Personas. Se encarga de la custodia y conservación del patrimonio documental para la identidad, compuesto por más de 140.000 libros. Para ello, se creó un taller de conservación y restauración de volúmenes.

- Convenios de cooperación internacional. Se han suscripto convenios con dos Registros Civiles modelos de Latinoamérica: el Servicio de Registro Civil e Identificación de Chile y Registraduría Nacional del Estado Civil de Colombia, para el proceso de modernización y fortalecimiento del Registro de las Personas.

- Acuerdos de Cooperación. Se firmaron convenios con el Ministerio de Desarrollo Humano para la apertura de una delegación dedicada a la

utilizado para la elección de intendente en Pinamar y en 2011, nuevamente para extranjeros en La Plata, Berisso, Pinamar, La Costa, Villa Gesell y Pilar 
documentación de niños, niñas y adolescentes, comprendidos en los programas de la Subsecretaría de Minoridad. Asimismo, se prevé la firma de un convenio con el Ministerio de Justicia.

b) Dirección Provincial de Informática Jurídico Legal y Entidades Profesionales:

- Se materializaron en el sitio web el libre acceso a la información, sin registración previa y un formato de visualización más "amigable" de los contenidos.

- Sistema de "Novedades normativas" que permite, en un rápido vistazo, conocer las recientes normas de interés para los ciudadanos bonaerenses.

- Ampliación de la base normativa. A las leyes provinciales se sumaron los decretos provinciales, las ordenanzas generales y algunas resoluciones ministeriales de interés general. Incorporación de un "Buscador normativo global" que permite efectuar búsquedas por palabra clave o por número. Publicación del texto completo de aproximadamente 1.500 leyes que, hasta el momento, no se encontraban digitalizadas.

- Mantenimiento del servicio de consultas normativas y solicitud de envío de normas no publicadas.

c) Dirección de Entidades Profesionales:

- Convenio de Colaboración con la Federación de Profesionales Universitarios de la Provincia de Buenos Aires (F.E.P.U.B.A) para la provisión de titularidades del Registro de Escrituras Públicas vacantes en la provincia de Buenos Aires. Se nombró un Tribunal de Calificación para la evaluación del Concurso de Escribanos.

- Se cooperó con otras provincias argentinas para la implementación de direcciones o reparticiones similares a la Dirección de Entidades Profesionales de la provincia de Buenos Aires, a fin de que puedan realizar la fiscalización de las Cajas previsionales.

d) Dirección de Impresiones Del Estado y Boletín Oficial:

- Se adquirieron maquinarias de última generación por un monto de $\$$ 5.000 .000 .

- Se realizaron mejoras edilicias, reacondicionándose los distintos sectores de la imprenta.

- Se llevó a cabo la capacitación del personal gráfico, realizándose cursos de encuadernación y mantenimiento de maquinaria.

\section{b) Subsecretaría de Relaciones Institucionales}

e) Dirección Provincial de ONG'S

- Se revisaron los procedimientos para el otorgamiento de personería jurídica o de firma de convenios.

- Se tipificaron las organizaciones asociadas a la política en cuestión. Se realizó asesoramiento y capacitación. Se articularon políticas con los Municipios. 
- Se realizó el Plan de Empadronamiento y Regulación de Organizaciones No Gubernamentales.

f) Dirección Provincial de Juventud

- Se elaboró el Programa de Capacitación "Un nuevo liderazgo político y comunitario", orientado a jóvenes dirigentes de la provincia de Buenos Aires.

- Se implementaron las Jornadas de Identidad Cultural y Globalización, organizadas en cuatro seminarios dirigidos a jóvenes dirigentes políticos, comunitarios y gremiales.

- Se establecieron acuerdos con la Comisión de Investigaciones Científicas (CIC) que derivaron en la confección de un convenio con el objeto de impulsar "Proyectos innovadores de desarrollo local".

\section{c) Subsecretaría de Asuntos Municipales}

- Se realizó el Programa de Regularización de Expedientes, reduciéndose el número de expedientes en trámite de 1800 a 290 que permitió reducir de la deuda de los municipios hacia el CEAMSE, de $\$ 8.300 .000$ a $\$$ 21.000, normalizar la verificación y asignación de deudas de nuevos municipios (ley 11.752) y reintegrar $\$ 2.100 .000$ a distritos en condiciones de ser beneficiarios en el marco de la Ley $\mathrm{n}^{\circ} 11.752$.

- Plan de Recopilación y Publicación de Normativa Municipal de Usos del Suelo en la Provincia.

- Se propicia reformar la Ley Orgánica Municipal. 


\section{CAPÍTULO IX. ESTUDIO DE CASOS II - SECRETARÍA EJECUTIVA DE GOBIERNO ELECTRÓNICO}

\section{El SINBA, el SIEP y la GUT}

\section{a) El SINBA}

El proyecto del Sistema Informático Normativo Bonaerense, SINBA, por primera vez se cristalizó documentadamente en el Expediente $n^{\circ}$ 2100-33446/04, con fecha de inicio el 18 de agosto de 2004. Sin embargo, la Secretaría Ejecutiva de Gobierno Electrónico venía trabajando en él desde inicios de ese año.

El proyecto buscaba establecer un sistema de consulta en línea de documentos normativos como herramienta eficaz en el desenvolvimiento de la actividad administrativa. El SINBA buscaba crear un registro de carácter público que compilara la producción normativa del Estado provincial mediante su publicación Web ${ }^{242}$. objetivos:

Según el Secretario Ejecutivo de Gobierno Electrónico, el proyecto tenía varios gobierno;

- garantizar el principio republicano de publicidad de los actos de

- fortalecer a las áreas de apoyo de la Administración, especialmente las asesorías jurídicas;

- contribuir a la rápida difusión de las normas hacia los ciudadanos.

Entre los fundamentos de la norma remarcó el Secretario Ejecutivo que la Provincia tiene un alto grado de "hipertrofia normativa que se genera como consecuencia natural de las dificultades que se le presentan a los ciudadanos en la defensa de sus derechos".

Según el funcionario, argumento que luego se tradujo en uno de los Considerandos del Decreto, el proyecto se apoyaba en la Constitución de la Provincia de Buenos Aires, garantizando el derecho de los ciudadanos a conocer la información vinculada a los modos de expresión jurídica de los Poderes del Estado.

Lo cierto es que existían bases objetivas para el proyecto: la dificultad que se presenta a los ciudadanos para obtener información referida a la normativa provincial vigente, especialmente la producción normativa emanada del nivel ministerial y de los

\footnotetext{
${ }^{242}$ El proyecto se presentaba como un sistema de gran valor para todas las áreas de la administración y tenía su antecedente en el exitoso portal de información jurídica gratuita del Ministerio de Economía de la Nación, INFOLEG, www.infoleg.gov.ar. INFOLEG es una base de datos jurídica que la actual Área Información Legislativa y Documental del Centro de Documentación e Información del Ministerio de Economía y Finanzas Públicas coordina y lleva adelante a través de la recopilación y actualización de la legislación nacional en materia económica, sus normas interpretativas y antecedentes.
} 
organismos descentralizados. Ese tipo de dificultades se incrementa en el interior de la Provincia, donde la distancia constituye un obstáculo para el ejercicio ágil de las tareas desarrolladas por los empleados públicos. Y son las TIC, reflejadas en los sistemas informáticos, las redes y los accesos remotos a través de Internet, los que permiten solucionar el problema de la brecha geográfica existente.

Se señalaba, como otro de los incentivos para su adopción, que el proyecto podía realizarse sin generar erogación alguna en el presupuesto, basándose exclusivamente en el aprovechamiento de los recursos existentes y en la cooperación de los distintos organismos que componen la Administración Pública.

El proyecto no suponía una fuerte reestructuración del Back Office aunque implicaba un fuerte conflicto entre el área que impulsaba el proyecto y otra área, de la misma Secretaría General, encargada del registro de los actos. En efecto, como veremos, uno de los mayores obstáculos al proyecto no fue ni económico ni normativo ni tecnológico sino de poder.

Originariamente, el proyecto preveía que los anteproyectos de leyes y decretos podían ser incorporados al módulo de gestión interna del SINBA por el Organismo propiciante una vez cumplimentado el trámite previo de la intervención de la Asesoría General de Gobierno y la Fiscalía de Estado. Se establecía, a renglón seguido, que el Organismo propiciante de la norma podría utilizar el procedimiento previsto en el artículo 123 del Decreto-Ley No 7.647/70 de la Ley de Procedimientos Administrativos, esto es, que el proyecto sea sometido a información y a consulta de las organizaciones profesionales y gremiales.

Esta posibilidad, que sin duda transparentaba el sistema de registro al hacer públicos los proyectos, generó un fuerte rechazo por parte de la Subsecretaría Legal, Técnica y de Asuntos Legislativos de la Secretaría General. Pese a que se había conformado un equipo de trabajo con integrantes de esa Subsecretaría en el período de elaboración del proyecto, una vez remitido el proyecto definitivo, se detuvo el expediente por más de un año. Se invocaron varias objeciones técnicas al proyecto aunque podemos advertir, "idas y vueltas" que denotan conflictos entre las Subsecretarías. $^{243}$

Diagrama de Gantt - Tiempos de tramitación proyecto SINBA

\begin{tabular}{|c|c|c|c|c|c|c|c|c|c|c|c|}
\hline \multirow[t]{2}{*}{ ld } & \multirow[t]{2}{*}{ Nombre de tarea } & \multirow[t]{2}{*}{ Duración } & \multirow[t]{2}{*}{ Corrienzo } & \multirow[t]{2}{*}{ Fin } & \multirow[b]{2}{*}{$\operatorname{tri} 32004$} & \multirow[b]{2}{*}{ tri 42004} & \multirow[b]{2}{*}{ tri 12005} & \multirow[b]{2}{*}{ tri 22005} & \multirow[b]{2}{*}{ tri 32005} & \multirow[b]{2}{*}{ tri 42005} & \multirow[b]{2}{*}{$\operatorname{tri} 12006$} \\
\hline & & & & & & & & & & & \\
\hline 1 & Subsecretaria de Gestión Tecnológica y Adrinis & 3 días & mié 1808004 & vie 2000804 & $h$ & & & & & & \\
\hline 2 & Asesoria General & 100,75 dias & vie 2000804 & vie 07010105 & & & & & & & \\
\hline 3 & Subsecretaría de Gestión Tecnológica y Adrininis & 4,75 dias & vie 07010105 & jue 13010105 & & & 1 & & & & \\
\hline 4 & Subsecretaría Legla, Técrica y Adrninistrtativa & 283,75 dias & jue 1301005 & $\operatorname{mar} 14020206$ & & & & & & & \\
\hline 5 & Subsecretariáa de Gestión Tecnológica y Adrinis & 0,75 dias & max 14,0206 & mar 14020206 & & & & & & & 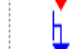 \\
\hline 6 & Subseccetaría Legla T, Técrica y Adrinisistrativa & 0,75 dias & mié 15020206 & mié 15020206 & & & & & & & \\
\hline
\end{tabular}

Fuente: Elaboración propia sobre la base del sistema de expedientes de la Provincia de Buenos Aires.

Nota: Gráfico de barras en trimestres.

243 Este dato pudo corroborarse consultando los movimientos de expedientes en la página Web de la provincia. 
Entre esas objeciones, la Subsecretaría Legal, Técnica y de Asuntos Legislativos solicitaba intervenciones de áreas dependientes del Ministerio de Gobierno luego de que el proyecto de Decreto fuera refrendado por el propio Ministro de Gobierno. Más aún, había inutilizado el proyecto impreso en hojas de uso oficial con motivo de esas supuestas faltas técnicas, que no habían sido observadas por el Ministro de Gobierno, paso previo a la firma del Gobernador.

Ello revela que detrás de las consideraciones técnicas existían otras motivaciones. Las razones invocadas estaban relacionadas con la posibilidad de que se generaran expectativas en proyectos que luego el Gobernador podría no suscribir. Pero también, la "caja de cristal" que suponía que los ciudadanos "vieran" proyectos hacía temer que esa Subsecretaría "perdiese" el poder de "vetar", "cajonear" o "cambiar" proyectos antes de que llegasen a la firma del Gobernador.

Lo cierto es que el conflicto se destrabó con la modificación al proyecto originario. Así, en la versión final, se consignó, en el artículo $9^{\circ}$ que

Los anteproyectos de leyes y decretos, podrán ser incorporados al módulo de gestión interna del SINBA por el organismo propiciante, una vez cumplimentado el trámite previsto en el artículo 123 del Decreto-Ley $\mathrm{N}^{\mathrm{o}} 7647 / 70$. En ese supuesto, se aplicará el procedimiento previsto en el artículo 124 de la citada normativa, y si resultaren susceptibles de modificación, el organismo responsable deberá reemplazar el documento por la nueva versión (el desatcado no es del original).

Es decir, no siempre los proyectos serán "visibles" para los ciudadanos sino sólo cuando el organismo propiciante así lo consignare expresamente.

Otro conflicto menor se suscitó respecto de la vigencia de las normas y su publicación en el SINBA. El proyecto originario establecía que el incumplimiento en la publicación en el SINBA determinaría que la norma no resultara aplicable a sus destinatarios. Según la Asesoría General de Gobierno, no podía establecerse en un Decreto la obligatoriedad de la publicación web pues la Ley de procedimiento administrativo, de mayor jerarquía, establece que

los reglamentos administrativos producirán efectos jurídicos a partir del día siguiente de su publicación en el "Boletín Oficial" de la Provincia, si en ellos no se dispusiere la publicación por otro medio (artículo 125 del Decreto-Ley No 7.647/70; el destacado es nuestro).

Consultado a este respecto, el Secretario Ejecutivo de Gobierno Electrónico señaló además que, sin la obligatoriedad de publicación en el SINBA para la vigencia de la norma, el proyecto del SINBA dependería exclusivamente de la voluntad de los funcionarios en enviar o no las Resoluciones o Disposiciones a la publicación web.

Como destacamos en la trascripción del artículo 125 de la Ley de Procedimiento Administrativo, la ley expresamente establecía la posibilidad de que la propia norma 
habilitara otros medios. Cierto es que esa publicación "por otros medios" se había previsto originariamente para los Edictos Policiales, pero esa habilitación hubiera permitido establecer la publicación obligatoria para que las normas sólo tuvieran vigencia con la publicación web.

Sin embargo, prevaleció la visión tradicional de la publicación papel y no se optó por la innovación en esta materia.

Con esas dos modificaciones, el proyecto fue aprobado mediante Decreto del Gobernador. Así, con la sanción del Decreto $\mathrm{N}^{\circ} 2.704 / 05$ de fecha 10 de noviembre de 2005, se logró dar inicio a un sistema que buscó una adecuada y rápida difusión de los actos de gobierno, contribuyendo a dar mayor transparencia al obrar de los poderes del Estado y al logro de los objetivos de las políticas públicas, facilitando el conocimiento por parte de la comunidad de las normas emitidas.

La norma en su parte dispositiva, establece que se deben incorporar al SINBA los siguientes textos normativos: ${ }^{244}$

- Las Leyes provinciales.

- Los Decretos de carácter general, emanados del Poder Ejecutivo.

- Las Resoluciones y Disposiciones de carácter general emanadas de los Ministerios.

- Las Disposiciones normativas de carácter general emanadas de los Organismos Descentralizados.

- Los Decretos de designación de personal sin estabilidad.

- Los convenios de alcance general suscriptos por el Estado provincial.

- Los Acuerdos, Acordadas y Resoluciones Generales de la Suprema Corte de Justicia de la Provincia de Buenos Aires.

- Las Ordenanzas y Decretos Municipales de alcance general. ${ }^{245}$

Esos textos normativos estarían disponibles en Internet para su consulta por los ciudadanos y organismos interesados en forma gratuita conforme la versión definitiva. La incorporación y registro de los textos normativos integrados al SINBA sólo tienen carácter informativo y no sustituyen la publicación de los actos en el Boletín Oficial de la Provincia. ${ }^{246}$

Respecto de las Leyes y Decretos, una vez publicadas en el Boletín Oficial, se enviarían al SINBA, con lo que sólo se incorpora un paso más al final del procedimiento. En el caso de actos normativos de alcance general emanados de las jurisdicciones de la Administración Pública Provincial (Resoluciones y Disposiciones de carácter general), la incorporación al sistema informático corre por cuenta del organismo que ha intervenido en la producción de la misma, luego de firmados por la autoridad competente.

\footnotetext{
244 La incorporación de los textos normativos al sistema debe efectuarse en forma completa, salvo los decretos de designación de personal, que podrán incorporarse de modo sintético.

245 En los últimos dos casos, se requiere un Acuerdo con la Corte y con los municipios.

246 Consecuentemente, ante la existencia de discordancia entre el texto publicado en el Boletín Oficial y el texto integrado en el SINBA, serán tenidos por auténticos los textos publicados en la versión impresa del Boletín Oficial.
} 
En cuanto a las competencias, la Secretaría General de la Gobernación se constituyó en la autoridad de aplicación del Decreto, quedando facultada para dictar la normativa complementaria que resultare menester para la ejecución de sus términos pese a las competencias de la Dirección Provincial de Informática Jurídico Legal y Entidades Profesionales dependientes del entonces Ministerio de Gobierno. La administración y mantenimiento de las Bases de Normas constituyen responsabilidad de la entonces Dirección Provincial de Informática y Comunicaciones de la Secretaría General de la Gobernación ${ }^{247}$.

\section{b) El SIEP}

El anteproyecto del Sistema Integrado de Emisión y Pagos No Impositivos de la Provincia de Buenos Aires (SIEP) tuvo inicio en el expediente 2100-7798/05 de fecha 23 de agosto de 2005. Sin embargo, dicho proyecto también venía trabajándose internamente desde hacía más de un año.

En la presentación formal del sistema, el Secretario Ejecutivo de Gobierno Electrónico sostuvo que el proyecto constituía un proceso de implementación secuencial de un sistema de recaudación electrónica de todos los pagos de carácter contributivo, no impositivos de la Provincia, esto es, cobro de tasas administrativas, servicios, aranceles, multas y todo otro tipo de contribución con excepción del impuesto inmobiliario, impuesto sobre los ingresos brutos, impuesto a los automotores, embarcaciones deportivas o de recreación e impuesto de sellos.

Según los considerandos del Decreto, el sistema propiciaba el uso de tecnologías y medios informáticos con el objeto de:

- Contribuir a la mejora en la atención al ciudadano, optimizando el uso de su tiempo y disminuyendo los obstáculos derivados de las barreras geográficas,

- Procurar el fortalecimiento de los sistemas de recaudación haciéndolos más seguros y eficaces y facilitando su control, y

- Mejorar la información sobre cobros para los organismos de la Administración Pública Provincial.

El sistema permitiría al ciudadano acceder a los formularios de pago de los diversos trámites que se gestionan ante los organismos provinciales a través de medios electrónicos desde cualquier ubicación geográfica. Por su parte, el organismo recaudador de los fondos, el Banco de la Provincia de Buenos Aires, percibiría los montos de los trámites pertenecientes a la Provincia por medio de la lectura de un código de barras para su acreditación en la cuenta destino de la transacción y la elaboración de informes de cobranzas. Los pagos podrían hacerse en las Sucursales y

\footnotetext{
${ }^{247}$ Respecto la implementación del proyecto, luego de sancionada la norma, el SINBA se "estancó" como consecuencia de inconvenientes logísticos: el área de informática no tuvo capacidad técnica para la realización de la plataforma que debía soportar el sistema y con la finalización de la gestión, el tema perdió "peso". Hoy sólo están disponibles en la Web los Decretos y Leyes, a través del área de informática jurídica del Ministerio de Jefatura de Gabinete de Ministros porque es el Boletín Oficial quien envía la información para que ésta sea publicada.
} 
Agencias del Banco, en los locales Bapro Pagos y a través de la Red Link y de los cajeros automáticos del sistema bancario, permitiendo a los interesados una amplia disponibilidad de horarios y bocas de cobro.

La implementación del sistema, ya existente para el pago de algunos servicios privados, suponía un desarrollo en etapas tendientes a evaluar el funcionamiento, generar la validación de los datos, determinar con mayor precisión los alcances y responsabilidades en cada uno de los procesos, así como la medición de los tiempos reales de gestión de la información y, a partir de la evaluación de resultados obtenidos, perfeccionar el sistema.

Por tal razón, desde el inicio se propuso la puesta en marcha del sistema en tres etapas. La primera de ellas, la suscripción de un Convenio con el Banco de la Provincia de Buenos Aires para la implementación de una "prueba piloto" sobre algunos de los trámites que se gestionan ante organismos provinciales, sin perjuicio de la coexistencia temporal con el sistema vigente. Esta etapa previa tendría como objetivo la evaluación de los resultados obtenidos, para perfeccionar el sistema y tener elementos de análisis que permitan fundamentar la implementación definitiva y total del sistema de recaudación de pagos de carácter contributivo, no impositivos de la Provincia.

De resultar para la Provincia satisfactoria la "prueba piloto", el Banco asumiría el compromiso de arbitrar los medios para garantizar la capacidad técnica y operativa para la percepción de todos los trámites que la Provincia emita y perciba; allí comenzaría la segunda etapa del SIEP, de aplicación obligatoria a todos los organismos de la Administración Pública Provincial, centralizada, descentralizada y autárquica, con el objeto de promover el acceso ciudadano a los formularios de pago a través de medios electrónicos disponibles tanto de uso privado como en lugares de acceso público.

Con la existencia de la capacidad técnica y operativa, se daría inicio a la tercera etapa: el acuerdo definitivo con el Banco de la Provincia de Buenos Aires para la implementación del SIEP, donde se preveía negociar con el Banco los cargos por las cobranzas que realiza para la Provincia, teniendo en cuenta las ventajas que el sistema le brinda y los menores costos de las transacciones electrónicas.

Para el funcionario entrevistado del Organismo propiciante del sistema, la Secretaría Ejecutiva de Gobierno Electrónico, el sistema generaría una mejora en la calidad de los servicios que el Estado Provincial brinda a sus habitantes y aumentaría el impacto de la gestión de recaudación de los recursos públicos de modo seguro y eficiente.

Más allá del proyecto en sí, el análisis de este proyecto es revelador para evaluar las convicciones subyacentes en los actores intervinientes en el proceso de aprobación del sistema.

El proyecto originario de la Secretaría Ejecutiva de Gobierno Electrónico era conciso. Sin embargo, tuvo intervención de varios organismos hasta llegar a su redacción definitiva, donde adquirió una nueva "fisonomía" adicionándosele algunos aspectos que resaltan los valores de los actores involucrados.

Haremos una comparación entre las distintas versiones seleccionando algunas palabras claves por su valor axiológico. Analizaremos sólo los considerandos de los proyectos del Decreto, párrafo por párrafo, atento a que allí se expresan los objetivos y justificaciones de los actos normativos. 
El primer proyecto fue elaborado por la Secretaría Ejecutiva de Gobierno Electrónico. Esa primera versión es del 21 de julio de 2004. El segundo proyecto, también perteneciente a la Secretaría Ejecutiva de Gobierno Electrónico, es del 11 de mayo de 2005, casi un año posterior, pero aún anterior a la fecha de inicio de las actuaciones administrativas. Sobre el tercer proyecto, del 12 de septiembre de 2005, concomitante con el inicio del Expediente, intervino e introdujo cambios la Subsecretaría de Gestión Tecnológica y Administrativa de la Secretaría General. Sobre el cuarto proyecto, intervino la Asesoría General de Gobierno con fecha 4 de noviembre de 2005. El proyecto definitivo, con la intervención de la Contaduría General y de la entonces Subsecretaría de Ingresos Públicos del Ministerio de Economía, a cargo del Lic. Santiago Montoya, fue aprobado como Decreto No 196/06 del 7 de febrero de 2006.

El primer Considerando del Decreto tuvo pocas modificaciones. La única relevante tiene que ver con la intervención de la Asesoría General de Gobierno que sugirió cambiar "Estado Inteligente" por "Estado eficiente". Evidentemente ambos son conceptos distintos, semántica e ideológicamente. Si bien fue la Asesoría General de Gobierno quien introdujo el cambio, sólo fue como sugerencia ya que sus dictámenes no tienen carácter vinculante. Por ello, el cambio también puede atribuirse a los organismos políticos.

\section{Cuadro 30 - Modificaciones primer considerando Decreto SIEP}

\begin{tabular}{|l|l|}
\hline $\begin{array}{l}\mathbf{1}^{\mathbf{0}} \text { al } \mathbf{3}^{\circ} \\
\text { proyecto }\end{array}$ & $\begin{array}{l}\text { Que el Gobierno de la Provincia de Buenos Aires se encuentra comprometido en la } \\
\text { construcción de un Estado Inteligente, impulsando politicas capaces de brindar respuestas } \\
\text { con rapidez, transparencia, eficiencia y calidad a sus ciudadanos; }\end{array}$ \\
\hline $\mathbf{4}^{\mathbf{0}}$ proyecto & $\begin{array}{l}\text { Que el Gobierno de la Provincia de Buenos Aires se encuentra comprometido en la } \\
\text { al Definitivo } \\
\text { construcción de un Estado eficiente, impulsando politicas capaces de brindar respuestas } \\
\text { conansparencia, eficiencia y calidad a sus ciudadanos; }\end{array}$ \\
\hline
\end{tabular}

El segundo y tercer párrafo, que hacían referencia al uso de las TIC y a la seguridad de la recaudación, tuvo mayores cambios.

\section{Cuadro 31 - Modificaciones segundo y tercer considerando Decreto SIEP}

\begin{tabular}{|l|l|}
\hline $\mathbf{1}^{\mathbf{0}}$ proyecto & $\begin{array}{l}\text { Que la Administración Pública Provincial puede recurrir al uso de nuevas tecnologías y } \\
\text { medios que posee el mercado, con el objeto de contribuir a la mejora en la atención al } \\
\text { ciudadano, optimizando el uso de su tiempo y disminuyendo los obstáculos derivados de } \\
\text { las barreras geográficas, procurando con ello garantizar su accesibilidad a los servicios } \\
\text { que presta el Estado; } \\
\text { Que el Estado necesita desarrollar sistemas de recaudación cada vez más seguros; }\end{array}$ \\
\hline $\mathbf{2}^{\mathbf{0}}$ proyecto & $\begin{array}{l}\text { Que a tales fines la Administración Pública Provincial puede recurrir al uso de nuevas } \\
\text { tecnologías y medios que posee el mercado, con el objeto de contribuir a la mejora en la } \\
\text { atención al ciudadano, optimizando el uso de su tiempo y disminuyendo los obstáculos } \\
\text { derivados de las barreras geográficas, procurando con ello garantizar su accesibilidad a } \\
\text { los servicios que presta el Estado; } \\
\text { Que el Estado Provincial necesita desarrollar sistemas de recaudación cada vez más } \\
\text { seguros y eficaces; capaces no sólo de asegurar la percepción de los recursos } \\
\text { indispensables para la acción de gobierno sino para contar con información confiable, } \\
\text { pertinente y actualizada sobre los montos y conceptos recaudados; }\end{array}$ \\
\hline
\end{tabular}




\begin{tabular}{|l|l|}
\hline $\mathbf{3}^{\mathbf{0}}$ proyecto & $\begin{array}{l}\text { Que resulta necesario desarrollar sistemas de recaudación cada vez más seguros, eficaces } \\
\text { al Definitivo } \\
\text { y transparentes, que permitan rendir cuenta a la sociedad de los fondos percibidos por el } \\
\text { Estado para el cumplimiento de sus fines públicos indelegables; } \\
\text { Que las Tecnologias de la Información y las Comunicaciones (TIC's) constituyen } \\
\text { herramientas de probada eficacia para la mejora en la gestión gubernamental, acercando } \\
\text { al ciudadano con sus representantes y facilitando la gestión de sus trámites; } \\
\text { Que en ese sentido, las TIC's coadyuvan a que la Administración Pública Provincial } \\
\text { mejore la atención al ciudadano, a través de la optimización del uso de su tiempo y de la } \\
\text { disminución de los obstáculos derivados de las barreras geográficas; }\end{array}$ \\
\hline
\end{tabular}

En la versión original, aparecen las TIC como medios que posee el mercado. El objeto de las TIC, para la Secretaría Ejecutiva de Gobierno Electrónico, era mejorar en la atención al ciudadano, optimizar el uso de su tiempo y disminuir los obstáculos derivados de las barreras geográficas.

A partir de la tercera versión, y con la intervención de la Subsecretaría de Gestión Tecnológica y Administrativa, se elimina la referencia al mercado y se conservan los objetivos, aunque se incluye un nuevo párrafo previo donde se refieren a las TIC como herramientas para la gestión gubernamental, para mejorar la democracia y facilitar a los ciudadanos la gestión de los trámites.

Como veremos en el siguiente Cuadro, con la intervención de la Subsecretaría de Gestión Tecnológica y Administrativa se agrega al proyecto un párrafo referente a las áreas que le han dado impulso al sistema y su objeto.

Cuadro 32 - Modificaciones considerandos Decreto SIEP

\begin{tabular}{|l|l|}
\hline $\begin{array}{l}\mathbf{1}^{\mathbf{0}} \mathbf{y} \mathbf{2}^{\circ} \\
\text { proyecto }\end{array}$ & - \\
\hline $\mathbf{3}^{\mathbf{0}}$ & $\begin{array}{l}\text { Que a los fines de aplicar las TIC's en los procesos de emisión y percepción de tributos, la } \\
\text { proyecto } \\
\text { al } \\
\text { Definitivosecretaría de Gestión Tecnológica y Administrativa de la Secretaría General y la } \\
\text { Secretaría Ejecutiva de Gobierno Electrónico juntamente con el Banco de la Provincia de } \\
\text { Buenos Aires, han trabajado en el diseño de un sistema electrónico de emisión y } \\
\text { percepción de tasas administrativas, servicios, aranceles, multas y todo otro tipo de } \\
\text { contribución, con excepción de los impuestos sobre los ingresos brutos, automotores, } \\
\text { embarcaciones deportivas o de recreación, inmuebles y sellos; }\end{array}$ \\
\hline
\end{tabular}

Hace referencia el Decreto a la existencia de otros proyectos tanto en el ámbito nacional como provincial que no cuentan con impedimentos ni legales ni en su implementación.

\section{Cuadro 33 - Modificaciones considerandos Decreto SIEP}

\begin{tabular}{|l|l|}
\hline $\begin{array}{l}\mathbf{1}^{\mathbf{0}} \mathbf{y} \mathbf{2}^{\mathbf{0}} \\
\text { proyecto }\end{array}$ & $\begin{array}{l}\text { Que los sistemas electrónicos para la emisión y cobro de impuestos Nacionales y } \\
\text { Provinciales se encuentran debidamente probados en su eficacia y su implementación no } \\
\text { presentan impedimentos legales; }\end{array}$ \\
\hline $\begin{array}{l}\mathbf{3}^{\mathbf{0}} \text { proyecto } \\
\text { al } \\
\text { Definitivo }\end{array}$ & $\begin{array}{l}\text { Que los sistemas electrónicos para la emisión y percepción de tributos ya implantados, } \\
\text { tanto en el ámbito nacional como en las jurisdicciones provinciales, no generan mayores } \\
\text { inconvenientes en cuanto a su operatoria ni existen obstáculos jurídicos para aplicación; }\end{array}$ \\
\hline
\end{tabular}


Finaliza el proyecto original con una referencia a la habilitación temporal del sistema.

\section{Cuadro 34 - Modificaciones considerandos Decreto SIEP}

\begin{tabular}{|l|l|}
\hline $\mathbf{1}^{\mathbf{0}}$ proyecto & $\begin{array}{l}\text { Que dado el vertiginoso desarrollo de la tecnología informática y la superación que puede } \\
\text { resultar de un nuevo sistema, resulta conveniente habilitar la coexistencia con el que se } \\
\text { encuentra vigente; }\end{array}$ \\
\hline $\mathbf{2}^{\mathbf{0}}$ proyecto & $\begin{array}{l}\text { Que el cambio propiciado requiere de una implementación gradual que durante el lapso } \\
\text { que se fija permita su coexistencia con el sistema de recaudación que se encuentra } \\
\text { actualmente vigente; }\end{array}$ \\
\hline $\begin{array}{l}\mathbf{3}^{\mathbf{0}} \text { proyecto } \\
\mathbf{a l} \\
\text { Definitivo }\end{array}$ & $\begin{array}{l}\text { Que pese a ello, al involucrarse una importante diversidad de trámites administrativos, } \\
\text { que impactará de forma terminante en los actuales procesos de trabajo y que, por tal } \\
\text { razón, generará un profundo cambio para los ciudadanos y para la cultura } \\
\text { organizacional de la Administración Pública, resulta conveniente que su instauración sea } \\
\text { progresiva por lo que el sistema será puesto en marcha como Prueba Piloto a los fines de } \\
\text { evaluar su funcionamiento y corregir eventuales debilidades; } \\
\text { Que el proceso gradual de implementación del sistema impone etapas, tendientes a } \\
\text { evaluar su funcionamiento, generar la validación de los datos, determinar con mayor } \\
\text { precisión los alcances y responsabilidades para la gestión de cada uno de los procesos, } \\
\text { así como la medición de los tiempos reales de gestión de la información y, a partir de la } \\
\text { evaluación de resultados obtenidos, perfeccionar el sistema; } \\
\text { Que en ese sentido, resulta conveniente habilitar temporalmente la coexistencia del } \\
\text { Sistema con los mecanismos que se encuentran actualmente vigentes; }\end{array}$ \\
\hline
\end{tabular}

Los últimos párrafos del decreto definitivo, introducidos por la Subsecretaría de Gestión Tecnológica y Administrativa, hacen referencia a la necesidad de centralización de la experiencia y a la Secretaría General como autoridad de aplicación. En el segundo proyecto, se lo justifica por la necesidad de coordinar las distintas experiencias existentes. En el tercer proyecto, por el carácter innovador de la experiencia a través del uso de tecnología.

\section{Cuadro 35 - Modificaciones primer considerando Decreto SIEP}

\begin{tabular}{|l|l|}
\hline $\mathbf{1}^{\mathbf{0}}$ proyecto & - \\
\hline $\mathbf{2}^{\mathbf{0}}$ proyecto & $\begin{array}{l}\text { Que ya existen organismos de la Administración Pública Provincial que han o están en vía } \\
\text { de implementar este tipo de sistemas; } \\
\text { Que es necesario coordinar dichas experiencias a través de una política centralizada; } \\
\text { Que a fin de materializar y normalizar el uso del sistema informatizado de pago de tasas, se } \\
\text { ha firmado un convenio entre la Secretaría General de la Gobernación y el Banco de la } \\
\text { Provincia de Buenos Aires, que esta Instancia debe aprobar; } \\
\text { Que adicionalmente deviene necesario establecer las pautas y normas administrativas a las } \\
\text { que deberán ajustarse los distintos Organismos de la Administración Pública Provincial } \\
\text { para el uso del sistema que se regula por el presente Decreto; } \\
\text { Que es oportuno mantener como autoridad de aplicación para llevar adelante los procesos } \\
\text { de su implementación, a la Secretaría General de la Gobernación, facultándola para } \\
\text { reglamentar los aspectos no contemplados en el presente; } \\
\text { Que finalmente y en orden con la politica de mejoramiento de los procesos de gestión que } \\
\text { este Gobierno propicia permanentemente, esta Instancia considera oportuno invitar a los } \\
\text { restantes Poderes del Estado Provincial y a los Municipios de la Provincia de Buenos Aires, } \\
\text { a adherirse al régimen que por el presente se instituye; }\end{array}$ \\
\hline
\end{tabular}




\begin{tabular}{|l|l|}
\hline $3^{\circ}$ proyecto & $\begin{array}{l}\text { Que por tratarse de una política innovativa en la gestión tecnológica, resulta necesario } \\
\text { al } \\
\text { Definitivo } \\
\text { implementación de dichos procesos; } \\
\text { Que por ello, resulta pertinente designar como autoridad de aplicación del presente } \\
\text { Sistema, a la Secretaría General de la Gobernación, facultándola para reglamentar los } \\
\text { aspectos no contemplados en el presente; } \\
\text { Que en orden a la política de mejoramiento de los procesos de gestión que este Gobierno } \\
\text { propicia permanentemente, esta instancia considera conveniente invitar a los restantes } \\
\text { poderes del Estado Provincial, Organismos de la Constitución y a los Municipios de la } \\
\text { Provincia de Buenos Aires, a adherirse al Sistema que por el presente se instituye; }\end{array}$ \\
\hline
\end{tabular}

Como se puede advertir, a partir de la intervención de la Subsecretaría de Gestión Tecnológica y Administrativa, se fueron introduciendo otros conceptos y valores, además de habérsele otorgado al proyecto una mayor consistencia.

Si se toma en cuenta el cuadro siguiente, mientras que en el proyecto elaborado por la Secretaría Ejecutiva de Gobierno Electrónico, palabras asociadas al mejoramiento de los servicios existentes, tales como eficiencia, optimización, rapidez, eficacia y seguridad tenían una importancia preponderante respecto otros aspectos, luego de la intervención de la Subsecretaría de Gestión Tecnológica y Administrativa aparecieron otro tipo de preocupaciones, como las referidas a los aspectos organizativos aunque sin aumentar el porcentaje de palabras asociadas a la innovación y participación de los servicios, tales como confiabilidad, transparencia, calidad e inteligencia.

\section{Cuadro 36 - Cantidad de palabras por versión}

\begin{tabular}{|c|c|c|c|c|c|c|}
\hline & & $\begin{array}{c}1^{0} \\
\text { proyecto }\end{array}$ & $\begin{array}{c}2^{\circ} \\
\text { proyecto }\end{array}$ & $\begin{array}{c}\mathbf{3}^{\mathbf{0}} \\
\text { proyecto }\end{array}$ & $\begin{array}{c}4^{0} \\
\text { proyecto }\end{array}$ & $\begin{array}{l}\text { Decreto } \\
\text { definitivo }\end{array}$ \\
\hline \multirow{5}{*}{$\begin{array}{l}\text { Innova- } \\
\text { ción/Parti } \\
\text { cipación }\end{array}$} & Confiabilidad & - & 1 & - & - & - \\
\hline & Transparencia & 1 & 1 & 2 & 2 & 2 \\
\hline & Calidad & 1 & 1 & 1 & 1 & 1 \\
\hline & Inteligencia & 1 & 1 & 1 & 1 & - \\
\hline & SUBTOTAL & $3(42,8 \%)$ & $4(28,5 \%)$ & $4(30,7 \%)$ & $4(28,5 \%)$ & $3(23 \%)$ \\
\hline \multirow{6}{*}{$\begin{array}{l}\text { eficiente- } \\
\text { zación }\end{array}$} & Eficiencia & 1 & 1 & 1 & 1 & 2 \\
\hline & Optimización & 1 & 1 & 1 & 1 & 1 \\
\hline & Rapidez & 1 & 1 & 1 & 1 & 1 \\
\hline & Eficacia & 1 & 2 & 2 & 2 & 2 \\
\hline & Seguridad & 1 & 2 & 1 & 2 & 1 \\
\hline & SUBTOTAL & $5(71,4 \%)$ & $7(50 \%)$ & $6(46,1 \%)$ & $7(50 \%)$ & $7(53,8 \%)$ \\
\hline \multirow{4}{*}{$\begin{array}{l}\text { Organi- } \\
\text { zativas }\end{array}$} & Progresividad & - & 1 & 1 & 1 & 1 \\
\hline & Centralización & - & 1 & 1 & 1 & 1 \\
\hline & Coordinación & - & 1 & 1 & 1 & 1 \\
\hline & SUBTOTAL & $-(0 \%)$ & $3(21,4 \%)$ & $3(23 \%)$ & $3(21,4 \%)$ & $3(23 \%)$ \\
\hline
\end{tabular}




\begin{tabular}{|l|l|l|l|l|l|}
\hline TOTAL & 7 & 14 & 13 & 14 & 13 \\
\hline $\begin{array}{l}\text { Cant. de palabras } \\
\text { totales del Decreto }\end{array}$ & 163 & 445 & 620 & 620 & 620 \\
\hline
\end{tabular}

Fuente: Elaboración propia.

El proyecto se aprobó como Decreto No 196/06, en Acuerdo General de Ministros, y estableció varias competencias para la Secretaría General de la Gobernación. Como autoridad de aplicación, coordinaría las acciones tendientes a la puesta en marcha del SIEP y se encuentra facultada para:

- $\quad$ establecer el cronograma de implementación, acordando sus modalidades con las jurisdicciones competentes por materia;

- aprobar los Manuales de Procedimiento para habilitar su funcionamiento, una vez concluida la Prueba Piloto;

- acordar con los Organismos de la Administración Pública Provincial su incorporación al sistema, dentro de un plazo máximo de ciento veinte (120) días corridos;

- celebrar convenios con personas físicas o jurídicas que posean los medios electrónicos aptos para su implementación;

- establecer los criterios de obligatoriedad de control de validez y uso de los comprobantes por parte de los organismos recaudantes, según su monto y tipo de trámite asociado.

Se estableció la obligatoriedad para los organismos de la Administración Pública Provincial, centralizada, descentralizada y autárquica que recauden cualquiera de las tasas administrativas, servicios, aranceles, multas o contribuciones incluidas en el SIEP, que dispongan en los lugares previstos para atención al público del equipamiento informático adecuado para facilitar al ciudadano la carga e impresión de sus comprobantes de pago, así como la responsabilidad de incorporar en la Guía Única de Trámites (GUT) los valores actualizados de las tasas que estén autorizados a recaudar. Con ello, se está dando un paso hacia las "Centrales de Atención al Público".

El funcionamiento del sistema, a diferencia del SINBA, supone una fuerte tarea de reorganización interna.

Conforme el Convenio suscripto, el Banco Provincia percibirá el monto de los trámites de la Provincia por medio de la lectura de un código de barras por ella confeccionado y procederá a su inmediata acreditación en la cuenta fiscal asignada. La definición de los trámites habilitados para su percepción mediante el SIEP, es determinada exclusivamente por la Provincia.

El Banco percibirá en pesos el importe a través de todas sus filiales, sucursales y agencias de los sistemas Bapro Pagos y Pagos Link y de su Home Banking, actuando únicamente como agente de percepción de los fondos.

Se establece asimismo que los Organismos se incorporarán al SIEP en la modalidad y en el plazo en que la Subsecretaría de Gestión Tecnológica y Administrativa acuerde con cada uno de ellos, siendo la Secretaría Ejecutiva de 
Gobierno Electrónico la encargada de controlar la realización de las gestiones que conforman el circuito interno del sistema.

\section{c) La GUT}

Con la oferta de buenos servicios y claros contenidos por Internet, es posible acelerar sustancialmente estas nuevas herramientas a muchos más usuarios. Pero las políticas de gobierno electrónico que no salen a buscar a los usuarios, a la espera de que ellos mismos accedan a los beneficios, no suelen ser exitosas. Es necesario luchar contra las costumbres, los usos y los hábitos, "captando" a un público que no es usuario frecuente de las TIC. Sólo así surgirán los beneficios más esperados, un servicio más cohesionado y cercano a los usuarios, que genere una acción de gobierno más transparente (Piana, 2007).

La Guía Única de Trámites (GUT), impulsada por la Secretaría Ejecutiva de Gobierno Electrónico es un caso testigo de los magros resultados que se obtienen con una política sin participación, sin difusión y con mala organización interna.

El Decreto No 184/03 del 18 de febrero de 2003 creó la Guía Única de Trámites de la Provincia de Buenos Aires con el objetivo de establecer una herramienta electrónica única para mejorar la atención de los ciudadanos, usuarios y empresas y canalizar inquietudes acerca de los requisitos necesarios para completar trámites "con información clara, pertinente y eficaz". Como se menciona en sus Considerandos, dicho Decreto se formuló en el marco del Plan Estratégico de Gobierno Electrónico.

Como argumentaciones centrales del Decreto, se señalan la deficiencia de la información y la consecuente incertidumbre como un obstáculo para la generación de negocios, ingresos y empleo. Expresamente se sostuvo:

- Que ... es un compromiso de la actual gestión de Gobierno de la Provincia de Buenos Aires, privilegiar un contacto más ágil entre los usuarios y los organismos gubernamentales a partir de una facilitación de las tramitaciones;

- Que ... resulta prioritario que los organismos públicos realicen las acciones conducentes para la atención de la ciudadanía simplificando los trámites, reduciendo el papeleo innecesario proveyendo a la rápida captación y eficiente uso de la información, limitando los requisitos innecesarios a través de la informatización y la seguridad de la información;

- Que el avance actual de las comunicaciones en general debe permitir ofrecer a la ciudadanía información clara, concisa y disponible de inmediato;

- Que el Gobierno está empeñado en dotar a la provincia de una administración que sea ágil, eficiente y dinámica; por lo que es preciso superar obstáculos tales como los plazos excesivos o indeterminados de decenas de trámites públicos que colaboran en la lentitud de la administración, provocando en algunos casos incertidumbre en los ciudadanos y perjudicando posibilidades de nuevos negocios, ingresos fiscales y generación de empleo; 
- Que la creación de la Guía Única de Trámites responde a todos los objetivos enunciados constituyéndose en una herramienta fundamental para mejorar la atención de los ciudadanos; ${ }^{248}$

Los principios que surgen del artículo $1^{\circ}$ del Decreto son la transparencia y simplicidad de la gestión con el fin de asegurar a los administrados el acceso a información completa, fehaciente y actualizada para la realización de todo tipo de trámites ante la Administración Pública Provincial centralizada y descentralizada y entidades autárquicas provinciales que deban ser cumplidos por los particulares, personas físicas o jurídicas. Se excluyen expresamente los trámites de carácter interno (G2G).

La GUT debía estar disponible para su acceso en forma libre e irrestricta a través del Portal de la Provincia de Buenos Aires en Internet. Para ese fin, se dispone que las jurisdicciones deban arbitrar los medios necesarios para permitir el acceso a la Guía Única de Trámites de la Provincia de Buenos Aires desde el equipamiento informático de los organismos y/o dependencias.

A los fines de la organización del sistema, la norma determinó que sean los Organismos quienes deban informar la totalidad de los trámites que tengan a su cargo y el funcionario encargado de "cargar" al sistema los trámites, formularios y la información asociada a cada uno de ellos. ${ }^{249}$

Con el fin de superar los obstáculos señalados en los considerandos del Decreto, la norma prescribe que la información se publicará en forma completa con los contenidos mínimos requeridos para la normalización y unificación de información según el modelo de formulario que forman parte del Anexo II del Decreto. Conforme surge de los datos requeridos por dicho Anexo, la información solicitada al funcionario para que cargue el trámite es completa. ${ }^{250}$

El diseño de la página a la que se podía acceder, efectivamente, desde el portal, intenta seguir un diseño amigable para el usuario ${ }^{251}$.

\footnotetext{
248 Los destacados nos pertenecen.

249 Así, cada jurisdicción u organismo es responsable de verificar la exactitud y pertinencia de la información publicada.

250 El Anexo, requería y estandarizaba, como mínimo, la siguiente información por trámite: a) Nombre del Trámite; b) Tema; c) Categoría; d) ¿Qué es? ¿De qué se trata?; e) ¿Para quién es?; f) ¿Quién lo puede realizar?; g) ¿Qué necesito para hacer el trámite?; h) ¿Cuánto demoro en hacerlo?; i) ¿Cuánto demoro en obtenerlo?; j) ¿Cómo recibo el resultado o producto del trámite?; k) ¿Cuánto cuesta?; l) ¿Dónde lo puedo hacer?; m) Horario de Atención Horarios; n) Horario y/o días y/o periodos de menor concurrencia; o) Canal de relación: Ampliación de Información, seguimiento y reclamo; p) Observaciones; q) Trámites relacionados; r) Organismo responsable; s) Fecha última actualización; t) Reemplaza a; u) Actualizado

${ }^{251}$ Luego de más de cinco años de ejecución, sólo cambió un poco el diseño, pero nada más.
} 


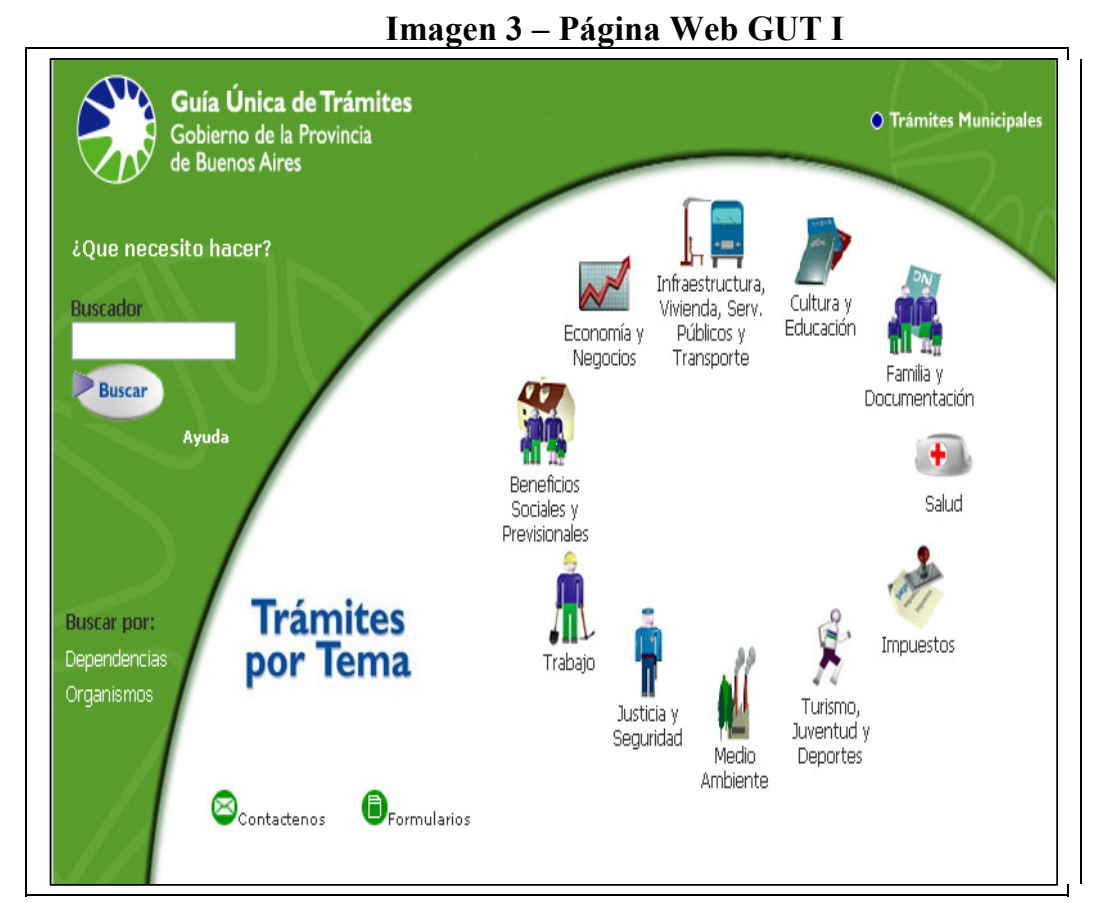

Fuente: http://sistemas.gba.gov.ar/consulta/guiatramites/ Fecha de Consulta: 1/04/06.

Lo más sencillo es buscar el trámite deseado en la página principal de la guía, específicamente en trámites por tema. Aquí los diferentes trámites se encuentran divididos de acuerdo a su temática. Posicionando el mouse sobre cada una de los temas se despliega el listado de trámites correspondiente.

Sobre la izquierda de la página se encuentra la leyenda “¿Qué necesito hacer?”, haciendo click sobre ésta se despliegan varias opciones, como se muestra en la imagen siguiente.

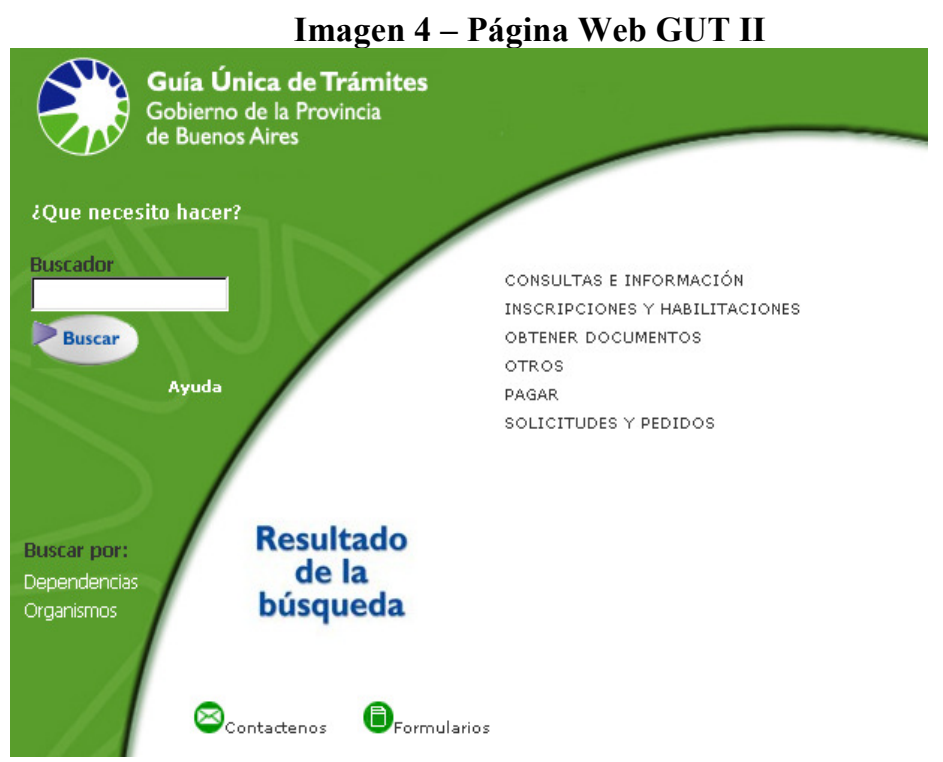

Fuente: http://sistemas.gba.gov.ar/consulta/guiatramites/ Fecha de Consulta: 1/04/06. 
Haciendo un click sobre alguna de las opciones se despliegan todos los trámites incluidos en esa opción.

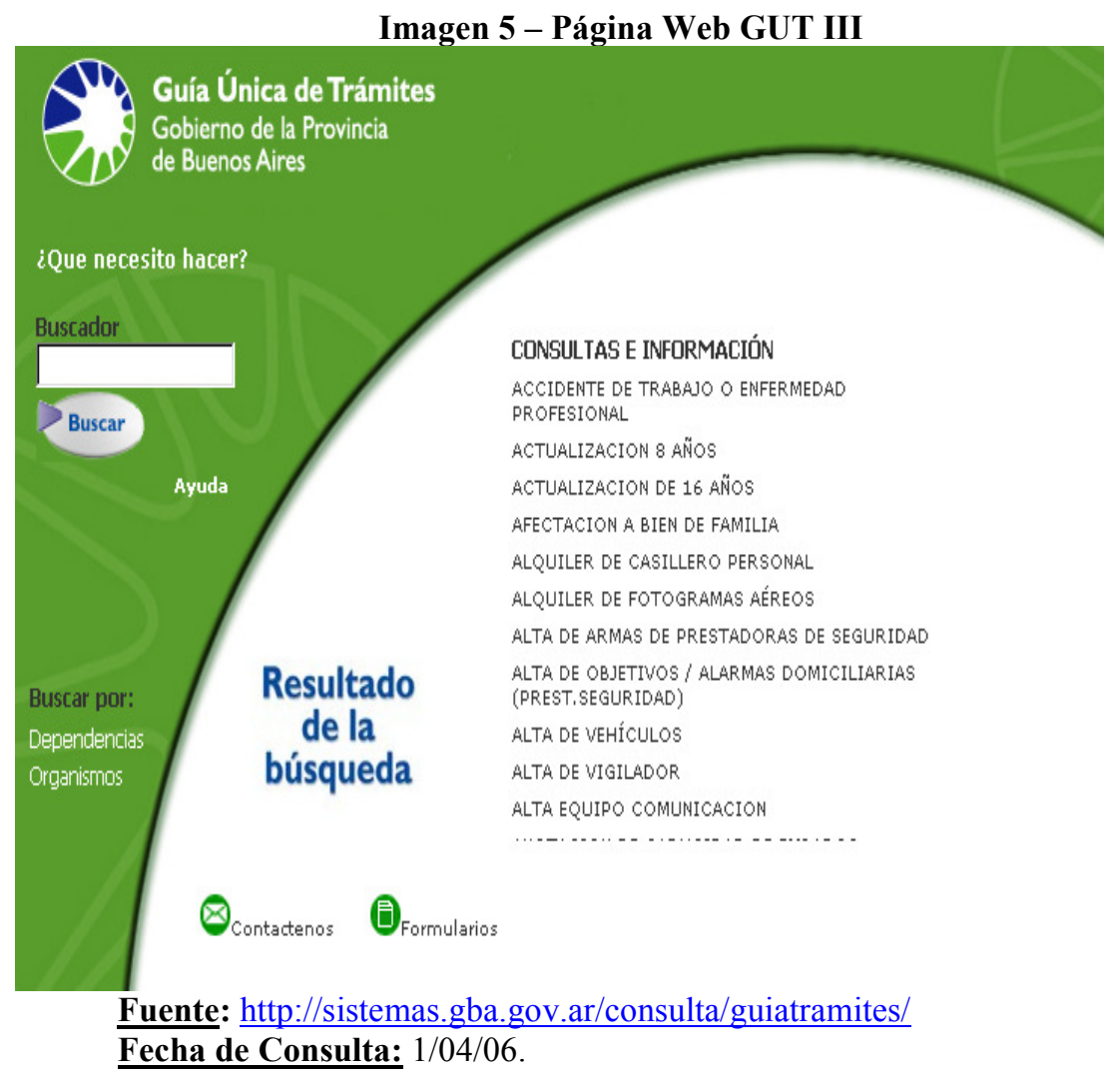

Pese a que se intentó agrupar los temas conforme eventos de vida, los subtemas demuestran su vinculación con las áreas organizativas. En efecto, desde el momento en que cada trámite es asociado a un organismo particular, se pierde la lógica de la organización de temas en torno a los eventos de vida ${ }^{252}$. Justamente, los eventos de vida no respetan la lógica de la organización ministerial pues son trascendentes y multidimensionales.

Cada uno de los temas se rotula, a su vez, en diferentes categorías de trámites:

$\begin{array}{ll}- & \text { Consultas e Información } \\ \text { - } & \text { Inscripciones y Habilitaciones } \\ \text { - } & \text { Solicitudes y Pedidos } \\ \text { - } & \text { Obtener documentos } \\ \text { - } & \text { Pagar } \\ \text { - } & \text { Otros }\end{array}$

Las estadísticas del sitio demuestran que para abril de 2006, última fecha en la que se tuvo acceso a los datos, la página de la GUT recibió un total de 933.586 visitas en casi

\footnotetext{
${ }^{252}$ Ejemplos de eventos de vida son: "me quiero casar", "quiero abrir una empresa", "me mudé", "voy a tener un hijo", etc.
} 
treinta meses de funcionamiento, cifra muy baja si se tiene en cuenta que la Provincia de Buenos Aires, para esa fecha, registraba una población de más de 13.800 .000 de habitantes. ${ }^{253}$

\section{Gráfico 10 - Accesos a la página del GUT}

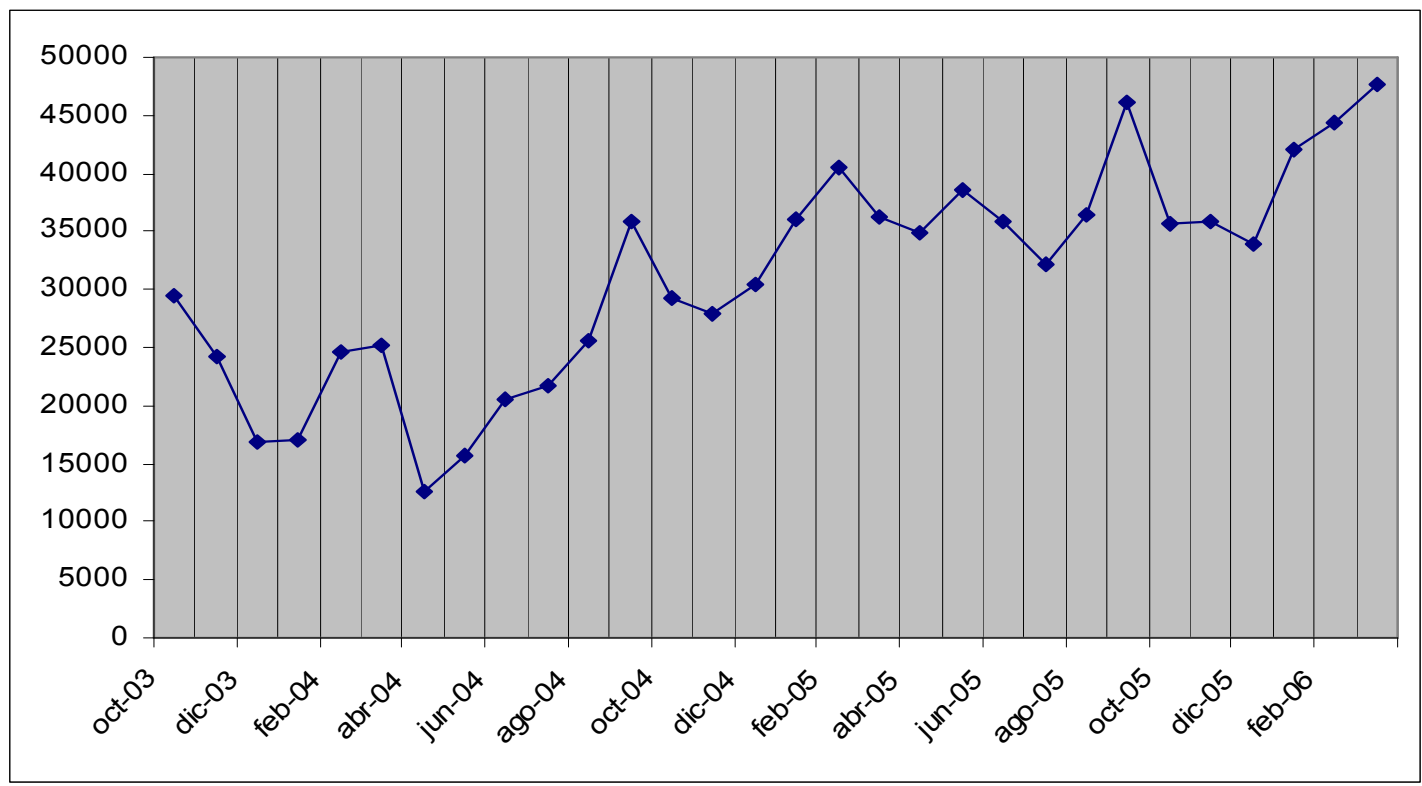

Fuente: Elaboración propia sobre la base de los datos del sistema.

Fecha de Consulta: 1/04/06.

En treinta meses de funcionamiento, se recibieron tan sólo 15.977 correos electrónicos. Del análisis de la distribución de los correos en los meses de funcionamiento no surge que haya habido una demanda acumulativa. En efecto, si bien durante todo 2005 aumentó la cantidad de correos recibidos en casi el doble (4460 y 8615 respectivamente), la cantidad de correos recibidos en el primer trimestres de 2006 es menor a la del primer trimestre de 2005 (1966 y 2565 respectivamente).

\footnotetext{
253 Si bien la página estuvo disponible desde julio de 2003, los pocos accesos demuestran que aún no había sido lanzada la campaña de difusión ni la carga de los datos. Por ello se han tomado los datos desde octubre de 2003 .
} 


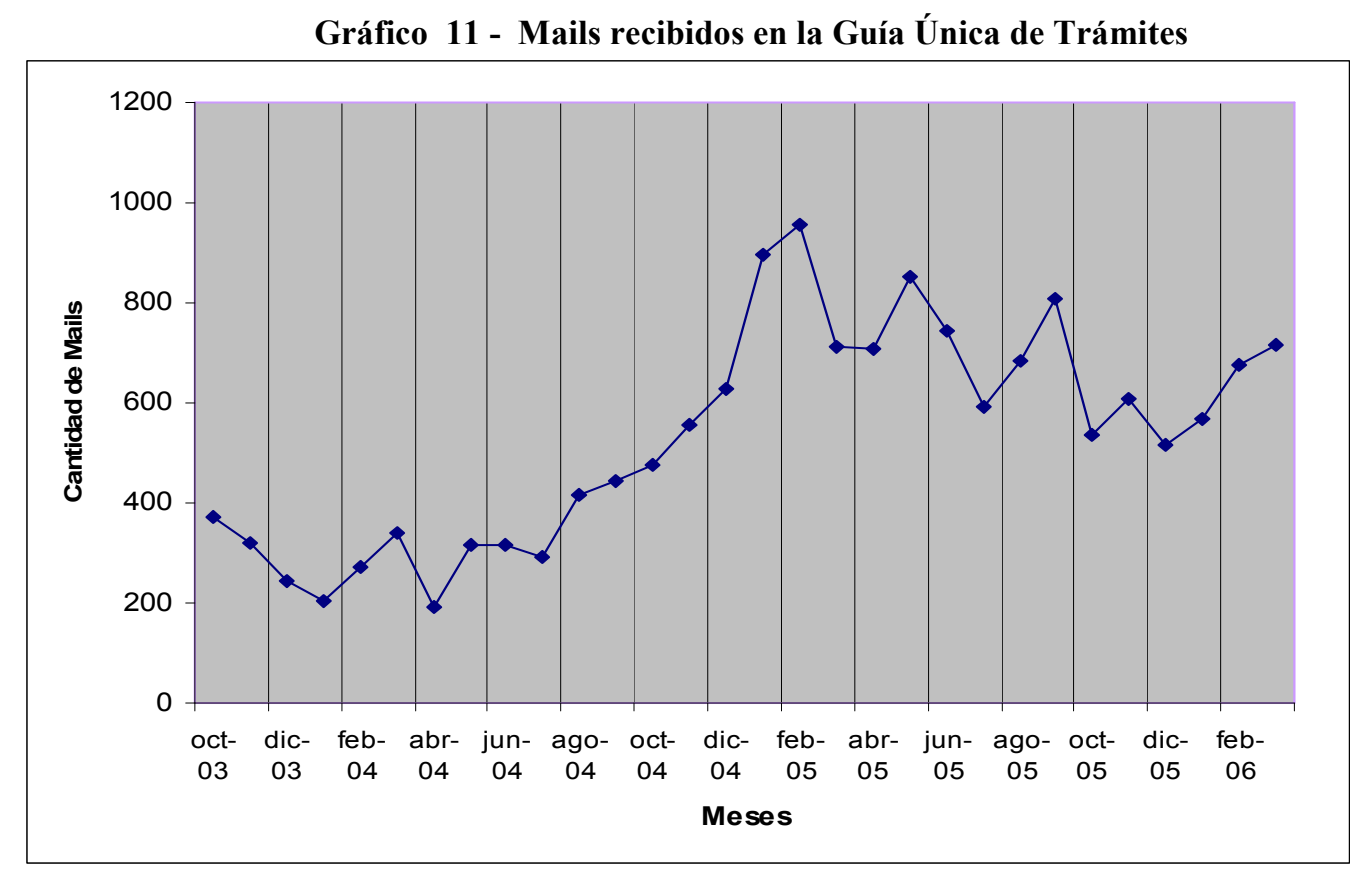

Fuente: Elaboración propia sobre la base de los datos del sistema.

La falta de difusión puede ser una explicación de los bajos resultados hasta ahora alcanzados en este buen sistema de información. Se detecta, además, la falta de participación de los beneficiaros del sistema, quienes mejor que nadie pueden sugerir los eventos de vida trascendentes. Pero se suma otra causa: según un informante clave, la organización del Back Office del sistema puede ser una de las concausas que explica sus resultados. Conforme los términos del Decreto, todos los comentarios, quejas y sugerencias realizados a través de un formulario habilitado a tal efecto en el Portal debían ser remitidos a los funcionarios provinciales responsables del trámite respectivo mientras que los mensajes referidos a la Guía y a su contenido en general debían ser respondidos por la Secretaría de Modernización del Estado, subsumida luego en la Secretaría General de la Gobernación. Se señalaba que las quejas, comentarios, sugerencias deberían ser respondidos con un acuse de recibo en un plazo máximo de dos (2) días desde su recepción por el funcionario responsable y en un plazo máximo de siete (7) días posteriores deberá darse la respuesta sustantiva si correspondiere.

Ahora bien, a la fecha de cerrar la investigación en esta área, se encargaban de esta tarea sólo 2 personas (marido y mujer) quienes desde la entonces Dirección Provincial de Informática y Comunicaciones asumían la tarea de recibir cada uno de los correos y contestarlos, si la respuesta estaba en la propia página del GUT, o bien remitirla a los organismos encargados de cargar la información cuando no eran suficiente. Esto generaba, sin dudas, un retraso y redundancia en las respuestas que no se condicen con el espíritu de la norma.

La falta de interés de los organismos, la ausencia de mecanismos de control y el poco peso propio de la Secretaría Ejecutiva de Gobierno Electrónico, es otra de las razones para explicar por qué existían tan pocos formularios cargados en el sistema y tan pocos usuarios del sistema. 


\section{Análisis cualitativo y cuantitativo de las páginas web}

Según el análisis del estado de situación realizado al momento de aprobar el Plan Estratégico de Gobierno Electrónico de la Provincia de Buenos Aires en 2002, los diferentes organismos de la Provincia habían desarrollado una enorme cantidad de aplicaciones y sitios de Internet; la mayoría de ellos fueron elaborados para brindar información institucional.

Entre ellos se mencionan como ejemplos la página web del Poder Ejecutivo Provincial, la página web de Rentas, entonces organismo de recaudación perteneciente al Ministerio de Economía; la página web Portal ABC perteneciente a la Dirección General de Escuelas, la página web de Compre Bonaerense perteneciente al Ministerio de la Producción, la página web del Instituto Provincial de Seguridad Social, la página web del Ministerio de Salud, la página web de la Contaduría General de la Provincia.

Se afirmaba que estos proyectos se han generado internamente, a veces sin participación ni objetivos de las autoridades políticas pretendiendo responder a las necesidades del organismo o de alguna de sus Direcciones.

Por ser páginas generadas en forma interna, no contemplan el uso compartido de sistemas similares de otros organismos y son habitualmente soluciones ad hoc que no tienen en cuenta la interacción con otros organismos provinciales, municipales o nacionales (Decreto $\mathrm{N}^{\mathrm{o}}$ 1.824/02, Anexo, página 12).

Según el Decreto, desde el paradigma del gobierno electrónico, esas páginas web son evidentemente incompletas pues solamente resuelven algunas etapas del proceso que debe completar el usuario ya que se limitan al interior de los organismos que las implantaron.

Así, un análisis del inventario de estas aplicaciones a inicios de 2002, según el mismo decreto, revelaba que no necesariamente respondían a las necesidades del Estado provincial en su conjunto $\mathrm{y}$, menos aún, a los requerimientos y demandas de los habitantes. ${ }^{254}$

¿Qué sucedió desde entonces? Luego del diagnóstico, ¿siguieron respondiendo a esa misma realidad o buscaron cumplir el "paradigma del gobierno electrónico"?

Poco tiempo después de la aprobación del Plan Estratégico de Gobierno Electrónico, a través del expediente $\mathrm{n}^{\mathrm{o}}$ 2156-25/02 la entonces Secretaría para la Modernización del Estado propició un Decreto por medio del cual se estableció el uso

\footnotetext{
254 Específicamente, a través de dichos objetivos generales, se intentaba desarrollar la estrategia de los portales de la Provincia para difundir las actividades del gobierno provincial y sus dependencias, informar a los habitantes sobre los servicios y trámites que presta la Provincia y los requerimientos para realizarlos, permitir a los habitantes requerir información, realizar trámites y pagar impuestos en forma remota, habilitar nuevos canales de comunicación entre los ciudadanos y las autoridades políticas y habilitar nuevos medios de participación ciudadana.
} 
de una imagen institucional única para la Administración Pública de la Provincia. Esta imagen institucional estará asociada al Gobierno de Felipe Solá.

Dicho Decreto, que lleva el No 2.835/02 del 22 de noviembre de 2002, definió la necesidad de reafirmar su identidad y facilitar su identificación por los ciudadanos, frente a la inexistencia de criterios que definan una imagen institucional propia en sus manifestaciones externas. Se señalaba que esta realidad generaba confusión y falta de identificación con lo que ha de constituir una organización homogénea en su proyección externa.

El Decreto estableció asimismo la necesidad de una nueva identificación visual que se corresponda necesariamente con un cambio en la realidad y en la propia cultura de la organización.

Según el artículo primero, la imagen institucional debía ser única para la Administración Pública de la Provincia de Buenos Aires para todos los organismos de la Administración Pública centralizada y descentralizada, entidades autárquicas y cualquier otra entidad donde la Provincia de Buenos Aires tenga participación mayoritaria en el capital o en la formación de las decisiones societarias.

Es importante destacar que el diseño de la imagen institucional única no sólo debía ser utilizada en la emisión, elaboración o utilización de documentos, material impreso, informaciones, publicaciones, comunicaciones, vehículos oficiales, así como los carteles de carácter informativo o publicitario, sino también en las páginas web de la Provincia ${ }^{255}$.

Poco tiempo después, se estableció una Guía de Estilo Institucional de Sitios Web Provinciales, basada en las normas gráficas que determina el Manual de Normas de Estilo. Según la Guía, la correcta unión de la comunicación lingüística con elementos gráficos constituye la interfase de usuario con la que "intentaremos atrapar la atención del destinatario final y ofrecerle así un servicio eficiente". A renglón seguido se establece que la interfase de usuario debe permitir que el mismo pueda navegar por nuestro sitio de forma rápida, simple y concreta, sin distracciones innecesarias.

Según la norma, la interfase gráfica del diseño de las páginas se compone de:

- El encabezamiento institucional

- El cuerpo, en donde se concentra la mayor información sobre un fondo institucional azul y otro blanco

- botones de enlaces e íconos

- banda institucional de cada organismo, la cual no deberá ser modificada ni alterada, que se insertará en la de todas las páginas del sitio.

- El pie de página, con la firma, fecha y correo electrónico del autor (en la página inicial).

\footnotetext{
${ }^{255}$ Algunos meses más tarde, a través del Decreto No $1.068 / 03$, se aprobó el Manual donde se estableció la obligatoriedad del uso de la tipografía Bliss en su variables Ligth y Bold. Sin embargo, este pequeño detalle causó no menores problemas pues la tipografía Bliss no es una de las que se encuentran por defecto en las computadoras y es necesario instalarlas en cada máquina.
} 
Según la Guía, la página inicial se presentará con un entorno gráfico sobrio y simple. Como señaláramos más arriba, la página inicial se diferencia de las secundarias por la imagen de fondo del cuerpo de página.

Todos los sitios debían contener Mapa del Sitio. Los "banner" que utilizarían los sitios de la Provincia deberán coincidir con las necesidades y prioridades comunicativas del organismo o dependencia, sin que esto se contraponga con los objetivos del gobierno provincial.

Según la misma norma, los textos debían ser siempre cortos, concretos y con un sumario descriptivo. Los textos no debían ser ni demasiado cortos ni demasiado extensos. Si los textos son extensos, se sugirió dividir la información en pocos módulos principales y éstos, a su vez, en sub-módulos. Los párrafos debían ser cortos para evitar el cansancio en la lectura de pantalla. Todo documento debía tener un título así como cada una de sus páginas.

Se estableció también que se utilizará el cuerpo 10 para el texto, a menos que el destinatario tenga problemas de visualización. Pero esta consigna hacía que los textos fueren poco legibles.

Se establecía como color para enlaces o links el gris claro para los enlaces en fondo azul y el naranja oscuro para los enlaces en fondo blanco. Esto también generaba mucho cansancio.

Hacia el final de la gestión que estamos estudiando, el Área Identidad Institucional de la entonces Jefatura de Gabinete, dictó un Manual de uso y aplicaciones gráficas de la marca institucional que expresamente se centra en el diseño de los sitios web oficiales como parte del Decreto $\mathrm{N}^{\mathrm{o}} 1.068 / 03$.

El Manual agrega a los colores oficiales (verde y azul) el gris como complemento a efectos de "enriquecer" el entorno gráfico. La tipografía continuaba siendo Verdana. Ahora la página principal sería siempre color Verde y en las secundarias, el color blanco, eliminándose el uso del isotipo como fondo. El cuerpo de letra continuaba siendo 10 aunque se admite ahora hasta el 12. 


\section{Gráfico 12 - Diseño página Web oficial}

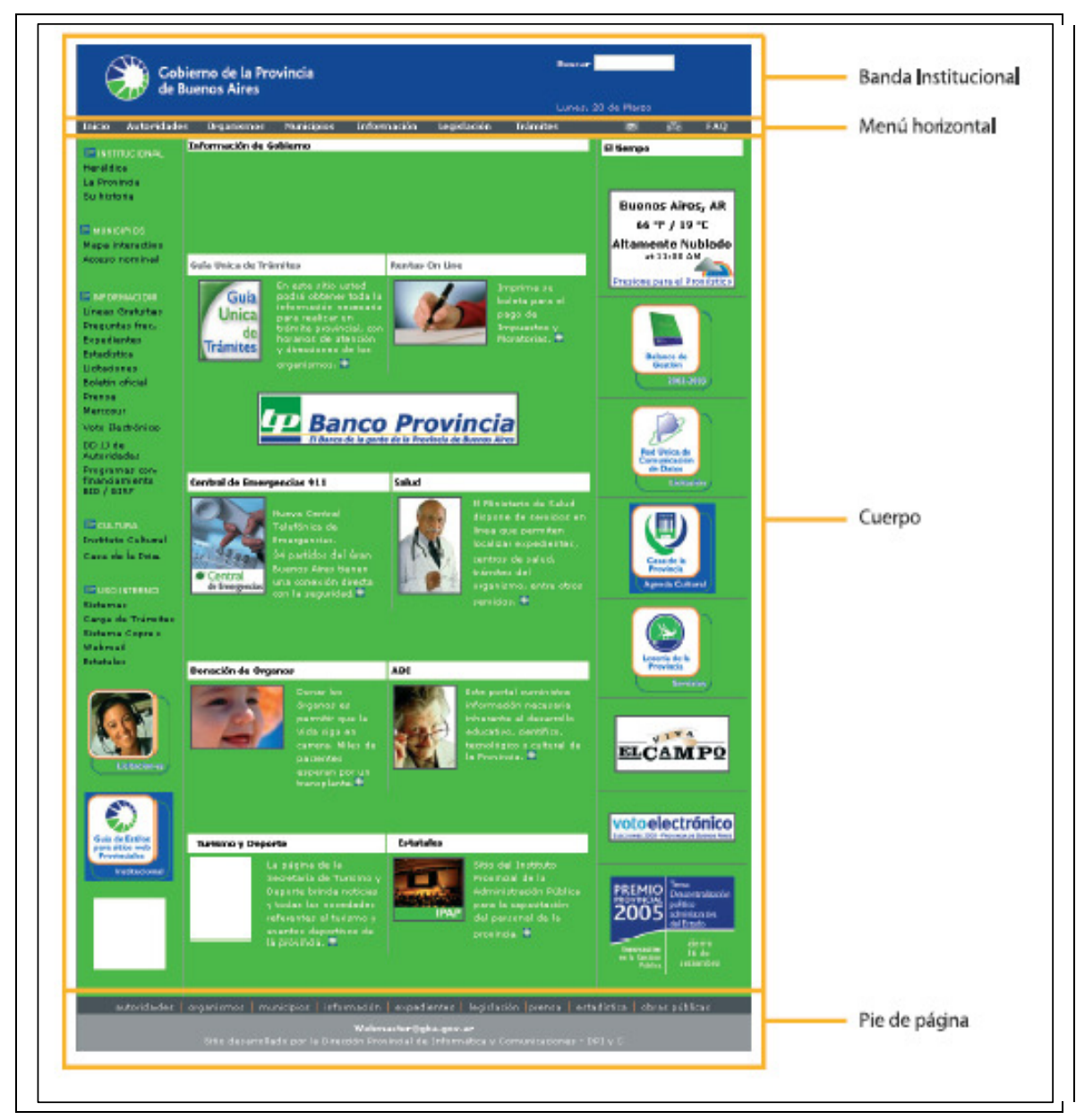

Fuente: Manual de uso y aplicaciones gráficas.

Se realizó un análisis del diseño de las páginas web oficiales de la Provincia. Atento a la gran cantidad de páginas que existen, se seleccionaron las páginas principales de los Ministerios, Secretarías y principales organismos autárquicos y de la Constitución -27 en total según la ley de ministerios vigente- ${ }^{256}$ La fecha de consulta fue entre el 9 de marzo y el 23 de marzo de $2006^{257}$.

256 Debe tenerse en cuenta que cada Subsecretaría tiene su propia página y que muchas de las más de 45 Direcciones Provinciales tenía la suya propia, sin contar a las empresas del Estado y organismos autárquicos y de la Constitución.

${ }^{257}$ Aún cuando cambió la norma, los resultados más de cinco años después, siguen siendo similares. 


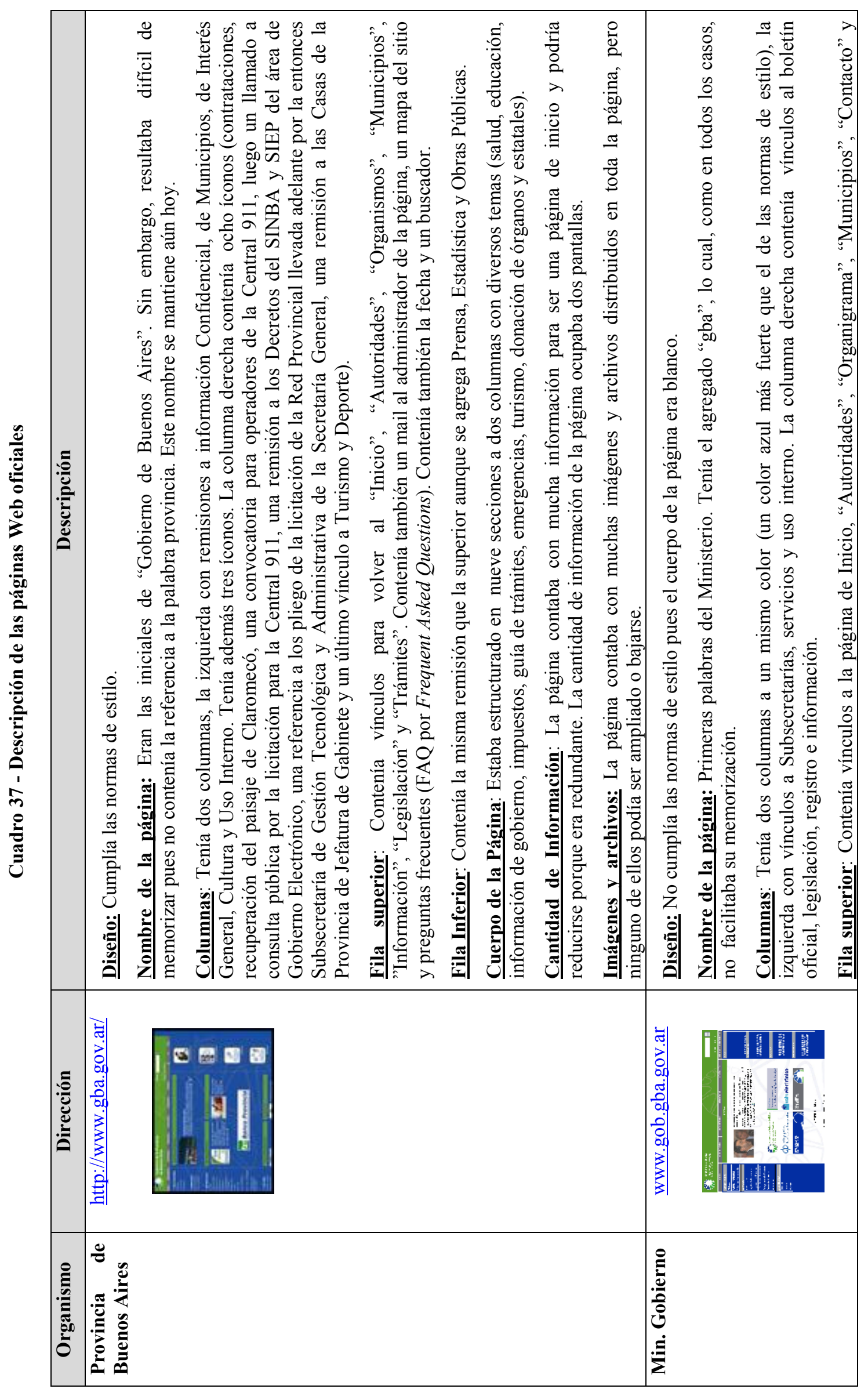




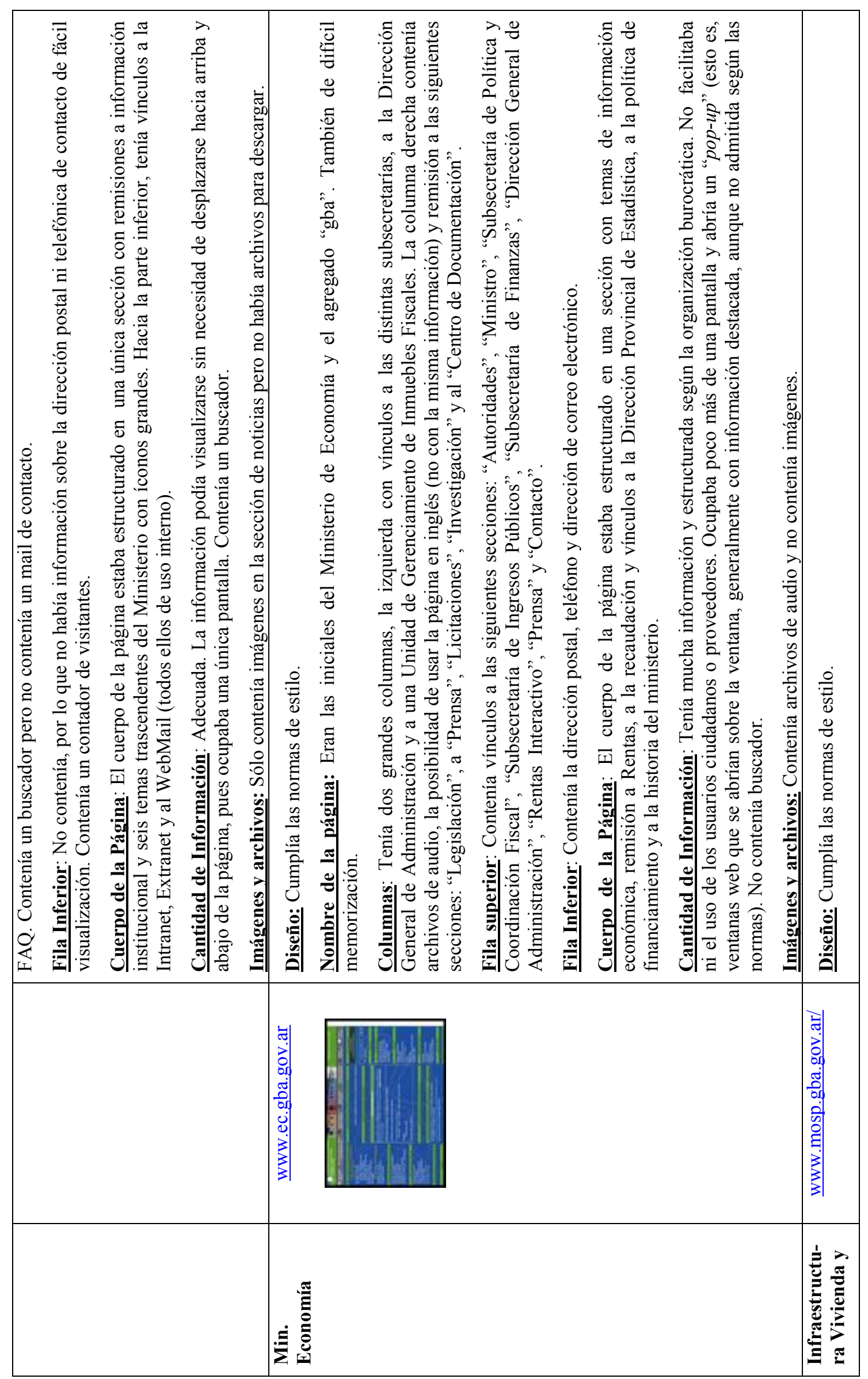




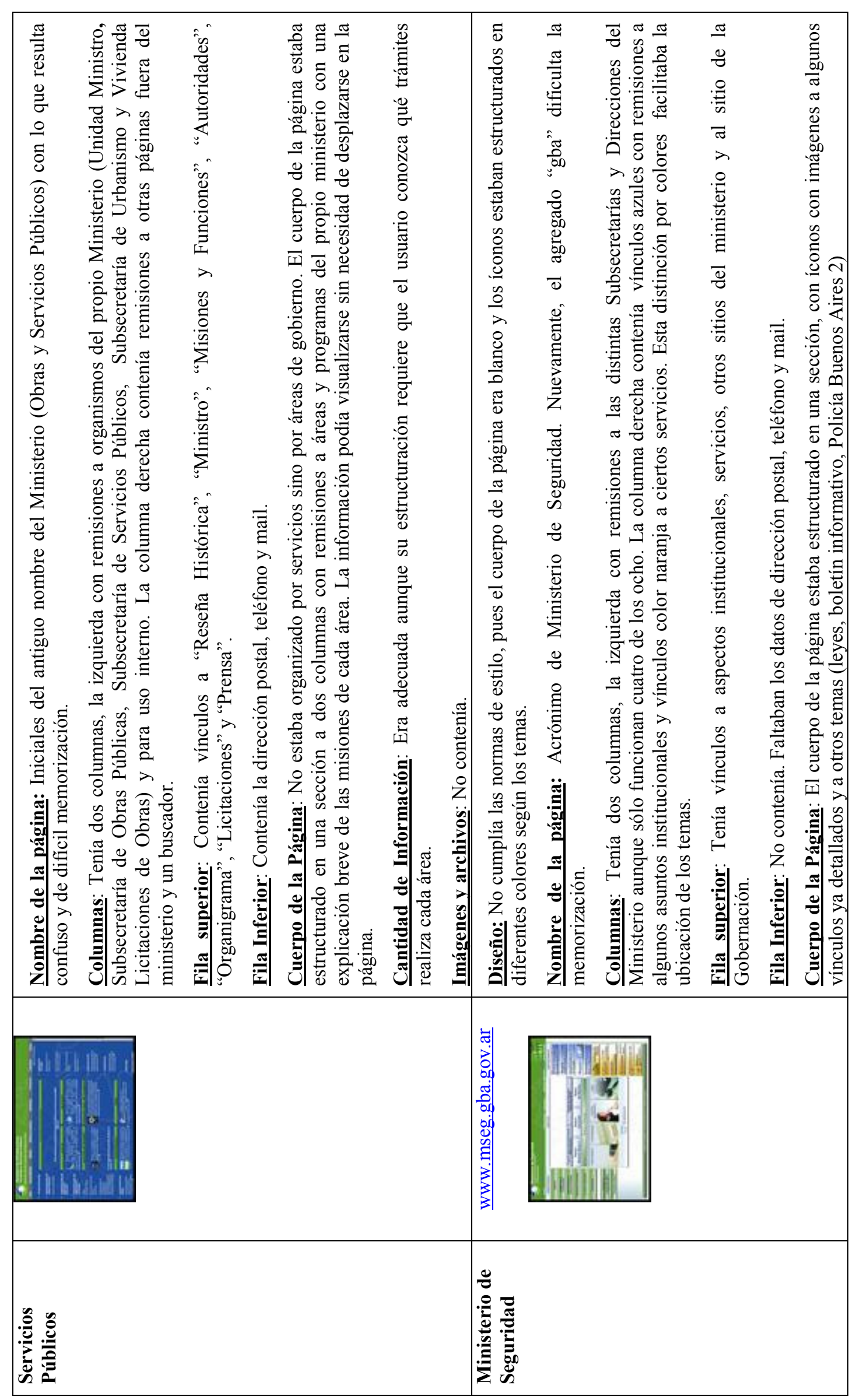




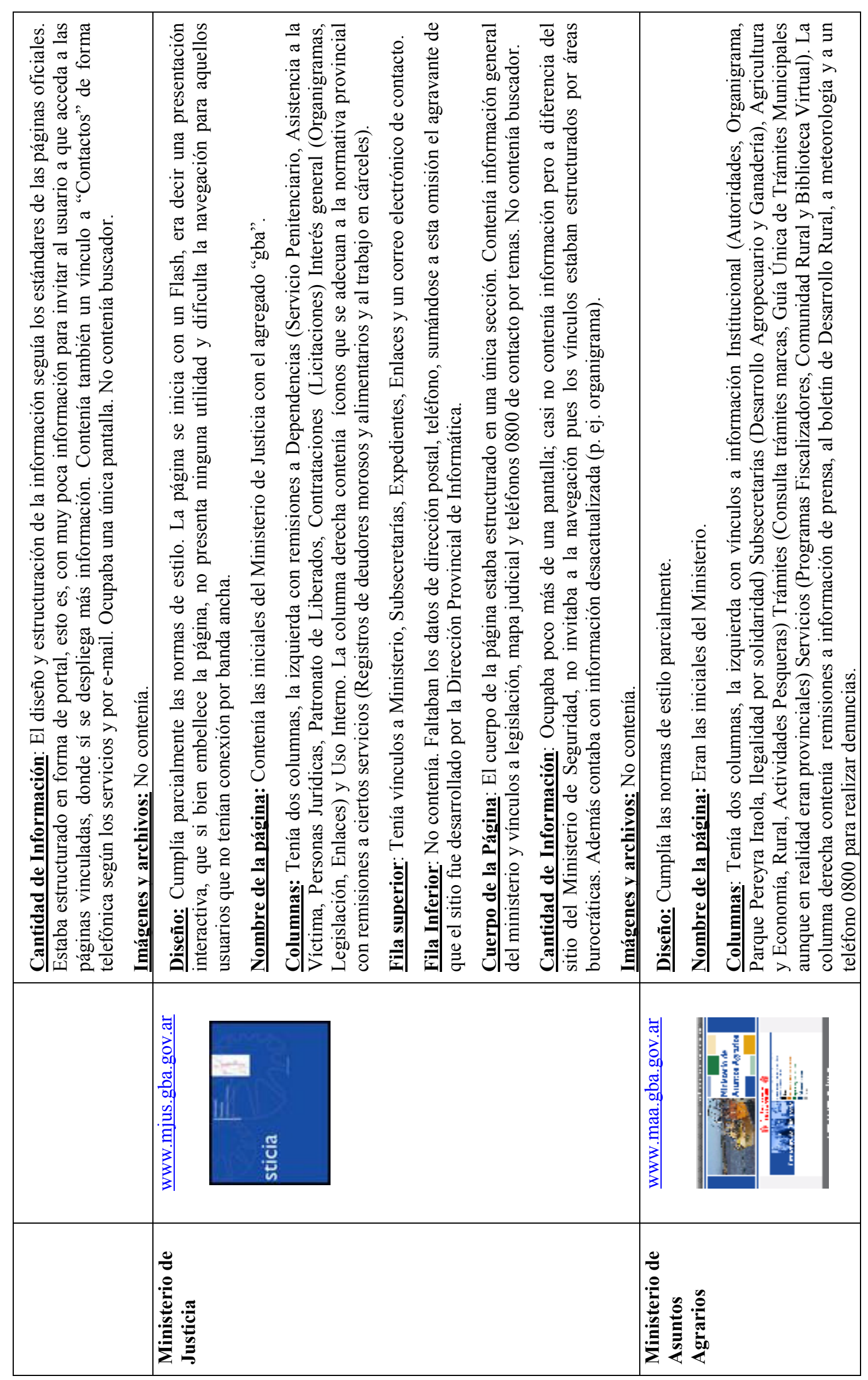




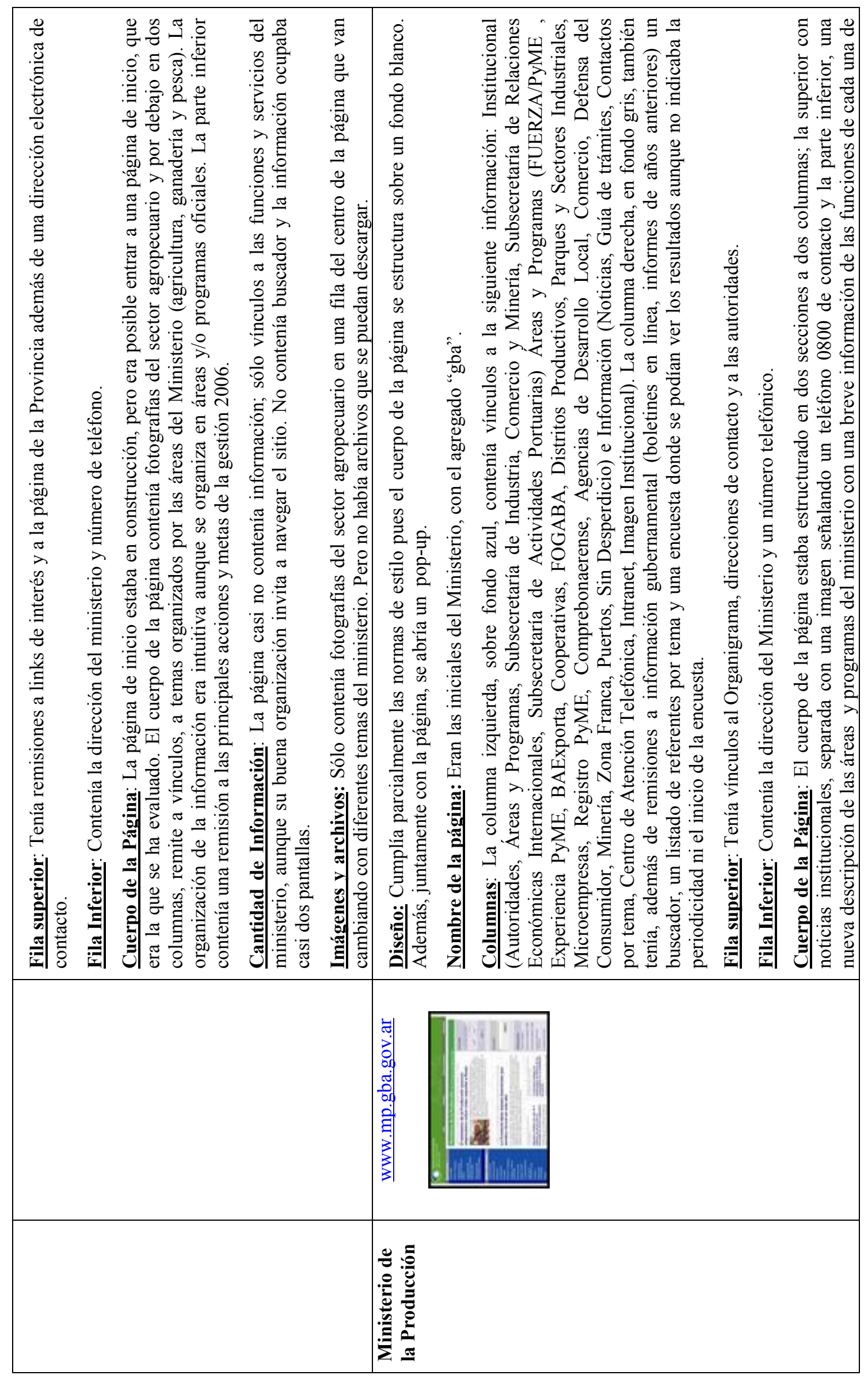




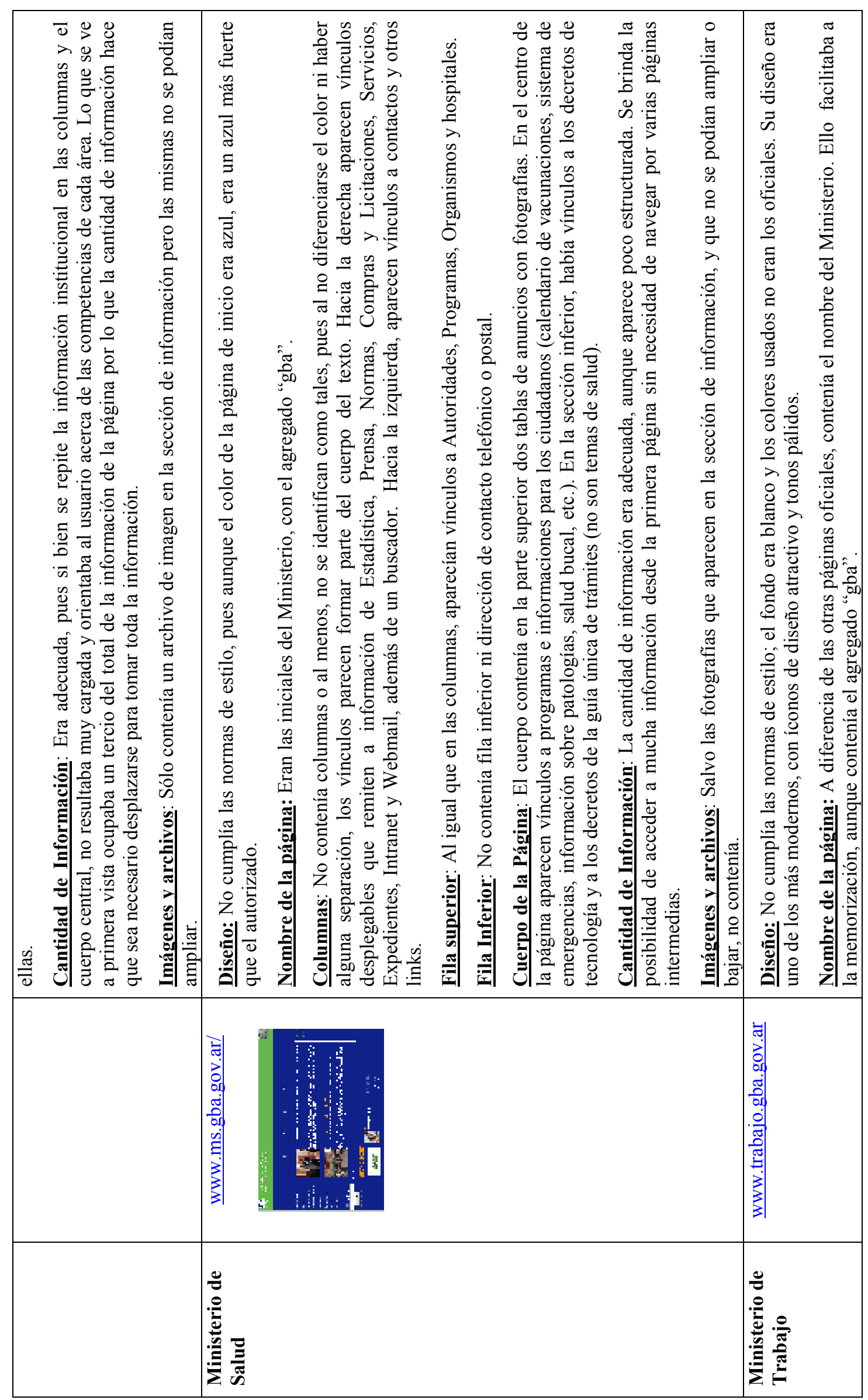




\begin{tabular}{|c|c|c|c|c|c|c|c|}
\hline 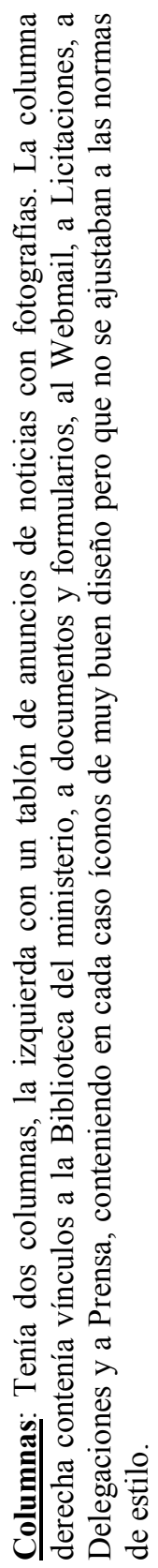 & 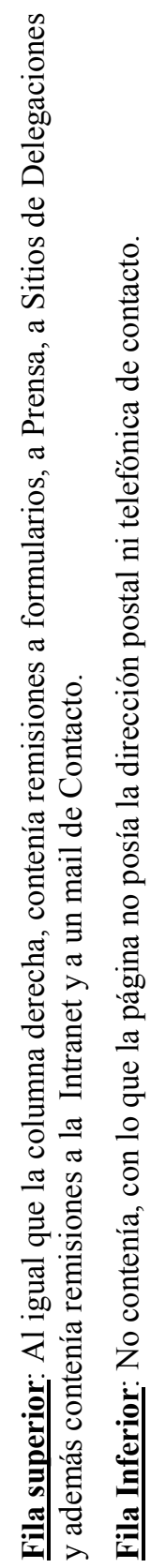 & 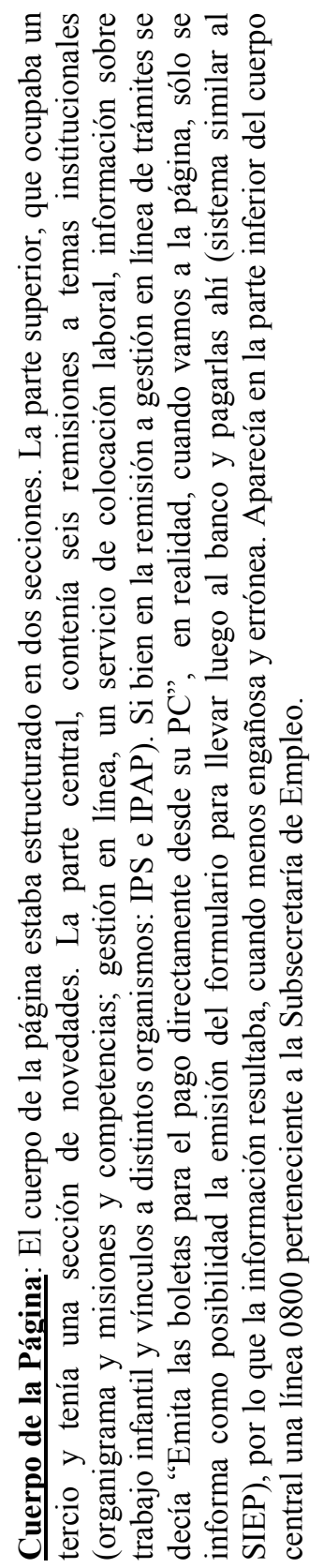 & 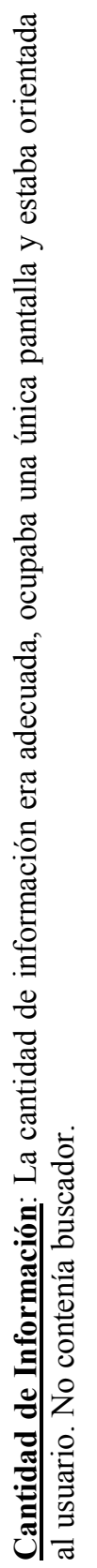 & 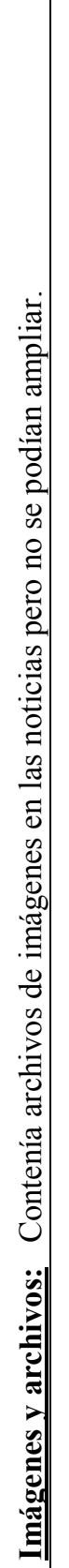 & 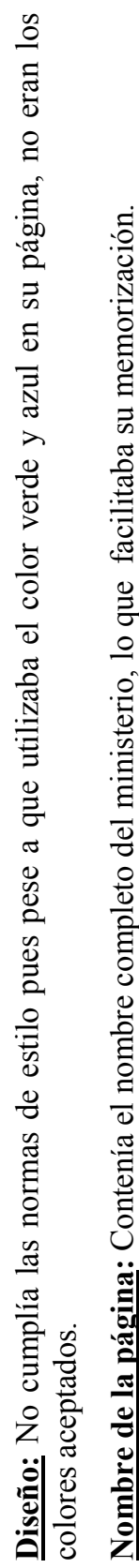 & 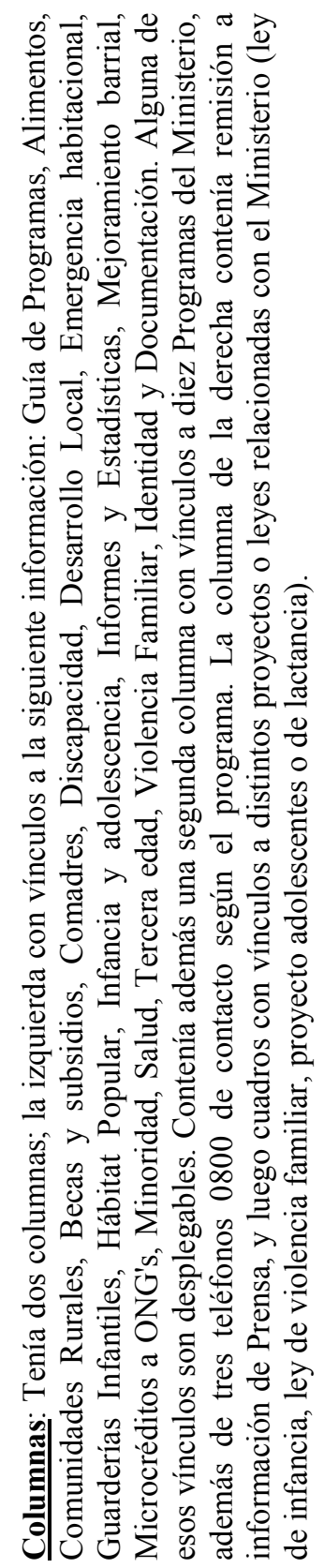 & 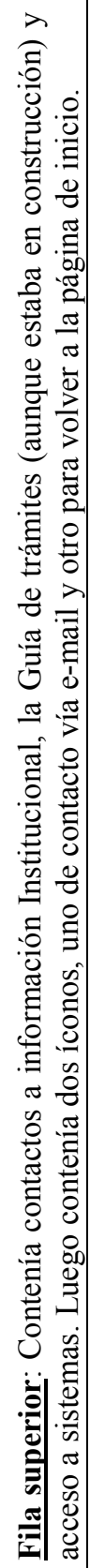 \\
\hline a & & & & & 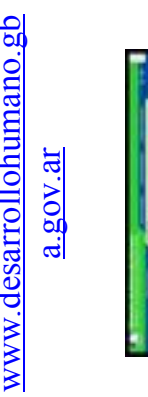 & $\frac{\mid \frac{3}{31}}{(n-2)}$ & \\
\hline & & & & & 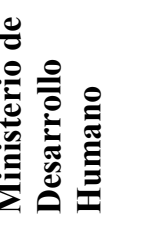 & & \\
\hline
\end{tabular}




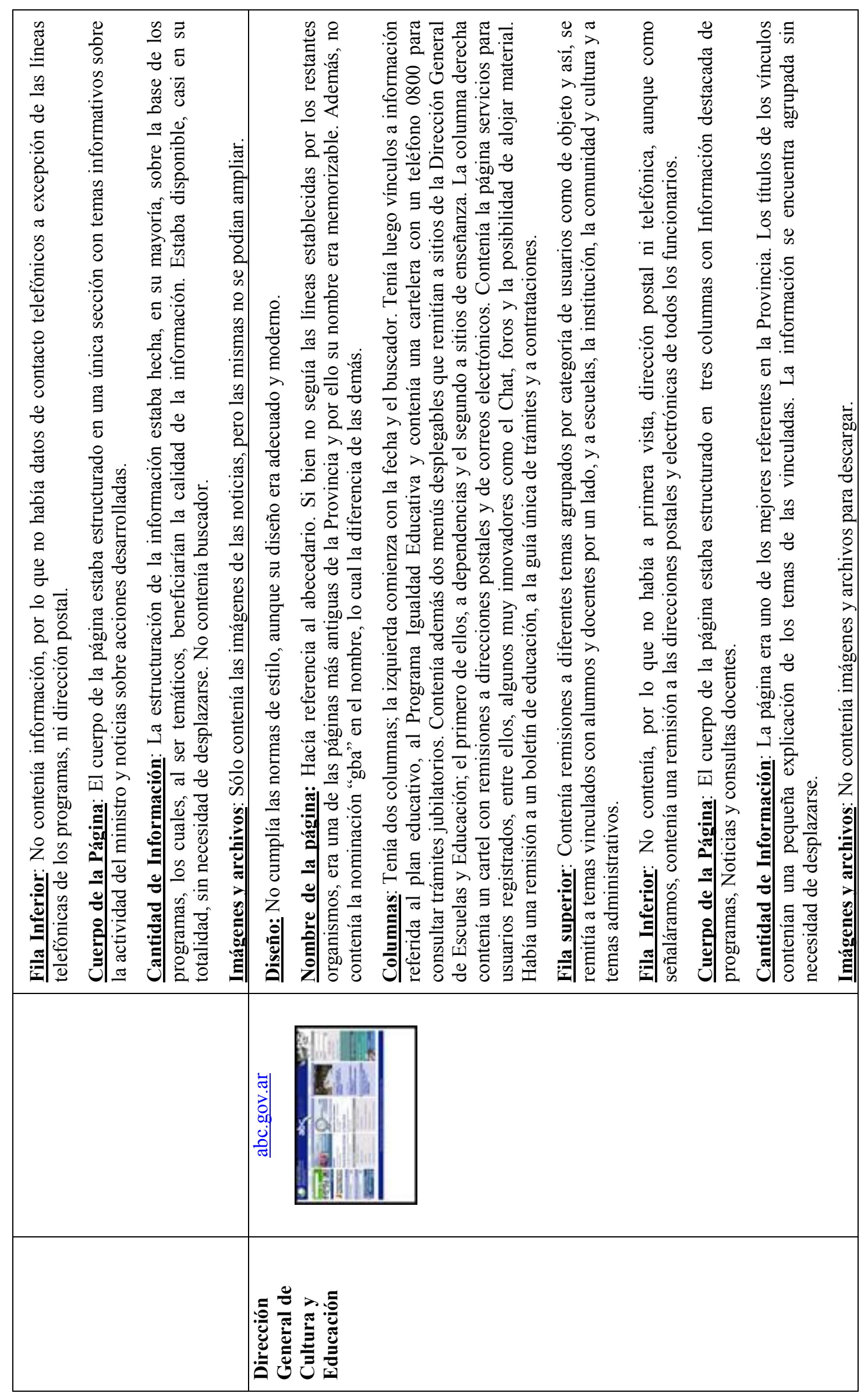

$\underset{\infty}{\infty}$ 


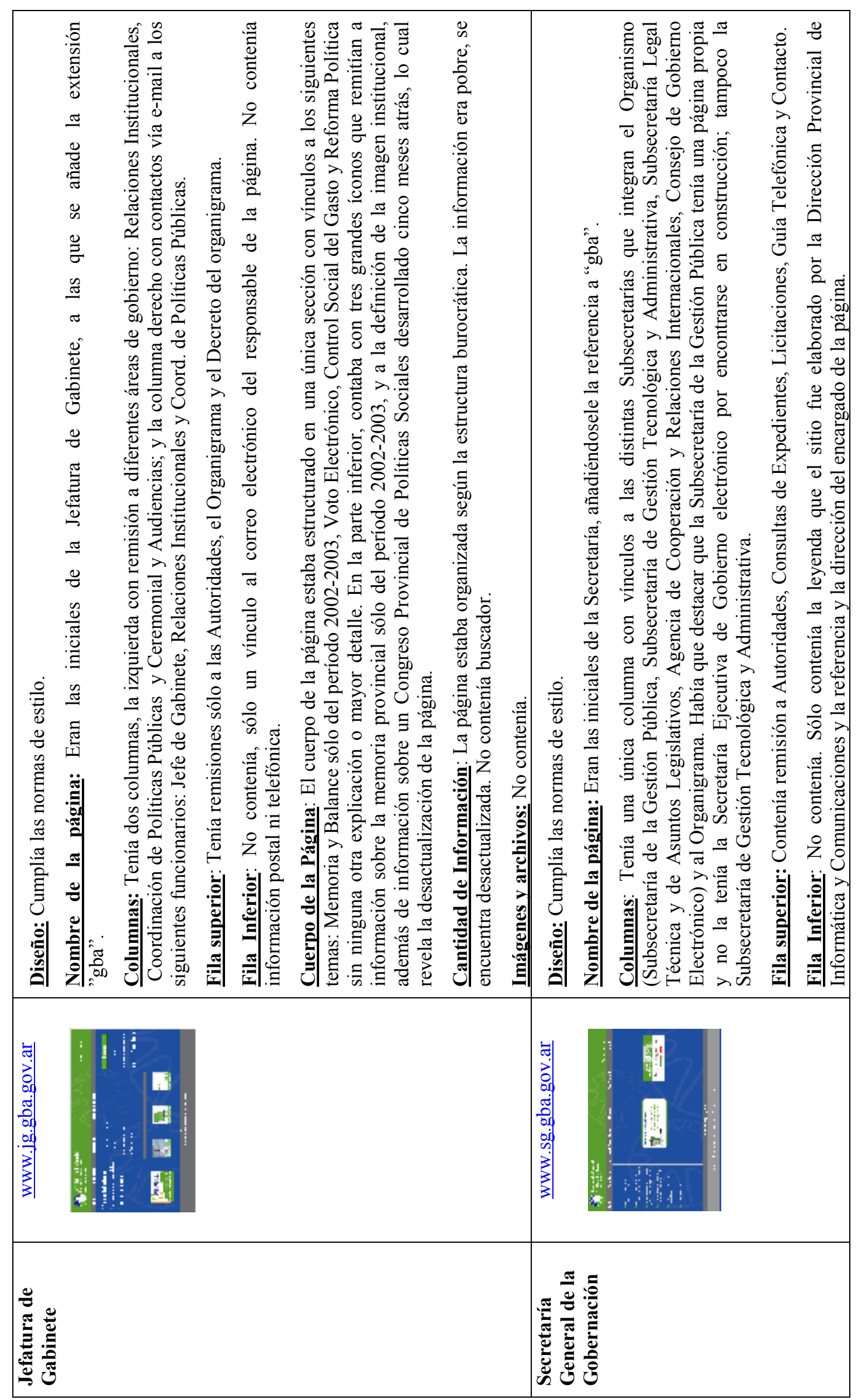




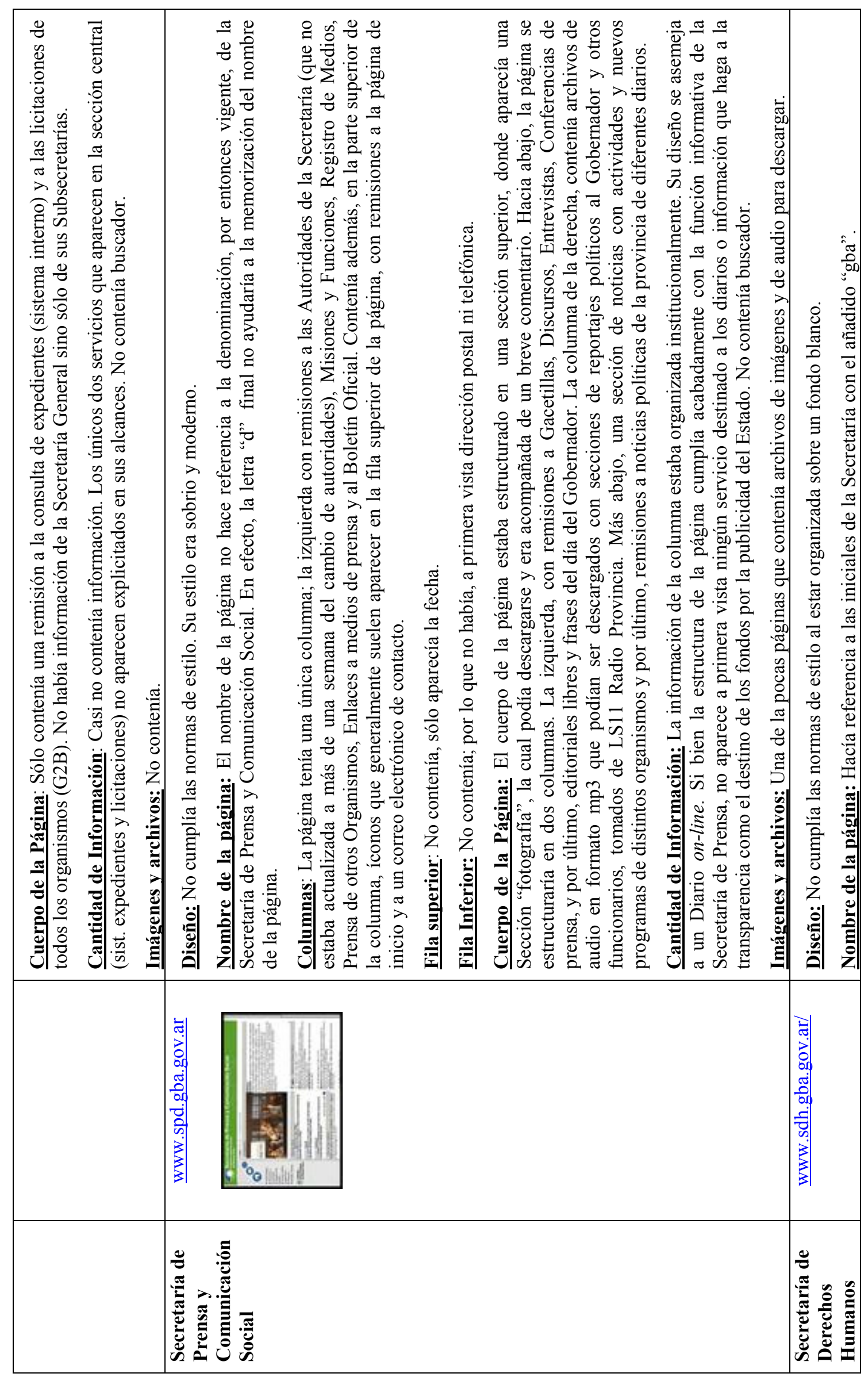




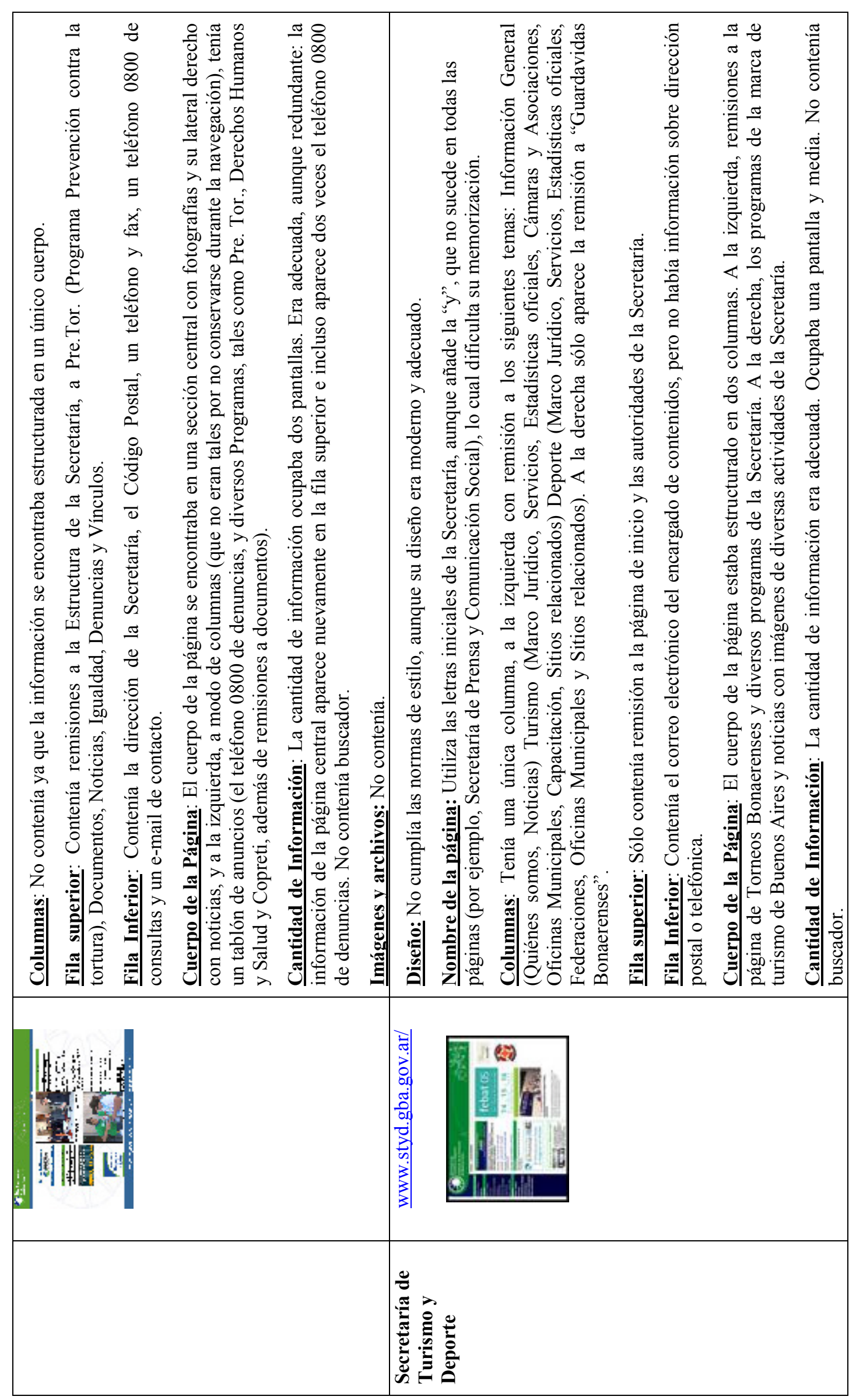




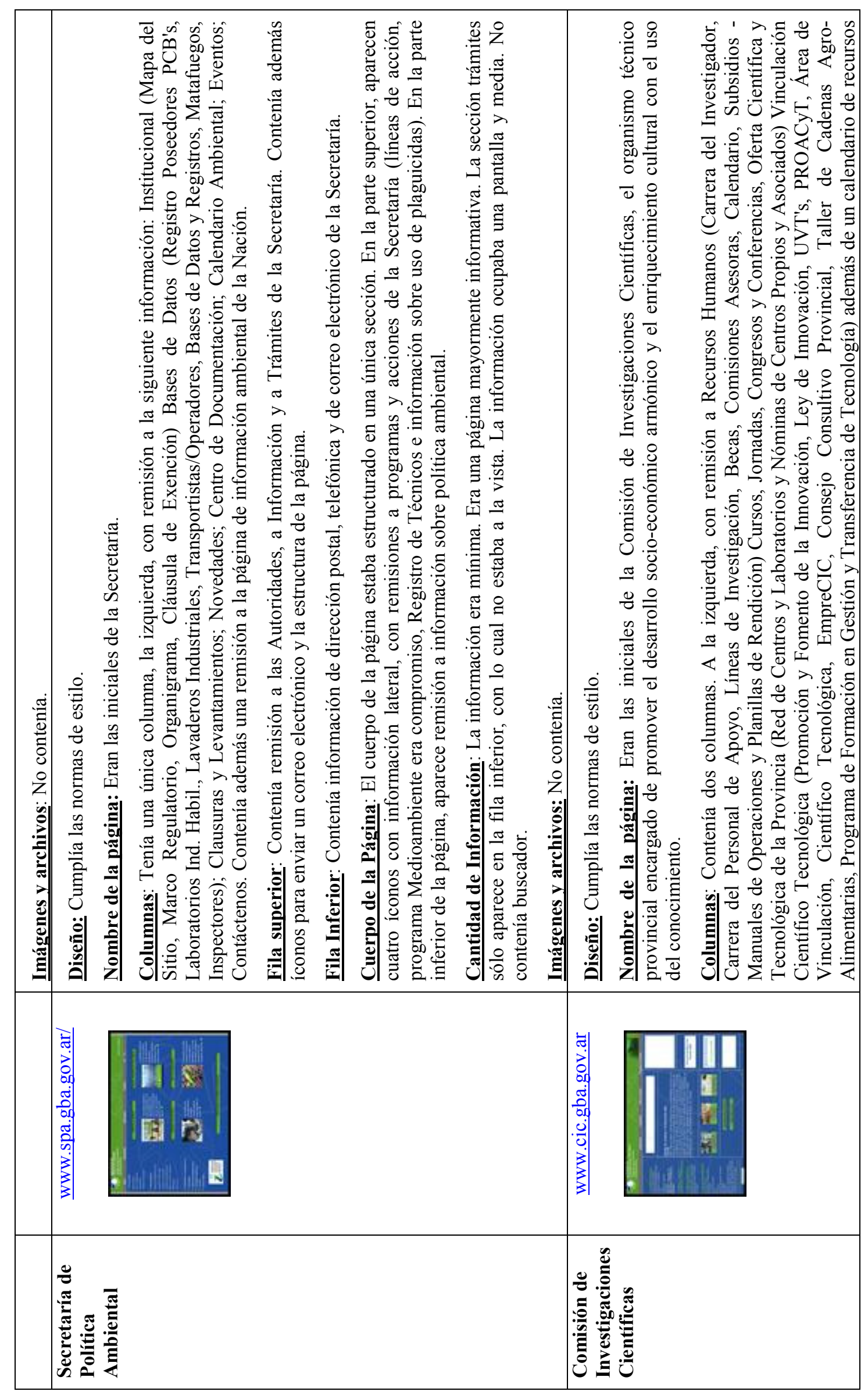




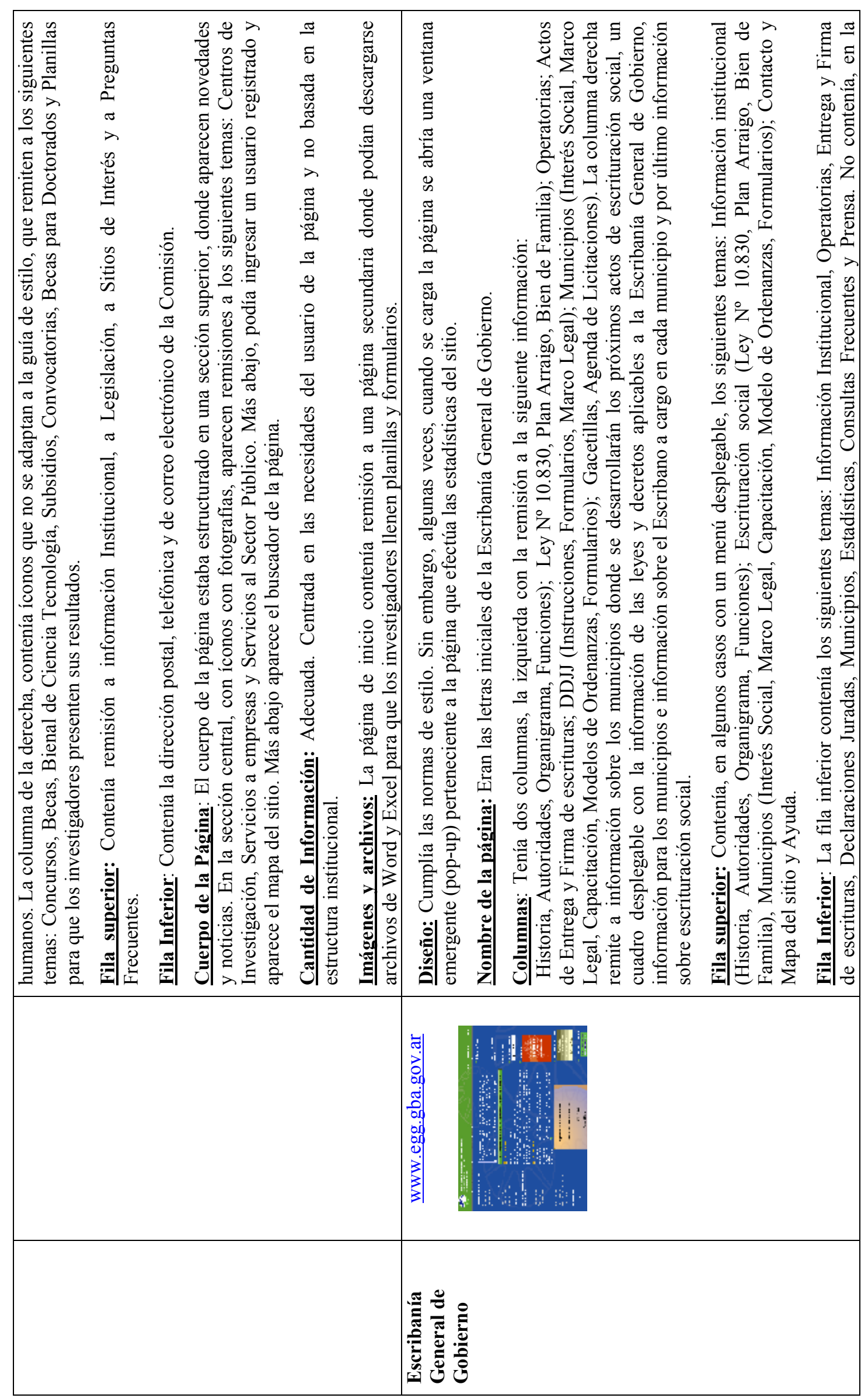




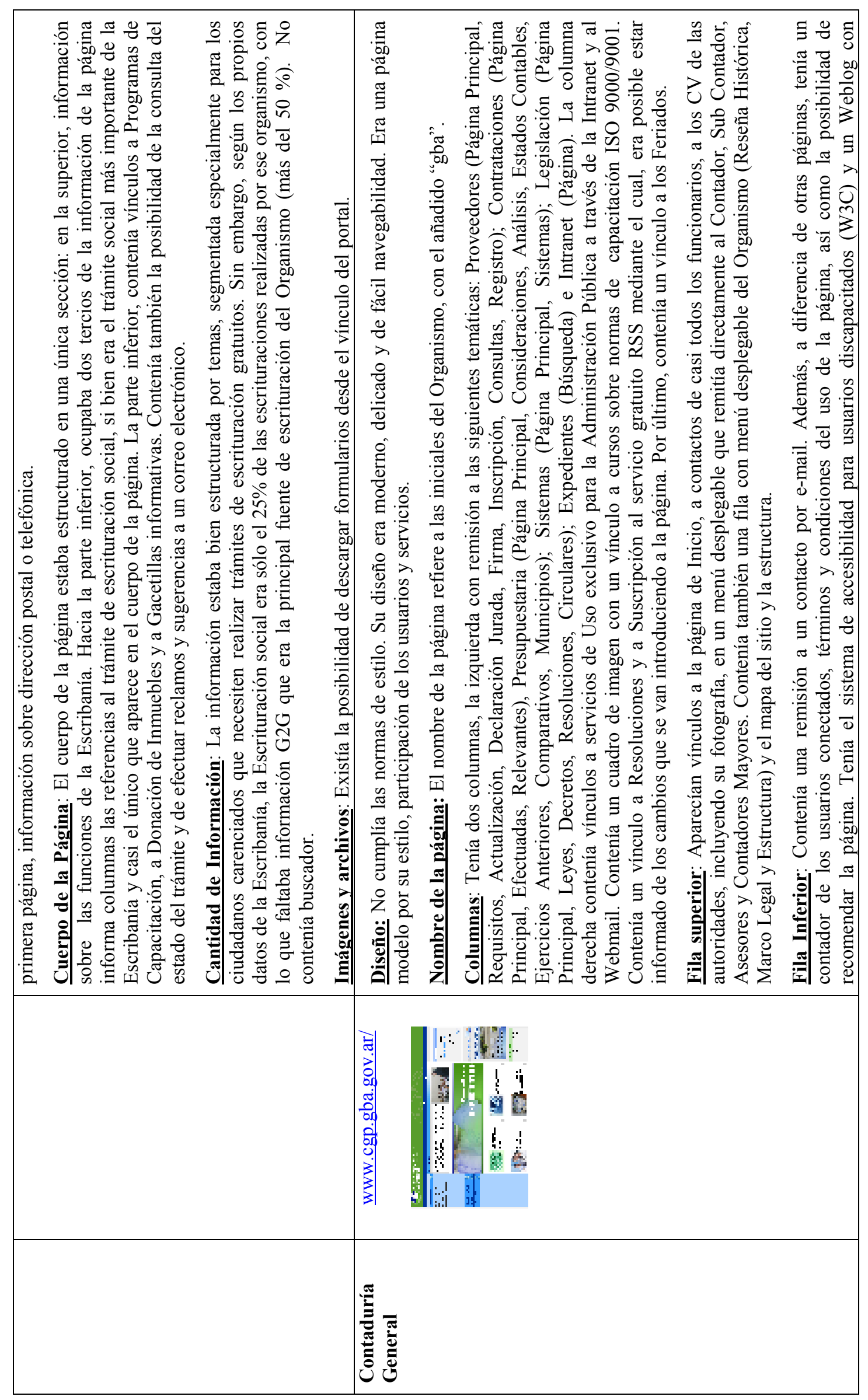




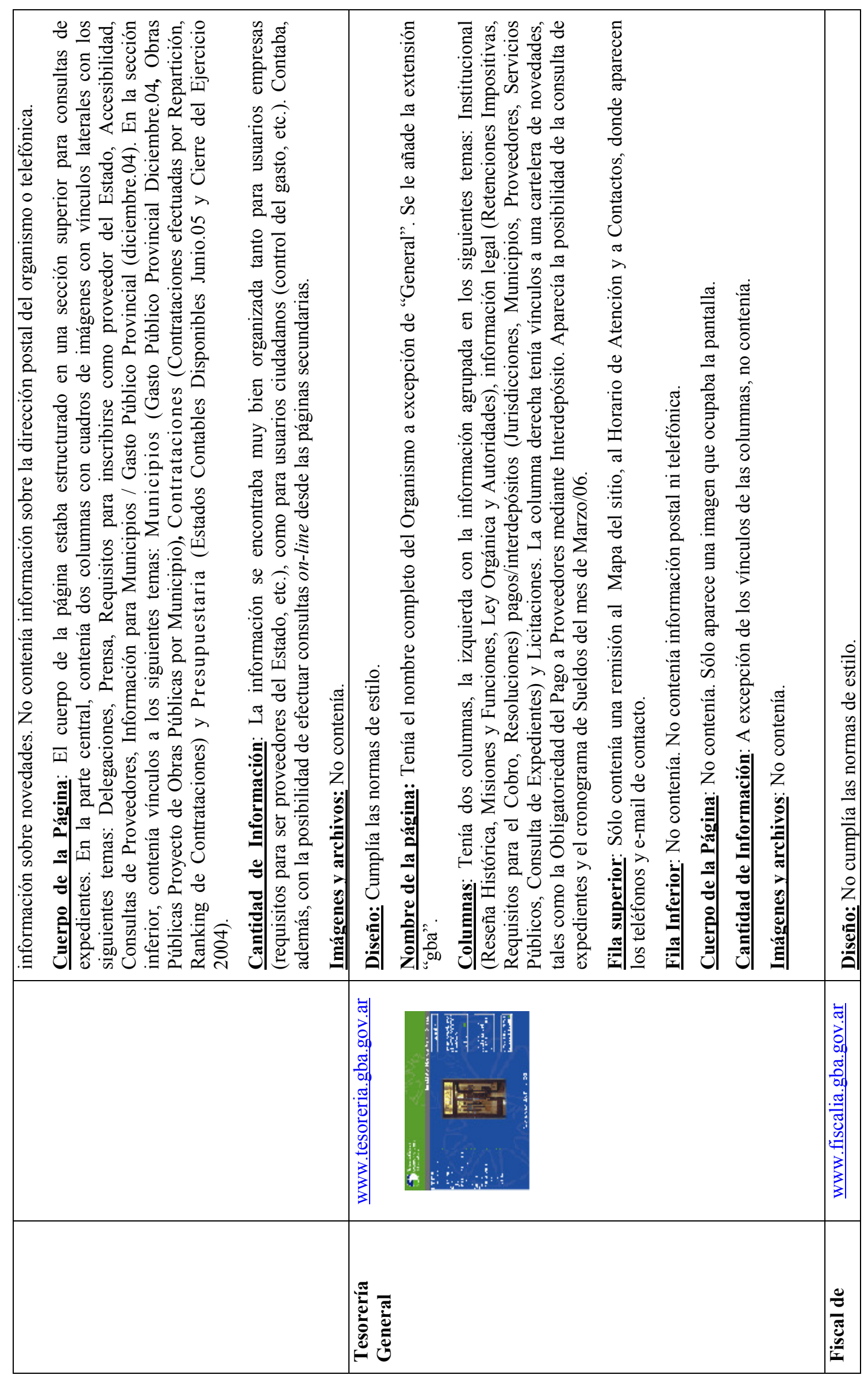




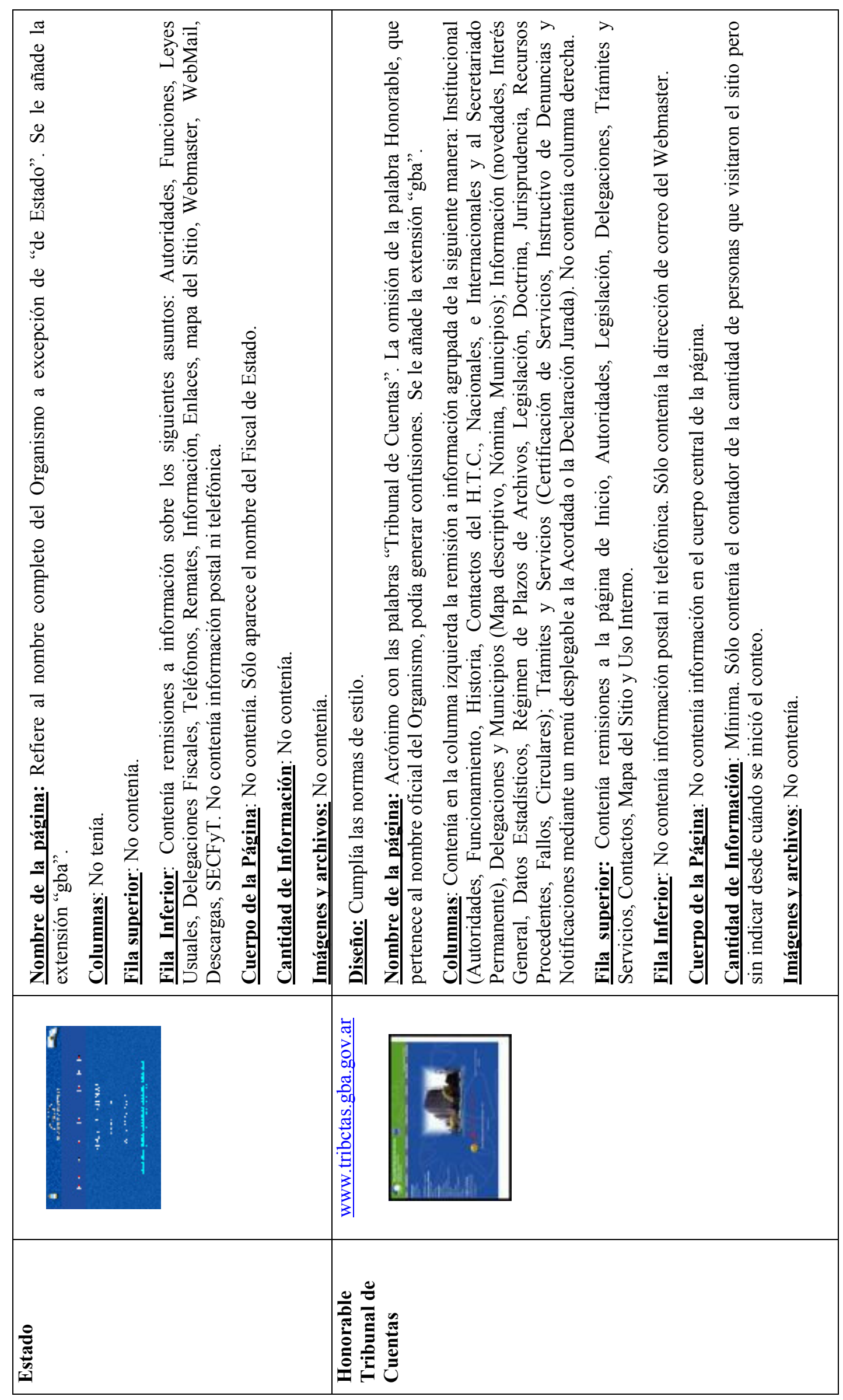




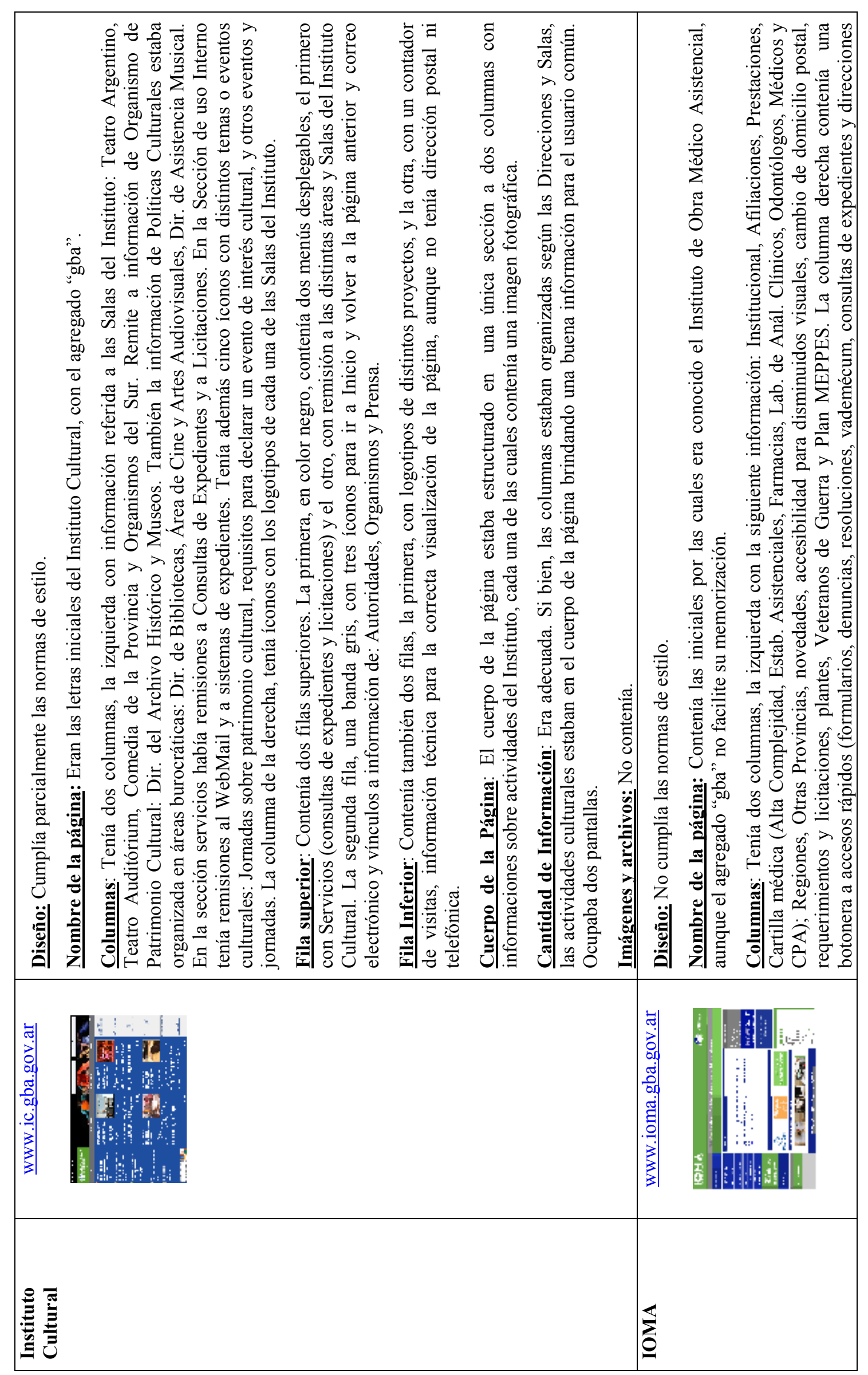




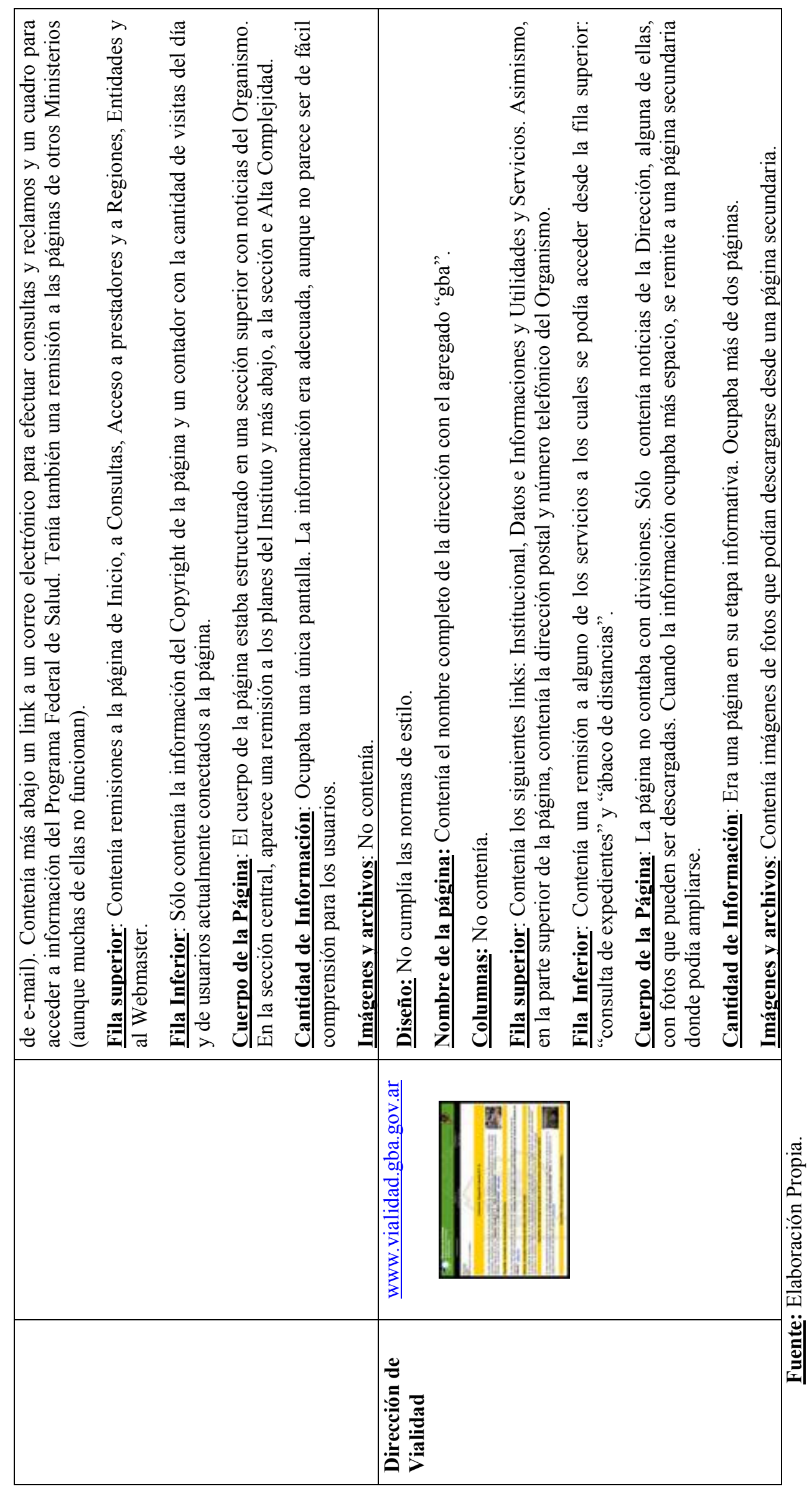




\section{Transparencia y rendición de cuentas de los funcionarios a través de las TIC}

La responsabilidad, rendición de cuentas y la transparencia constituyen importantes requisitos para cualquier gobierno que pretenda alcanzar altos niveles de gobernanza. La publicidad, rendición de cuentas y transparencia de los actos de gobierno, principios derivados del republicanismo, no sólo permiten el control social sino que generan una mayor interacción entre gobernados y gobernantes permitiendo la participación en el diseño y gestión de las políticas por parte de ciudadanos más informados y políticos más responsables.

Es por ello que siguiendo a otros estudios en la materia, hemos medido la respuesta de los funcionarios de los distintos ministerios del Poder Ejecutivo realizando consultas o peticiones reales a través de sus correos electrónicos. Se buscó con ello analizar si existe o no respuesta, y en su caso, la velocidad de la respuesta.

En primer lugar, para determinar los correos electrónicos de los funcionarios, siguiendo el mismo procedimiento de un ciudadano común, se tomó la lista de Ceremonial de la Provincia que se encontraba cargada en la página web de Gobernación. Esta base de datos, se obtuvo para fines de 2005.

Del listado completo, se seleccionó a todos los funcionarios políticos hasta el cargo de Director. El número total de funcionarios así seleccionados fue de 296. De ese total, sólo 120 habían consignado en el listado sus correos electrónicos oficiales. En definitiva, siendo el porcentaje de funcionarios con correo electrónico menor a la mitad $(40,54 \%)$, se disminuyen las posibilidades de contacto y de participación.

Gráfico 13 - Porcentaje funcionarios con e-mail

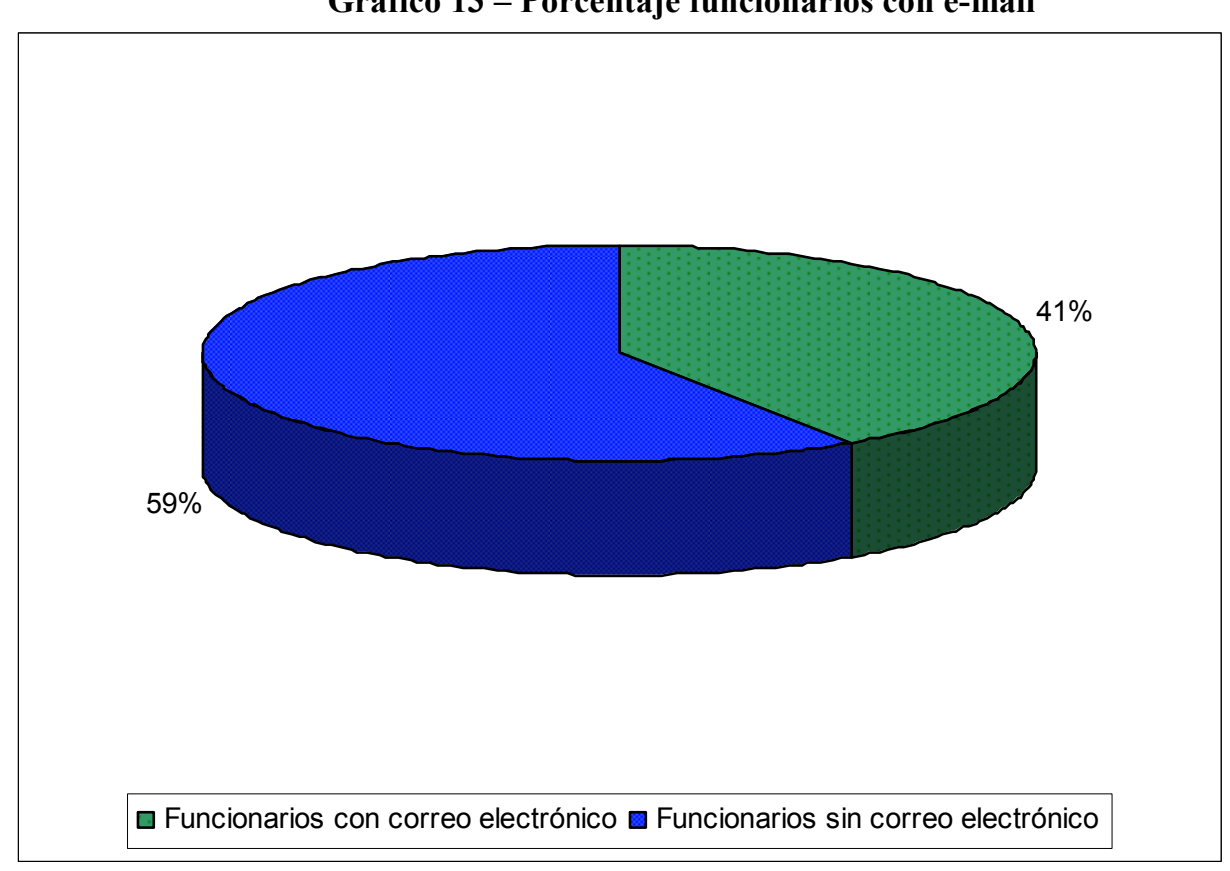

Fuente: Elaboración propia. 
Si agrupamos los datos por organismo, advertimos que la Dirección de Cultura y Educación es el organismo con mayor porcentaje de funcionarios con correos electrónicos (más del $90 \%$ ), siguiendo en orden decreciente el Instituto Cultural, con el $80 \%$ y el Ministerio de la Producción con $78 \%$. En cambio, el entonces Ministerio de Seguridad, con 45 funcionarios con rango equivalente o superior a Director, sólo una Dirección, la de protocolo, publicó su correo electrónico $(2,22 \%)$.

\begin{tabular}{|c|c|c|c|c|c|}
\hline & $\begin{array}{l}\text { Total } \\
\text { funciona- } \\
\text { rios }\end{array}$ & $\begin{array}{l}\text { Porc. sobre } \\
\text { total del } \\
\text { Poder } \\
\text { Ejecutivo }\end{array}$ & $\begin{array}{l}\text { Funciona- } \\
\text { rios con e- } \\
\text { mail }\end{array}$ & $\begin{array}{c}\text { Porc. de } \\
\text { funcionarios } \\
\text { dentro del } \\
\text { org. con e- } \\
\text { mail }\end{array}$ & $\begin{array}{c}\text { Porc. } \\
\text { Funcionarios } \\
\text { con e-mail } \\
\text { sobre total del } \\
\text { P.Ej. }\end{array}$ \\
\hline Gobernación & 6 & 2,03 & 3 & 50,00 & 1,01 \\
\hline Ministerio de Gobierno & 15 & 5,07 & 7 & 46,67 & 2,36 \\
\hline Ministerio de Economía & 28 & 9,46 & 8 & 28,57 & 2,70 \\
\hline $\begin{array}{r}\text { Min. Infr. Viv. y } \\
\text { Servicios Públicos }\end{array}$ & 29 & 9,80 & 10 & 34,48 & 3,38 \\
\hline Ministerio de Justicia & 13 & 4,39 & 3 & 23,08 & 1,01 \\
\hline Ministerio de Seguridad & 45 & 15,20 & 1 & 2,22 & 0,34 \\
\hline Ministerio de Salud & 19 & 6,42 & 8 & 42,11 & 2,70 \\
\hline $\begin{array}{r}\text { Ministerio de Asuntos } \\
\text { Agrarios }\end{array}$ & 12 & 4,05 & 8 & 66,67 & 2,70 \\
\hline $\begin{array}{r}\text { Ministerio de Desarrollo } \\
\text { Humano }\end{array}$ & 13 & 4,39 & 6 & 46,15 & 2,03 \\
\hline $\begin{array}{r}\text { Ministerio de la } \\
\text { Producción } \\
\end{array}$ & 14 & 4,73 & 11 & 78,57 & 3,72 \\
\hline Ministerio de Trabajo & 9 & 3,04 & 1 & 11,11 & 0,34 \\
\hline $\begin{array}{r}\text { Dcción. Gral. de Cult. y } \\
\text { Educ. }\end{array}$ & 29 & 9,80 & 27 & 93,10 & 9,12 \\
\hline $\begin{array}{r}\text { Secretaría General de la } \\
\text { Gobernación }\end{array}$ & 22 & 7,43 & 5 & 22,73 & 1,69 \\
\hline Jefatura de Gabinete & 11 & 3,72 & 4 & 36,36 & 1,35 \\
\hline $\begin{array}{r}\text { Instituto Cultural de la } \\
\text { Provincia }\end{array}$ & 15 & 5,07 & 12 & 80,00 & 4,05 \\
\hline $\begin{array}{r}\text { Secretaría de Política } \\
\text { Ambiental }\end{array}$ & 9 & 3,04 & 2 & 22,22 & 0,68 \\
\hline $\begin{array}{r}\text { Secretaría de Prensa y } \\
\text { Comunicación Social } \\
\end{array}$ & 3 & 1,01 & 2 & 66,67 & 0,68 \\
\hline $\begin{array}{r}\text { Secretaría de Derechos } \\
\text { Humanos } \\
\end{array}$ & 4 & 1,35 & 2 & 50,00 & 0,68 \\
\hline TOTALES & & & & & \\
\hline SUMA & 296 & & 120 & & \\
\hline PROMEDIO & & 5,56 & & 44,48 & 2,25 \\
\hline
\end{tabular}

Fuente: Elaboración propia

Así, de este primer relevamiento puede advertirse que no todos los funcionarios de la Provincia de Buenos Aires poseen publicado en el listado oficial una cuenta institucional de correo electrónico donde cualquier ciudadano podría dirigirse personalmente y plantear sus dudas, inquietudes o formular sus reclamos, sea esta cuenta de carácter individual o del organismo que representan. 
La segunda parte del análisis consistió en la evaluación del uso de esas cuentas de correo. En efecto, disponer de una dirección de correo anunciada de forma pública, constituye obviamente un indicador para calibrar el grado de compromiso de los funcionarios con la democracia y las nuevas tecnologías. Pero tal anuncio podría reducirse a un elemento decorativo para transmitir la imagen de 'estar al día' (Dader, 2001).

Para comprobar empíricamente la interacción, el grado real de compromiso, interés y pericia de los funcionarios en el uso de estas nuevas tecnologías, se realizaron algunas pruebas sobre el uso real de Internet.

El ejercicio consistió en el envío de un correo electrónico a 60 funcionarios de distintos rangos y ministerios. Se enviaron correos electrónicos al $50 \%$ del universo de funcionarios con e-mail. Además, en la medida de lo posible, la muestra intentó respetar la integración de los funcionarios a distintos ministerios y organismos por lo que, en la mayoría de los casos, se envió e-mails de prueba a la mitad de los funcionarios con correo electrónico de cada área, y nunca a menos a un cuarto de los integrantes de cada organismo.

Bajo un nombre supuesto y presentándose como un ciudadano común, desde una cuenta de correo electrónico creada al efecto, se redactó un mensaje informal. El mensaje era personal, solicitando información, un dato para completar un trámite o una entrevista. Cada uno de los temas de los correos se encontraba relacionado con el área a la que pertenecía el funcionario. ${ }^{258}$

El envío de los correos electrónicos fue realizado en el mes de febrero de 2006, luego de los cambios del Gabinete del gobernador de forma de tener los datos actualizados -funcionarios y cuentas de correo-. ${ }^{259}$

Si entramos a considerar la respuesta, el resultado no es bueno. Sólo tuvieron respuesta 11 de los 60 correos enviados, es decir, el 18,33\%.

\footnotetext{
258 No se comunicaba que se había enviado otro correo a distintos funcionarios. La solicitud de entrevista, se realizó, principalmente, a los titulares de los diversos organismos, requiriéndoles cómo contactarlos para efectuar una entrevista desde una Radio del interior de la provincia para tocar temas de actualidad del organismo.

${ }_{259}$ Los correos fueron enviados con fecha 6 de febrero de 2006, con el nombre de Juan Carlos Satrino, desde la cuenta jcsatrino@yahoo.com.ar y de Sonia Marcusi, desde la cuenta sonia_24_2005@yahoo.com.ar.
} 


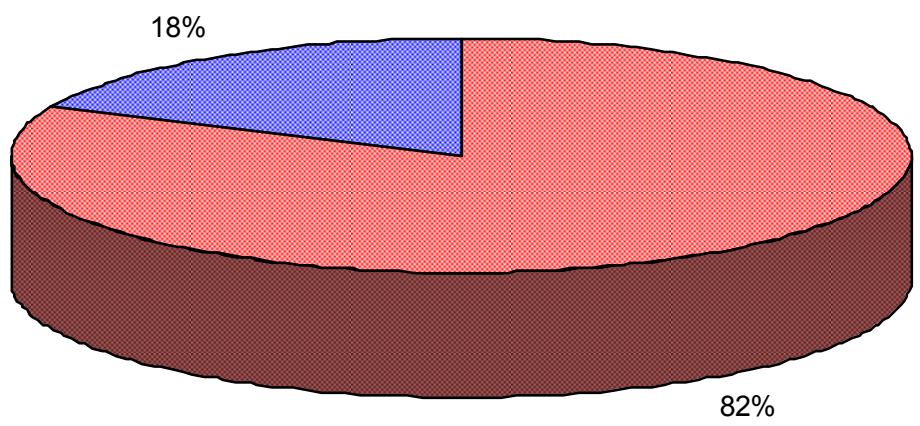

e-mails no contestados 圆 e-mails contestados

Fuente: Elaboración propia.

Los datos agrupados por organismo revelan que el entonces Ministerio de Desarrollo Humano era el único Ministerio que contestó todos los correos, siguiendo en orden decreciente el Ministerio de Salud (50\%) y la Secretaría General de la Gobernación y el entonces Ministerio de Infraestructura, Vivienda y Servicios Públicos $(33,33 \%)$.

Cuadro 39 - Cantidad e- mail contestados por organismos

\begin{tabular}{|c|c|c|c|c|}
\hline & $\begin{array}{l}\text { Cant. func. } \\
\text { con e-mail }\end{array}$ & $\begin{array}{l}\text { Cant. e- } \\
\text { mails } \\
\text { enviados }\end{array}$ & $\begin{array}{l}\text { Porc. de e- } \\
\text { mails } \\
\text { enviados }\end{array}$ & $\begin{array}{l}\text { Cant. e-mail } \\
\text { contestados }\end{array}$ \\
\hline Gobernación & 3 & 2 & 66,67 & 0 \\
\hline Min. de Gobierno & 7 & 4 & 57,14 & 1 \\
\hline $\begin{array}{l}\text { Ministerio de } \\
\text { Economía }\end{array}$ & 8 & 4 & 50,00 & 1 \\
\hline $\begin{array}{l}\text { Min. } \\
\text { Infraestructura, } \\
\text { Vivienda y Serv. } \\
\text { Púb. }\end{array}$ & 10 & 6 & 60,00 & 2 \\
\hline $\begin{array}{l}\text { Ministerio de } \\
\text { Justicia }\end{array}$ & 3 & 2 & 66,67 & 0 \\
\hline $\begin{array}{l}\text { Ministerio de } \\
\text { Seguridad }\end{array}$ & 1 & 1 & 100,00 & 0 \\
\hline Ministerio de Salud & 8 & 4 & 50,00 & 2 \\
\hline $\begin{array}{l}\text { Ministerio de Asu. } \\
\text { Agrarios }\end{array}$ & 8 & 4 & 50,00 & 1 \\
\hline $\begin{array}{l}\text { Ministerio de D. } \\
\text { Humano }\end{array}$ & 6 & 2 & 33,33 & 2 \\
\hline $\begin{array}{l}\text { Ministerio de la } \\
\text { Producción }\end{array}$ & 11 & 3 & 27,27 & 0 \\
\hline $\begin{array}{l}\text { Ministerio de } \\
\text { Trabajo }\end{array}$ & 1 & 1 & 100,00 & 0 \\
\hline
\end{tabular}




\begin{tabular}{|l|r|r|r|r|}
\hline $\begin{array}{l}\text { Dccion. Gral. de } \\
\text { Cult. y Educ. }\end{array}$ & 27 & 13 & 48,15 & 1 \\
\hline $\begin{array}{l}\text { Secretaría Gral. de } \\
\text { la Gobernación }\end{array}$ & 5 & 3 & 60,00 & 1 \\
\hline $\begin{array}{l}\text { Jefatura de } \\
\text { Gabinete }\end{array}$ & 4 & 2 & 50,00 & 0 \\
\hline Instituto Cultural & 12 & 6 & 50,00 & 0 \\
\hline $\begin{array}{l}\text { Secretaría de } \\
\text { Política Ambiental }\end{array}$ & 2 & 1 & 50,00 & 0 \\
\hline $\begin{array}{l}\text { Secretaría de } \\
\text { Prensa }\end{array}$ & 2 & 1 & 50,00 & 0 \\
\hline $\begin{array}{l}\text { Secretaría de } \\
\text { Dchos. Humanos }\end{array}$ & 2 & 1 & 50,00 & 0 \\
\hline TOTAL & $\mathbf{1 2 0}$ & $\mathbf{6 0}$ & $\mathbf{5 0 \%}$ & $\mathbf{1 1}$ \\
\hline
\end{tabular}

El siguiente gráfico, cruza la cantidad de mails enviados con la cantidad de mail contestados.

Gráfico 15 - Cantidad funcionarios con e-mail y cantidad de e-mail contestados

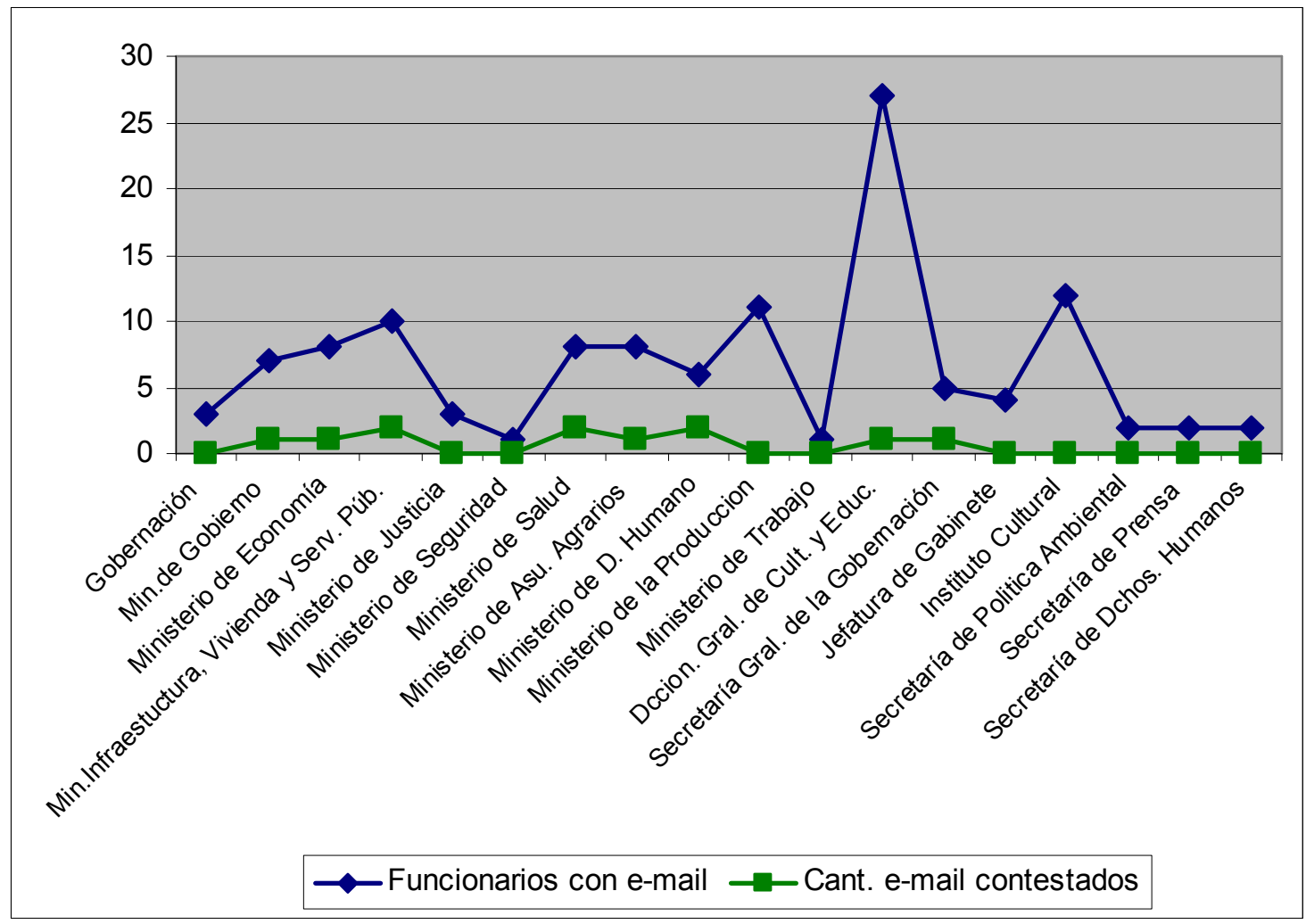

Fuente: Elaboración propia.

Los resultados no nos permiten asociar positivamente el mayor porcentaje de correos publicados por área (transparencia) con el porcentaje de correos contestados (responsabilidad/rendición de cuentas). En efecto, como sosteníamos, la Dirección de Cultura y Educación es el organismo con mayor porcentaje de funcionarios con correo 
electrónicos (más del $90 \%$ ), pero el nivel de respuesta no llega al 8\% de los correos contestados; el Instituto Cultural, con el $80 \%$ de e-mails publicados tiene $0 \%$ de correos contestados. El Organismo que más correos contestó, el Ministerio de Desarrollo Humano (100\%), no se encuentra entre los organismos con más e-mail publicados. ${ }^{260}$

Cuadro 40 - Porcentaje e- mail contestados por organismos

\begin{tabular}{|c|c|c|}
\hline & $\begin{array}{l}\text { Porcentaje de funcionarios } \\
\text { con e-mail }\end{array}$ & $\begin{array}{l}\text { Porcentaje de e-mail } \\
\text { contestados }\end{array}$ \\
\hline Gobernación & 50 & 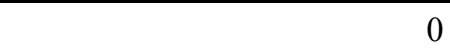 \\
\hline Min. de Gobierno & 46,67 & 25 \\
\hline Ministerio de Economía & 28,57 & 25 \\
\hline $\begin{array}{l}\text { Min. Infraestructura, Vivienda y } \\
\text { Serv. Púb. }\end{array}$ & 34,48 & 33,33 \\
\hline Ministerio de Justicia & 23,08 & 0 \\
\hline Ministerio de Seguridad & 2,22 & 0 \\
\hline Ministerio de Salud & 42,11 & 50 \\
\hline Ministerio de Asu. Agrarios & 66,67 & 25 \\
\hline Ministerio de D. Humano & 46,15 & 100 \\
\hline Ministerio de la Producción & 78,57 & 0 \\
\hline Ministerio de Trabajo & 11,11 & 0 \\
\hline Dccion. Gral. de Cult. y Educ. & 93,1 & 7,69 \\
\hline Secretaría Gral. de la Gobernación & 22,73 & 33,33 \\
\hline Jefatura de Gabinete & 36,36 & 0 \\
\hline Instituto Cultural & 80 & 0 \\
\hline Secretaría de Política Ambiental & 22,22 & 0 \\
\hline
\end{tabular}

Fuente: Elaboración propia.

Sin embargo, a excepción de la Secretaría General de la Gobernación, aquellos organismos con menos nivel de publicación (menos del $25 \%$ ) tuvieron nulo porcentaje de respuesta, con lo que la asociación bajo nivel de publicación de datos vía Web con bajo nivel de respuesta se puede correlacionar. ${ }^{261}$

\footnotetext{
260 Se encuentre en el noveno lugar, entre los dieciocho organismos relevados.

261 La excepción de la Secretaría General de la Gobernación, que pese a tener publicado menos del $25 \%$ de sus funcionarios con e-mail contestó el 33,33\% de los correos enviados, no desmiente la correlación negativa pues, el porcentaje es también bajo $(33 \%)$.
} 


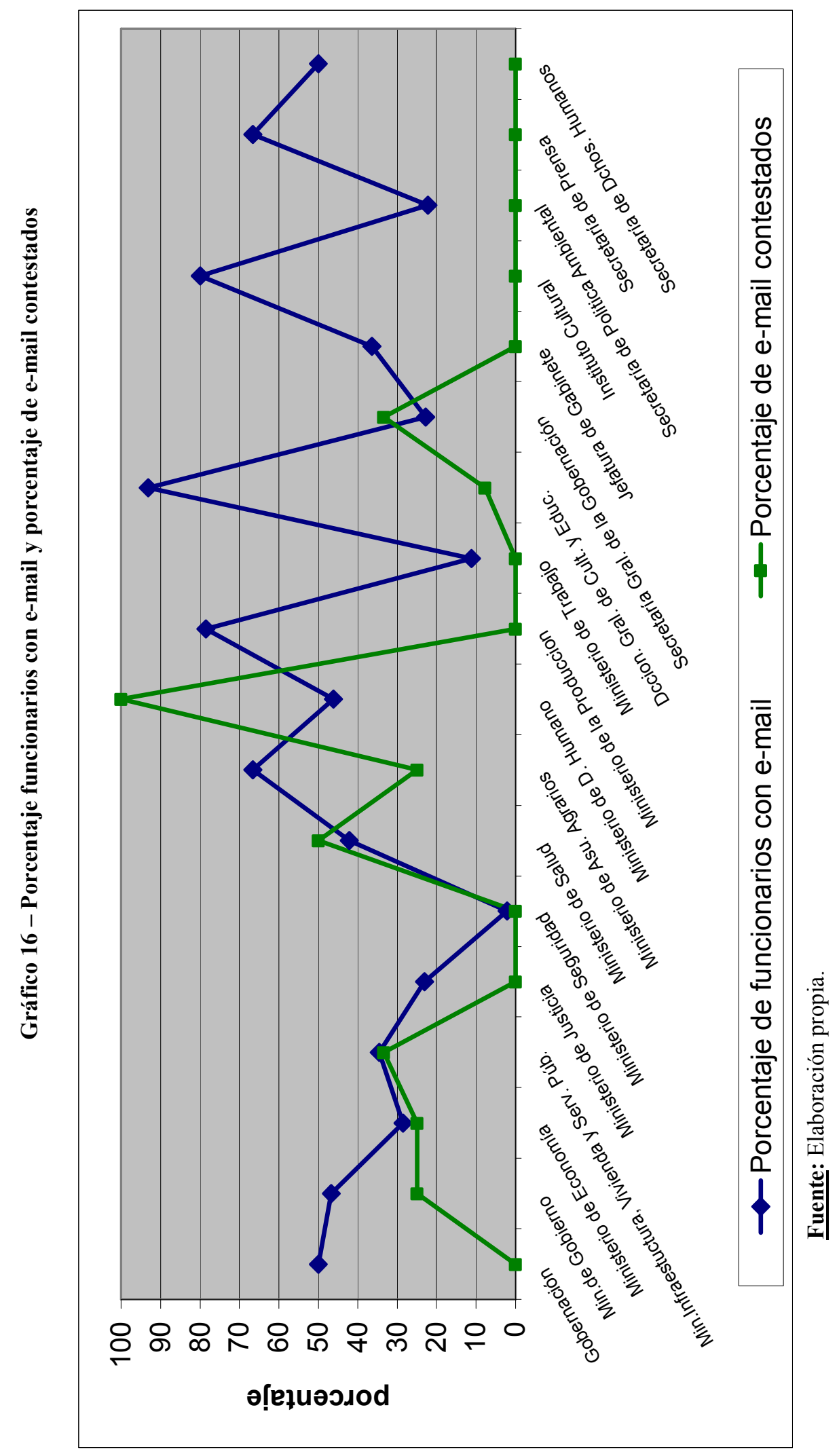




\title{
4. Firma Electrónica
}

Otra de las experiencias que analizaremos son las acciones llevadas adelante por el Poder Ejecutivo para la utilización de la firma electrónica en la Administración Pública.

Conforme el artículo $2^{\circ}$ de la Ley Nacional de Firma Digital, Ley $\mathrm{N}^{\mathrm{o}} 25.506$, se entiende por firma digital al resultado de aplicar a un documento digital un procedimiento matemático que requiere información de exclusivo conocimiento del firmante, encontrándose ésta bajo su absoluto control. Como reza la Ley:

\begin{abstract}
ART. 2 LEY $\mathrm{N}^{\mathrm{o}}$ 25.506. La firma digital debe ser susceptible de verificación por terceras partes, tal que dicha verificación simultáneamente permita identificar al firmante y detectar cualquier alteración del documento digital posterior a su firma.
\end{abstract}

Por el contrario, firma electrónica es el conjunto de datos electrónicos integrados, ligados o asociados de manera lógica a otros datos electrónicos, utilizado por el signatario como su medio de identificación, que carezca de alguno de los requisitos legales para ser considerada firma digital. En caso de ser desconocida la firma electrónica corresponde a quien la invoca acreditar su validez (conf. art. 5 Ley $\mathrm{N}^{\mathrm{o}}$ 25.506).

Dicha Ley no resultaría de aplicación obligatoria para las jurisdicciones provinciales, quienes en uso de su autonomía podrían establecer mecanismos propios para la firma digital de los documentos internos y su intercomunicación ${ }^{262}$. Sin embargo, previendo la necesidad de compatibilizar los instrumentos, la propia Ley nacional en su artículo 50, invita a las provincias a dictar los instrumentos legales pertinentes para adherir a la presente ley.

En uso de esa facultad, la Secretaría Ejecutiva de Gobierno Electrónico, elevó a la Legislatura un proyecto de ley (PE- 10/02-03-0), mediante el cual la Provincia de Buenos Aires adhería a la Ley Nacional $\mathrm{N}^{\circ}$ 25.506, "Ley de Firma Digital" en sus capítulos I a IV, IX y Anexo.

El objeto de la norma, según lo reconoce el documento de elevación, es reconocer el empleo de la firma electrónica y de la firma digital, como así también su eficacia jurídica en las condiciones que ella misma establece. Se señala que con este mecanismo se contribuye a aumentar la productividad de los organismos y a optimizar

\footnotetext{
${ }^{262}$ Sin ser especialistas, esta interpretación es errónea. Si la firma es condición esencial para la existencia de todo acto bajo forma privada, conf. art. 1012 del Código Civil, es porque ella es expresión y manifestación de voluntad asertiva. Y este efecto, está dado por la legislación de fondo, no de forma. Si la firma ológrafa, que es el trazo particular por el cual el sujeto consigna habitualmente su nombre y apellido logra ese efecto, la firma digital, que se la equipara con aquella sobre un documento digital, también es legislación de fondo, no de forma, salvo que se considere, al "trazo particular" como cuestión procedimental.
} 
el manejo de la información y reducir los costos de almacenamiento y de traslado de papel.

Sumariamente, la adhesión a los capítulos de la Ley Nacional arriba expresados trata sobre los siguientes tópicos:

- Capítulo I: Define los conceptos de firma digital y firma electrónica conforme las normas nacionales. ${ }^{263}$ Además establece que todo documento que requiera una firma manuscrita, será válido con firma digital. Prevé la presunción de autoría y la presunción de integridad del certificado digital y que la firma pertenece al titular del certificado digital y que el mismo no ha sido modificado desde el momento de su firma, salvo prueba en contrario. También en este capítulo se enumeran los requisitos que se deben cumplir para que la firma digital sea considerada válida.

- Capítulo II: Refiere a los Certificados Digitales, a los que define como el documento digital firmado digitalmente por un certificador, que vincula los datos de verificación de firma a su titular. Establece sus requisitos de validez, período de vigencia y la presunción de que el documento firmado proviene del remitente.

- Capítulo III: Regula sobre el Certificador Licenciado, al que define como "toda persona de existencia ideal, registro público de contratos u organismo público que expide certificados, presta otros servicios en relación con la firma digital y cuenta con una licencia para ello, otorgada por el ente licenciante" (artículo 17). Para el certificador licenciado se prevén expresamente sus funciones, obligaciones y los casos en los cuales cesa tal calidad. Faculta a las entidades que controlan las matrículas para emitir certificados digitales en lo referido a esa función. Para ello deberán cumplir con los requisitos para ser certificador licenciado.

- Capítulo IV: Se definen los derechos y las obligaciones que tiene a su cargo el titular de un certificado digital.

- Capítulo IX: Se establece la responsabilidad entre el certificador licenciado y el titular del certificado y entre aquél y los terceros ajenos a la relación contractual.

- Anexo: Contiene un glosario con las definiciones de términos relacionados con la materia legislada, a los efectos de aclarar el alcance de los mismos y evitar distintas interpretaciones.

La Provincia adhería pues a las normas de fondo de la Ley Nacional $\mathrm{N}^{\mathrm{o}} 25.506$ pero no a las normas de procedimiento que, según el Mensaje del Ejecutivo, son de competencia exclusiva y excluyente de las jurisdicciones provinciales, como facultades reservadas ${ }^{264}$

A los efectos de regular los instrumentos pertinentes que permitirían establecer la firma digital, el proyecto de ley disponía que la Autoridad de Aplicación establecería los estándares tecnológicos y de seguridad, procedimientos de firma, verificación, certificación y auditoría para la firma digital y que el Poder Ejecutivo designaría al o los organismos de la Administración Pública que actuarían como certificadores en el ámbito público provincial.

\footnotetext{
263 No podemos dejar de destacar el error técnico legislativo pues siendo la firma legislación de fondo, la norma provincial no puede establecer qué es firma y qué no es firma.

264 Sin embargo, aún con igual criterio al de la Ley Nacional, volvía a definir qué es firma electrónica y digital, cuestión que no podía aún cuando la definición fuera idéntica.
} 
En efecto, disponía que fuera la Autoridad de Aplicación Provincial, creada por esa ley, la única que pudiese designar los organismos públicos que actuarían como autoridades certificantes, auditantes o autoridades de registro. El mismo criterio se aplicaría también a los estándares tecnológicos y de seguridad, que por los Decretos Provinciales No 4.015/93 y No 1.824/02 eran competencia de la Dirección Provincial de Informática y Comunicaciones, dependiente de la Secretaría General de la Gobernación. ${ }^{265}$

Asimismo, autorizaba al Poder Ejecutivo a dictar un reglamento a los fines de instalar en forma efectiva y progresiva el expediente digital que contemple excepciones al régimen de procedimientos administrativos, Decreto-Ley $\mathrm{N}^{\circ} 7.647 / 70$.

Estas competencias reservadas se refieren solamente a los certificados de firma digital de los agentes de la Administración Pública Provincial y Municipal y destinados a la gestión interna de los organismos. Los actos entre particulares y los realizados entre particulares y la jurisdicción provincial, serían regidos por la legislación nacional. Es decir, la gestión de certificados de particulares y las eventuales Autoridades Certificantes privadas en el ámbito de la Provincia deberían someterse a las normas y reglamentos que establezca la Autoridad de Aplicación Nacional.

Dicho proyecto tuvo, luego de un año de su presentación, a inicios de 2004, media sanción de la Honorable Cámara de Senadores. Pero las modificaciones introducidas por la Cámara generaron más dudas que certezas:

- No se incluyó expresamente en el texto con media sanción la facultad de la Autoridad de Aplicación para instrumentar Acuerdos con la Nación y con otras Provincias para el reconocimiento mutuo de la validez de los certificados emitidos en cada jurisdicción. Aunque habla de "reconocimiento recíproco de certificados" sin siquiera hacer referencia a quién puede firmarlos ni a qué jurisdicciones se refiere, la ausencia de esta facultad haría incompatible el sistema de la Provincia con el de la ley Nacional dificultando enormemente las actividades interjurisdiccionales y las de los habitantes de la Provincia.

- La posibilidad de establecer Acuerdos mediante el "reconocimiento recíproco de certificados" no prevé a los particulares, por lo que se corre el riesgo de que con una interpretación estricta de la ley, se exija a un titular de un certificado digital emitido en otra Jurisdicción, que deba tramitar otro para utilizarlo en la Provincia.

- El texto original especificaba que los particulares gestionaran sus certificados en alguna Autoridad de Certificación licenciada por la Autoridad de Aplicación Nacional, pero en el texto con media sanción se obliga al Organismo Provincial a emitir certificados a particulares, generando enormes costos para el erario provincial.

- Se había propuesto facultar al Poder Ejecutivo para designar la Autoridad de Aplicación Provincial, que se contempló en el despacho de Comisión. Sin embargo, este punto no aparece en el texto con media sanción ni se designa a ningún ente como tal, lo cual generó en el proyecto de ley una laguna importante que podría

\footnotetext{
265 Sin embargo, con el objeto de de facilitar la uniformidad e interoperabilidad con otras jurisdicciones, la Provincia adhería a los estándares que en esas materias establezca la Autoridad de Aplicación de la Ley Nacional, sin perjuicio de mantener su potestad de modificarlos si lo considerara necesario.
} 
originar un problema grave en la instrumentación de la Ley ya que la misma hace mención a dicha Autoridad en varios artículos pero la deja indefinida.

- El texto enviado a la Legislatura incorporaba la figura de Autoridad de Registro diferenciada de la de Autoridad de Certificación a fin de certificar la identidad y demás atributos de los titulares de certificados digitales. Esta alternativa además permitía a cada Poder (Ejecutivo, Legislativo y Judicial) reservarse para sí el control de los certificados que se gestionan en el ámbito de sus funciones específicas, estableciendo su propia Autoridad de Registro. Este punto tampoco fue contemplado ni el texto de la Comisión ni en el que tiene media sanción.

Como consecuencia de ello, el texto con media sanción omitió algunos aspectos fundamentales cuyo impacto en el resultado final de la vigencia de la ley hubiera dificultado su rápida difusión y encarecido el proceso. Un análisis global de las cuestiones que no fueron atendidas o modificadas, tales como la obligatoriedad de la emisión por parte de la Provincia de certificados para particulares, falta de designación de la Autoridad de Aplicación y no previsión de los acuerdos de reconocimiento con la Nación, muestra a las claras que las modificaciones fueron hechas sin mayor estudio de las consecuencias. En efecto, los resultados dan muestra de la improvisación y la falta de interacción entre el Poder Ejecutivo y el Poder Legislativo pues ninguno de los cambios entre el proyecto de aquel y la media sanción de la Cámara de Senadores, responde a necesidades políticas ni a cambios estratégicos sobre el proyecto en sí.

La Cámara revisora no trató el proyecto inmediatamente y el Ejecutivo, habida cuenta del esfuerzo que debía hacer para retomar su proyecto original no lo impulsó. Como consecuencia de ello, y el transcurso del tiempo, el proyecto perdió vigencia legislativa y sólo al finalizar la gestión de Solá, como veremos más adelante, hubo ley de firma digital.

Teniendo en cuenta la lentitud con que el Parlamento bonaerense estaba tratando el proyecto de ley de firma digital y las erráticas modificaciones que se estaban introduciendo, desde el Poder Ejecutivo se sancionó el Decreto $N^{\circ}$ 919/04 por medio del cual se autorizó por el plazo de dos años el empleo de la firma electrónica en la instrumentación de actos internos del sector público provincial. ${ }^{266}$

Asimismo, se habilitó a los organismos a utilizar la tecnología de firma electrónica para la transferencia de información con terceros, previa celebración de un convenio cuyo modelo estaba delineado en el Anexo V del Decreto.

El Decreto resultó de aplicación a todo el sector público provincial, incluyendo a la administración centralizada y descentralizada, a los organismos de la Constitución, los entes autárquicos, los bancos y entidades financieras oficiales y todo otro ente en que el Estado Provincial o sus organismos descentralizados tengan participación suficiente para la formación de sus decisiones, quienes podrían arbitrar, en coordinación con la autoridad de aplicación, los medios que resulten necesarios para extender el empleo de la tecnología de la firma electrónica.

El Decreto estableció que la Autoridad Certificante, esto es, la institución que certifique la correspondencia entre una clave pública y el agente titular de la misma,

\footnotetext{
266 La fecha del Decreto es 13 de mayo de 2004, pero el plazo de dos años es a contar del dictado de los manuales de procedimiento y de los estándares aludidos en el artículo $6^{\circ}$ del Decreto.
} 
sería acreditada mediante un certificado de clave pública emitido por la Escribanía General de Gobierno. Por su parte, la Secretaría General de la Gobernación, además de autoridad de aplicación de la normativa, cumpliría las funciones de Organismo Licenciante. ${ }^{267}$

La Contaduría General de la Provincia, tendría las funciones de Organismo Auditante y finalmente, la Dirección Provincial de Informática y Comunicaciones, sería responsable de administrar y operar la infraestructura tecnológica de la Autoridad Certificante de la Provincia en su centro de cómputos.

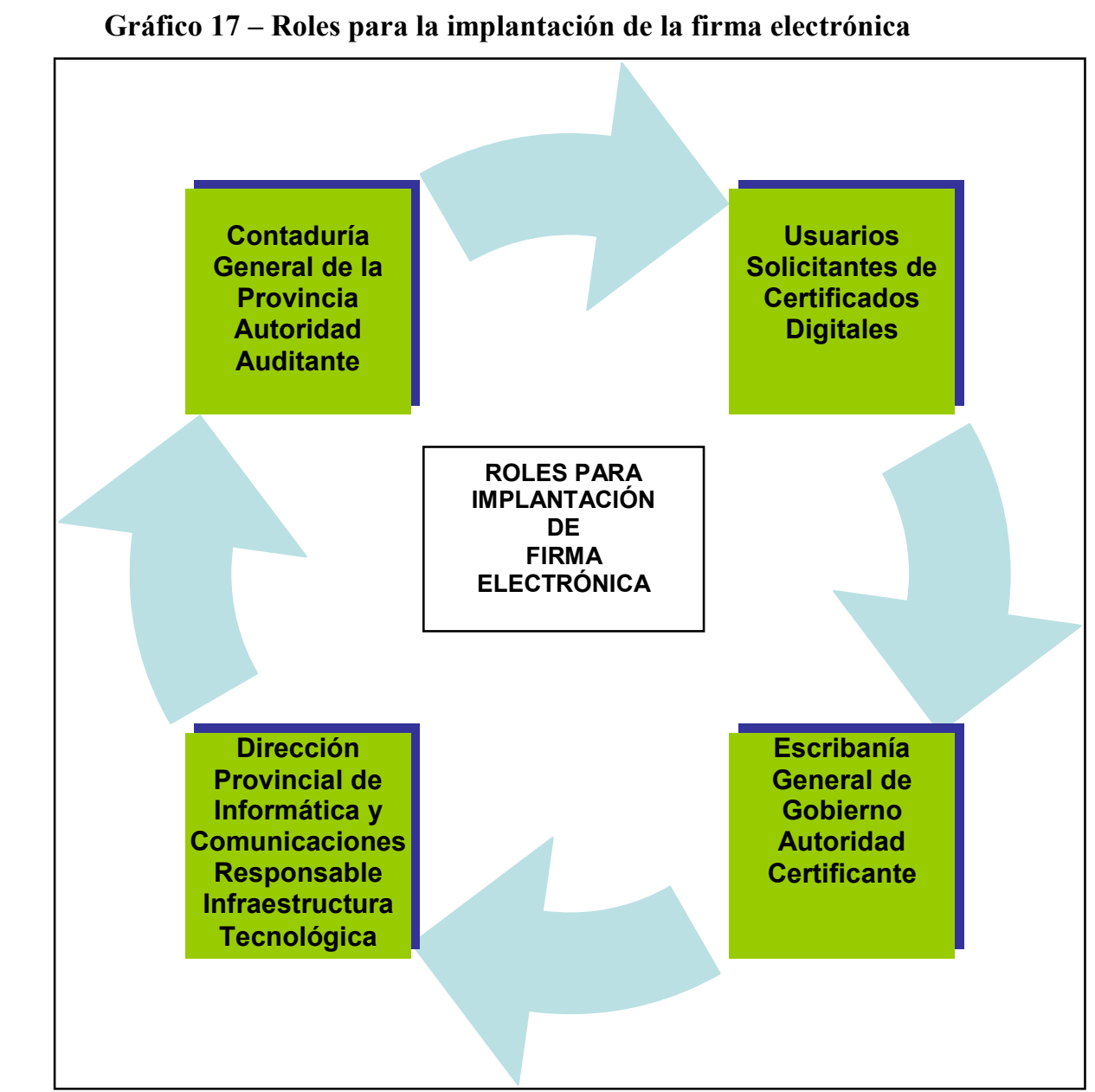

Fuente: Elaboración propia sobre la base de la Resolución $\mathrm{N}^{0}$ 113/05 del Secretario General de la Gobernación.

El día 17 de octubre de 2005, esto es, a más de un año de la sanción del Decreto No 919/04, el entonces Secretario General de la Gobernación dictó la Resolución N ${ }^{\circ}$ 113/05 que habilitó el inicio de la experiencia de firma electrónica en la Administración Pública Provincial ${ }^{268}$. Se consideró necesario y oportuno autorizar la metodología para

267 Los manuales de procedimiento de la Autoridad Certificante y de los Organismos Auditantes y Licenciantes así como los estándares tecnológicos aplicables a las claves que debían ser definidos en un plazo no mayor de ciento ochenta días corridos.

${ }^{268}$ Conforme pudiera consultarse con los informantes claves de los organismos intervinientes, una vez más, las distintas concepciones existentes entre la Dirección Provincial de Informática y Comunicaciones 
incorporar procesos administrativos tendientes a la implementación de la firma electrónica como "Prueba Piloto".

Se estableció en esa Resolución que las TIC constituyen herramientas de probada eficacia para la mejora en la gestión interna, facilitando la realización de los trámites administrativos, aumentando la velocidad de las comunicaciones $\mathrm{y}$ disminuyendo los obstáculos derivados de las barreras geográficas. Por ello, se afirmó que la implementación de la firma electrónica en el ámbito interadministrativo aportaría la seguridad y certeza necesarias para el intercambio de la información y de los actos administrativos enviados a través de las TIC.

Previa solicitud por nota, explicitando los procesos dónde se habilitará la firma, la Autoridad de Aplicación comunicaría la habilitación del proceso a la Autoridad Certificante y al organismo solicitante, quien podría requerir a dicha Autoridad Certificante la emisión de los certificados de clave pública de los funcionarios de la jurisdicción intervinientes en el proceso habilitado, hasta el nivel de Jefaturas de Departamento titulares de subdominios del dominio gba.gov.ar.

El procedimiento estaba detallado en el Anexo I de la Resolución: todo funcionario solicitante de un certificado debía iniciar el trámite de solicitud ingresando al sitio web de la Autoridad Certificante, https://pki.gba.gov.ar, o a través del sitio web principal del Gobierno de la Provincia "www.gba.gov.ar". Debía completar el formulario habilitado, incluyendo sus datos identificatorios y generar su propio par de claves, lo que permitiría la remisión de datos a la Autoridad Certificante.

Una vez finalizado el proceso de validación de la identidad del solicitante, se iniciaba el proceso de emisión del certificado, los que tendrían un período de vigencia de un año.

La entonces Dirección Provincial de Informática y Comunicaciones como responsable de la Infraestructura Tecnológica, mantendría un sistema de archivos que permitía la conservación, en condiciones adecuadas de seguridad, de toda la información referida a los procesos de emisión y administración de los certificados. Asimismo, debía poseer un plan de contingencias que permitiera garantizar el mantenimiento mínimo de la operatoria y la recuperación de los recursos comprometidos dentro de las veinticuatro horas de producida una emergencia. Para ello implementaría controles de seguridad físicos, lógicos y personales a fin de dotar de un adecuado marco de seguridad a las funciones que se desarrollen, entre ellos, generación de claves, autenticación, emisión y revocación de certificados, archivos, etc.

En el marco de ese proceso, se presentaron algunos Organismos para firmar electrónicamente parte de sus procesos. Entre ellos, merece destacarse el proyecto del Patronato de Liberados Bonaerense. A 2006, el Patronato contaba con una planta de personal de alrededor de 700 personas, de las cuales 600 prestaban servicios en los diferentes Municipios. Ello hacía de la dispersión de su personal un problemática real, y la firma electrónica aparecía como una solución eficiente para ello.

El Patronato fue uno de los Organismos innovadores en materia de modernización a través del uso de las TIC. En efecto, aún sin el respaldo normativo, y a modo de prueba, con más de un año de avance a la reglamentación, los agentes del

y la Secretaría Ejecutiva de Gobierno Electrónico en cuanto la existencia o no de la tecnología necesaria para la prueba retrasó la sanción de la norma. 
Patronato efectuaron pruebas con la utilización de certificados digitales en correos electrónicos que vincularon al Director de Sistemas de Información para el Control, los responsables de Administración de Redes y Administración de Bases de Datos y el Responsable de la Unidad Presidencia del Patronato.

Como señaló uno de los informantes clave del Organismo, la experiencia arrojó resultados sumamente positivos. Se llevó a cabo mediante la utilización de certificados digitales que se tramitaban desde la Autoridad de Certificación de la entonces Subsecretaria de la Gestión Pública del Gobierno Nacional y al mismo tiempo se utilizaron dispositivos token de almacenamiento externo de los certificados. ${ }^{269}$

A los efectos de darle validez jurídica a las experiencias, el Patronato realizó una presentación para sumarse al proceso. Se planteó digitalizar el circuito de comunicación entre las Direcciones Provinciales de Ejecución Penal en Libertad, de Regiones, la Dirección de Sistemas de Información para el Control, y las Subdirecciones de Control y Ejecución Penal de las Regiones II y VI. Según el informante, esta decisión buscaba incluir en el proyecto diferentes variables:

- Ubicación geográfica. Dependencias ubicadas tanto en la Sede Central, en la ciudad de La Plata pero en otro inmueble, y en el norte de la Provincia de Buenos Aires.

- Competencia temática. Las Direcciones y Subdirecciones seleccionadas responden directamente a la tarea medular del Organismo, con experiencia en la utilización y administración de las herramientas tecnológicas.

- Dimensión. Al incluir cinco (5) actores con alto nivel de responsabilidades, se obtendría un diseño acotado, controlable y de fácil monitoreo.

Las Dependencias seleccionadas intercambiaban frecuentemente todo tipo de comunicaciones, informes, memos, notas, pedidos, que en un año representaban un volumen aproximado de entre 2000 y 3500 comunicaciones, que válidamente podrían ser pasados al circuito electrónico. En la práctica, estas comunicaciones escritas en soporte papel con las Delegaciones se materializaban según la urgencia mediante dos canales: correo privado 24 hs., y a través del sistema de correo oficial (SODIC). En el primer caso existía una demora total el proceso de despacho y recepción de tres (3) días y en el segundo, de entre cinco (5) y diez (10) días.

Según el informante del Patronato, el organismo contaba con la suficiente disponibilidad de recursos de software y hardware, tanto en la sede en La Plata como en el interior, como para poner en práctica el proyecto y probada capacidad para soporte técnico, experiencia en el manejo de las herramientas y fundamentalmente un compromiso expreso desde la máxima autoridad del Organismo y del Ministerio de Justicia para acompañar, apoyar, difundir y promover el éxito de la iniciativa. ${ }^{270}$

El primer certificado digital expedido por la Autoridad Certificante (Escribanía General de Gobierno), correspondió precisamente a un funcionario del Patronato que se

\footnotetext{
269 Dos llaves de autentificación de dos factores modelo iKey 1000 USB de Rainbow, provistos al efecto por la empresa SITEPRO.

270 Tal es así que la solicitud del pedido no fue efectuada por Presidente del Patronato, sino por el propio Ministro del área.
} 
constituyó así en el primer usuario de esta nueva tecnología en la Provincia de Buenos Aires. ${ }^{271}$

De este modo y a partir de la utilización de tecnología de firma electrónica mediante el método de par de claves (clave pública y clave privada), se garantizaría que la información enviada y recibida entre las cuentas de correo institucional de las áreas involucradas cuente con la certeza de que el mensaje haya sido enviado de la cuenta del remitente y no de otra, y la seguridad de que el mensaje desde que fue firmado no haya sido alterado (autoría e integridad).

Como consecuencia de los resultados de las pruebas efectuadas por el Poder Ejecutivo, hubo en el Poder Legislativo nuevo interés en tratar el tema el proyecto de adhesión a la ley nacional de firma digital.

Finalmente, con algunas modificaciones al proyecto originario, se sancionó la Ley Provincial No 13.666, la que fue promulgado para mayo de 2007.

Finalmente, conforme el texto de la Ley, la Provincia de Buenos Aires adhirió a la Ley Nacional $\mathrm{N}^{\circ} 25.506$ en los términos del artículo $50^{\circ}$ de dicho cuerpo legal, en sus Capítulos I a IV, V en su artículo $26^{\circ}$, VII, IX y Anexo, en las condiciones y términos dispuestos en la presente Ley.

Se dispuso que el Poder Ejecutivo Provincial, designara el (o los) Organismos de la Administración Pública que actuarán como certificador para el ámbito de la Administración bonaerense pero inscribiéndose como certificador licenciado en los términos de la Ley Nacional No 25.506 y su Decreto Reglamentario No $2.628 / 02^{272}$.

Ahora, según la ley aprobada, queda claro que las certificación son emitidas intraadminsitración bonaerense sin perjuicio del reconocimiento con otras Jurisdicciones, convenio mediante.

\begin{abstract}
ARTICULO 7.- Las certificaciones para agentes de la Administración Pública Provincial y Municipal, destinados a la gestión interna de los Organismos, y la Certificación de particulares para cumplimiento de trámites ante la Administración Pública Provincial y Municipal, con la correspondiente emisión de la clave pública, serán emitidas por el Organismo Provincial de acuerdo al procedimiento que se establezca en orden a lo expresado en el artículo anterior. Sin perjuicio de ello, la Autoridad de Aplicación podrá reconocer certificados de particulares emitidos por certificadores de otras jurisdicciones para la realización de trámites ante la Administración Pública Provincial y Municipal.
\end{abstract}

La Ley, por su parte, autorizaba al Poder Ejecutivo a dictar un reglamento a los fines de instalar en forma efectiva y progresiva el expediente digital, autorizándoselo a

271 Los otros Organismos que pudieron acceder a la firma electrónica fueron la Dirección Adjunta de Fiscalización (dependiente de la Dirección Provincial de Rentas) y el Organismo de Control de la Energía (OCEBA) además del Patronato de Liberados.

272 Para el cumplimiento de las responsabilidades a su cargo, continúa el artículo $5^{\circ}$ de la Ley provincial, que el Organismo Certificador deberá delegar en Autoridades de Registro las funciones de validación de identidad y otros datos de los suscriptores de certificados y de registros, de las presentaciones y trámites que le sean formuladas. Se agregaba, en otro artículo, que cada Poder establecerá en el ámbito de su competencia una Autoridad de Registro distinta. 
contemple excepciones al régimen previsto en los capítulos VII y VIII de la Ley de procedimientos administrativos (conf. art. 10, Ley $\left.\mathrm{N}^{\mathrm{o}} 13.666\right)^{273} \mathrm{y}$, a renglón seguido, equiparaba ${ }^{274}$ la firma digital con la ológrafa para todos aquellos actos administrativos donde la Ley de Procedimientos Administrativo donde ésta los requiriera (conf. art. 11, Ley $\mathrm{N}^{\mathrm{o}}$ 13.666).

Finalmente, fue durante la primera gestión del gobernador Scioli, aunque con un proyecto proyectado por los equipos técnicos de la gestión anterior, que se dictó el Decreto $\mathrm{N}^{\mathrm{o}} 1.388 / 08$ el cual completa el marco legal para la firma digital intraadministración en la Provincia de Buenos Aires. El texto de la reglamentación sigue, en líneas generales, las establecidas en el Decreto $N^{\circ}$ 919/04 aunque está más clara su dependencia respecto de las políticas y normas de la autoridad nacional en la materia.

${ }^{273}$ Inconstitucionalmente, por el carácter delegativo de la medida que modifica la Ley de procedimientos.

${ }^{274}$ La Ley nacional no lo llega a decir expresamente. 


\section{CAPÍTULO X. ESTUDIO DE CASOS III - SUBSECRETARÍA DE GESTIÓN TECNOLÓGICA Y ADMINISTRATIVA}

\section{Documentos estandarizados}

\section{a) Los Pliegos Tipo}

El surgimiento de los contratos tipo, especialmente el Pliego Único de Condiciones Generales y el Pliego Particular para la contratación de Bienes y Servicios, cuyo fin primordial fue el ordenamiento de las contrataciones en toda la Provincia, tiene antecedentes en varios decretos impulsados por el Cr. Luis Deniro entonces a cargo de la Subsecretaría de Gestión Tecnológica y Administrativa (antes Subsecretaría Administrativa) dependiente de la Secretaría General de la Gobernación.

La sanción de los Pliegos Tipo, como veremos, estuvo antecedida de grandes modificaciones al Reglamento de Contrataciones. Si bien, como hemos dicho, durante el período de estudio la relación entre el Ejecutivo y el Legislativo fue tirante, no fue necesario hacer modificaciones a la Ley de Contabilidad, Decreto-Ley $N^{\circ} 7.764 / 71$, que regula los proceso de contratación y remate públicos, pues salvo algunos principios generales en esa ley establecidos (como el de publicidad o la licitación pública como regla y sus excepciones), los procedimientos se encuentran delegados en el Ejecutivo que los ha regulado en el Reglamento de Contrataciones, Decreto $\mathrm{N}^{\circ} 3.300 / 72$.

Aparece como una necesidad básica, en todo el proceso de reforma, el reordenamiento luego de la emergencia económico y social de 2001-2002. Obviamente que el Estado no estuvo ajeno a esa crisis y, como veremos, el principio de legalidad que debe orientar las contrataciones administrativas estuvo muy resentido. Así, por ejemplo, en 2001, sólo tuvieron intervención previa de legalidad por la Contaduría General de la Provincia menos de 130 licitaciones (licitaciones públicas y privadas), que representaban sólo el $28 \%$ del gasto y el $4 \%$ de las actuaciones sometidas a su control de legalidad. Por el otro lado, hubo una gran elusión de los procedimiento, no sólo por los procedimientos de excepción autorizados por la ley, esto es, las contrataciones directas, que

... han resuelto el $7 \%$ de los trámites (unos 270 ) y el $42 \%$ de la inversión (menos de $\$ 42,0$ millones)- sino y fundamentalmente por formas de contratación no autorizadas (legítimos abonos - casi 3300 trámites), que generaron el $28 \%$ de las erogaciones, unos $\$ 57,0$ millones, mediante el $86 \%$ de las actuaciones (Considerando del Decreto $\left.\mathrm{N}^{\circ} 787 / 04\right)$. 
Cuadro 41 - Controles previos de legalidad 2001

\begin{tabular}{|c|c|c|c|c|c|}
\hline \multirow[t]{2}{*}{ Tipo Erogaciones } & \multicolumn{2}{|c|}{ Actuaciones } & \multicolumn{2}{|c|}{ Importes Autorizados } & \multirow{2}{*}{$\begin{array}{l}\text { Promedio } \\
\text { Transacción } \\
\text { Miles de \$ }\end{array}$} \\
\hline & Cantidad & $\%$ & Millones de \$ & $\%$ & \\
\hline Legítimo Abono & 3250 & $86 \%$ & 57 & $28 \%$ & 18 \\
\hline $\begin{array}{l}\text { Contrataciones } \\
\text { Directas }\end{array}$ & 273 & $7 \%$ & 84,4 & $42 \%$ & 309 \\
\hline Licitaciones Públicas & 62 & $2 \%$ & 48,9 & $24 \%$ & 789 \\
\hline Licitaciones Privadas & 63 & $2 \%$ & 6,3 & $4 \%$ & 100 \\
\hline $\begin{array}{l}\text { Locaciones de Obra } \\
\text { y Otros }\end{array}$ & 119 & $3 \%$ & 3,5 & $2 \%$ & 29 \\
\hline Totales & 3767 & $100 \%$ & 200,1 & $100 \%$ & 53 \\
\hline
\end{tabular}

Fuente: Informe de Gestión Ejercicio Financiero 2001- Contaduría General de la Provincia Estadísticas Abril 2001 - Diciembre 2001

Como veremos, en el Decreto $\mathrm{N}^{\circ} 787 / 04$ y subsiguientes modificaciones, la complejidad aparece como obstáculo y de allí deriva la necesaria simplificación impulsada. Pero también aparece el principio de mayor delegación a los funcionarios pero con la correspondiente mayor responsabilización. Además, estas reformas buscaron la reducción del gasto, promoviendo un esquema que, respetando la descentralización administrativa, unificara el proceso de toma de decisión.

Precisamente, para dar cuenta de esta línea, indicaremos los decretos antecedentes y extraeremos de sus Considerandos, algunas de las orientaciones que fundamentan su dictado. 
Cuadro 42 - Considerando de Decretos antecedentes al Pliego Tipo de Bases y Condiciones Generales y Pliego Tipo de Condiciones Particulares para la Contratación de Bienes y Servicios.

\begin{tabular}{|c|c|}
\hline Decreto $\mathrm{N}^{\circ}$ & Considerandos \\
\hline $787 / 04$ & 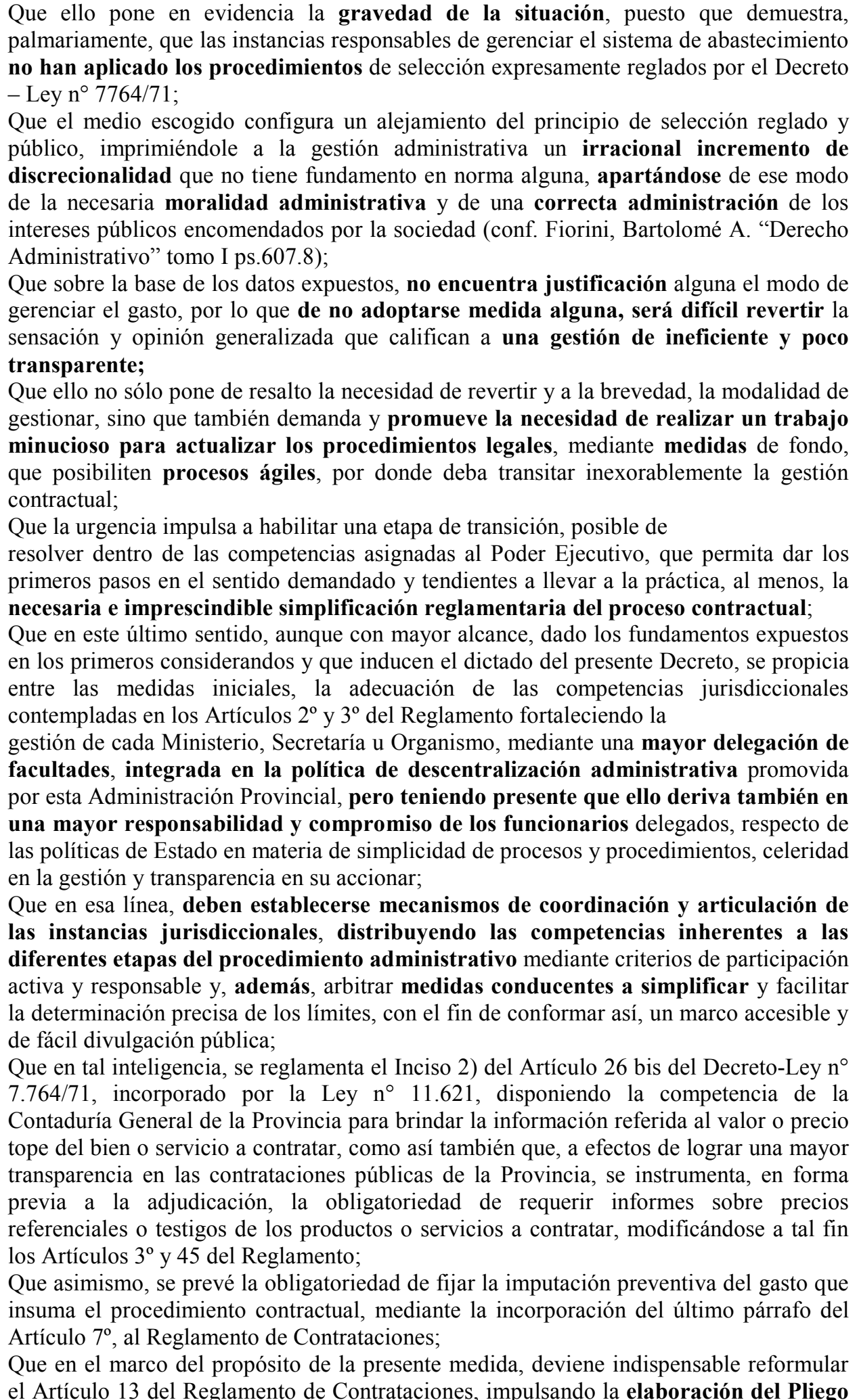 \\
\hline
\end{tabular}




\begin{tabular}{|c|c|}
\hline & 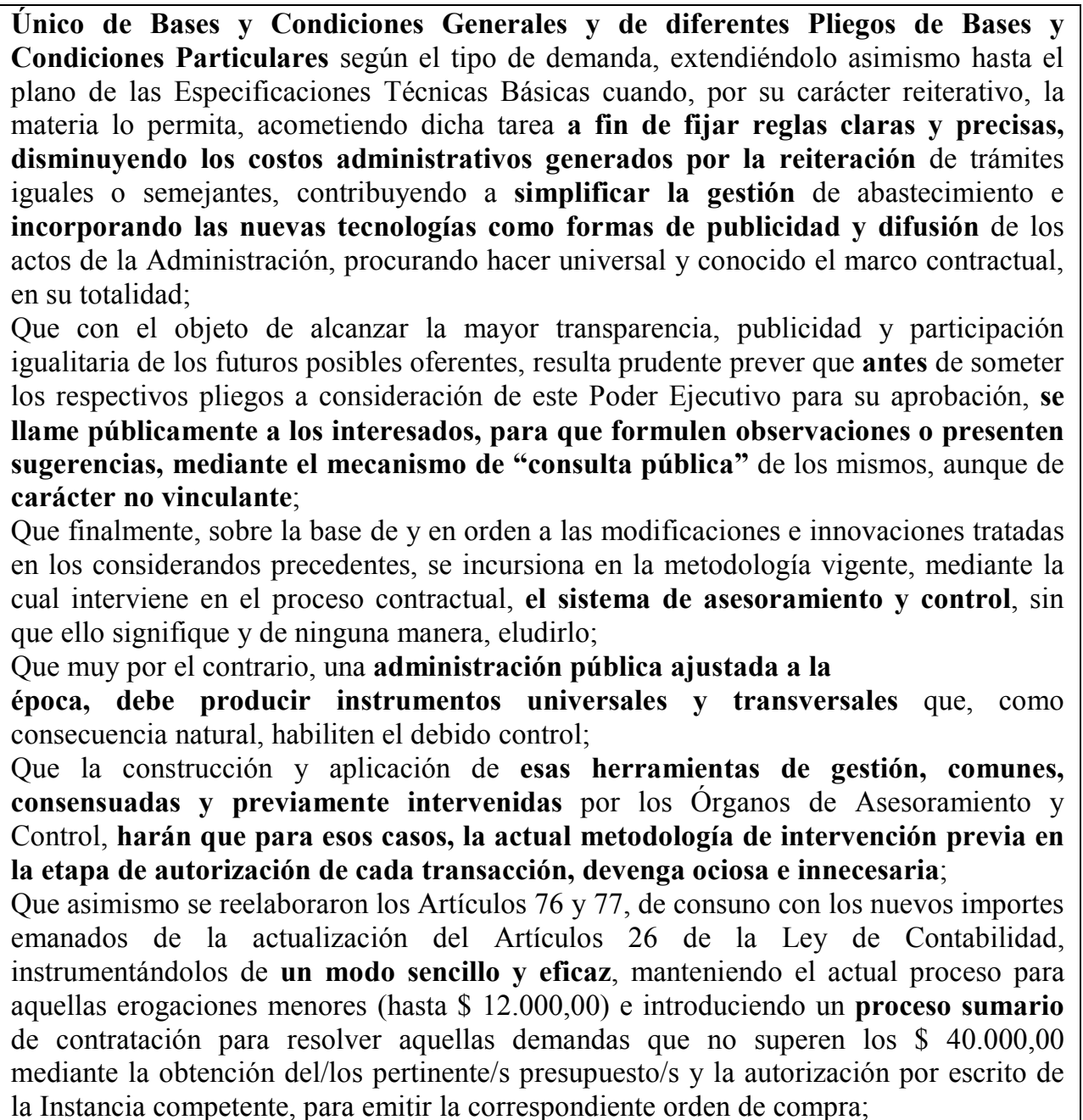 \\
\hline $1.344 / 04$ & $\begin{array}{l}\text { Que las modificaciones introducidas en el Reglamento de Contrataciones por el citado } \\
\text { decreto } 787 / 2004 \text {, han simplificado significativamente los procedimientos de } \\
\text { contratación, fortaleciendo las competencias jurisdiccionales y promoviendo una } \\
\text { mayor responsabilidad y compromiso en la gestión de cada ministerio, secretaría, ente } \\
\text { u organismo; } \\
\text { Que es decisión de este Poder Ejecutivo profundizar ese proceso con el objeto de } \\
\text { construir un modelo administrador, cuya política explícita es garantizar la } \\
\text { transparencia y legalidad de los procedimientos de contratación pública; } \\
\text { Que para hacer efectivas tales aspiraciones, deviene necesario adoptar medidas } \\
\text { complementarias que neutralicen las acciones que pudieran habilitar la adquisición } \\
\text { de bienes y la contratación de servicios, en el marco cuestionado; } \\
\text { Que para alcanzar tal objetivo, debe cerrarse toda brecha que pueda inhibir en la } \\
\text { práctica, la decisión política explicitada y por lo tanto reservar un procedimiento de } \\
\text { naturaleza excepcionalísima, como es el reconocimiento de gastos sin el correspondiente } \\
\text { amparo contractual establecido en la Ley de Contabilidad y el Reglamento de } \\
\text { Contrataciones, para aquellos casos en que la realidad de los acontecimientos } \\
\text { sustantivos, superen toda posibilidad de actuar en oportunidad, a través de los } \\
\text { procesos reglados; } \\
\text { Que por esa razón debe asumirse su control directo y quedar sujeto ese } \\
\text { procedimiento, a la evaluación y decisión de las instancias políticas de la } \\
\text { Administración provincial y su aprobación, circunscripta al exclusivo juicio del poder } \\
\text { administrador; } \\
\text { Que en tal inteligencia, deviene necesario concentrar en esta instancia la competencia } \\
\text { específica para aprobar el reconocimiento de gastos por legítimo abono, sobre la } \\
\text { base de causas y razones debidamente justificadas y ponderadas por parte de la instancia }\end{array}$ \\
\hline
\end{tabular}




\begin{tabular}{|c|c|}
\hline & $\begin{array}{l}\text { generadora del gasto y avaladas por la autoridad superior jurisdiccional; } \\
\text { Que por su carácter y naturaleza excepcional, cabe requerir inevitablemente, la previa } \\
\text { intervención de los organismos de asesoramiento y control, para que evalúen la } \\
\text { procedencia de las causales y razones aducidas y los argumentos y fundamentos } \\
\text { esgrimidos; }\end{array}$ \\
\hline $2.698 / 04$ & 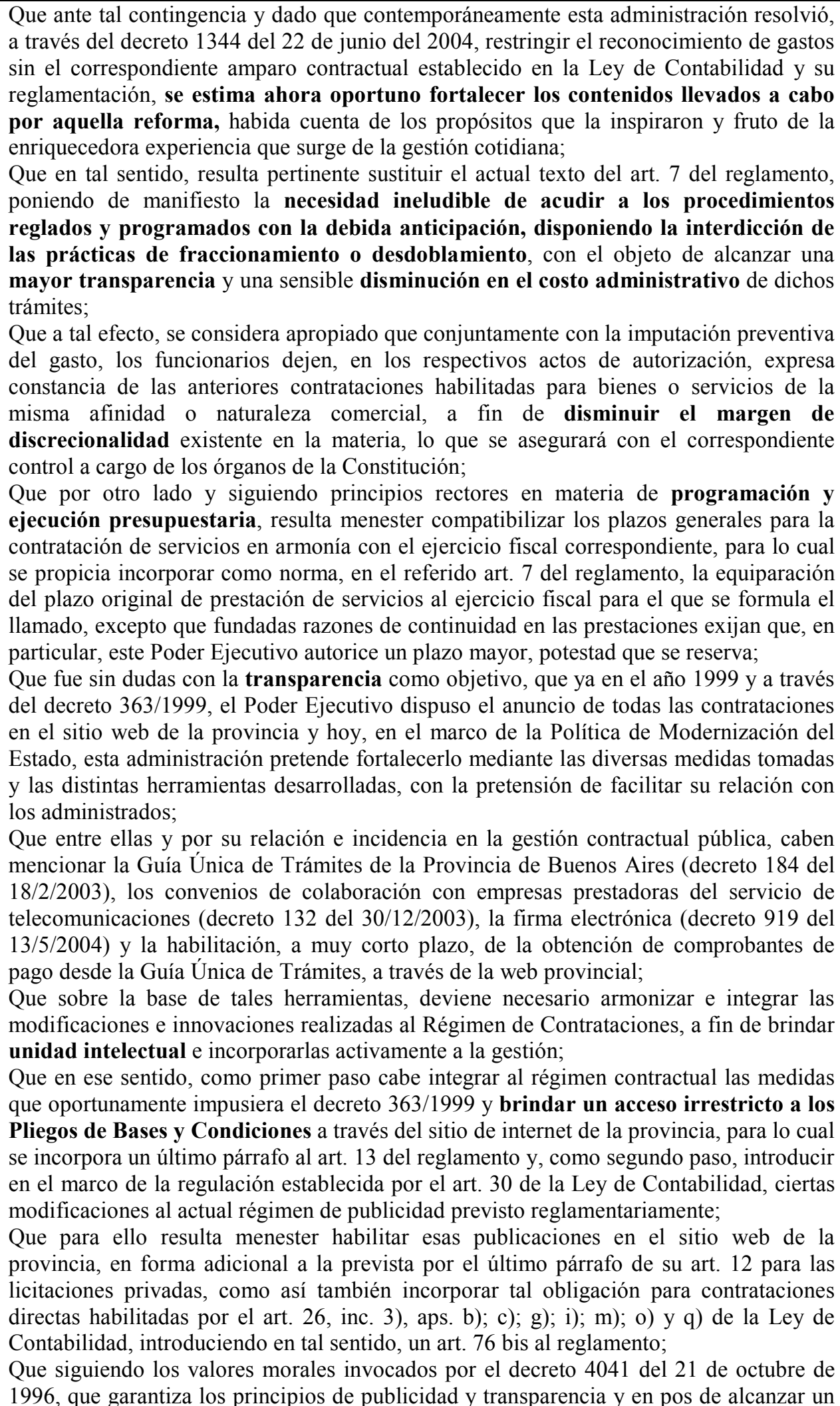 \\
\hline
\end{tabular}




\begin{tabular}{|l|l|}
\hline cuerpo reglamentario único, deviene necesario integrarlo al decreto 3300/1972 y sus \\
modificatorios; \\
Que resulta necesario revisar el texto del art. 21 del Reglamento de Contrataciones, \\
incorporando mecanismos que agilicen los pagos a proveedores, de acuerdo con los \\
parámetros de factibilidad realizados por la Tesorería General de la Provincia, \\
disponiendo su implementación directamente sobre las cuentas bancarias de los \\
beneficiarios, aportándole así, mayor seguridad jurídica y certeza al sistema de pagos; \\
Que asimismo, en la línea de pensamiento que inspira al presente, deviene necesario \\
alcanzar una mayor simplicidad técnica-administrativa respecto a la garantía de \\
mantenimiento de oferta, fijando a tal fin el monto del art. 22 del reglamento, en la suma \\
de pesos doce mil (\$ 12.000); \\
$\begin{array}{l}\text { Que por otra parte y como por cuestiones de desenvolvimiento operativo en la gestión } \\
\text { contractual, pueden generarse al momento de la adjudicación, desfasajes en los plazos de } \\
\text { prestaciones de servicios respecto de los previstos inicialmente, con el fin de preservar la } \\
\text { mayor celeridad y eficacia pretendidas en los procedimientos, se hace necesario revisar } \\
\text { el régimen de perfeccionamiento de las prórrogas de contratos preexistentes determinado } \\
\text { en el art. 55 del reglamento, modificado por el decreto 787/2004, adecuando por un lado } \\
\text { el límite temporal para su prolongación al término originalmente previsto en el llamado y } \\
\text { por otro, el material, permitiendo aumentar dentro del plazo original del contrato, la } \\
\text { cantidad o nivel de prestaciones contratadas (v.g. personas a transportar, pacientes a } \\
\text { alimentar, metros a limpiar, etc.), lo que sin dudas, aportará mayor claridad al sistema de } \\
\text { ampliación y prórroga de contratos; }\end{array}$ \\
\hline
\end{tabular}

Con la sanción de los decretos anteriores se fijaron las necesidades de avanzar hacia las contrataciones estandarizadas mediante la aprobación de cláusulas únicas para toda la Administración bonaerense, por un lado, las que debían ser elaboradas por la Subsecretaría cualquiera fuere la materia, y por el otro, hacia las compras centralizadas o unificadas como veremos en la siguiente sección a propósito de la compra de equipamiento informático. Así, se imponía por un lado una obligación la propia Subsecretaría propiciante de las reformas, pero cerraba también un círculo que le daba más poder.

Las modificaciones analizadas fijaron que los procedimientos de contratación se regirán por el Pliego Único de Bases y Condiciones Generales y por los Pliegos Tipo de Bases y Condiciones Particulares y de Especificaciones Técnicas Básicas por Tipo de Demanda, cuando ésta fuere reiterativa.

Es en ese marco que la Subsecretaría de Gestión Tecnológica y Administrativa de la Secretaría General de la Gobernación redactó el proyecto de Pliego Único de Bases y Condiciones Generales para la Contratación de Bienes y Servicios, que fue sometido a consideración del gobernador, previa intervención de los organismos de asesoramiento y control, y que, con algunas modificaciones menores, fue aprobado por Decreto $\mathrm{N}^{\circ} 1.676 / 05$.

El Decreto aprobatorio señala que este documento estandarizado "habilita una herramienta que tenderá sin dudas, a convertirse en uno de los puntales de la gestión de abastecimiento". Añade que cabe valorar e institucionalizar la modalidad de compra unificada, que implica la consolidación de la demanda común y de su trámite, pero manteniendo desconcentrados el perfeccionamiento y cumplimiento del contrato.

Los objetivos de los Pliegos, según se informa, buscaron implementar un procedimiento claro y transparente, dotado de la necesaria agilidad y eficiencia a fin de obtener una mayor y mejor concurrencia al llamado del Estado Provincial a efectuar ofertas, que paralelamente respete los principios de publicidad e igualdad. 
Dado que no es la pretensión de la tesis realizar un análisis de las clausulas jurídicas, que en verdad, son una reproducción y/o aclaración de los términos ya indicados en el Reglamento de Contrataciones, sino de los aspectos innovativos del proceso de reforma, cabe destacar:

- la inclusión de una declaración jurada del oferente que, en sus procesos de fabricación o producción, no utiliza mano de obra infantil, como medio administrativo de implementar y asegurar en las contrataciones que celebra el Gobierno Bonaerense, el efectivo respeto a los Derechos del Niño, tal como lo garantiza el Artículo 36 inciso 2 de la Constitución de la Provincia de Buenos Aires.

- la publicidad en la página Web de la Provincia de los pliegos que, en principio resultarán gratuitos y de libre acceso, sin perjuicio de la posibilidad de fijar el valor del mismo, cuando resulte oportuno y conveniente en relación de su extensión, complejidad y/o costo de reproducción;

Pero tal vez uno de los aspectos más innovadores, en contra de una clara cultura del papel dentro de la administración, es la estructura del acto administrativo. En efecto, teniendo en cuenta que la autorización de los llamados se hace con arreglo al Pliego de Condiciones Generales y, de corresponder, Particulares, aprobado por Decreto $\mathrm{n}^{\mathrm{o}}$ 1.676/05, no resulta necesaria la revisión jurídica de ellos, ganando en tiempo y simplificando la tarea de los organismos gestores como de los de control pero tampoco resulta necesario incorporarlos al expediente de autorización (ni firmarlos e incorporarlos en la Oferta por parte de los oferentes pues se presumen conocidos y aceptados como consecuencia de su presentación).

Así, sólo cabe incorporar al expediente las Plantillas de Campos Editables del Pliego de Condiciones Particulares (Bienes e Insumos Anexo IV Decreto $n^{0} 1.676 / 05$ ) o Condiciones Particulares (resto de los bienes y servicios); las Especificaciones Técnicas Básicas; las Planillas de Convocatoria y de Cotización.

Conforme al gráfico que agregamos elaborado por la propia Subsecretaría se esperaba con esta reforma acortar el proceso de autorización a sólo 32 días hábiles máximo. 
Gráfico 18 - Tiempos esperados de gestión con los Pliegos Tipo

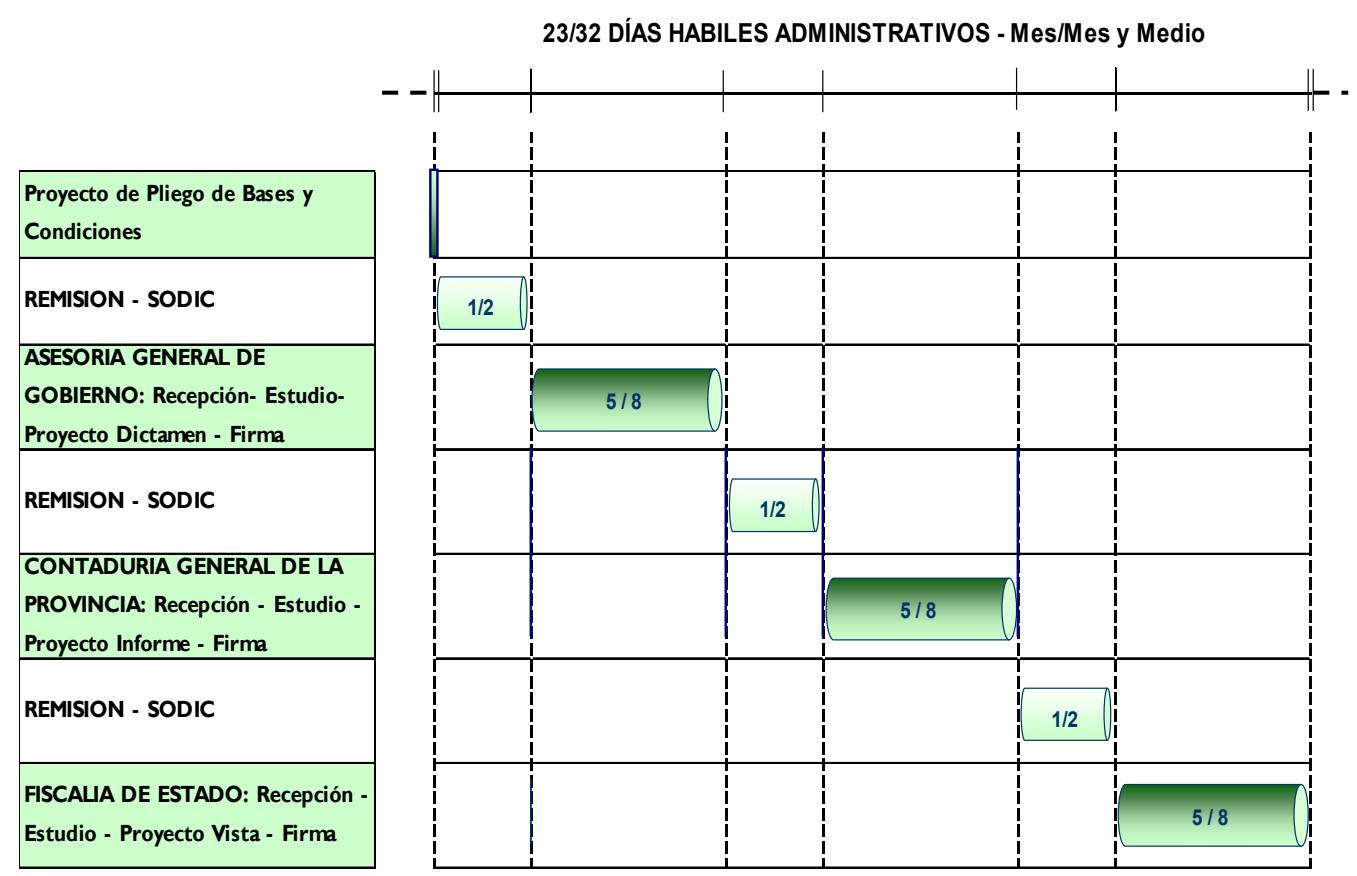

Fuente: Subsecretaría de Gestión Tecnológica y Administrativa.

En verdad, los plazos de intervención a esta altura, eran sólo viables para los llamados a contrataciones de Bienes incluidos dentro del catálogo. En efecto, no sólo por los cambios normativos propiciados sería viable esta reducción de tiempo, sino también por la vigencia, a través del Decreto $\mathrm{N}^{\mathrm{o}} 1.103 / 03$, del Convenio de Cooperación y Asistencia Técnica que se firmara entre el Gobierno Nacional y ese Poder Ejecutivo Provincial para incorporar el Catálogo de Bienes y Servicios del Sistema de Identificación de Bienes y Servicios de Utilización Común, mediante la cesión acordada con el Gobierno Nacional a través de la firma del "Acta Complementaria - Cooperación Técnica y Cesión Gratuita y su Addenda Complementaria", aprobadas en la Provincia por el Decreto $\mathrm{N}^{\mathrm{o}} 2.754 / 04$. Con este catálogo, que permite la identificación del bien cuya contratación se pretende, resulta viable la aplicación del pliego pues el producto y sus especificaciones se encuentran estandarizadas y hace posible el control del precio mediante los Valores referenciales de la Contaduría General de la Provincia. Con Pliegos Particulares para la contratación de servicios, los plazos de demora son mucho mayores.

\section{b) Otros documentos estandarizados}

El éxito que se vislumbraba con diseño de los Pliegos Tipo impulsó la sanción de otros decretos que estandarizan algunos procesos repetitivos de la Administración y que insumían plazos casi anuales, como los contratos de locación de obra que eran 
usualmente rechazados por los Organismos de Control o la Dirección Provincial de Personal por ser, por su objeto, contratos de servicios.

La primera experiencia resultó con la aprobación de contratos modelos para la contratación de artistas y co-producción para Radio Provincia. Este modelo fue aprobado por Decreto $N^{\circ} 414 / 05$. Allí no sólo se estableció un modelo de locación de obra $^{275}$ sino también de coproducción autorizando a los productores a comerciar el espacio aéreo de conformidad con la vigencia de la prórroga de la excepción a lo normado en el Artículo 107 de la Ley $\mathrm{N}^{\circ}$ 22.285, dispuesta por el Poder Ejecutivo Nacional mediante los Decretos $\mathrm{N}^{\mathrm{o}} 2.355 / 92$, No $621 / 98$ y $\mathrm{N}^{\mathrm{o}} 104 / 03$ y a lo dispuesto por el Poder Ejecutivo Provincial mediante el Decreto $\mathrm{N}^{\circ} 1.025 / 94$, prorrogado a su vez por los Decretos No 1624/94, No 2410/98 y No 943/03, por los cuales LS 11 Radio Provincia de Buenos Aires se encontraba habilitada a propiciar la ocupación de espacios radiales con fines de publicidad y propaganda. Para agilizar el proceso de pago a los productores se recurrió a la constitución de un Fondo Rotatorio en el marco de lo establecido por el artículo 59 de la Ley de Contabilidad y su Reglamentación.

Así, luego de esta experiencia, se aprobó un contrato tipo para la contratación de locaciones de obra, de aplicación especialmente, aunque no únicamente, a personas. Por Decreto $\mathrm{N}^{\circ}$ 944/05, aprobado el 10 de mayo de 2005, se afirma que es necesario deslindar claramente cuándo una determinada actividad debe encuadrarse jurídicamente en el marco de un contrato de locación de obra evitando con ello la prestación encubierta un servicio o de trabajo bajo la figura del contrato referenciado. Se aclara, asimismo, que la Administración Pública Provincial debe recurrir a la contratación de profesionales, especialistas y técnicos en determinadas áreas del saber cuándo requiere, de forma circunstancial, una especial capacidad para alcanzar un resultado concreto, aclaración necesaria, nuevamente para evitar el contrato de servicio encubierto que puede generar, a posteriori reclamos por parte de los contratados para su incorporación a planta estable. Por ello, continúa el decreto, el contratado debe contribuir, a través de su especial idoneidad, a la ejecución de una actividad específica incluida en un determinado proyecto, programa, plan o acción de gobierno, con la entrega de un producto concreto, predeterminado con claridad y precisión y cumplirla en un lapso acorde con la misma y encuadrar su profesión dentro de los términos de las disposiciones legales y administrativas vigentes que regulan el ejercicio de su actividad, finalizando su actividad con la entrega encomendada por la Administración.

Es a fin de evitar elusiones y posibles reclamos y teniendo en cuenta que se trata de un medio de contratación al que el Estado Provincial recurre en forma repetitiva, se aprobó un modelo tipo de contrato de Locación de Obra para que, en el marco del actual Artículo 14 del Reglamento Contractual, se contribuya a evitar confusiones, dispendio de actividad administrativa y rechazos de proyectos de contrataciones. En el contrato se especifica cada uno de los requisitos expresados más arriba, previendo un Anexo donde, a modo de esquema, se determine los objetivos esperados, las actividades comprometidas, las productos requeridos y su plazo de entrega, detallando, asimismo, el cronograma de pago contra la aprobación del producto ${ }^{276}$. Nuevamente, entre los objetivos explícitos buscados aparece la unificación de los criterios existentes entre las

\footnotetext{
${ }^{275}$ Los que se aprueban en forma directa el marco del artículo 26, inc. $3^{\circ}$, apartado h) de la Ley de Contabilidad.

${ }^{276}$ Asimismo se elaboró una Guía para la Preparación de Contratos de Obra para facilitar su redacción, y en cada cláusula del contrato (a completar) existen términos de referencia.
} 
diversas dependencias de la Administración Pública Provincial ${ }^{277}$ y la agilización del proceso de suscripción de las contrataciones.

Otro de los contratos especialmente aplicables para la contratación de personas fue el régimen de contratación para artistas del Teatro Argentino fue impulsado cuando esta Subsecretaría intervino la administración del Teatro por continuos conflictos gremiales dentro del Teatro y con el propio Instituto Cultural. El régimen fue aprobado por Decreto $\mathrm{N}^{\circ} 307 / 06$.

Allí se reconoce que el Instituto Cultural formula y perfecciona una importante cantidad de contratos de locación de obra, los cuales poseen una naturaleza y prácticas propias, derivadas de su carácter artístico, que demandan una atención y regulación específica. Es en ese marco que se aprueban ocho proyectos de Contrato Tipo de Locación de $\mathrm{Obra}^{278}$. Por otro lado, según se afirma, y teniendo en cuenta que en cada caso sólo varían una mínima cantidad de elementos circunstanciales, se consideró conveniente que los contratos se celebren bajo la modalidad de Contratos de Adhesión, conforme a las Planillas que como Anexos forman parte integrantes de cada uno los Contratos Tipo, donde se rubricaran las firmas de los contratantes, que siendocompletados los elementos variables de cada caso.

También se aprobó un sistema simplificado, con un modelo contractual, para la adquisición de espacios de publicidad oficial para ser utilizados por la entonces Secretaría de Comunicación. Según el Decreto $\mathrm{N}^{\circ} 1.868 / 05$, este tipo de contrato, por efectuarse mediante un esquema de compra global y corporativa, con previsiones de gasto hasta fin de año, permiten obtener tarifas preferenciales respecto de las vigentes en el mercado, que implicarán una mayor presencia en los medios de los actos de gobierno. Se afirma, asimismo, que el sistema no sólo implicará obtener importantes ahorros, sino también establecer un mecanismo ágil y dinámico de contratación y de acuerdo a las necesidades de la Provincia y a un mundo cada vez más intercomunicado. En verdad, el sistema es un esquema de compra anticipada de espacios de publicidad, una orden de compra abierta luego de la cual, mediante la indicación de las áreas competentes y de acuerdo a los precios de antemano pactados, se van asignado a publicidades específicas y "consumiéndose" el crédito ${ }^{279}$.

Nuevamente, aparece en las consideraciones, que el establecimiento de Contratos Tipos, coadyuvará a la unificación de los criterios existentes entre las diversas dependencias de la Administración Pública Provincial y brindará la necesaria agilidad y eficiencia al proceso administrativo de suscripción de los futuros contratos.

Pese al relativo éxito en la utilización de los Pliegos y contratos estandarizados, relatividad dada por la dificultad en su uso por algunas Jurisdicciones y no por la

\footnotetext{
${ }^{277}$ El modelo de contrato es aplicable a toda la Administración Pública.

278 Estos están destinados, el primero, a vincular al personal regido por la Ley $\mathrm{N}^{\mathrm{o}} 12.268$ y sus modificatorias; el segundo, para artistas no pertenecientes a la Administración Pública Provincial que deban desempeñarse en las obras líricas; el tercero, para contratar artistas para la realización en obras organizadas directamente por el Instituto; el cuarto, para la contratación de actuaciones artísticas determinadas; el quinto, para contratar múltiples actuaciones artísticas; el sexto, de producción artística; el séptimo, para contratar múltiples producciones artísticas y el último, para la contratación de talleres.

${ }^{279}$ Este esquema en verdad se reconoce cuando se establece que la modalidad de pago anticipado parcial a cuenta de precio, pero del ochenta por ciento $(80 \%)$ del precio total convenido, debiéndose tomar compromiso por un quince por ciento $(15 \%)$ adicional ante el agotamiento del monto anterior.
} 
política en sí mismo, con posterioridad a la finalización de la gestión no se aprobaron nuevos Pliegos ni contratos estandarizados.

\section{Compras de elementos informáticos}

Otro aspecto importante para analizar es la política de compras del Estado en materia de equipamiento informático y software pues esa política es decisiva no sólo respecto a la infraestructura para el desarrollo del gobierno electrónico sino también para dar cuenta de los procesos de modernización del Estado a través del uso de elementos informáticos. Es cierto que su uso no garantiza per se una mejora en la prestación de los servicios pero da muestras, al menos, de una cierta preocupación por ello.

Sobre la base de los Pliegos estandarizados, y con el objeto de afianzar el "poder de compra corporativo" de la Provincia, la Subsecretaría previó un esquema de centralización de la demanda común y del primer trayecto contractual, por el cual se "fijan los precios", manteniendo descentralizados el perfeccionamiento y cumplimiento del contrato. ${ }^{280}$

Durante el período de estudio, la Subsecretaría de Gestión Tecnológica y Administrativa de la Secretaría General de la Gobernación concentró el proceso de compra de elementos informáticos a través de esquemas de compras anuales unificadas de software y hardware para todos los organismos de la Administración Pública Provincial. ${ }^{281}$

Estos esquemas unificados habilitan -como se ha dicho- a la Provincia, para actuar como corporación pero sin los perjuicios de la concentración de funciones, alcanzándose valores -respecto de los de mercado y conforme las experiencias referidas- que legitiman ese accionar (Deniro, 2005:7).

En razón del presupuesto y en función de un análisis técnico, cada organismo determinó el software y hardware de su conveniencia y el precio se determinó en función del poder de compra, procurando mayor transparencia.

Según el Informe de Gestión de la Subsecretaria, con la compra de hardware consolidada se obtuvieron rebajas del orden del $45 / 50 \%$ respecto a los precios pagados por la Provincia en anteriores ocasiones (Informe de Gestión 2002-2004, 2004). La primera experiencia implicó reducción de costos y simplificación administrativa del

\footnotetext{
${ }^{280}$ El antecedente se reconoció en la experiencia y los resultados obtenidos en las convocatorias realizadas en el marco del "Régimen Simplificado de Contratación y Pago" autorizado por el Artículo 62 de la Ley $\mathrm{N}^{\circ} 12.874$ y reglamentado por los Decretos $\mathrm{n}^{\circ} 2404 / 02$ y n $^{\circ} 55 / 03$, que fuera absolutamente beneficiosa para el interés fiscal, tanto por la reducción de costos como por la simplificación administrativa del trámite y su reciente réplica,

${ }^{281}$ Si bien la mayor proporción de las compras se ha hecho por medio de este mecanismo centralizado, han existido excepciones por parte de organismos con poder político propio, como la compra del Ministerio de Gobierno para el servicio de documentación.
} 
trámite. El Decreto $\mathrm{N}^{\mathrm{0}} 2.643 / 04$ aprobó el llamado a Licitación Pública para satisfacer la demanda de equipamiento informático en 2004 y los Decretos $\mathrm{N}^{\circ} 3.399 / 05$ y $\mathrm{N}^{\circ}$ $3.400 / 05$ hicieron lo propio para la compra de hardware y software, respectivamente, para los ejercicios 2005 y $2006 .^{282}$

Si analizamos los montos globales, el Ministerio de Seguridad es el Organismo que más invirtió en compra de elementos informáticos durante esos tres años $(\$ 14.621 .583,7)$, seguido por el Ministerio de Economía $(\$ 7.294 .568,32)$ y por la Secretaría General de la Gobernación $(\$ 3.897 .428,01)$, aunque vale aclarar que la compra de esa última Jurisdicción incluyó a las Secretarías de Estado cuya administración dependían de ella: Secretaría de Derechos Humanos y las entonces Secretarías de Política Ambiental y de Prensa y Comunicación Social. ${ }^{283}$

\section{Gráfico 19 - Gastos en TIC en 2004-2006 en pesos}

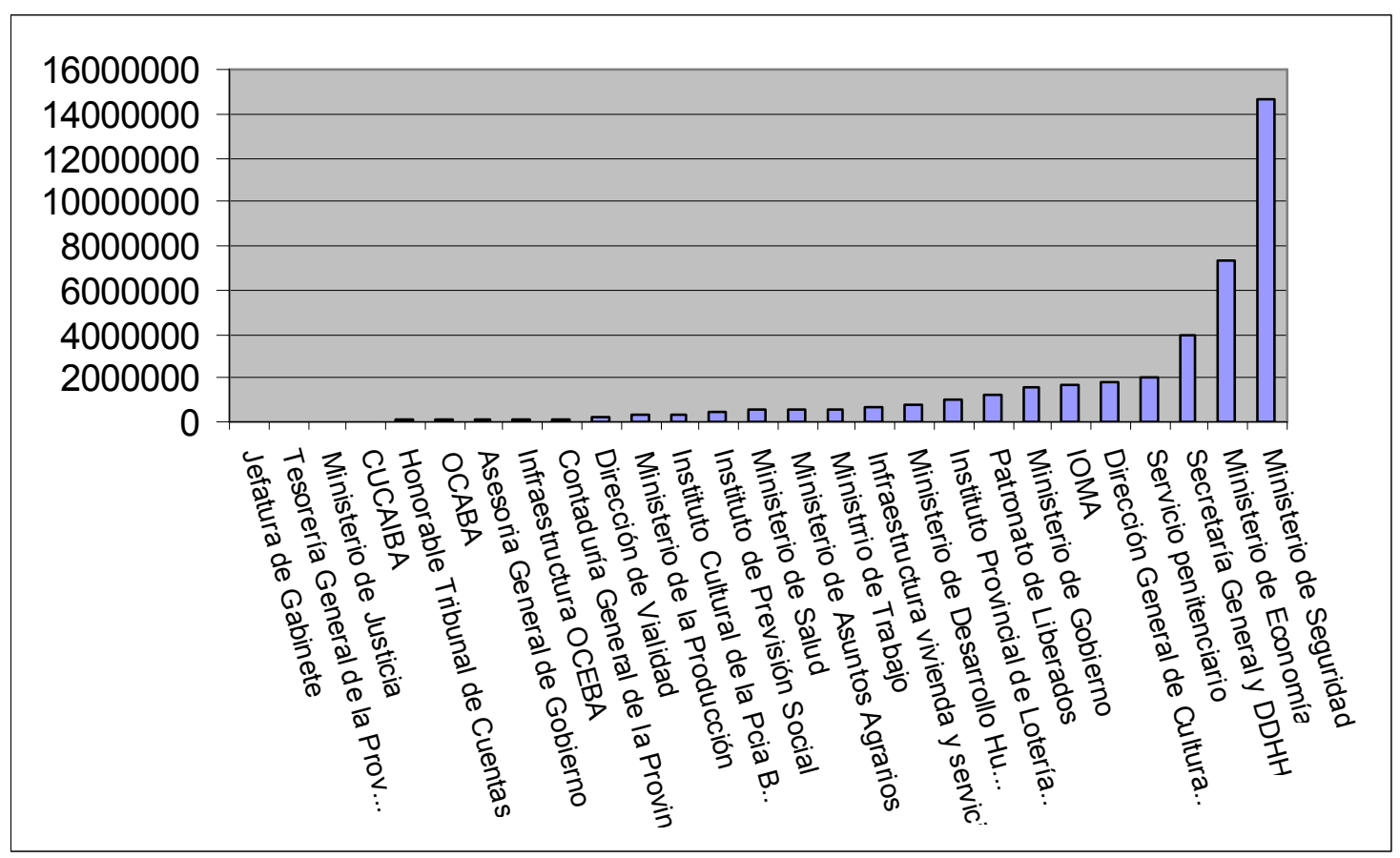

Fuente: Elaboración propia.

Pero en términos relativos, esto es, analizando la cantidad de presupuesto de cada uno de los Organismos durante esos tres años y el monto global invertido, advertimos que los Organismos que menos invirtieron en TIC fueron el Ministerio de Justicia, con un $0,0019 \%$ de su presupuesto, lo cual confirma el bajo monto absoluto de inversión, el Instituto de Previsión Social con un 0,004 \% y la Dirección General de Cultura y Educación con un 0,008 \% de sus respectivos presupuestos.

\footnotetext{
282 En el caso del software, la adquisición se hizo por contratación directa fundado en razón de la exclusividad del proveedor de las licencias.

283 Los Organismos que menos han invertido en términos absolutos fueron la Jefatura de Gabinete (\$ 1.6359), la Tesorería General de la Provincia $(\$ 17.702,16)$ y el Ministerio de Justicia $(\$ 32.457,55)$.
} 
Desde el otro lado, el Organismo que más porcentaje de su presupuesto invirtió en TIC fue la jurisdicción de la Gobernación con el 0,61\%, el Ministerio de Gobierno con el $0,64 \%$ y Patronato de Liberados con el 2,19\% de sus respectivos presupuestos.

\begin{tabular}{|c|c|c|c|}
\hline ORGANISMO & TOTAL GATO & PRESUPUESTO & $\begin{array}{l}\text { PROCEN } \\
\text { TAJE }\end{array}$ \\
\hline Ministerio de Justicia & 32457,55 & 1624059000 & 0,002 \\
\hline Instituto de Previsión Social & 415058,37 & 8513049000 & 0,005 \\
\hline Dirección General de Cultura y Educación & 1827398,36 & 21570317019 & 0,008 \\
\hline Instituto Provincial de Lotería y Casinos & 1001149,59 & 10346067000 & 0,010 \\
\hline Dirección de Vialidad & 230232,4 & 1365849390 & 0,017 \\
\hline Ministerio de Desarrollo Humano & 745150,96 & 3397771200 & 0,022 \\
\hline Ministerio de Salud & 523437,51 & 1689909699 & 0,031 \\
\hline Infraestructura, Viv. y Servicios Públicos & 629697,84 & 2052462810 & 0,031 \\
\hline CUCAIBA & 34882,3 & 98093385 & 0,036 \\
\hline IOMA & 1737381,65 & 3665997000 & 0,047 \\
\hline Jefatura de Gabinete & 16359 & 23333820 & 0,070 \\
\hline Tesorería General de la Provincia & 17702,16 & 24272040 & 0,073 \\
\hline Honorable Tribunal de Cuentas & 84085,26 & 110206800 & 0,076 \\
\hline Infraestructura OCEBA & 140431,32 & 127075380 & 0,111 \\
\hline Servicio penitenciario & 2023782,66 & 1538754600 & 0,132 \\
\hline Ministerio de la Producción & 330424,22 & 247664805 & 0,133 \\
\hline Instituto Cultural de la Pcia Bs. As. & 364424,09 & 234406800 & 0,155 \\
\hline Contaduría General de la Provincia & 141703,34 & 60051900 & 0,236 \\
\hline Asesoría General de Gobierno & 130574,45 & 51176340 & 0,255 \\
\hline Ministerio de Seguridad & 14621583,7 & 5681748900 & 0,257 \\
\hline Ministerio de Asuntos Agrarios & 556848,49 & 123066540 & 0,452 \\
\hline OCABA & 115681,01 & 24504600 & 0,472 \\
\hline Ministerio de Economía & 7294568,32 & 1520788257 & 0,480 \\
\hline Ministerio de Trabajo & 594258,68 & 107358000 & 0,554 \\
\hline Gobernación (Sec. Gral. y Secretarías) & 3897428,01 & 638843940 & 0,610 \\
\hline Ministerio de Gobierno & 1626134,8 & 251379300 & 0,647 \\
\hline Patronato de Liberados & 1208355,79 & 54996000 & 2,197 \\
\hline
\end{tabular}

\section{Fuente: Elaboración propia.}




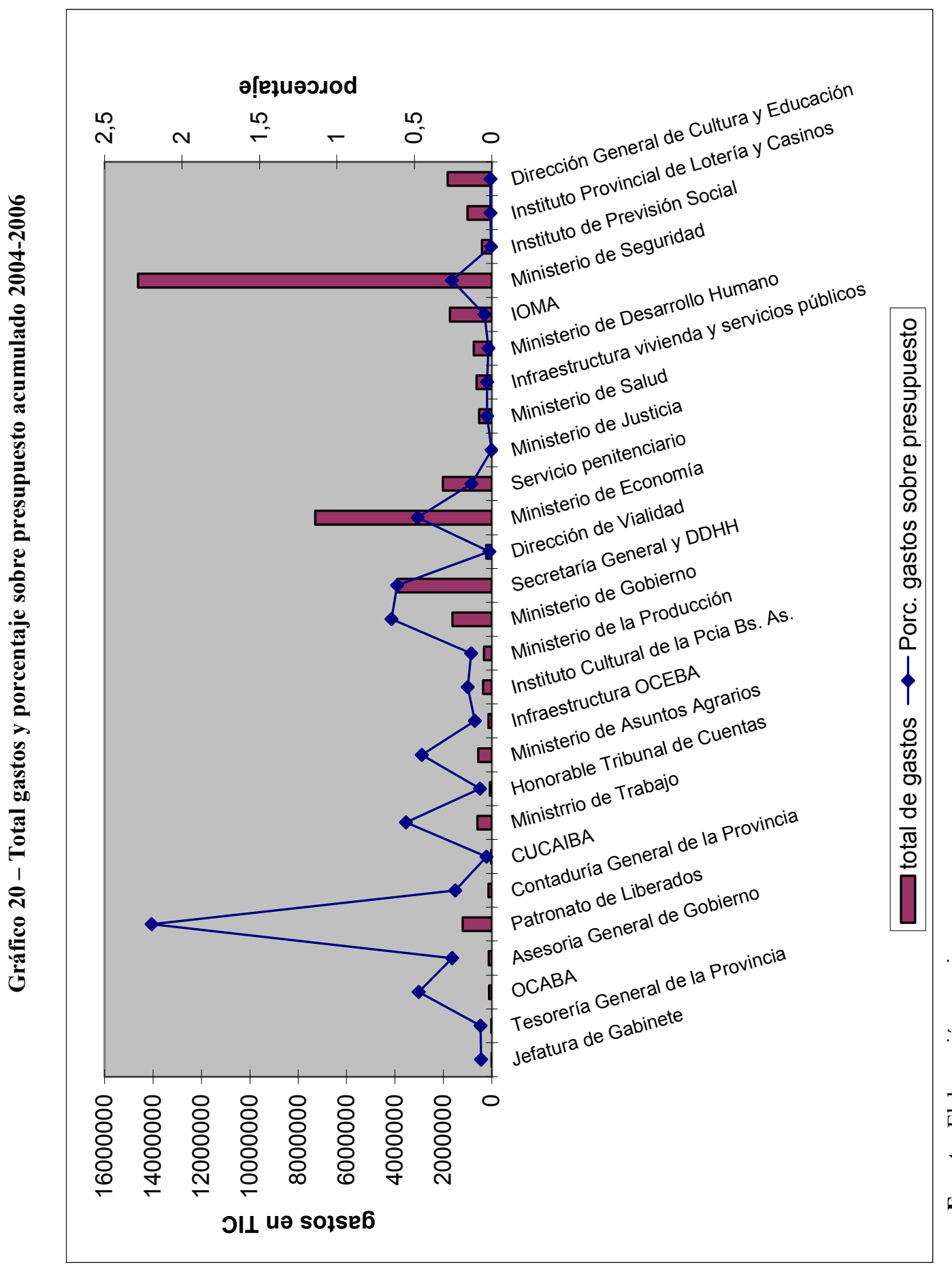


Si ahora cruzamos los datos de la cantidad de inversión en tecnología por empleado público, advertimos que la Gobernación es el Organismo que más gasta por empleado en TIC (\$ 1.834), seguido por Patronato de Liberados, el Ministerio de Economía y OCEBA, todos con más de $\$ 1.000$ por empleado.

\begin{tabular}{|c|c|c|c|}
\hline ORGANISMO & $\begin{array}{c}\text { TOTAL } \\
\text { GASTOS }\end{array}$ & $\begin{array}{c}\text { TOTAL } \\
\text { EMPLEADOS }\end{array}$ & $\begin{array}{l}\text { INVERSIÓN POR } \\
\text { EMPLEADO }\end{array}$ \\
\hline Gobernación (Sec. Gral. y Secretarías) & 3897428,01 & 2124 & 1834,95 \\
\hline Patronato de Liberados & 1208355,79 & 700 & 1726,22 \\
\hline Ministerio de Economía & 7294568,32 & 4754 & 1534,41 \\
\hline OCEBA & 140431,32 & 107 & 1312,44 \\
\hline IOMA & 1737381,65 & 2330 & 745,66 \\
\hline Ministerio de Trabajo & 594258,68 & 932 & 637,62 \\
\hline Ministerio de Gobierno & 1626134,8 & 2597 & 626,16 \\
\hline Instituto de Previsión Social & 415058,37 & 726 & 571,71 \\
\hline Ministerio de la Producción & 330424,22 & 584 & 565,79 \\
\hline Ministerio de Asuntos Agrarios & 556848,49 & 1015 & 548,62 \\
\hline Infraestructura, Viv. y Servicios Públicos & 629697,84 & 1606 & 392,09 \\
\hline Contaduría General de la Provincia & 141703,34 & 393 & 360,57 \\
\hline Instituto Provincial de Lotería y Casinos & 1001149,59 & 3096 & 323,37 \\
\hline Ministerio de Seguridad & 14621583,7 & 46295 & 315,84 \\
\hline Honorable Tribunal de Cuentas & 84085,26 & 406 & 207,11 \\
\hline Ministerio de Justicia & 32457,55 & 176 & 184,42 \\
\hline Instituto Cultural de la Pcia Bs. As. & 364424,09 & 2125 & 171,49 \\
\hline Ministerio de Desarrollo Humano & 745150,96 & 4720 & 157,87 \\
\hline Servicio penitenciario & 2023782,66 & 13706 & 147,66 \\
\hline Dirección de Vialidad & 230232,4 & 1697 & 135,67 \\
\hline Jefatura de Gabinete & 16359,00 & 122 & 134,09 \\
\hline Tesorería General de la Provincia & 17702,16 & 134 & 132,11 \\
\hline OCABA & 115681,01 & 880 & 131,46 \\
\hline Ministerio de Salud & 523437,51 & 42519 & 12,31 \\
\hline Dirección General de Cultura y Educación & 1827398,36 & 215521 & 8,48 \\
\hline
\end{tabular}

Fuente: Elaboración propia.

Elaborando un índice con los dos indicadores (inversión en TIC por empleado/porcentaje inversión del presupuesto en TIC) veremos que el Patronato de Liberados es el organismo mejor posicionado (primer y segundo lugar respectivamente), seguido por Gobernación (tercer y primer lugar) y el Ministerio de Economía (quinto y tercer lugar).

Cuadro 45 - Organismos lideres en inversión en TIC

\begin{tabular}{|l|l|r|}
\hline & \multicolumn{1}{l}{$\begin{array}{l}\text { Posición } \\
\text { inversión en TIC } \\
\text { por empleado }\end{array}$} & \multicolumn{2}{l|}{$\begin{array}{l}\text { Puesto porcentaje inversión del } \\
\text { presupuesto en TIC }\end{array}$} \\
\hline Patronato de Liberados & 1 & 2 \\
\hline Ministerio de Gobierno & 2 & 7 \\
\hline Gobernación (Sec. Gral. y Secretarías) & 3 & 1 \\
\hline
\end{tabular}




\begin{tabular}{|l|r|r|}
\hline Ministerio de Trabajo & 4 & 6 \\
\hline Ministerio de Economía & 5 & 3 \\
\hline OCEBA & 6 & 4 \\
\hline IOMA $\quad 17$ & 5 \\
\hline \multicolumn{2}{|c|}{ Fuente: Elaboración propia. } &
\end{tabular}

\section{La Red Única Provincial de Comunicaciones de Datos}

El estudio de caso del proceso de licitación de la Red Única de Comunicación de Datos resulta relevante por tanto el monto involucrado en la operación como por el procedimiento utilizado.

En la Provincia de Buenos Aires la existencia de una Red de Comunicación resulta más que necesaria teniendo en cuenta que debe interconectar a todos los organismos provinciales y municipales distribuidos en una superficie mayor a los $307.000 \mathrm{~km}^{2}$.

La Red de Comunicaciones de la Provincia es de larga data: se creó en el año 1977 con el fin de interconectar a los Municipios Provinciales con el Gobierno Central. En el año 1992, en el marco de la Ley de Reconversión Administrativa y con el fin de optimizar los recursos y servicios en la materia, se introdujo el concepto de "servicio único de transmisión y recepción de datos", que ha regido hasta la fecha y que ha sido llevado a la práctica por la mayoría de las Dependencias Provinciales y los Municipios. Por medio del Decreto $\mathrm{N}^{\mathrm{o}} 1.204 / 03$, impulsado por la Secretaría General de la Gobernación, el Poder Ejecutivo estableció que la Red de Comunicaciones creada por el Decreto $\mathrm{N}^{\mathrm{o}} 1.522 / 79$ debía ser única para todo el ámbito de la Administración Pública bajo la denominación de "Red Única Provincial de Comunicación de Datos". ${ }^{284}$

Sin embargo, algunos organismos provinciales y municipios contaban con conexiones a redes independientes, generando recursos ociosos e ineficaces y provocaban múltiples e innecesarias erogaciones. Por ello, la Administración Provincial decidió integrarlos a la Red Única Provincial de Comunicación de Datos.

La siguiente imagen representa la estructura, demasiado anárquica, de la entonces Red Provincial.

\footnotetext{
284 A las razones de seguridad explícitas en los Considerandos del Decreto, hay que agregar otro tipo de razones: las económicas, centralización de las contrataciones, y políticas, acumulación de poder de la Secretaría General.
} 
Imagen 6 - Esquema de la red antes de la licitación

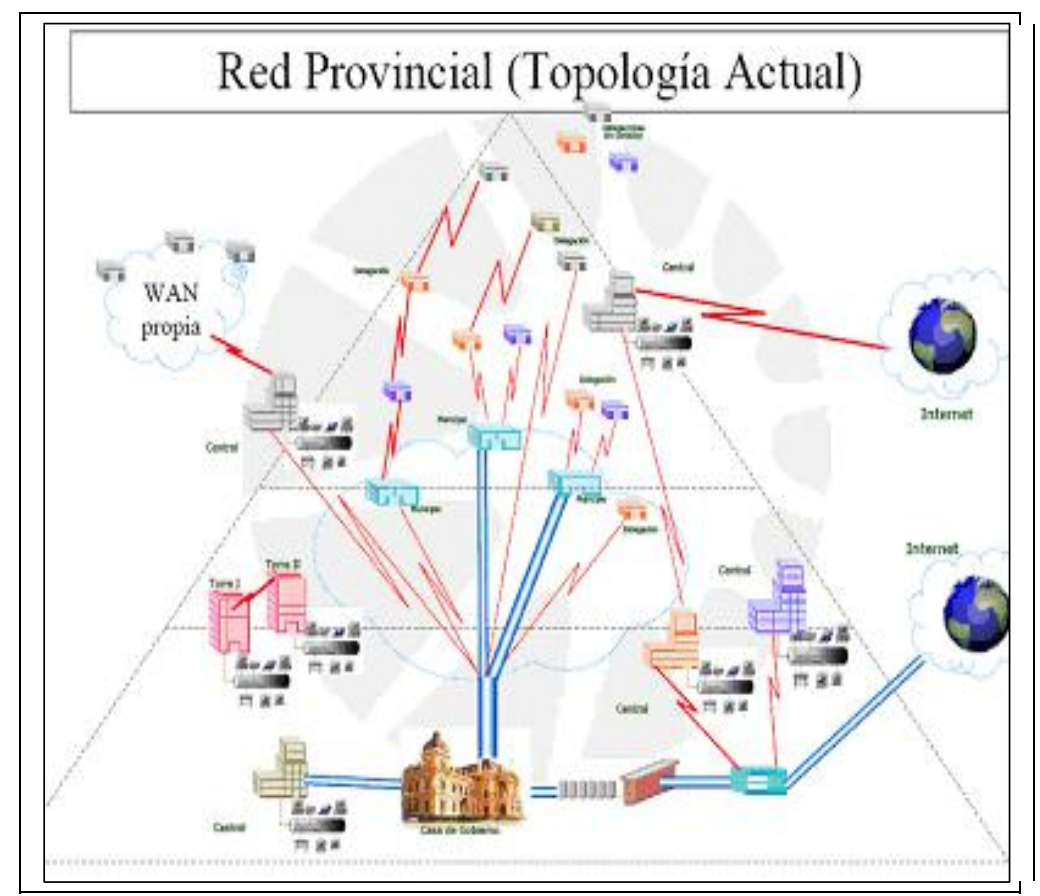

Fuente: ex Dirección Provincial de Informática y Comunicaciones

Para reordenar esa estructura, se llamó a Licitación Pública. Se establecía en el Decreto de autorización que no debería existir ninguna preferencia tecnológica sobre la cual dar conectividad a la Provincia, sino que se vincularían a las dependencias a través de las soluciones tecnológicas que resulten adecuadas a las necesidades de la Provincia sobre la base de la tecnología disponible al momento de perfeccionar los contratos (artículo $1^{\circ}$ del Decreto $\mathrm{N}^{\mathrm{o}} 1.204 / 03$ ). ${ }^{285}$

Se buscó la descentralización administrativa y la interconectividad de la totalidad de los organismos del Poder Ejecutivo, sus delegaciones y oficinas y los entonces 134 gobiernos municipales a través de unos 1.200 puntos de conexión, distribuidos en todo el ámbito de la Provincia de Buenos Aires y la Ciudad Autónoma de Buenos Aires. El presupuesto estimado del servicio a contratar, por un período de 5 años, se calculó en U\$S 40 millones.

La contratación del servicio de transmisión de datos y canales de órdenes para la "Red Única Provincial de Comunicación de Datos" configuró, según el Subsecretario del área, uno de los mayores negocios que se haya presentado en la Argentina en los últimos 10 años y el más importante en términos de infraestructura tecnológica.

Las características propias del objeto a contratar, la complejidad del análisis de los datos de las Ofertas, así como la necesidad de realizar un procedimiento transparente por los altos costos de la contratación, fueron desafíos que pudieron ser superados a través del uso de las TIC. La experiencia se caracterizó por la utilización intensiva de recursos informáticos, tanto en el desarrollo de los procesos de generación del modelo de negocio, entre ellos, interacción con los proveedores de servicios de comunicaciones, de equipamiento e integradores, confección de pliegos, consultas públicas a los

${ }^{285}$ Ello permitiría a la Red evolucionar junto con la evolución tecnológica. 
interesados y el propio llamado a licitación hasta obtención del pliego, presentación de las ofertas y apertura del llamado y análisis y evaluación de las Ofertas obtenidas (Deniro, 2005).

La Subsecretaría de Gestión Tecnológica y Administrativa de la Gobernación fue la dependencia encargada de llevar adelante la licitación. La entonces Dirección Provincial de Informática y Comunicaciones, como área responsable de la administración de la Red, intervino en las definiciones de su configuración técnica.

Alguno de los objetivos e implícitos desafíos, según se definieran desde esa área, fueron: garantizar la transparencia de la licitación; lograr la participación de todas las tecnologías desarrolladas y disponibles; garantizar un proceso competitivo con múltiples oferentes; obtener la mejor oferta técnico-económica posible para la Provincia; innovar en la ingeniería del Pliego de Bases y Condiciones y del consecuente Contrato (conf. Deniro, 2005).

El uso de las TIC fue intensivo y pese a no contar la Provincia con firma digital durante el proceso de la licitación, se utilizaron archivos digitales y se recurrió a la publicación web en varias instancias de la licitación.

Desde un inicio un borrador del pliego estuvo publicado en el sitio web de la Provincia y se utilizó el correo electrónico para que los proveedores enviaran sus comentarios y observaciones al pliego. La modificación del pliego llevaba a una nueva publicación web además de la comunicación por correo electrónico a todos los interesados. $^{286}$

Cerrada la etapa de elaboración del Pliego, luego de la aprobación previa de los Organismos competentes, se realizaron dos Consultas Públicas no vinculantes, donde se recibieron más de 120 observaciones, cuyas respuestas dieron lugar a un nuevo documento que fue publicado en la Web para información de todos los interesados. ${ }^{287}$

Una de las innovaciones más importantes estuvo dada como respuesta a una problemática a la que se enfrentaba el área encargada de la licitación. Se debían analizar más de 50.000 valores por cada oferente y se podrían presentar entre de 5 y 7 proveedores. La carga y análisis manual, según el procedimiento tradicional, no sólo hubiera desplazado en el tiempo los resultados de la licitación sino que existía el riesgo de un importante margen de error atendiendo a la magnitud de los valores a registrar y evaluar. $^{288}$

Desde el inicio del proceso de Licitación se tuvo en claro que era imposible realizar la evaluación de las ofertas y la posterior adjudicación en forma manual con garantía de un resultado seguro.

La problemática era igualmente importante para todos los actores. Para la empresa oferente, que debía presentar una planilla de más de 1000 filas y 60 columnas, el problema del error formal en la carga manual podría plantearle la pérdida de la

\footnotetext{
${ }^{286}$ Debe tenerse en cuenta que ello era posible en esta etapa vía web porque era el proyecto de Pliego y no el Pliego definitivo.

287 Algunas observaciones llevaron a la modificación del pliego y fueron agrupadas en una addenda que formó parte del mismo.

288 El Pliego de Licitación contenía 5 Anexos, tres de los cuales estaban destinados a que los oferentes presentaran sus ofertas técnico-económicas. Dado que debían cotizarse más de mil vínculos y que para cada uno de ellos debían consignarse entre 30 y 60 valores, cada oferta requería el procesamiento de más de 50.000 datos (Deniro, 2005.).
} 
licitación y para la Provincia, que recibiría una planilla en papel, por cada oferente, podría cometer errores de trascripción en el proceso de evaluación informático.

Fue por ello que las TIC proveyeron una solución mediante una metodología innovadora basada en recursos tecnológicos en la presentación de ofertas. Se propuso que los oferentes, además de presentar sus propuestas en la forma obligatoria según la Ley de Contabilidad y el Reglamento de Contrataciones -en papel firmadas- las presentaran en formato MS-Excel en dos CD's, los que alimentarían directamente un programa de evaluación computadorizado. Sin embargo, teniendo en cuenta que la oferta escrita es la única válida, ¿cómo se garantizaba a los oferentes que todos estaban recibiendo los mismos archivos para cotizar?; ¿cómo evitar diferencias entre la planilla electrónica digitalizada entregada por el oferente y la oferta escrita?

Para solucionar estos inconvenientes se decidió utilizar el algoritmo MD5, que es un algoritmo computacional de validez internacional que produce para cada archivo informático una serie de 32 dígitos hexadecimales que es único para cada archivo procesado. El cambio de un solo bit en el archivo, genera una serie distinta de dígitos hexadecimales. Esta serie de dígitos se denomina "Digesto Digital", "Hash" o simplemente "Clave".

El MD5 que ya se había utilizado inicialmente para entregar información a los oferentes, informando cada vez que se publicaba una nueva versión del pliego en la Web, fue la misma solución tecnológica a la hora de la evaluación de los archivos entregados por los oferentes. Así, se requirió que la oferta estuviera certificada por escribano público dando fe de que la oferta escrita había sido producida por el archivo entregado en la oferta en Disco Compacto, consignando en el acta notarial el Hash correspondiente.

La entonces Dirección Provincial de Informática y Comunicaciones desarrolló un sistema integrado de evaluación de ofertas con herramientas de Software Libre que posibilitó validar las propuestas, verificar que el Hash producido por cada archivo fuera idéntico al informado en el Acta Notarial por cada oferente y determinar el conjunto de Ítems/Oferentes a adjudicar, más conveniente para la Provincia (Deniro, 2005).

A fin de asegurar su funcionamiento y garantizar la transparencia del proceso, el software estuvo disponible con su código fuente en Internet para que pudiera ser evaluado y utilizado por los interesados para validar sus ofertas. Por otro lado, se convino la intervención de la Universidad Nacional de La Plata como actor externo que validara el proceso desde su conocimiento académico.

La propuesta técnico-económica solicitada debía ser impresa directamente desde el Formulario Electrónico, el que a su vez, debía grabarse en no menos de dos Discos Compactos.

El Acto de Apertura fue llevado a cabo el día 31 de agosto de 2004 en el Salón Dorado de la Gobernación de la Provincia de Buenos Aires a través de una red de datos "segura", sin acceso desde la Internet, compuesta por PC's principales y de respaldo, impresoras láser, cámara digital. El objeto fue brindar tranquilidad a los oferentes y la transparencia de todo el proceso.

Mediante las distintas PC, se validaron las Garantías de Ofertas, utilizando una planilla electrónica preparada para tal fin; se capturaron las imágenes de las "Claves" electrónicas del Acta Notarial impresa y entregada por cada oferente, que serviría para 
validar los Cd's presentados; se validaron los dos Cd's (Oferta y propuesta en formato digital) mediante su procesamiento para obtener el digesto digital seguro, el que debía coincidir con "la Clave" capturada desde el Acta Notarial; se ingresaron las Ofertas a la Intranet Provincial una vez validada la "identidad" de "las Claves".

Luego de todo ello, se confeccionó el Acta Notarial de Apertura en la que se volcaron mediante su captura automática, las "Claves" obtenidas en el proceso de validación de los Cd's a fin de incorporarlas sin alteraciones ni errores y se emitieron en pantalla gigante, donde podía constatarse la publicación en línea del formulario electrónico con las propuestas técnico-económicas presentadas y validadas. ${ }^{289}$

Así, casi todos los hitos trascendentales de la licitación fueron realizados a través de archivos digitales, sin perjuicio de la instrumentación en soporte papel y de la publicación de los actos administrativos por los medios tradiciones, como el Boletín Oficial, para darle validez jurídica al proceso. ${ }^{290}$

Para el Subsecretario encargado de la licitación, el éxito de la experiencia fue consecuencia de la concertación y aceptación previa de la utilización de las TIC por parte de los distintos involucrados.

La comunidad empresaria que participó de una u otra manera en este proceso licitatorio tuvo, desde el inicio una actitud de amplia aceptación y transmitiendo, en distintos ámbitos, comentarios elogiosos sobre la iniciativa del Gobierno Provincial (Deniro, 2005:11).

En efecto, para la elaboración del pliego se realizaron numerosas reuniones técnicas con las principales empresas tecnológicas a través de invitaciones específicas realizadas por medio de las TIC, correo electrónico y teléfono.

Como se menciona en los considerandos del Decreto $\mathrm{N}^{0} 1.761 / 05$, que aprobara la Licitación Pública, "se instrumentó un mecanismo de consenso a través de la publicidad y participación de eventuales interesados que tuvieren interés en conocer y aportar ideas sobre el Pliego de Bases y Condiciones Generales y Particulares destinado a regir la licitación", luego de lo cual, se recurrió a una doble secuencia

\footnotetext{
289 Como resultado de la licitación, realizada para un período de cinco años, se adjudicó el Renglón 1 a la firma Telecom Argentina SA, por la suma total de \$4.222.023,13, el Renglón 2 a la firma Impsat S.A., por la suma total de $\$ 1.584 .820,01$ y el Renglón 3 a la firma Telecom Argentina SA, por la suma total de \$ 34.247.242,14 y a las firmas Primera Red Interactiva de Medios Argentinos (PRIMA) S.A. y Millicom Argentina S.A.- UTE en formación, por la suma total de \$78.923.501,66.

${ }^{290}$ Otros aspectos innovativos en el diseño del pliego, aunque no relacionados al uso de tecnología fueron: a) licitar servicio y no tecnología pues la especificación de la tecnología de comunicaciones limita la participación a aquellos proveedores con esa tecnología instalada por lo que se indicó únicamente la capacidad requerida habilitando así a los prestadores a utilizar su propia tecnología, quienes sólo debían especificar en su oferta y para cada vínculo el ancho de banda a proveer; b) posibilitar un modelo sensible al crecimiento de la demanda gubernamental; c) apertura al avance tecnológico y a la baja de precios derivado de dicho avance; d) posibilitar las consultas públicas no vinculantes; e) permitir que la adjudicación se hiciera a más de un prestador; f) garantizar la participación de la mayor cantidad de oferentes dividiendo la red en 36 ítems, cada uno de los cuales cubre la red de un municipio de alta densidad de tráfico, uno de mediana capacidad y dos o tres de baja densidad; g) adjudicación por costo ponderado y el pago por costo cotizado.
} 
consultiva con el propósito de oír adecuadamente todas y cada una de las opiniones al respecto y definir así, un instrumento conducente con el interés público perseguido.

También tuvieron activa participación los Organismos de Control, quienes a través de sucesivas reuniones y procesos informales de consultan, se convirtieron en copartícipes del proceso de decisión.

Actualmente, la Intranet provincial es la mayor red en términos de transmisión de datos, mayor que las redes bancarias Link y Banelco, y la segunda Red en términos de puntos conectados. ${ }^{291}$

\section{Las normas de uso responsable}

Uno de las innovaciones más importantes sobre el uso de las tecnologías en el ámbito público está dado por el Régimen sobre el Uso Responsable de Elementos Informáticos que la Provincia de Buenos Aires adoptó a través de la sanción del Decreto $\mathrm{N}^{\mathrm{o}} 2.442 / 05$. El estudio de este caso es relevante por el proceso participativo que se le imprimió al proyecto como por los alcances de la norma en sí.

Este decreto define la política sobre el uso de software y hardware en los organismos públicos, incluyendo los productos y activos informáticos y tecnológicos que el Estado provincial provee a sus empleados en toda la Administración Pública Provincial centralizada y descentralizada y de los Organismos de la Constitución. El Régimen no sólo es de aplicación a todos los agentes, sino también a toda persona que utilice elementos informáticos, cualquiera fuere la relación contractual que lo uniere con los organismos mencionados.

El Régimen también fue impulsado por la Subsecretaría de Gestión Tecnológica y Administrativa de la Secretaría General de la Gobernación aunque otros dos Organismos bajo su dependencia, política o jurídica, pulseaban por imponer proyectos distintos. Por un lado, la Secretaría Ejecutiva de Gobierno Electrónico, que conforme a su Plan Estratégico, debía liderar las acciones que tiendan a establecer un marco normativo del uso de las TIC dentro del área de Infraestructura Legal del Gobierno Electrónico. Por el otro, la entonces Dirección Provincial de Informática y Comunicaciones entre cuyas competencias también se establecía la de participar en el desarrollo del Proyecto de Gobierno Electrónico de la Provincia de Buenos Aires.

En los considerandos del proyecto de decreto se explicitaron las siguientes razones para la sanción de la norma:

- la nueva Red Única Provincial de Comunicación de Datos;

- el crecimiento de la demanda de recursos informáticos;

- la necesidad de lograr un mejor aprovechamiento y administración de los elementos informáticos, definidos como recurso y activo de la Provincia;

- la necesidad de crear un marco normativo único y claro;

- generación de condiciones de un uso confiable, legal y eficiente;

291 La mayor es Banelco, y Link es la tercera. 
- el deber de respetar la información, los recursos y el trabajo de los usuarios que, de forma compartida, utilizan los mismos recursos;

- el respeto a la Ley de Propiedad Intelectual y los distintos Acuerdos Corporativos suscriptos por la Provincia;

- la necesidad de avanzar en la implementación de políticas de seguridad, contingencia y uso de software y hardware;

- la posibilidad de generar mecanismos de negociación hábiles para alcanzar precios preferenciales con las empresas privadas;

- deslindar la responsabilidad del usuario de la responsabilidad de la Provincia, para evitar acciones legales que afecten el erario provincial;

¿Pero cuáles eran las necesidades reales detrás de las consideraciones explícitas? ¿Qué querían los diversos actores involucrados?

Todos partían de una misma preocupación: existía un uso y abuso sobre los elementos informáticos; muchos organismos tenían instalado software ilegal en sus máquinas; las conexiones a Internet no tenían, en la mayoría de los casos, un uso oficial, sino más bien privado; el crecimiento de los usuarios y la limitación del recurso amenazaba con saturar y empobrecer la calidad del acceso a Internet que se había logrado con el proceso de la licitación de la Red.

Sin embargo, los informantes claves de los organismos consultados señalaron intenciones divergentes en cada una de las áreas. La Dirección Provincial de Informática y Comunicaciones buscaba contar con un recurso normativo del máximo nivel para cortar con el uso abusivo de los recursos de la Red. El documento debía plantear, desde su visión, los límites y prohibiciones. Desde la Secretaría Ejecutiva de Gobierno Electrónico se quería reconocer un uso personal de las TIC en el entendimiento de que ello permitiría aumentar la calidad del trabajo y ayudaría al Estado a retener a empleados calificados, además de considerar contraproducente la sanción de una norma totalmente prohibitiva.

El proyecto original fue elaborado por la Secretaría Ejecutiva de Gobierno Electrónico en forma de Manual $^{292}$ y tenía una visión más abierta pues se sostenía que:

Resulta necesario establecer pautas de uso de los bienes informáticos del Estado por parte de sus agentes, reconociéndolos como individuos responsables cuya participación es clave para lograr un Estado con respuestas adecuadas a los requerimientos de la comunidad en materia de información y servicios públicos. (...) La confianza pública en la Administración se incrementará cuando se perciba una correcta gestión y un adecuado manejo de los activos del Estado. (...) se espera que los empleados cumplan con las normas y regulaciones, sean responsables por sus actos personales y se conduzcan de manera profesional. (...) Por ello, y sujeto a las pautas que se indican a continuación, habilitar el uso personal limitado de dichas

\footnotetext{
292 Podría considerarse un antecedente del Decreto el documento titulado las "Políticas de uso responsable de los sistemas de información y computadores de la fundación universitaria Juan $\mathrm{N}$. Corpas", las cuales pueden consultarse en http://www.juanncorpas.edu.co/inicio/comunicaciones-yprensa/politicas-de-uso-de-sic/ Fecha de Consulta: 1/08/08.
} 
herramientas resulta conveniente pues permite aumentar la calidad del trabajo y ayuda al Estado a retener a empleados calificados (Expediente $\mathrm{N}^{\mathrm{o}}$ 2100-34922/04; el destacado no es del original).

Como política general, se establecía que los bienes y servicios informáticos del Estado deberían ser empleados exclusivamente para el cumplimiento de las funciones específicas asignadas, respetando el derecho de otros usuarios, responsabilizándose por la integridad y buen funcionamiento de las instalaciones asignadas, cumpliendo con las normas y pautas de seguridad y control emanadas de la autoridad competente y observando las licencias y acuerdos contractuales suscriptos por la Provincia.

Luego de ello, el Manual, "acepta" que los empleados del Estado usen en forma limitada dichos bienes y servicios para sus necesidades personales,

(...) si dicho uso no interfiere con la misión y gestión oficial del organismo o dependencia e involucra un mínimo gasto adicional para el organismo. Este uso personal limitado debe darse fuera del horario de trabajo normal del empleado y no debe violar principios éticos socialmente aceptados (Expediente $\mathrm{N}^{\circ} 2100-34922 / 04$ ).

Pese a la ambigüedad de la norma, estaba claro que se establecía un aspecto verdaderamente innovador respecto a otras concepciones que afirman que siendo elementos del Estado, los recursos informáticos deben tener un uso exclusivamente oficial. Ciertamente, la norma establecía varias limitaciones a dicho uso personal, pero el principio era la admisión. Sin embargo, a pesar de la innovación del proyecto, se afirmaba por otro lado que el uso de los activos informáticos de la Provincia y el acceso a los diferentes sistemas de información que existen en la misma "conforman un privilegio y no un derecho, y debe ser tratado de ésta forma por todos los usuarios de dichos sistemas", contrastando esa concepción fuertemente con el Plan Estratégico de Gobierno Electrónico en cuanto establecía la necesidad de establecer los denominados "derechos digitales".

Se definía al uso permitido como la utilización de las herramientas informáticas para propósitos de uso oficial.

Los usuarios deberán utilizar las herramientas informáticas particularmente Internet- para mejorar su conocimiento y aplicarlo al ámbito laboral; para acceder a información científica, técnica, o toda otra relativa a temas que tengan relevancia para el Organismo (Expediente $\mathrm{N}^{\mathrm{o}} 2100-34922 / 04$ ).

Sobre dicho proyecto, intervino la Dirección Provincial de Informática y Comunicaciones. De ser un Manual, pasó a tomar forma de un proyecto de decreto buscando dar más imperatividad a esas políticas. Algunas modificaciones sobre el proyecto original confirman ese propósito. Expresamente se sostenía que: 
- La Dirección Provincial de Informática y Comunicaciones (...) aplica las políticas informáticas a seguir con el propósito de facilitar el acceso hacia todas las fuentes de información.

- La Dirección Provincial de Informática y Comunicaciones define las normas, procedimientos y acciones, con el propósito de establecer un nivel de acceso adecuado a los recursos y provee además de los medios de acceso a la importante y creciente cantidad de información disponible a través de los dispositivos electrónicos de información instalados en cada Organismo.

- El incumplimiento de esta política puede resultar en la negación de acceso a los sistemas de información del/los Organismo/s u otras organizaciones que actúan en forma coordinada con la Provincia, además de la aplicación de las medidas disciplinarias que correspondan en cada caso.

- El personal (...) está sujeto a ser monitoreado en sus actividades por parte del personal de sistemas o de seguridad informática.

Además, la Dirección Provincial de Informática y Comunicaciones había eliminado el "uso aceptado" para fines personales. Se afirmaba que el uso aceptado daría lugar a ambigüedades difíciles de "manejar" y se buscaba poner límites sabiendo que la flexibilización viene de hecho. En otras palabras, el objetivo era tener un marco donde se establecieran límites y responsabilidades para que la Dirección Provincial de Informática y Comunicaciones tuviera las facultades, que de hecho ya tenía, para imponer restricciones a los Organismos. El decreto sólo buscaba dar mayor legitimidad al Organismo para el control y la eficientización económica del recurso.

Intervino luego la Subsecretaría de Gestión Tecnológica y Administrativa que, como organismo políticamente superior a ambos, realizó un nuevo análisis del proyecto. Se estableció, en primer lugar, que el proyecto de decreto debía ser aprobado en Acuerdo General de Ministros para darle la máxima jerarquía política a la norma dentro del ámbito del Poder Ejecutivo.

Luego de tres meses de análisis, se destacan importantes cambios. Se establece, por primera vez, que el objetivo de las TIC es mejorar la eficiencia en la prestación de las actividades. Nuevamente se reintroduce el concepto de uso aceptable. Se lo define como un uso personal que derive en la mejor capacitación, jerarquización y/o especialización en los conocimientos, prácticas y habilidades del usuario o para aprovechar los beneficios de la Sociedad de la Información y el Conocimiento. Sin embargo, se reglamentaban y establecían limitaciones a ese uso. Entre ellas:

- no podrá interferir con las actividades o funciones que el usuario cumple, ni con la misión y gestión oficial del organismo o dependencia;

- debe darse fuera del horario de trabajo normal del empleado, siempre que el recurso se encuentre disponible y no exista otro usuario que precise utilizar el recurso para sus funciones oficiales;

- no debe generar un gasto adicional para el organismo; ${ }^{293}$

- no puede ser aprovechada para realizar actividades indebidas o prohibidas;

293 Se exceptuaba de esta regla, el gasto que derive del uso normal de los recursos informáticos. 
Se establecía también que el uso personal no se considera un derecho del usuario y que el mismo se encuentra sujeto al estricto control permanente de la autoridad de aplicación y de la autoridad del organismo donde el usuario desempeña sus funciones. Asimismo, se determinaba que el uso aceptado puede ser controlado, revocado o limitado en cualquier momento por razón de la función, por cuestiones operativas y/o de seguridad de la Red, ya sea por la autoridad de aplicación y/o por los funcionarios responsables del organismo.

Se agregan a la lista original algunos usos prohibidos, entre ellos, el uso de los recursos informáticos para la difusión de ideas políticas, la adhesión a campañas o movilizaciones para captar el voto, el envío o reenvío de correo masivo o cualquier otro tipo de práctica de políticas partidarias. Tampoco podría derivar en un uso discriminativo, delictivo, ilegal o que de cualquier manera afectare a la moral o las buenas costumbres salvo que existiese debida autorización previa por escrito de la autoridad o que se tratare de una actividad inherente a la función propia del empleado. Y expresamente se establecía que "Se encuentra incluido la descarga, transmisión, distribución o almacenamiento de música, imágenes $y / o$ cualquier otro archivo protegido por las normas de propiedad".

Fue en este momento en que el proyecto se estancó. Para la Dirección Provincial de Informática y Comunicaciones, la reintroducción del concepto de uso aceptable era ambigua y podría derivar en un uso incontrolado. Desde la Secretaría Ejecutiva de Gobierno Electrónico, con un criterio práctico, se pretendía redireccionar el uso existente haciéndolo más productivo. La Subsecretaría de Gestión Tecnológica y Administrativa, encargada de la última redacción del proyecto, frente a posiciones tan encontradas, decidió finalmente terciar remitiendo el proyecto a los tres gremios más representativos de la Provincia. El proyecto que se remitió contenía la propuesta del "uso aceptado": si se lograba el consenso de los gremios, no sólo la norma gozaría de más legitimidad sino que se los hacía parte de la custodia de las nuevas reglas de juego.

Sólo dos de los tres gremios respondieron a la invitación a introducir modificaciones o presentar sugerencias. Uno de los pedidos giró en torno a la necesidad de dar un tiempo prudencial para que la norma entrara en vigencia. En virtud de ello, el proyecto introdujo un nuevo artículo en el cual se establecía que

El Régimen sobre el Uso Responsable de Elementos Informáticos será de aplicación a partir de los 180 días posteriores a su publicación en el Boletín Oficial, período durante el cual, la Autoridad de Aplicación, a través de las áreas competentes, dará amplia difusión a su contenido (Expediente $\left.\mathrm{N}^{\mathrm{o}} 2100-34922 / 04\right)$.

Sobre el proyecto final intervino también activamente la Contaduría General de la Provincia en la redefinieron los usos prohibidos e indebidos. En los primeros proyectos, se facultaba a la Contaduría General de la Provincia a realizar las auditorías y/o inspecciones necesarias para verificar el cumplimiento de las presentes normas. La intervención de un Organismo de control a la Administración Pública Provincial había sido solicitada por la Dirección Provincial de Informática y Comunicaciones. Según el informante clave de la Dirección Provincial de Informática y Comunicaciones, una de la razones para esa intervención giraba en torno a que ese era el Organismo que, según el 
Decreto de Firma Electrónica No 919/04, debía cumplir las funciones de Organismo Auditante. Sin embargo, las funciones en uno y otro caso no estaban vinculadas. Puede deducirse que, atento al carácter restrictivo que tenía el régimen de uso responsable para la Dirección Provincial de Informática y Comunicaciones, ésta podría deslindar en la Contaduría la responsabilidad sobre las decisiones de cortes o restricciones en el uso de los recursos y la Contaduría ganar en este esquema con más facultades de decisión en la gestión.

Finalmente, a más de un año del inicio del expediente sobre un proyecto, el 12 de octubre se sancionó el Decreto $\mathrm{N}^{\mathrm{o}} 2.442 / 05$ de Uso Responsable de Elementos Informáticos aprobado en Acuerdo General de Ministros.

La sanción de la norma tuvo alta repercusión entre el personal de la Provincia e incluso en los medios gráficos. Así, la noticia anunciando la sanción de la norma fue publicada en el Diario LA NACIÓN del 19 de noviembre de 2005 y en los diarios HOY y EL DÍA, de La Plata. Pero las repercusiones en los medios periodísticos sólo reflejaron los aspectos restrictivos de la norma. El Diario EL DÍA tituló "Habrá castigos en la Provincia por chatear en oficinas públicas. Solá firmó un decreto que prevé sanciones y hasta denuncias judiciales contra empleados y funcionarios. Buscan limitar el uso abusivo de Internet"; el Diario Hoy "En la Provincia prohíben a funcionarios chatear, bajar música o ver porno. Los funcionarios y empleados de la administración pública bonaerense no podrán chatear, bajar música o visitar sitios pornográficos durante su horario de trabajo, de lo contrario serán sancionados administrativamente y podrán ser denunciados judicialmente"; el Diario La Nación tituló "En el empleo público. Ahora, Solá prohíbe el chateo. Ordenó restringir el uso de la Web". Ninguno de ellos reflejó la innovación, dentro del ámbito de la administración en Argentina, del reconocimiento del uso personal de los elementos informáticos para la capacitación y el aprovechamiento de los beneficios de la Sociedad de la Información.

El Decreto finalmente estableció que el uso de las TIC tiene por objeto mejorar la eficacia y eficiencia administrativa y que ese uso no puede ser un obstáculo para el cumplimiento de las tareas encomendadas.

Asimismo se definió que ...

la Dirección Provincial de Informática y Comunicaciones o el organismo que en el futuro la sustituya, definirá las normas, procedimientos y acciones, con el propósito de establecer un nivel de acceso adecuado a los recursos y necesidades del Organismo. (...) El incumplimiento de esta normativa puede resultar en la negación de acceso a los sistemas de información del/los Organismo/s u otras organizaciones que actúan en forma coordinada con la Provincia, además de la aplicación de las medidas disciplinarias que correspondan en cada caso. (...) El usuario deberá respetar los derechos de otros usuarios, la integridad de las instalaciones físicas y sus métodos de control (Punto 3. Principios Generales).

Si bien el Decreto sobre Uso Responsable de Elementos Informáticos establecía que cada Jurisdicción, según sus necesidades y funciones, debía reglamentar en forma conjunta con la Autoridad de Aplicación las modalidades de uso aceptable, las 
sanciones específicas por los usos prohibidos e indebidos así como realizar las actividades de su difusión necesarias, hasta el momento de finalizar la investigación, no existieron reglamentaciones de la norma conforme al procedimiento previsto.

Sin perjuicio de ello, sí se detectaron algunas limitaciones al uso de la Red establecidas por los Organismos. Así, desde la página web del Ministerio de la Producción se publicó una noticia en la que el Departamento de Informática y Comunicaciones comunicaba que a partir del 14/12/05, de 10.00 a 14.00 hs., no se encontraría habilitado para los niveles inferiores al rango de Dirección, el acceso libre a Internet, a excepción de las páginas oficiales gubernamentales (extensión gov.ar y edu.ar), las organizaciones (extensión org.ar), y las paginas BCRA (Banco Central de la República Argentina) y BAPRO (Banco Provincia de Buenos Aires) para racionalizar el uso del ancho de banda disponible. ${ }^{294}$ Asimismo, desde el Patronato de Liberados, se anunció que se había comenzado a proyectar la reglamentación interna de la norma pues el uso indebido de las TIC había generado inconvenientes que afectaron al mecanismo de comunicación de su "Mesa de Ayuda".

En definitiva, si bien el proyecto incluyó el Uso aceptado para los usos personales, la Dirección Provincial de Informática y Comunicaciones se afirmó como organismo encargado de definir las normas, procedimientos y acciones, con el propósito de establecer un nivel de acceso adecuado a los recursos y necesidades del Organismo $^{295}$.

\footnotetext{
294 http://www2.mp.gba.gov.ar/intranet/cms/principal_nov.php?nov_area_id=1. Fecha de Consulta: 06/01/06.

295 Más aún, y como consecuencia de esta norma, la Dirección Provincial de Informática y Comunicaciones propició una nueva norma, que con la misma fecha de la sanción del Régimen, le otorgó más facultades para el control de la Red. En efecto, el 12 de octubre un nuevo Decreto con el número 2.450/05, creó el Comité de Usuarios de la Red Única Provincial de Comunicación de Datos, integrado por un responsable informático por cada Ministerio, Secretaría y Organismo de la Constitución, renovables por períodos de un (1) año, todos ellos bajo la coordinación del Director Provincial de Informática y Comunicaciones. La Dirección Provincial de Informática y Comunicaciones, a través del Comité, se dio facultades para controlar el funcionamiento de la Red, evaluar las necesidades de uso de cada Organismo, monitorear el uso y evaluar los usos de las herramientas informáticas y proponer reformas al Régimen sobre el Uso Responsable de Elementos Informáticos.
} 


\section{CAPÍTULO XI. ESTUdio DE CASOS IV - LA SUBSECRETARÍA DE GESTIÓN PÚBLICA}

\section{El proyecto de reforma de la Ley de Procedimiento Administrativo}

En primer lugar analizaremos el proyecto de reforma de la Ley de Procedimiento Administrativo, Decreto-Ley $N^{0} 7.647 / 70$ y su proyecto de reglamentación según la versión definitiva puesta a consideración de la comunidad política, académica y del público, en noviembre de 2005 . $^{296}$

Nos detendremos en los aspectos jurídico-institucionales del proyecto de reforma de la Ley y su reglamentación en los aspectos que hacen a la organización de la gestión y su adecuación (o no) a los procesos de reforma administrativa y del Estado ${ }^{297}$.

Como objeto de ley se señala el regular el procedimiento general de la función administrativa, el que debe resguardar la juridicidad, la razonabilidad, la eficacia, así como garantizar los derechos e intereses de carácter administrativo. En una presentación del proyecto elaborada por la Subsecretaría de la Gestión Pública elaborada por la Subsecretaria Claudia Bernazza y el Escribano adscripto de la Escribanía General de Gobierno y Consejero Directivo del Instituto Provincial de la Administración Pública de la Provincia de Buenos Aires, Luciano Scatolini, afirman que:

El objetivo de la propuesta de ley es asegurar la juridicidad de la actuación de la administración y el respeto pleno de los derechos de los administrados, a través de la búsqueda del equilibrio entre el obrar eficaz de la administración y de los derechos individuales y colectivos de la ciudadanía ${ }^{298}$.

\footnotetext{
${ }^{296}$ Dicha versión (junto con el proyecto de reglamentación y un análisis interno) puede consultarse en http://www.dpgp.sg.gba.gob.ar/html/procedimiento reforma.doc, http://www.dpgp.sg.gba.gob.ar/html/procedimiento decreto reglamentario.doc, http://www.dpgp.sg.gba.gob.ar/html/power/proy ley procedimientos.pps, http://www.dpgp.sg.gba.gob.ar/html/biblioteca/proced admin.doc Fecha de Consulta: 05/3/12.

${ }^{297}$ Una primera versión de la ley, de circulación interna, definía aspectos que luego pasaron al proyecto de reglamentación. Es interesante destacar que en este primer proyecto se establecían algunos principios de funcionamiento de la Administración. La forma de organización jerárquica es reafirmada cuando se establece que "Los órganos superiores con competencia en razón de la materia tienen, sobre los funcionarios y agentes que de ellos dependen, poder jerárquico que (...) implica potestad de mando..." (artículo 20), principio y obligación que se presume siempre dentro de toda organización centralizada. Este principio se reitera en el artículo siguiente cuando se dispone que "Todos los agentes estatales deben obediencia a sus superiores" salvo frente a directivas manifiestamente ilegítimas. El segundo proyecto no contiene referencias específicas respecto a la organización pública ni al curso de la tramitación de los expedientes pues se ha considerado que todo ese tipo referencias debe estar instrumentado en la reglamentación de Ley marco.

${ }^{298}$ En una versión anterior, en este primer artículo y como segundo párrafo se advertía la adscripción de los proyectos de ley a aquellas posiciones que ponen el acento de la reforma administrativa en la eficientización de los procesos vigentes cuando establece que "Deberá ser interpretada en la forma en que mejor asegure el equilibrio entre la eficacia de la Administración Pública y los derechos individuales y colectivos de la ciudadanía". Sin perjuicio de que bajo ningún concepto, ante el conflicto, puedan los
} 
Consideramos al administrado un colaborador de la administración aún cuando defienda sus derechos subjetivos, y así debe ser tratado por el poder administrador, ya que la administración pública en los mismos casos que representa un interés o un derecho propio, lo hará siempre en menor grado, ante la gravitación que tienen los intereses de la colectividad (Subsecretaría de la Gestión Pública, 2006:3-4).

Sin embargo, el proyecto no tiene grandes innovaciones técnico jurídicas ni organizacionales.

El proyecto establece criterios generales para la actividad administrativa en la Provincia de Buenos Aires pero también resultaría aplicable a la actividad de los Poderes Legislativo y Judicial en tanto ejerzan funciones administrativas, e invita a la adhesión municipal.

Más adelante, artículo $4^{\circ}$, se establecen los principios del procedimiento (juridicidad, determinación de la verdad, derecho de defensa, igualdad, razonabilidad, buena fe, oficialidad, contradicción, eficiencia y eficacia, publicidad, manifestación expresa, formalismo moderado, participación, respeto, decoro y orden procesal y colaboración) y se dan definiciones para cada uno de ellos.

Se crean las Unidades Responsables del Trámite, conforme lo reglamente el Ejecutivo, para la sistematización, dirección y control de los procedimientos ${ }^{299}$.

Se determinan los criterios de legitimización para actuar más amplios que los actuales; se fijan los requisitos de las presentaciones en forma detallada así como las del acto administrativo (competencia; causa, procedimiento; contenido; motivación; finalidad y forma); se establecen vías recursivas más sencillas.

Se establecen las normas del domicilio y se establece en su artículo 35 que " $E l$ interesado puede constituir, además del domicilio real y procedimental, un domicilio por medios tecnológicos donde se tendrán por válidas las notificaciones que se le efectúen ...", remitiendo al artículo 52 que fija que

Esta notificación se tendrá por válida cuando permita tener constancia de la fecha de recepción y la identidad del acto notificado. En su defecto será necesario para otorgarle validez que la copia de la notificación sea devuelta por el receptor con su firma y aclaración.

Así, no cumple los efectos de una verdadera notificación y el alcance es muy limitado hasta la implantación de la firma digital.

En cuanto a la forma del acto se establece que "La autoridad administrativa tiene la obligación de manifestar su voluntad por escrito" reconociendo excepciones

derechos individuales y colectivos ceder frente a la eficiencia de la Administración, de la redacción de la norma parece que aquellos fueran obstáculos para la eficiencia administrativa.

${ }^{299}$ En verdad, deberían ser de los expedientes pues los procedimientos deben ser custodiados por los organismos con competencia en la ejecución y control. La versión anterior, en su artículo 28, establecía que "La autoridad administrativa superior (...) debe determinar, para cada trámite, la unidad con responsabilidad primaria para entender en el mismo, la que se constituye en Unidad de Responsabilidad Primaria (URP)" como responsables directos de la prosecución del trámite. 
verbales por urgencia ${ }^{300}$. En el proyecto se establece que "Los escritos serán redactados por medios técnicos o manuscritos (...) y en tinta que impida la alteración de su contenido", con lo que la norma no deja lugar a los documentos electrónicos. No existe, en verdad, ninguna referencia específica a los documentos electrónicos ni a la firma electrónica en todo su articulado. Este tipo de imprevisión constituye una gran involución, pues ni aún el establecimiento de la firma electrónica podría salvar este tipo de omisiones. Más aún, teniendo en cuenta que estas leyes tienen una larga vigencia, las consecuencias de este retroceso son graves.

En el proyecto del decreto reglamentario, se advierten algunas líneas teóricas más claras. Así, el Capítulo, el IV, titulado "Sistema de gestión por resultados", fija como política que ...

\begin{abstract}
ARTÍCULO 20. El procedimiento administrativo tiene por objeto el logro de resultados de gestión previstos por la Ley de Ministerios, por las competencias de cada organismo asignadas por leyes orgánicas o por vías reglamentarias $\mathrm{y} / \mathrm{o}$ por los planes y programas institucionales. La Secretaría General de la Gobernación es la Autoridad de Aplicación del sistema de gestión por resultados definido en el presente capítulo. En virtud de ello queda facultada para proponer, elaborar y dictar las normas de carácter técnico, complementarias o aclaratorias, relativas al régimen estatuido en el presente Capítulo (el destacado es nuestro).
\end{abstract}

A esos fines, el proyecto establece que cada organismo de la Administración Pública provincial debe constituir, formalmente, una o más Unidades Responsables del Trámite $^{301}$, las que tendrán a su cargo el correcto cumplimiento de los objetivos de cada proceso de gestión, como así también la confección de los actos administrativos finales y el definitivo, informes, dictámenes, actas o cualquier otro documento que resulte de la intervención de ese organismo. Dichas Unidades deben estar a cargo de un funcionario no inferior a Director o equivalente.

A estas Unidades se les encomienda ...

ARTÍCULO 24. ... la puesta en práctica de sistemas administrativos que agilicen la tramitación y simplifiquen la relación del Estado con la ciudadanía, los que al mismo tiempo deberán permitir una comunicación permanente del estado de los trámites.

ARTÍCULO 26. Asignar a la Unidad Responsable del Trámite la responsabilidad primaria de establecer mecanismos de actuación que tiendan a asegurar la eficacia, agilización y transparencia de los trámites administrativos, custodiando las formalidades y plazos

\footnotetext{
${ }^{300}$ Una versión anterior admitía la presentación de solicitudes, escritos, comunicaciones y documentos de los particulares, además del soporte papel, pueden ser presentados por medios informáticos, electrónicos o telemáticos.

${ }^{301}$ No obstante, más adelante se establece que la Unidad Responsable del Trámite es la que tenga asignadas acciones equivalentes en la pertinente estructura o en su defecto la Dirección General de Administración (DGA) del Organismo al que le competa intervenir (conf. art. 25 del proyecto de decreto reglamentario).
} 
procedimentales previstos por las normas, de manera de posibilitar el cumplimiento de los resultados que establece el ordenamiento jurídico (el destacado no es del original).

Se establece que la Unidad Responsable del Trámite debe sistematizar y fijar el circuito administrativo de las actuaciones observando lo establecido en los instructivos, guías y/o manuales de procedimiento que al efecto se dicten. Asimismo, se le asigna al funcionario a cargo de Unidad la responsabilidad directa del procedimiento para lo cual organizará en su jurisdicción áreas de despacho, mesa de entradas y archivo, así como de información al público, a fin de garantizar la correcta gestión de la documentación administrativa para el logro del resultado objeto del trámite, así como para la expresión de las decisiones intermedias o finales correspondientes, el control de los plazos, la debida tramitación del expediente, el acceso público y la comunicación interna y externa del estado de las actuaciones, entre otros. Y, para el cumplimiento de los fines previstos se le encomienda:

ARTÍCULO 28 in fine
a) Adoptar las medidas oportunas para remover los obstáculos que
impidan, dificulten o retrasen la decisión final o definitiva.
b) Realizar un relevamiento periódico de las gestiones
administrativas en proceso en jurisdicción del organismo por
vía de expediente o por la que se haya optado en cada
oportunidad, a fin de realizar el seguimiento en el
cumplimiento de los plazos establecidos

c) Recibir las quejas o denuncias que puedan surgir con motivo de tardanzas, desatenciones u otras anomalías que se observen en el funcionamiento de los respectivos organismos ().

Para el cumplimiento de los plazos sugiere la creación de mesas de trabajo ${ }^{302}$ cuando el retardo sea consecuencia de inconvenientes o dudas propias del trámite. Pero lo novedoso es que los responsables tienen la obligación de informar a la Autoridad de Aplicación aquellas situaciones de demoras en los trámites que no puedan resolverse por este medio. Puede advertirse aquí la pretensión de la Secretaría General de absorber funciones e incumbencias procedimentales internas de otros Ministerios y Secretarías. Este mismo principio se advierte cuando se fija que es la Subsecretaría de Gestión Pública la que asesora y aprueba los Manuales, Guías e instructivos del procedimiento interno de cada ministerio o secretaría (conf. art. 64 del proyecto de reglamentación).

Otra innovación es que las actuaciones administrativas deben encontrarse, en todo momento, en sede del organismo competente, bajo la responsabilidad de la Unidad Responsable del Trámite, creándose la figura de Consulta para sustanciar las actuaciones cuando se requieran datos, constancias, informes o dictámenes previos, remitiéndose al Organismo consultado copias de las mismas, debiendo sus resultados

\footnotetext{
${ }^{302}$ Más adelante señala que a fin de simplificar las actuaciones administrativas se prevé la conformación de Mesas de Trabajo con el fin de formar y compatibilizar criterios cuando la complejidad del trámite lo requiera y en aquellos casos que involucren la competencia de dos o más unidades orgánicas o a los fines de evitar trámites innecesarios en los expedientes (artículo 37 del proyecto de decreto).
} 
agregarse al original. Asimismo, cuando sea estrictamente necesaria la remisión o movimiento del expediente, el proyecto sólo autoriza la remisión de copias pudiéndose utilizar cualquier medio electrónico o informático.

Entra en la lógica de este esquema que el articulado prevea que la Unidad Responsable del Trámite mantiene su responsabilidad hasta la culminación de la gestión, la elaboración de la actuación administrativa correspondiente y la remisión a archivo de las actuaciones.

El proyecto incorpora el principio de Ventanilla Única cuando establece en su primera versión que

ARTÍCULO $7^{\circ}$. Todas las actuaciones deberán ser iniciadas ante el órgano administrativo competente. No obstante, no podrá rechazarse la presentación argumentando incompetencia del órgano, en cuyo caso el organismo receptor la remitirá al que sea competente, con notificación al interesado.

O bien, en su segunda versión

ARTÍCULO 12. El interesado no será afectado en sus derechos, cuando por error la presentación se realice ante un órgano distinto del competente para su tratamiento, debiendo la propia Administración derivar el trámite al que considere corresponde intervenir, si depende del Estado Provincial. Caso contrario procederá a su archivo notificando previamente tal circunstancia al presentante.

La versión definitiva, aunque en una forma mucho más clásica, establece que ...

ARTÍCULO 13. La presentación que se realiza por error ante un órgano distinto del competente para su tratamiento, debe derivarse por el receptor al organismo que corresponda, si este pertenece a la Administración Pública Provincial. Si la presentación hace referencia a temas ajenos a dicha Administración, éste procederá a su archivo notificando previamente tal circunstancia al presentante.

El proyecto de reglamentación del proyecto de reforma de la ley de procedimiento establece que los órganos administrativos pueden encomendar a otros órganos o entidades de la Administración Pública Provincial o de otra administración, la realización de actividades de carácter material, técnico o de servicios de su competencia cuando no posean los medios técnicos necesarios para llevarlas a cabo, o razones de eficacia así lo aconsejen pero ello no supone cesión de titularidad. Ahora bien, cuando ello se establece entre órganos administrativos de distintos niveles territoriales o entre entes públicos, se adoptará mediante convenio, instrumento formal que permite la seguridad jurídica pero que, en principio, no permite respuestas rápidas a necesidades urgentes o circunstanciales.

Sigue un esquema verticalista cuando, siguiendo las clásicas orientaciones en materia de distribución de competencias, establece que: 


\begin{abstract}
ARTÍCULO 13. Las cuestiones de competencia entre órganos dependientes de un mismo Ministerio o Secretaría de Estado son resueltas definitivamente por el titular de dicha cartera. Si el conflicto es interministerial, o entre órganos centralizados o desconcentrados y entidades descentralizadas, o entre éstas, resuelve el Gobernador. En los demás casos será resuelto por el órgano inmediato superior a las áreas en conflicto.
\end{abstract}

En cuanto a la gestión de la documentación el proyecto de reglamentación establece que la documentación se gestione a través de un expediente. Se establece normas similares a las actuales que siguen los principios de la organización en papel aunque se admite, en forma genérica, que la Administración Pública Provincial podrá

\begin{abstract}
ARTÍCULO 40 ... adoptar toda otra forma de tramitación que surja de la aplicación de las Tecnologías de Información y Comunicación (TICs), dirigidas a mejorar la relación del gobierno provincial con los habitantes y ciudadanos, aumentar la eficacia y eficiencia de la gestión y de los servicios públicos e incrementar la transparencia y la participación que posibiliten una mayor integración, inclusión y desarrollo de la sociedad en su conjunto.

Los organismos pueden optar indistintamente entre la metodología de soporte mediante el uso de las Tecnologías de Información y Comunicación (TICs), o la de soporte en papel, procediendo según lo establecido en el presente Decreto.
\end{abstract}

Un lugar destacado merece el Capítulo IX sobre "Participación Ciudadana" para que la administración centralizada, descentralizada, entes autárquicos, y cualquier otro ente $u$ órgano dotado de potestad pública, cree un mecanismo que permita, a todo interesado en la norma a dictarse, intervenir en un procedimiento de elaboración participativa de normas de acuerdo a las modalidades que en el presente se fijan.

Se señala que el procedimiento de elaboración participativa de normas se inicia mediante acto administrativo expreso de la autoridad responsable del área a cargo de la elaboración de la norma a dictarse, la que tendrá una jerarquía no inferior a Subsecretario o equivalente, quien es el encargado de dirigir el procedimiento de elaboración participativa ${ }^{303}$.

Se establecen sobre el propio proyecto de creación del procedimiento participativo, normas que permitan su elaboración participativa, normas éstas que, debe inferirse, luego deberían trasladarse a estos proyectos aprobados como base de su articulado. Entre estas pautas debe establecerse la autoridad responsable de llevarlo adelante, el texto del proyecto y sus fundamentos, el lugar donde se puede tomar vista del expediente, efectuar opiniones, propuestas u observaciones y el plazo para efectuar dichas presentaciones. Además, al menos durante diez (10) días, debe publicarse el contenido del acto de apertura del procedimiento de elaboración participativa de

\footnotetext{
${ }^{303}$ Se establece que puede delegar tal responsabilidad en un funcionario competente en razón del objeto, con jerarquía no inferior a Director.
} 
normas, invitando a la ciudadanía a expresar sus opiniones, propuestas u observaciones, las que no tendrán carácter vinculante. ${ }^{304}$

En cuanto al aspecto participativo, el proyecto establece que:

ARTÍCULO 74. La autoridad responsable puede encargar estudios o dictámenes de personas públicas o privadas, especializadas en la materia motivo del procedimiento, a fin de generar información útil para la toma de decisión. Asimismo, de considerarlo conveniente, pueden llevarse adelante una o más audiencias públicas, debiendo incorporarse al expediente las opiniones que se viertan en las mismas. ARTÍCULO 75. Cuando la autoridad responsable lo considere oportuno, puede solicitar la participación de la Subsecretaría de la Gestión Pública o quien tenga asignadas acciones equivalentes, quien operará como Organismo Coordinador a los fines de asistir técnica y metodológicamente a la autoridad responsable del procedimiento de elaboración participativa de normas.

ARTÍ́CULO 76. En los fundamentos de la norma debe dejarse constancia de la realización del procedimiento de elaboración participativa.

Finalmente, sólo en el último Capítulo encontramos una breve remisión a una futura reglamentación en materia de documentos electrónicos. ${ }^{305}$

\section{El Decreto de diseño de las estructuras del Estado Provincial}

Resulta trascendente analizar el contenido del Decreto $\mathrm{N}^{\circ} 1.322 / 05$ de "Diseño de las estructuras del Estado Provincial" por cuanto el Gobernador había anunciado en su discurso de apertura de las sesiones legislativas en 2002 que

... reformularemos todas las estructuras Ministeriales de acuerdo a un nuevo modelo organizativo. Queremos introducir la herramienta de la gestión por resultados, que transparentará y facilitará la rendición de cuentas de los funcionarios, permitiendo un mayor control social" (Subsecretaría de la Gestión Pública, 2004-a:10)

\footnotetext{
${ }^{304}$ Cuando el interés público comprometido en la norma a dictarse, a juicio de la autoridad responsable amerite una más amplia difusión, se llevarán a cabo publicaciones en medios nacionales, locales o especializados en la temática en cuestión.

305 “Articulo 77. Los organismos de la Administración Pública de la Provincia de Buenos Aires deben establecer mecanismos que garanticen la opción de remisión, recepción, mantenimiento y publicación de información electrónica, siempre que esto sea aplicable, tanto para la gestión de expedientes y documentos entre organismos como para con los ciudadanos, tendiendo a la eliminación del papel en las tramitaciones. En la medida de la necesidad de aplicación de los medios previstos, el Poder Ejecutivo Provincial reglamentará su implementación".
} 
El análisis de la norma, que deroga el Decreto $\mathrm{N}^{\circ} 18 / 91$, podrá darnos cuenta si las instrucciones para el diseño de estructuras se ajustan o no a las consignas del Gobernador y a los postulados de reforma del aparato burocrático.

Para la entonces Directora Provincial de la Gestión Pública de la Provincia, Patricia Rodrigo, se requería de un marco normativo que confiriera legalidad y una estructura organizativa a todo plan de gobierno, que pusiera en acción sus proyectos, así como los recursos permitiendo hacerlos realidad y expresamente señaló que ...

no existe diseño de estructura organizativa que no implique o revele una cierta concepción del ser humano, de la sociedad y del Estado, así como de un horizonte utópico que se intenta alcanzar (Rodrigo et al., 2005:3).

El Decreto constituye, en verdad, un instructivo para guiar el diseño de estructuras orgánico funcionales en todo el ámbito de la Administración Pública Provincial, centralizada y descentralizada, cualquiera fuera la naturaleza jurídica del organismo o entidad pública de que se trate (art. $1^{\circ}$ del Decreto $N^{\circ} 1.322 / 05$ ). Se buscó garantizar la expresión organizativa de los planes o proyectos de gobierno en la elaboración de organigramas y descripciones de competencias y asegurar su viabilidad.

Según el documento explicativo elaborado desde la Subsecretaría de la Gestión Pública, si en una estructura las partes están integradas, la estructura debe ser flexible y permeable a esos cambios cuando estos son un aporte para el logro de una situaciónobjetivo determinada por la visión de una organización (Rodrigo et al., 2005:5).

Se sostiene que la estructura formal debe reflejar las pautas de comportamiento informal y que ...

el diseño de las estructuras en la Administración Pública Provincial intenta representar de modo más fiel posible esa estructura no formal en permanente movimiento, con el objetivo de contribuir con un cambio cultural o sustrato esencial del nuevo papel que el Estado se propone asumir (Rodrigo et al., 2005:6).

Para la Subsecretaría de Gestión Pública, las misiones y funciones dotan de sentido y justifican la creación del organismo y para el cumplimiento de la misión, los objetivos y las metas institucionales, todos los niveles deberán presentar acciones a realizar que, en cualquier nivel jerárquico podrán ser de tipo estratégico, táctico u operativo. $^{306}$

Según el Decreto, por debajo de los Ministerios y Secretarías de Estado, se reconocen como niveles jerárquicos a la Subsecretaría, la Dirección Provincial -que requiere justificación territorial o programática-, la Dirección General ${ }^{307}$-de igual nivel

\footnotetext{
306 Siguiendo a Cohen y Franco (1992), la Subsecretaría encomienda que las acciones se enumeraren agrupadas por tema, desde las más estratégicas hasta las más instrumentales.

307 Se utiliza esa denominación sólo para unidades dedicadas al servicio administrativo de apoyo.
} 
jerárquico que la dirección provincial-, la Dirección, la Subdirección y el Departamento.

Se prevé, además "como respuesta a las necesidades actuales que exigen estructuras dinámicas y flexibles" (Anexo 1.3 del Decreto) la posibilidad de crear dependencias ad-hoc, tales como institutos, agencias, oficinas provinciales, oficinas, unidades de coordinación, programas, proyectos, consejos, comisiones, mesas de trabajo u otras, siempre y cuando se aclare la equivalencia de sus titulares a cargos de la conducción superior, previstos en la legislación vigente. Estas dependencias ad-hoc responden a la necesidad de organizar el Estado según los objetivos a cumplir (Rodrigo et al., 2005:11).

Sin embargo, se establece una limitación en relación a la cantidad de unidades organizativas que se reflejan en el siguiente Cuadro ${ }^{308}$ :

Cuadro 46 - Cantidad de unidades organizativas por áreas hasta segundo nivel

Subsecretarías dependientes Direcciones Provinciales del titular dependientes de la Subsecretaría

\begin{tabular}{|c|c|c|}
\hline $\begin{array}{c}\text { Ministerios } \\
+4 \text { asesores de gabinete }+1 \text { secretario } \\
\text { privado }+2 \text { Direcciones Provinciales } \\
\text { de dependencia directa }\end{array}$ & $\begin{array}{c}3+1 \text { unidad ad hoc } \\
+1 \text { Dirección o Departamento de } \\
\text { dependencia directa }+3 \text { asesores de } \\
\text { gabinete }+1 \text { secretario privado por c/u }\end{array}$ & $2+1$ unidad ad hoc \\
\hline Secretarías & $2+1$ unidad ad hoc & $2+1$ unidad ad hoc \\
\hline
\end{tabular}

Fuente: Elaboración propia.

Leídos de izquierda a derecha deben dar cuenta, sucesivamente, de los procesos de planificación, ejecución y control de la gestión y de arriba hacia abajo, deben reflejar cómo la organización garantiza la instrumentación creciente de su competencia a través del despliegue de programas, proyectos y/o servicios, desde un nivel estratégico hasta un nivel táctico que haga efectivo un servicio o un resultado concreto.

Se establece que los servicios informáticos deberán guardar dependencia funcional con Dirección Provincial de Informática, aduciendo que ello fue establecido en cumplimiento del Plan Estratégico Provincial del Gobierno Electrónico (Decreto $\mathrm{N}^{\mathrm{o}}$ 1.824/04). Algo similar sucede con las Direcciones de Personal que guardan dependencia funcional con la Dirección Provincial de Personal.

El Decreto $\mathrm{N}^{\circ} 1.322 / 05$ introduce algunos aspectos innovadores cuando dispone que el análisis de la viabilidad de las estructuras lo realizará una Mesa de Trabajo conformada por representantes de la Secretaría General -Subsecretaría de la Gestión Pública y la Dirección Provincial de Personal-, el Ministerio de Economía -Dirección Provincial de Presupuesto- y la Asesoría General de Gobierno (artículo $5^{\circ}$ Decreto $\mathrm{N}^{\circ}$ $1.322 / 05)$.

\footnotetext{
308 Hay que recordar que, pese a que la presente norma emanó de la propia Secretaría General de la Gobernación, tenía 3 Subsecretarías y 2 Unidades Ad-Hoc con rango de Subsecretaría y 10 Direcciones Provinciales, además de varias unidades ad hoc con rango de dirección provincial. En verdad, contabilizando al máximo la apertura, es posible crear un Ministerio con 4 subsecretarías; 8 Direcciones Provinciales; 12 Direcciones y 36 Departamentos.
} 
Se señala que antes de la sanción de la norma, cualquier expediente de solicitud de creación o modificación de un organigrama pasaba sucesivamente por esos organismos con un tiempo aproximado de tramitación superior a los seis meses; ahora, con el trabajo simultáneo y coordinado, se podría reducir el tiempo a quince días o un mes (Rodrigo et al., 2005).

Así, en lugar de la lógica del traspaso sucesivo por distintos organismos de asesoramiento y control, se introduce la lógica del trabajo con enfoque participativo, cooperación y coordinación entre los organismos. Sin embargo, ese análisis de la viabilidad es previo y al mero efecto de la preparación del proyecto de decreto, pues una vez elaborado, debe seguir los pasos normales, entre ellos, las intervenciones en los mismos Organismos que ya habían participado en la Mesa de Trabajo, con lo que la lógica del trabajo conjunto y sus beneficios se desvanecen. 


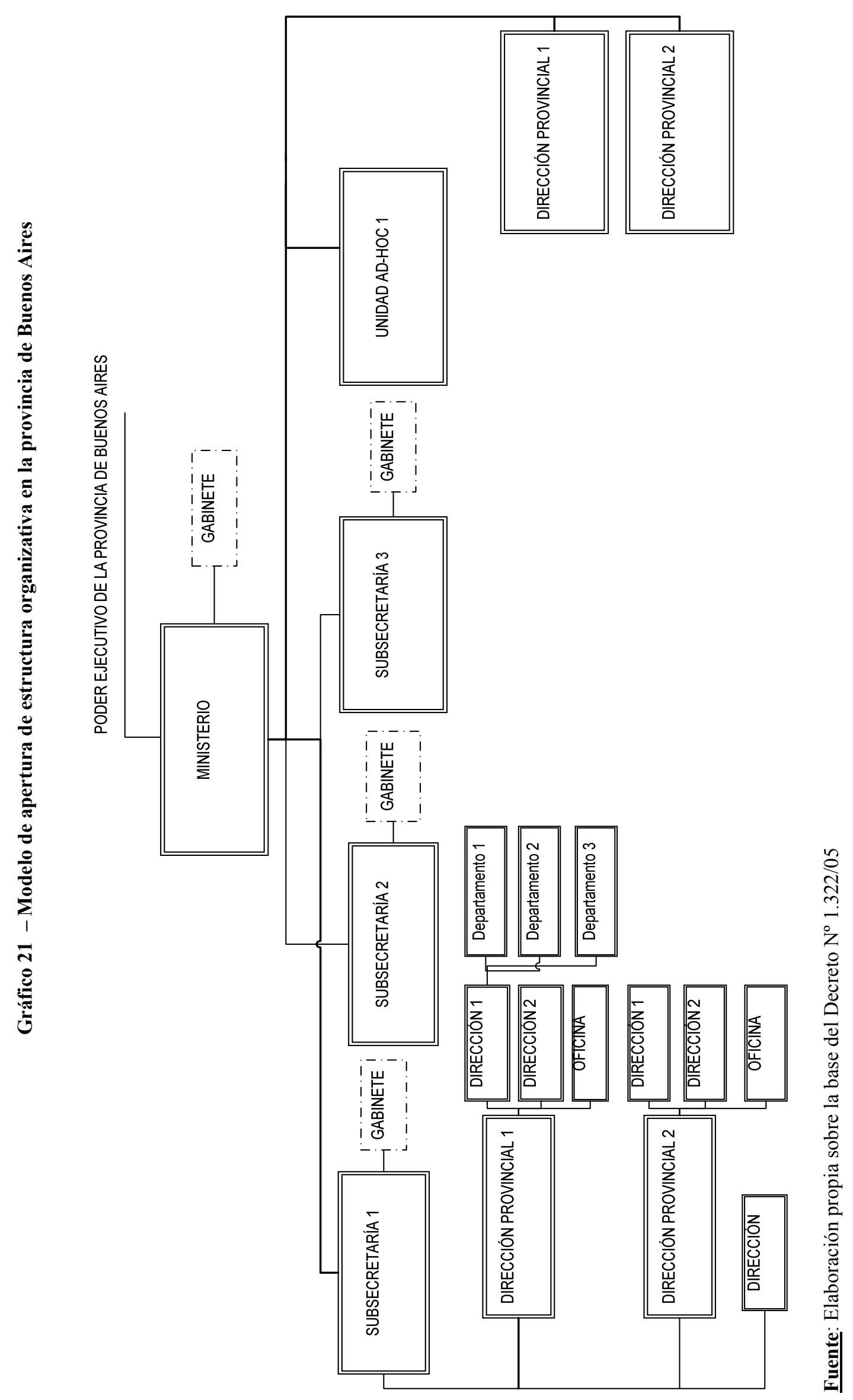

ฆ 
En efecto, el artículo $7^{\circ}$ del Decreto bajo análisis sostiene que:

Los Expedientes de aprobación de estructuras organizativas, una vez iniciados por la jurisdicción de inicio, se remitirán en primer término a la Subsecretaría de la Gestión Pública a los efectos del análisis técnico de la estructura propuesta, posteriormente se dará intervención a la Subsecretaría de Finanzas del Ministerio de Economía para su evaluación económica y su impacto presupuestario, seguidamente se girará a la Asesoría General de Gobierno para su revisión legal y por último se remitirá a la Subsecretaría Legal, Técnica y de Asuntos Legislativos quien, luego de evaluar los aspectos legales y técnicos del proyecto, requerirá la intervención en el mismo del ministro del área y lo pondrá a consideración del señor Secretario General de la Gobernación para la posterior firma del señor Gobernador. En el caso en que alguno de los organismos intervinientes con posterioridad a la Subsecretaría de la Gestión Pública, realizara alguna modificación al proyecto en tratamiento, el expediente deberá volver a ésta para su informe y posterior devolución (Articulo $7^{\circ}$ Decreto 1.322/05).

Se establece que el sistema tendrá un esquema participativo, al establecerse en el artículo 11 del Decreto que ...

Las actuaciones por las que se gestione la aprobación de las estructuras organizativas no tendrán carácter reservado en la etapa de su elaboración. Las Jurisdicciones, Organismos, Unidades o Dependencias de la Administración Pública Provincial deberán asegurar en sus respectivos ámbitos la máxima difusión y participación en la elaboración de las mismas.

Se fijan algunos criterios importantes para la justificación de la creación de las estructuras. Así, se distingue entre la misión ${ }^{309}$ y la fundamentación ${ }^{310}$.

¿Innova la norma respecto de la estructura jerárquica de la organización? Entendemos que no.

Si bien el decreto, y con especial referencia a las unidades flexibles reconoce que en algún caso, estas unidades podrán dar cuenta de acciones coordinadas entre diferentes jurisdicciones u organismos, la necesidad de su adscripción a una estructura les hace perder esta flexibilidad.

\footnotetext{
309 "Es el conjunto de funciones que se espera lleve a cabo un organismo a fin de transformar algún aspecto de la vida comunitaria. Ese conjunto de funciones lo dotan de sentido y justifican su creación" Anexo 1; punto 1.1 .

310 “Las propuestas de modificación o creación de estructuras ... deberán ser acompañadas por el plan estratégico preliminar - institucional- ... a fin de dar motivo y justificación a la presentación. Dicho plan deberá expresar claramente las prioridades políticas definidas por el Poder Ejecutivo que serán atendidas por la nueva organización o por la organización modificada”. Anexo 1; punto 1.2.
} 
Además, cuando el Decreto hace referencia a los organigramas como expresión gráfica de las estructuras, contiene expresas consignas que descartan modificaciones a las formas verticales de mando-obediencia.

Pueden leerse expresamente en el documento elaborado por la Subsecretaría de la Gestión Pública (2004-b) las siguientes técnicas de diseño:

- $\quad$ El organigrama estará compuesto por entegramas ordenados por niveles y líneas de dependencia jerárquica, pudiendo, además, existir líneas de dependencia funcional. ${ }^{31}$

- Las líneas de dependencia jerárquica son aquéllas que expresan la relación jerárquica entre los entegramas.

- A un entegrama se podrá llegar o salir por una sola línea de dependencia jerárquica.

- $\quad$ Las líneas de dependencia no se entrecruzarán.

La prohibición de establecer organigramas en los que una unidad orgánica de la estructura tenga vinculación a otras dos unidades orgánicas de la estructura impide que se pueda pensar en una lógica no vertical, más aún cuando todas las estructuras deben tener una dependencia jerárquica a una superior.

Con ello, la norma deja de lado otro tipo de diseño de estructuras, tales como las estructuras matriciales, que se asocian a las organizaciones de proyectos. ${ }^{312}$

Por ello, del análisis de la norma no surgen grandes cambios a la lógica ni al esquema del funcionamiento de la estructura jerárquica y de organización burocrática. No se introdujo el sistema de gestión por resultados, ni de flexibilidad y no se prevén esquemas que ayuden a compartir recursos conforme al principio de organización en red. Por ello, el diseño de estructura organizativa continúa revelando una concepción del Estado organizado jerárquico-burocráticamente.

\section{La Guía para el diseño de procesos}

La Resolución No 16/07 aprobada por la Subsecretaría de la Gestión Pública creó una guía para el diseño de procesos y la elaboración de manuales e instructivos de procedimiento aplicables a toda la Administración Pública Provincial, justificando su competencia para el dictado de la norma en su carácter de órgano asesor y de estimación

\footnotetext{
311 Entegrama es la representación gráfica de cada unidad orgánica de la estructura.

312 Las estructuras ad-hoc y matriciales posibilitan la flexibilidad necesaria para las situaciones de cambio rápido, articulándose mediante coordinación lateral. El trabajo se desarrolla a partir de proyectos. Este tipo de organización no reniega de la estructura jerárquica. Por el contrario, poseen un doble flujo de autoridad, el tradicional, vertical desde el punto de vista jerárquico, al que se suma uno horizontal desde el punto de vista técnico o de los proyectos. Este tipo de estructura puede estar conformado mediante la formación de equipos con integrantes de varias áreas de la organización para llevar a cabo un proyecto de carácter transversal.
} 
en los procesos institucionales del Estado Provincial, especialmente en lo referido a reforma, modernización, desconcentración, descentralización político-administrativo, participación, planificación integral y diseño organizacional, sistemas administrativos y de información y comunicación (conf. Decreto $\mathrm{N}^{\mathrm{o}} 2.100 / 04$ ).

La Subsecretaría identifica como uno de los problemas centrales de la Administración, la tramitación de las actuaciones y es por ello que señala como necesario aprobar un documento que contenga pautas básicas para el diseño de procesos y la elaboración de manuales e instructivos de procedimiento e implementar procesos operativos y administrativos eficaces "para el logro de objetivos y la obtención de resultados de gestión de cara a la sociedad que los origina y justifica" (Considerando $4^{\mathrm{o}}$ de la Resolución).

La Guía, aprobada como Anexo Único,

... se señalan los principales aspectos jurídicos del Procedimiento Administrativo Provincial y se presentan una serie de criterios, técnicas e instrumentos para el diseño de procedimientos y trámites de gestión eficaces y eficientes. El documento busca constituirse en una guía orientadora tanto para las administraciones provinciales $\mathrm{y}$ municipales, como para cualquier otra persona de derecho público que solicite la asistencia técnica del Estado Provincial en la materia.

Uno de los fundamentos - o fuentes - es la Carta Iberoamericana de la Función Pública pero el Anexo abunda en consideraciones teóricas y retóricas como cuando afirma

Como roles indelegables del Estado, resulta interesante sumar a las definiciones de la preservación de la identidad histórica y cultural de los pueblos y la definición de un destino compartido

ó

La gobernabilidad, en este marco, puede definirse como una situación de equilibrio entre las demandas y aspiraciones sociales y la forma en que el Estado ejerce la autoridad y gestiona los bienes y servicios públicos.

Relacionado más específicamente con el objeto de la Resolución, se señala que el vínculo entre las organizaciones públicas y la ciudadanía está deteriorado por el sinnúmero de reglamentaciones y formalismos y que una de las prioridades del Estado es alcanzar una mayor calidad en la prestación de sus servicios, en la producción de bienes públicos y en la implementación de políticas, lo que permitirá, al mismo tiempo, alcanzar un mayor grado de legitimidad.

La Guía reconoce como necesidad primordial "una visualización de los procesos de la organización para reconocer el objetivo que cumplen y el resultado que se espera" y para ello la Guía presenta, en primer término, un marco conceptual en el que 
se inscribe el estudio, análisis y revisión de los procesos administrativos, y los principios y criterios que la Provincia de Buenos Aires sostiene en esta materia. Posteriormente presenta el marco normativo que rige los procesos y tramitaciones en el ámbito público provincial y a continuación, se presentan la modalidad de relevamiento, descripción y análisis de procesos, para luego recomendar las herramientas y técnicas que pueden utilizarse para llevarlos a cabo, con especial referencia a las guías, instructivos y manuales de procedimiento que deben confeccionarse en el caso de procesos críticos.

Según la Guía

La gestión por objetivos y resultados constituye una forma de conducción y organización de las administraciones públicas que se basa en la previsión y preparación anticipada de logros, y en la delimitación y asignación de responsabilidades para conseguirlos ...

Y asigna especial importancia a la relación impactos-resultados-productos y a la relación recursos disponibles-recursos afectados "a diferencia de las formas tradicionales de gestión basadas en el cumplimiento de las normas y procedimientos." Y a renglón seguido señala:

Esta concepción permite una mayor autonomía en la toma de decisiones, pues establece relaciones de autoridad $\mathbf{y}$ responsabilidad claras, flexibiliza el uso de recursos sobre la base de su asignación a resultados previamente establecidos, genera sistemas de autocontrol que permite la retroalimentación de las acciones y vincula e interrelaciona la toma de decisiones cotidianas, el planeamiento estratégico, el proceso presupuestario, el monitoreo y la evaluación, el control y la rendición de cuentas (el destacado es nuestro).

El enfoque de calidad -en el que se basa el documento- centra su atención en la elaboración de propuestas innovadoras, lo que requeriría, a su vez, de la implementación de modelos de gestión que sustenten valores y principios que hagan a la calidad institucional y ello, con el objeto de brindar productos o prestar servicios que vinculen los compromisos asumidos por la organización con las necesidades de la comunidad.

A riesgo de ser extenso, pero buscando claridad en el análisis, se transcribirán algunos párrafos de la Guía que nos indican su orientación:

La gestión de la calidad busca apoyarse en valores y principios enfocados a la mejora continua, para dar respuesta a la ciudadanía y las demandas sociales. Se atiende especialmente sus necesidades y expectativas, transparentando la gestión. Por esta razón, la gestión de la calidad requiere focalizarse en los destinatarios de políticas, dado que supone que la organización planifica y realiza sus procesos con el objetivo de satisfacer requerimientos de los destinatarios. Conocer y 
satisfacer sus necesidades pasa a ser la preocupación prioritaria de la organización.

La evaluación continua de la gestión se alimenta de información objetiva acerca del grado de satisfacción de los destinatarios como dato sustantivo que retroalimenta la planificación y la revisión de objetivos.

El abordaje está asociado a la implementación de mejoras a partir de estándares, generalmente los relacionados con la familia de normas ISO.

Para el diseño de procesos, resulta necesario contar previamente con objetivos explícitos y una agenda/plan o presupuesto acorde. A partir de este insumo, se procede al diseño de estructuras y procedimientos. En síntesis, podemos decir que la gestión de la calidad es un modelo de gestión que interrelaciona como modelo o sistema las actividades de una organización con el objetivo de optimizar la asignación de recursos y garantizar la provisión de servicios/productos y la obtención de resultados.

Para este documento, una organización puede ser analizada desde diversos enfoques: la estructura y los equipos o puestos de trabajo. Según el primero de ellos, la organización responde a determinados esquemas que le permiten alcanzar sus objetivos. La estructura: a) Define el flujo de decisiones y comunicaciones, así como las relaciones de poder; b) Define la disposición de los recursos; y c) Facilita la realización de las actividades a partir de un funcionamiento coordinado. Es la estructura la que define las relaciones y aspectos más o menos estables de la organización. Según el otro enfoque, la organización puede orientarse a unidades más operativas dentro de la estructura organizativa, revisando los Equipos o Puestos de Trabajo, analizando las distintas unidades de trabajo y en el perfil de las personas que ejecutan las diversas tareas. Finalmente, la Guía opta por un enfoque sistémico según el cual la organización debe ser analizada como un sistema que interactúa con el medio, que capta insumos, los procesa (agrega valor) y entrega resultados (bienes o servicios) para satisfacer determinadas necesidades del medio. La visión sistémica, asociada al proceso como línea de producción fordista, es evidente. Los productos o servicios son el resultado de los procesos que lleva a cabo el sistema. Y agrega:

En cualquier caso, la gestión debe estar enmarcada en un plan estratégico, como acuerdo social de pretensión de logros en determinados plazos, lo que permite priorizar objetivos, diseñar programas, proyectos y acciones, definir la agenda temporal y asignar recursos. Por esta razón, el modelo por el que este documento opta es el de dirección o gestión por resultados. ... Una vez definidos y formulados los objetivos finales, las estrategias, las acciones y los recursos necesarios para un período, se diseñan los diferentes aspectos de la organización: Estructura, Procesos, Equipos o Puestos de Trabajo.

El documento distingue el conjunto de funciones que conforman las competencias organizativas de los procesos como secuencias de actividades que van atravesando las distintas divisiones funcionales que se observan en un organigrama 
formal (departamentos, direcciones) o funcional (coordinaciones, responsables) y distingue, finalmente entre procesos sustantivos (o primarios); de apoyo (o secundarios o administrativos) de los de gestión.

\section{Cuadro 47 - Distinción por tipos de proceso}

\begin{tabular}{|c|c|c|}
\hline Procesos sustantivos o primarios & $\begin{array}{l}\text { Procesos de apoyo, Secundarios o } \\
\text { Administrativos }\end{array}$ & Procesos de gestión \\
\hline $\begin{array}{l}\text { Administración, coordinación y control } \\
\text { del desarrollo de actividades productivas, } \\
\text { comerciales, deportivas etc. } \\
\text { Promoción de la inserción de empresas } \\
\text { recuperadas en el espacio productivo } \\
\text { local de manera sostenible. } \\
\text { Prestación alimentaria básica. } \\
\text { Formación básica común a todos los } \\
\text { niños y adolescente garantizando su } \\
\text { acceso, permanencia y promoción en } \\
\text { igualdad de condiciones y oportunidades. } \\
\text { Organización, Dirección Técnica y } \\
\text { Control de los establecimientos del } \\
\text { Servicio Educativo y el Servicio de Salud } \\
\text { Provincial. } \\
\text { Organización y dirección del servicio } \\
\text { penitenciario, para el tratamiento integral } \\
\text { de ciudadanos que deban cumplir con } \\
\text { sanciones judiciales. }\end{array}$ & $\begin{array}{l}\text { Gestión jurídico-legal (incluye } \\
\text { control de legalidad; instrucción } \\
\text { sumarial, etc.). } \\
\text { Administración de Personal (entre } \\
\text { otros, Control de asistencia, } \\
\text { capacitación, etc.). } \\
\text { Administración y Gestión económico- } \\
\text { financiera (Gestión presupuestaria; } \\
\text { Compras y contrataciones; registro } \\
\text { contable; administración patrimonial, } \\
\text { etc.). } \\
\text { Sistema de Información (manejo, } \\
\text { procesamiento de datos, etc.). } \\
\text { Gestión documental (Despacho, } \\
\text { Entradas y Archivo de } \\
\text { documentación; Gestión documental } \\
\text { a través de Centro de Documentación } \\
\text { o Biblioteca; Sistema Provincial de } \\
\text { expedientes, etc.) } \\
\text { Servicios generales (Comunicaciones, } \\
\text { seguridad, traslados; servicios de } \\
\text { movilidad y refrigerio o alimentación, } \\
\text { etc.). }\end{array}$ & $\begin{array}{l}\text { Planeamiento estratégico. } \\
\text { Control de gestión. } \\
\text { Monitoreo de la Gestión. } \\
\text { Evaluación de impacto. } \\
\text { Sistema de evaluación través de } \\
\text { Gestión por Resultados } \\
\text { Sistema de Indicadores de } \\
\text { Gestión (Tablero de Comando). } \\
\text { Coordinación de Programas de } \\
\text { Innovación (Incluye Programas } \\
\text { de Calidad en la Gestión } \\
\text { Pública; Certificación de } \\
\text { Normas IRMA-ISO) }\end{array}$ \\
\hline $\begin{array}{l}\text { Desarrollo y promoción de una economía } \\
\text { inclusiva. } \\
\text { Promoción y control de las actividades } \\
\text { agropecuarias, industriales, turísticas, de } \\
\text { prestación de servicios, en el marco de un } \\
\text { modelo de desarrollo sustentable. } \\
\text { Promoción y protección de derechos. }\end{array}$ & & \\
\hline
\end{tabular}

Fuente: Resolución No 16/07 Subsecretaría de la Gestión Pública.

Tal vez el punto más importante del documento y que marca los valores orientativos son los principios y criterios orientadores para el diseño de procesos y procedimientos que determina la Guía, fijando parámetros de actuación. Entre ellos, destacamos:

1. Legalidad: ... es presupuesto de una actuación regulada por normas entrelazadas que determinan la competencia, el contenido $\mathbf{y}$ el procedimiento en el que debe desenvolverse la actividad estatal. Es 
presupuesto de validez del resultado, de modo que todas las actividades de la Administración deberá enmarcarse en el campo legal objetivo vigente (Constitución Nacional y Provincial, Leyes, Decretos, etc.), incluso las realizadas por facultades discrecionales.

2. Derecho de defensa: comprende el acceso efectivo a las actuaciones, derecho a ser oído, oportunamente, a ofrecer $\mathbf{y}$ producir prueba y controlarla y a una decisión fundada. ...

3. Publicidad de los actos: es una exigencia que se desprende del Sistema Republicano de Gobierno. ...

4. Búsqueda de la verdad objetiva: ... Le permite a la Administración asumir actitudes y decisiones flexibles y abiertas tendientes a incorporar todo tipo de prueba que permita cumplir con este objetivo.

5. Oficialidad: la Administración, siempre que esté en juego el interés general, debe impulsar el proceso...

6. Igualdad: ... darle un trato similar a todos aquellos que se encuentren en una misma situación de hecho o jurídica. ...

7. Informalismo: deben evitarse ... requisitos meramente formales ...

8. Buena fe: ... se va a actuar conforme lo determinan las normas, en el marco de intereses legítimos y principios éticos.

9. Celeridad, economía y eficacia: necesidad de que los procesos y procedimientos sean rápidos, expeditivos y que los resultados lleguen en tiempo y forma. ... (los destacados no son nuestros).

Se agrega, también, criterios orientadores con la finalidad de mejorar la gestión de lo público son, entre otros, el de dinamismo de las prácticas procesales y las herramientas ${ }^{313}$; fluidez de la comunicación interna ${ }^{314}$; transparencia de las actuaciones $^{315}$; actitud proactiva e innovadora ${ }^{316}$; idoneidad ${ }^{317}$; visión transversal $^{318}$; búsqueda de nuevas formas de trabajo ${ }^{319}$; titularidad compartida de los datos ${ }^{320}$.

\footnotetext{
313 “.... este criterio exige que las mismas no se constituyan en un fin en sí mismo sino que tiendan a contribuir al logro de los objetivos para los cuales fueron diseñadas. De este modo se busca evitar que no se tornen rígidas, carentes de significación y que se tienda a su actualización constante".

314 "este criterio se traduce en la libertad y responsabilidad que tienen los agentes de requerir y brindar información, recabar datos y realizar cualquier clase de comunicación sin limitarse a los carriles formales y burocráticos, utilizando vías alternativas que permitan agilizar y dar respuesta a los procesos, dentro del marco legal de actuación"

315 “... además que los agentes administrativos intervinientes demuestren en todo momento una actitud transparente y de colaboración con la ciudadanía y los demás agentes públicos con la finalidad de canalizar sus necesidades o inquietudes".

316 “.... generación de espacios para el desarrollo de iniciativas novedosas y creativas, promoviendo una cultura de la innovación. Este criterio conlleva la responsabilidad sobre las decisiones tomadas".

317 “.... se pretende que los agentes actúen con pleno conocimiento de las materias pertinentes, inspirando confianza en la comunidad, evitando acciones que puedan poner en riesgo la finalidad de la gestión pública, el patrimonio del Estado o la imagen de sus servidores".

318 "fomento y construcción de enfoques sistémicos que permitan considerar integralmente la actividad la actividad administrativa y sus órganos, atravesando sus funciones y competencias para poder adaptar los procesos a la gestión por resultados"

319 "este criterio permite al decisor conformar equipos de trabajo multidisciplinarios e interorgánicos, con un enfoque común de trabajo y objetivos comunes, para lo cual se hallan mutuamente disponibles".

320 "todos los órganos de la Administración comparten la titularidad del conjunto de datos y documentos incorporados en algún momento en cualquiera de sus áreas. Se deben evitar sistemas de información
} 


\title{
4. Guía para la cobertura de cargos y funciones mediante procesos de selección.
}

El último de los procesos que analizaremos ${ }^{321}$ es la Guía de orientadora para la cobertura de cargos y funciones mediante procesos de selección de personal en la Administración Pública Provincial ${ }^{322}$.

Dicha Guía, de 32 páginas, con Modelos y Planillas de evaluación, dice enmarcarse en la política del Plan Trienal de dar protagonismo social, cuyo lugar destacado -el documento- lo identifica en los trabajadores estatales y sus organizaciones gremiales, en tanto actores ineludibles de un nuevo proyecto político y social y un nuevo Estado.

La Subsecretaría de la Gestión Pública por Decreto Nº 2.100/04, en el marco de sus competencias ${ }^{323}$ y de los acuerdos paritarios alcanzados, presenta esta Guía a fin de colaborar con las jurisdicciones y los representantes gremiales en la implementación de dichos acuerdos.

En efecto, el documento debe enmarcarse en la indicación de la Secretaría General $^{324}$ para que, a partir del 30 de junio de 2005, la cobertura de cargos jerárquicos sea puesta en marcha de un proceso de selección. La intención, asimismo, no sólo pretende ser un freno a los nombramientos discrecionales, sino también la cobertura por procesos de selección de cargos vacantes por cese definitivo, ingresos y la asunción de funciones específicas. En definitiva, se propone garantizar la plena operatividad de los principios de idoneidad, igualdad de oportunidades, transparencia e imparcialidad, mediante la publicidad, la participación y la eficacia, fiabilidad y validez de los instrumentos que se utilicen en los procesos de selección.

En primer lugar destacamos la definición de proceso de selección por su carácter participativo:

\begin{abstract}
A los efectos de esta guía, se entenderá por proceso de selección al proceso participativo que se inicia en una jurisdicción a los efectos de la ocupación de cargos o la asunción de funciones específicas por parte de las personas que reúnen los requisitos y el perfil para dicho cargo o función en el marco de programas a implementar o servicios a brindar.
\end{abstract}

\footnotetext{
duplicados o el acceso dificultoso a datos de utilidad para dos o más áreas. Asimismo, se debe evitar solicitar a los destinatarios de los trámites datos o documentos ya informados o adjuntados a la Administración, siempre que sea factible su obtención".

321 Más información, documentos y artículos producidos durante el período bajo estudio de la Subsecretaría de la Gestión Pública pueden encontrarse en: http://www.gestionpublica.sg.gba.gov.ar/html/biblioteca/ Fecha de Consulta: 27/03/12.

322 www.dpgp.sg.gba.gov.ar/html/guia_seleccion_personal.doc. Fecha de Consulta: 28/03/12.

323 "promover el estudio y diseño de sistemas de carrera para el personal de la administración pública provincial y participar en proceso de negociaciones colectivas de trabajo en el sector público"

${ }^{324}$ Lo cierto es que sólo fue por Nota del Secretario General de la Gobernación a los titulares de las Jurisdicciones de fecha 4 de junio de 2005.
} 
Entre estos procesos, cabe distinguir los relativos a la ocupación de puestos jerárquicos, dado que, en estos casos, las competencias necesarias abarcan cuestiones claves como el diseño de programas y proyectos, la conducción de personal, etc.. En tal sentido, la presente Guía, si bien ofrece una orientación para todos los procesos, focaliza su atención en la selección de personas que asumen funciones ejecutivas o directivas. En los demás casos (ingresos, categorías superiores, etc.), los procesos podrán simplificarse $\mathrm{y}$ realizarse en forma sumaria.

En todos los casos, deberá garantizarse la participación de todos los actores involucrados, la transparencia y la formalización del proceso (el destacado es nuestro).

Así, en el modelo propuesto por la Subsecretaría, las funciones no se asimilan a cargos, sino que se someten a procesos de selección o evaluación cada determinado período de tiempo.

La Guía propone que cada Jurisdicción elabore un proyecto de reglamento que regirá los procesos de selección en sus dependencias y que será puesto a consideración de las asociaciones sindicales con actuación en el organismo. Como Anexo del documento, se presenta uno a modo de ejemplo.

En ese marco, se sugiere que los procesos de selección sean de carácter interno respecto de la jurisdicción, correspondiendo participen en primer término los empleados de la planta permanente; luego ampliado a otras dependencias cuando aquellos sean menores a tres y sólo excepcionalmente, abiertos. La publicación del llamado a la selección se hará por el término de diez (10) días hábiles. Se sugiere, asimismo, la creación de una Unidad Técnica de Selección integrada por el Director/a Provincial y Director/a del área donde está radicada la vacante a cubrir, quienes podrán ser representados por quienes designen, siempre que posean jerarquía no inferior al cargo motivo de la selección; el/la titular de la Delegación de la Dirección Provincial de Personal de la Provincia donde se realiza el concurso, o su reemplazante natural y un/a representante por cada gremio con actuación en el Organismo, quienes actuarán en calidad de veedores ${ }^{325}$. La norma también permite incorporar expertos así como solicitar la asistencia técnica que crea conveniente.

Esta Unidad Técnica de Selección tendrá la atribución de evaluar las competencias ético institucionales, técnico profesionales y actitudinales, mediante la evaluación de los resultados, entre otros, de antecedentes; pruebas de oposición; presentación de proyectos referidos al cargo a cubrir; entrevistas grupales e individuales; pruebas del campo de la psicología y la sociología laboral; métodos de evaluación de competencias técnico profesionales y métodos de evaluación del desempeño individual en el marco grupal e institucional. Sobre esas evaluaciones la Unidad Técnica de Selección establecerá un orden de mérito y conformará una terna, a partir de la cual la autoridad competente seleccionará al candidato a designar.

La Guía señala que en todo proceso de selección debe definirse el marco institucional en el que se inscribe y este proyecto institucional se inscribe en una

\footnotetext{
${ }^{325}$ La Subsecretaría de la Gestión Pública y la Dirección Provincial de Personal podrán actuar como veedores.
} 
concepción del desarrollo económico, social y cultural provincial y nacional que es, en último término, el que otorga sentido y funcionalidad a cada ámbito o sector de la Administración Provincial.

En principio, la misión, las competencias y los planes institucionales son el insumo básico para elaborar perfiles de puesto. El Anexo D, acompaña un modelo de presentación de la Descripción del marco institucional, requisitos y perfil del puesto. Identificamos, de ese Anexo, las siguientes competencias y sus indicadores:

- Competencias ético institucionales: Compromisos y principios que se deben expresar en el ejercicio del rol, convenciones internacionales y principios del derecho que deberá reconocer en su tarea, etc.

○ Indicadores: antecedentes en el cargo, en otros sectores y organismos públicos, contenidos en legajo y C. Vitae, cartas de referencia, certificados de participación en foros y convenciones, presentación y defensa de un proyecto institucional, participación en programas solidarios y en organizaciones sociales y civiles.

- Competencias técnico profesionales: Conocimiento sobre misiones, estructura y procedimientos administrativos, conocimientos específicos para realizar las acciones inherentes al cargo a cubrir, conocimiento de la legislación aplicable a la tarea, manejo de tecnologías y herramientas de gestión, elaboración y/o lectura de estadísticas, informes o registros contables, redacción de notas, memos, actos administrativos, manejo de programas informáticos, etc.

- Indicadores: títulos, acreditaciones, trabajos profesionales, superación de pruebas de gestión, de pruebas de redacción técnica o administrativa, realización de trabajos en soporte informático, presentación y defensa de un proyecto institucional, dictado de clases, etc.

- Competencias actitudinales: Capacidad para solucionar problemas ante la ausencia del Director del área, para interactuar con autoridades superiores del organismo en caso de ausencia del Director, para resolver situaciones nuevas o conflictivas, para integrar, coordinar y/o dirigir un equipo de trabajo, para comunicarse de manera clara, fluida y oportuna con interlocutores diversos expresando un trato cordial y respetuoso, etc.

- Indicadores: reconocimiento de pares y colegas sobre su desempeño, participación en coloquios y defensas, integración de equipos de trabajo, etc.

A pesar del gran desarrollo de esta Guía y sus modelos de implementación, sólo hemos detectado 22 procesos de utilización de esta Guía que, para marzo de 2012, sólo 6 se encontraban ya finalizados ${ }^{326}$.

${ }^{326}$ http://www.dpgp.sg.gba.gov.ar/html/seleccion_personal.htm. Fecha de Consulta: 30/3/12. 


\section{CONCLUSIONES}

Según hemos podido detectar en el análisis de las políticas estudiadas, creemos encontrar una matriz de funcionamiento en los procesos de reforma en la Provincia durante el período 2002-2007.

En primer lugar, existe un claro diagnóstico de las deficiencias. La elección de la norma jurídica como institución para el cambio organizacional parece ser el instrumento para la modificación del estado de cosas, algunas veces precedida de consideraciones ideológicas y teóricas (como han sido los Planes de reforma). Finalmente, y luego de la norma, poco cambio como regla, por deficiencias en la implementación o seguimiento; incoherencia, cuando no disputas, entre los actores; falta de recursos; desinterés, etc.

Lo hemos visto en el correcto análisis que se hace desde la Subsecretaría de la Gestión Pública en cuanto al estado de las estructuras organizativas entonces vigentes en la Administración, la pretensión de cambio mediante la sanción del Decreto $\mathrm{N}^{\mathrm{o}}$ 1.322/05 (el cual, dicho sea de paso [aunque no tanto para los objetivos de la tesis] no se adecuaba a las pretensión del Gobernador de querer "introducir la herramienta de la gestión por resultados" que en el Decreto aparece sólo para unidades ad hoc) y la constante excepción en casi todos los Decretos de estructura a la nueva norma general.

Lo hemos detectado también en el proyecto de la Guía Única de Trámites o con la pretensión de reforma política que, de modernización del Estado que "transparente y legitime la relación de los ciudadanos con la política y sus dirigentes" según expresó el Gobernador, pasó a ser una experiencia de voto aplicable a una ínfima parte de la población.

También lo advertimos en el análisis del diseño gráfico institucional de las páginas Web: la identificación de un claro problema en la imagen de la Provincia, la pretensión de solucionarlo mediante un manual pero fallas para la sanción del desvío (en verdad ni siquiera se previó sanción alguna).

La asociación "más transparencia más rendición de cuentas" no se pudo demostrar entre los funcionarios bonaerenses. Las políticas de gobierno electrónico, que se pretendieron instrumentar, no pudieron modificar la opacidad de la Administración Pública bonaerense: menos de la mitad de los funcionarios políticos de la Administración Pública difundían su cuenta oficial de correo electrónico y menos del $20 \%$ de los funcionarios respondieron una consulta específica sobre su área utilizando este medio de comunicación.

Pero advertimos también una visión cuasi mágica sobre los efectos "transformadores" de la norma sobre el funcionamiento del Estado: el SINBA produciría transparencia; la firma electrónica aceleraría las notificaciones; la Guía para el diseño de procesos y la Guía para la cobertura de cargos y funciones mediante procesos de selección modificarían la forma de plantear los proyectos dentro de la Administración y los cargos se harían por concurso.

Hay, también, una hipertrofia de los instrumentos: el voto electrónico, como parte (aún cuando en los hechos fue lo único) de la reforma política, acercaría a los ciudadanos con los funcionarios. Un par de agentes de modernización cambiarían la cultura institucional o harían innecesarias las asesorías externas. 
Otras veces, se pretende adaptar (y no modificar) la estructura formal a la informal cristalizando los comportamientos informales no deseados, tal como hemos visto a propósito del Decreto $\mathrm{N}^{\circ} 1.322 / 05$ a partir del comentario de la Directora Provincial de la Gestión Pública.

Las políticas participativas, como las que se crearon especialmente en el marco del Programa Reforma Política, evidenciaron su escaso resultado. En efecto, si bien se señaló que las mesas integradas lograron consensos, ninguno de ellos se trasladó al ámbito legislativo. Existe ciertamente un déficit de participación de la sociedad civil. Distinta es la política que se imprimió desde la Subsecretaría de la Gestión Pública con procesos participativos en el diseño, por ejemplo, del proyecto de ley de procedimiento administrativo o la licitación de la Red Única Provincial de Datos desde la Subsecretaría de Gestión Tecnológica y Administrativa.

En verdad, advertimos disidencias teórico-ideológicas sobre el objeto de la reforma del Estado. No podemos identificar, dentro de los Planes, documentos y acciones que reseñáramos, la existencia de una clara línea en materia de reforma del Estado y de la gestión por parte de las grandes áreas que tuvieron competencia en esta materia.

Por un lado, el marco teórico que le da sustento al Plan Rector de Modernización impulsado por el Cr. Randazzo es el gerencialismo. En efecto, la serie de "premios" y "castigos" que se otorgan a los Organismos, la competencia por los recursos, así como los compromisos-contratos que contiene el Plan Rector, son una clara muestra de la adscripción del Plan de modernización a las políticas de la Nueva Gestión Pública.

Los "Acuerdos Programa" son otro ejemplo. Se preveía que los Acuerdos Programa fueran suscriptos por los titulares de organismos y de unidades ejecutoras de programas presupuestarios bajo la supervisión del Ministerio de Economía. Contra la elaboración de un compromiso de cumplimiento de políticas, objetivos y metas debidamente cuantificables y mensurables, se le otorgaría al organismo beneficios de naturaleza presupuestaria o la pérdida de las flexibilidades otorgadas ante su incumplimiento. Estas especies de "contratos" hacia dentro de la Administración son propios de las políticas de la Nueva Gestión Pública.

También hemos visto que en la creación de la Unidad de Coordinación Central para la Modernización expresamente se señalaba que su integración no generaría costos como si estos costos, necesarios para la implementación de todo proyecto, fueran disvaliosos. En verdad, lo que advertimos aquí, una vez más, es la confirmación de la adscripción a las políticas de la Nueva Gestión Pública.

Del análisis del Plan Trienal de la Gestión Pública 2004-2007 impulsado por la Subsecretaría del área, puede afirmarse que las acciones de modernización del Estado se asociaron a la innovación, descartando el término "reforma" por identificárselo a la concepción del Estado vigente en la década del '90. Se comienza a hablar de la recuperación del Estado y aunque se pretende diferenciar de las acciones iniciadas por la entonces Secretaría de Modernización, cuando se estudian alguno de los proyectos y acciones propiciadas desde esta Subsecretaría, se advierte que no hay grandes cambios. El Decreto de estructuras no modifica el esquema del funcionamiento de las estructuras jerárquicas y de organización burocrática. No se introdujo el sistema de gestión por resultados, ni de flexibilidad y no se prevén esquemas que ayuden a compartir recursos conforme al principio de organización en red. Las Unidades de Coordinación o Enlace que cruzan las estructuras jerárquicas por competencias funcionales o proyectos 
transversales apenas son descriptas. El proyecto de ley de procedimiento administrativo, en su redacción final, es "conservador".

¿Dentro de qué esquema teórico podemos identificar el Plan Trienal? Aún cuando no hay elementos expresos que señalen su adhesión, creemos identificarlo con otra de las corrientes de la Nueva Gestión Pública, la Teoría de la Elección Pública, con poca recepción en Latinoamérica, pero que sin duda marcó una tendencia en la región a través de su difusión por consultores ingleses y neocelandeses. Y si bien no encontramos en el Plan Trienal el discurso de la Teoría de la Elección Pública, ya totalmente inviable para el período de su presentación, especialmente en las propuestas privatistas de cambio, creemos que en el debate propiciado por la Subsecretaría de la Gestión Púbica en torno a la recuperación del espacio público, el fortalecimiento del Estado y la ausencia de la burocracia en este proceso, todo ello como precondición para reconstituir el tejido social y relegitimar al Estado, nos sitúa dentro de similares presupuestos que dan origen a las propuestas de la vertiente de la Teoría de la Elección Pública.

¿Dentro de qué paradigma puede ubicarse el Plan de Gobierno Electrónico? Si analizamos los beneficios que se esperan como consecuencia de la aplicación de las acciones necesarias para desarrollar sus objetivos, podremos advertir que entre la calidad, el aumento del impacto de los programas, la eficiencia, la legitimidad y la integración de la información, surge con claridad que los beneficios relacionados con una visión del gobierno electrónico asociada a la organización (eficiencia e integración de la información) son centrales frente a los objetivos relacionados con una visión del gobierno electrónico asociada a la participación (legitimidad y calidad). Ya hemos señalado que en su redacción intervino la entonces Secretaría para la Modernización del Estado pero también de las acciones propiciadas que aquí describimos (Guía Única de Trámites, Sistema de Información Normativo Bonaerense, Sistema Integrado de Emisión y Pagos No Impositivos y Firma Electrónica), ninguno de ellos estuvo orientado a mejorar la participación, transparencia o rendición de cuentas, y consecuentemente, la legitimidad estatal y en este sentido, puede decirse que, más allá de la retórica, la ejecución del plan respondió a los presupuestos subyacentes del Plan.

Por último, de las transcripciones y los destacados de los Considerandos de los Decretos propiciados por la Subsecretaría de Gestión Tecnológica y Administrativa, advertimos que pese a la ausencia de un Plan, existen ciertas palabras clave sobre las que se insiste a lo largo de los años: concentración, eficiencia, simplificación y TIC's. La reconstitución del orden administrativo, con una fuerte dosis de concentración parece haber sido el leitmotiv. Tal vez haya sido la ausencia de un Plan y la complejidad y variedad de temáticas a su cargo las que le imprimieron la fuerte dosis de pragmatismo necesaria a la Subsecretaría como para encontrar soluciones a problemas concretos que, a la luz de los resultados medidos en términos de acumulación de poder, nos dan cuenta de su éxito. Y sin embargo, este éxito no pudo sobrevivir a la gestión: desde el inicio de la gestión de Daniel Scioli, pasaron por esa área cinco Subsecretarios hasta el término del primer mandato; con el inicio del segundo mandato el área se desmembró. E independientemente de las personas, tampoco hubo continuidad en los proyectos. La política de reducir los tiempos de tramitación a través de los Pliegos tipo y contratos estandarizados finalizó cuando finalizó la gestión, no habiendo podido institucionalizarse dicha iniciativa. Luego de casi 7 años desde su aprobación, los Pliegos Tipo están próximos a convertirse en un obstáculo ante la cambiante realidad. 
Más allá de las líneas trazadas por el ex gobernador Solá, si analizásemos distintas estrategias o políticas teóricas de reforma, no es posible identificar una clara política al respecto. Y aún cuando pueden correlacionarse las políticas impulsadas por la Secretaría para la Modernización del Estado, y luego Ministerio de Gobierno, dentro de las líneas teóricas del New Public Managment, no menos cierto es que estas políticas presuponen una institucionalidad técnica del comportamiento burocrático, con poco espacio para la ambigüedad dado el control por resultados medibles. Y sin embargo, no hay elemento más político en los procesos de decisión pública que la presupuestación, desde su diseño, distribución, control, hasta su ejecución. Tampoco resulta evidente que las políticas de reforma de la Subsecretaría de la Gestión Pública puedan ser claramente identificables con las enroladas en las de segunda generación, ya que políticas centrales para esta visión, tales como la implantación de sistemas de carrera administrativa basados en el mérito, a la capacitación y desarrollo permanente del personal no pasaron más allá de un objetivo declamado. No queremos decir con ello que las acciones de la Subsecretaría no hayan orientado sus acciones hacia ello. Pero son los resultados (o no) de las políticas impulsadas los que nos hacen calificar como declamatorios. En definitiva, el cambio de gestión implicó, en materia de Gestión Pública, más que un mero cambio de direccionalidad: una concepción distinta de la modernización, más centrada en la recuperación del Estado y la participación ciudadana, pero con pocos instrumentos eficientes para ello.

Resulta evidente a esta altura del conocimiento y de la experiencia que antes de comenzar a diseñar cualquier política pública es preciso delimitar con claridad los objetivos buscados: ¿para qué se quiere esa política?, ¿qué objetivos deben buscarse? Y ello supone identificar, además de los actores y sectores beneficiarios, la problemática sobre la que se quiere intervenir. Ahora bien, los problemas centrales del período que estudiamos (seguridad, corrupción, desocupación, inserción de los jóvenes en la política), no fueron parte de los ejes de la reforma lo que nos muestra una desvinculación entre los problemas sociales y los de la agenda de reforma.

Entendemos, desde esta perspectiva, que no hubo verdadera reforma del Estado. En efecto, no encontramos una verdadera política modificatoria del Estado pese a las consignas del Gobernador en ese sentido: no se modificó la estructura política; no se modificó la composición del gasto público; no existieron políticas que transparentasen las decisiones. Resulta evidente que la reforma, asumida como política de Estado no existió en el período estudiado porque esa preocupación ha sido interpretada y reinterpretada por cada uno de los actores de diversa manera.

No obstante, creemos poder identificar en los actores involucrados, incluyendo al Gobernador, una problemática común, tal vez un eje sobre el cual evaluar/comprender estas políticas. Ese eje fue la crisis de gobernabilidad. En efecto, es evidente la concreta preocupación del gobernador por la gobernabilidad en el contexto de la crisis en que asumió. El análisis cuantitativo de su discurso nos reveló que, más allá de identificar los males de la burocracia, en la agenda diaria, ésta no ocupó un aspecto central sino que éste fue el problema de poder y la legitimidad del Estado.

Pero la resolución de esa crisis fue asumida desde distintas perspectivas por los actores estudiados. Desde una visión, asumida especialmente por la Secretaría para la Modernización del Estado, el problema de la eficacia ha sido central; desde otra, asumida por la Subsecretaría de la Gestión Pública, la legitimidad y la inclusión social; desde otra, la estabilidad, interpretada por la Subsecretaría de Gestión Tecnológica y 
Administrativa sobre la idea de orden. En otro lado se ha escrito -y muy bien- acerca de cada una de estas concepciones relacionadas con la gobernabilidad (Camou, 2001).

Es evidente que la sociología de la modernización no puede limitarse a la elaboración de un listado o conjunto de pre-requisitos y necesidades tomados de las sociedades que están ya modernizadas. Las políticas de mimetismo han fracasado; sin detectar necesidades, sin exploración sobre el funcionamiento interno se corre el riesgo de replicar los errores pero también los éxitos. Replicar los éxitos en una política de mimetismo, aunque parezca contradictorio, también es un problema porque la modernización no termina nunca. Si no conozco las causas del éxito, no podré replicarlas cuando cambie el contexto (contexto que en el actual macro-contexto cambia cada vez más rápidamente) y necesitaré, por ello, "comprar" un nuevo asesoramiento externo.

Habíamos afirmado, a modo de hipótesis, que las experiencias exitosas de modernización están asociadas a la innovación y exploración, siendo central para ese éxito la detección de las necesidades reales y concretas. ¿Podemos confirmar esa hipótesis?

Entendemos que los casos exitosos identificados, entre ellos, la licitación del servicio de acceso a Internet de la Red Única Provincial de Comunicación de Datos llevada adelante por la Subsecretaría de Gestión Tecnológica y Administrativa o el cuerpo de Agentes de Modernización (más allá de las limitaciones que tuvo por la escasez de recursos y apoyos puestos a su disposición), confirman la hipótesis.

Como ya hemos puesto de manifiesto en el proceso de licitación estudiado, resultó trascendental la participación tanto de los Organismos internos de control como de los propios actores involucrados en la licitación para generar una asociación positiva participación-confianza-aceptación. Pero también, la existencia de una necesidad real en el caso analizar más de 250.000 datos para adjudicar- llevó al Organismo a superar el desafío y a dar una respuesta -challenge-and-response-. Esa participación-confianzaaceptación posibilitó superar muchas de las resistencias y obstáculos organizacionales y miedos a las TIC.

En el caso de los Agentes de Modernización, la detección de la subutilización de los recursos humanos capacitados dentro de la propia administración.

De igual modo, y aún sin el respaldo normativo, con más de un año de avance a la reglamentación, los agentes del Patronato de Liberados efectuaron pruebas con certificados digitales en correos electrónicos que vincularon al Director de Sistemas de Información para el Control, los responsables de Administración de Redes y Administración de Bases de Datos y el Responsable de la Unidad Presidencia del Patronato. Este es también un caso de asociación positiva en proyectos innovadores que encuentran en las TIC una respuesta para superar la dificultad que enfrentaba el Organismo -en el caso, la dispersión geográfica de sus agentes en todo el territorio de la Provincia-. Esa innovación y exploración permitió que, cuando el proceso de firma electrónica implantado por el Decreto $\mathrm{N}^{\circ}$ 919/04 se aprobó, el Patronato de Liberados fuera el primer Organismo de la Administración Pública de la Provincia con firma electrónica atento a su capacitación, experiencia y estructura tecnológica.

Los proyectos exitosos que se pretenden implementar en nuestra región que vienen "enlatados" y financiados por organismos de crédito casi nunca ponen el acento en nuestras peculiaridades, idiosincrasias y necesidades. Se explora poco ... se innova menos. Se piensa que la legitimidad de origen del proyecto derivará en el éxito de su implantación en otro contexto, soslayando los necesarios acuerdos previos que requiere 
la implementación de toda política de Estado. Pero no puede pensarse que el traslado de procesos de modernización foráneos pueda conducir a similares resultados en regiones culturalmente diferentes. El desajuste entre las pautas formales y normativas de funcionamiento de las instituciones y lo que efectivamente ocurre dentro de la organización es una respuesta lógica.

Cuando no se innova ni se explora, las políticas suelen concentrarse en automatizar la lógica de los procesos vigentes, que comúnmente tienen incorporados los sesgos, vicios y hábitos ineficientes e ineficaces de las organizaciones. Por ello, si bien existen innumerables posibilidades para la innovación en la gestión pública, las organizaciones tienden a reproducir las pautas de funcionamiento y de relación que se pretendían superar.

Esta lógica de reproducción de los procesos y poca innovación, la hemos advertido con los procesos de compra informática. En efecto, los resultados del análisis de la compra informática nos llevaron a identificar el mayor gasto relativo (por empleado y por presupuesto) en Organismos de la Administración Pública que proveen insumos para la propia Administración.

Nótese que a excepción del Ministerio de Trabajo que destinó el 0,554\% del presupuesto 2004-2006 para la compra de elementos informáticos, los organismos identificados con la Acción Social invirtieron un porcentaje muy inferior (Instituto de Previsión Social, 0,005; Ministerio de Desarrollo Humano, 0,022\%; Ministerio de Salud, 0,031\%). Por el contrario, como ya marcáramos, organismos proveedores de recursos e insumos para el resto de la Administración invirtieron cifras muy superiores: el Ministerio de Economía invirtió el 0,480\% del presupuesto 2004-2006, la Gobernación (Sec. Gral. y Secretarías) el 0,610\% y el Ministerio de Gobierno, 0,647\%.

Encontramos una clara prueba de ello con el proyecto de la Guía Única de Trámite. No sólo vimos la resistencia de algunos organismos en cargar sus trámites y de tenerlos actualizados, sino también cómo en el Back Office se reproducían las prácticas propias de la Administración Pública: como hemos visto, y consecuencia de una errónea política de concentración, un matrimonio que trabajaba en la Dirección Provincial de Informática concentraba la tarea de recibir y contestar electrónicamente las dudas de los ciudadanos usuarios de toda la Provincia respecto de la información cargada en el sistema siempre que la respuesta estuviera en la propia página del Guía Única de Trámite; cuando la información no era suficiente, remitía la duda a los organismos encargados de cargar la información. Esto generaba, sin dudas, retraso y redundancia en las respuestas que no se condicen con el espíritu del proyecto. Y como eran los únicos encargados del sistema de respuesta, cuando tomaban vacaciones, el sistema se detenía. Es cierto que el Back Office de la Guía Única de Trámite se reformó, pero situaciones como éstas no son casos excepcionales en la Administración Pública.

Pero no sólo la necesidad de superar un desafío - challenge- es condición para dar el salto hacia una reforma inteligente -response-. Hay algo que no se mide ni se sopesa, un elemento casi tan intangible como el bosón de Higgs que la "Máquina de Dios" se empeña en encontrar... una autoridad que no se encuentra en el Derecho, sino en una mística que hace que sucedan cosas que de otra forma no hubieran sucedido. 


\section{BIBLIOGRAFÍA}

\section{Sección primera - Proyecto de Investigación}

ALFORD, Roger y FRIEDLAND, Robert, 1991: Los Poderes de la Teoría. Ed. Manantial, Bs. As.

BLUTMAN, Gustavo, 1998. Aproximaciones a la Reforma del Estado en Argentina. Eudeba, Bs.As.

BOUZA-BREY, Luis, 1999. "El poder y los sistemas políticos" en CAMINAL BADIA, Miquel (ed.), 1999. Manual de Ciencia Política. Tecnos, Madrid.

CALSAMIGLIA BLANCAFORT, Helena y Amparo TUSÓN, 2002. Las Cosas del Decir. Manual de Análisis del Discurso. Ariel. Barcelona.

CAMOU, Antonio, 2001. Gobernabilidad y democracia. Instituto Electoral Federal. México.

CAMOU, Antonio (dir.), 2005. "Estudio de permeabilidad de las estructuras organizativas del Estado provincial respecto de las políticas sociales y del control de los recursos económicos. Programa de Subsidios para Proyectos de Investigación y Desarrollo y Transferencia con Organismos Públicos de la Provincia de Buenos Aires". Instituto Provincial de la Administración Pública y Departamento de Sociología de la Universidad Nacional de La Plata.

FLEURY, Sonia, 1999. "Reforma del Estado en América Latina. ¿Hacia dónde?” Nueva Sociedad, No.160, Marzo-Abril, '1999. Caracas.

FREUND, Julien, 1968. La Esencia de lo Político, Editora Nacional, Madrid.

GUERREIRO RAMOS, Alberto, 2008. "A modernização em nova perspectiva: em busca do modelo da possibilidade" en HEIDEMANN, Francisco y SALM, José Francisco, (org), 2008, Políticas Públicas e desenvolvimento. Bases epistemológicas e modelos de análise, UnB, Brasilia.

GROISMAN, Enrique, 1991. Políticas administrativas para el sistema democrático. CEAL, Buenos Aires.

HINTZE, Jorge (2001). Gestión presupuestaria de estructuras: un instrumento para la gestión por resultados. VI Congreso Internacional del CLAD sobre la Reforma del Estado y la Administración Pública, Buenos Aires, Argentina, 5-9 noviembre 2001. Disponible en: http://www.clad.org/portal/publicaciones-del-clad/revista-clad-reformademocracia/articulos/021-octubre-2001/0041005

LÓPEZ, Andrea (coord.), 2005. "Indicadores de Gestión para el Monitoreo de las Políticas de Modernización en el Sector Público: Revisión teórica y propuesta para su elaboración". Rev. Desarrollo Institucional y Modernización del Estado, No 71, Instituto Nacional de la Administración Pública, Dirección de Investigaciones, Junio 2005.

OSZLAK Oscar, 2003. "Escasez de recursos o escasez de innovación?: la reforma estatal argentina en las últimas dos décadas". VIII Congreso Internacional del CLAD sobre la Reforma del Estado y de la Administración Pública, Panamá, 2003.

OSZLAK, Oscar, 1999. "De Menor a Mejor: El Desafío de la "Segunda" Reforma del. Estado". Nueva Sociedad, No.160, Marzo-Abril, `1999. Caracas.

OSZLAK, Oscar, 2000. "El mito de Estado mínimo: Una década de reforma estatal en Argentina". IV Congreso Internacional del CLAD sobre Reforma del Estado y de la Administración Pública, Santo Domingo, 2000. 
PARAMIO, Ludolfo, 2002. "Reforma del Estado y desconfianza política". Revista del CLAD Reforma y Democracia. No. 24. Caracas.

PASQUINO Gianfranco, 1982 "Modernización" en BOBBIO, N., MATTEUCI, N. y PASQUINO, G. (Orgs.). Diccionario de política. Siglo XXI, Madrid.

REYNOSO, Diego, 2005. "Bicameralismo y sobre representación en Argentina en perspectiva comparada". Revista de la Sociedad Argentina de Análisis Político Volumen 2 Número 1, pp.69-94, Buenos Aires.

VAN DIJK, Teun, 1997. Estructuras y funciones del discurso. Siglo Veintiuno, México.

ZELLER, Norberto, 2007. Las Políticas de Reforma Estatal en Democracia (19832003): sus Etapas Gubernamentales $y$ las Principales Transformaciones. Ministerio de Jefatura de Gabinete, Buenos Aires.

\section{Sección segunda- Marco Teórico}

ABERBACH Joel D. y ROCKMAN Bert A., 1999. "Reinventar el Gobierno: Problemas y Perspectivas" en Gestión y Análisis de Políticas Públicas no 15, pág. 3-17, cit. por CRIADO GRANDE Juan Ignacio, María Carmen RAMILO ARAUJO y Miguel SALVADOR SERNA, 2002.

AGLIETTA Michel y ORLÉAN André, 1990, La violencia de la moneda, Ed. Siglo XXI, México.

AGUILAR VILLANUEVA, Luis, 2006. Gobernanza y gestión pública, Fondo de Cultura Económica, México.

ARAYA DUJISIN, Rodrigo, 2004. "Introducción: Gobierno electrónico en América Latina" en Araya Dujisin, R. y Porrúa Vigón, M. A., Editores, 2004. América Latina Puntogob. Casos y Tendencias en Gobierno Electrónico. Ed FLACSO Chile; OEA. Santiago de Chile. Versión digital en: hasp.axesnet.com/contenido/documentos/Am\%E9rica\%20Latina\%20Puntogob\%20final .pdf. Fecha de Consulta: 01/06/11.

ARELLANO GAULT, David, 2001. "Dilemas y potencialidades de los presupuestos orientados a resultados: límites del gerencialismo en la reforma presupuestal". VI Congreso Internacional del CLAD sobre la Reforma del Estado y la Administración Pública, Buenos Aires, Argentina, 5-9 noviembre de 2001. Disponible en: cdi.mecon.gov.ar/biblio/docelec/clad/cong6/7nov/65/arellano.pdf. Fecha de Consulta: 01/06/11.

ARELLANO GAULT, David, 2002. "Nueva Gestión Pública: ¿el meteorito que mató al dinosaurio? Lecciones para la reforma administrativa en países como México". Revista del CLAD Reforma y Democracia No. 23. Caracas. Disponible en: http://www.clad.org/siare isis/fulltext/0041700.pdf. Fecha de Consulta: 01/06/11.

ARELLANO GAULT, David, 2003. "Nueva Gestión Pública y diseño políticoinstitucional. Implicaciones para un país como México". Revista IAPEM, enero-abril 2003, México.

AUGE, Marc, 2000. Los «no lugares» espacios del anonimato. Una antropología de la Sobremodernidad. Gedisa, Barcelona. 
BALBIS Jorge, 2001. "ONGs, Gobernancia y Desarrollo en América Latina y el Caribe". Documento de trabajo de MOST, $\mathrm{N}^{\circ} 53 . \quad$ Internet: http://www.unesco.org/most/dsp53_sp.htm.

BAÑÓN, Rafael y CARRILLO BARROSO Ernesto, 1997. "La legitimidad de la administración pública” en BAÑÓN, Rafael y CARRILLO BARROSO Ernesto (eds.) La Nueva Administración Pública. Alianza Universidad. Madrid.

BARBER, Benjamin, 1984. Strong Democracy. Participatory Politics for a New Age. Univ. of California Press, Berkley.

BECK Ulrich, 1998. ¿Qué es la globalización? Piados, Barcelona.

BID, 2003. manual.gob. Estrategias de gobierno electrónico en los países de la región 1: La definición de un modelo de análisis y estudio de casos. En: www.iadb.org/sds/itdev/doc/manual gobes.pdf. Fecha de Consulta: 01/03/08.

BLANCO VALDÉS Roberto L., 1996. "La democracia y el poder de los partidos" en Revista Claves de Razón Práctica nº 63, Junio de 1996, pág. 24 a 33, Madrid.

BOBBIO Norberto, 2000. El futuro de la democracia. F.C.E.; México.

BOBBIO, Norberto 1989. Estado, gobierno y sociedad. F.C.E. , México.

BODIN, Jean, 1997 (1576). Los seis libros de la República. Ed. Tecnos. Madrid.

BÖRZEL, Tanja, 1997. "¿Qué tienen de especial los policy networks? Explorando el concepto y su utilidad para el estudio de la gobernación europea". Disponible en línea en: revista-redes.rediris.es/webredes/textos/policynet.doc. Fecha de Consulta: 01/06/11.

BOVAIRD, Tony, 2005. "Le gouvernance publique: commment maintenir um juste equilibre entre le pouvuoir des intervenants des une societé en réseau?" en Revue Internationale des Sicencias Administratives, v. 71 n $^{\circ}$ 2, Junio 2005, pags. 223-235.

BRESSER-PEREIRA, Luiz Carlos, 1990. Technobureaucratic capitalism. Disponible en http: http://bresserpereira.org.br/Books/1990TechnobureaucraticCapitalism.i.pdf. Fecha de Consulta: 01/06/11.

BURDEAU, Georges, 1983. El Liberalismo Político. Eudeba, Buenos Aires.

CAMOU, Antonio (dir.), 2005. "Estudio de permeabilidad de las estructuras organizativas del Estado provincial respecto de las políticas sociales y del control de los recursos económicos. Programa de Subsidios para Proyectos de Investigación y Desarrollo y Transferencia con Organismos Públicos de la Provincia de Buenos Aires" en Instituto Provincial de la Administración Pública y Departamento de Sociología de la Univrsidad Nacional de La Plata.

CAMOU, Antonio, 2001. Gobernabilidad y democracia. Instituto Electoral Federal. México.

CARDERNAS RINCÓN, Erik y VELANDIA Ramiro C., 2003. "Reforma a la administración pública a través del gobierno electrónico". VIII Congreso Internacional del CLAD sobre la Reforma del Estado y de la Administración Pública. Panamá, 2003 en http://unpan1.un.org/intradoc/groups/public/documents/CLAD/clad0047116.pdf. Fecha de Consulta: 01/03/10.

CASSAGNE, Juan Carlos, 2000. Derecho Administrativo, Tomo II, Abeledo Perrot, Buenos Aires.

CLEARY Eda, 2006. "El eterno dilema del control de la gestión pública en América Latina y el caribe: Desconfianza, control y castigo versus Confianza, verificación y estímulo. Una contribución hacia la contextualización del tema". TOP. Disponible en línea en: www.top.org.ar. Fecha de Consulta: 01/06/11. 
CORBETTA, Juan Carlos y PIANA Ricardo Sebastián, 2005. Constitución política de la República argentina. Dimensión normativa y jurisprudencial de la realidad política argentina. Scotti, La Plata.

CORBETTA, Juan Carlos y PIANA, Ricardo Sebastián 2009. Ensayos sobre la democracia contemporánea. EDULP, La Plata.

CRIADO GRANDE Juan Ignacio y RAMILO ARAUJO, María Carmen, 2001. "eAdministración: ¿un Reto o una Nueva Moda para las Administraciones del Siglo XXI?. Algunos Problemas y Perspectivas de Futuro en torno a Internet y las Tecnologías de la Información y la Comunicación en las Administraciones Públicas", en Revista Vasca de Administración Pública, 61, Instituto Vasco de Administración Pública.

CRIADO GRANDE Juan Ignacio, María Carmen RAMILO ARAUJO y Miguel SALVADOR SERNA, 2002. "La Necesidad de Teoría(s) sobre Gobierno Electrónico. Una Propuesta Integradora" en XVI Concurso de Ensayos y Monografías del CLAD sobre Reforma del Estado y Modernización de la Administración Pública. Caracas. Disponible en línea: http://www.clad.org/siare isis/fulltext/0043103.pdf. Fecha de Consulta: 01/06/11.

CROZIER, Michel, HUNGTINTON, Samuel P. y WATANUKI, Jioji, 1975. The Crises of Democracy. Report on the Governability of Democracies to the Trilateral Comision. University Press, New York.

CROZIER, Michel, 1995. Cómo reformar al estado: tres países, tres estrategias: Suecia, Japón y Estados Unidos. FCE, México.

DAHL, R. 1989, La poliarquía. Participación y oposición, Tecnos, Madrid.

DEL GIORGIO SOLFA, Federico, DE SIO Natalia y GIROTTO Luciana Mercedes, 2009. "Aportes conceptuales y metodológicos para la implementación de Carta Compromiso con el ciudadano en el ámbito de la Provincia de Buenos Aires" en Revista virtual de Escuela de Gobierno y Formación de Lideres. Disponible en: http://www.gob.gba.gov.ar/portal/documentos/reflexiones5.pdf

DICCIONARIO DE LA REAL ACADEMIA ESPAÑOLA, 2001. Disponible en www.rae.es. Fecha de Consulta: 01/06/11.

DIMAGGIO Paul y POWELL Walter (Comp.), 1999. EI nuevo institucionalismo en el análisis organizacional. FCE. México.

do COUTO BEMFICA Juliana, Ana Maria PEREIRA CARDOSO y Carlos Aurélio PIMENTA de FARIA, 2005. "Estado y mercado en la construcción de la sociedad de la información global" en Revista Nueva Sociedad No 196, Caracas.

DROR, Yehezkel, 1990. Enfrentando el futuro. FCE. México.

DWORKIN, Ronald, 2006. Is Democracy Possible Here? Principles for a New Political Debate. Princeton University Press, New Jersey.

ECHEBARRIA ARIZNABARRETA, Koldo, 2000. "Reivindicación de la reforma administrativa: significado y modelos conceptuales". Ponencia presentada en el V Congreso Internacional del CLAD sobre la Reforma del Estado y de la Administración Pública, Santo Domingo, Rep. Dominicana, 24 - 27 Oct. 2000. Disponible en: http://unpan1.un.org/intradoc/groups/public/documents/clad/clad0038545.pdf. Fecha de Consulta: 11/05/12.

ESTESO Roberto y Horacio CAO, 2001. "La reforma de las Administraciones Públicas Provinciales: balance de la década de los 90 y nueva agenda". TOP. Disponible en línea en: www.top.org.ar. Fecha de Consulta: 01/06/11.

FERNÁNDEZ SANTOS, Yolanda, José Miguel FERNÁNDEZ FERNÁNDEZ y Alicia RODRÍGUEZ PÉREZ, 2008. "Modernización de la Gestión Pública. Necesidad, 
incidencias, límites y críticas" en Revista Pecvnia n ${ }^{\circ}$ 6, Revista de la Fac. de Ciencias Económicas y Empresariales de la Universidad de León. Disponible en http://www3.unileon.es/pecvnia/pecvnia06/06_075_106.pdf. Fecha de Consulta: $09 / 05 / 12$

FIORAVANTI, Maurizio, 2004. "Estado y Constitución” en FIORAVANTI, Mauricio (ed.), 2004, El Estado moderno en Europa. Instituciones y derecho, Trotta, Madrid.

FISICHELLA, Doménico, 1982, "Tecnocracia", en BOBBIO, N., MATTEUCI, N. y PASQUINO, G. (Orgs.). Diccionario de política. Siglo XXI, Madrid.

FLEURY, Sonia, 1999. "Reforma del Estado en América Latina. ¿Hacia dónde?" en Revista Nueva Sociedad, No.160, Marzo-Abril, '1999. Caracas.

FOUNTAIN, Jane E., 2001. Building the Virtual State. Brookings Institution Press, Washington D. C.

FREUND, Julien, 1968. La Esencia de lo Político, Editora Nacional, Madrid.

FREUND, Julien, 1984. "La Esencia de lo Político" en Revista Signos Universitarios, Año VI, No 12 , noviembre de 1984.

GARCÍA DELGADO, Daniel, 2006. "Código Iberoamericano de Buen Gobierno CLAD. Comentarios al Docuemento", IPAP, Buenos Aires, Disponible en www.claudiabernazza.com.ar/.../documentos/comentarios buen_gobierno.doc. Fecha de Consulta: 03/12/10.

GARCÍA PELAYO, Manuel, 1982. Burocracia y tecnocracia y otros escritos. Alianza Universidad. Madrid.

GASCÓ, Mila, 2010. "Una aproximación neoinstitucioalista al gobierno electrónico. ¿A qué se enfrenta el Cio en el contexto latinoamericano?". XV Congreso Internacionald del CLAD sobre Reforma del Estado y Modernización de la Administración Pública, Santo Domingo, 2010.

GASCÓ, Mila, 2004. E-Gobierno en Bolivia y Paraguay, en ARAYA DUJISIN, Rodrigo; PORRÚA VIGÓN, Miguel A., Editores, 2004. América Latina Puntogob. Casos y Tendencias en Gobierno Electrónico. Ed FLACSO Chile; OEA. Santiago de Chile.

GIDDENS, Anthony, 1999. "El futuro del estado benefactor" en Revista Estudios Públicos, 74 (otoño 1999).

GIDDENS, Anthony (s/f). "Reflexiones sobre la mundialización". Extractos de su discurso de apertura en la Conferencia de UNRISD sobre Mundialización y Ciudadanía en http://www.scribd.com/doc/7271016/GIDDENS-Anthony-Reflexiones-Sobre-LaMundializacion. Fecha de Consulta: 01/06/11.

GIRARD, Fernando, 2002. "Políticas públicas y tecnología: el Comité Nacional para la Sociedad de la Información. Un proyecto en red". Colección de Documentos. Instituto Internacional de Gobernabilidad. Disponible en línea en: esterkaufman.com.ar/wpcontent/uploads/2010/02/girard.pdf. Fecha de Consulta el 01/06/11.

GORDILLO Agustín, 2003. Tratado de derecho administrativo. $\mathrm{T}^{\mathrm{o}} 1$, Parte General. F.D.A, Buenos Aires.

GOZZI, Gustavo, 1986. “Administración Pública” BOBBIO, N., MATTEUCI, N. y PASQUINO, G. (Orgs.). Diccionario de política. Siglo XXI, Madrid.

GROSSI, Paolo, 2003. Mitología jurídica de la modernidad. Trotta, Madrid.

GUERREIRO RAMOS, Alberto, 2008. A modernização em nova perspectiva: em busca do modelo da possibilidade en HEIDEMANN, Francisco y SALM, José Francisco, (org), 2008, Políticas Públicas e desenvolvimento. Bases epistemológicas e modelos de análise, UnB, Brasilia. 
HABERMAS, Jürgen, 1986. Problemas de legitimación en el capitalismo tardío. Amorrortu. Buenos Aires.

HEEKS, Richard (ed.), 2001. Reinventing Government in the Information Age: International Practice in IT-Enabled Public Sector Reform. Routledge. London/New York.

HELLER, Hermann, 1992. Teoría del Estado. F.C.E. México.

HELMKE Gretchen y LEVITSKY Steven (2003) "Informal institutions and politics in Latin America" en Brinks, D. M. (2003). Courts, norms and laws: competing rules and legal rights in Salvador, Sao Paulo and Buenos Aires. Trabajo presentado en la conferencia Informal institutions and politics in Latin America Kellogg Institute for International Studies, University of Notre Dame, 24-25 de Abril.,

HINTZE, Jorge (2003). Gestión por procesos y por resultados en el aparato estatal: una cuestión abierta. SEGUNDO CONGRESO ARGENTINO DE ADMINISTRACIÓN PÚBLICA - Sociedad, Gobierno y Administración Pública " Reconstruyendo la estatalidad: Transición, instituciones y gobernabilidad ", Córdoba , 27, 28 y 29 de noviembre de 2003, República Argentina. Disponible en: http://www.aaeap.org.ar/ponencias/congreso2/Hintze Jorge.pdf

HINTZE, Jorge (2011). Guía para la evaluación de estructuras organizativas. Material correspondiente al Curso Evaluación Institucional de Organizaciones Públicas (EIOP) dictado por TOP y la UNL.

MAIJA, Jansson, 2007. Realities of Representation. State Building in Early Modern Europe and European America. Palgrave MacMillan, New York.

Kaufman, Ester, 2007. "Introducción" en Kaufman, E. (Coord.), 2007, Políticas Públicas y Tecnologías. Líneas de acción para América Latina. Ed. La Crujía , Buenos Aires.

KELSEN, Hans (1988). Teoría general del derecho y del Estado. UNAM., México. KLIKSBERG Bernardo, 1975. “¿Qué se entiende por escuela tradicional en administración? en El pensamiento organizativo: del taylorismo a la teoría de la organización. Paidos, Buenos Aires.

KNIGHT, Jack (2002). "Informal institutions and the microfoundations of politics". Trabajo presentado en la conferencia Informal institutions and politics in the developing world, Weatherhead Center For International Affairs, Harvard University, 5-6 de Abril de 2002 cit. por Leiras M. (2004). LEIRAS Marcelo (2004) “¿De qué hablamos cuando hablamos de instituciones informales?" en Fernández Arturo, comp. (2004) Estudios de Política Comparada. Universidad Nacional de Rosario, Rosario.

KÜHNL, Reinhard, 1971. "El Liberalismo"; en Wolfgang Abendroth y Kurt Lenk, 1971. Introducción a la ciencia política. Barcelona. Anagrama.

LAGROYE, Jacques (1991) Sociología política. Buenos Aires, Fondo de Cultura Económica.

LAPORTA Francisco J., 2000. "El cansancio de la democracia" en Claves de Razón Práctica $n^{\circ}$ 99, Enero- Febrero de 2000, pág. 20 a 25, Madrid.

LEÓN y RAMÍREZ, J. Carlos, 2003. “Estado, mercado y espacios públicos”. VIII Congreso Internacional del CLAD sobre la Reforma del Estado y de la Administración Pública, Panamá, 2003. Disponible en línea en: http://www.clad.org/siare isis/fulltext/0047106.pdf. Fecha de Consulta: 01/06/11.

LEVI, Lucio, 1986. "Gobierno" en BOBBIO, N., MATTEUCI, N. y PASQUINO, G. (Orgs.). Diccionario de política. Siglo XXI, Madrid.

LOEWENSTEIN, Karl, 1964. Teoría de la Constitución. Ariel, Barcelona 
LUHMANN, Niklas, 1996. Confianza. Anthropos, México.

LUKES, Steven, 1988. "Poder y autoridad" en BOTTOMORE, Tom y NISBET, Robert, 1988. Historia del análisis sociológico. Amorrortu, Buenos Aires.

MARCH, James G. y Johan P. OLSEN, 1997. El redescubrimiento de las instituciones: La base organizativa de la política. FCE. México.

MARIENHOFF, Miguel, 2003. Tratado de Derecho Administrativo, Tomo I, 5 ed., Abeledo Perrot, Buenos Aires.

MATTEUCCI, Nicola, 1998. Organización del poder y libertad. Historia del constitucionalismo moderno. Trotta, Madrid.

MATUS, Carlos (1987). Política, planificación y gobierno. Fundación ALTADIR, Caracas.

MAYNTZ, Renate, 1985. Sociología de la Administración Pública. Alianza Editorial, Madrid.

MERTON Robert, 1960. "Estructura burocrática y personalidad" en Sociología del Poder, editorial Andrés Bello, Santiago de Chile.

MEYNAUD, Jean, 1968. La tecnocracia ¿Mito o realidad? Tecnos, Madrid

MOLINA, Jerónimo, 2000. Julien Freund. Lo político y la política. Sequitur, Madrid

NORRIS Pippa, 2003. "Deepening Democracy via E-Governance". Draft chapter for the UN World Public Sector Report. Harvard University. Disponible en línea en: www.hks.harvard.edu/.../pnorris/.../World\%20Public\%20Sector\%20Report.pdf. Fecha de Consulta: 01/06/11.

O' DONNELL Guillermo, 1979. Democracy and Bureaucratic Authoritarianism in Latin America, Berkeley: Institute of International Studies.

O’DONNELL, Guillermo (1997) “Otra institucionalización” en Contrapuntos: ensayos escogidos sobre autoritarismo y democratización. Paidós, Buenos Aires.

OFFE, Klaus, 1988. "Democracia de competencia entre partidos y el Estado de bienestar keynesiano. Factores de estabilidad y desorganización”, en Partidos políticos y nuevos movimientos sociales. Sistema, Madrid.

OFFE, Klaus.1990. Contradicciones del Estado de Bienestar. Ed. Alianza. México.

OLÍAS DE LIMA, Blanca, 2001. La Nueva Gestión Pública. Alhambra. Madrid.

ONU, 2004. Plan de Acción de la Cumbre Mundial sobre la Sociedad de la

Información. Cumbre Mundial sobre la Sociedad de la Información Ginebra 2003, Túnez 2005.

OSBORNE David y GAEBLER Ted, 1994. La Reinvención del Gobierno: cómo el espíritu empresarial está transformando el Sector Público. Paidós, Barcelona.

OSZLAK Oscar y Ruth FELDER, 1998. "La capacidad de regulación estatal en Argentina: Quis custodiet custodes?" en Aldo Isuani - Daniel Filmus (comp.), La Argentina que viene, FLACSO/EUDEBA, Buenos Aires.

OSZLAK, Oscar, 1997. “Estado y Sociedad: ¿nuevas reglas de juego?” En Revista

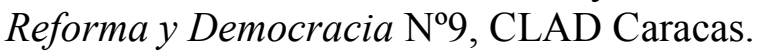

OSZLAK, Oscar, 1999. "De Menor a Mejor: El Desafío de la "Segunda" Reforma del. Estado" en Revista Nueva Sociedad, No.160, Marzo-Abril, '1999. Caracas.

OSZLAK, Oscar, 1999 b. "Quemar las naves (o cómo lograr reformas estatales irreversibles)". Revista Aportes para el Estado y la Administración Gubernamental. N ${ }^{\circ}$ 14., Buenos Aires, 1999. http://www.asociacionag.org.ar/pdfaportes/14/a14 06.pdf. Fecha de Consulta: 01/06/11.

OSZLAK Oscar, 2003. "Escasez de recursos o escasez de innovación?: la reforma estatal argentina en las últimas dos décadas". VIII Congreso Internacional del CLAD 
sobre la Reforma del Estado y de la Administración Pública, Panamá, 2003. http://www.clad.org/siare isis/fulltext/0047320.pdf. Fecha de Consulta: 01/06/11.

OSZLAK, Oscar, 2000. El mito de Estado mínimo: Una década de reforma estatal en Argentina. IV Congreso Internacional del CLAD sobre Reforma del Estado y de la Administración Pública, $\quad$ Santo Domingo, 2000. http://www.clad.org/siare isis/fulltext/0038429.pdf. Fecha de Consulta: 01/06/11.

PASTORI, Gorgio, 1982 "Administración" en BOBBIO, N., MATTEUCI, N. y PASQUINO, G. (Orgs.). Diccionario de política. Siglo XXI, Madrid.

PELLICANI, Luciano, 1986. "Estado de Bienestar" BOBBIO, N., MATTEUCI, N. y PASQUINO, G. (Orgs.). Diccionario de política. Siglo XXI, Madrid..

PETERS, B. Guy, 1999. La política de la burocracia. F.C.E., México.

PIANA, Ricardo Sebastián, 2007. Gobierno Electrónico. Gobierno, tecnologías y reformas. EDULP, La Plata.

PIGNATARO DE OLIVEIRA, Diogo, Fabiano André DE SOUZA MENDONÇA y DE ALENCAR XAVIER, Yanko Marcius, 2008. "A governança pública e o estado regulador brasileiro na efetivaçáo do direito fundamental ao desenvolvimento" en ALENCAR XAVIER, Yanko Marcius de (Coord.) Regulaçao Economica e proteçao dos diritos humanos: Um enfoque sob a optinca do direto economico. Konrad Adenauer Stiftung, Fortaleza.

POGGI, Gianfranco, 1997. El desarrollo del Estado Moderno. Una introducción sociológica; Universidad de Quilmes, Quilmes.

POUlantZAS Nicos (1990). Poder Político y Clases Sociales en el Estado Capitalista, Ed. Siglo Veintiuno Editores, México.

PORRAS José Ignacio, 2005. "Internet y las nuevas oportunidades para la deliberación pública en los espacios locales". Revista Nueva Sociedad No 195, Caracas.

PORTINARO, Pier Paolo, 2003. Estado. Léxico de politica. Nueva Visión, Buenos Aires.

POSADA CARBÓ Eduardo, 1994. "Corrupción y democracia. La rebelión del ciudadano indignado" en Revista Claves de Razón Práctica nº 45, Septiembre de 1994, pág. 2 a 11.

PRZEWORSKI Adam, 1988. "Democracy as a Contingent Outcome of Conflicts", en: Elster, J y Rume, S. (Eds.) Constitutionalism and Democracy. Cambridge, Cambridge University Press.

PRZEWORSKI, Adam, 1998. "Acerca del diseño del Estado. Una perspectiva principal-agente" en A reforma do estado na América Latina e no Caribe, Seminario internacional Ministerio de Administración Federal y Reforma del Estado, BID-ONU, Brasilia, 16-17 de mayo.

RAMIÓ, Carles, 2001. "Los Problemas de la Implantación de la Nueva Gestión Pública en las Administraciones Latinas: Modelo de Estado y Cultura Institucional" en Revista

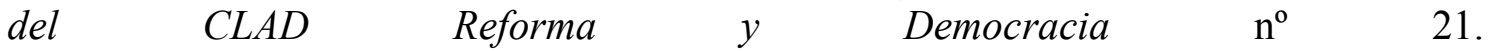
http://www.clad.org/siare isis/fulltext/0041100.pdf. Fecha de Consulta: 01/06/11.

RAMIÓ, Carles, 2002. "El papel de la e-administración ante los retos de las administraciones públicas de América Latina: e-administración y sector público en el siglo de la globalización". VII Congreso Internacional del CLAD sobre la Reforma del Estado y de la Administración Pública, Lisboa, Portugal, 8-11 Oct. 2002 Disponible en línea en: http://www.clad.org/siare isis/fulltext/0043805.pdf. Fecha de Consulta: 01/06/11. 
REILLY, Katherine, 2004. Estrategias de E-Gobierno en ocho países de América Latina, en ARAYA DUJISIN, Rodrigo; PORRÚA VIGÓN, Miguel A., Editores, 2004. América Latina Puntogob. Casos y Tendencias en Gobierno Electrónico. Ed FLACSO Chile; OEA. Santiago de Chile.

RIVERA URRUTIA, Eugenio, 2003. Nueva Economía, gobierno electrónico y reforma del Estado. Chile a la luz de la experiencia internacional. Ed. Universitaria y FLACSO - Chile. Santiago de Chile.

RODAL, Eduardo, 2003. "Programa para el establecimiento del gobierno electrónico en América Latina y el Caribe (PEGE-LAC): conceptos, estrategias y aplicaciones que el Banco Interamericano de Desarrollo viene desarrollando en la región". VIII Congreso Internacional del CLAD sobre la Reforma del Estado y de la Administración Pública, Panamá, 28-31 Oct. 2003. Disponible en línea en: http://www.clad.org/siare_isis/fulltext/0047346.pdf. Fecha de Consulta: 01/06/11.

RUBIO CARRACEDO José, 2000. “¿Cansancio de la democracia o acomodo de los políticos?" en Revista Claves de Razón Práctica no 105, Septiembre de 2000, pág. 76 a 82, Madrid.

SALVADOR SERNA, Miguel, 2002. "Gobierno electrónico y gobiernos locales: transformaciones integrales y nuevos modelos de relación más allá de las modas". VII Congreso Internacional del CLAD sobre la Reforma del Estado y de la Administración

Pública, Lisboa, Portugal. Disponible en línea en: http://www.clad.org/siare_isis/fulltext/0043804.pdf. Fecha de Consulta: 01/06/11.

SANZ, Ana, 1999. "La administración Pública" en CAMINAL BADIA, Miquel (ed.), 1999. Manual de Ciencia Política. Tecnos, Madrid.

SARTORI Giovanni, 1992. Elementos de teoría política. Alianza Editorial. Madrid.

SARTORI, Giovani, 1999. "En defensa de la representación política" en Revista Claves de razón práctica, núm. 91, Madrid, 1999.

SCHMITTER, Philippe C., 1994. "¡El corporatismo ha muerto! ¡Larga vida al corporatismo!" en Revista Zona abierta n 67-68, 1994, Fundación Pablo Iglesias, Madrid.

SIDICARO, Ricardo, 2003. La crisis del Estado y los actores políticos y socioeconómicos en la Argentina (1989-2001). EUDEBA, Buenos Aires.

SMITH, Adam, 1958 (1776). Investigación sobre la naturaleza y causas de la riqueza de las naciones. Fondo de Cultura Económica, México.

STRÅTH, Bo, 2003. "The state and its critics: is there a post.modern challenge?" en SKINNER, Quentin y STRÅTH, Bo (ed), 2003. States \& citizens: history, theory and prospects. Cambridge University Press, Cambridge.

SUBIRATS Joan, 2002. "Los dilemas de una relación inevitable. Innovación democrática y tecnologías de la información y de la comunicación". Universidad Autónoma de Barcelona. Disponible en línea en: www.comunitats.localret.cat/../Innovación\%20democrática\%20y\%20TIC.pdf. Fecha de Consulta en 01/06/11.

TESORO, José Luis A., ARAMBARRI Alejandro J. y GONZÁLEZ CAO Rodrigo L., 2002. "Factores endógenos y exógenos asociados al desempeño del gobierno electrónico: hallazgos emergentes de un análisis exploratorio de experiencias nacionales". XVI Concurso de Ensayos y Monografías del CLAD sobre Reforma del Estado y Modernización de la Administración Pública "Gobierno Electrónico". Caracas, 2002. Disponible en línea en: 
www.sgp.gov.ar/contenidos/inap/publicaciones/docs/estado/gobel.pdf. Fecha de Consulta: $01 / 03 / 10$.

TUSELL Javier, 1994. "La revolución posdemocrática" en Revista Claves de Razón Práctica ${ }^{\circ}$ 42, Mayo 1994, pág. 2 a 10, Madrid.

VALENCIA, Angel, 1995. "La teoría política en la era de la tecnocracia" en Vallespín, Fernando, ed., 1991. Historia de la Teoría Política. Madrid. Alianza Editorial.

VALLESPÍN Fernando, Giovanni SARTORI y Robert DAHL (1999) "El futuro de la democracia. Problemas, reglas y medios de la nueva convivencia política" en Revista Claves de razón práctica, núm. 97, Madrid, 1999.

VALlespín, Fernando, ed., 1991. Historia de la Teoría Política. Madrid. Alianza Editorial. Vol. $3^{\circ}$, pág. 7 y ss.

VALLESPÍN, Fernando, 2003. El futuro de la política. Taurus, Madrid.

van CREVELD, Martin, 1999. The Rise and Decline of the State. University Press, Cambridge.

VIDAL JIMÉNEZ, Rafael, 2001. "La Red y la destrucción de la identidad” en Espéculo. Revista de estudios literarios. Universidad Complutense de Madrid. Disponible en línea: http://www.ucm.es/info/especulo/numero17/vidal.html. Fecha de Consulta: 13/01/11.

VILAS Carlos, 2003. "Descentralización de Políticas Públicas: Argentina en la Década de 1990". Dirección de Estudios e Información, Instituto Nacional de la Administración Pública, Buenos Aires.

WEBER, Max, 1999 (1922). Economía y Sociedad. FCE. México.

WILLIAMSON, John, 1990. Latin American Adjustment. How Much has Happened? Institute for International Economics. Washington DC.

ZELLER, Norberto, 2007. Las Políticas de Reforma Estatal en Democracia (19832003): sus Etapas Gubernamentales y las Principales Transformaciones. Ministerio de Jefatura de Gabinete, Buenos Aires.

ZELLER, Norbeto, 2007, b (Coord.) Marco conceptual metodológico para el estudio de las políticas públicas. Dirección de Investigaciones. Instituto Nacional de la Administración Pública, Buenos Aires.

ZIPPELIUS, Reinhold, 1998. Teoría general del Estado. Ed. Porrúa, México.

\section{Sección tercera - Estudio de las reformas en la Provincia de Buenos Aires}

AGUILAR VILLANUEVA, Luis, 1993. La hechura de las políticas. Porrúa, México. BESADA, Patricia, Jorge BLASETTI, Juan Martín CRESPO, Stella DEL FRATE, Luciana GIROTTO y María PISANO, 2005. "Hacia la construcción de una metodología de gestión alineada a la demanda social: Una experiencia bonaerense". Ponencia presentada en el $3^{\circ}$ Congreso Argentino de Administración Pública. Disponible en http://www.ag.org.ar/3congreso/Ponencias/Besada.pdf. Fecha de Consulta: 10/04/12.

BLUTMAN Gustavo y MENDEZ PARNES Soledad, 2003. "Reformas Administrativas del Estado y Cultura Organizacional". Ponencia presentada en el Segundo Congreso Argentino de Administración Pública "Sociedad, Gobierno y Administración Pública" "Reconstruyendo la estatalidad: Transición, instituciones y gobernabilidad", 2003. Disponible en: http://www.aaeap.org.ar/ponencias/congreso2/Blutman_Gustavo.pdf. Fecha de Consulta: 14/05/12. 
BOTASSI, Carlos A., 2002. El derecho administrativo de la emergencia, I, FDA, Buenos Aires.

CAFFERATA, José María, 2008. El centralismo porteño en jaque: federalismo: ficción en la Argentina, realidad en los Estados Unidos. Ed. Teseo. Buenos Aires.

CAMOU, Antonio (dir.), 2005. "Estudio de permeabilidad de las estructuras organizativas del Estado provincial respecto de las políticas sociales y del control de los recursos económicos. Programa de Subsidios para Proyectos de Investigación y Desarrollo y Transferencia con Organismos Públicos de la Provincia de Buenos Aires”. Instituto Provincial de la Administración Pública y Departamento de Sociología de la Universidad Nacional de La Plata.

COHEN Ernesto y Rolando FRANCO, 1992. Evaluación de proyectos sociales. Siglo XXI, México.

DENIRO, Luis Alfredo, 2005. Utilización de recursos informáticos para transparentar, asegurar y agilizar el proceso licitatorio para la contratación del servicio de comunicación de datos de la intranet provincial. X Congreso Internacional del CLAD sobre la Reforma del Estado y de la Administración Pública, Santiago, Chile.

CHERESKY, Isidoro (Comp.), 2006. La política después de los partidos. Prometeo, Buenos Aires.

DADER, José Luis, 2001. La ciberdemocracia posible: reflexión prospectiva a partir de la experiencia de España. Disponible en línea en: http://www.ucm.es/BUCM/revistas/inf/11357991/articulos/CIYC0101110177A.PDF.

Fecha de Consulta: 12/01/12.

DOYLE Alicia Susana y Carmen Susana LOZANO (s/f) "Banco de proyectos de innovación en la gestión pública de la Provincia de Buenos Aires". Disponible en www.gestionpublica.sg.gba.gov.ar. Fecha de consulta 30/12/11.

GODIO, Julio, 2003. Argentina, luces y sombras en el primer año de transición: las mutaciones de la economía durante el gobierno de Duhalde. Biblos, Buenos Aires.

HINTZE, Jorge (2001). Gestión presupuestaria de estructuras: un instrumento para la gestión por resultados. VI Congreso Internacional del CLAD sobre la Reforma del Estado y la Administración Pública, Buenos Aires, Argentina, 5-9 noviembre 2001. Disponible en: http://www.clad.org/portal/publicaciones-del-clad/revista-clad-reformademocracia/articulos/021-octubre-2001/0041005

HELLER, Agnes, 1987. Sociología de la vida cotidiana. Península, Barcelona

LONGO, Gustavo, 2005. Fortalecer el Estado para mejorar la transparencia institucional. X Congreso Internacional del CLAD sobre la Reforma del Estado y de la Administración Pública, Santiago, Chile.

OLLIER, María Matilde, 2011. Atrapada sin salida. Buenos Aires en la política nacional (1916-2007). UMSAN Edita, Buenos Aires.

QUIROGA, Hugo, 2006. "La arquitectura del poder en un gobierno de la opinión pública” en CHERESKY, Isidoro (Comp.), 2006. La política después de los partidos. Prometeo, Buenos Aires.

RANDAZZO, Aníbal Florencio, 2004. Modernización el estado para fortalecer la democracia. El proceso de modernización del Estado de la primera provincia argentina. Buenos Aires, Ed. Promteo.

RODRIGO Patricia, Silvia PARÍS y Teresita BONET, 2005. El diseño de estructuras en el Estado Provincial. Documento de trabajo. Subsecretaría de la Gestión Pública. Provincia de Buenos Aires. 
RODRIGUEZ, Darío y RODRÍGUEZ BLANCO, Marciel, 2004. “¿Lealtad peronista o desafección partidaria?. Las elecciones de 2003 en la provincia de Buenos Aires" en CHERESKY, Isidoro y POUSADELA, Inés (comp.), 2004. El voto liberado: elecciones 2003: perspectiva histórica y estudio de casos. Biblios, Buenos Aires.

RODRÍGUEZ, Darío, 2006. "Liderazgos y partidos «partidos»" en CHERESKY, Isidoro (Comp.), 2006. La política después de los partidos. Prometeo, Buenos Aires.

PASQUINO, Gianfranco, 1997. "Gobernabilidad y calidad de la democracia". En GINER Salvador y Sebastián SARASA (edits.), 1997. Buen gobierno y política social. Ariel, Barcelona.

PIANA, Ricardo Sebastián, 2007. Gobierno Electrónico. Gobierno, tecnologías y reformas. EDULP, La Plata.

SCHEIN, Edgar (2004). Organizational cultur and Lidership. Jossey-Bass, San Francisco.

SOLANO, Mauro y DIÉGUEZ, Gonzalo. Los ciclos de la agenda de reforma política en la Legislatura Bonaerense. Una mirada al comportamiento legislativo en el período 1999 - 2005. Ponencia presentada en el VII Congreso Nacional de Ciencia Política de la Sociedad Argentina de Análisis Político (SAAP), Córdoba, Noviembre de 2005.

TULA, María Inés, Gonzalo DIÉGUEZ, y Úrsula EYHRABIDE, 2005. "Repaso por las experiencias de voto electrónico en la Argentina" en Voto Electrónico. Entre votos y máquinas. Las nuevas tecnologías en los procesos electorales. Ariel, Buenos Aires, 2005.

VARGAS HERNÁNDEZ, José Gpe., 1999. "Las relaciones de los fundamentos teóricos entre la "Nueva Economía Política", la "Nueva Gerencia Pública" y la "Nueva Política Social"' en Revista Instituciones y Desarrollo $\mathrm{N}^{\circ} 4$, Instituto Internacional de Gobernabilidad/PNUD, septiembre de 1999, Barcelona.

\section{Informes y Documentos oficiales.}

BANCO MUNDIAL, s/f. http://go.worldbank.org/M1JHE0Z280. Fecha de Consulta: 01/03/08.

CARTA COMPROMISO CON EL CIUDADANO DE LA PROVINCIA DE BUENOS AIRES, Secretaría para la Modernización del Estado, 2003. Disponible en: http://www.modernizacion.gba.gov.ar/html/manualcartadecompromiso.pdf. Fecha de Consulta: 30/12/11.

CARTA IBEROAMERICANA DE LA FUNCIÓN PÚBLICA. www.clad.org/documentos/declaraciones/cartaibero.pdf/view. Fecha de Consulta: 10/04/12.

CARTA IBEROAMERICANA DE GOBIERNO ELECTRÓNICO. www.clad.org/documentos/declaraciones/cartagobelec.pdf. Fecha de Consulta: 10/04/12.

CARTA IBEROAMERICANA DE CALIDAD EN LA GESTIÓN PÚBLICA. biblioteca.icap.ac.cr/rcap/56 57/carta ibero.pdf. Fecha de Consulta: 10/04/12.

CARTA IBEROAMERICANA DE PARTICIPACIÓN CIUDADANA.

http://www.clad.org/documentos/declaraciones/carta-iberoamericana-de-participacionciudadana/at download/file. Fecha de Consulta: 10/04/12. 
CÓDIGO IBEROAMERICANO DE BUEN GOBIERNO .

www.clad.org/documentos/declaraciones/codigoiber.pdf/view. Fecha de Consulta: $10 / 04 / 12$.

DIRECCIÓN PROVINCIAL DE ESTADÍSTICA, del 2006. Disponible en http://www.ec.gba.gov.ar/Estadistica/pbg/pbg3.html. Fecha de Consulta: 1/2/08.

INFORME DE GESTIÓN, 2002-2004, 2004. Subsecretaría de Gestión Tecnológica y Administrativa, Secretaría General de la Gobernación, La Plata.

INFORME LATINOBARÓMETRO, 2005, 2007 y 2011. Disponibles en: http://www.latinobarometro.org/latino/LATContenidos.jsp. Fecha de Consulta: 6/01/12.

INFORME NACIONAL SOBRE DESARROLLO HUMANO 2010, Desarrollo humano en Argentina: trayectos y nuevos desafios, 2010. http://www.undp.org.ar/desarrollohumano/docsIDH2010/PNUD_INDH_2010_Nov_20

$10 . p d f$

INFORME SOBRE DESARROLLO HUMANO DE LA PROVINCIA DE BUENOS AIRES, 2002. Disponible en http://www.fundacionbapro.org.ar/informes.php. Fecha de Consulta: 6/01/12.

INFORME SOBRE DESARROLLO HUMANO EN LA PROVINCIA DE BUENOS AIRES, 2003.2 Disponible en http://78.46.95.73:8080/jspui/bitstream/123456789/475/1/Cap\%20II-

\%20Condiciones\%20de\%20vida\%20en\%20el\%20Conurbano\%20y\%20el\%20Interior\% 20de\%201a\%20Provincia.pdf. Fecha de Consulta: 6/01/12.

INFORME SOBRE EL BARÓMETRO GLOBAL DE LA CORRUPCIÓN DE TRANSPARENCY INTERNACIONAL, 2005. Departamento de Investigación y Política. Secretaría de Transparency Internacional, Berlin. Versión resumida disponible en español: http://www.transparencia.org.es/INFORME\%20GLOBAL\%202009\%20y\%20anteriores /Inf_Global_2005.htm. Fecha de Consulta: 6/01/12.

INFORME SOBRE EL DESARROLLO HUMANO EN LA PROVINCIA DE BUENOS AIRES, 2004-2005. Disponible en http://www.fundacionbapro.org.ar/informes.php. Fecha de Consulta: 6/01/12.

INSTITUTO DE INVESTIGACIONES EN COMUNICACIÓN SOCIAL, 2003. "Estudio del comportamiento sociológico del electorado. Voto Electrónico. Séptima Sección Electoral. Padrón de Extranjeros". Informe Final, Octubre 2003. Facultad de Ciencias de la Educación y de la Comunicación Social. Universidad del Salvador. Buenos Aires, Argentina.

JEFATURA DE GABINETE, 2003. Memoria de Gestión 2002-2003. Provincia de Buenos Aires.

JEFATURA DE GABINETE, 2003. voto electrónico. Provincia de Buenos Aires. MINISTERIO DE GOBIERNO, 2005. Voto electrónico 2. Provincia de Buenos Aires. MINISTERIO DE GOBIERNO, 2006. REFORMA POLÍTICA. Informe de Avance 2005 / 2006. Diebo. La Plata.

OCDE, 1998. Impact of the emerging Information Society on the policy development process and democratic quality. OECD Publications Service, Paris.

OCDE, 2005. e-Government Studies e-Government for Better Government, vol. 2005, no. 30 .

Plan de Regionalización. Un nuevo paradigma de Estado, 2011, Disponible en: http://www.regionalizacionba.com.ar/index.htm. Fecha de Consulta: 06/01/12. 
SECRETARÍA PARA LA MODERNIZACIÓN DEL ESTADO, 2002. Plan Estratégico de Gobierno Electrónico para la Provincia de Buenos Aires. Informe.

SUBSECRETARÍA DE LA GESTIÓN PÚBLICA, 2004-a. SOBRE EL ROL DEL ESTADO Y MODERNIZACIÓN ESTATAL. Compilación sintética de los discursos del Sr. Gobernador Felipe Solá. Subsecretaría de la Gestión Pública, Secretaría General de la Gobernación. La Plata. Disponible en: http://www.modernizacion.gba.gov.ar/html/solaestadomodernizacion.doc. Fecha de consulta: $25 / 7 / 11$.

SUBSECRETARÍA DE LA GESTIÓN PÚBLICA, 2004-b. Plan Trienal de Gestión Pública 2004-2007. Una gestión pública para la inclusión. Fortalecimiento e innovación para un nuevo modelo de Estado. Documento $\mathrm{N}^{\mathrm{o}} 1$. Conceptos y convicciones que guían el proceso de recuperación y modernización estatal en la provincia de Buenos Aires. Secretaría General de la Gobernación. La Plata. Disponible: http://www.claudiabernazza.com.ar/htm/memoria_ssgp/Contenido/Documentos/docume nto1.doc. Fecha de consulta: 25/7/11.

SUBSECRETARÍA DE LA GESTIÓN PÚBLICA, 2004-c. Plan Trienal de Gestión Pública 2004-2007. Eje 2 Modernización e innovaciones en el ámbito público. Innovar para mejorar el Estado Documento $\mathrm{N}^{0}$ 2. Secretaría General de la Gobernación. La Plata.

Disponible:

http://www.claudiabernazza.com.ar/htm/memoria_ssgp/Contenido/Documentos/docume nto1.doc. Fecha de consulta: 25/7/11.

SUBSECRETARÍA DE LA FUNCIÓN PÚBLICA, 2004. Relatoría de la Reunión "Evaluación del Proyecto Carta Compromiso". Documento elaborado Marcos Contardo y María Laura Pagani. La Plata, julio de 2004.

SUBSECRETARÍA DE LA GESTIÓN PÚBLICA, 2006. Hacia una nueva ley de procedimientos administrativos en la Provincia de Buenos Aires. Disponible en www.dpgp.sg.gba.gov.ar/html/biblioteca/proced_admin.doc. Fecha de Consulta: 13/03/12.

U.E., 2003. El papel de la administración electrónica en el futuro de Europa. Disponible en: http://eurlex.europa.eu/LexUriServ/LexUriServ.do?uri=COM:2003:0567:FIN:ES:PDF. Fecha de Consulta: 01/03/08.

U.E., 2006, Plan de acción sobre administración electrónica i2010: Acelerar la administración electrónica en Plan Europa en beneficio de todos. Disponible en: http://www.csi.map.es/csi/pdf/com_2006_0173_f_es_acte.pdf. Fecha de Consulta: $01 / 03 / 08$.

UE, 2009. Ministerial Declaration on eGovernment. Approved unanimously in Malmö, Sweden, on 18 November 2009. Disponible en: http://ec.europa.eu/information_society/activities/egovernment/events/past/malmo 200 9/press/ministerial-declaration-on-egovernment.pdf. Fecha de Consulta: 13./01/11.

UE, 2010. The European eGovernment Action Plan 2011-2015. Harnessing ICT to promote smart, sustainable \& innovative Government. Disponible en: http://ec.europa.eu/information_society/activities/egovernment/action_plan_2011 2015/ docs/action plan en act part1 v2.pdf. Fecha de Consulta: 13/01/11. 


\section{DIARIOS}

Diario LA NACION, "El Ministerio de Economía bonaerense ya tiene nuevo titular", 19 de febrero de 2002.

Diario EL DIA, "Elecciones sin boletas ni urnas y sin variantes para la bronca", 30 de enero de 2003.

Diario EL DIA, "Avanzan las gestiones para poner en marcha el voto electrónico", 1 de marzo de 2003.

Diario EL DIA, "Reforma administrativa en el Estado bonaerense", 11 de abril de 2003.

Diario EL DIA, "El voto electrónico se estrenará en setiembre", 21 de mayo de 2003

Diario EL DIA, "Voto electrónico: dura pelea en la Provincia ", 19 de Junio de 2003

Diario EL DIA "El jefe del bloque de diputados bonaerenses dice que "es un capricho del Gobernador", 19 de Junio de 2003

Diario EL DIA, "Voto electrónico sí, cheque en blanco no", 15 de Julio de 2003

Diario EL DIA, "Naufraga en la Provincia el debut del voto electrónico". 9 de Agosto de 2003.

Diario EL DIA, "La experiencia piloto en 8 distritos no se podría realizar. Hay reparos de la Justicia Electoral", 9 de Agosto de 2003.

Diario EL DIA, "Otro round con la Justicia por el voto electrónico", 6 de Septiembre de 2003.

Diario EL DIA, "Estatales: el 41\% no terminó el secundario", 12 de noviembre de 2005

Diario CLARÍN, "Más tiempo libre, la meta de los argentinos para 2006", 31 de diciembre de 2005.

Diario EL DÍA “Habrá castigos en la Provincia por chatear en oficinas públicas. Solá firmó un decreto que prevé sanciones y hasta denuncias judiciales contra empleados y funcionarios. Buscan limitar el uso abusivo de Internet”, 19 de noviembre de 2005.

Diario HOY "En la Provincia prohíben a funcionarios chatear, bajar música o ver porno. Los funcionarios y empleados de la administración pública bonaerense no podrán chatear, bajar música o visitar sitios pornográficos durante su horario de trabajo, de lo contrario serán sancionados administrativamente y podrán ser denunciados judicialmente", 19 de noviembre de 2005.

Diario LA NACIÓN "En el empleo público. Ahora, Solá prohíbe el chateo. Ordenó restringir el uso de la Web", 19 de noviembre de 2005. 


\section{NORMATIVA}

\section{Nacional}

Constitución de la Nación Argentina

1. Ley $\mathrm{N}^{\circ} 15.262$

2. Ley $\mathrm{N}^{\circ} 20.744$ - Ley Nacional de Contrato de Trabajo

3. Ley $\mathrm{N}^{\mathrm{o}} 22.285$

4. Ley $\mathrm{N}^{\circ} 23.696$ - Ley de Reforma del Estado

5. Ley $\mathrm{N}^{\circ} 23.697$ - Ley de Emergencia Económica -

6. Ley $\mathrm{N}^{\circ} 24.629$

7. Ley $\mathrm{N}^{\circ} 25.152$ de Regulación de la Administración de los Recursos Públicos (Ley de Solvencia Fiscal)

8. Ley $\mathrm{N}^{\mathrm{o}} 25.233$ de Ministerios

9. Ley $\mathrm{N}^{\mathrm{o}} 25.246$ Unidad de Información Financiera

10. Ley N ${ }^{0} 25.326$ de Protección de los Datos Personales

11. Ley N $\mathrm{N}^{\mathrm{2}} 25.467$ de Ciencia, Tecnología e Innovación

12. Ley $N^{\circ} 25.506$ de Firma Digital

1. Decreto $\mathrm{N}^{\mathrm{o}} 2196 / 86$

2. Decreto $\mathrm{N}^{\mathrm{o}} 817 / 92$

3. Decreto $N^{\circ} 558 / 96$

4. Decreto $\mathrm{N}^{\circ} 958 / 92$

5. Decreto $\mathrm{N}^{\mathrm{o}} 2.355 / 92$

6. Decreto $\mathrm{N}^{\circ} 660 / 96$

7. Decreto $\mathrm{N}^{\mathrm{o}} 2284 / 91$

8. Decreto $\mathrm{N}^{\circ} 2293 / 92$

9. Decreto $\mathrm{N}^{\circ} 1493 / 92$

10. Decreto $N^{\circ} 1494 / 92$
11. Decreto $N^{\circ} 1813 / 92$

12. Decreto $N^{\circ} 1187 / 93$

13. Decreto $N^{\circ} 103 / 01$

14. Decreto $N^{\circ} 357 / 02$

15. Decreto $N^{\circ} 2.628 / 02$

16. Decisión Administrativa $\mathrm{N}^{\circ}$ 123/00 - Jefatura de Gabinete de Ministros - Solvencia Fiscal y Calidad de la Gestión Pública

\section{Provincial}

Constitución de la Provincia de Buenos Aires

1. Ley $\mathrm{N}^{\circ} 5.109$ Electoral

2. Decreto-Ley $N^{\circ} 7.543 / 69$

3. Decreto-Ley $N^{0} 7.647 / 70$

4. Decreto-Ley $N^{\circ} 7.764 / 71$

5. Ley $\mathrm{N}^{\mathrm{o}} 10.430$
6. Ley $\mathrm{N}^{\mathrm{o}} 11.184$ de Reconversión Administrativa modif. Ley $\mathrm{N}^{\circ}$ 11.369 y por la Ley $\mathrm{N}^{\circ} 11.489$

7. Ley $\mathrm{N}^{\circ} 11.612$

8. Ley $\mathrm{N}^{\circ} 12.155$

9. Ley $\mathrm{N}^{\mathrm{o}} 12.268$

10. Ley $\mathrm{N}^{\mathrm{o}} 12.355$ de Ministerios 
11. Ley $\mathrm{N}^{\mathrm{o}} 12.475$

12. Ley $\mathrm{N}^{\mathrm{o}} 12.727$ prorrogada por Leyes $\mathrm{N}^{\mathrm{o}} 12.774,12.775$, $12.789,12.836$ y 12845,13242 y 13850

13. Ley $\mathrm{N}^{\circ} 12.748$

14. Ley $N^{\circ} 12.874$

15. Ley $\mathrm{N}^{\mathrm{o}} 12.856$ de Ministerios

16. Ley $N^{\circ} 12.915$

17. Ley $\mathrm{N}^{\mathrm{o}} 12.999$ de Ministerios
18. Ley $\mathrm{N}^{\circ} 13.002$

19. Ley $\mathrm{N}^{\mathrm{o}} 13.082$

20. Ley $\mathrm{N}^{\mathrm{o}} 13.154$

21. Ley $\mathrm{N}^{\circ} 13.175$ de Ministerios

22. Ley $\mathrm{N}^{\mathrm{o}} 13.640$

23. Ley $N^{o} 13.666$

24. Ley $\mathrm{N}^{\mathrm{o}} 13.727$

25. Ley $\mathrm{N}^{\mathrm{o}} 13.834$

26. Ley $N^{\circ} 14.331$
1. Decreto $\mathrm{N}^{\circ} 3.300 / 72$

2. Decreto $\mathrm{N}^{\mathrm{o}} 1.522 / 79$

3. Decretos $N^{\circ} 4.015 / 93$

4. Decreto $\mathrm{N}^{\circ} 1.025 / 94$, prorrogado por los Decretos N ${ }^{\circ} 1624 / 94, \mathrm{~N}^{\mathrm{o}}$ $2410 / 98$ y N $\mathrm{N}^{\mathrm{0}} 943 / 03$

5. Decreto $\mathrm{N}^{\mathrm{o}} 18 / 91$

6. Decreto $\mathrm{N}^{\circ} 61 / 99$

7. Decreto $\mathrm{N}^{\circ} 1960 / 01$

8. Decreto $\mathrm{N}^{\circ} 1.966 / 01$

9. Decreto $N^{\circ} 2.040 / 01$

10. Decreto $N^{\circ} 29 / 02$

11. Decreto $N^{\circ} 159 / 02$

12. Decreto $N^{\circ} 819 / 02$

13. Decreto $N^{\circ} 1.465 / 02$

14. Decreto $N^{\circ} 1.738 / 02$

15. Decreto $N^{\circ} 1.824 / 02$

16. Decreto $N^{\circ} 2.404 / 02$

17. Decreto $N^{\circ} 2.419 / 02$

18. Decreto $N^{\circ} 2.835 / 02$

19. Decreto No $2.905 / 02$

20. Decreto $N^{\circ} 43 / 03$

21. Decreto $N^{\circ} 47 / 03$

22. Decreto $N^{\circ} 55 / 03$

23. Decreto $N^{\circ} 184 / 03$

24. Decreto $N^{\circ} 540 / 03$

25. Decreto $N^{\circ} 1.068 / 03$

26. Decreto $N^{\circ} 1.103 / 03$

27. Decreto $N^{\circ} 1.097 / 03$

28. Decreto $N^{\circ} 1.097 / 03$

29. Decreto $N^{\circ} 1.204 / 03$

30. Decreto $N^{\circ} 1.215 / 03$

31. Decreto $N^{\circ} 1.443 / 03$

32. Decreto $N^{\circ} 787 / 04$
33. Decreto $N^{\circ} 919 / 04$

34. Decreto $N^{\circ} 1.344 / 04$

35. Decreto $N^{\circ} 1.786 / 04$

36. Decreto No $2.100 / 04$

37. Decreto $N^{\circ} 2.549 / 04$

38. Decreto $N^{\circ} 2.643 / 04$

39. Decreto $N^{\circ} 2.698 / 04$

40. Decreto $N^{\circ} 2.754 / 04$

41. Decreto N ${ }^{\circ} 2.935 / 04$

42. Decreto $N^{\circ} 414 / 05$

43. Decreto $N^{\circ} 859 / 05$

44. Decreto $N^{\circ} 944 / 05$

45. Decreto $N^{\circ} 1.322 / 05$

46. Decreto $N^{\circ} 1.676 / 05$

47. Decreto $N^{\circ} 1.761 / 05$

48. Decreto $N^{\circ} 1.868 / 05$

49. Decreto $N^{\circ} 2.442 / 05$

50. Decreto $N^{\circ} 2.455 / 05$

51. Decreto $N^{\circ} 2.704 / 05$

52. Decreto N³.399/05

53. Decreto $N^{\circ} 3.400 / 05$

54. Decreto $N^{\circ} 196 / 06$

55. Decreto $\mathrm{N}^{\circ} 307 / 06$

56. Decreto $N^{\circ} 3.130 / 06$

57. Decreto No $3.578 / 06$

58. Decreto $N^{\circ} 3.687 / 06$

59. Decreto $N^{\circ} 1.859 / 07$

60. Decreto $N^{\circ} 2.524 / 07$

61. Decreto $N^{\circ} 3.313 / 07$

62. Decreto $N^{\circ} 3.435 / 07$

63. Decreto $N^{\circ} 1.380 / 08$

64. Decreto $N^{\circ} 1.388 / 08$

65. Decreto No 2.133/09

Resolución N 16/07 - Subsecretaría de la Gestión Pública 